Atlas of Avian Hematology ALFRED M. LUCAS : CASIMIR JAMROZ

\author{
Agriculture Monograph 25
}

UNITED STATES DEPARTMENT OF AGRICULTURE 
Marine Biological Laboratory Library Woods Hole, Massachusetts

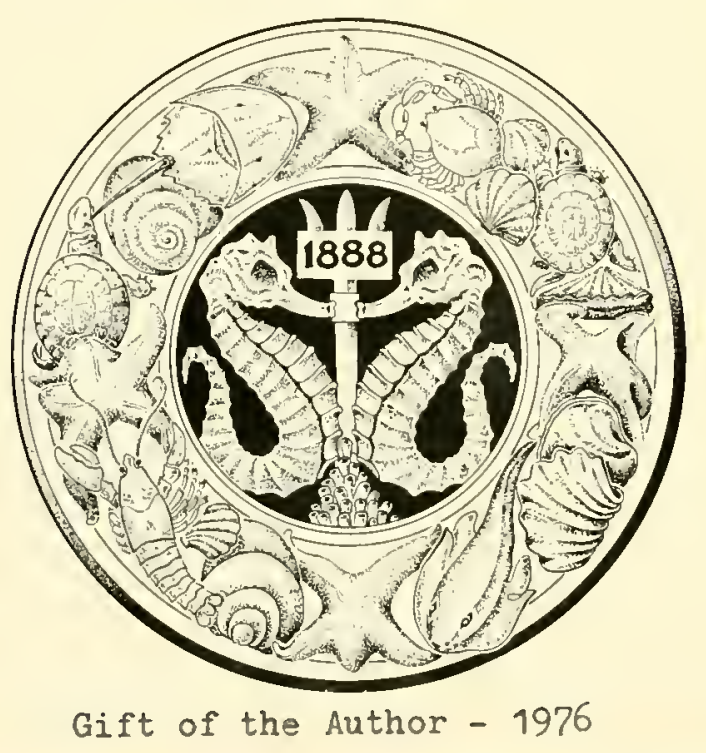


7o the tilezary 7.the

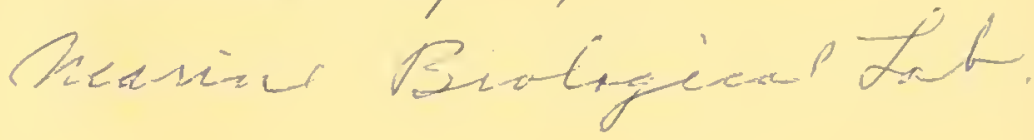

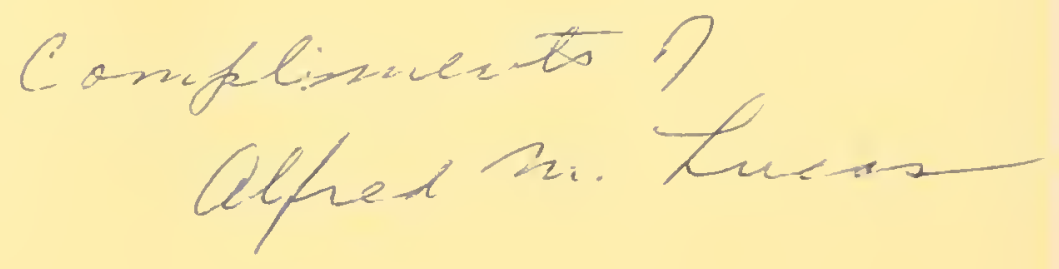





\section{Atlas of Avian Hematology}

Alfied M. Lucis, A.B., Ph.D., Cytopathologist

CAsmur Jamroz, B.S., A.B., Medical Illustrator

Regional Poultry Research Laboratory: East Lansing. Mich.

Animal Husbondry Research Dicision

Agricultural Research Service

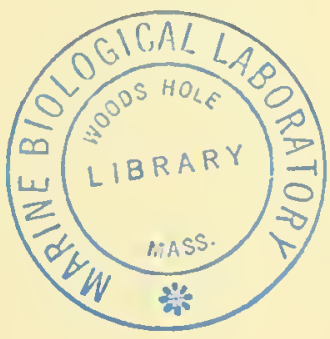

Agriculture Monograph 25

UNTED STATES DEPARTIENT OF AGRICULTURE

WISIINGTON : 1961 



\section{Preface}

An atlas of hematology is a picture book that functions as a dictionary. Minot, in his foreword to Atlas of the Blood in Children, by Blackfan, Diamond, and Leister (1944), aptly expressed the need for illustrations in hematology when he stated, "Illustration is essential in hematology. The inadequacy of language to convey the appearance of disease to the mind renders an appeal to the senses desirable whenever it can be employed, and when the oljects themselves cannot be presented the lest substitute for them is to be found in pietures."

It is loped that this Atlas will enable investigators to forge ahead without the necessity for long delay in determining how the normal cell types and developmental stages should appear. The identification of the early and intermediate stages of development for most of the cell types has been worked out for the first time. The results of this research have heen integrated with previous knowledge. All of the illustrations are original.

With the population expanding at an ever-inereasing rate, the demand already is upon us to have available a stockpile of sound biological information on many subjects in order quickly and aceurately to solve future problems of agrieulture that will grow ont of the necessity for making farm production more efficient. The control of disease is an ofvious methor of increasing our efficiency and is the objective of the long-range program on normal avian hematology that was undertaken at this Laboratory.

The subject matter covers not only the circulating blood of the aduh bird. hut also that of the embryo during its incubation from 2 days to hatching, and it includes the developmental stages found in blood-forming organs of both the adult and the embryo. The illustrations and text are coneerned not only with the appearance of typical blood cells but also with the recognition of the atypical the unusual. the abnormal, and the false. It is helieved that future investigators of hlood diseases of poultry will rarely find a cell in their preparations that has not been illustrated here, except cells invaded by organisms such as protozoan and other parasites.

A hiopsy that involves blood is simpler and easier to procure than is a liopsy of any other tissue of the body, and even from a drop of hlood much useful information eoncerning the health of the organism can be olstained.

It is intended that this pullication shall serve the needs of the poultry. man. the veterinarian, and the research worker in zoology, embryology, endocrinology, physiology, virology, and nutrition when these persons are confronted with the prollem of identifying blood cells in birds. It will 
serve the ornithologist and the research worker in bird willlife, in that representalive studies have been made on species other than the domes ie chicken; and where cells of wild speeies differed from those of chickens. they have heen illustrated and described.

Innmerable names hate been applied to the different blood cells and their developmental stages. Many of these ale synongms. many carry the implication of atherence to a particular theory of hematopoiesis. and many are the products of the clinical laboratory and of the anatomical laboratory. Wthether all workers agree on the suitability of the names that. in this book. have been attached to the drawings and are smmmarized in table 2 is not important but it is important that the mental inage of a particular cell should he the same in the minds of all who discuss it. and to this end an atlas functions as liaison among many persons.

No attempt is made to champion any theory of hematopoiesis: the totai effort has gone into recording what was seen and putting the cells in serial order whenever possible. In some cases it has been impossible to cary a revies back to a stem cell and, rather than forre a point, blank have been left in the recond. In the avian field, we are just heginning a study of nomal blood morphology and thus are now at the stage attained in the human freld 50 to 75 years ago. When investigations on histology and anatony in the mammalian and human fields were heing vigorously pusned at ahout the turn of the century. the comnterpart of such stndies in the arian field was neglerted. perhaps hecanse it was not realized that the same kind of prerequisite information was needed to form the foundation for later exact investigations in poultry diseases. pathology, physiology, embryology. and nutrition.

Critical studies in the field of bloot diseases of poultry have been retarded becanse a reference work on the morphology of normal and abnormal cells has not previonsly existed. The Atlas of Arian Hematology is the first publication within the framework of a broad program on the basic histology and anatomy of the fowl. It is loped that the program ean be carried to completion.

In the interim following the completion of the manuseript. new information on the subject of avian and mammalian henatology has heen published. Therefore, a few references have been auded on page 242. Two addenda, wne on page 93 and another on page 140. have heen inserted at the end of chapters so that pagination would not be disturbed.

\author{
Alfred MI. Lucas \\ Casmin Jamroz
}




\section{Contents}

Chapier

P'RIFICE. . . . .

I GEVERIL REM URKS IVD DEFIYTTOS

Merburlouf sourly

Terminology.

Magnifieation.

Irrangement of suljeret mater

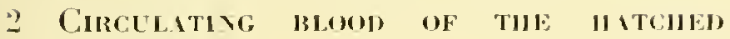
Glickex..................... 1?

Erythrocstes................... 17

Dormal mature ery throeytes.......... 17

Developmental stages foumd in circulatiog blowl..................... 21

Aty jeal and abmormal ery throen tes.... 30

Terhnir artifarts. . . . . . . . . . . 33

Thromluestes.................. 11

Tormal malure thrombocy tes......... 12

Developmental stages fouml in eimulatiog Jiliml

Alunormal rells.

Techuic artifarts.

VOYGR IVULAR I.ELOCYTLE.

lynphocy tris

Vormal mature lymphoestes.

Developmental stages fomd in rimenting l, limil.

Ahmormal lymphoretro............ 51

Momorytes.................... 65

Vormal mature monosy tes. . . . . . . . 65

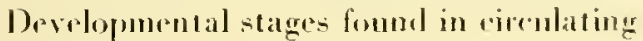
lolised.

Mlonormal nochosites..............

Techmic artifarta............

GRANULAR LEUKUCITES............. 73

Jetrophils....................

Vormal mature lunterophils...........

Drvelopmental otages found in circulating blood

Ahoormal heterophils.

Terlunic artifacts.

Eosinophils.

Dormal mature eosinophils
Chapler

Puge

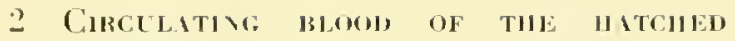
CHCKEY Continued

GRIVIHAR LELKOGTTE-COMtimmed

Eosinophil:-Contimmed

Developmuntal mages found in eireulating blomel

Ilonormal colls.................. 9]

Technic artilatets...............91

Batsophids.................... 91

Dormal mature loanphils............ 91

Developmental stages foumb in rimentating l’loorl . . . . . . . . . . . . . . . . . 92

Trebnie artilarts............. 92

HEMOKOUI IN SERUM GRIXULLS..... 93

3 CIRELLITIVG HIOON OF TIE HMBRIO..... 101

Frylurocyte rhanges during inculation.... 104

Description al $\mathrm{th}^{\circ}$ redl. . . . . . . . . . . II5

Jrimars ersteroestes............. 115

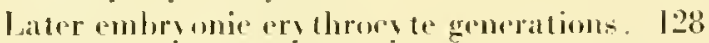

Embryothromburates............ 130

Colls oreasionally foumd in reirculating blowel of the muleryo . . . . . . . . . 133

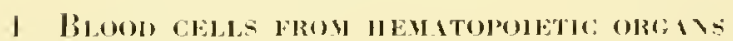
OF THE EMHRYU................ 111

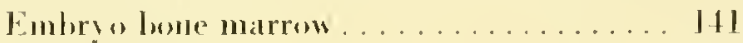

lindorio sploen . . . . . . . . . . . . 155

Blowl rhanges at hatching........... 157

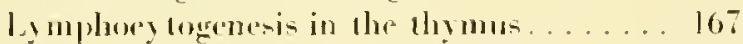

Fivather sheath erill . . . . . . . . . . . . . 169

5 BLOOL CELLE FROM BODE MURBOW OF THE

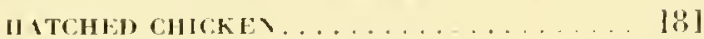

Em throestas and thombery tes........ 181

Gramulocites................... 193

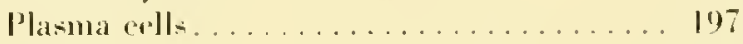

Osterelasts. . . . . . . . . . . . . . 198

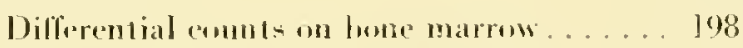

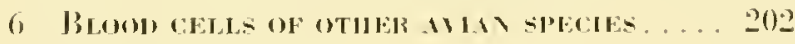

Description of endl. . . . . . . . . . . 202

Size of cells.................... 21]

Ciell counts. hemogholin bevels. and hemato(rits................. . 14

Inted counto................. 20 
¡ TeCHVICS FOR MUIV RLOOD ... . . $\quad 2.22$ The mierosecope and light........ ... 22.2 Procuring blower . . . . . . . . . . . . . . 225

Preparation of rammlas for laking blood from early embryos. . . . . . . . .

Nethod for taking hlowel forme the dorsal alorta of the 18-to-72-lowe emliryo. . . 2.26

Wethod for tahing blowd from the heart of embryos of 96 homrs and oleler.

The infrared lamp and its use in thying and waming slides.............. . 207

Method for eollecting and rarrying blowl samplos. . . . . . . . . . . . . . 227 Staining. . . . . . . . . . . . . . . . . 20

Selection. preparation, and use of Wright"s stain . . . . . . . . . . . . . . . 20.28

Bulh staming with Wright"s stain. . . . . 220

May-Grïnald Giomsa . . . . . . . . 230

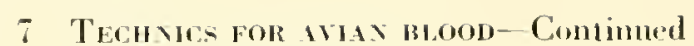
Staining-Contimed

Wright-Girmsa............... . 230

Petrunkeriteh No. 2 and MI. G. C. . . . 230

Methis alcohul and thionin. . . . . . . . 230

Reliruloeyte stain. . . . . . . . . . . 230

Ralphis modifieation of the benzidine tech nir for hemoglobin in rell. . . . . . . . 231

Misedlanenns technies. . . . . . . . . . 231

Mrehor] for hemogholin determination . . . 231

Methor for hematorrit dorermination. . . 232

Mrthod for making thrombucyte commts. 232

Hedoul for white-cell roumls. . . . . . 2. 232

LITER ITURE CITEN. . . . . . . . . . 235

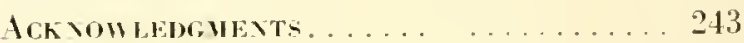

TrHex.................... 245 


\section{General Remarks and Definitions}

\section{METHODS OF STUDY}

Blood cells may he studied in a variety of ways. A perusal of the literature sometimes gives the impression that one techuical method is far superior to another; but actually each method has its particular merit, and it is often found that the adrantages of a different approach compensate for the shortcoming of the method that has lieen selected as the one generally to be followed.

Some of the prineipal methods for studying blood and some of the advantages and disadvantages that have been claimed for each method are listed in table 1. The method chosen for this $\mathrm{At}$ as is the air-uried smear. It was chosen for the reasons given in table 1 and lecease it is the method most commonly used for routine blood examination.

Wright's stain was employed for the circulating blood because it is the stain that is most familiar to a large number of veterinarians and research workers who are not specialists in the field of blood. Other stains would undoubtedly have made it possille to carry ont certain phases of the study with greater precision, but Wright's stain, in solution, keeps well, is easy to apply, and may be procured from any medical or hiological supply louse.

\section{Table I.-Advanlages and disadvantages of various methods Ibat have loeen used to sludy blood cells \\ Method of study. \\ KIILLIJ CELIS \\ Alvantages \\ 1. This method permits a great variety of terelunirs lo lering varions compunents and reactions of rells into view. Many technies ean loe used that are sufficiently sperific (o) be micredirmical tests. \\ Disaderantages \\ 1. Comsileralde alteration oresurs in the tran- sition from life to deatl: thus it becomes diffirult to distinguish between structures that "xistad in life and artifacts bronght about by deatl.}

1. Tissue, fixed, sectioned, and stained.

An csample would l, androp a piere of lissue such as embrvo spleen in Zenker formol. wash, run lhrough alowhols, embed, sortion, and slain in lematexylin anel azure II an:in.

2. Wel fixed smpars.

A thin smear of lihoml or other lissu" cells on a slide that is dropped into llw lixalive before it iries. Itsual inchunines from liere on.
1. Colls are fixed in approsimately their normal sliape: that is, they are mol flattened as in irs swears.

2. Maintains topographie retationship of cells so that daughter cells and elusters of rells having a common anrestor can lie identified ly their proximity.

3. Shows fixed cells of tissue as well at blond rells.

1. Some regard the eytologiral alprearance of fixed and sectioned bluod anls as mure roliable llan smars for distinguishing differences.

1. Cells hy this method duplicate the apluarame ihey have in fixed proparations so hat r.lls stublied ly eiller mellowl can be reallily compared.

2. I fixine arent can he chosen that will serve a fiarticular fourpme- i. e.. the use of metlyl alcobol for preservation of gramules in blund and lissue basophils.

3. Requires lese time and equipmont than the fixed-tissne method.

1. Cells usually not as severely llatlened as in dry fixed silears.

1. Cells are mo kitled as "puirhly in the center of a mass of tissue as lly.y are in a smear. so lhat allerations in shape and organization can ueeur.

2. Tly mutumd is time consuming. especially if a cellowlin torlunic is empluy al. This impuses a greater limitation on a survey type of stidy than dives the smear method.

3. Vost investigators consiler that minue differences in nurlej and rytoplism are not as rlearly differmtiated in lissue seetions as in dry simuars.

1. Topngraphic relations with other cells and tisenes are lust.

2. Colls do not slow the delirate struetural and tinetorial gradations seen in dry smears.

3. Ilas some practical disadvantages in the firles, since it involves rarryine a number of solutions. 


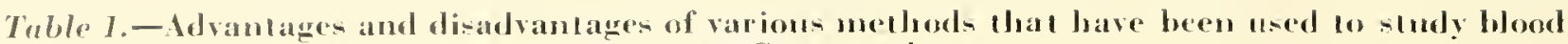
cells-Continued

\section{Method of study.}

3. Drz fixed smars.

A hin smear of blund or ollur.r lis-ut" wells on a slidts. driesl in the air, stained, and dried again after staining.

\section{Eleetron microscopy.}

Spread cello on a gelatin srren and plare in a vacuum chamber of the apparatus. Killed cells sometintes previon-ly treated will anmin acid or ollier inelals.

\section{I I \G CELLS}

\section{In vivo metherls.}

All terlunirs where rells are sumlied within the horly. surls as lhe blowl sturlire made on the living tadpole tail, the Iransparent rhamber lumil in the rabluil ear, and the lase of the quartz tulve wo ronomitrate lightu for the study of vasular prohlens in the interial organs.

\section{1i. In vitro methods.}

Tisolle rullure rhiefly, lut il in-

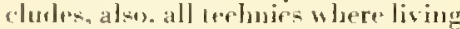

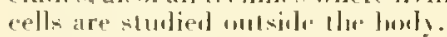

\section{Advantages}

1. Reveral maximum struclural and tine. lorial gradation- that permit differentiation beineon closely similar colls.

2. liasy 10 prepare. A toethir usful for work in feclol or laboratory renareh. Mini. mum erpipmusn and time respuired.

\section{Disaderontages}

1. Luse tuprographio relations with other colls and lissues.

2. Berante cells in dry surars appear struclurally different from cells in fixed-tissue preparations, thery rannel be radily come pared with cells in fixed tissues.
1. Offers higher magnifualion and reoulsing jumer than any previnum mothol. lis greatest usefulness is to mahe visiblo minute structural details within the intl.
1. It is neresars, nut only 10 kill the cells, dout also to doligdrat: them completely in rarum, thu romosing all volatile mole. culps.

2. This treatment of tissue folls may proThere disturtionz ren greater than those that onenr in the usual fixed and stained preparatione.

3. Stainine technirs thus far are limited to the use of netallic stains.

i. In orler tu see most cells witl the electron micrusope. Ilse material needs to be cut into aretions lhinner than one micron.
1. Living cells are generally llumght to give a better stamlard for modiring reality of struelures than do hillerl and siained cells.

2. Neasurements of size are more acuu. rately mate ou live than on teanl cells.
1. The perceptimn oi the cell and its internal struecurr. is drependen: upon tifferenos in refrative iudiets. Tluerefore. the fact that an oljert cannot be seen within a living cell is mol prow that the ohject's presence in killerl and staned cell is an artifact.
1. Stumly of relle in liseir natural lowation within the lonly loatsed lor normal bouls fluids gives the most reliable informalion wi any mellowl. That "hioh can he rearly

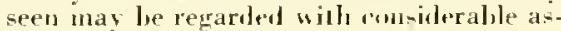
surance as a true jicture.

2. The same cell pan lie follownd over a com. siderable periol in all of its reaction- 10 surromuling resllo of the body. Valualile in following the Iran-formation of an indivilual cell from une type into amolier.
1. Terhnic diffrulties are often in-urmountable. Lom-pmer studies have their uspfulness, lun indiviclual rells are starcely visible. Use of waler or ril immersion lenses means a short working rlistanes with all its limitalions.

2. It is often diffirult to transmit emough

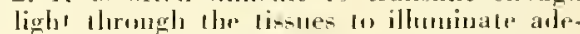
quately the fielal for high power work.

3. Somelines lighl ilself, even free from heat, will disturb the unrmal physiology of cells.

1. Often an operation is required to ste the oplls aud this introduces a disturloing factor.
1. Cedls taken outsiale the lenly can be sub-

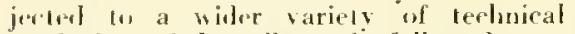
methodm and the rellocan be followed more ilusply than within the berly.
1. Cells remued from the borly are no lomger bouml by the mame plivisial and fhemical envirnimental forces that existed in-itle the burs, amb new equilibrims are sel up that may lie alypiral.

2. In temporary mounts pxpected tolast for merely a matlior of hours, Ilece cells lorgin their ilegenerative frorens as swon as they leave the luds, and it hecontes difficult in determine belinen the extremes of mormal variability and lle early olages of irrorresible degeneration. 
Table 1. - Advantages and disadvantages of varions methods that have been used to study blood cells-Contintued

\section{Vital staining. \\ Methorl of sturly}

Wethwlene blue (vital), nemtral red. fanu green 1:, aud brilliant cresyl lolure are examples of vital dyes that have been used exten-ively.

\section{Adeanteges}

1. Motility amol reactivis can be correlated will cell cylotogy.

2. Gives a tharper separation of lympluscytes and monorytes than with ether trecle. nics.

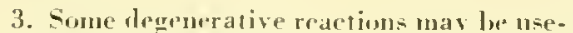
ful, surle as the occurrence of vardiolization in grantolyt $:$ : 1 hat appear 30 (6) 10 minntes after the preparation is made.

\section{Disadvantages}

1. Vital dyes nted in studie- of this sort are usnally aghtly uxir.

2. Claan slides are very impurtant in supravilal ter.hnirs and mas reyuir. 3 (1) 4 works

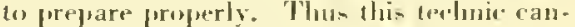
not lie set up on shurt mutire.

3. Faila 10 slow variations in cy coptasmic bascophilia and in melear details an well as they are shown in dry smears.

1. Desencrative prowentes inluerent in vital preparation- are a limiting factor in clue number of slirles llat mav lo -lurliesl at one time; 1hus. weehls arunts an 25 hirds would be

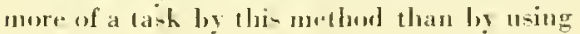
dry- -mears.

\section{Darkfielel illuminatim!}

I mieroseopic technic (usually with a sprial conlenter) wherrlis light enters the behl at such a wirle angle that the field appears blach except where the light strikes a particle and bends upward tow ard the roberver.

\section{Pthase mircoseopy.}

I microsenpic technic that ntilizes some principles of darhfield. inter. ference phenumena. and differences in refrartive indices of various materials willin the cell.
1. Often reveals extremely delirate protoplasmic presecses surl as filanments of

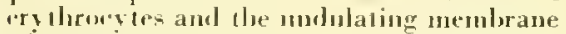
of monueytes.

3. Useful for study of formed structurewithin the coll and moxements of cells withont the introduction of toxic argents.
1. Dos adaplable to rontine stuly of cello or lo mahing rlifferential commis.

2. The rellucted light gives a disturted inprosinn of the real size of lines and losts.

1. Nlas advantages of vital staining in showing movements and the eximbone of preformed struretures thel a- gramules and miturhondria withent the disadvantage of introturing toxic dyes.

2. Reveals almost as wile a variels of structures as may bo slown in fixed and stained preparations.

3. Exrellent for pxpoing terlunic artifact imluced by hillsug and staining cells.
1. Does not ged the full range of tinctorial variations olstain.el in stained slides.
Wright's stain is often caprieions when applied to circulating hlood of embryos to hone man'ow, to spleen, and to pathological hlood that contains blas cells. The ehief objection is its frequent failure to penetrate aderpuately and stain the nuclei; the nuclei remain pale blue and seemingly structureless, but close examination under oil immersion reveals that the structures are actually present, and duplicate slides stained with May-Grinwald Giemsa demonstrate that the lack of staining is not dne to degeneration of the eell. Additional comments on $\mathbb{W}$ right's stain are given in chapter 7. page 228. May. Grïnwald Giemsa has been nsed routinely in this Laboratory for a number of years and in this study has been applied to all embryonic blood and to impression smears of embryonic and adult hematopoietic tissues.

The great variability of approaches to the surdy of hood-cell morphology has been linought out in table 1. and it is quite evident that no one method has all the advantages with no disadvantages. The numerous theories of blood-cell genesis and developmental potentialities often have heen associated with a particulan technie: for example. the Maximow school developed and uned relloidin on fixed and eut sections and arrived at the unitarian theory of hemocytogenesis. and many proponents of this theory continue with the same technics. The 
elinical hematologists use the smear method extensively and, in general, hold to the polyphyletic theory. The statement that the theories are determined by the technic used would. of course, be too broad, but teehnie has certainly exerted an influence that cannot be ignored.

Much of the early basic concept of general cell eytology was procmed from sectioned material, and the hundreds of textbook figures depicting the mucleus of the typical cell show its internal sucture only, the surface structure heing practically ignored. Studying only the internal structure of a cell, or only the surface structure, is comparable to gaining an impres. sion of a house by noting the arrangement of the rooms or by looking at it from the outside; thus it is no wonder that hematologists seen so far apart in their basic concepts when often a particular school sees only one aspect of the nuclens.

The realization that the internal structure amd external surface of a nucleus ran present entirely different pictures came with the study of the cytology of intramuclear inclusions prodnced hy viruses. In these cells the chomatin that marginated hid not disappear (Lueas and Herrmann. 1935), and the appearance of a thin line against the nuclear menlmane was not a line at all hut part of a reticulnm just beneath the nuclear membrane (Lucas, 1940): that this was actually a reticulum conld be seen only by focusing on the membrane surface. Then, during degeneration, the marginated chromatin aggregated into larger and larger clumps. In crosssection these appeared to be a string of closely set beads, lut in surface view they proved to be rather widely spaced, irregular clumps, arranged at the interstices of a network. Still another example illustrating that what appears as dots in eross section may be a network upon surface view eame from study of a prophase figure of a liver cell containing a plasmosome nucleolus (Lucas and Riser, 1945, fig. 29).

A cell that has been fixed and sectioned has approximately its normal size and shape, whereas a cell fixed by the smear method is spread out and distorted into a very thin, flat disk. The rough treatment might seem to be ample reason for disearding the latter method as reliable procedure, lnt cells flattened in this way show many cytological details that are never seen in a see. tioned cell. A series of thee diagrams (fig. 1 . $A, B$. and $C$ ) illustrates what an observer sees when viewing a sectioned nuclens, $A$, as compared to a surface view of a flattened cell, $C$, and, as alrearly pointed out, this is a change from the study of the interior of the meleus to the surface of the muelens. These figures are merely diagrams but if $A$ and $C$ of figure 1 are compared with the nuclear structures seen in section and surface views, as illustrated in the detailed drawings presented hy Kirschbaum and Downey (1937). the sinilarity is striking.

In order to detemine what happens to a cell when it is spread on a slide, an experiment was performed in which a slide was furst coated with a thin layer of celloidin and. when dry, a blood smear was made in the normal manner on the surface. The celloidin with the flattened cells was peeled off and embedded in fluid celloidin. hardened, and seetioned transversely to the blood cells. When these flattened cells were finally located muder the microscope. they were found to be exceelingly thin, certainly no more than a mieron in thickness. The region of the nuclens was scarcely thicker than that of the cytoplasm alone. This means that the whole content of the rell lies in the same level and. being thin, the

Figure 1 .

A, B, C: Three stages in the shift of riewpoint from the interior of the nuclews to the surface.

A Cut section of a molens, showing nuclear membrane, chromatin clumps, and a plasmosone meleolus (stipplect disk).

13 A transitional step slowing both interior and surface viens of the mucleus.

C A flattened nuclens as it appears in ablood smear in which the muclear plattern is determined by the ehromatiu reticulum at the nuclear membrane.
D, E: Scales for masuring cells.

D Scale for neasuring cells drawn at low magnification, $1,370 \times$.

E Seale for measuring cells drawn at high magnification, $2,170 \times$.

F, G: Appearance of hlond smears from chickens.

F Smear from gomng birds, males and nonlaying females.

G Smear from jaying hens. Clear areas due io droplets of fat that flatten and spread when the smear is made. 

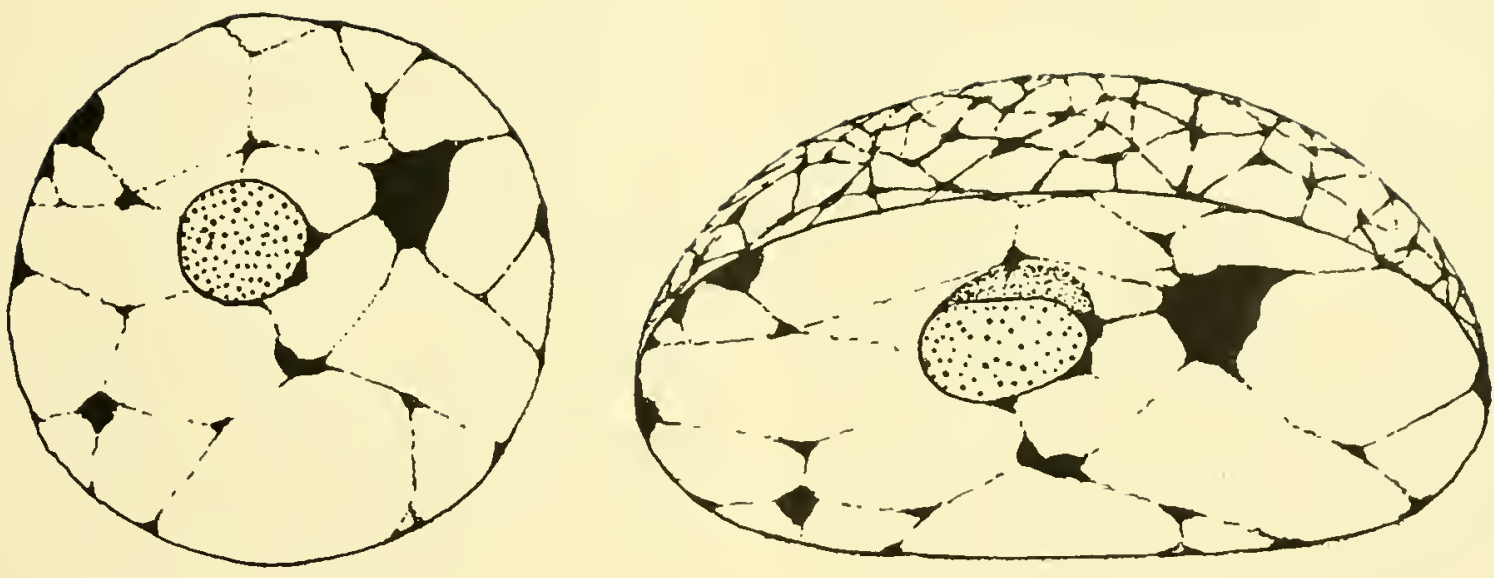

A

B

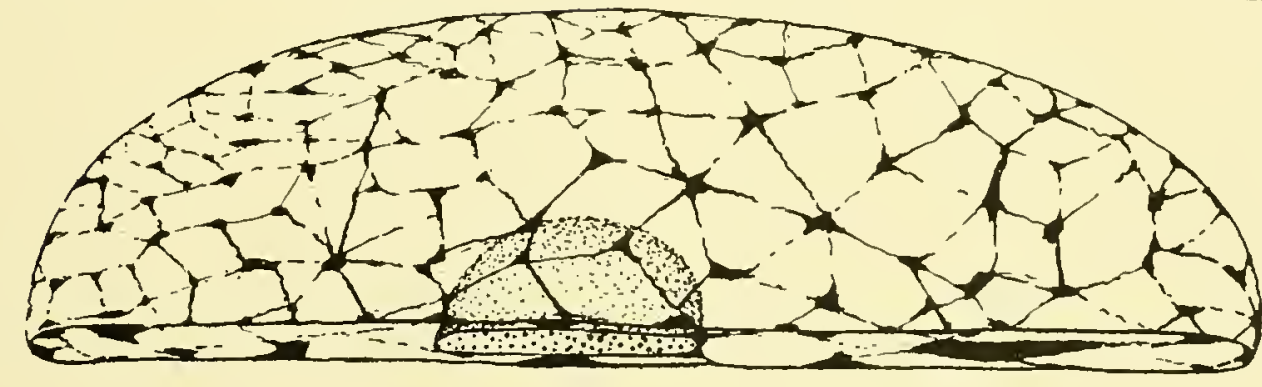

C

$0 \quad 10 \quad 20 \quad 30 \quad 40 \mu \times 1370$

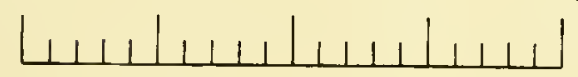

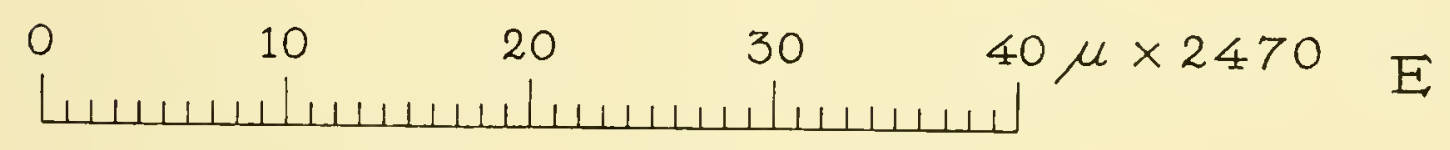

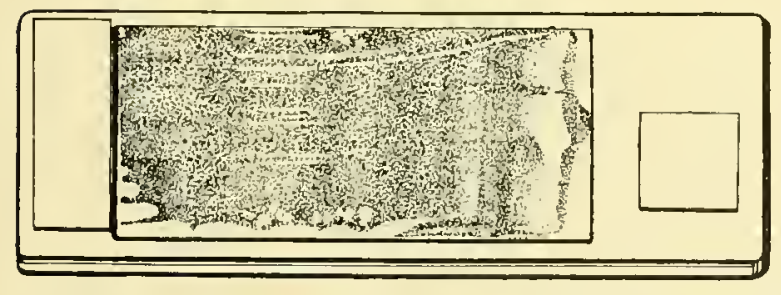

E

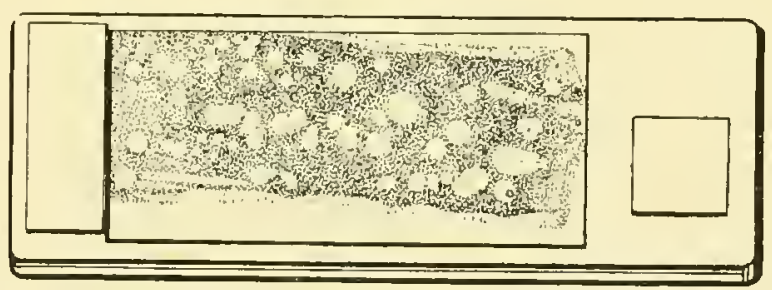

G 
whole cel! falls within the depth of forus of even the oil immersion lens. This is readily confimed by looking at any dried hlood cell of average size.

The crtosome is flattencel in the same way as the moleus, and the disk-shaped muleus is eovered by a thin layer of cytoplasm ahove and another below. The stainalile bodies of the ey toplasm ma thus he superimposed on the muclear structure; likewise stainal,le particles in the fluid around the cell may come to lie upon the flattened cell, and it in impossible, becanse of the -hallow depth of forms to tell whether they are inside or outside the rell.

There are numerous illustrations of the points that have lieen presented thus far. Figures 70 . 7]. and 72 show examples of sulstances outside the cell that appear to he inside: in figures 70 and 71, parts of smudged unclei from other cells fell upon the cytosome and produced stained hodies. In figure 72. stained serum granules fell upon the cell, and had not other granules aromul them heen stained also. they might have heen considered as lying within the cell instead of on it. In other instances, granules having an identical appearance may lie inside the cell. Consilerable judgment may be reruired to determine what is artifact and what is real.

Fignres 103. 105-707. and 110 show cytosomal inchoions that appear to he in the nuclei: ther stain intensely, and the nuclei in some cases are lighter than normal, so that the particles stand out in contrast to the lyackoround. Cyloplasmic inclusions such as pale straining azurophilic bodies of the monocyte usually are not visible when they overlie a darkly stained nucleus (figs. 132-134) but they may appear to be located inside the meleus if they stain intensely ifig. $135)$.

There is need at this point to explain more fully what has been said regarding the desirability of riewing both the outside and the inside of the nucleus. It was stated that in the flattened, dried cell one sees primarily the surface of the nucleus rather than its interior. It is the coarseness of this network at the surface that in part determines the extent to which olnjects within become visihle. It is the same experience that one has in attempting to view an object through a very fine screen, as against a eoarse wire net: the former almost completely blorks the view of things berond and attention is antomatically formsed on the structure of the screen itself; the latter offers vers little obstruction to a clear view of the objects leyont: in fact. attention must be shifted in order to see the wire net. Examples will bring out these differences as they oceur in avian blood cells.

Erythoblasts and thromboblasts are charaeterized hy the presence of nucleoli: whereas, granuloblasts, lymphohlasts. and the most immature monoevtes that we have heen able to find, do not appear to have nucleoli. owing in part at least to the difference in screen effeet as determined lis the coarseness of the chromatin retionlum. If hether nucleoli aetually exist in all blast cells is not the point for consideration at this tine. Gramblolasts (figs. 366 and 367) have a rlose screenlike pattern of chromatin retirulum and. if a mucleolus exists, it ramot be seen. The same is true for the lympholilast (fig. 331). So far. all efforts to demonstrate a meleohs in the gramuloblast and lymphohlast of dhicken l,lood have failed. Yet. in a few cells, a rague bluish image seemed to be present below this network (fig. 382). For practical purposes of rell-1ype identification. it makes no difference whether a mucleolus is actually present or not. Jut it is important and would have a bearing on the acceptance of one hematopoietic theory over another. In the box-turtle the immature heterophil possesses a bhue-staining plasmosome uncleolus. according to Ryerson (1943). In sectioned chick material studied by Dantschakoff (1908h) a muleolus was present inside the mucleus of the granulohlasl.

The blast stages of hoth ervthrocytes and thromboctes show mucleoli (figs. 345. 346. 357 , and 3.58$)$ : the former is shown more clearty than the latter. which is to be expected. since the latter has a denser chromatin layer at the nuclear surface. Tet at best. these plasmosome mucleoli are never sufficiently sharply defined to show clearly the loundary of this body. There seem to be two reasons for this-(1) the masking effect of overtying surface elromatin particles which has already lieen discussed. and (2) the penetration of the stain.

Tormally, when the cell dries it does not rupture: instead, the cell and nuclear membranes remain intact and merely flatten out like halloons partly filled with water. and membrane resistance to penctration is far more effective in a dried rell. even though the cell is compressed to a thick- 
ness of less than ene mincron, than it in in sectioned tissue of 5107 microns in thickness. Drying. like taming, seens to toughen the memlianes. Lack of stain penctration is well illustrated in the nse of "Wright's stain on hetrophils (figs. 151-167) where the nuclens does not stain in those portions that lie within the central part of the rell. Then the eharacter of the membrane is changed by a strong fixative, the stain penctrates readily and colors the ehromatin brilliantly (figs. 203-214). Another example is the hasophil muclens, which often appears to he pale and ghostlike with no evidence of chromatin or other structure. This effect is in addition to the masking of the muchens by the basophilic granules (figs. 190 and 191). In these illustrations, the stained bodies simulating chromatin clumps within the boundary of each nucleus are actually cytoplasmic basophilic granules: yet when the membrane resistance is broken down, the cel] proves to have a nomal nuclens eapalole of in. temal staining (fig. 221).

Dried immature cells appear to offer greater resistance to penetration of stain than do mature cells, and thus Wright's stain, which is able to penetrate the membranes of nomal cirmlating cells, does not readily to so in the ease of precursor cells found in bone marrow, spleen, thymus, and other hematopoietic organs. On the other hand. May-Grïnwald Giemsa can penetrate immature cells quite well, with an occa. sional exreption (figs. 259, 281, and 334). Neo. plastic lilood cells are usually at various stages of immaturity, and it is for this reason that following Wright's stain they often appear as basophilic rings with empty melei. A May-Grünwald Giemsa stain on these cells will generally lring out the details of muclear smoture. Although Enmel (1936) did not give the stain used in his studies on hemocytoblasiosis, many of the figures he has depieted as degenerated cells are identieal in appearance with rells that have been inadequately colored with Wright's stain. His fignte $3 \mathrm{~B}$ is a gond example. In this sudy such conditions are regarded as defective technic, not as degenerated cells.

Jones (1948) discnssed the problem of the appearance of nuclei in cut sections versus dried smears for enbryo rat blood. and on most points we are in agreement, except that he considers the nuclear pattern as due to overlying mitochondria: whereas, we recognize that cell organelles may play a part. ret believe that the pattern is dne chiefly to the arrangement of chromatin at the nurlear membrane.

The question can justifial,ly lie raised. How should the sturly of normal hematology he atpproached? ln one look on human hematology approximately the first humbed pages are deroted to the crtology of hlast-rell trpes and their terivalives. Theme figures form the hasis of comparison for the subjeet matter of the boty of the hook on blood dieeares. ret approximately 85 percent of the cells selected for illustration and rescription in the section illustrating stages in development of each blood-cell type came from patients suffering from different types of leukemias or infections diseases. Only a few were aken from normal, healthy individuals. and usually these were the mature stages of rell hines. It is recognized that pathologic conditions often reveal what cammet be deciphered readily from the normal. where all processes of formation and destruction of hlood cell lines are in halance: yed from on limited experience with pathologic avian blood. molonbtedly we wonld have gone astray had the pieture of the nomal been built "pon almormal blood conditions. It was ob. served for example, that helerophil myelocytes fouml in circulating hlood after irrarliation were slightly different in general appearance and ertologic detail from those found in normal bone malnow of the chicken. In lenkemias as well as in this example from irradiation, inmature cells have heen pushed into a new enviomment. and thus two varialiles are operating. either of which may he responsils to for their slightly different appearance-11) the chenical constitution of the new environment and (2) the abnotmal condi. fions that produced them.

lsaacs (1928) was dealing with esentially the same problem when he noted that bone-marrow cells and tumor rells stained more hrilliantly when mixed wils bloorl serun than when im. prints from these lissues were marle diredly on the slide.

As a side effect, the fact must not he overlooked that often disease conditions weaken and change the permeability of the rell menlmane: thus it may well be that some of the differences we see are merely a matter of degree derived from the more effeetive penetration of the loloot stains used. Determination of the correct answer must await further collection of data. 
The same complaint was made by Dantsehakoff (19081) against the use of blood from cases of leukemia and other blood diseases as source material for establishing the normal. She says (p. 477). … Nach meiner Meinung ist es z. B. heute bei der verwirrenden Menge von einzelnen, nicht systematischen Beobachtungen geradezu aussiehtslos, aus Beobachtungen an krankhaft verändertem Blut des erwachscnen Menschen z. B. lei den versdierlenen Leukämien ete.. auf alie normale Entstehung und die Verwandtsehaft der verschiedenen B!ıtzellenformen zu schliessen, wie es jetzt von vielen tatsäehlich gemacht wird."

\section{TERMINOLOGY}

One of the hig moblems in morphologic hemarology is the choice of an aeeptable teminology. Theories of hematology have influenced the terminology and for the early stages. at least, each school has its own set of names. This fact makes a selection of working terminology. independent of any particular theory, often impossible to find. The reader slould bear in mind. therefore. Iliat when a particular term is applied to a cell, the authors have selected it without any implieation that they favor the theory of hematopoiesis commonly assoriated with the term. No single inrestigator has lieen able to encompass the whole field of hematology from his own researhes. and the terms he uses in his own studies are influenced ly the appearance of the rells as revealed lyy the particular teclunies he las used. Were one muliased person ahte to thoroughly review the whole hematologic picture of the normal and almormal of the emliryo and of the adult for just one speeies of reptile. bird. or manmal, ly sectioned tissue, ly smear method, and by vital technic. supplemented ly tissue culure, prohalily all conflicting theories conld he merged into a miform concept of hematopoiesis in health and discase. A similar thought was expressed by Doan (1932) when he said, ". . . It is agreed that all [hlood cells] take their first beginnings from the mesencluymal rells of the mesolermal

\footnotetext{
${ }^{1}$ Trambation: In my opinion, it is lowuright hopeless, for instance to lraw conclusions ahout the normal origin and the relationslips of the various bloorl cell forma from today's hewilclering mass of separate unsystematir olservations of pathologically altered hlood of adults in varions leukemias, for example: lut this is artually done today ly many students.
}

layer in the embryo. But thereafter the theories and hypotheses diverge more or less radically, though I would venture to assert that the differences arise more in the interpretation than in opposing oljective observations. where experiments have paralleled in materials and methods." A survey of comparative liematology by Jordan (1938) hrings out the point that regardless of the wide differences in form and habitat from fish to man, the general blood patterns are remarkably constant and similar.

Kindred (1940). using the rat. illustrated the appearance of the same cell type as seen ly the section and by the smear method. This work hrought ont clearly the difference in appearance of the muctei of cells by these two different technics. A still more striking comparison was made by Kirschloum and Downey (1937) when they placed some of Maximow's drawings (1909) derived from celloidin sectionel material beside drawings of corresponding cells made from airdried smears. The material for both came from 14-day-old rabhit embryos. The wide differences in cell identifieation and even terminology that can be attributable largely to the different appearance of similar celts in two different technics is provorative. Our own studies on cell identification agree closely with those of Kirseh. batum and Downey. except that we have avoided the use of the term "megaloblast" because of the controversy associated with the identity of the cell and the correct usage of the term (Jones, 1943).

Kracke and Garver (1937) and Osgood and Ashworth (1937) emphasize in their atlases the need for standardized teminology and in the first of the books mentioned. the origins of the words commonly and uncommonly used are discussed rather fully. Exact terminology often moves contrary to simplified teminology. Proposal. made by a committee for standardized terminol. ogy are highly commendalile (Anonymons, 1919). but the names proposed are specifically adapted to man and are not broad enough to fulfill entirely the needs for terminology in other rlasses of vertebrates. Althomgh a serious offort has been made by the anthors to fit the teminology of the lind into the exaet framework designed for clinical medieine of the lumman, the effort did not sueceed and one eannot avoid the conclusion that any satisfactory miversal rerminology should he broal enough to include 
all vertelmates and, if possible, all theories of hematopoiesis.

Table 2 shows the lineages of cell lines as seen in the birds. For each line, there is listed at the top of the column a primordial stem cell or blast cell. In human hematology, hlast cells are pictured and described as containing one or more nucleoli that appear as pale blue homogeneous bodies following the commonly used blood stains. In avian blood. no more than one nucleolus has been seen in any cell line except in the primary generation of embryonic erythrocytes, and nucleoli are absent from granuloblasts, lymphoblasts, and probably monoblasts, at least by the same technics that have revealed them in human blood.

Erythroblasts, thromboblasts, lymphoblasts, gramuloblasts, and primordial osteogenic cells of birds are somewhat more easily distinguished than in the hmman species. Each represents the earliest recognizable member of its respective line, and althongh some do not show nucleoli, each is believed to be equivalent functionally to the same blast cell hy the same name in the human series. The important point is that in many cases they can be separated on the basis of their structure, even when isolated from the other cells on the slide. This does not alway loold true in the human field, and in the atlas by Osgood and Asliworth (1937) it is stated (p. 36), "In the author's opinion [Osgood]. the individual granuloblast (myeloblast) is morphologically indistinguishable from the most immature lymphoblast, monoblast, plasmoblast, or karyoblast (megalohlast). The differentiation of the type of cell has to be made by identification of the cells found associated with the stem cell under consideration. A stem cell found in association with a progranulocyte (promyelocyte) is classed as a gramuloblast." (References to figmes have heen omitted in the quotation just given.) It is this type of dependence upon the presence of more higlly differentiated cells in the same field for exact placement of the different blast cells that has led the unitarian hematologist to suggest that if lilast cells all look alike and are al] characterized by a narrow rim of blue-staining cytoplasm around the nucleus, and the nucleus contains a mucleolus, it is just as logical to say that there is a single common stem cell capable of differentiation into any blood cell type. As already montioned, the criticism leveled at this view of blast cells in mamnals cannot be applied as readily to avian blood because, as seen by the smear method, cytologic differences do exist among the blast cells.

All schools of hematology recognize the fact that if the genealogy of cell types is carried far enough lyack into the embryology of the organism, there will be a common cell for all blood-cell types. The point of controversy is not on this matter but on whether a blast cell of a particular cell line is a fixed type, incapable of differentiation under stimulus into other cell types. Answers to such questions must come from experimentation and, as far as the present study is concerned, there is no evidence that blood cells have or have not any potentiality beyond the particular line that they represent.

On the basis of what has been observed in the chicken. its embryology, and its hematopoietic organs, a blast cell may be defined as the earliest recognizable cell belonging to a particular cell type, and all following stages observed consist of progressive steps toward the mature cell. To this should he added the observation that if, antecedent to the blast cell. there does exist a totipotent cell type other than mesenchyme, reticular, and possibly connective and endothelial tissues, it has not been found in this study. It shonld be added, also, that the terminology presented in table 2 is based on the assumption that the usual medium and small lymplocyte found in circulating blood is a mature cell, on a par with all other fully differentiated mature cells found in the circulating blood, and that it is not a totipotent primordial cell capable, at least in the course of normal hematopoiesis. of producing all other blood-cell types. In normal blood only two types of mature lymphocytes exist, medium and small; the large lymphocyte is not a mature cell but is an immature cell usually standing early in the lineage of the cell line to which it belongs, which may not necessarily be the lymphocyte line. ${ }^{2}$

More than one erythrocyte series exists in the life of the embryo up to hatching. There is a primary series representing the first generation of red cells in the embryo; then follow several generations, each less precocious in its hemoglobin formation than the preceding one and.

\footnotetext{
${ }^{2}$ For further clarification of viewpoint see:

Lucas, 1. M. 1959. A discussion of synonymy in avian and mammalian hematotogic nomenclature. Amer. Jour. Vet. Res. 78: $887-897$.
} 


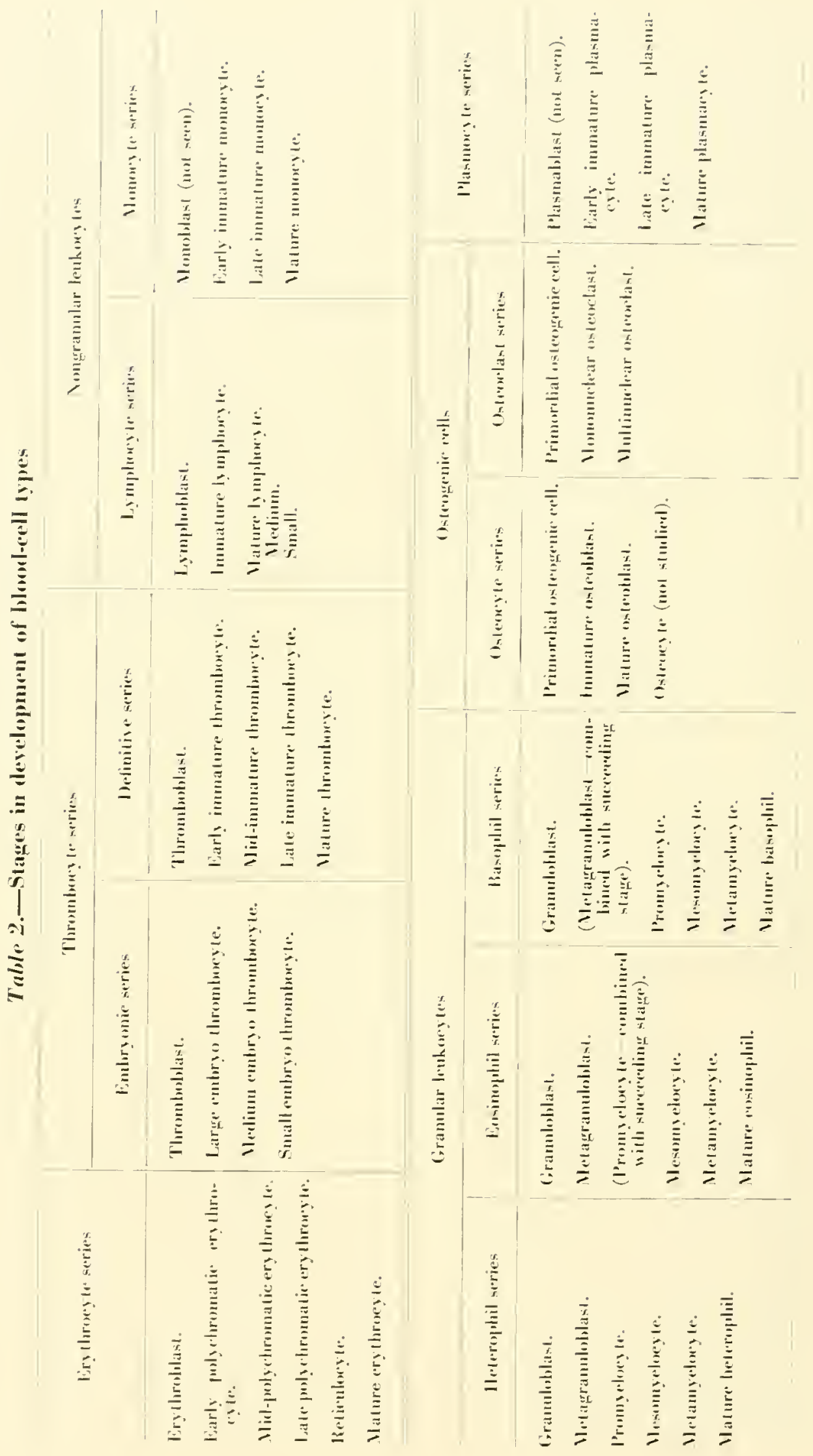


funally, the defmitive cell line arises. Thrombocyte stages of development in the embryo differ morphologically also from those found in the de. funitive stages. Therefore, to cover all these variations, definitions must be broad.

\section{ERYTHROCYTE SERIES}

Erythroblast. - A large cell with more cytoplasm in relation to the nucleus than in most blast cells. The cytoplasm of the primary generation is strongly basophilic, but in the rlefinitive cell line it stains less intenscly. The cytosome shows mitochondrial spaces and may have an amoeboid shape. The nucleus is an open, coarse network with chromatin that is clumped more than usually found in other blast cells. The plasmosome nucleolus is large and more conspicuous than in the thrombollast.

Early polychromatic erythrocyte.-A smaller cell than the blast stage, and the cylosome is rounded. Mitochondrial spaces are largely replacerl by a more homogeneous cytoplasm. The cytosome has a strong basophilic color. The chromatin of the nucleus is definitely clumped. The nucleolus is smaller than in the llast stage but is often risible.

Mid-polychromatic erythrocyte.-This cell is usually smaller than in the preceding stage, of rounded shape, and has a gray cytoplasmic colur that ranges from nearly basophilic to slightly eosinophilic. No mitochondrial spaces are visible but the eytosome often shows an artifact of fractured spaces usually concentric to the cell perimeter. The nucleus is small relative to the crtoplasm. It is round and has a clumped chro. matin pattern. No nucleolus is scen in the definitive cells.

Late polychromatic ery/hrocyle.-This cell is round to slightly oval. Staining of the crtoplasm varies from an eosinophilic gray culor to a pale eosin and, in the older cells. to a moderate eosin color. Fracture artifacts tend to appear in the younger forms of this stage. The nucleus is round to slightly oval and there is irregular clumping of the chromatin.

Reficulocyte.-Without special stain. this cell appears as a late polychromatic errthrocyte with almost full development of hemoglohin or even as a mature erythrocyte. A reticulocyte stain reveals the presence of granules in the cytosome. concentric to the nucleus. The basophilic granules characteristic of a typical reticulocyte may be found at earlier stages of develop. ment. after the appearance of hemoglobin in the cell.

Muture erythrocyte.-This cell has an oval shape and a cytosome of uniform texture, colored a reddish orange. The nucleus is elongated. oval. and sometimes rodlike with rounded ends. The nucleus is leptochromatic to pachychromatic. Aged cells have dense homogeneous or nearly structureless nuclei.

\section{THROUBOCYTE SERIES}

Thromboblast.-A cell with hasophilic cytoplasm that is amueboid in the carly embryonic generations. The cytosome forms a narrow rim around the nucleus. Spaces are present in the cytosome. It has a round nucleus with a plasmosome nucleolus that may lie masked by the density of chromatin granules. The chromatin tends to he punctate in contrast to that of the erythroblast, where it is more angular, merging into the linin network.

Thrombocytes appear to be functional in the embrro from an early stage and hence probalbly should not be called immature; thus, in table 2 two columns of terms are given for the thrombocytes-one for the embryo and one for the bone marrow of the adult and circulating hlood.

\section{Embrya Thrombocyles}

Large embryo thrombocyte.-This is a large cell with a moderate amount of cytoplasm around the nucleus. The cytosome shows partial to nearly complete vacuolization and stains more lightly than in the preceding stage. The nucleus has large irregular chromatin clumps and no visible nucleolus.

Vedium embryo thrombocyte.-A cell of nedium size with about the same mucleocell ratio as hefore. The eytosome is fully vacuolated and specific granules sometimes are present. Early degeneration is marked by pinkish coloration and by crumpling of the borders of the crtosome. The nucleus is pachychromatic.

Small embryo thrombocyte. - A small cell of which the eytosome is highly racuolated and pale staining. The nucleus is dense and individual chromatin clumps are fairly distinct. Nearly all cells of this type. as seen in the smear of embryo blood, have lost most of the cytosome and are clumped.

\section{Definitive Thromhocrles}

Early immature thrombocyte.-A large cell, often not round. and with the nucleocell ratio less than in the preceding stage. The cytoplasm is basuphilic hut the overall color is lightened by the presence of vacu. oles. The muclcolus may still be visible and the chromatin is aggregated into clumps of nonuniform size.

Mid-immature thrombocyte.-A cell of medium size that is often elongated slighty or has an irregular shape. The crtoplasm is racuolated and stains a light blue color. Specific granules may be present. The chromatin is clumped extensively but linin network is still risible.

Late immature thrombocyte. - This cell is clongated but the nucleus fills up a larger proportion of it than at the mature stage. Clumps of chromatin are still clearly visible. Specific cyloplasmic granules are generally present. 
Mature thrombocyte.-The mature definitice thrombocyte has an ovoid shape and is slightly smaller than the mature crythrocyte. The cytosome takes on a pale blue color with most blood stains. The intensity of color is varied by the presence of vaguely defined rarefied areas.

The nucleus is usually round rather than elongated as in the mature erythrocytes. The chromatin is clumped and the clumps are closely packed, which gives to the nuclens an effect of density equal to or greater than that of the small lymphocyte.

One or more specific granules, having a weak affinity for acidophilic dyes, are visible in most mature thrombocytes. These granules usually lie at one end of the cell.

\section{LYMIPIOCYTE SERIES}

Lymphoblast.-This is a large round cell with a narrow rim of cytoplasm that stains dark blue but may contain colorless spaces. The cliromatin forms a delicate reticular patterm. No nucleolus is visible.

Immuture lymphocyte.-General appearance the same as in the blast stage. except that the chromatin of the nuclems shows clumping and the cell is smaller.

Nature lymphocyte- Nucleocell ratio is similar to that of the blast cell. The chromatin of the nucleus is definitely clumped but not always in massive blocks even in the small mature lymphocyte. The separation of size into "medirm" and "small" is purely arbitrary.

\section{MONOCYTE SEIRIES}

Monoblast. - Thus far the monolylast stage has not been definitely identified.

Early immature monocyte.-The cytoplasm of this cell stains a clear blue color with or without basophilic granules. Azuroplitic granules may be present. The nucleus has a granularity on a reticulum quite similar to that of the mature cell. The cytosome is large relative to the nucleus.

Late immature monocyte.-The cytoplasm often shows a basophilic grantation, or reticulum, and azurophilic bodies may be present. The nucleus is ronnd and has an eccentric position in the cell and a $l l o f$ may be present.

Hature monocyte. - The eytosone is large relative to the nucleus. The cytoplasm has a reticular structure and contains azurophilic substances. either on the reticulum or as discrete granules. The nucleus usually is indented and adjacent to it is a $H o f$ area with spheres faintly stained an orange color present in the racuoles. The chromatin is usvally a delicate reticulum hut may be composed of coarse blocks.

\section{IIETEROPIIL SERIES}

Gramuloblast.-A large round cell with a narrow rim of cytoplasm around the nuclens. The crtosone stains an intense blue color and is only slightly interrupted by light-staining areas. The chromatin forms a reticulum more delicate than for any other blast cell. The smear method would indicate that a nucleolus is absent. The morphology of the granuloblast is the same for heterophils, eosinophils, and basophi]s.

Metagramuloblast.-The cytoplasm on the side opposite the eccentrically placerl nucleus is vacuolated with spaces of approximately equal size. The nuclear chromatin may be aggregated slightly, but more often the chromatin remains in the form of a delicate reticulum. and the houndary between the nuclens and cytoJlasm hecomes indistinct. At this stage no granules characteritic of this cell line have appeared.

Promyelocyte.-This stage also precedes the appearance of specific granules. The boundary of the nucleus often becomes indistinct and in the cytosome there appear dark-stained magenta granules and rings. The magenta bodies are highly characteristic for the heterophil but are not specific for it. Orange-stained spheres are present in the vacuolated cytoplasm and these are the precursors of the definitive rods.

Hesomyelocyte.-From the precursor orange spheres come the definitive rods. Cells witl less than half the number of definitive rods are included in this stage. Magenta rings and granules may still be present. The nuclear boundary often is still vague. In some cells there is evidence of nuclear condensation.

Metamyclocyte.-This cell usinally is smaller than the preceding one. The cytosome contains more than half the normal complement of rods. The chromatin of the nucleus is condensed and in older stages the nucleus may have a bean shape. The nucleus begins to show staining refractiveness characteristic of adult cells.

Iature heterophil.--The cell contains a full complement of rods and the nuclear lobes may vary from 1 to 5 or more. The chromatin of the nucleus is aggregated into clumps.

\section{EOSIVOPIIIL SERIES}

Granuloblast.-Morphologically this cell is the same as described for the heterophil series.

Metagramuloblust.-The nucleus is ercentric and this position produces a crescent of cytoplasm at one side. The racnoles are more miform and more sharply defined than in the heterophil at this stage. The nuclear structure is more definite than in the heterophil, and chromatin chumps are larger.

Promyelocyte.-This stage is defined as the one in which only precursor substance that produces the de- 
finitive specific granule is present, but in immature eosinophils, all degrees of development from the precursor substance to the definitive granule may be found. Therefore, this stage overlaps the next, and the term "mesomyelocyle" has been used to cover both stages.

Mesomyeloeyte.-Definitive granules arise at this stage, and all cells are included under this term that have less than half the usual mumber found in the adult cell. The nucleus is more definite and chromatin more condensed than in the heterophil.

Metamyelocyte.-This is an immature myelocyte with more than half the number of specific granules. The nucleus may be round, indented, or constricted, and its chromatin clumped irregularly.

Mature eosinophil.-Contains a full complement of specific granules, and the number of loles in the nucleus may vary from one to five. The chromatin clumps are close together.

\section{BASOPIIL SERIES}

Granuloblast.-Morphologically this cell is the same as described for the heterophil series.

Metagranuloblast.- This stage is present but, concurrently with the characteristic vacuolization of the cytosome. the magenta granules apprear also. and thus the term "promyclocyte" has been used for the two stages combined.

Promyelocyte.-Scattered magenta bodies are present. They are closely similar to those of the heterophil. except that there is less tendency to form rings. If rings are present, they are usually small. Vacuoles are present in the cytoplasm but they are less uniform in size than for the other two preeeding granulocytes. The nucleus is eccentric and has a coarse chromatin pattern.

Mesomyelocyte.-This cell is smaller than the preceding one. The nucleus usually is not in the center but is not completely eccentric. The cytosome contains less than half the number of granules found in the adult cell. The water solubility of the granules is a confusing factor in estimating number.

Metamyelocyte.--This cell contains more than half the total number of basophil granules. The nucleus is near the center and is composed of a dense chromatin network.

Mature basophil.-This cell contains a full complement of granules. The nucleus is a single body in most cases, but occasionally it is divided into two lobes.

\section{OSTEOGENIC CELLS}

Primordial osteogenic eell.-A large amoehid cell with lightly stained cytoplasm containing clear vacu- oles. There are relatively few mitochondrial spaces. The cytosome is large relative to the nucleus. The nuclear chromatin is finely punctate and a nucleolus is present that stains light blue.

\section{Osteocyte Series}

Immature osteoblast.-The nucleus is placed eccentrically. Large and definite mituchondrial spaces are present. Usually there is a clear area on the side of the nucleus toward the center of the cell. Clear sphcrical vacuoles are present in the eytosome. The nucleus stains darkly with uniform granulation, and usually one blue-stained nucleolus is present.

Mature osteoblast.-A darkly stained cell with well developed, elear areas adjacent to the nucleus. All parts of the cytosome are filled with mitochondrial spaces. The nucleus has a pattern of granular chromatin, and a nucleolus is present.

Osteocyte.-This cell has not been seen in smear preparations of bone marrow since it is emberded within the substance of the bone.

\section{Osteoclast Series}

Mononuclear osteoclast.-This cell elosely resembles the primordial osteogenic cell. The nucleus may be in the center of a round cell or at one end of an elongated cell. It contains a mixture of delicate racuoles com. posed of mitochondrial spaces and eosinophilic accumulations. Also present are some clear vacuoles with a definite spherical shape. The nucleus is composed of particulate granules on a linin network and beneath this a nucleolus is visible.

Multinuelear osteoclast.-This is the only giant cell of the arian lone marrow. The cytosome contains hasophilic and sometimes eosinophilic substances, and the latter usually are concentrated in the central part of the cell. Many vacuoles and granules and sometimes irregularly shaped hodies are present in the cytosome. The borders of the cell are poorly defincd. The nucleus is large and round; it contains relatively fine, punctate granules; a single nucleolus is present.

\section{PLASMACYTE SERIES}

Plasmublast.-This cell may be a primordial osteogenic cell or a reticular type cell. It has not been identified thus far.

Early immature plasmacyte.-The ratio of cytosomal to nuclear size is about the same as in the monocyte. The cytosome contains vacuoles and mitochondrial spaces, and the ground substance stains a clear blue that is more transparent than the basophilic cytoplasm of most other young cells.

Late immature plasmacyte.--The cytoplasm in this cell is colored the same shade of blue as in the preceding stage, but there are fewer mitochondrial spaces 
and more racuoles. 'The uncleus is small in relation to the cell area, and is darkly stained. There is a clear area in the cytosome at the side of the nucleus.

Mature plasmacyte.-The cell may vary in size from large to small, and the cytosome contains numerous granules, ranging from large to small. The nucleus contains condensed blocks of chromatin and is located against the cell wall. A clcar area adjacent to the unclens is present in most mature plasmacytes.

The definitions that have been presented are in reality brief deseriptions of each cell type, and the nse of these, combined with the illustrations, should make it possible to put together quickly the necessary facts for identification of any mature or immature cell without extensive reading.

Brief mention of some terms used in general eytology may be helpful. The cell is composed of two main parts-nucleus and cytosome; the former contains nucleoplasm and the latter, cytoplasm. If a large dense mass of basichromatin lies within the nuclens, it is called a karyosome or karyosome mucleolus, and if the mass or sphere takes acidophilic dyes, it is called a plasmosome or plasmosome nucleolus, and if both karyosome plasmosome are present, the two form an anphinucleolus.

Wherever color is mentioned, it is understood that Wright's stain was used on smears of the circulating blood of the hatched chicken. and MayGrimwald Giemsa was usel for immature cells found in embryos and in hemalopoietic organs of both emhryo and hatched chick. Any exceptions to this lave been noted in the legends or text. These two stains give closely similar colors on the same cell, lut the latter produces a somewhat more intense coloration.

\section{MAGNIFICATION}

The measurement of blool cells is an im. portant field of study, and especially so on erythroeyles, which have a definite shape and are held by a firm stroma. Some measurements of length and of width of elongated cells and of diameters of circular cells and of areas of irregularly shaped cells have heen undertaken in this sudy. Not as much emphasis has been put on cell size as in some atlases on luman blook.
Size is a helpful adjunct to cellular morphology for the categorizing of eells into types and into stages of development, but if one takes away color, form, and internal strueture, then size alone becomes a rather inadequate tool for cell identification. This is especially true of eells prepared for sudy by the smear method, which flattens them as broadly as their membranes will permit. Smears from bone marrow and other hematopoietic organs showed this quite clearly: in an area where the smear was thick, the cells were smaller, but at the elges of a group of cells they were larger and, in many cases, were stretehed to the breaking point in drying. In the wet-fixed smear the cells are much smaller than in the dried smear and they often appear slrunken. Compare, for example. the size of basophils that have heen fixed by drying in air ( figs. 385-387) with similar cells fixed in methyl alcohol (figs. 388-390).

Most often the visual impression of size as seen microscopically forms the hasis for the statement that a cell is large, or medium, or small and, only rarely, is the filar micrometer taken out of the box and actual measurements of size made. True, actual measurements should be taken more often than they are, but the fact remains that we depend to a great extent on mental impressions for a comparative estimate of the size of objects. Therefore, in order to avoid confusion in making these impressions from the il. lustrations, only two magnifications have been used-one called low power and the other, high power. Two scales have been construeted (fig. $1, D$ and $E$ ). One. $D$, is equivalent to the measurements in microns at a magnification of $1370 \times$ and the other, $E$, at $2470 \times$. With these seales the size of any cell or its part can be esti. mated fairly closely, since all cells. both at low and high magnification, were drawn carefully with a camera hueida.

The low-power drawings were made at an optical magnification of $400 \times$ and a magnification when projected on drawing paper of $913.3 \times$. The high-power drawings were made at an optical magnification of $1125 \times$ and a projected magnification of $2470 \times$. By optical magnification is meant the theoretical value obtained when the magnification of the oljective is multiplied by the magnification of the eyepiece. The lowpower drawings were made hy using a $20 \times$ objective and a $20 \times$ ocular. and the high-power 
drawings were made with a $90 \times$ objective and $12.5 \times$ ocular. During the engraving process, all the low-power drawings that originally were approximately $3 \times 3 \% / 8$ inches were increased in size 50 percent, so that, as presented here, they are $4 \frac{1}{2} \times 5^{13}, 16$ inches or slightly more. Therefore, in the low-power drawings, the cells are shown at about 1370 times their natural size.

The purpose of the low-power drawings is to give the overall impression that one has when looking throngh the microscope and observing different kinds of cells in the same field. Under such conditions one can distinguish minute differences in color, tone, or textme that often vanish when single cells are removed from the en. viromment of other cells, even when they have been drawn at a much higher magnification. The low-power drawings serve another purpose in that they contain about four times as many cells as are represented in the high-power drawings; therefore, the same cell type shown at high magnification can be presented sufficiently often so that deviations from the typical are fully illustrated. If all these variations were presented as high-power drawings the Atlas would be unduly large.

An outline of the individual cells of each lowpower drawing is given on the facing page along with the legend. Identification of the cells in the field is made by numbers placed on or near the cells of the outline drawing.

Blood from mammals often spreads mevenly over the slide when the smear is made and in particular shows a clumping of platelets and an aggregation of leukocytes along the margins of the preparation. In order to reduce this tendency as much as possible, the mammalian hematologist has often used coverglass smears. This has not been necessary for preparations of avian blood because the cells in the average well-made smear do not segregate, there is no clumping of thromlocytes, and the erythrocytes do not rearrange themselves in rouleaux formation. The simplest and easiest method is to place a small drop of blood on the end of a "pusher" slide and to touch this to one end of another slide where it is held for a moment-long enough for the drop to spread to each edge of the pusher slide. The latter slide is then steadily and rather quickly slid to the opposite end of the "smear" slide at an angle of about 45 degrees.

The appearance of the typical blood smear in which there is a relatively even distribution of cells is obtained from all hatched chickens, except laying hens, as shown in figure $1 F$. The scratches and abraded spots that often come when the slides are blotted or handled ronghly are included. The appearance of a smear made from the blood of a laying hen is shown in figme $1 \mathrm{G}$; the fat globules in the serum spread when the smear was made and pushed the cells of the undried layer aside. This, however, disturbed only slightly the mniformity of distribution of cells and did not cause certain cell types to segregate.

\section{ARRANGEMENT OF SUBJECT MATTER}

It is often helpful to the reader of a scientific hook if the writer reviews briefly the general plan of organization and what was in his mind when seemingly unrelated things sometimes were placed beside each other. In this study, the list of chapter headings reflects the scope and sequence of the fields covered.

Nore emphasis has been placed on the sulject matter of the second chapter than on any other. It contains almost as many drawings as do all other chapters combined. The purpose of this emphasis is to give as much help as possible to the field worker in poultry diseases, whose first consideration when confronted with an mnknown condition is to arrive as quickly as possible at a preliminary diagnosis.

The four categories into which the study of each cell type is grouped is best exemplified in the erythrocyte series from the circulating blood of the hatched chicken. These series fall into the following classifications: (1) Normal mature cells, (2) normal inmature forms found in circnlating blood, (3) abnormal cells, and (4) artifacts. Sometimes the varicty of immature cells found in circulating blood is so greal that these cells appear to represent the complete developmental series, but they were inchuded moder the circulating blood to indicate the range of cell types that might he picked up in a general examination. In the study of embryo circulating blood and blood from hematopoietic organs, these cells are shown in their proper setting in the form of a complete series. This may appear to be a duplication of effort. but it has proved to be of great hely, in the exact characterization 
of a cell type or stage of development hecause, as already mentioned, immature cells when they are carried by the circulating blood often have an appearance that is different from that presented when they are in the cnvironment of the organ from which they came.

A distinction has been made between abmormal cells and artifacts; actually there is a third category, namely, variations from the typically normal, and to place cach atypical cell in the correct one of these three categories has taken far more study and experimentation than finding, illustrating, and describing the "typical" cells. Likewise, the possibility of error is greater, so that future research may well discover that what has been called abnormal is, in reality, an artifact, or merely a variation of the normal. Cells are called abnormal on the assumption that the abnormality in them was present within the body of the bird, and artifacts are considered to be deviations from the normal that presumably were cansed in the process of taking blood, or drying it, or applying the stain. Since so much less is known of the cytology of immature blood cells than of the mature types, the series of $\mathrm{cx}$ - amples showing abnormalities and artifacts are much fewer in the chapters on embryo blood and on bone marrow cells than in chapter 2 .

Chapters 3, 4, and 5 have much in common in regard to their subject matter; they all deal with cells during development. This is true, whether the cells were collected from functional circulating blood of the embryo or from various hematopoietic organs of embryo or adult.

Chapter 6 is devoted primarily to a description of blood cells of avian species other than the chicken. It was soon discovered that similarities in the morphology of blood cclls of different species were much greater than differences. Included also in this chapter is tabular material on cell sizes and cell counts.

A chapter on technic was included at the end of the volume. Sometimes it happens that seeming differences in cell morphology can be traced to the use of different technics by different investigators. It was hoped that this difficulty might be avoided if the technics used in this study were set forth. Many methods in addition to those discussed here have been applied to avian blood sudies. 


\section{Circulating Blood of the Hatched Chicken}

\section{ERYTHROCYTES}

\section{Normal mature erythrocytes (figs. 1-8)}

The "lypical" erythrocyle of birds has often been described as an oval cell with an oval nucleus (Goodall, 1909; Foot, 1913; Magath and Higgins, 1934; and many others). Forkner (1929) has described in detail its appearance in vital slainerl preparations. The muclems is not quite concentric with the contour of the cell: there is a wider margin at the poles of the cell than at the sides. The cytoplasm takes an orange pink color with Wright's stain and with May. Grünwald Girmsa gives a distinctly more red. dish color. The micleus stains intensely but reveals a pattem of chromatin clumps more or less uniformly distributed. If the nucleus has an oval shape, there are no massive chromatin chumps. If the nueleus is contracted to an elongated ror-shaped structure, dense clumps of chromatin are nsually present. A nucleolus is absent.

Low-power views are presented in figures 2 and 3 . The slide from which figure 2 was made came from the flock of Single Comb White Leglorn chickens maintained at this Laloratory, and figure 3 was drawn from a set of 25 slides obtained from the same breed at another location, which for convenience has been designated as Laboratory No. 2. Thus, even in these two samples, differences can be observed and prob. ably could be extended if a careful study were made of blood from many sources.

A typical cell is shown in fignre 4. It was necessary to do considerable searching to find this "typical" cell. Examples are shown also in figures 2, 7 and 3, 7. All the other cells deviate from it in shape of mucleus or cytosome or holls. The cells may be too round or too elongate or irregular (fig. 3,5). The unclei may be too large or too small for the cytosome (figs. 2. 10 and 3,10 ); the long axis of the nuclei may not coincide with those of the cells that contain them, or they may be eccentrically placed (figs. 2, 9 and 3,9 ); the muclei may not be in the center of the cells and may be blunt at one end and pointerl at the other. Nost conspicuous of all are the indentations (figs. 2, 11,12 and $3,11,12$ ), constrictions (fig. 2, 13), and protrusions (figs. $2,14$ and 3,14$)$. Even duplications of the nu. clei (figs. 7, 8, and 29) may be found. As far as can be determined, these are all normal cells and in spite of their multiplicity of shape they are all instantly recognizable as mature erythrocyles, hecause the hemoglobin gives to the cyto. some a strong affinity for acid dyes and a nearly homogeneous texture. In some cases a narrow rim of cylosome around the mucleus stains lighter than the more peripheral part, but this is probably an artifact that dereloped when the cell was flattened in the process of making the smear. This perinuclear space is shown in figure 2 but not in figure 3. The clear space, as suggested, may arise as an artifact but its occurrence in one smear and not in another may be worthy of further study. A perinuclear space appears in all types of blood cells. except the heterophil. when the smear has heen fixed in Petrunkevitch No. 2 , and tained in Nay-Grünwald Ciemsa (figs. 198-202, 215, and 221). Following this technic the nucleus of the erythrocyte appears to be almost a solid chromatiu mass.

Suggestions conceming the origin of multipolar and giant erythrocytes and lenkocytes in man have been given by Schwarz (1946). He helieves these conditions can be traced back to multinuclear conditions in the immature stages.

Certain types of variability have significance. Anong the 25 blood smears received from Laboratory No. 2 there were several in which the nuclei of the erythrocytes were longer and nar. rower (figs. 3, 8, and 5) than any found in smears from our flock. Also, the chromatin was more condensed and more heavily stained. The significance is not known but the same type of erytlrocyte has been observed in some of the smears 


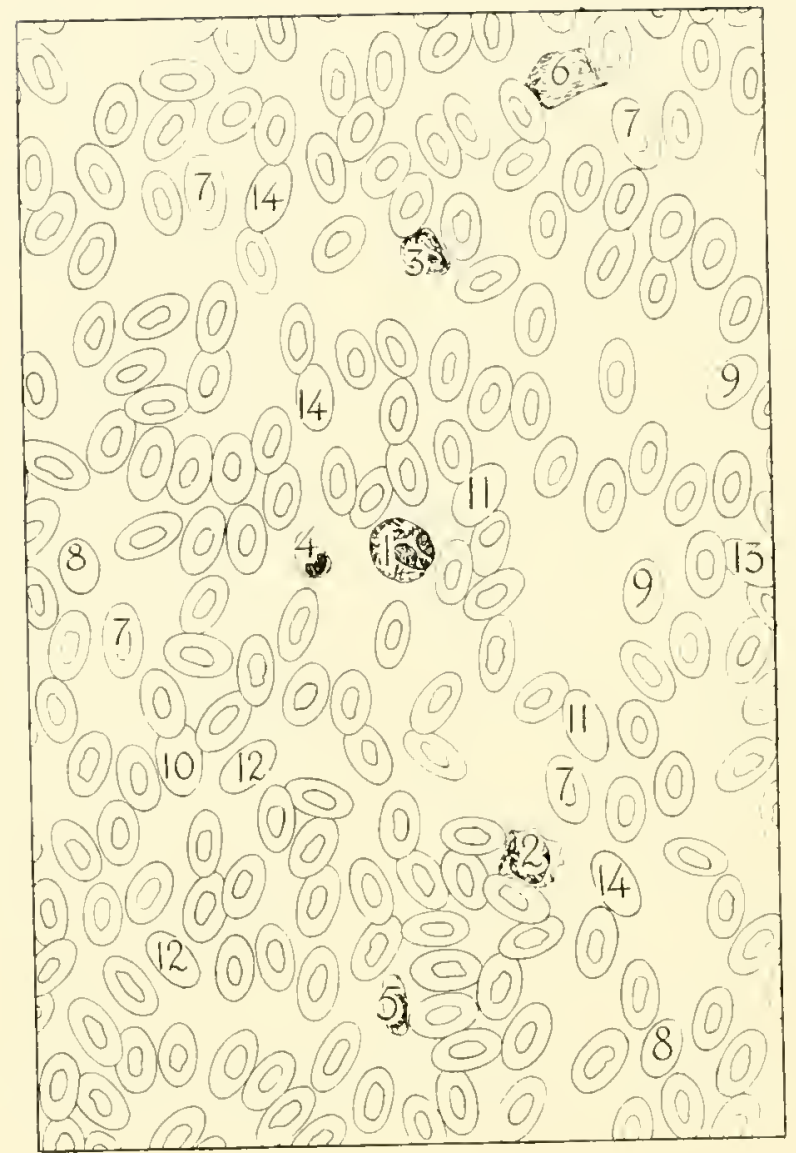

Figure 2.-Appearance of a typical smear made from the blood of the basilic (cubital) rein of a single Comb White Leghorn chicken. This bird, raised in isolation, was 2,095 days of age when the smear was taken. $1,370 \times$.

I Heterophil.

2, 3 Lymphocytes.

4,5 Thrombocytes.

6 Squashed erythrocyte nueleus.

7 Typical erythrucytes.

8 Erythroeytes smaller than average.

9 Erythrocytes with eecentrically placed nuelei.

10 Round undersized nucleus.

II Erytlurocrte nuclei indented at one end.

12 Ervthrocrte muclei indented on one side.

13 Errthrocyte with constricted nucleus.

It Erythrocyte nuclei with protrusions. 
8

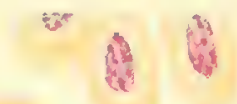

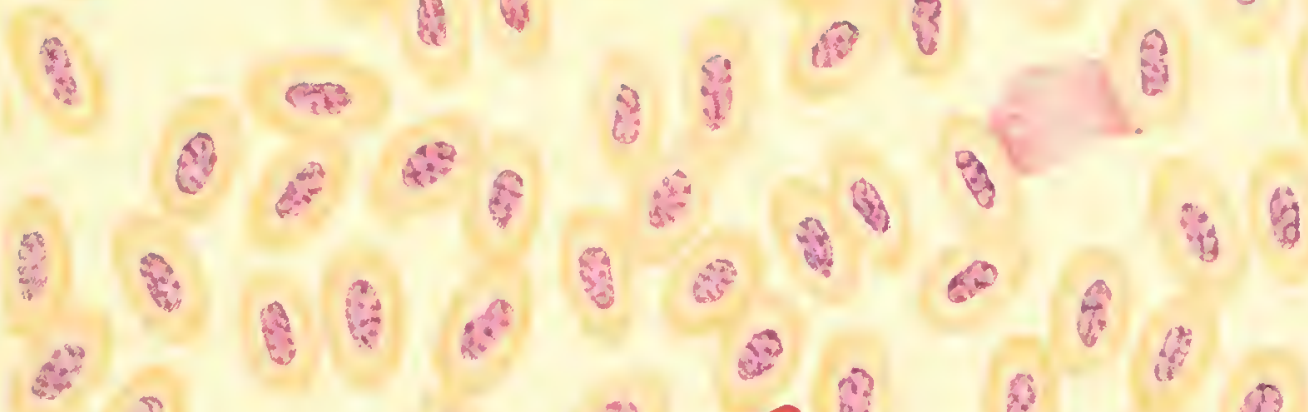

술

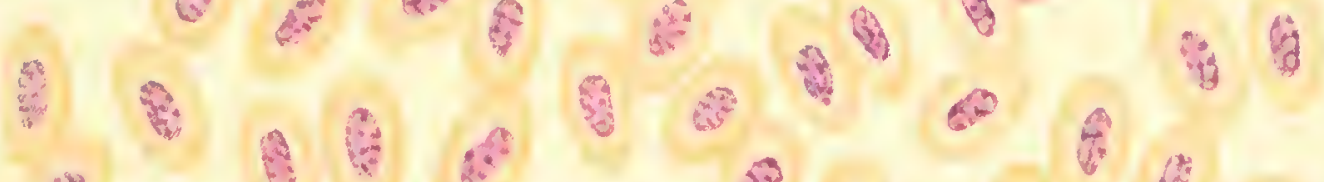

(4)

(6)

(9) 8

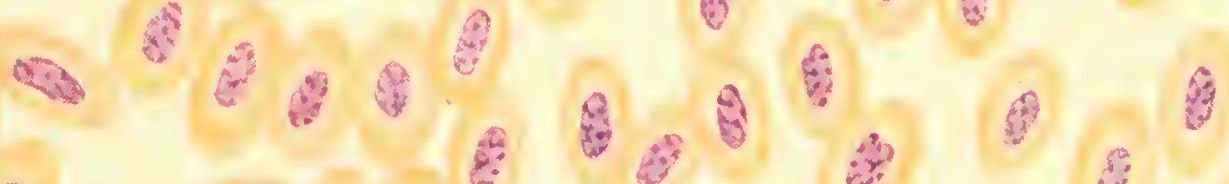

(2)

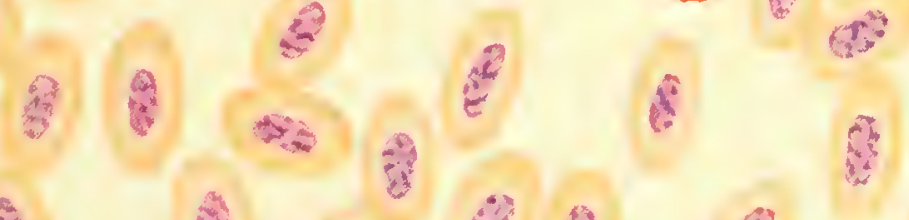

2.

象

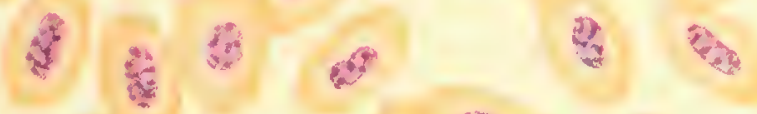

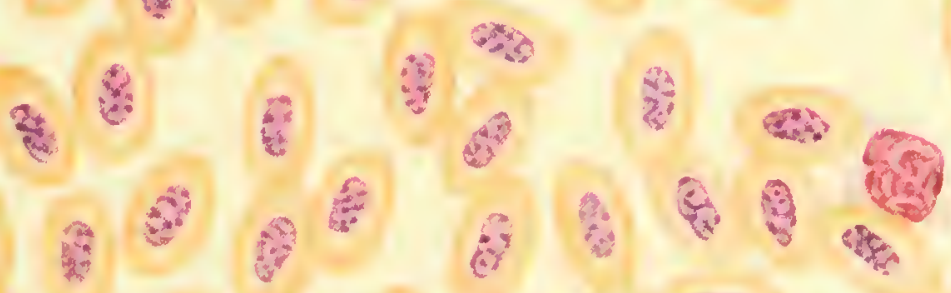

a 9

ค1

중

(3) a. 6 


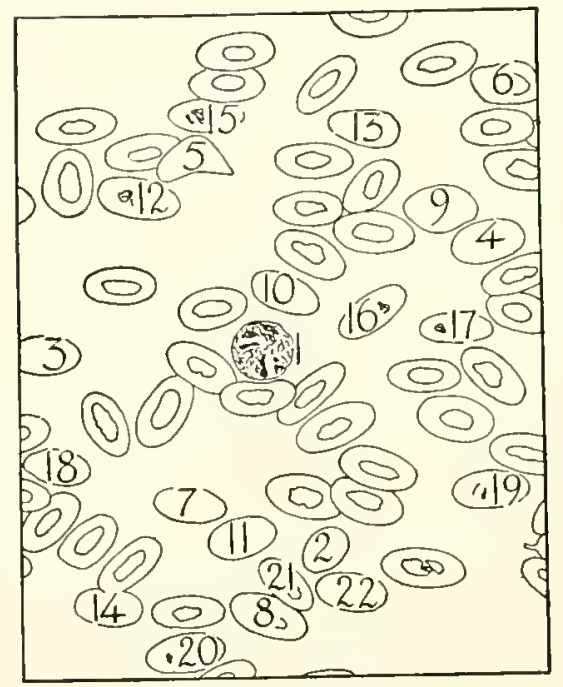

Figure 3.--Appearance of an atypical smear from a Single Comb White Leghorn. The cause of the chromophobic bands in the nuclei of heterophils and of erythrocytes is not known. $1,370 \times$.

1 Heterophil showing chromophobic bands across the nuclear lobes.

2 Erythroplastid.

3,4 Late polychromatic erythrocytes.

5, 6 Erythrocytes in which the distorted shapes may have been acquired during the making of the smear.

7 A "typical" erythrocyte.

8 Erythrocyte with an elongated, dense nucleus.

9 Erythrocyte with nucleus eccentrically placed.

10 Erythrocyte in which the nucleus is undersized and almost round.

11 Erythrocyte with nucleus indented at one end.

12 Erythrocyte with nucleus indented on one side.

13 Erythrocyte with a pyknotic nucleus.

14 Erythrocyte nucleus with a protrusion.

15-22 Erythrocytes showing chromophobic bands across the nuclei. 


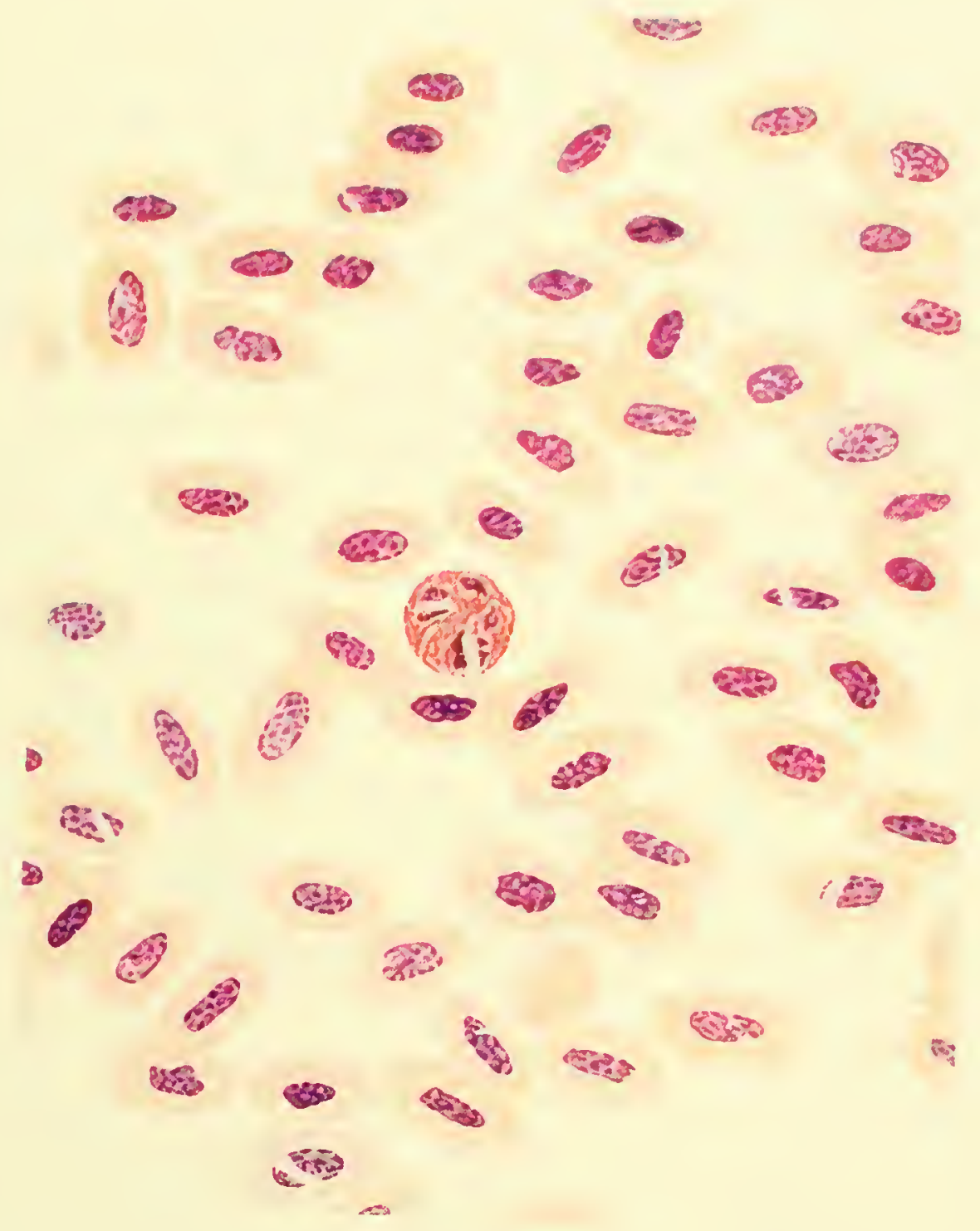

3 


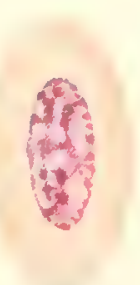

4

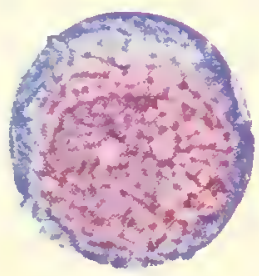

9

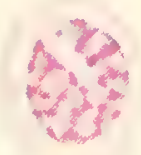

14

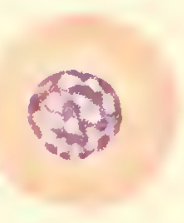

19

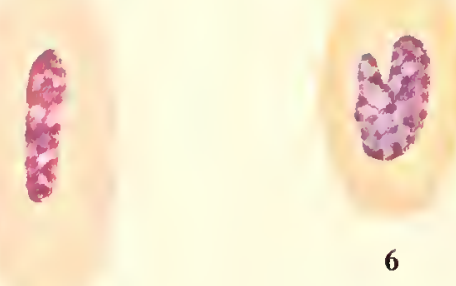

5
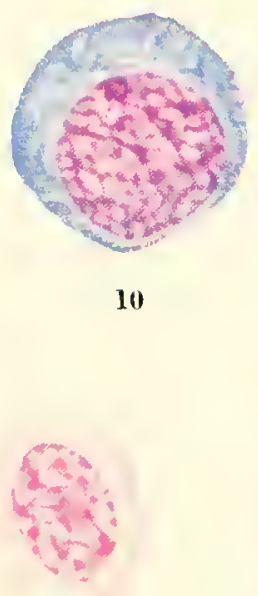

15

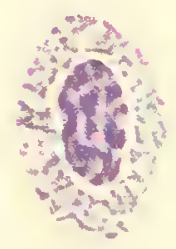

20

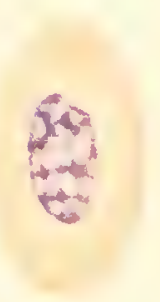

21

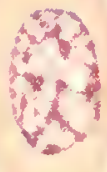

16

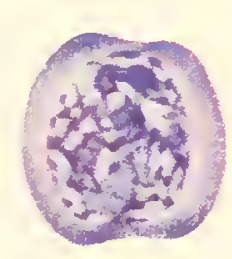

11

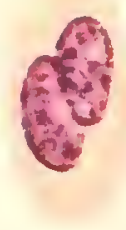

7

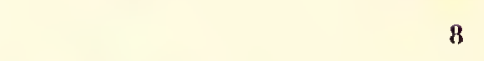

3
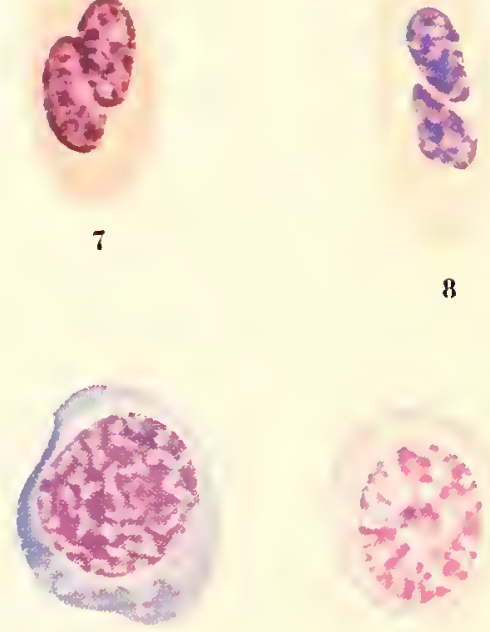

12

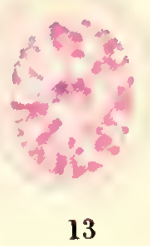

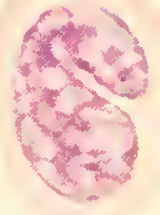

17

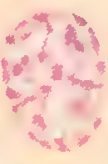

18

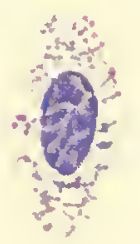

22

23
21

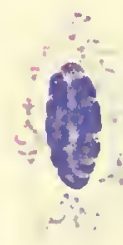

21

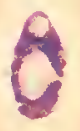

27

28
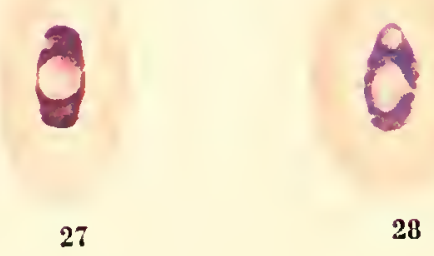
from wild birds. In starking blood, for example, the condensed chromatin beneath the nuclear membrane produces a bumpy conlour like that of a mulberry. A narrow condensed nuclens is found also in the common mallard duck. In fact, in this species cells showing the two nuclear types are found in the sane smears. For convenience, one (fig. 4) may be designated as the ovoid, leptochromatic type, and the other as the elongated, pachychromatic type (fig. 5). Breusch (1928) makes the statement (p. 224), “. Allgemein kann man weiterhin feststellen, dasz je jumger die orthochromatische Zelle is, um so mehr bezitzt der Kern Blaschenform. . . ." However, no data to support this opinion are presented.

Studies are needed on blood physiology and chemistry that would aid in the evaluation of the

'Translation: In general one may state that the younger the orthochromatic cell is, the more its nucleus has the vesicutar form. relative merit of each type in relation to the general vigor of the bird. This is a point of more than academic interest. One hypothesis might be that a smaller, more condensed nucleus permits the existence of a proportionally larger cytosome and hence a greater content of hemoglolin. Another hypothesis stems from the fact that an oval leptochromatic nucleus is characteristic of immature cells and a conden. sation of chromatin is associated with older cells. The condition in the common mallard duck of at mixture of these two types of erythrocytes is some evidence for this hypothesis. Therefore, it is possible that in our Laboratory stock the erythrocytes show a type of nuclens not fully developed because the cells are destroyed before they reach full maturity.

The existence of amitosis in mature erythrocytes has been suggested in amphibians (Charipper and Dawson. 1928). Up to a certain point

Figures 4-28.- Normal erythrocytes immature, mature, and aged-found in the circulating blood of the hatched chicken. $2,470 \times$.

Figures 4-S: Typical mature erythrocytes and variations.

4 Nature erythrocyte, typical for our I aboratory stock. Nucleus-oral leptochromatic type.

5 Mature erythrocyte, typieal for some other stoclis and breeds of chickens, for other domesticated birds, and for wild birds. Nucleus-elongated, pachychromatie type.

6 Normal erythocyte with nueleus indented at the end; similar to figure 2,11 .

7, 8 Mature erythroeytes with two muelei. The eell in figure $S$ shows that the two nuelei may be eompletely separated.

Figures 9-23: Immature cells.

9 An erythroblast, equivalent to that in figne 25., which is from the embryo.

10 A late erythroblast, equivalent to, but smaller than, that in figure 347 , which is from the bone marrow.

11 Early polyehromatie erythrocyte, equiralent to those in figures 264 and 348 , which are from the enbryo and the bone inarrow, respectively.

12 Early polychromatic erythrocyte. A few lightly stained spaces characteristie of the erythroblast are still risibte in the cytoplasm.

13 Mid-polychromatic erythrocyte, equivalent to those in figures 350 and 351 , which are from the bone marrow.

14 Mich-polychromatie erythrocyte.

15 Transition between mid- and late-polychromatic erythrocyte, but included with the latter type.

16 Late polychromatic erythroeyte.
17 An atypical late potychromatic erythroeyte.

18 Late polychromatic erythrocyte. This and figure 16 are typieal of cells at this stage.

19 Mature erythrocyte. Nucleus and stroma differentiated ahead of changes in cell shave, and thus the round shape is fixed. A similar reaction is often found in first generation of erythrocytes in the embryo.

Ficteres 20-23: Reticulocytes from the circuloting blood of 1-day-old chicks.

20 Early stage of reticutoyete; granules are abundant.

21 Sane stage as preeeding cell. The color obtained with Wright's counterstain indicates that reticulocytes have full complement of hemoglobin.

22 Partial loss of reticulocyte granules.

23 Granular material is minimal in amount but is sufficient to establish the cell as a reticulocyte. Smaller amounts are confused with precipitated stain.

Figures 24, 25: Malure erythrocytes.

24 The type characteristic of Laboratory stock.

25 A eell approaching senility in Laboratory stock but typical for most other stocks of chickens and for most other birds. Compare with figures 2 and 3.

FiguREs 26-2S: Agcd erythrocyles.

26 Aged erythroeyte, undergoing pyknosis.

27 Aged erythrocyte with vacuolization of the meleus.

28 Aged ery throeyte showing continuity between intramuelear vaeuole and cytosome. 
there is some evidence for it in birds, such as shown in figures 2,12 and $13 ; 3,12$; and 6,7 . 8,17 , and 29 . Some indentations extend rather far into the nucleus and sometimes there are two completely separate unclei in the cell. Figure 29 demonstrates fairly clearly that a cell with two nuclei such as shown in figures 7 and 8 can be derived by constriction of a single nuclens and not by mitosis in which the cytosome failed to divide. Figure 17 is an early stage in the process of nuclear constriction. Cells $A$ and $B$ of figure 29 were from chickens used in an irradiation experiment. The history of the birds that furmished these cells is given in the legend. Nerilher of these two cells can be considered normal, but in $B$ the cytosone is partly divided and even though abortive, as it obvionsly is in this cell, fulfills some of the criteria for amitosis.

Charipper and Dawson (1928) believed that the erythrocytes of amphibians. which showed the same range of morplological variations found here in chickens. offered evidence for the occurrence of amitosis. As already discussed, cells with two nuclei or cells with constricted eytosomes (figs. 34, 35, and 36) may be found in avian blood, but the same two processes liave not yet been found in the same cell except in figure $29 B$ and in a primary erythrocyte (fig. 246). The idea of annitosis would be more convincing if one could find series of stages in which the nuclens was first involved and divided into hal res and each half moved to opposite poles when the cytosome divided. The point will be discussed again when artifacts are considered.

\section{Developmental stages found in circulating blood (figs. 9-28)}

Cells more immature than reticulocytes are so rare in the circnlating blood of the normal, healthy mammal that the presence of even an occasional one in a smear is suggestive of a pathological condition. In avian blood the presence of immature erythrocytes is common and as far as we know now, an occasional immature cell does not indicate a blood dysfunction. Inmature stages are found in birds of all ages, and three birds that were over 5 years of age contributed examples of polychromatic erythrocytes in the series of figures presented here. If one seeks stages earlier than polychromatic erythro- cytes, considerable searching is necessary, but even erythroblasts so immature that they might be classed as large lymphocytes have been found (figs. 9 and 10).

Since blast cells of various sorts and potentialities have close morphologic similarity among themselves and in turn resemble what has been called a large lymphocyte, it seemed best as far as circulating blood is concerned to discuss them ninder the subject of lymphocytes, and four examples have been illustrated (figs. 121-124). Some differential counts given in the literature would indicate that large lymphocytes were pres. ent to the extent of 1 percent and over. This must be a different cell from the one described here since the "large lymphocytes" observed in these studies occurred so infrequently that they would not be included in a differential count. Further amplification of the point will be made later (p. 50), but figure 121 has the characteristics that identify it as an erythroblast and thus could be inchuded among the series of developmental stages shown in figures 9-23. A discussion of other stucural features that distinguish an erythroblast from other blast cells is given on page 9 .

Then development has reached the stage of an early polychromatic erythrocyte, there is no longer confusion with other cells, and typical examples are shown in figures 11 and 12 . Mitochondrial spaces may or may not be present in the cytosome, and cells at this stage of development have not as yet aequired the homogeneity of cytoplasm that comes later. Sometimes the cytoplasm is vacuolar as shown in basophil erythrocytes from hone nuarrow (figs. 348 and 349 ). In figure 11 there is a faint suggestion of a mucleolns near the lower nuclear margin. The term "erythroblast" has been reserved for the early stages of development where a meleolus is present. yet in the red-cell line the nucleolus may still be visible at the early polychromatic stage and in the primary generation of the embryo, even to the mid- and late stages. The early polychromatic erythrocyte often has been called a basophil erythoblast, hut actually sone hemoglobin has already been acquired at this stage.

The polychromatic phases of erythrocyte development are represented by cells in which the cytoplasm possesses an affinity for both basophilic and acidophilic dyes in various propor- 
tions. Thus, there may be found a complete range of color from a basophilic cytoplasm with a trace of hemoglobin (fig. 11) to a cell that has a high hemoglobin content and only a trace of basophilia (figs. 16-18). The early polychromatic erythrocyte is characterized by a blue cytosome, the mid-polychromatic erythrocyte by a gray coloration, and the late stage by various tints of orange. A mixture of blue and orange produces gray, and in some cases the yellow portion of cosin mixed with blue adds a slightly greenish tinge. With a shift from a predominantly basophilic to predominantly acidophilic cytoplasm there is an accompanying progression of changes involving cytoplasmic texture, melear structure, nucleocytoplasmic ratio, and cell shape. Each cell passes through an infinite number of steps, but for purposes of communication we arbitrarily break up a continuous series into segments; three seems to be the most workable number, and these, as already indicated, are called, early, micl-, and late.

The color of the cytoplasm serves as the primary criterion in identifying each of these three phases. Figures 11 and 12 are examples of early polychromatic erythrocytes, as has already been mentioned. An important nuclear change is an increase in the amount of chromatin chmping beyond that observed in the erythroblast. The cytoplasm has taken on some of the homogeneous textural characteristics found in the mature erythrocyte. This is variable, as shown in these two figures, and is not very closely synchronized with the degree of basophilia. The size of nucleus in comparison with the size of cytoplasm usually shows a definite decrease in the shift from erythroblast to early polychromatic erythrocyte, but this, also, is not constant. In general, this cell is somewhat smaller than the crythroblast but size in itself is not a reliable criterion for separating the two stages of development. These points are examples of the lack of close synchronism between different parts of the cell during development. Actually the cell in figure 11 is relatively rare, even in bone marrow. Its homogeneous cytosome combined with strong basophilia is not typical. Figure 12 is more typical in that there is some evidence of mitochondrial spaces and of irregularities in cytoplasmic structure. These may persist even up through the mid-polychromatic erythrocyte stage of development (figs. 13 and 14).
The classification of stages in the development of erythrocytes on the basis of hemoglolsin content has not found general acceptance by hemotologists working on hmman blood, and the point is illustrated by Osgood's (1938) statement (p. 67 ), "However, it seems to the author unjustifiable to use the amount of hemoglobin in the cytoplasm as the criterion of the age of the individual cell since many polychromatophilic akaryocytes (nomucleated red cells) are secn which contain practically no liemoglobin and these must certainly be more mature than nucleated red cells which contain much hemoglobin. If one uses the nucleus alone, however, as the criterion of the maturity of the coll, one can arrange a continuous series, cach one differing from the neighboring cell by an ahmost imperceptible degree, from the most immature karyoblast (megaloblast) to the most mature metakaryocyte (normoblast) which is just losing its mucleus." This point of view is probably entirely justified for erythogenesis of mammalian blood, but in avian blood where the red cells do not lose their nuelei, the color changes within the cytosome seem to be a much more relial,le criterion of progressive cellular differentiation than the alternate ones suggested by Osgood for man. It is agreed that hemoglobin uptake and structural differentiation are not always synchronized.

Dantschakoff (1908b) faced the same problem in her" use of the term "polychromatic." Her comments (p. 519) are interesting.

"Da die jungen, eben erst aus den farblosen Elementen entstandenen primitiven Erythroblasten noch sehr wcnig Hämoglohin enthalten, erscheint ihr Protoplasma nach D., EA- und G. Färbung in einem Mischton von blan und rosa tingiert, weil es eben seine ursprïngliche Basophilic nur noch zum kleinsten Teil eingebiisst hat. Hämoglobinführende Zellen mit ähnlich reagierendem Protoplasma werden hekanntlich bei verschiedenen Tieren und auch beim Menschen im erwachsenen Körper bei verschiedenen Krankheitszuständen im Blute gefunden and sie erhielten in der Pathologie den Namen "polychromatophile Erythrocyten resp. Erythroblasten’. Das Wesen dieser sogen. Polychromatophilie wurde von verschiedenen Autoren sehr verschieden aufgefasst. Ehrlich (15 u. 16) betrachtet sie als Folge anänischer Degeneration, wobei die Erythrocyten den Blutfarbstoff ins Plasma diffundieren lassen; einen ähnlichen 
Standpunkt nehmen ferner fiir manche Fällc auch Aschheim (2) unl Pappenhcim (37) ein, wohei sie jedoch in anderen Fällen die Polychromatophilie fïr den Ausdruck einer noch nicht vollendeten Reifc der Zelle erklären. In Gegensatz dazu halten Heinz (23) und Troje (49) die Polychromasie als Folge der Auflösung des Chromatins in Zellleib.

"In meinem Falle treten ausgesprochen polychromatophile Hämoglobinzellen, die primitiven Erythroblasten in frühen Stadien normaler Em. bryonalentwickelung auf; in diesem Fall ist also diese Erscheinung sicherlich das Symptom der Jugendlichkeit der Zelle. Für das Blut kann man vielleicht überhaupt den Satz aufstellen, dass die Basophilie das typische Merkmal junger, noch nicht differenzierter Zellformen ist."

Cells of the mid-polychromatic erythrocyte stage of development (figs. 13 and 14) are usually smaller than they are in the preceding stage. The nucleus may he large or small in relation to the total cell size, and the pattern of chromatin condensation is intemediate between the two extremes represented by the erythroblast and the mature erythocyte, in that there is considerable condensation, yet there still remain numerous open spaces in the linin network through which the nonstaining nucleoplasm is exposed. The cytosone in many cells is not entirely homogeneous, and vague traces of mitochondrial spaces

\footnotetext{
${ }^{2}$ Translation: Since the young primitive erythroblasts that have just appeared from the colorless elements still contain very little hemoglobin, their protoplasm appears tinged a very little hemoglobin, their proter D., Ea-, and G-coloring, since it has so far lost just the least bit of its original hasosince it has so far lost justuring cells with protoplasm of a similar reaction are known to be found in the blood in differ. ent animals and also in men in the mature body, under various pathological conditions. In pathology these lave the name "patholiromatophilic erythrorytes or erythroblasts." The na"fore of very differently by different authors. Ehrlich (15 and 16) viewed it as the result of anemic degeneration, in which the erythrocytes let the blood pigment diffuse into the plasma; ex many cases by Ascheim (20) and Pappenheim (37), wha explain the polychromatophilia even in other cases as the expression of a still uncompleted maturity of the cells. On the other hand, lleinz (23) and Troje (49) consider polychromasia as the result of the dissolution of the chromatin in the cell body.

In ny case, pronounced polychromatophilic hemoglobin cells appear in the early stages of normal embryonic development: the primitive erythroblasts; thus in this case this phenomenon the primitive erythroblasts; thus in this case this phenoment. Pertans one can establish the principle generally for the blood, that basophilia is the typical sign of ynung, still un differentiated cell forms.

The numbers in parentheses rofer to references in Dantscha. koff's bibliography. "D.," "Ea-," and "G-" refer to Dominici, Eosin-azure, and Giemsa stains.
}

often remain. The characteristic by which this stage is identified is the presence of a graystained cytoplasm that may vary from bluish gray to a slightly orange gray.

The late polychromatic erythrocyte is the thind stage of the polychomatic series. The cytoplasm shows a definite orange tinge. In figures 15-18, which are examples of this stage, the cytosome. both from circulating blood (fig. 3. 3 and 4) and from bone marrow (figs. 352-354), is ahout as homogeneons as in the mature erythrocyte. Clumping of nuclear chromatin has progressed ahmost to that of the mature erythrocyte but the mucleus itself is not as compressed laterally as it will be hater. Even at this stage there is evidence of the variability in nuclear form found in the mature cell; the nucleus in figure 17 is deeply indented on one side. It may be a stage leading to a binucleated cell but, as al. ready stated, this is insufficient evidence that amitosis is a common method of multiplication for these cells. Figure 29, $A$ and $B$, which clearly shows separation of the nucleus into two parts, was made from late polychromatic erythrocytes, also.

The cell shape in the late polychromatic erythrocyte is approaching that of the mature erythrocyte but, like the nucleus, is still less compressed than it will be later. The slight angularity of cells found in dried smears has no biological significance; it is part of the tendency toward a hexagoual form due to crowding on the slide. As already mentioned, shape alone is a poor criterion of cell age-some cells assume an oval shape quite early during the process of hemoglobin acquisition while others accumulate their full complement of hemoglobin and still retain the spherical cell and nnclear shape usually associated with a relatively undifferentiated cell. Such a cell as figure 19 cannot be cata. loged properly as a mature erythrocyte. It might be laheled an orthochromatic erythrocyte, or with equal justification a cell showing anisocytosis."

\footnotetext{
s Another interpretation might be made from the observations of Sluatuck (1928), who followed the changes in shape tions of red cells under the action of lysins. He noted that chicken cells lost their oval shape and became round. $A$ similar cells lost their oval to a round shape was noted by Nesterow (1935) as an initial degeneration reaction when chicken (1935) as an initial degered intravenously into dogs and rabbits. Therefore, it is at least possible that the round shape of an erythrocyte in the chicken night, in some cases, indicate the first stage in degeneration.
} 


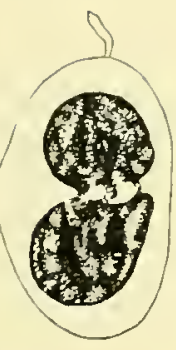

A

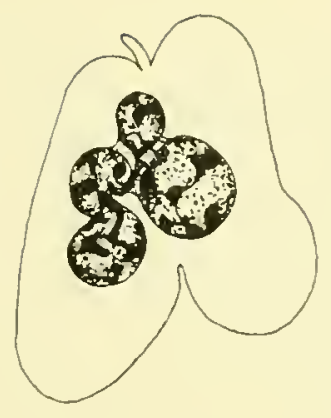

P
Figure 29.

A A double nucleus in an erythrocrte from a 6-rekt old Single Comb White Leghorn that, 3 days earlier, had received 900 c total body irradiation.

B An atypical erythrocyte found in a noniradiated bicd from the same stock and the same age.

This again points to the fact that the shape of the cell is not closely symehronized with color change, and not infrequently a cell may show its full complement of hemoglobin and yet remain as round as an early polychromatic erythrocyte. Thus, in any attempt to pigeonhole cells, one must select one "chief" criterion and let all others become subsidiary to it. Color. in the erythrocyte series, has been selected as the chief criterion, whereas nuclear development, vacuolization of the cytosome, and cell shape are regarded as subsidiary. This does not minimize the importance or significance of these subsidiary eriteria. They are indispensible for identification of cells and for an understanding of progressive change, but terminology based on multiple criteria leads to ambiguity and contradictions.

It was probahly some such cell as that represented by figure 19 that led Bizzozero and Torre (1881) to divide erythroeytes into three types(1) the typical erythrocyte, oval in shape; (2) the type that is spherical but has an oval nueleus and is intensely stained; and (3) a rare type distinguished from the typical erythrocyte by its more delicate contour, weaker staining, and somewhat shorter length, as well as by its larger and sometimes ahmost spherical nueleus. That type 2 includes immature cells is suggested by the further statement that these spherical forms appear somewhat nore abundantly in the blood of anemic animals and correspond to an earlier developmental form found in bone marrow. Their type 3 might be a thrombocyte, since thromboeytes are not otherwise mentioned in their. paper.

Reticulocytes have been mentioned occasionally in avian literature. Nagath and Higgins (1934) found that the percentages of reticulocytes for adult mallard ducks varied from 16.6 to 27.7 percent. This is considerably higher than the normal value of 1.47 pereent given for ehildren of various ages (Osgood, Baker, and Wilhelm, 1934). Wills (1932) demonstrated that in pigeons, reticulocyte counts do not remain at a steady and low level. Individual birds showed high counts during the holding period, for no accountable reason. Peabody and Neale (1933) had a somewhat similar experience. During 25 days confinement, the counts usually fell from 15-22 percent to $8-10$ percent, but in some individuals the counts went up again to 11-13 percent. To our knowledge no one has as yet earried out a study on the changes in reticulocyte counts in birds from the day of hatching to maturity, such as was done by Orten and Smith (1934) on rats. According to Magath and Higgins, the reticulations in the avian erythrocyte are composed of little dots along the strands of a basket network. As the cells grow older, the network disappears, leaving a few strands and dots.

Their description agrees closely with the cytol. ogy of this stage as observed in the day-old chick, where at first (fig. 20) there was an abundance of granules arranged on a reticulım. These form a band of uniform width around the nucleus, and when cells of this type are given a counterstain it is evident that the cell, if the reticular gramules had not been revealed. would he elassed as a mature cell (fig. 21), but others with reticulations appear to be late polychromatic erythrocytes. During the final step in the maturation of the cell the reticulum breaks apart and the amount grows less, but it stil] retains the perinuclear arrangement (fig. 22) and later becomes dissipated throughout the cytosome (fig. 23). It was hoped that the last stages in the disappearance of the reticular granules could be traced, but with the technics used (ch. 7. p. 230). there always persisted a certain amount of precipitate orer the slide, which, as it fell on the cells, resembled in size and color those granulations. These illustrations for reticulocytes are 
similar to those given by Hewitt (1940) in the frontispiece.

Richardson (1937) connted only those cells as reticulocytes in which the gramules completely surrounded the nucleus. In his material he found the normal count to be 7.8 percent with a standard deviation of \pm 2.39 . Robertson et al. (1947) showed that chicks that had been depriver of folic acid for 4 wecks held a relatively low percentage level of reticulocytes. One injection of folic acid gave a sudden increase in proportion of reticulocytes. The peak of the increase was reached on the sixth day. The percentage curve subsided to a normal level by the thirteenth day.

An excellent review of the occurrence of reticulocytes among various classes of verteluates and of the significance of the basophilic granulations in these cells has been presented by Orten (1934). His statement that sometimes nearly all of the erythrocytes in pigeons, chickens, reptiles, frogs, and fisles may be in the reticulocyte stage, is based on observations made by Seyfarth (1927). Graam (1931) fonnd a similar result in pigeons when she staincd for 10 to 30 minutes, but Scyfarth was aware of the fact that staining for a long time damaged the cells. He found that reticulocyte granules took up the stain in a few seconds. Yet, in spite of the precaution to keep the staining time short, sometimes he olstained preparations from lower vertebrates with a large proportion of the erythrocyles with reticular granulations. From his colored illustrations of reticulocytes in the bone marrow and blood of the fowl, he has included in the last onc or two steps of his developmental scries, cells which contained only a fer granulations. Had we included such cells in our studies as being reticulocyles, then we also would have been forced to the point of view that practically all erythrocytes in the circulating blood of either chicks or adult birds were reticulocyles hecause, as mentioned (last paragraph, p. 27), a precipitate was present orer these slides and stainable granules existed both between the cells and on the cells. Those on the cells resembled reticular cell granulations.

From our sludy of blood from normal adult birds, the reticulocytes are extremely rare and the possibility at least exists that the chicken would be a better experimental animal than the pigeon for the types of study that in the past have been applied to pigcons.

These are all points that can be settled by further study, but more significant at present are the observations of Seyfarth (1927) that reticulate granulations in mammalian blood are not limited to the phases of erythrocyte maturation that follow the extrusion of the normoblast nucleus. By the use of reticulocyte staining on cells from bone marrow, he found that these granulations were present at very early stages of development, when the cytoplasm was only a narrow rim around the erythroblast nucleus. As the nucleus became pycnotic at the late normoblast stage, the granules retained a perinuclear position, forming a ring around the last of the chromatin. After the chromatin had been entirely discharged, the reticular granules (he calls them substantia granulo-filamentosa) again scattered throughout the cytosome of the erythrocyte and then gradually disappcared.

An exactly comparable serics of stages was prescnted by Scyfarth from studies on the bone marrow and blood of the chicken, except that the nucleus was not eliminated from the cell. In birds the reticular granulations almost entirely fill the narrow rim of cytoplasm in the late erythroblast or the early polychromatic erythrocyte and as the nucleus condenses, the granules accompany its peripheral margin, thus leaving the periphery of the cytosome free from gramules. There is no normoblast stage in birds at which stage the nucleus is eliminated. but the behavior of the reticular granules gives an indication when this stage of development has been reached in the maturation process of the avian reticulocyte. This is indicated by the change from a condensed band of reticular granulation around the nucleus to a subsequent scattering of the granules throughout the cytosome. Disappearance of the gramules is taking place at the same time.

From these observations, it would appear that the mature erythrocyte of the bird is homologous to the mature erythrocyte of the mammal, and not to the erythroblast of man, as suggested by Burckhardt (1912).

The relicular granulations first appear in the ccll, immediately following the development of hemoglobin in the cell (Scyfarth, 1927). This agrees with Dawson's data on the occurrence of vitally stained granules in primary erythrocyles 
over a wide range of developmental stages (Dawson, 1936a).

A normal mature erythrocyte (fig. 24) has been included in order to make the developmental series complete. This forms the point of departure for the discussion of over-aged cells that follows. In summary, it is quite evident that all stages in erythropoiesis from the erythroblast to the mature erythocyte may le found in the circulating blood. It would appear that birds in general, inchuding the chicken, have a more labile hematopoietic system than manmals, and the presence of an occasional immature red cell cannot, at present, be regarded as abnormal or indicative of a pathological or diseased condition in birds. Wirth (1950) also observed greater reactivity in chickens than in mammals and stated that regeneration in the chicken was very vigorous; that it ends in abont a week, and that in mammals about 3 weeks are necessary for the same result. Polychromatic erythrocytes and erythrol,lasts occurred in very large numlers (up to a half million per cubic millimeter) and the reticulocytes became so numerous that they rose from 0 to 33 percent.

Splenectomy in pigeons (Toryû, 1930) raises the number of polychromatic erythrocytes from a control level of none to a quarter of a million and more. This increase comes the frrst day after splenectomy and continues for about 2 weeks and even after 50 days the level of immature erythrocytes does not return to the normal. Jordan and Robeson (1942) observed that splenectomy in pigeons increased the number of plugged vessels and lymphoid foci in the lone marrow. These authors interpret this as a compensatory reaction but the possibility of a different interpretation is discussed on page 181 .

Toryû (]931) also performed splenectomy on pigeons and an abstract of his article (1933) states:

"After complete splenectomy the marrow of the femm and tibia becomes fatty and inactive for erythrocyte formation, but active for lymphocyte formation: new haemopoietic tissne appears in the lobules of the liver and various stages of erythocytes are seen in the central veins and the capillaries of the acini. Splenectomy in adult carrier pigeons brings about a general circulation of polychromatophil cells, which amount to 3-8 percent of the red corpuscles in the blood. The hemoglolin content after the operation does not reach the normal level, probably owing to the presence of polychromatophils in the circulation."

Some physiological differences between mature and immature erytlirocytes of birds, the rate of maturation and the differences in these respects between hirds and mammals have been brought out in studies made by Wright (1930a and b) and Wright and VanAlstyne (1931), and reviewed by Orten (1934). Wright made use of the well-established fact that immature erythocyles have a lower specific gravity than mature erythrocytes. By centrifugation he separated the reticulocytes and other more immature erythrocytes from mature cells of chicken blood. He obtained the immature cells by repeated bleeding of adult birds and by injection of phenylhydrazine hydrochloride. He established the fact that the oxygen consmmption of all types of inmature cells was greater than for mature cells. This was true for mammals also, and it has been suggested that perhaps most of the respiration which occurs in mammalian erythrocytes is due to the reticulocytes present. In summary, Wright (1930b) says (p.213):

"A comparison is made of the respiration of the reticnlated nucleated red cells present in the blood of anemic fowls and the nomncleated reticulated red cells of rabbits. On the basis of equal volumes of cells, the respiration of the former is about twice that of the latter, while this in turn is ahout six times as great as the nucleated but nomreticulated normal red cells of the forvl."

Wright and VanAlstyne (1931) has bronght ont some significant points conceming the rate of maturation of avian erythrocytes that may help to account for the fact that recovery from injury apparently is more rapid in linds than in mammals. They found in vitro that young red cells could differentiate into matme erythrocytes within 36 homs, with a full complement of hemoglobin. In fact, they state (p. 36):

$\because$. . the conclusions are drawn that the laasophilic staining characteristic of the more primitive cells is no indication of any lack of hemoglobin. Indeerl the most primitive cells examined seem to have possessed ahmost. if not quite. as much of this sulsstance as the ordinary red corpuscles."

On the subject of rate of maturation they ohserved (p. 32): 
"This matmation of the fowl's Hood takes a shorter time than the equivalent development of mammalian cells. Erythropoiesis can be mobilized much more rapidly in the fowl than in the rabbit, as can be seen from the regeneration curves for the two (Wright, 1930il, and 1930b), even though on the basis of relative blood rolumes the loss of blood is greater in the fowl. Possibly the delay in the mammal is related to the additional time necessary for the disposal of the nucleus."

Sinee inmature stages are not hard to find in circulating blood, it was thought that over-age eells might also be easy to find. A few were discovered but only after much searching. They are not nearly so common as are the immature slages. However, this statement is applicable only to stages showing pyknosis and degeneration; the early indications of aging are fairly abundant (fig. 25). Within any one slide there usnally exists considerable variability in the intensity of nuclear staining. This variability is illnstrated in figure 2 and particularly in figure 3 ; the chromatin in some nuclei has the form of fune particles and gives to the nuclei a light color. but in others the ehromatin is condensed and the nuclei are darkly stained. It is these latter that presumably are the older cells, and were they not removed from the circulation by the spleen, they would go on to a pyknotic condition (fig. 26). The pyknotic stages are rare.

In pyknosis the first reaetions consist of chromatim condensation and nuclear eontraction. and the spaces between the chromatin clumps are no longer clear lut take the same staining reaction as the chromatin, although in a lighter shade. On sectioned material it is hard to decide whether this reaction is due to dissolution of basichromatin into the uncleoplasm or to the filter effect of underlying chromatin clumps that are out of focus because the nucleus has greater thickness than the oil inmerision Jens has depth of focus. The flattened nueleus of a cell in a blood smear. however, lies within sharp-focus range of the lens; thus, the conclusion may be justified that in the process of pyknosis some basichromatin is dissolved in the nucleoplasm. This conclusion is in agreement witl observations made on a previous study (Lucas, 1940) in which the Feulgen test gave a positive reaction on the mucleoplasm of degenerating tissue cells.

As pyknosis proceeds in most tissue cells of the body, there is usually extensive contraction of the nucleus that lrings about considerable change in the nucleocytoplasmic ratio. Some evilence of this shift is shown in figure 26 but a different type of reaction is equally common, namely, vacuole formation within the nucleus (figs. 27 and 28). This would appear to be a compensatory reaction. The nucleus during pyknosis should shrink but apparently the attachment of nucleus to stroma will not permit an overall retraction of the nuclear membrane. The goblet-shaped vacuole in figure 28 , with its stem extending to the nuclear surface, suggests that cytosomal fluids lave been sueked in to form these vacuoles, permitting increased condensation of the chromatin without loss of nuclear volume.

Degenerating erythrocytes in the spleen exhibit predominantly nuclear contraction without vacuolization; some show karyorrhexis. The latter has never been olserved in circulating blood in mature erythocytes from normal birds.

These degradation changes in the cell and its nucleus are included under the section describing normal circulating blood because aging and the processes leading to death, as well as death itself. are all normal phases of life's progression. But whether degenerating cells normally occur in the circulating blood of a healthy bird is another question for which there is no answer at present. A study on the occurrence of over-aged cells in the cireulating blood under various experimental eonditions should produce some interesting results. The lind lends itself to this type of study hecause the nucleus is a more delicate indicator than is the hemoglobin-bearing cytosome. In mammalian bloor there is no means for recognizing the old erythrocyte because the nucleus is ejected or disintegrated before the cell enters the circulation.

\section{Atypical and abuormal erythocytes (figs. $30-19)$}

Cells included in this group are those in which, presumably. the atypical condition observed existed in the bird before the blood was drawn. but there is always the possibility that a particu. lar result observed was produeed by the technic employed.

Spindle cells (figs. 30-32) are rare in blood from normal birds. It is conceivable that the 
oceasional cell of this type in nomal blood is a technic artifact, produced when the smear is nade by the mechanical stretching of the cell. On the other hand, poikilocytosis does occur in chickens; it is indicative of a disturbance in the blood, and among the various shapes are many that have a spindle form. Poikilocytosis obviously develops within the bird and is not a technic artifact, but this does not exelude the possibility that teel.nic can play a role. Spindle cells have been seen in the counting chamber of the hemocytometer and, of conrse, under these conditions there would be no stretching effect on the cells.

Such spindle cells have been observed by others, even in the embryo. Sugiyama (1926) in his study says (p. 134), "It is noteworthy that there are a few spindle-shaped red cells in the llood of chicks, not only in embryonic life but also after hatching. These red cells ordinarily vary from medium size to exceedingly small. sometimes with one end pointed and the other rounded, sometimes with both ends pointed. Such red cells have appeared by the lime the embryo has 22 to 29 somites, ahat is to say. from the stage of early ery throblasts; at this stage they are usually pointed at one end and rounded at the other (figs. 17, 18)." His figure 17 is similar to our figure 32 and his figmre 18 is equivalent to our figure 30 . He goes on to say, "As an eridence that such spindle-shaped red cells are by $n o$ means to be considered as artificial products. one finds them in the cireulating blood within the vessels of the area pellucida."

Distortions of cells often produce rarefied areas in the cytosome; an example of this is shown to a slight extent in figure 30 and more clearly in figure 31. A variation in the production of a spindle cell is shown in figure 32 . One end is round and the other drawn out into a long tapering point. The fact that intermediate slages between figures 31 and 32 can be found leads to the suggestion that all these various distortions of cell shape have a common underlying cause.

Distortion of cells may not necessarily produce pointed ends. There may loe a slight break in the side of the cell (fig. 34), a splitting apart of the nucleus (fig. 33), a constriction of one end of the cell (fig. 35), an elongation of the cell (fig. 36), and the production of erythroplastids of various sizes (figs. 41-43).

The erythroplastid is probably produced loy some process such as indicated in figures 35 and 38, and the anisocytosis sometimes observed in cells could be accounted for by a diminution in size following the production of an erythroplastid. It is conceivable that a small one (fig. 41) could be derived from a cell like figure 37 , and a medium-sized erythroplastid (fig. 42) from figure 40, and large ones (figs. 3, 2, and 43) from such a cell as figure 39. Primary erythrocytes of embryonic blood break off anucleated portions of cytosome more frequently than do the definitive eryllineytes.

Amitosis has already been mentioned in connection with the study marle by Charipper and Dawson (1928) on the blood of Necturus. They include the elongations of cells and constrictions of either nucleus or cytosome under their evidence for amitosis, but, as already pointed out, only rarely has there been any evidence of division of nucleus followed by division of eytosome. The opinion is leeld that they are extending the definition of amitosis too far when they include the formation of erythroplastids. They state, "Thein formation may be considered to be by an amitotic division of the erythroeytes involving only the cytosome." Wilson (1925) in his glossary defines amitosis as "mass-division of the nuclens without the formation of spireme, chromosomes or spindle-figure." Erythroplas. tid formation is equivalent to the throwing off of blels of cytoplasm, which occurs so frequently in lymphocytes, or to the pinching off of psendopodia. After discussing the evidence for and against amitosis as a normal process of cell multiplication involving genetic continuity of cells, Wilson (1925) states (p.221), "It is clear. therefore, that evidence of amitosis, unless based on direct study of the living cell, must be received with the greatest caution; ..." This point deserves reemphasis. The existence of amitosis in avian blood can only be established after careful in vivo studies of the type Speidel (1932) has carried out on the tadpole tail and Knisely, et al. (1917) on mammals.

In birds, erythroplastids are relatively common and somewhere during the course of evolution from reptiles to the ancestor of the mammals the process of erythroplastid formation became fully established. It would be interesting to know whether the survival value of such cell fragments depended upon the more economical utilization of space without the nucleus present or 
came ahout because the nucleus aged and hied before the cytosome had reached its senility and by the elimination of the nucleus, a longer life span was obtained.

The life span of erythrocytes anong mammals raries greatly, from 8 or 9 days for rabbits and rats to about 100 days for monkeys (Harne, Lutz. Zimmerman, and Davis, 1945); for chickens it is said to be about 28 days (Hevesy and Ottesen, 1945). In the pigeon after bemornage there followed recurrent reticulocyte peaks at about 11 . day intervals (Graam, 1935).

Another type of abnormal cell involves only the nucleus and is illustrated in figure 3, 15 to 22, and figures 44-49. This defect was found only in slides from Laboratory No. 2 and has never been observed in any of the hundreds of slides made at this Laboratory or in slides made from farm stock. These cells are included here because it is not known whether these abnormal nuclei develop within the bird or appear on the slide as a result of faulty technic. The preponderance of evidence points to an abnormal cell. If this is true the cytopathology deserves thorongh study since it is a very conspicuous hanIlle, or label, that the reterinarian could easily use in the identification of a disease condition. It is the type of abnormality that could be recognized readily from field cases and requires only low-power magnification to locate the cells. Winth (1950) in his figure 43 pictures cells showing the same type of cleft muelei. He labels them pathological erythrocytes of birds hut gives 110 further information about them or the species of bird in which they were found. It is possib]e to go one step further than this and say that it is not a breed difference since Laboratory No. 2 and this Laboratory are using the same breed, namely. Single Comb White Leghorn.

The defect appears as an achromatic or chromophobic band across the nueleus: sometimes it is narrow (figs. 3, 16, and 44) and sometimes broad (figs. 3. 19 and 20, and 45). Someimes it does not cut all the way through the nueleus (fig. 3, 21). Sometimes it cleaves straight across the middle (fig. 44) but frequently it is diagonal (figs. 3, 17 and 18. and 15). Sometimes there are two clefts (frg. 46) and sometimes the break is subterminal (figs. 3. 15 and 19. ant 45) with nuclear substance visible at the tip, or it may appear as if the tip of the nuclens had been lost (fig. 3, 22). These achro- matic bands are not indentations because there is usually enough of the nuclear boundary still visible to see that it is not curred inward. When individual cells are examined closely there is no evidence that the nueleus has been fractured and the two portions pulled apart by pressure in making the slide.

Sometimes the chromophobic streaks extend lengthwise in the nucleus (fig. 47), leaving a central axis of chromatin granules that stains normally. The washed-out band shows no trace of chromatin granules; it shows only a faintly stained linin network (figs. 47-49). These three figures illustrate a transition leading to a completely chromophobic nucleus. The late stage (completely empty nucleus) might be confused with the illusion of emptiness sometimes found after. Wright's stain on immature cells. They are, howerer, different; the former is practically structureless and colorless but the latter shows a pale blue color orer the nucleus although structural details are hardly visible.

The chromophobic reaction might be a type of chromatolysis but, if it is, it differs from the commonly observed liquefaction process in that there is a sharp boundary between the staining and nonstaining parts of the nucleus, whereas usually chromatolysis is a progressive process affecting all parts of the nucleus equally.

Nuclear fractures are not limited to erythrocrtes. In the same set of slides they were found also in heterophils (fig. 3, 1) and in lymphocytes (figs. 1]7-120). In the heterophil illustrated, the elear areas extend lengthwise down the middle of two of the nuclear lobes. The nuclear degeneration seen in lymphoeytes will be described later. It is msually more vacuolar and irregular than in the erythrocytes, and rarely are the clefts of uniform width. The fact that nuclei of several different kinds of colls are affected might be considered as evidence that this is a technic artifact. If these ehromophobic bands are dise to faulty technic, it would be expected that some slides prepared at this Lahoratory would also show them. becanse certainly every one of the many thonsands made here has not been of top quality. Noreover. Laboratory No. 2 was asked several years later to prepare another set from the same flock and stain them. and mone in the second set showed this particular defect.

Numerous risitors to this Laboratory who had 
worked with poultry diseases or in the field of hematology have been asked if they had ever observed this type of reaction in any of their studies and thus far the answer has always heen in the negative.

Tate and Vincent (1.932) have reported the occurrence of sharply delimited spherical hodies in the cytoplasm of erythrocytes of canaries and mice treated with R59 and P25-two compounds used in antimalarial tests. The bodies stained blue in dried smears following Leishman's stain hut were not visible when other types of fixatives were used. and could not be seen in dark field. The peculiar bodies were found, not only in erythrocytes, but also in eosinophils, leukocytes and reticuloendothelial cells. Their significance is not known but nothing similar to these bodies has been seen in our studies. Nor were the small spherical bodies called stigmata described by Nittis (1930) after vital staining with hrillianteresyl-blue observed in our preparations. He found these bodies associated with nucleated erythrocytes of various classes of vertebrates. They were not visible after Wright's stain. Although Nittis did not believe that the stigmata were the same as the refractile granule found in nearly mature mammalian erythoocytes by Isaacs (1925) yet the gramules resemble each other in appearance as illustrated by the two authors.

\section{Techuic artifacts (figs. 50-72)}

All smears of avian blood will show some defective cells. It often becomes a difficult prob. lem to separate those that are atypical because they are truly abnomal from those that have been made to appear abmormal by the technics used to make the smear and stain the blood. Under the previous heading were listed those abnormalities abont which there might be some question of whether they occurred in situ or were related to the technics used, but the group of cells now to be consiclered are all quite probably technic defects. Since it is difficult to tell whether a peculiar appearance found in cells should be referred hack to the animal or to technir, a rule of thumb has heen adopted and found helpful. It is based on the distribution of the abnormal cells on the slide; if a number of cells showing the same defect are grouped in the same region on the smear and are absent from other intervening areas, it is concluded that this is a technic defect.

The defect shown in figure 50 is commonly found in polychromatic erythrocytes and, therefore, is quite characteristic for embryonic blood at certain ages (figs. 227 and 273-275) and for leukemic blood. It is readily recognizable by the irregular pale spaces scattered through the cytosome and by a loss of homogeneity in the remaining chromophilic masses of cytoplasm. The spaces are not vacuoles in the cytoplasm or breaks in the contimity of the cell membrane, since sharp boundaries or refractile margins are never associated with this type of artifact. It occurs predominately in the mid-polychromatic and the early part of the late polychromatic ery. throcyte development. This fact aids in understanding what causes this atypical reaction. The mid-polychromatic erythocyte is in a delicate transitional condition. It has lost approximately half of its basopliilic substance and has replaced it with about half of its final content of hemoglolin. The transition from basophilic to acidophilic cytoplasm in immature blood cells, like the molting of insects, is a vulnerable period. The cytoplasm is distorted when the smear is dried. The distortion occurs most readily where the serum layer is thick and the slide dries slowly; in thin portions of the smear the cells dry quickly and here the normal homogeneous appearance of the cytoplasm is retained.

Cells pulled into two pieces have already been shown (figs. 35, 36, and 38) but those illustrated in figures 51 and 52 differ from them in that the cytoplasm was already fixed before the pulling began or in that the stretching took place when the smear was made. It is obvious in the latter two figures that the cytoplasm had some rigidity before it was forced apart. Cells do not divide normally by the kind of process indicated in figures 51 and 52. In both of these cells the nuclei lie at one pole and it is quite probable that these cells were caught in the process of producing erythroplastids. The cytoplasm was weakened and the pressure from surface tension when the smcar was made or when it was blotted was sufficient to pull the halves of the cells apart along the planes already set up for the separation of the cell into nucleated and anucleated portions.

Price-Jones (1910) studied the differentiation of the erythrocyte in the early chick embryo. 
The technic used was equal parts of glycerine and distilled water, followed by drying. His colored drawings illustrate examples of lack of homogeneity in the cytoplasm of the partially developed erythocyte, formation of erythroplastids, and elongation and distortion of the cell body. He regarded these atypical cells as evidence of degeneration, but some of then appeared atypical probably because of the technic uned.

Too much pressure exerted during hlotting of the slide will damage the cells in other ways, as shown in figures 53 and 54 . These fractures of the cytosome and the cell membrane are of the kind that come after the cytoplasm has become rigil; the clefts have sharp borders and extend no farther than the nucleus. In figure 54 the damage is greater than in figure 53 in that the nucleus, as well as the cytosome, has been partly squashed. The former does not show fractures but the chromatin is spread out into a thimner layer than normal and stains more lightly.

The peculiar nuclear reaction shom in a series of three cells. figures 55 to 57 , has been observed only once. It occurred in a routine slide made from a morilund young chick that had previously been inoculated with neoplastic lymphoid tumor cells. It is listed under the heading of technic artifacts because additional smears made from the same bird, only an hour or two later, failed to produce these odd-looking cells. The hasichomatin of the nucleus was clumped into a dense mass and it seemed to pass, phantomlike, through the nuclear membrane without rupturing it or even denting it. Often the basichromatin mass lay beyond the limits of the cell, and again apparently withont rupture of membranes. It must lue assmed that the dense basichromatin leaves by the top of the mucleus and cell instead of laterally, so that, as viewed from above, the breaks in the nembranes were not visible. Sometimes the chromatin masses did not retain their original shapes but were drawn out into elongate bodies with bizarre forms. The nuclear hull remaining behind was firmly anchored to the stroma of the cytosome and showed no evidence of displacement, and it retained micleoplasm that was tinged with dissolved basichromatin.

The displaced basichromatin masses are so suggestive of peas popped out of a pod that slides were made later from normal birds and the unstained cells vigorously pressed against another side laid on top of the smear. There were no effects on the nuclei. The whole phenomenon is an intriguing one and needs to be studied further.

Sometimes other slides are found in which the muclear contents have been drawn out into long streamers. Usually they are ronghly parallel and they may he straight or curved. Flies and cockroaches should be suspected when this type of muclear dissolution is observed. Flies tend to clean up the spot tonched by their proboscis better than do cockroaches. which have a different type of mouth structure. The salivary secre-

Figures 30-49.-Atypical and abnormal cells found in smears from chickens considered to be normal. $2,470 \times$.

Figures 30-43: Poikilocyles (P), anisocytes (A), and
crythroplastids.

30 Bipolar spindle cell (P).

31 Large clongated bipolar spindle cell, with light staining areas at the ends $(P)$.

32 Tripolar spindle cell (P).

33 Cell with nueleus constricted longitudinally.

34 Transwerse constriction of nucleus with infolding of eytoplasm on one side $(\mathrm{P})$.

35 Cunstriction of the cytoplasin at one pole $(P)$.

36 Elongated cell and nucleus (P).

37 Cell with ecentric nucleus (A). Probably a portion of the cytuplasm has been lost.

38 Cell with nucleus carıied into protrusion of cytosome. Probably a stage in the formation of erythroplastid.

39 Nicrocyte (A).

40 Microcyt? (A).
41 Small erythroplastid.

42 Medimm erythroplastid.

43 Large erythroplastid.

FlGUREs 44-49: Cells showing chromophobic reactions in the nuelci. Compare with figure 3, 1, and 15-22.

44 Chromophobic band across the nucleus and a small area at one pole.

45 A single chromophobic band diagonally across the nucleus at its lower end.

46 Two transverse chromopholic bands.

17 Chromophilic area restricted to a narrow band down the center of the nucleus.

48 Chromoplailic area limited to the center of the nucleus.

49 Tueleus entirely chromophobic. 


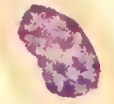

30
6

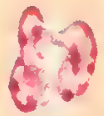

33

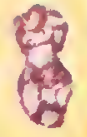

31

32

31

6

35
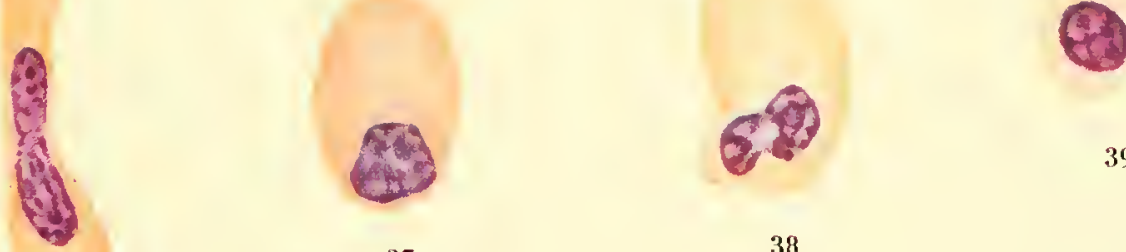

39

38

36

8

40

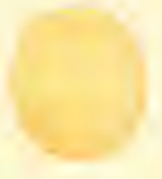

12

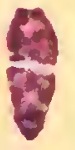

43

41

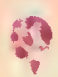

18

19 
Figures 50-72.--Technic artifacts in erythrocytes. 2,470X.

50 Late polychromatic erythrocyte with internal fracturing of the cytosome. Probably occurs as the slide dries.

FIgURES 51-54: Mechanieal rupturing of the eell; occurred when smcar was made or when it was blotted.

51 Pulling apart of a cell that already liad its nucleus at one pole prior to pinching off an erythroplastid.

52 Partial rupture of a cell in which nucleus lies near one pole.

53 Fracture of the cytosone.

54 Partial squashing of the nucleus and fracture of the cytosome.

Figures 55-57: Extrusion of nuclei, found in a bird previously inoculated with lymphoirl tumor cells. Manifestation of the technic artifact probably enhanced by the disease condition.

55 Conrlensition of basichromatin.

56 Shifting of the basichromatin outside the nucleus.

57 Complete displacement of Jasichromatin outside the nuclear membrane.

Figures 58-60: Smudged cclls. Fragile cells broken ot the time the smear was madc.

58 Partially ruptured cell with squeezing ont of liquid basichromatin. Later stage shown in figure 2,6 .

59 Partially ruptured cell with early chromophobic reaction of the nucleus.
60 Partially ruptured cell in which the nucleus was almost completely chromophobic.

Frgures 61-63: Cells shawing varying degrees of nonrefractile vacuolization of the cytosome.

61. A few vacuoles of varving size lateral to the nucleus.

62 Half the cytosome filled with large vacuoles.

63 Small vacuoles filling the entire cell.

Figures 61-69: Artifacts due to overheating the slide.

64-Heating has produced a few scattered refractile vacuoles in the cytosome.

65 Large and small refractile vacuoles in the cytosome.

66 Coalescence of refractile vacuoles.

67 A single large refractile vacuole at one pole of the mucleus.

68 Effect of excessive heat. Substancc of refractile vacules driven off leaving empty spaces.

69 Staining of serum granules in an overheated slide.

Frotres 70, 71: Artifacts due to parts of smudged cells falling on top of normal cells.

70 Vacuoles and chain of three bodies beside the nucleus due to overlying snudged nucleus.

71 Two cells with it smudged nucleus orerlying both of thein.

72 Serum granules which have taken the stain. Compare with figure 322 . 


\section{6}

50

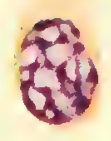

51

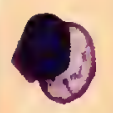

56

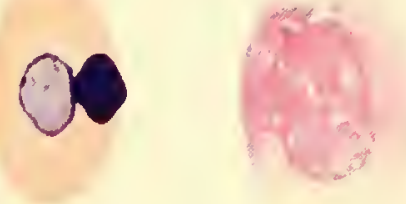

5

58

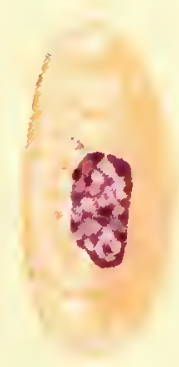

62

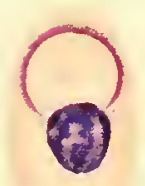

67

66

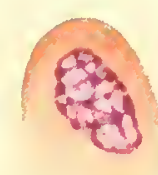

52

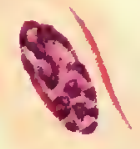

Q6)

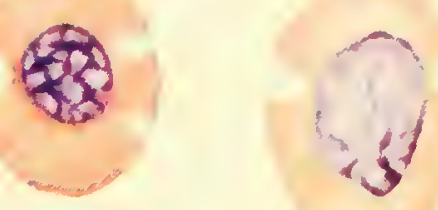

5.3
0

5.5

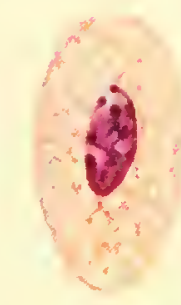

63

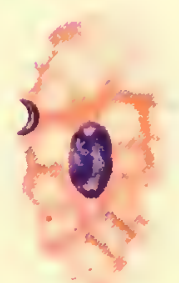

68

\section{$-i$}

59

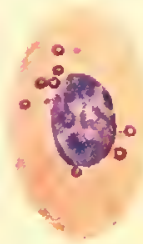

61
60

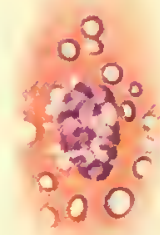

65
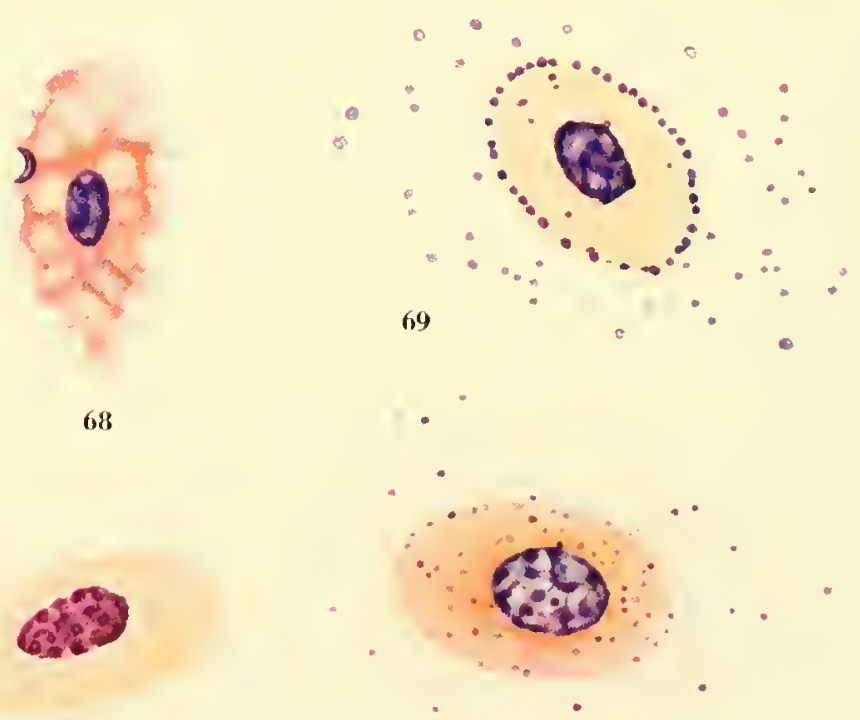

71 


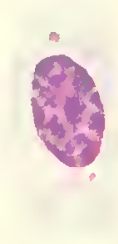

73

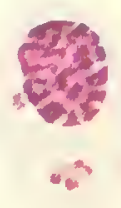

74

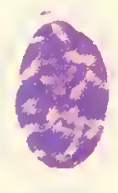

79

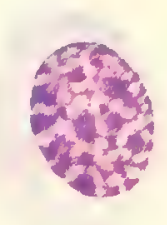

75

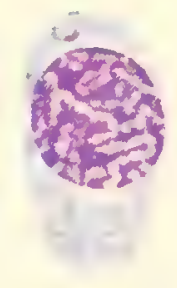

76

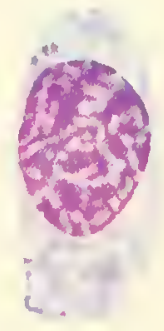

77

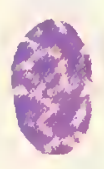

78

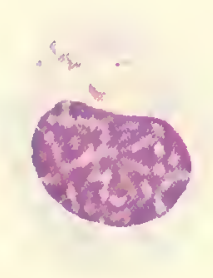

83

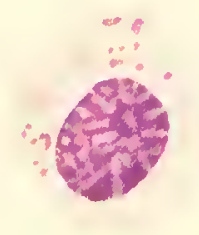

34

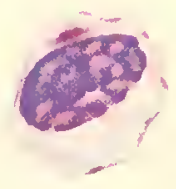

85

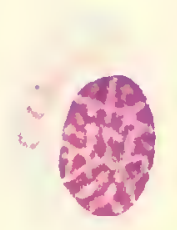

81

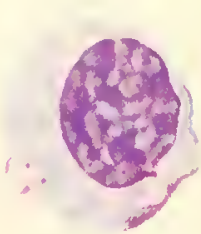

82

Figures 73-87.-C'Thrombocytes. 2,470X.

Figures 73, 74: Normol thrombocytes.

73 A typical thrombocyte.

74 A variation from the typical toward the reactive thrombocyte type.

Ficures 75-79: Developmental stages found in the circulating blood.

75 Stage about midway in the differentiation process.

76 Early elongation stage. Cytoplasm about the same as in preceding cell. Specific granule present.

77 Early clongation, beginuing rarefaction. Two specific granules present.

78 Thrombocyte eharacter definitely established. Lightly stained cytoplasm. Granulation still very faint.

79 Nearly mature thrombocyte.
Flgures S0-84: Reactive thrombocytes.

so Multiplication of specific thrombocyte granules to form a sphere.

S1 Multiplication of specific thrombocyte granules to form spheres.

82 Vacuolization of cytosome and presence ef two irregular spheres.

83 Aggregation of specific thrombocyte granules around vacuoles of various sizes.

84 Numerous faint splyeres and large, dark granules.

Figures 85-87: Stoges in disintcgration of the thrombocyte when exposed to alr.

85 Early stage of disintegration of the eell membrane.

86 Mid-stage of disintegration.

87 Late stage of disintegration. Specific granule still visible. 
tions put the proteins from the nucleus into solution and in the wet condition they are spread aromnd the slide. These dry and later, when stained, appear as long strands, irregnlar masscs, and fine filaments that take the typical nuclear. stain. If the slides are on edge, there will be long streamers flowing downward.

It has been found from experience that if blood slides must be kept over until the next day before staining, the rack should be put inside a glass dish with a good cover and the edges sealed with adhesive tape. No drawings have bcen made show. ing these effects but there should be no difficulty in recognizing them and in reproducing them. If a slide held up to the light shows minute clear areas punched ont here and there over the smear. those areas are a faily good indication that flies have had access to the slide.

Squashed cells arc exceedingly common in avian blood (fig. 2,6 ). The part of the cell that stains is the nucleus, and in the case of the cell mentioned the cytoplasm has disappeated entirely. When it has been squashed to this degree it often becomes impossible to detcrmine whether it had been an erythrocytc, lymphocyte, monocyte, or thrombocyte. If granulocyte cells become broken they can be identified by their specific inclusions (figs. 175, 176, 187, 195, and 196). Broken monocytes can sometimes be identified (figs. 148 and 149).

Smudged cells are much more abundant in bird than in mammalian blood, because, in birds all blood cells are nucleated and there is much more opportmity to find a smudged cell, than where only the leukocytes carry muclei, as in nammals.

It was noted by Furtl, Seibold, and Rathlione (1933) that in mice, smudged cells were rare in normal animals but very numerous in cases with lymphomatosis. They suggested that the incidence of smudged cells might represent a measure of the cells that were fragile, but they knew of no way to put this idea to the test. They were not found in the counting chamber. A1though no adequately controlled studies have been made on chickens, the indications are the same as for mice, that there are fewer squashed cells from smears of normal individuals than from those inoculated with tumor transplants. Kyes (1929) found a certain proportion of erythrocytes in fowl and pigeon so susceptible to hemolysis that nucleated stromata appeared even when blood was diluted with the animals own serum.

Smudged cells in chickens are so numerous that it is easy to find all stages. The initial reaction is liquefaction of chromatin which gives the nucleus a light staining homogeneons appearance, and the cytosome is flattened beyond its usual limits. In anything beyond this initial stage, the liquefied chromatin flows beyond the nuclear membrane (fig. 58) and the cytoplasm shows various stages of rapid disintegration.

In most smudged cells the reaction goes all the way and the nuclens is recognizable only as an irregular, magenta-colored mass (fig. 2, 6). The eytoplasm is less durable than the nuclens and even when slightly flattened it loses its affuity for the stain (fig. 60). With only slightly more pressure, the cytoplasm becomes almost completely lysed (figs. 58 and 59). When cells are severely squashed, the nucleus also disappears and the only indication that a cell previously existed is found when some of the squashed material happens to overlie the cytoplasm of another cell (figs. 70 and 71 ). Mere gossamer traces of squashed chromatin can be seen hetween the cells but that which falls on top of other cells takes an intense stain. In figure 70 the remains of the squashed nucleus hare taken the form of a row of bearlike structures, and lave inierfered with the proper slaining of the cytoplasm of the underlying cell. In figure 71 the nuclear substance has been stretched between two cells; the cell to the left received a bow-shaped strand extending half way around the nucleus. The other portion of the same squashed nucleus is only faintly visible on the cell to the right, and a small portion extends beyond the lower side. The vacu. ole at the upper edge of the same cell is caused by the presence of the squashed nuclens, which interfered with the straining of the cytoplasm. These small fragments of darkly stained material that fall on the eytoplasm of normal cells are confusing in that they may resemble foreign bodies, parasites, bactcria, or cren Cabot's rings. Careful study may sometimes be necessary to distinguish hetween such artifacts and some types of pathogenic organisms.

Two drawings of partially squashed cells from Laboratory No. 2 (figs. 59 and 60) have been included because they contribute some additional information on several subjects-squashed cells, 
chromophobic nuclear bands, and bird differences. In the set of slides, squashed cells were rare but those that ocenred did not show the type of nuclear reaction illustrated in figure 58; instead, the chromatin clumps remained discrete. There was no indication of basicromatin liguefaction and spread. The nucleus in figure 59 , before squashing, was probably similar to the cell in fignre 45 , where a clromophobic band cut across one end of the nucleus, and the cell in figure 60 was probably something like that shown in figure 48. As the flattened nuclei with chromoplobic bands expanded, their structural details became increasingly clear. When one looks at figures 59 and 60 with that thought in mind, it becomes questionable whelher "clnomophobic" is the best term to use in designating the clear nuclear areas. The basichromatin failed to reveal itself, not becanse it liad lost its affinity for nuclear stains but becanse it had actually disappeared. A study of chromophobic reactions in lymphocytes (figs. 117-120) raises the same question.

It is pertinent to ask whether such differences between birds in respect to nuclear reactions are genetic or pathologic in origin. In any case, these diflerences emphasize the fact that full use has not yet been made of cytologic details that could be applied as labels in various kinds of experimental studies.

A common artifact is the presence of vacuoles in the eytoplasm (figs. 61-68). Two types are illustrated in this series of drawings-nonrefractile vacuoles (figs. 61 and 63 ) and refractile vacuoles (figs. 64-68). The former type was found in slides from Laboratory No. 2 and the latter in slides from this Laboratory. The canse of the nonrefractile vacule is not known, but it is undoubtedly a technic fault since it was found on localized regions of the slides with large expanses of normal erythrocytes intervening. The vacuoles are fairly uniform in size, perhaps with some coalescence. They vary from a few to many and may fill up the entire cytosome. The muclens was not affected by vacuole formation in the cell body even when the condition became extreme (fig. 63).

In an attempt to produce similar structures. slides were overheated; the only result obtained, however, was a vacuole that was refractile. The spheres may vary from very minute bodies (fig. 64) to relatively large ones (figs. 65-67). They contain either air or moisture and the bubbles often break through the cell wall as shown in figure 6.5. An extreme condition is slown in figme 68 where all the bubbles have left the cell except one, which is in the process of extrusion, and with the extrusion of the bublites the cytoplasm is still vacuolated but not refractile. Often the bubbles coalesce and form bizarre shapes (figs. 66 and 67). They may form one large vacuole with its margin intensely colored (fig. 67), or a refractile, sansage-shaped mass, or irregular bodies (fig. 66). The last named is a common type and often appears in slides in which there was 110 indication that too much heat had been applied. The problem of the cause of these artifacts still exists, and causes for their production, other than heat, are not excluded. Dawson (1931) has photographed erythrocytes of Necturus that appear very similar to figmre 67 and they occurred in fresh, unstained blood. In conclusion he stated, "The vacuoles have been interpreted as degenerative in nature, but no specific cause for such changes in the erythrocytes has been discovered."

Some artifacts produce appearances simulating cell abnormalities (figs. 69-72). The cause of the magenta bodies found in the erythro. cyte cytoplasm (figs. 70 and 71) and their possible confusion with Cabot's rings or intracellular parasites have already been discussed. A red cell falling on top of another cell produces a refractile curved line across the cell underneath and a concentric clear band of cytoplasm. It is so obvious that the clear cytoplasmic line is caused by pressure from the overlying cell that no questions are raised, but the same phenomenon originating from a small granule or dust particle falling on the surface of the cell before it dries will often lead to erroneous interpretation. The tiny particle, if it is heavy enough to depress the cell surface as it dries, will thin ont the underlying cytoplasmic layer and this will look like a vactiole when the slide is stained. That one sees is a granule lying in the center of a vacuole that appears to be located inside the cytosome. Focusing does not help to determine whether it is on top or inside, because the cell is flattened to such an extent that its whole thickness lies within the depth of focus of the lens, and even if focal levels could be separated it would still look as if it were inside the cell, becanse the particle has depressed the surface. 
Avian blood serum contains more particles than mammalian serum. Usually the serum does not give trouble in stained smears from young lirds or males, but it may be quite annoying in laying birds, in circulating blood from emlryos, in bone nuarrow of older birds, and espe. cially in bone marrow of embryos (fig. 322). The gramules in the serum (figs. 69 and 72) tem] to stain more readily with Wriglut's than with May-Grimwald Gicmsa. Whenever they stain they spread a veil or screcn over the cells (fig. 72) and obviously make it diffeult to observe cellular detail. In addition, they modify the color reaction of the underlying eells so that identification of cells under these conditions becomes unreliable. In some cases only the granules take the stain and in other" cases both the fluid serum and its contained granules take the basophilic dye. Extreme examples are shown in embryo hone marrow (fig. 322), spleen (fig. 329), and thymus (fig. 332).

Sometimes the gramules that fall on top of the cell and not belween the cclls will take the dye, which causes the cell to look as if it contains many small organisms. Oftentimes the serum granules will remain uncolored except near a ruptured or smudged cell (figs. 175 and 176). In these figures the small. darkly stained particles are the serum granules. Hetcrophil granulcs from the rods may closely resemhle those in the serum hut are larger and take a more reddish color.

Occasionally the serum bodies are larger than usual, resemble cocei. and may cluster around the cells (fig. 69). This cxample was from a heated slide but similar reactions have lreen seen in unlieated specimens.

Another type of almormality observed both in mammalian and in avian blood is the production of slender, flexible, protoplasmic processes from the surface of erythrocytes. They are not found in fixed and dried smears lont the projections on cells $A$ and $B$ of figure 29 indicate their appearance. execpt that they are longer in the living cell where they are usually seen. Shipley (19]6) olserved them in tissue culture from cells of the area opaca, and found that they appeared to be beaded for part or all of their length and termimated in a small round knob. They were actively motile and the end of the process whipped back and forth.

Knowles et al. (1929) have depicted in color many artifacts, alnormal cells, and cellular para- sites that are frequently found and misinterpreted. Their studies covered several classes of vertelrates, including birds. Some additional artifacts and parasites found in avian blood are shown in the colored illustrations by Balfour (1911). Neave (1906) pietured, in figures $b$ and $e$ of plate XXI, two pointed olyjects found in his blood smears. Similar oljects have been found on rare occasions in smears made from the blood of chick embryos. Neave describes these bodies as follows (pp. 196-197): “. . Length varies fron $50-58 \mu$ and it occurs plentifully. It would appear to consist of a sheath pointed at each end which contains protoplasm segmented into two or more portions." Balfour (19]1) considers these to be yeast cells that have fallen on the slide and which have come from the air. We are in agreement that they are contaminants on the slide from ontside the specimen itself.

\section{THROMBOCYTES}

The mucleated thrombocyles of birds, reptiles, amphibians and fishes have the same function as the blood platelet in mammals.

Bradley (1937) called these cells thigmocytes. "Spindle cells" is another term used commonly, espeeially in the older litcrature. When blood is drawn, thromlyocytes and platelets clump rapidly and soon disintegrate. The disintegration is part of the mechanism of blood coagulation. In mammals platelets are pinched off from the cytosome of megakaryocytes located in the bone marrow and lungs. The parent cell is large, and is casily recognized and identified. It has a polymorphonucleus in contrast to the multime cleated condition of giant cells in birds. The megakaryocyte is lacking in avian bone marrow and, instead, thrombocytes arise from antecedent mononucleated cells that have a blast stage like that of other blood cells. Blount (1939b) noted that thrombocytes of $5 \times 10 \mu$ were smaller than erythrocytes of $7 \times 12 \mu$. and Magatl and Higgins (1934) gave the average size at $3.9 \times 8.1 \mu$. The distribution curves for width and length, based on 10 cells measured from cach of 9 chick. ens, gave means of 4.7 and 8.5 for these two dimensions (fig. 89). These data are discussed further in chapter 6 . Similar distribution 
curves have been prepared for the pigeon by Schoger (1939) who gave the range in length as $7.5-8.5$ microns and the width as $3.0-4.5$ microns.

In birds, thrombocytes derclop as monomcleated cells and remain so throughont their life span. Unfortumately, for purposes of stuty, they acquire early in their development a triggerlike fragility that makes them as readily reactive to damage in the immature as in the matnre stages. In contrast, during the process of mammalian evolution a shift in fragility apparently arose, so that developmental stages represented by the megakaryocyte lost this high degree of fragility and retained it only in the functional platelet. It is becanse the avian thrombocyte is so easily and quickly damaged at all stages that we know so little about its cytomorphosis. Fewer than half a dozen papers have been written on the subject.

When the thrombocyte disintegrates, not only does the cytoplasm go to pieces but the nucleus rapidly reaches a pyknotic condition. Beeanse the disintegration mechanism is held in such delicate balance the thombocyte would seem to be an ideal tool for the physiologist in his study of cell equilibrinm and dismption. Because the avian thrombocyte luas many points of association and similarity with erythocyles and with lymphocytes they have been placed between these two cell types in the arrangement of subject matter in the Atlas. Bradley (1937) and Blomnt (1939h) regard thrombocytes and erythrocytes as closely related genealogically, and the latter anthor nentions the existence of thromboplastids, but enucleated thrombocytes liave not been olserved in these studies. Hartman (1925) and Goidon (1926) extensively reviewed the various theories of the origin of thrombocytes. From Gordon's own experiments, he conchuded that thromlocytes were derived from erythrocytes. This conchusion was hased in part on the fact that when he bled a beath-lien repeatedly the number of thrombocytes increased when the number of erytlurocytes decreased. The ratio of thrombocyles to erythocytes was 15:1000 at the heginning of the experinent and after 5 bleedings it was 45:1000. The absolute number of lirombocytes had inereased from 35,000 to 86.000 and the number of erythrocytes had decreased from 2,350,000 to 1,900,000. Hartman (1925) ronchded from his studies that they were of extravascular origin and thus thrombocytogenesis was not related to erythocytogenesis.

\section{Vormal mature thombocytes (figs. 73, 74)}

The typical thrombocyte (fig. 73) has been described many times as a cell slightly smaller than an erythrocyte, elongated with rounded ends, but not having the regular oval contour of the erythrocyte. The thrombocyte nuclens also has a slightly oval shape but is not as elongated as that of the erythrocyte. The cytosome usually consists of a framework with large spaces. Some have called them vacuoles but they do not have the discrete nature and regular contour of vacuoles. Sometimes the cytosome shows structural uniformity. Considerable variability in color is taken on by the cytoplasm-pale blue as in figure 73 or pale purple as in figure 74. Often the rell membrane appears as a distinetly purplish line (fig. 85): this is especially true in cells in which disintegration is just begimning.

Thrombocytes contain specific gramules that take a pink to reddish purple color. The variability in number. size. intensity of color., and position in the cell is extremely great. In figure 73 there is a single compact granule at each nuclear pole with a suggestion of diffuse orange material beside the lower one. In figure 74 there is a definite single granule between the muclens and the side wall, and at the lower pole there are four gramules surounding a lighter stained homogeneons mass of similar material. In figure 81 there is a chain of four rings. The intensity of staning is less than in the two cells previously described.

The outline drawings (figs. $88 a$-s) have been arranged so that the cells in the first horizontal low are examples illustrating a single granule. The second row shows 2 granules per cell, the thind row shows 3 gramules, and the cells in the fourth row contain 4 or more granules. The granules may lie at the poles of the cell or at the side. If multiple, they may he close together or far apart, and they may be compact and dense or diffusely organized.

The significance of the specific gramulation is not known. Blount (1939)) is of the opinion that these gramulations do not represent hemoglobin. Possibly it is part of the trigger mechanism that brings about the rapid disintegration 


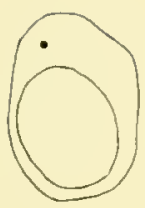

a

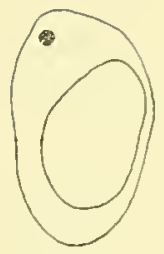

b
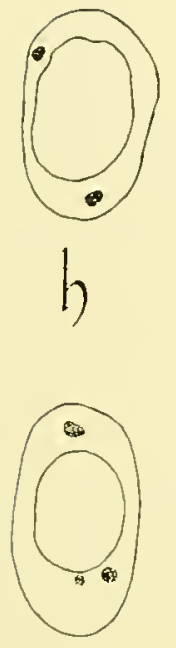

1

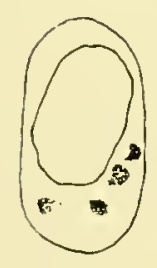

p

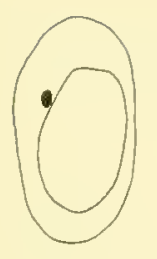

c
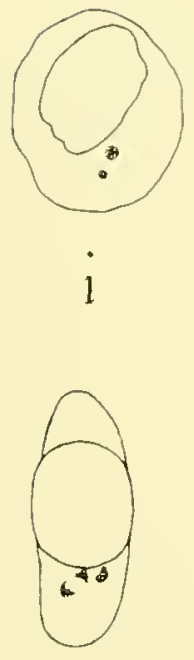

m

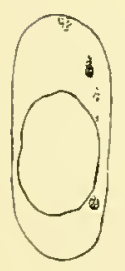

$q$

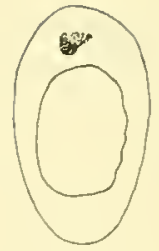

$d$

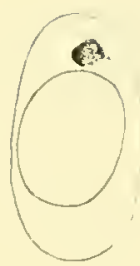

f

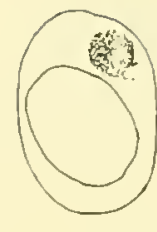

9
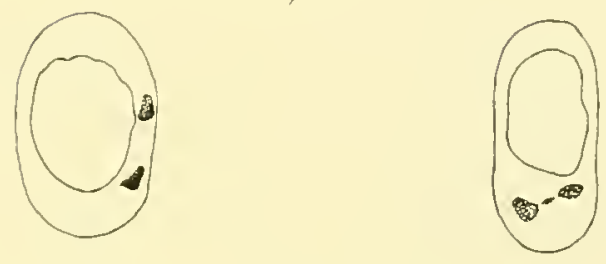

$k$

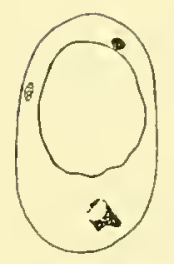

n

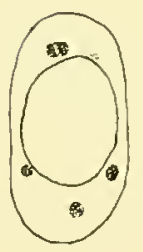

r

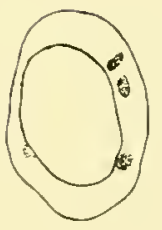

0

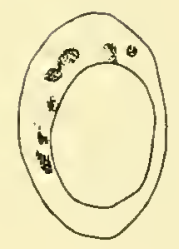

5

Figure 88.- Outlines of nomal thromboeytes and their nuclei, showing variability in shape, and in number and size of gramules. $2,470 \times$.

a-g One specific granule per cell. Size of granules ranges from small to large. Cell $g$ tending toward a reaetive thrombocyte.

of the cell. When the specific granules are absent or are hidden by the nucleus, the throm. bocyte becomes a difficult cell to identify. Forkner (1929) observed that thrombocytes have a clear cytoplasm at first but during the progress of staining with neutral red and janus green, vacuoles developed at one or both ends of the nuclei. These stained a muddy, brown color, were non- h-k Two specific granules per cell.

I-o Three specific granules per cell.

p-s Four or more specifie granules per cell. refractile, and increased in sizc with long exposure. If the cells are elongated, like those in figures 73 and $88, k, m$, and $q$, they could pass for poorly developed erythrocytes; on the other hand, if rounded like figures $88 \mathrm{~g}, i$, and $s$, they would simulate lymphocytes. Usually the nucleus is smaller than that of the lymphocyte. The nucleus of figure 80 is an exception and is 


\section{FREQUENCY of LENGTH and WIDTH of THROMBOCYTES}

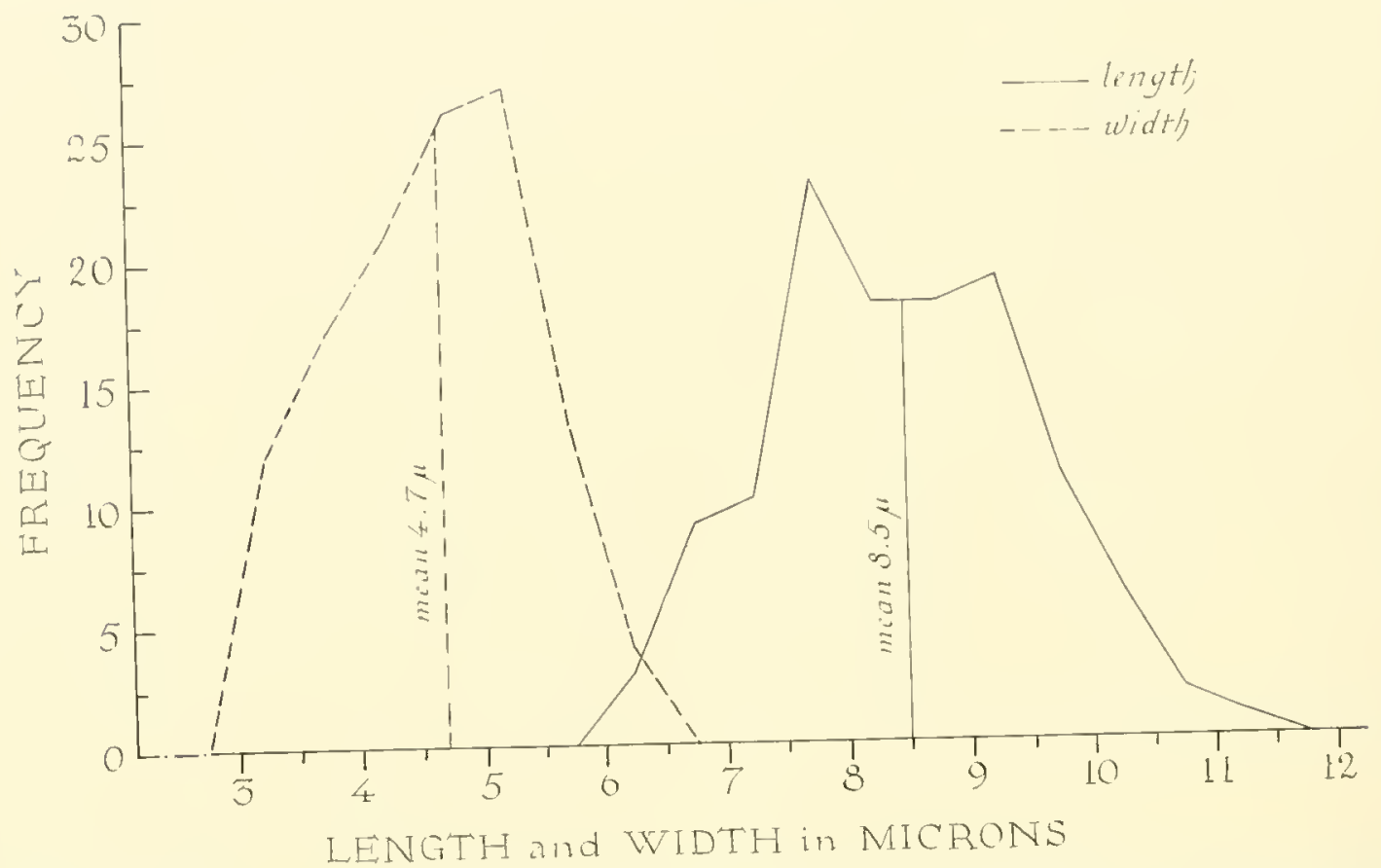

Figure 89.-Frequency distribution enres for tength and wicth of 90 normal thromborgtes.

larger than that of the lymphocyte figure 102, and if it were not for a few faint specific granules it would be classed as a lymphocyte. The cytoplasm does not always contain spaces or vacuoles; instead, its texture and coloration sometimes may be indistinguishable from that of lymphocytes. Fortunately the specific orange granules are very constant in their occurrence if not in their number and arrangement.

\section{Developmental stages found in circulating blood (figs. 75-79)}

Developmental stages for the thrombocytes were first worked out from the circulating blood of the embryo isucubated for about 4 days and then in older embryos. These observations provided clues for recognition of thrombocytogenesis in bone marrow and it was only following this that they were recognized in the circulating blood of the hatched chicken. Developmental stages represented by figures 75-79 were found in 1 specimen 6 days posthatching. At this early age the probability of discovering develop- mental stages is greater that at older ages, just as immature erythrocytes are more abundant soon after hatching than they are later.

There are about 75 red cells to one throm. bocyte; therefore, considerable more searching is necessary to find immature thrombocytes than corresponding stages of the erythrocyte series. None were found that were younger than about the middle of the developmental process (figs. 75-77), which is approximately equivalent to cells (figs. 288-290) found in the circulating blood of an embryo incubated 4 days, or (fig. 363) from adult bone marrow. The nucleus is still large relative to the cytosome, but at this mid-stage of immaturity the cytosome has more area than merely a narrow rim of in. tensely stained basophilic material as it had at the thromboblast stage. By the mid-immature stage, the cytoplasm has lost some of its basophitia and has become vacuolated. The vacuoles tend also to lighten the staining. Specific granulation may (figs. 76 and 77) or may not (fig. 75) be evident. The nuclear pattern is intermediate between the punctate reticulum of the blast stage and the closely packed, dense 
chromatin clumps of the fully mature cell. The areas occupied by linin network and basichromatin are about equal.

The late immature stage (figs. 78 and 79) shows certain changes from the preceding phase. The cell has usually attained a slightly oval shape but this is not always the case (fig. 364 from bone marrow); the cytoplasm has nearly the same degree of coloration found in the mature cell and it shows extensive vacuolization; the nucleus may still have a round eontour or may be slightly oval, but more important is the increased rensity of chromatin clumping. Specific granulation is present, but a point to which reference will be marle later is the faintness of the granules and the fact that there is seldom more than 1 or 2 small granules present.

\section{Alnormal cells (figs. 80-87)}

Probably neither of the two types of cells included under this heading could be called pathological. The eells in the first gromp have been classified as reactive cells (figs. 80-84) and those in the second group illustrate the cellular breakdown that begins as soon as the blood is liberated from the body (figs. 85-87). The latter might even be classed as a teehnic artifact because it takes place ontside the body. Clotting, on the other hand, also takes place outside the body and yet is a normal function of blood, but from the point of view of cytology this proeess is degeneration.

The type of cell shown in figures $80-84$ is often scen in hlood smears from birds that have been inoculated with lymphoid tmmor cells or filtrate, and occasionally it will be found in large mumbers in seemingly normal hirds. All the examples selected for illustration were taken from apparently normal hirds, but the chicken that furnished the cell for figure 84 died with extensive neural lymphomatosis 44 days after the smear was taken. A 5-week-old ehicken furnished the material for figures 80,82 , and 83 , and in the same slide there were an musnal number of smudged monocytes of which figure 149 is an example. Not enough has lieen done to use the blood picture as an indicator of incipient lymphomatosis. It is a problem that should be investigater, not on the basis of a certain number of cells of each kind but rather on the basis of various cytologie effects produced in each cell type. Cellular reactions of the kind shown for the thrombocytes appear so frequently in birds inoculated with lymphoid tumor material that they deserve further study.

Kasarinoff (1910) described hypertrophy of thrombocytes with an increase in vacuolization following the subcutaneous injection of sodimm cantharidate. Schogar (1939) described the morphology of thrombocytes in pigeons and di. vided them into four categories: Normal, youthful forms, forms in old age, and forms nunder stimulus. It secms prohable that our reactive thromlocytes inclule his last two categories. The aging of thrombocytes has received practically no attention, except by Schogar, and yet it is a subjeet that might be pursued with considerable profit. There seems little douht that the reactive thrombocytes are the ones with vacmoles. Gray, Snoeyenbos and Reynolds (1954) have pholographed this type of cell in their study on the hemorrhagic syndrome of chickens. Aged cells may possibly be of the types shown in our figures 81 and 84 .

In the amplibian, Necturus. Dawson (1933b) found that thrombocytes had the power to phagocytose colloidal particles of carbon. These particles tended to aggregate at the poles. like the speeific acidophilic granules of thrombocytes. Iater (1936b) he showed that the particles of carbon persisted in the eytoplasm of circulating thromboeytes as long as a year, hut he concluted that the individual cell probably surviver only about 5 months. The thromlocyte is a highly labile cell and survival even this long seems rather surprising. yet his conclusion is justified by the data of his experiment.

This property of phagocylosis may be peculiar to particular species. Hartman (1925) in his classification of different types of thrombocyles among vertebrates, noted phagocytosis in the thomboeytes of the amphibian Bathrachoceps attenuatus (Eisen) and in the reptile, Imnana tuberculata.

Figures 80, 82, and 83 illustrate a structural series but it is not known whether progression in this series is from right to left or from left to right. As already mentioned, figure 80 rlosely resembles a lymplocyte except for the identifying specific gramules. Figure 90 is a lymphoeyte from the same slide; it has a similar cytoplasmic texture and unclear structure. In fig- 
nre 82 the cytosome is frothy and contains two imegularly shaped masses of specific gramular material, and in figure 83 the entire eytoplasm has a pinkish color, and abundant specific material surrounds the vacuoles. Figure 84 shows the specific subatance scattered in clusters and clmmps throughout the cytosome, and the cytoplasm itself has a pinkish color. The cell (fig. 81) is probably least removed from the nomal in that it is not moommon to fund thrombocytes with four clusters of specific gramules (figs. 88 . $p^{-s)}$.

When cells of the type exemplified by these figures were first olserved, it was assumed that lecause the cells were large and tended to have a rounded shape. they were immature: but after the developmental series had been worked out both in the embryo and in the adult. and it had been repeatedly demonstrated that the specific granules of thromborytes come relatively late in the developmental process and that when they appear only 1 or 2 small gramules are present, it was concluded that the overprodurtion of such gramules must have some other explanation. Becanse they often occurred in hirds suspected of lreing in ill health or known to have been inoculated with tumor transplants, they have been ealled reactive thrombocytes.

A second type of abnormal cell, the degenerating thrombocyte (figs. 85-87). is very common. As previously stated, degeneration is part of the nomal function of the thrombocyle: yet degeneration from the standpoint of the individual cell ean hardly be considered normal. Death and the processes leading up to it are not normal for the individual: yet from the standpoint of the race and the replarement hy successive generations, death must be considered as normal.

Chotting of the blood of birds proceeds at about the same rate as in mammals (Dorst and Mills, 1923). When smears are made, however, there is not as rapid elmmping of thromhocyles as there is of platelets. and cytologic changes can he followed in more detail in avian cells than in the latter. The first reaction involves a shift in staining color (fig. 85) of the cell membrane from a pale blue to a reddish violet or reddish orange. Whether this is brought about by a condensation of cell substance or by shrinkage logimning at the cell surface has never been determined. Diesem (1956) has illustrated this affuity of the thrombocyte margin for eosin in his plate 1. His figure is similar to that shown in our figure 85 . Usually the accentuation of the edge of the cell is accompanied by a shift in cell and nuclear thape from an oval to a more romded condition. More often the perimeter of the cytosome hreaks away from the cell and there remains only a relatively narrow rim of eytoplasm drawn out into irregular peaks (figs. 86 and 87). In both these illustrations, specific granules served to identify the cell type. but again there is considerable similarity to a lymphocyte. This is especially true when the specific granules are absent, as is usually the case in thromborytes reaching this stage of degencration. When the thrombocyte is small like figure 87, the possibility of confusion is not very great hecause this shrumken pyknotic cell is smaller than even a small lymphocyte, but a large thrombocyte with a nucleus of corresponding magnitude can often raise a question of how it should be classified.

The rate at which the thrombocyte arrives at this terminal stage of degeneration is variable, and the predisposing factors are known only in part. It has been observed that usually a smear made within a few seconds after pricking the wing vein will give well-preserved thrombocytes, evenly distributed; but with some birds, even a few seconds of delay, such as occurs in taking the second drop of blood instead of the first, will produce many cells showing early reactions similas to figure 85. The taking of the firsi drop is contraindicated for good smears in mammals but has leen found by experience to give the best result in birds. On the other hand, in some chickens one may be quite careless, even allowing a pool of blood to accumulate on the feathers, and after waiting 20 to 45 seconds before making the smear one may yet ohtain thrombocytes that are well preserved. Even a 2-minute delay may not cause much nore degeneration than may be fonnd in certain hirds from which the blood is taken immediately.

\section{Techuic artifacts}

No figures have been made because nothing has been found that could be so classified although it is most probable that it does occur. Just as there are many smudged erythrocytes, there are probalily smudged thrombocytes. A partially smudged thrombocyte would resemble 
a smudged erythrocyte too closely to permit identification, and it has ahready been pointed out that, after the cytoplasm is gone, all smudged nuclei look very much alike.

In conclusion, it should again be emphasized that less is known about thromloocytes- their cytology, pliysiology, development, and reactiv- ity-than about any other cell in avian blood. For the solution of some of these problems the phase microscope would be useful in that it reveals in the fresh living cell nearly ath the retails that can be seen in the stained preparation, and with it many of the rapid changes in the cell could be followed directly.

\section{Nongranular Leukocytes}

The term "nongranular leukocytes" groups lymphocytes and monocytes under one heading. The term is applicable to these two cell types because stainable granules are usually alssent from the cytoplasm of these cells; however, this characteristic should not be applied too broadly, because some lymphocytes contain magenta-colored bodies and some monocytes contain azmrophilic granules. In mammalian hematology these two cell types in some theories of hematology are said to arise within the lymph nodes, and have a conmon cell of origin. A revicw of the theories of hematopoiesis of lymplocytes and monocytes was given by Bloom (1938) and Bessis (1956).

The nongranular leukocytes offer many complex problems and some answers must be given to them before any workable basis of identification can be set up. It is true that practically any answers given will he arbitrary or empirical; nevertheless, they are indispensible and must be presented and discussed before considering the individual figures and the accompanying descriptive text.

Kasarinoff (1910) has reviewed the earlier literature on the number of types of leukocytes in avian blood. He demonstrated by colored drawings his division into six types: (1) Small lymphocyte, (2) large lymphocyte, (3) lympholeukocyte, (4) mast cell, (5) pscudoeosinophil, and (6) true eosinophil. In this study, small and large lymphocytes have been grouped together" and his lympholeukocyles have been identified as monocytes. Mast cells are called basophils, pseudoeosinophils are called eosinophils, and true cosinophils, heterophils.

Shall lymphocytes and monocytes be treated as a contimuous series extending from lymphocyte to monocyle? Maximow and Bloom (1931) have stated (p. 63), "When preparations of blood are examined and viewed objectively, it is seen that the nongranular leukocytes consist of a series of transition forms which begins with the smaller lymphocytes and ends with larger cells of quite different appearance, the monocytes, ... But in the midportion of this series of transitions is a group of cells which camnot he classified as either typical lymphocytes or typical mono. cytes." The same statement is applicable to avian blood, and this miglt be considered as lending weight to the ideas expressed by the unitarian school, but it does not exchude assessment of the problem in a different way, as fol. lows: Lymphocytes and monocytes show but hittle structural differentiation-neither cell type is far removed from the conventional generalized or typical resting cell so frequently depicted in texthooks.

In the blood there are no lopographic tissue relationships. It is as if a sncar were to he prepared for study from cells of the respiratory mucosa, epithelium of the digestive tract, of the liver, connective tissues, reticular tissues, and thyroid, and these cells had all been isolated from their usual habitat, allowed to round up and then spread out and dried for identification. Identification in many instances would be difficult. Another example could be cited that is probably more pertinent - the similarity of appearance be. tween certain heterophils and eosinophits. This similarity will be discussed more fully later but it may be said here that these cell types atso could be arranged in a structural series from heterophil to eosinophil, and the literature on avian blood reflects this confusion; yet at present there are no suggestions that the mature form of one develops into the other. From what has been 
said it is apparent that inability to catalog with. out question, or the mere existence of a structural series, is not in itself proof of genetic contimuity. Having applied this reasoning to lymphocytes and monocytes, it nust be pointed out at once that studies made on spleen, bone marrow, and early embryonic blood make use of a structural series of cells to trace developmental stages. On the basis of such series one is led to an opinjon, but the diversity of opinions on hematologic principles of cell relationships is evidence enough that such an approach falls short of carrying the weight often assigned to it.

The most convincing evidence that lymphocytes and monocytes are as distinctly different as are any other two cell types came from their treatment with X-rays (Lucas and Denington, 1957). Single total hody irradiation from $50 \mathrm{r}$ to $300 \mathrm{r}$ applied once to clickens at different ages has clearly demonstrated that lymphocytes are highly susceptible to this treatment, and by 1 to 3 days after irradiation had reached a maximm degree of depression in which the nommal value of 20.000 to 30.000 cells had dropped to about 2,000 to 3,000 cells. The recovery was rapid and, depending upon age of the bird and severity of treatment, was half to fully completed by the 15th day after imadiation. The monocytes reacted entirely differently; only the higher doses gave any indication that these cells had been affected at all, and the drop in number reached its maximum between the third and eighth days.

The typical lymphocyte and the typical monocyte are easily distinguished hut to describe and illustrate merely the typical cells would defeat an important function of an atlas on blood, that of slyowing variability so that questionable and midentified cells in differential counts are reduced to a minimum. As Lucas and Denington (1956) noted in a study on the morphology of the liver. the "typical" is very rare. On the other hand, what is normal may include a wide variability as was shown to be true for the avian erythrocyte. In the case of lymphocytes and monocytes there is overlapping in respect to the various cliaracteristics commonly associated with each of these cells.

It is simple and convenient to classify cells on the basis of a chief and supporting characteristic as was done for polychromatic erythrocytes. Unfortunately, this method will not work on lymphocytes and monocytes because their vari- ability ranges overlap, and one is forced to use multiple characteristics with the confusion that often results. Characteristics of monocytes and lymphocytes have been presented in table 3 . Relatively few cells will show all the characteristics listed under each rell type. The confusion comes when cells show characteristics partly of one cell type and partly of the other. Examples will be pointed out when individual figures are discussed (pp. 50-73).

In table 3 the characteristics are set up on the basis that all mature lymphocytes are either small or medium in size. A group referred to as "large lymphocytes" has not been considered in the preparation of criteria for the table for several reasons. It is only rarely that cells of this type have been seen in the circulating blood of normal adult birds. Four of them are illus. trated (figs. 121-124) but it is misleading to call them lymphocytes when obviously it is much more probable that they are immature cells in the process of development toward some other particular cell type. To make the term "lymphocyte" so inclusive that it designates both a fully mature functional cell of circulating blood and also the other extreme, a stem or blast cell from which other cell types arise, may be entirely justifiable when proponnding a unitarian theory of blood-cell interrelationships." However, this is not workable when the term is used merely to identify a defunite structural cell type without reference to any hematopoietic theory. It is for this reason that the "large lymphocyte" is treated separately from the small and medium-sized cell. To do this will not change the values obtained for differential comnts since, as already pointed out, the "large lymphocyte" occurs so rarely in the

\footnotetext{
"The unitarian point of view has been clearly stated by Dantschakoff (1909a, p. 157): “... Speziell ist der kleine Lymphozyt im erwachsenen Organismus nicht eíne reife Zellform, sondern, im Gegenteil, es ist eine ganz differente junge Zelle mit sehr mannigfaltiger, prospektiver Entwicklungspotenz. Gewiss entstehen die kleinen Lymphozyten in den Keimzentren durch Tucherung der grossen, aber sie können sich dann später, vielleicht nach einer längeren oder kürzeren Ruheperiode wieder lurch Hypertrophie in typische grosse Lymphozyten zurückverwandeln und zum Ausgangspunkte der Hänıtopoese werden."

Translation: In particular, the smalt lymphocyte in the mature organism is not a mature cell form, but on the conirary it is a quite distinct youthful cell with most manifold prospec. live developmental potential. Certainly the smatl lymphocytes arise in the germinal center through proliferation of the large, but they can later change back again through hypertrophy into typical large lymphocytes. perhaps after a short or long period of rest, and become the point of emergence of hematopoiesis.
} 
Table 3.-Characteristics of Iymphocytes and monocytes ${ }^{1}$

Characteristic

Cell size. . . . . . . .

Cell shape.........

Nuclear position.......

Nucleoeytosomal ratio...

The muclens is centrally plared or nearly $\varepsilon_{1}$ in many cases hut is ecentric sufficiently often 10 uffer a point of confusiom with monocyles.

Size is contimuons from a small cell with ahmost nu cytoplasm to one that is as large as the average betrophil.

Lympluocytes may lse round and regular or have a contour made irregular by projerting blels. of protoplasm or loroal protuplasmic lobes.

The nuclens rolative to the cytoplasm is large. The latter may var! from a narrow to a rather broad rim. A larger proportion of eytoplasm assuciated with an eccentric nucleu way make the cell appear to be a momocyte.

Cytoplasmic strueture... The cyoplasm may be relatively homogencous or contain closely parked irregular basophilic masses. Tneler pathologir conditions the cyto. plasm may become conspicuonsly aml extensively atveolar.

Hof and orange-staining spheres.

There usually are no $H o f \cdot$ like areas in the cyto. plasm even when the nurleus is eccentrically placed.

Specific cell inclusions.... Intrmely slained magenta granules are freguenty found in the cytoplasm of Iymphocytes. Cells containing them are regarded as almormal, even thongh those lodies are probaloly the countrrpart of the azurophilic granules reported for manmalian lymphorytes. They are very different structurally and tinctorially from the azurophilir granules of monoevtes. In some wild species of birds they are so conspicuons as to cause the cell to superficially resemble a basophil.

Nuclear shape........ The mucleus of the lymphoryte is roumd, or nearly so. It rarely slows an indentation and when it does it is the sort of eonstriction that comes from folding the mucleus on itself.

Nuclear structure

Cell division. .
Snall lymphocyte and some medinm byupho. crtes show large blorks of luasichromatin ihat accupy most of the nuclcar space. In many medium lymphocytes, the nucleus shows a mixture of chromatin clumps and a delicate reticulum. The nucleoplasm is tinged with dissolved lasimhromatin.

Division of lymplorytes in the circulating hlood is ly milosis.

\section{Momocte}

A few rells are smaller tlan 1 lic average heterophil lint most momocytes are largar.

Mature monorytes are of ten roum] with a smonth contour. Munocytes with a hyaline mantle are usually irregnlar. Immature rells may slwm lobes. Nature monorytes often acquire an irregular bajpe if squeczed brtween other rells at the time the smear is made. This distorts the eell and its rontents and makes it difficult t. identify.

The nucleus is nsually eccentrie.

The munoryte mucleus occupies a proportionatcly smaller area of the cell than does the lymphocx te mucleus. The difference in nucleocytosomal ratio appears to he greater than it actually is herause the monocyte nucleus lras an ecrenuric position.

The cytoplasm cuntains unifurm alveolar spaces, especially well developed in the region of the Hof. In the literature lle croplasin is often descrilued as laving a gromed-glass appearance. Many monocytes slow two structural regins in the rytomme a lyaline mantle forming the distal and of broad jotoplasmic lohes and a denser, darker staining, granular portion adjacent to the murleus.

Inst monocytes show a rarefied area of alveolar cytoplasm adjacent to the indentation of the nirclens. This Hof sometimes contains an orange-staining substance filling the alveolar spaces. I well-defined flof is not common in the wild species studied.

The dark magenta lowlies of lymplocytes are rare in monocytes. Instead the azurophlilie sul,stance in these rells stains a delirate pinkisly orange and are dustlike flecks in the eytoplasm. Isually the color appears at the denser interstices of the protoplasmic ground substanere and merges into the bhe color of the reticulum. (dreasionally these pinkish-orange bodies are punctate and discrete.

Nearly all monocye nurlei are either flat on one side or show a broarlly curverl depression in whirl lies the Hof. Round nuclei are more fre. quently found in small nonoeytes than in large ones.

Monocytes slow chromatin clumps that are small and an interral part of the nuclear reticnlum. The nucleoplasm is usually more nearly colorless than in lymphorves.

Division of the monocyte nucleus in circulating blood is liy ramatriction.

The characteristics chosen are those that can he seen after using Wright's stain and they do not include mitochondria. neutral red bodies or other cell structures that are revealed winh viral stains. 
circulating blood of a normal chicken that differential connts would have to be based on one or two thousand cells, instead of one or two hundred, to find any to count. Of course, if monocytes are included with lymphocytes, as has leeen done sometimes in the literature. the total agranulocyte count would be 3 to 10 percent higher than the lymphocyte comt alone. Large lymphocytes are present in fowl lenkemias $\mathbf{~}^{\circ}$ after cell transplants of lymphocytomas, but these blast cells usually identify themselves by their assocjation with some particular cell line.

\section{LYMPHOCYTES}

\section{Normal mature lymphocytes (figs. 90- 101)}

Cell size.-These 12 cells illustrate the various characteristics of lymphocytes presented in table 3. No one cell shows them all, and some of them reveal structures that are usually ascribed to monocytes. Figure 90 is probably as close to a typical lymphocyte as any; it is average in size, it has a fairly round and regular contour, the nucleus lies in the center of the celt, the cytoplasm forms a narrow rim that has neither a distinctly granular nor a hyaline texture, and the nucleus contains large dense clumps of chromatin and a tinged nucleoplasm. This cell comes from the same slide that produced the reactive thrombocytes, figures 80, 82. and 83. Lymphocytes are usually classified as small, medium, and large, but too often the subjective impression is based on nuclear size rather than the whole cell. or, stated differently, by what is left of the cell after the cytoplasm has lobulated and broken off. Thus, if a medium-size cell with its medium-size nucleus loses its eytoplasm it is counted as a small lymphocyte. Since lymphorytes often throw off blelos of cytoplasm, perhaps they should be elassified by size of nucleus rather than by size of cell; errors in estimating would certainly be less.

The cells shown in figures 92, 102. 103, and 104 are consilered as small lymplocyles. In figure 102 all cytoplasm is gone except for barely perceptible bits on one sicte of the cell and several lightly stained magenta gramules. The cell in figure 92 is somewhat larger, hut after it has lost the blebs that are in the process of pinching off, it will be ahout the same size. The cells of fig- ures 93-95 and 99-101, and others are medium in size. Whether a cell such as shown in figure 92 can reconstitute its cytosome is not known.

The range in size of lymphocytes is illustrated also in the outline drawings (fig. 150) and by the graph (fig. 152). None of the cells in these examples are as large as blast cells. Nore on the subject of size will be given in chapter 6 . The variations in size and shape shown in the colored illustrations are further extended in figure 150. Each rom represents samples of lymphocytes taken from a different breed or source, but there were no obvious differences: however, it has often been noted that on a slicle from a particular bird a small cell may be dominant and that in another bind the medium size may be more alomdant; or in one, blebs may be common and in another a hyalin cytoplasm may appear frequently. It is these points of difference, when their significance becomes known. that will make for critical studies on avian blood.

Blast cells may be found oceasionally in the circulating blood and four are illustrated here (figs. 121-124), and in the legends suggestions are given as to the line that each represents. but there is much room for error. The cells of fig. ures 121 and 124 have nucleoli and show a coarse nuclear pattern; the erythocyte relationship is moderately certain for figure 121 hut is questionable for 124, and the intensely stained nuclens and cytosome are indications that it belongs to the thrombocyte line. The general appearance of figure 122 , particularly the tendency of the cytoplasm to be frothy or vacuolated. and the vagueness of nuclear pattern are suggestive of the early lymphoryte as seen in the thymus ( figs. 335 and 336$)$. The narow rim of dense bhe rytoplasm of figure 123 with its moderately miform meshlike nuclear structure suggests a gramuloblast. but this cell is not as typical as those seen in the spleen and the bone marrow.

Cell shape.-Avian lymphocytes may have a regular contour but in certain slides from apparently normal hinds the lymphocytes will exhibit many protoplasmic hjebs (figs. 92-94). This reaction in nammals has been identified as stimulation of the blood toward antibody formation by pathogenic agents or other causes. In view of this, the history of the three individmals in which these cells were found is interesting. Figure 91. which shows a few small lobes; was taken from a hird killed at 619 days of age, 
at which time it had a wryneck but no lesions of lymphomatosis or other diseases to account for the condition. The cell represented in figure 93 has several broad lobes with restricted bases. as if the cell had been taken just at the moment the cytoplasm was leing pinched off. The smear was taken when the pullet was 113 days old, and when killed at 151 days she showed severe gasping and emaciation. At gross necropsy there was atonicity of the crop and a slightly incegular pupil. suggestive of ocular lymphomatosis. In figure 92 the lobes are numerous. At their tips are basophilic gramules that in size and shape look as if they were intracellular organisms, but this is incorrect; instead, they are some of the basophilic masses that are commonly found throughout the cytoplasm of most lymphoeytes (frgs. 90 and 96-98). The smear from which figme 92 was made was taken from a hen at 113 days. At 288 days she showed a prolapserl uterus from which an unexpelled egg was removed. She recovered and then was killed at 312 days because of lack of holding space. The bird was still in production and apparently normal.

When the lobes are discharged into the plasma of the blood, there remain cells that look like figure 102, in which there is barely enomgh cytoplasm around the nucleus to exclude it from being a naked nucleus. This cell came from a smear taken at 108 days. When the hen was killed at 668 days she was a strong vigorous bird. At gross necropsy some urates in the kidney and white spots in the air sacs were found.

The evidence furnished by these few examples is certainly not suffecient to permit us to draw any generalizations conccrning the association of blebs and the health of the bird. No extensive quantitative sludy has ever been made along these lines: yet, obriously, this should loe done and it might lead to some interesting and important information concerning the actual health of birds that seem nomal. In any study of this sort it would be necessary to take blood samples at closely spaced intervals in order to catch the rise and fall of bleb formation. The discharge of blebs probably occurs quickly.

Johnson and Comner (1933) sought to associate budding in lymphocytes with manifestations of the avian leukosis complex. They state:

"In 14 birds of the 31 studied with symptoms of paralysis of the limbs but no gross lesions no. ticed on autopsy, budding of lymphocytes occurred. In 10 of the 14 sturlied with symptoms of paralysis of the limbs and lymphatic hyperplasia of visceral organs, butding of lymphocytes was marked. In only three of the 15 para. lyzed birds with tumors found on autopsy was budding of lymphocytes noted. Threc of the 12 birds with iritis or gray eyes also had numerous lymphocytes."

For comparison. a study of budding phenomcnon in normal birds and in hirds with various types of diseased conditions is needed.

Frauk and Dougherty (1953) were able to produce ludding in lymphocytes of man in vitro by treatment of the buffy coat with cortisone and hydrocortisone. The mean percentage of lymphocytes showing budding in normal controls was $1.2 \pm 4$ percent, and for those treated with hydro. cortisone it was $11.63 \pm 1.25$ percent.

The outline drawings in figure 150 have already been mentioned. In some it appcars that lymphocytes are capable of locomotion hy throw. ing out hroad psendopodia, and many of the cells look as if they had been caught during amoeboid movement. Others, however, lave small protrusions more or less equally distributed around the cell. These are probably blebs of protoplasm pinching off. Vany others, with almost no cytoplasm left, look as if they had already lost the blelss.

Nuclear position.-The nucleus lies at one side of the rell (figs. 91, 94, 99, 101, and some of the cells in fig. 150) almost as often as it does at the center (figs. 90 and 104). Sometimes the amount of cytoplasm is so small that the nucleus can only he in the center (figs. 92. 102, and 150 $D, c$ and $F, b$ and $e$ ).

Nucleocytosomal ratio.-Nucleocytosomal ratio is influenced not only by the pinching off of lobes, which is a regressive type of change, but also by a change in character of the cytoplasm in which it takes on a hyaline appearance and flows out like a thin fuid in all directions (fig. 100). This was found quite frequently in chicks aloout 5 weeks old. The cytoplasm was pale and as seen in the microscope gave an impression of fluidity without adergate framework. These lobes are different from the type where the cytoplasm is pinched off. Often it spreads out between the boundaries of ncarby cells, and it was 
difficult to find examples for drawing that were not misshapen beyond recognition. Even in figure 100 two of the projections were flattened against adjacent erythrocytes. The example shown is large enough to be a monocyte but its structure is quite different from that of monocytes taken from the same slide, an example of which is slown in figure 125 .

In general there is less cytoplasm relative to the nuclear area than in monocytes, but again there is overlapping of their ranges, as may be seen by comparing figures 150 and 151 and graphs on figures 152 and 153 . If the ontline drawings on these two plates were cut apart and and shuffled it would be impossihle to separate them correctly in many cases into the two cell types; this fact emplasizes the point that separation of lymphocytes and monocytes is based on more than just size, shape, nuclear position, and nucleocytosomal ratio.

Cytoplasmic structure.--The cytoplasm may stain intensely or faintly. It may be granular or nearly homogeneous. The granular condition is quite common and appears as a flocculation of basophilic material (figs. 95-99). These figures illustrate variations in the size of the basophilic masses and in the intensity of staining. In figure 98 the gramles near the edge of the cell are large and dark, those near the mucleus are smaller. In figure 96 the basophilic material gives texture to the cytoplasm but there are no distinct basophilic masses. The flocculent appearance of the cytoplasm lies at the limit of microscopic visibility and sometimes the cytoplasm appears to he a reticulnm with denser masses at the interstices, such as shown in figures 95, 99, and 101.

All the cells mentioned so far have heen stained with Wright's stain. The cell in figure 91 was stained with May-Grünwald Giemsa, which accounts for a coloration different from the rest of the cells. It also shows the basophilic masses in the cytoplasm but here they are more nearly spherical and are more definite than in the previous examples.

The cytoplasm in figure 90 is nearly homogeneons with only slight irregularities in density. Further change toward a hyaline structure is shown in figure 100. When the cytoplasm reaches this hyaline condition it tends to flow out away from the nucleus. In the hyaline type, the quantity of cytoplasm is great enough in relation to nuclear size to establish the cell as a monocyte, if only the one character of nucleocytosomal ratio is used for identification.

Sometimes a lightly stained area is present in the cytoplasm adjacent to the nucleus. The cell in which this is illustrated (fig. 97) is classed as a lymphocyte, although in the tahle on lymphocyte and monocyte characteristics, such a light area is more typical of a monocyte (see, for example, figs. 126, 127, 129, and 144). This is another example illustrating the point that the presence or absence of only a single characteristic is insufficient basis for a satisfactory separation of these two cell types. Looking over the entire group of lymphocytes from figure 90 to figure 101, there is little question that the cytoplasmic structure of these cells is highly diverse and that no narrow characterization will cover them all.

Hof and orange-stained spheres.-These are characteristic of monocytes and so will be discussed later. Specific cytoplasmic inclusions are not normally present in lymphocytes but in cells, considered to be abnormal, they do exist as magenta bodies (figs. 102-116); therefore the details of their structure will be deferred until abnormal cells are discussed. These magenta bodies are almost specifically associated with lymphocytes and thus are useful for identification purposes.

Nuclear shape.-The lymphocyte nucleus is approximately round, as shown in figures 90,93 , 105, and in many of the cells in figure 150. Deviations from that shape are common and, as would be expected, they occur by imperceptible structural differences in various directions. When the nucleus is eccentrically placed, the contour of the portion adjacent to the mass of cytoplasm is more flattened than the remainder, which is adjacent to the outside wall (figs. 97, 101, and 107). If the cytosome of the cell is lobulated, often the contour of the nucleus is irregular also but not necessarily concentric with the cell outline.

Indentation of the meleus is not common in lymphocytes but does occur sometimes (figs. 91, 94,11]. and 114). Usually the depression is not. deep and the margins curve inward to a sharp

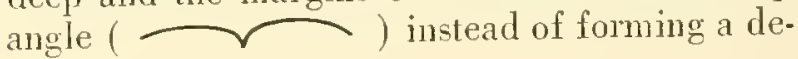


pression with a rounded base as often occurs in monocytes ( $\longrightarrow$ ). In lymphocytes there is usually no Ilof opposite the depression; the cytoplasm appears the same opposite the depression as in the more lateral areas, but sometimes the nuclens shows an indentation and there is a rarefied area opposite. In figme 131 there is such a cell and it has been classed as a monocyte, but some might be of the opinion that this cell should be included with the lymphocytes because of its small size and high nucleocytoplasmic ratio. Fortunately, borderline examples of this type are not numerous.

Nuclear structure.-The muclei of lymphocytes are typically described as filled with dense chromatin chmps. Probably figure 102 fits the usual description best and a similar effect is given in figure 90. Dense clumps of basichromatin are common in small lymphocytes but rare in larger cells. In lymphocytes of medium size the reticular network with small chromatin masses at the interstices is the usual arrangement (figs. 95-99 and 101). As we study the change in cell size from the larger to the smaller, it is easy to find all corresponding degrees of change in chromatin clumping. Figure 98 shows two phases of the process in the same nucleus-on one side there is the reticnlar appearance of the larger cell and on the opposite side are dense clumps commonly associated with the smaller cell.

When there is a delicate reticular pattern in the nucleus the spaces between are clear and transparent-the nucleoplasm is colorless (figs. 97-99 and 101). When the nuclear pattern takes the form of dense clumps there is some dissolution of basichromatin, which gives to the nuclear sap a color almost as dense as the chromatin itself (figs. 100 and 104). The wide varjation in size of chromatin clumps and density of nuclear pattern is clearly demonstrated when a smear containing lymphocytes of small and medium sizes has been fixed in Petrunkevitch No. 2 and stained in May-Grïnwald Giemsa (figs. 199 and 200). When this technic is used the nucleus of the medium-sized lymphocyte may resemble closely the nucleus of the monocyte (compare figs. 200 and 201).

Cell division.-Cell division is rare in circulating blood and in fact its occurrence in lymphocytes has been questioned. One of the arguments against the lymphocyte as an undif. ferentiated blast cell has been the absence of mitosis, a process that has been olserved only a few times and then in birds that had been irradiated. Cells undergoing mitosis are usually difficult to name because identifying characteristics are lost in the process; however, in the case of figure 108, magenta bodies were present that have a high specificity for lymphocytes. Blood stains and air-dried fixation do not give a sharp delineation of the individual chromosomes but there is no question that the cell is dividing mitotically. It is interesting that the magenta bodies should arrange themselves approximately midway between the poles. The division of lymphocytes by mitosis is in contrast to that of monocytes that divide by nuclear constriction.

\section{Developmental stages found in circulating blood}

Probably less is known about the cytomorphosis of lymphocytes than about any other lenkocyte. Immature lymphocytes have been identified in the thymus where they are developed in large numbers, and it has been snggested that figure 122 represents a young lymphocyte, but in general they are difficult to identify. There are identifying structural features, it is true, but fitting them into a maturation series is not easy. The developmental series of lympliocytes depicted in atlases of mammalian hematology are usually derived from cases of lymphoblastic lenkemia. Here the association with many other cells, all developing in the same direction, makes a kind of pure culture, as it were. from which a developmental series can be constructed. After it has been put together there still is not much in the way of specific cell identification by which an occasional immature lymphocyte, which one might find in the circulating blood, can be satisfactorjly distinguished from various types of blast cells.

The curve for the sizes of avian lymphocytes shows approximately a normal distribution (fig. 152). It is generally recognized that specific criteria useful for the identification of age and maturation are generally lacking in the lymphocyte series. Wiseman (1931b and 1932) considered that the degree of basophilia of the cytoplasm could be used as such a measure and under 
stress that there could be a shift toward greater basophilia among the cells counted. This would have the same significance for the lymphocytes that Arneth found for nuclear changes in granulocytes. In a study of lymphocylogenesis in the thymus (cliap. 4) it was coucluded that lymphoblasts are larger than the next stage in maturation and that matne lymphocytes were relatively small. With increasing age there was a loss of mitochondria and a change from delicate reticular pattem in the nucleus to demse chromatin clumps.

It is true that there are certain examples sug. gestive of nuclear change from an open, lightly stained reticnlar type (fig. 99) to one showing dense clumps of chromatin. Some nuclei, such as the one shown in fignre 98 , show a transitional condition from reticulum to clumps. It is a question whether this nuclear variability is a measure of increasing cellular differentiation or an inseparal, le arcompaniment of decreasing cell size. There is no evasion of the fact that cell size and nuclear structure are very closely associated: and if clromatin clumping is a miark of cytomorphosis, decreasing cell and muclear size must carry the same comnotation.

\section{Abuormal lymphocytes (figs. 102-120)}

It is anticipated that a number of hematologists will question the accuracy of cataloging as ab- normal al! the cells included in thi- section. It is armitted that the evidence is not extensive Jut it seems sufficient to tip the balance of opinion toward the abnormal. It will be noted that all cells from figures $102-116$ show various kinds of gramules; in table 3 these have been called magenta bodies and they prohably are equivalent to what has been called azurophilic granules in mammalian lymphocytes. "Magenta body" is a new term that does not carry any implication of function or origin. A new expression has been devised to replace the term "azurophilic granules" because the colors and affunities for the stain of these granules in lymphocytes and in monocytes of birds are so different that to give botll the same name would he confusing. This confusion does not occur in the mammalian agramulocyte because in both cell types the azurophilic granules appear similar. It is not the presence of these granules that led to designating these cells as abnormal hut rather their frequent association with nuclei that are degenerating and with cells whose cytoplasm is lolown up and vacuolated. The magenta bodies stain intensely, whereas the azurophilic granules of the monocytes are small, stain rather faintly, and have an orange color.

Ahout the largest magenta bodies observed, as well as some small ones, are shown in figure 104 . All of them are spherical, which is the usual shape, lut not infrequently they appear diploid or crescent shaped as in figures 105 and 106 .

\section{Figures 90-108.- Formal and almormal lymphorytes. 2,470X.}

Frgures 90-101: Normal lymphocytes.

90 A typical lymphocyte.

91 LFmphocyte staned with May-Grimwald Giensa.

92 Lymphocyte pinching off cytoplasmic blebs containing basophilic granules.

93 Lymphocyte with hyaline cytoplasm like figure 100 , in the process of pincling off cytoplasmic blebs.

94 I ymphoeyte with finely gramular nucleus.

95 Typieal lymphocy te with maclens less dense than in figure 90 .

Figures 96-99: Four cells that show stages between pachychromatic and leptorhromatic nuclei.

96 Basichromatin of lower lialf of nucleus coaricly and finely granular, upper half in clumps.

97 Granular and slightly elumped basichromatin intermingled.

98 Slightly clumped basichomatin in the right side and granular basichromatin in the left sicte of the nucleus.
99 Tucleus furgely filled with granular basichromatin.

100 Normal lympliocyte with hyaline cytoplasm.

101 Nearly maxinum size for a normal lymphocyte.

Figtres 102-108: Abnormal Tymphorytes with magrntu bodies in the cytosome.

102 Smalt amount of eytoplasul remaining after blel formation. Several small magenta bodies are present.

103 Magenta bodies often in pairs. Slight autelysis of the nucleus.

104 Larg"magenta bodies.

105 Some of the magenta bodies are arranged in pairs. Nucleus partially autolysued.

106 Nucleus almost completry autolysed.

107 Magenta bodics in a reactive lymphocyte. For the rest of this series, see figures 109-112.

los Iymphocyte in telephase of mitotic division. Magenta bodies between poles in spindle region. 


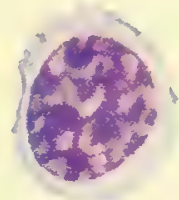

90

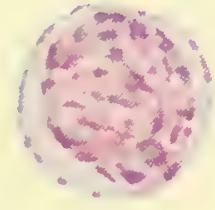

95

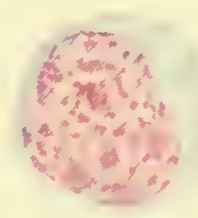

99

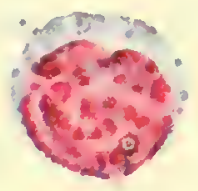

91

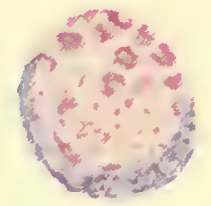

96

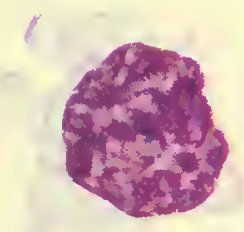

100

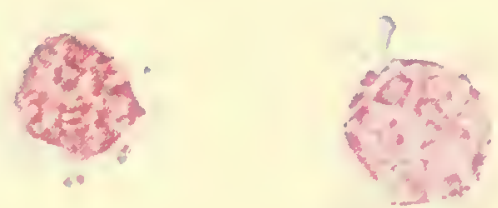

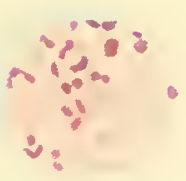
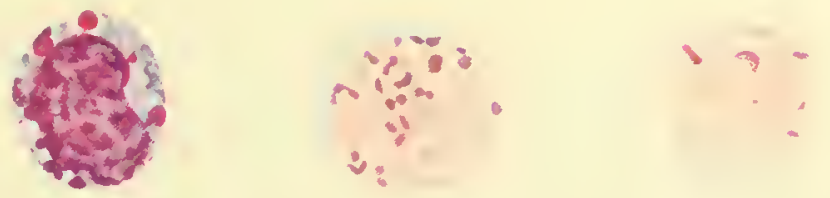

105
104
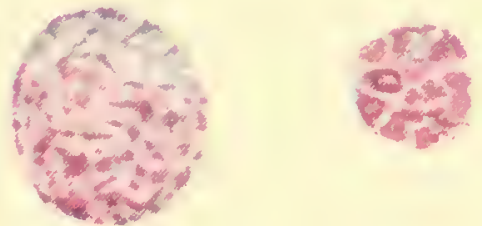

102

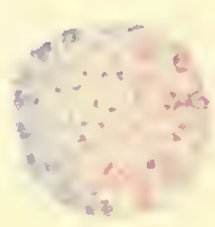

97

98

93

91
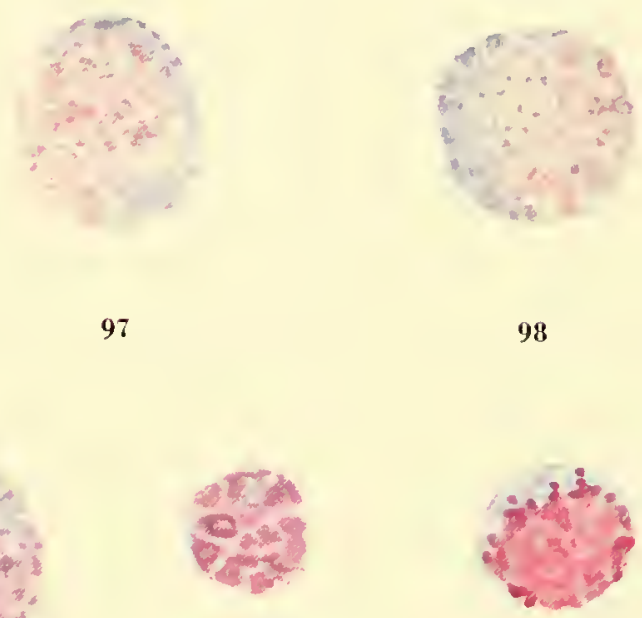

103

101
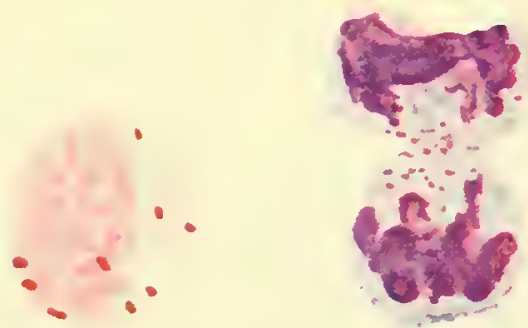

106

107
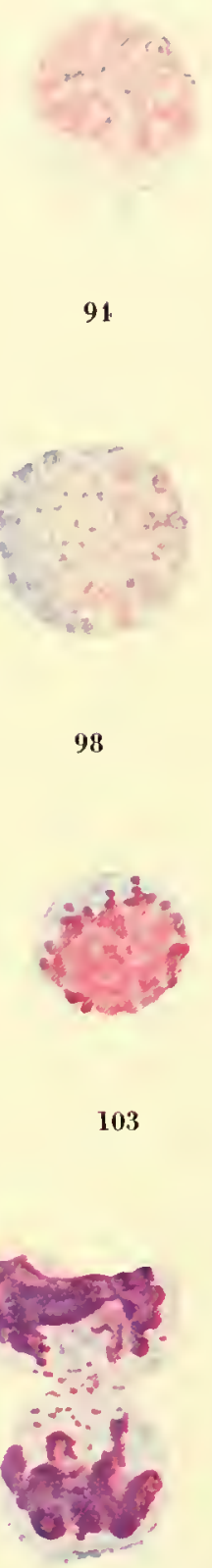

108 


\section{Figures 109-124.-Abnormal and so-called large lymphocytes. 2,470×.}

Figures 109-112: Reactive lymphacytes with magenta badies and vacuolization of cytoplasm.

109 Vacuolization has begun but nucleo-cytoplasmic ratio is about like that of a normal lymphocyte.

110 Lymphocyte with leptochromatic type nueleus; slight hypertrophy of nucleus and cytosome.

111 Reactive Iymphocyte. Typical lymphocyte nucleus. Magenta bodies and cytoplasmic vacuoles relatively few.

112 Typical reactive lymphocyte; hypertrophy of the cell cytoplasm, frayed and vacuolated and containing abundant magenta bodies.

Figures 113-116; Questionable obnormal and reactive lymphocytes. These may be monocytes.

113 Azurophilic granules, concentrated mostly above the nucleus; lymphocyte type nucleus.

114 Mixture of azurophilic and magenta bodies.

115 Magenta bodies and vacuolated and frayed cytoplasm.

116 Lymphocyte with a few pale magenta bodies. From same slide as the preceding three cells.
FIGURES 117-120: Abnarmal lymphacytes that show varying degrees of chromaphotia of the basichromatin. Same set of slides from which figures 3 and 44-49 were taken.

117 Lymphocyte with two chromophobic fractures.

118 Chromophobic areas surrounded by normal basichromatin.

119 Normal basichromatin restricted to about one-third of the nucleus.

120 An almost completely chromophobic nucleus.

Figures 121-124: So-callcd large lymphacytes, which are early immaturc blood cells (blast cells). All found in circulating blood of chickens 4 months to 5 ycars old.

121 Delicate reticular nucleus type with nucleolus probably belongs to the erythrocyte or thrombocyte series.

122 Blast cell; probably belongs to the lymphocyte series.

123 Blast cell; probably belongs to the myelocyte series, although nucleolus is faintly visible.

121 Blast cell; probably belongs to the erythrocyte or thrombocyte series. 


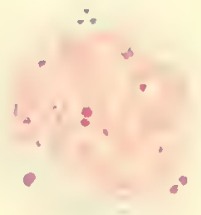

110

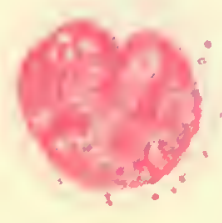

114

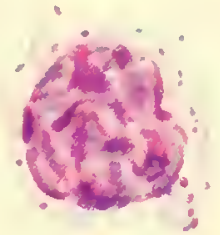

111

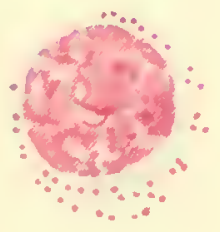

115

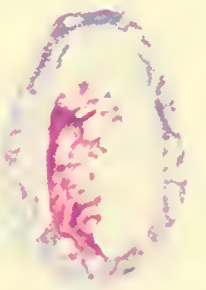

119

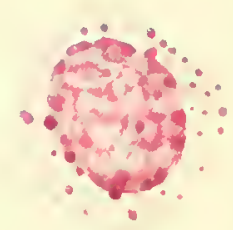

112

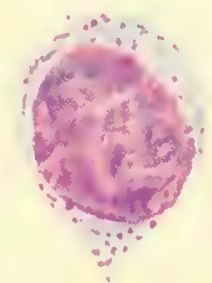

116

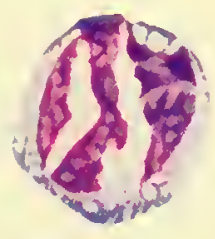

117

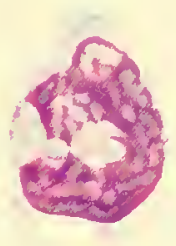

118

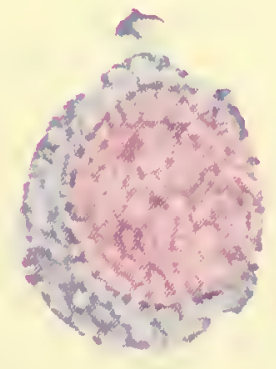

122

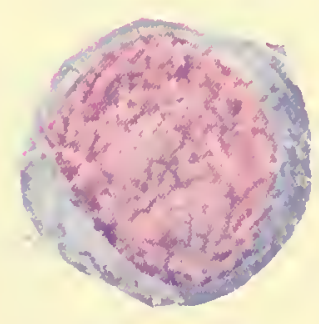

123

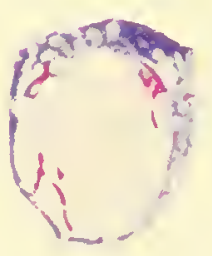

120

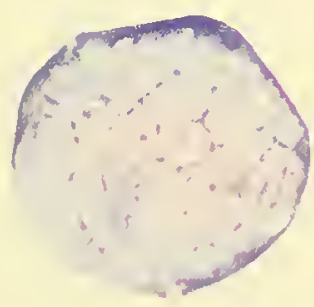

121

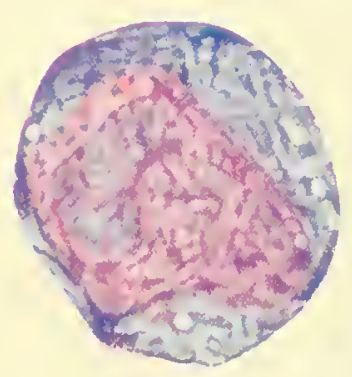

121 


\section{Figures 125-138.--Normal monocytes. 2,470×.}

Figures 125-131: Tariations in sizc and appearance of normal monocytes.

125 A typieal monoeyte. A hyaline mantle extends beyond the reticular portion of the endoplasm. The eytoplasm is a mixture of azmophilic and basophilic substanees.

126 Monocyte with well-cleveloped Ilof, or clear area, filling the nuclear indentation.

127 Monoeyte nueleus but with a nucleocytoplasmie ratio of the lymplocyte.

128 Deeply indented monocyte mucleus but no IIof.

129 A type of monocyte frequently seen in smears of avian blood.

130 A monoeyte that shows the polychromasia of the cytoplasmic reticulum.

131 A monoeyte having the size and nucleoeytoplasmic ratio of the lymphocyte. See table 5 , page 71 .
FinuRes 132-135: Monocytes with numerous azurophilic granules.

132 Azurophilie granules eoneentrated on the side of the nueleus opposite the llof.

133 Ilof absent. Azurophilie bodies filling most of the cell.

13.4 Bilobed nueleus. Azurophilic grumules conspicuous against the blue-stained cytoplasm.

135 Azurophilic granules larger and more abundant than normal.

Frotres 136-135: Bilobed and double nuclei in monocytes.

136 Shightly constricted nuclens, similar to the one in figure 134, which is a larger cell. No Hof present in either of these cells.

137 Nuelens nearly eompletely eonstrieted. Mletachromatic cytoplasm. A small questionable $H$ of present.

138 A binucleated monocyte. A definite Hof on the upper side in the angle between the nuclei. 


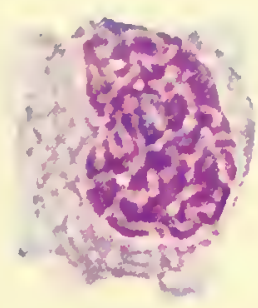

125

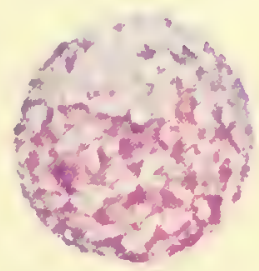

129

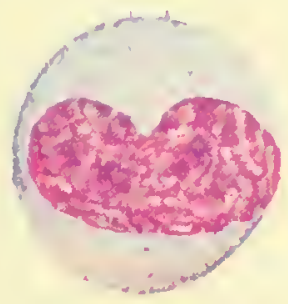

132

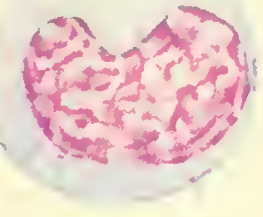

126

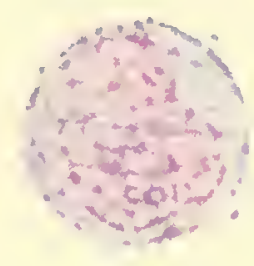

$12 \%$

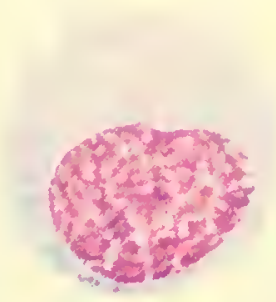

130
128

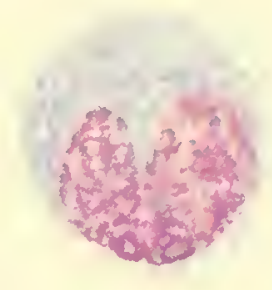

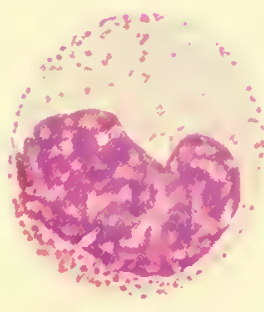

133

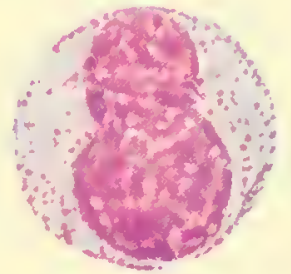

131

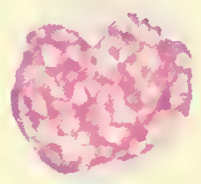

131

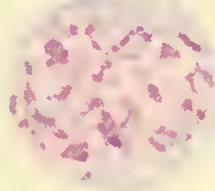

136

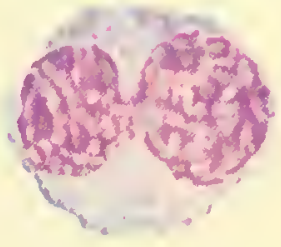

137

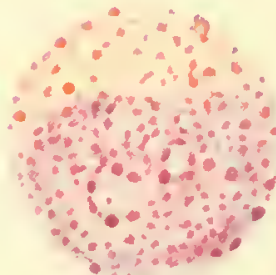

135 
Figures 139-149.-Developmental stages of monocytes as found in the circulating blood, also abmormal cells and artifacts. $2,470 \times$.

Figures 139-142: Developmental stages with intensely stained nuclei, ranging from leptochromatic to pachychromatic type.

139 The young amoeboid cell of the monocyte series; possibly a monoblast. A nucleolus is faintly shown.

140 Amoeboid monocyte with both azurophilic grautes and magenta bodies.

141 A round young monocyte.

142 A roung monocyte with a rounded nucleus. The cell has a well-developed $/ 10 f$, and a concentration of azurophilic granules around the periphery.

Figrres 143, 144: Developmental stages with lightly stained nuclei.

143 Amoeboid monocyte, more differentiated than the blast stage.

144 Nearly mature monocyte. The contents of the IIof vacuoles arc slightly stained.
Figures 145-147: Abnormal monocytes.

145 The accumulation of basophilic granules around the periphery of the cell is not typical. The faint reddisl tinge of the cytoplasm is suggestive of early autolysis.

146 A monocyte definitely undergoing autolysis.

147 Some Hof vacuoles have become abnormally large. Vacuolar content stains a light orange color.

Figures 148, 149: Technic artifacts. Smudged monocyles.

148 A monocyte in which the cytosome, but not the nucleus, has broken.

149 Identification of this as a squashed monocyte nucleus is based on the fact that this slide contained many such cells with transitional stages from normal intact monocytes to this type of large basoplilic mass. 


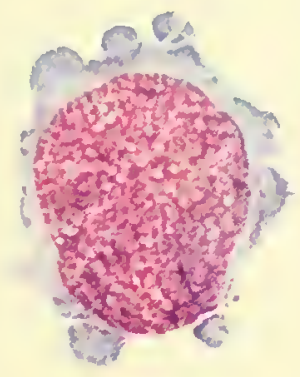

139

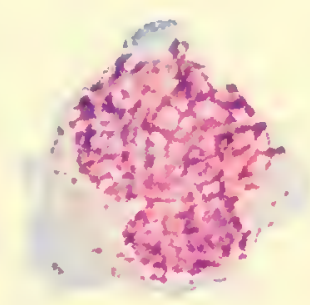

140

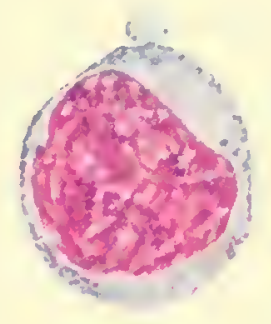

141

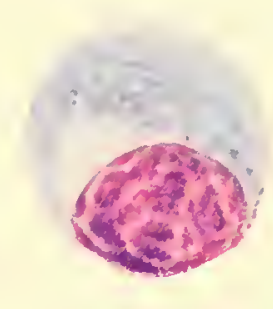

142

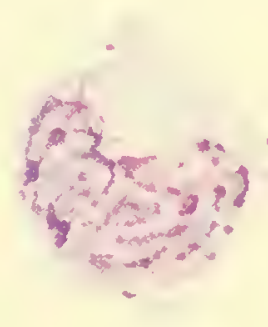

14

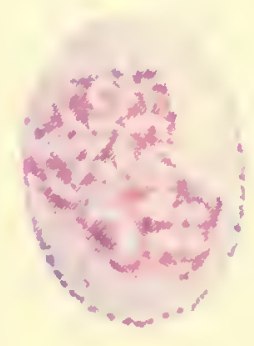

145

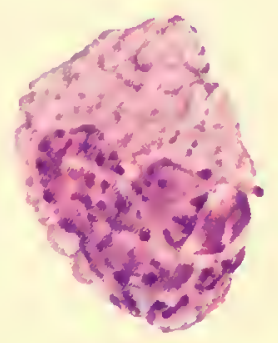

146
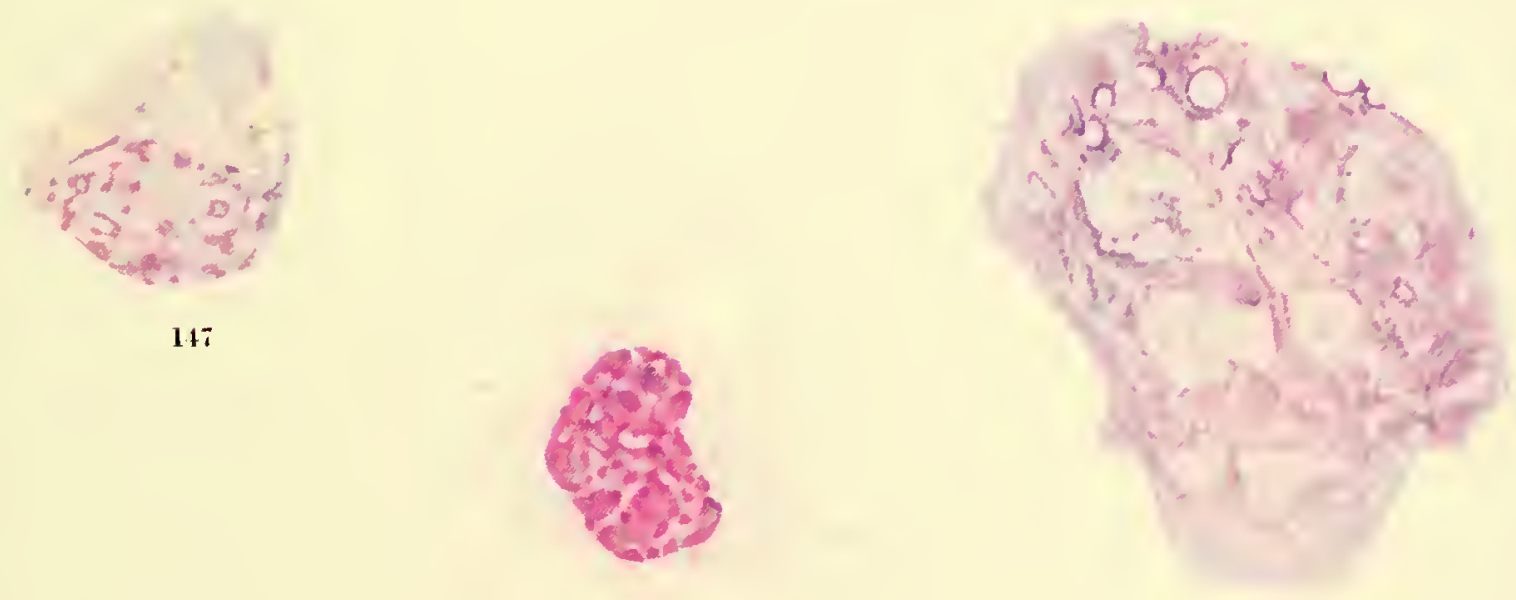

149 


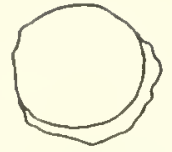

a

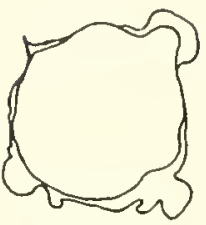

B

a
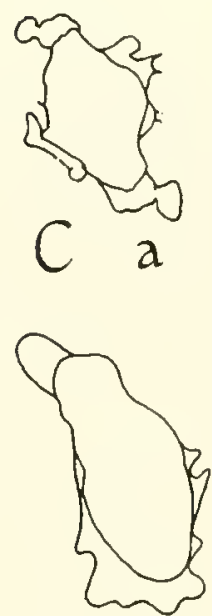

$\mathrm{D}$

a

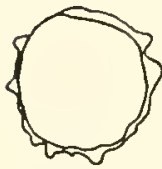

E

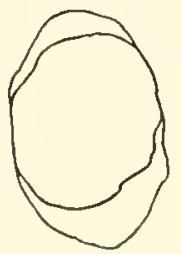

E $a$

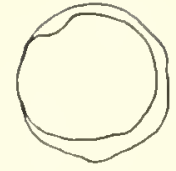

b

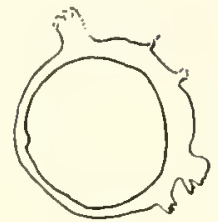

b

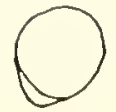

b

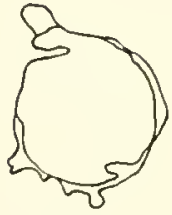

b

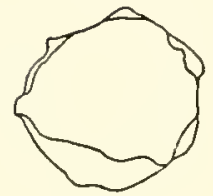

b

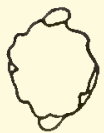

b
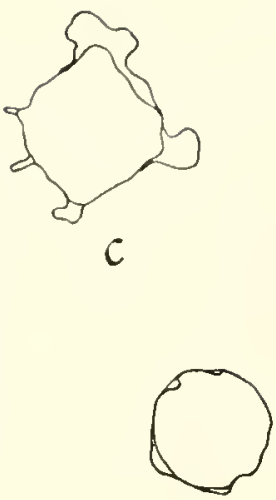

$\mathcal{C}$

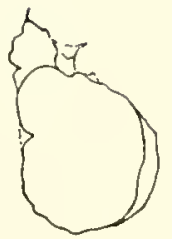

C
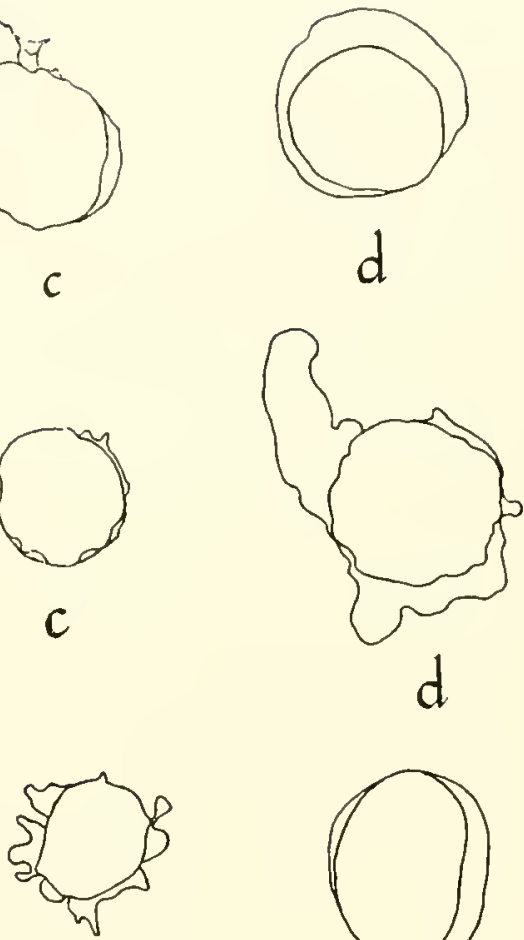

c

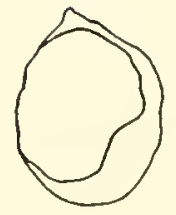

$\mathcal{C}$ d
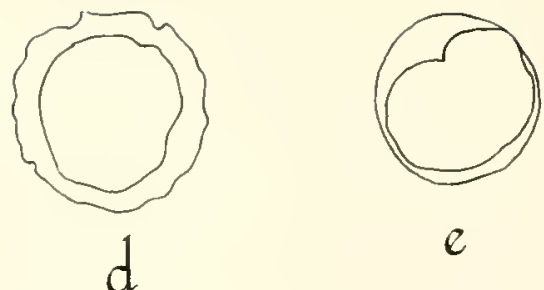

$\mathfrak{e}$

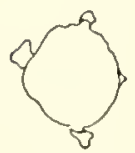

d

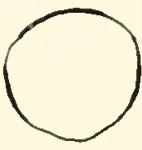

e

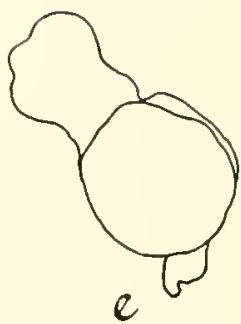

e

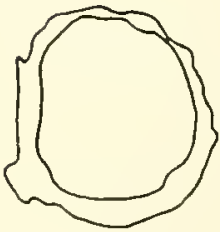

e

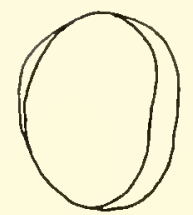

d

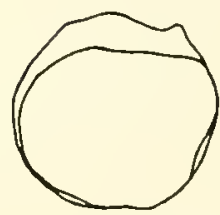

e

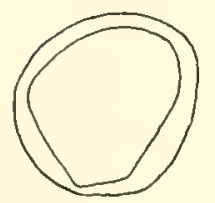

d

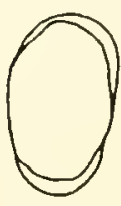

e

FigURE 150.-Outline of normal lymphocytes and their nuclei to show variations in size and shape within and between breeds or stocks of chickens. 2,470X.
A, a-e Ancona, from Hy-Line Poultry Farms, Iowa.
D, a-e Single Comb White Leghorn, from Iowa State
B, a-e Barml Plymontl Rock, from Hy-Line Poultry Farms, Iowa.
E, a-e Single Comb White Leghorn, from Hamilton Single Comb Wureau, Hichigau.
C, a-e New flanpshire, from Hy-Line Poultry Farms,
F, a-e Rhode Island Red, from Hamilton Farm Bureau, Michigan. 


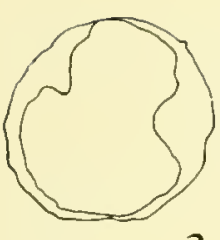

A

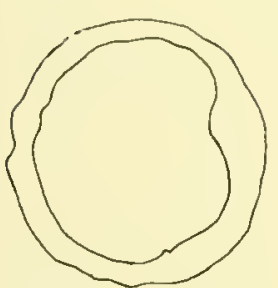

B

a

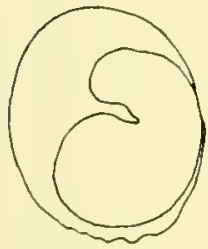

C a

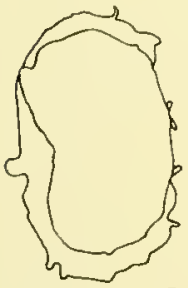

D
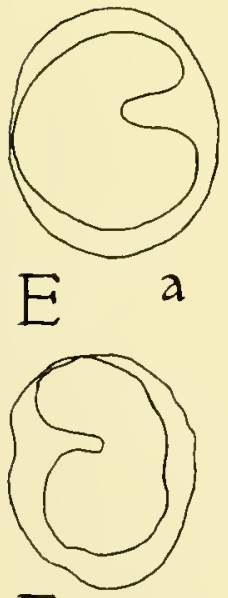

$\mathrm{F} a$

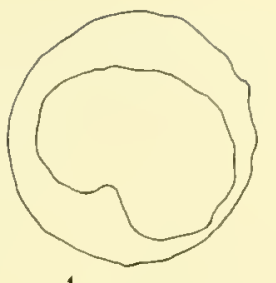

b
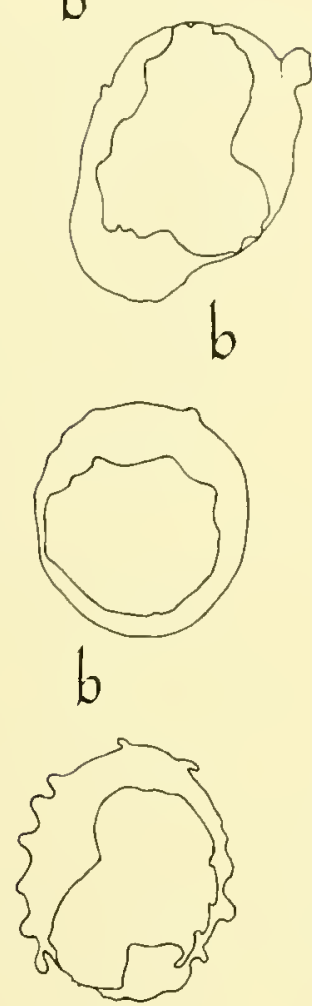

b

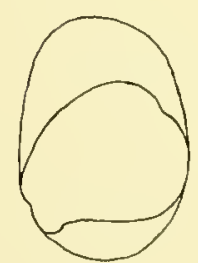

b

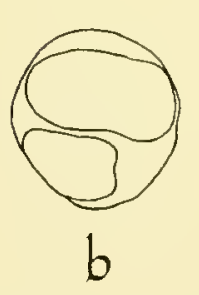

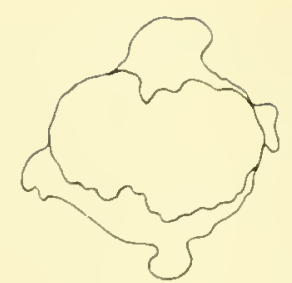

c
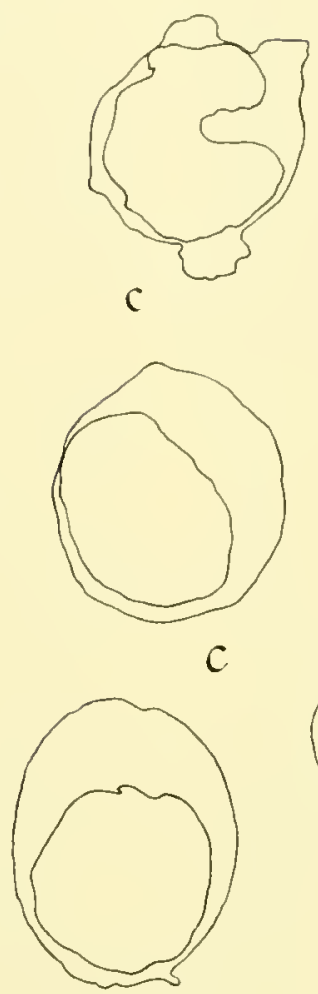

C
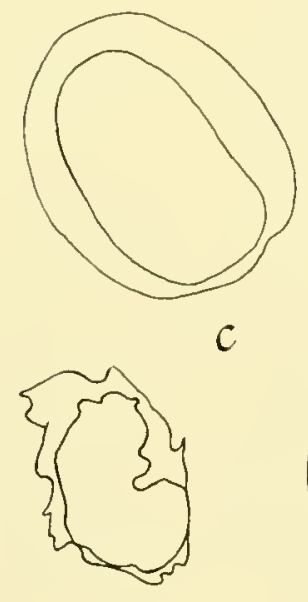

C

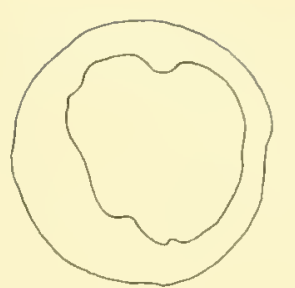

d
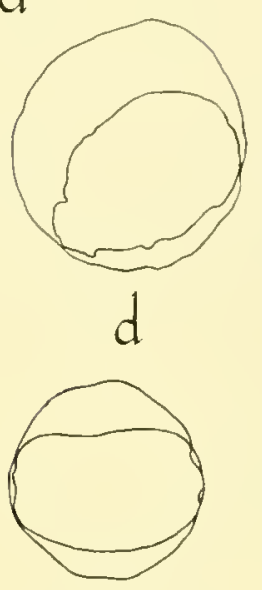

d
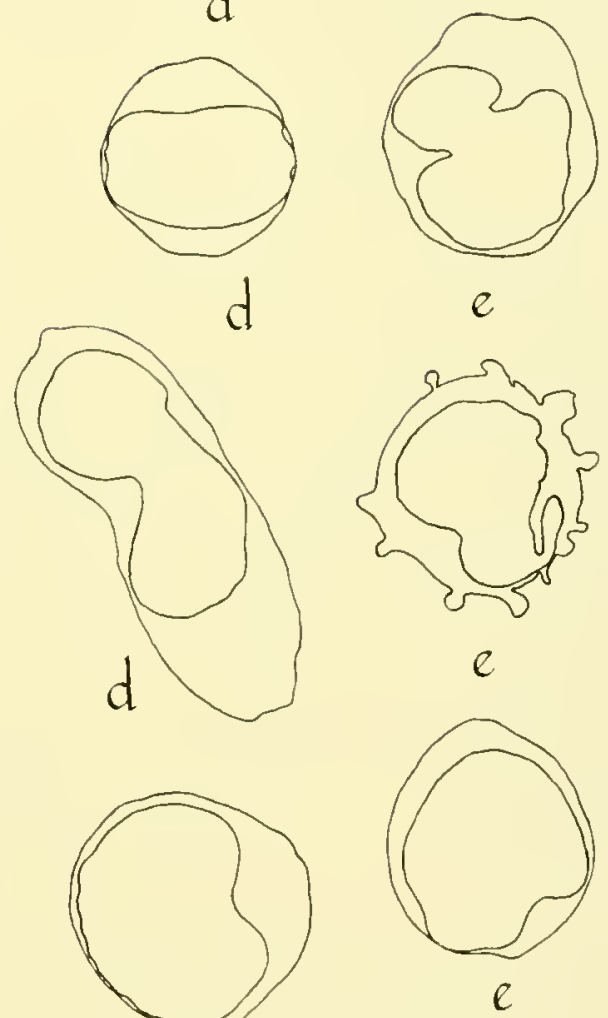

d
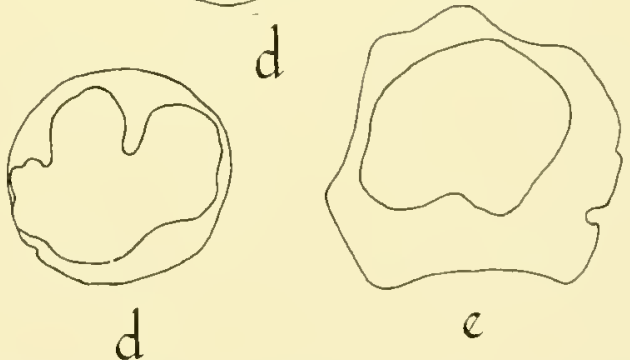

Figute 151. - Outlines of normal monoeytes and their nuclei to show rariations in size and shape within and between breeds and stocks of chickens. $2,470 \times$. 
When the nucleus stains darkly, the overlying magenta bodies that have the same staining affinities are not clearly visible (figs. 104 and 109). When the mucleus is extensively lysed as in figures 105-107 the overlying magenta boties are usually conspicuous.

No one has yet associated the presence of magenta bodies with any particular pathological condition in birds, but the impression has been gained that they are often associated with birds that have a disposition toward early mortality. Olson (1952) noted them in lymphocytes taken from cases of avian leukosis but he does not say that they are specifically associated with the disease. There is much speculation concerning the presence of a lymphomatosis agent of viral size that, by acting upon the lymphocyte, ultimately stimulates the cell into a neoplastic condition. These magenta bodies may have no relationship to lymphomatosis infection but their sporadic appearance in lymphocytes of chickens would seem to justify further study in an effort to fund out what they are and what they are doing in the cell. Their presence does not necessarily indicate a dying cell; mitosis can occur (fig. 108).

Michaelis and Wolfe (1902) are said by Doan (1932) to be the first to describe azurophilic granules in lymphocytes. They used blood from man. Their description agrees closely with the observations made on avian blood. They established the fact that it was actually a lymphocyte that contained the gramules. In circulating blood about one-third of the lymphocytes contained these granules, hut they were absent from the lymphocytes of lymph nodes. The significance of these granules is still not adequately established.

Another type of cell response that produces atypical lymphocytes is hypertrophy with vacuolization of the cytoplasm (figs. 109-112). The stain taken by the cytoplasm is faint compared with that of the typical normal lymphocyte. The vacuoles may be small as in figure 109, irregular in size as in figure 11. and large as in figure 112 . There may be few or many magenta bodies and these may show considerable variation in size; they may lie either in the vacuoles or between them or at their margin. From the appearance of the cytoplasm in which many vacuoles are present, a transformation toward a macrophage might be suggested. The nuclei of such vacuolated cells as seen in figures 109-112 show a closer resemblance to those of lymphocytes than to those of macrophages. The nucleus of the macrophage was studied in blood spots (Lucas, 1946) and in cardiac punctures of the embryo (figs. 309-317) where the typical chromatin pattern was a uniform reticulnm with evenly distributed, dothike bodies of chromatin at the interstices of the network. This punctate appearance of the macrophage nucleus is quite different from the delicate reticulum or massive irregular clumps of the typical lymphocyte.

Downey and MeKinlay (1923), and Blackfan, Diamond and Leister (1944) illustrated and described the lymphocytes found in cases of infectious mononucleosis. The azurophilic bodies and the vacuolated cytoplasm of human Jymphocytes in infections monomucleosis simulate, in part, the magenta bodies and hypertrophied, vacuolated cytoplasm of avian lymphocytes, which may be seen in some seemingly normal birds. Although chickens do not carry the virus of infectious mononteleosis, as far as we know, the fact should not be ignored that lymphomatosis is also an infectious disease, and that it has a stimulating effect on the mononuclear cells accumulating within the tissues of the avian body (Lucas, 1949; Lucas, Craig, and Oakberg, 1949; Lucas and Oakberg, 1950; Lucas, Denington, Cottral and Bumester, 1954; Oakberg, 1949, 1951).

Osgood (1935) described fenestration in lymphocytes from cases of mononucleosis. He observed a vacuolization and canaliculization of the nucleus somewhat similar to, yet different from, the clefts of nuclei of avian cells.

A further variant of the magenta bodies is shown in figures 113-116, in which the colors range from a pale orange to the typical magenta color. Some of these cells show the slight nuclear lysis that already has heen mentioned as occurring in lymplocytes with magenta bodies. The cytoplasmic inclusions in figure 114 show gradation from the light to the dark type of gramule but the direction in which the reaction is going is not known. Cells of this type are rare and it should be noted that these cells came from birds having the same parents. In these same slides monocytes were present that seemed to have an musually large quantity of azurophilic granules. The history of this family of nine birds is interesting. All were hatched June 19, 1944. The blood smears were taken at 112 days of age. except from F205C5. 
F205W4-Female. At 66 and 115 days reactions were normal but at $\mathbf{1 6 3}$ days there was a slight loss of weight. Died at 166 days. Questionable visceral lymphomatosis.

F205X4-Male. Showed gasping at 163 days. Died at 339 days. Extreme emaciation and atrophy of the musculature.

F205Y4-Male. At 115 and 163 days bird showed vigorous reactions. Died at 518 days. Bird appeared to be in good condition. Cause of death undeterminer (figs. 113-115 and 134).

F205Z4-Female. At 163 days reactions fair. At 253 days ill and put in a separate cage. Died at 292 days. Emaciation and impaction of crop (fig. 133).

F205A5-Female. At 110 days showed poor reactions and at 151 days ill and put in separate cage. In moribund condition and killed at 157 days. Neural and questionable visceral lymphonatosis.

F205B5-Male. At 163 days reaction fair. Died at 658 days. Cause of death undetermined.

F205C5-Female. Moribund at 75 days. Killed at 77 days. Lymphomatosis, neural.

F205D5-Male. At 115 days reaction was fair. Unsteady on feet at 155 days and moribund at 165 days. Killed. Lymphomatosis, neural and ocular.

F205E5-Female. At 65 days reactions were fair. At 126 days atonicity of crop. Moribund at 151 days and killed. Emaciation and dehydration (figs. 93, 116, 130, 132, and 142).

Various conditions were shown by the nine birds, both clinically and at necropsy, and all died hefore they were 2 years of age. At the time the smears were made the birds seemed to be reasonably healthy but in their subsequent listory their performance was poor; thus it would seem inadvisable to represent some of these as normal cells from normal birds. It certainly should be determined, however, whether cellular reactions of this type have any value in understanding the causes of death in birds that die from tumors or in a generally mhealthy condition.

Another type of abnormal cellular reaction was found in the slides that showed, in the nuclei of erthyrocytes, chromophobic bands that usually liad a uniform width. In lymphocytes these spaces were quite irregular (figs. 117-120). The clefts in figure 117 are irregular; yet, as in the erythrocytes, there is 110 actual break in the ccll membrane but rather a sharply demarked transition from a densely stained area to one that did not take the stain; in the latter, a very faint reticulum ean be seen. The lack of staining can affect small lymphocytes with lobes (fig. 118) as well as larger cells (figs. 119 and 120). Whatever the reaction may he, it can canse complete disappearance of basichromatin. Figures 117120 show a transitional series leading to an "emply" nucleus.

The cytoplasm of erythrocytes was not affected when the nuclei showed chromophobic bands; about the only difference noted in lynphocytes was a somewhat more vacuolar organization than is generally found in lymphocytes. The possibility that these nonstaining effects are due to technic is not exchded but for the present it seems more likely that they represent some abnormal disturbance of the cell. If technic prodnces the defect, we have the question of how it alone could cause the chromatin to disappear and yet leave so sharp a boundary with the basichromatin that remains. If the defect truly represents cell pathology, tracing it back to the disease condition that is producing it should be relatively simple.

\section{MONOCYTES}

\section{Normal mature monocytes (figs. 125-138)}

The monocyte eytoplasm has been descrilued in the literature as having the appearance of glass beads, and this effect is given as an important characteristic for separating monocytes from lymphocytes. This cytoplasmic quality probably does aid in the identification of these cells but actually it is of little value as a sole point of reference. The necessity of using multiple characteristics has already been emphasized. Owing to the overlapping of characteristics of lymphocytes and monocytes, it is necessary to consider each of their 10 points of difference. These will be taken up in the same order as they were for lymphocytes.

Cell size.-The ranges in size of lymphocytes and monocytes overlap as already seen in the comparisons from outhine drawings and graphs. It is obvious that on the average the monocyte is larger than the lymphocyte; in fact, the average area of the whole lymphocyte is slightly smaller than the average area of the monocyte nucleus.

The maximum, minimum, and average values in table 4 are based on 300 planimeter measurements of cells projected and traced with a eamera lucida. Half of these were from our Labora. tory chickens and half from two different breeds from a commercial lahoratory. The possibility 
of hreed or inbred line differences is discussed in chapter 6. These curves indicate that nuclear size is much less variable than the area of nucleus plus cytosome (fig. 153). For the nucleus of both lymphocytes and monocytes the size is symmetrically distributed on each side of the mean: whereas, when cytoplasm is added, there is a definite tendency toward sewness with relatively few low values. but a trailing off in incidence of the high ralues. Approximately 2.5 percent of the lymphocyte muclei overlap 22 percent of the monocyte nuelei in size, whereas only about 15 pereent of the lymphocyte total cell area ovcrlaps 7 percent of the monocyte cell area.

Another interesting point brought out by table 4 is the broad range from minimum to maximmm areas, which for lymphocytes is 9.2-fold and for monocytes is 3.8-fold. In terms of diamelers one could expect. therefore, a 3-fold range for lymphocytes and alout a 2-fold range for monocytes. Since there is a 3 -fold range in diameters. one may separate lymphocytes arbitrarily into 3 categories-small, medium, and large. Cells with a diameter up to $7.8 \mu$ would be classed as small, those from 7.9 to $10.3 \mu$ as medium, and those ahove $10.1 \mu$ as large. Of the 300 lymphocytes measured and plotted, 55 percent would be classed as small. 36 percent as medium, and 9 percent as large. ${ }^{5}$ Blast cells have not been in-

\footnotetext{
${ }^{5}$ Wiseman (1932) reported that in dried blood smears from man the range for small lymphocytes is considered to be from $6 \mu$ to $9 \mu$; for medium, from $9 \mu$ to $12 \mu$; and for targe, $12 \mu+$.
}

Table 4.-Nuclear and cell areas and diameters for lymphocytes and monocyles

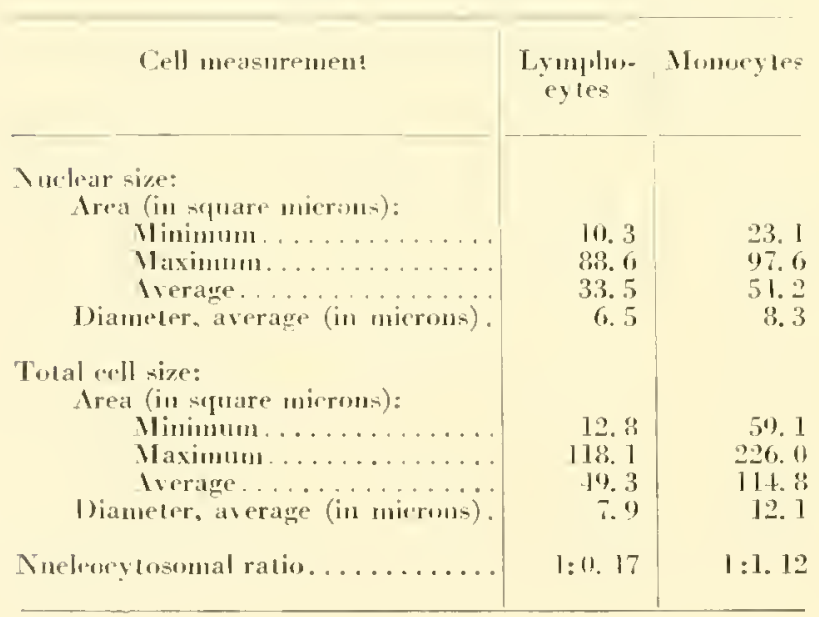

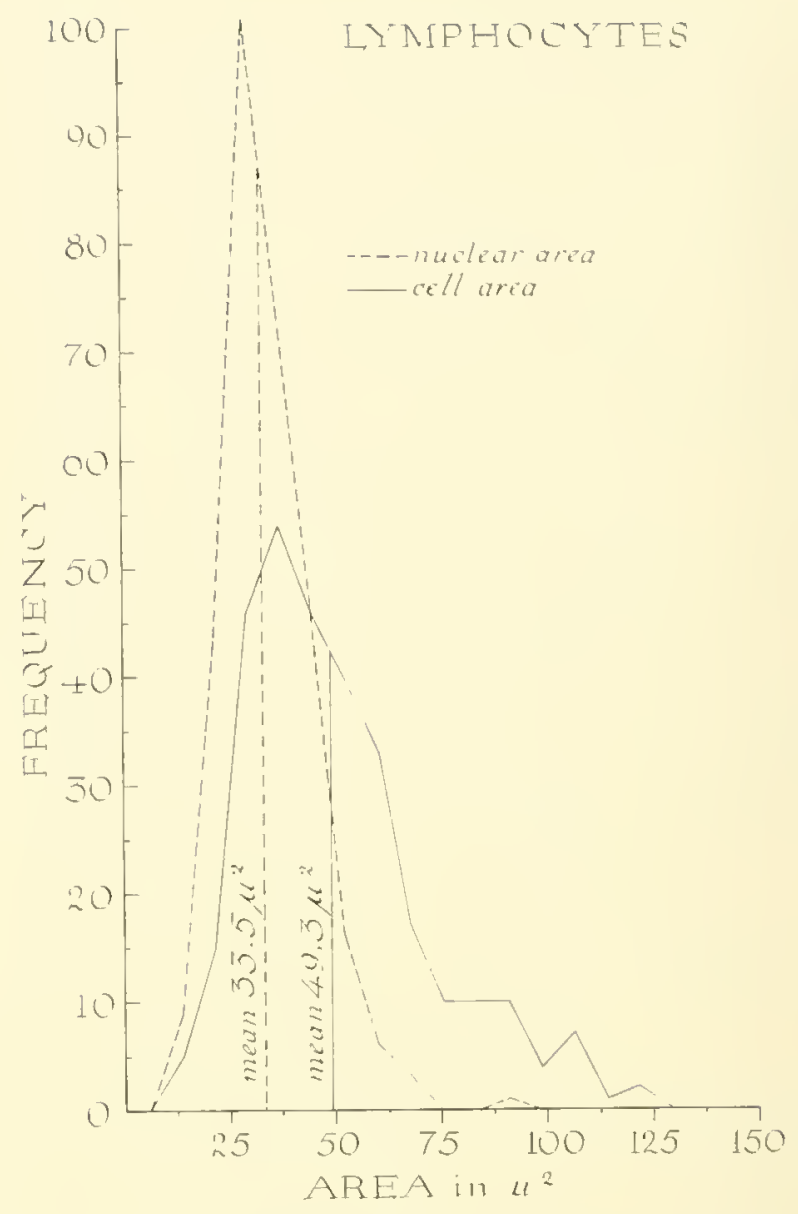

Figuliz 152.-Frequency distribution empres of cell area and nuclear area for 300 lymphocytes chosen at random.

cluded in these data-the term "large," therefore, merely indicates the upper end of the range. For practical purposes, two divisions of lymphocytes ale alout as many as one can judge accurately from mental impression. From an examination of the two curves for lymphocytes and monocyles, there would seem to be no reason for separating either lymphocytes or monocyles into groups of various sizes; yet, for convenience, lymphocytes are so separated; monocytes are not. Cell size may have functional significance and cestainly one bird will show a higher average of one cell size than will another hird; lunt until there is some clue concerning the physiologic significance of cell size, there is little point in recording it in the data. If it should be established that diminishing cell size is a corollary of aging, perhaps a recoul of size would serve the 


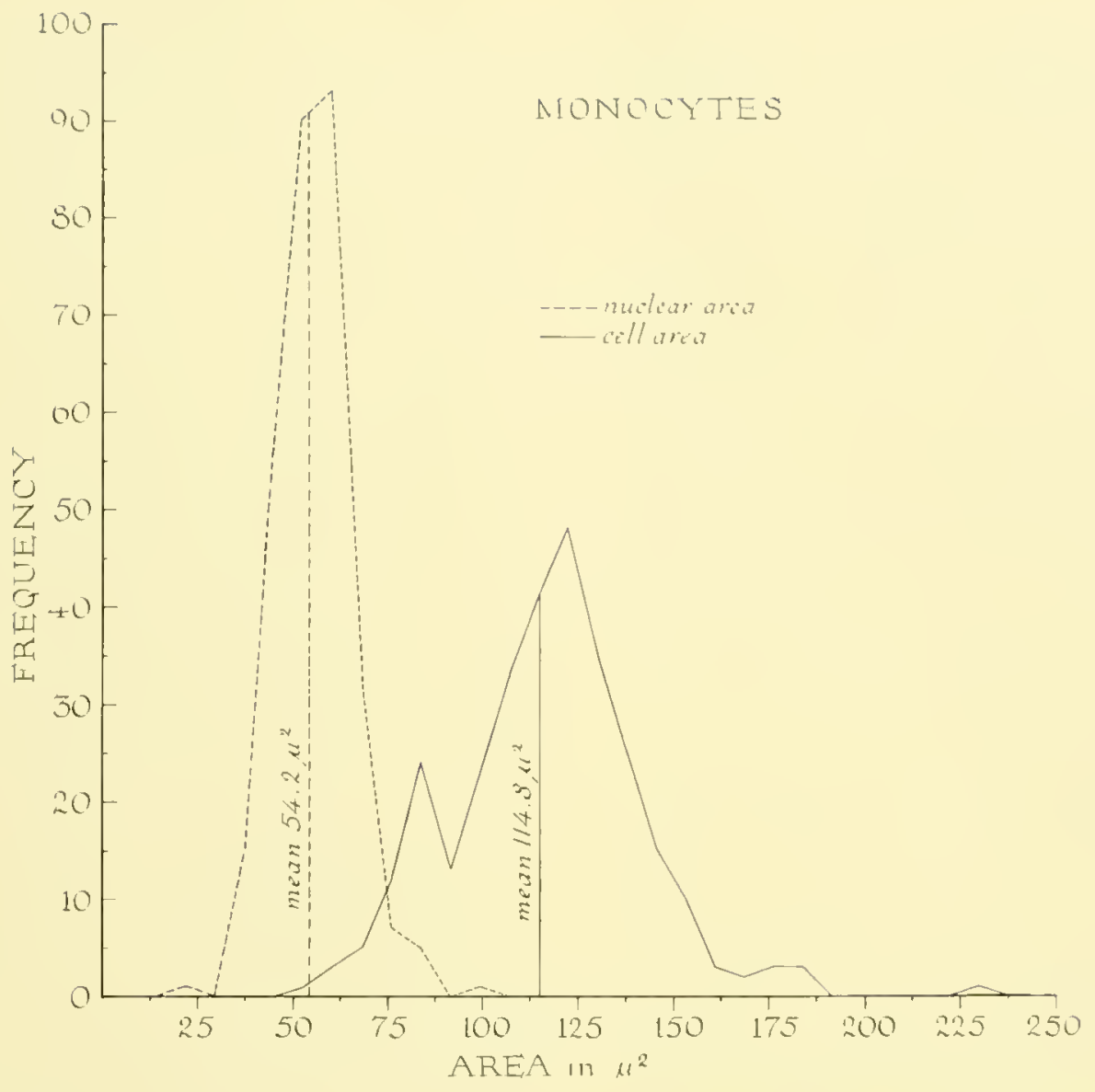

Figurf 153.--Frequenry distribution curves of cell area and nurlear area for 300 monocytes chusen at random.

same usefulness for the agrannlocytes that the Arnetlı counts do for the granulocytes.

Mainland et al. (1935) studied statistically the significance of lymphocyte size in the human species and concluded that cell size was a mimodal curve, lut with skewness in most eases, and that a small and a large lymphocyte did not exist as classes. From their data, there was no indication that age, sex, or state of health were factors influencing the size of lymphocytes in man.

These opinions on size are in agreement with those of Magath and Higgins (1934), who measured the diameters of Iymphocytes from each of eighit ducks and conchnded that they all belong to one series with a size range from 4.0 to $8.1 \mu$ and that all attempts to classify thenn into small, medium, and large were futile. Cul- len (1903) finds that monocyte dianeters range from 6.7 to $9.3 \mu$; both of these values are helow the average given in tal,le 4. Nlagath and Higgins found the average to be between 11 and 13.5.

Cell shape.-The variety of slapes exhilited hy the monocyte can he appreciated besí by glancing over figures 125-138 and the cells ontlined in figure 151. In general. the monocyte has a round shape. Oceasionally there may be small bleb projections such as seen in figures 126, 127 . and 138 . Whether they serve the same function in monoeytes that they are said to serve in lymphocytes, namely, contributing globulins to the plasma, is not known.

There is anotler type of eytosomal protrusion that occurs rather frequently. It is a hyaline 
mantle that extends in irregular fashion beyond the denser endoplasmic portion of the cell (figs. 125 and 143). The hyaline mantle in the latter figure is somewhat more lightly stained. In contrast to the mantle, the central reticulum retains an approximately round shape.

Weiss and Fawcett (1953) mention the existence of a mantle in avian monocytes when grown in tissue culture. The mantle was found to be visible when cells were examined under the phase microscope. It is not altogether clear that the type of mantle (thin undulating membrane) they observed, and the type we have described are identical. Weiss and Fawcett believed that mantle formation is part of the process whereby monocytes become macrophages. Additional support for the idea that monocytes may become macrophages comes from Dawson's (1933a) study of blood cell reactions to lead poisoning in Necturus.

Since monocytes are large cells they are distorted more readily during the process of making dried smears than are small cells. The cytosome and even the mucleus often are squeezed between other cells, and so take various angular shapes, or they may overlap other cells. These variations occur most readily when there is a hyaline mantle. If, however, they happen to fall in an open space free from other cells, they usually show a round contour and cells such as these are the ones usually selected for drawing.

Nuclear position.-The mucleus in many monocytes is cccentrically placed. as may be seen in figmes 126-133 and 135: sometimes it forms a bridge across the middle of the cell (figs. 134 and 136). The wide diversity of position is shown in the outline drawings. In the first row only 1 of 5 conld he said to have the typical or eccentric position. The proportion is about the same in the other rows. The ratio of 1 eccentric wucleus to 5 contrally placed is probably not a true one becanse a disproportionate number of cells selected for making the outline drawings were atypical but were selected to show as wide a range of morphologic expression as possible. The eccentric position of the nucleus is of considerable value in distinguishing between a mono. cyte and a lymphocyte but it must be borne in mind that a monocyte can have a contrally-placed mucleus (fig. 151, $A, b$ and $B, a$ ), as do many lymphocytes.
Nucleocytosomal ratio.--Not only are monocytes larger than lymphocytes on the average but the cytosome is proportionately larger than it is in lymphocytes. This difference is not so great, however, as superficial examination of cells might lead one to believe. The eccentric position of the nucleus gives the impression that there is a large mass of cytoplasm; but when the same quantity of cytoplasm is uniformly distributed around a contrally placed nucleus there seems to be only a narrow rim. This false impression is magnified by the indentation of the monocyte nucleus. The nucleocytosomal ratios for the two cell types are given in table 4 . They average 1: 0.47 for lymphocytes and $1: 1.12$ for monocytes. In other words, the cytosomal area in relation to nuclear area in monocytes is 58 percent greater than in lymphocytes. In terms of nucleocell diameters the ratio is $1: 1.22$ for lymphocytes and $1: 1.46$ for monocytes.

Cytoplasmic structure.--The descriptive term "gromnd-glass effect" has been used by numerous writers on avian blood. It is important to try to understand what the structural elements are that create the ground-glass illusion. Actnally, we have failed to see what others call the "groundglass effect." Any one of the following three elements within the cell might be responsible for the optical cffect:

(1) The open reticular framework such as seen in figures 138 and 143, where there exist nmmerous uniform spaces bounded by a delicate reticulum. These spaces, however, have low refractility; the term "ground-glass" suggests rather conspicuous refractility.

(2) The delicate orange-stained substance that sometimes fills the vacnolar spaces in the Hof (fig. 144). Figure 126 shows similar spaces in the Hof but the material that fills them has not taken an orange color. When the orangestained substance is present, it increases the contrast with the reticulum and thus gives the illusion of greater refractility. This may be what has been called the ground-glass appearance of the monocyte cytoplasm.

(3) The polychromatic reaction of the protoplasmic network (figs. 130 and 137), which gives a textural effect to the cytoplasm. The interstices of the network that in the previous figures took either a light or a dense basophilic stain show in the last two cells mentioner a shift in 
staining of this substance in an azuropliilic direction. Because of the mixture of salmon and blue colors, the eytoplasm has been given a textural effect that does not occur when the same strueture shows a uniform single hue. Dual coloration of the reticulum gives the optical effect of thickness and density. Of the three structural elements listed, this is the one that offers the best explanation of the "ground-glass effect."

There is only one other possibility-the presence of definite azurophilic granules. They, however, are relatively rare (figs. 132-135) and thus would not be mentioned as typical for monocytes. Some of the cells sliown in the drawings came from the same parents that produced the reactive lymphocyles, as has already been stated. The azurophilic bodies may give to the monocyte a tinged margin (fig. 142). The only other cell type that shows a tinged border of this sort is an immature thrombocyte (figs. 296-299 and 303). This particular monocyte shows a well-defined Hof that helps to identify it as a monocyte. In other examples drawn from the same family of lirds (fig. 132, 134, and p. 65), there is an increasing number of azurophilic granules in the cytoplasm. Sometimes they are on the side of the mucleus opposite the IIof; at other times they are on the same side; and they may be more or less uniformly scattered orer the whole cell. Figure 135 is an extreme example. Here the azurophilic bodies are larger than normal. They show considerable variability in staining intensity, and in some respects resemble an early heterophil myelocyte. This type of azurophilic gramule is so atypical for monocytes in general that only rarely indeed would a cell of this appearance be picked up in a differential count.

Hof and orange-staining spheres.-The IIof has lieen mentioned a number of times as a lightly stained, vacuolated area in the cytosome that has considerable value in the identification of monocytes. It may or may not contain orange-stained material. The meaning of the term as used here is slightly different from that stated in the broad definition given in Dorland's Medical Dictionary- "The area of the cytoplasm of a cell encircled by the concavity of the nucleus." This defunition may fit quite well in some cases. Typical examples of a $H o f$ are shown in figures 126,138 , and 144. The clear space in figure
142 is called a Hof also, although it is olvviously not encircled or even bounded by an identation of the nucleus. The area, nevertheless, is clearly demarked from the rest of the eytoplasm. Figures 128 and 133 are good examples of cells that show indented murlei but there is no 11 of in the sense in which the term is used here. The Hof shown in figure 129 is rather indistinct, and in figme 132 it is present as a broad space that fills most of the cytosome on one side of the nucleus. The next three figures contain none. The vacuolar space opposite the indentation of the nucleus in figure 131 conld be called a IIof, as could the clear space in the lymplocyte (fig. 97). The IIof is nearly always found in monocyles but there may be exceptions, as already mentioned.

Just low closely associated are the Hof and the rosette obtained with neutral red vital stain is not known. It is assumed that they are closely associated but it has not been determined whether cells that fail to show a 11 of, in the sense in which the term is used here, would also fail to show a rosette.

Specific cell inclusions.-The vacuolar spaces of the Hof often contain a homogeneous substance that takes a very faint orange color with Wright's stain, a stain that is better for this purpose than May-Grünwald Giemsa. Perhaps the orange spheres could he classed as an azurophilic sulstance also, although the coloration is dis. tinctly more yellowish than in the small azurophilic gramules deseribed under the heading "Cytoplasmie stmcture." It takes an excellent light source and microscope correctly nsed to show any tinge of color in the $H$ of; yet it is a real substance, as may be demonstrated in the abnor. mal cell, fignre 147, where the Hof sulustance has become concentrated into large spheres.

All three substances-(1) the azurophilic granules, (2) the azuroplitic tinge of the reticulum. and (3) the orange splieres of the Hofare useful in the identification of the monocyte and carry much weight in separating monocytes from lymphoeytes. The only specifie eell inclusions found in lymphoeytes are the magenta bodies, which are nearly always darker and more intensely colored than any of the three listed for monocytes.

Nuclear shape.-Nuclear shape needs very little additional discussion. The difference be- 
tween the shape of the indentation in Iymphocytes and in monocytes has been mentioned, and the examples shown in the varions fignres of monocytes bear out the observation that the nuclear depression is usually lroad with a romded bottom. as diagramed on page 53.

The presence of this type of indentation is helpful in identifying monocytes but certainly it camnot be relied upon entirely; many monocrtes have round or elongated nuclei withont any Jepression (figs. $] .51, B, d, C, c, D, c$, and $E, c$ ). Some have irregularly shaped molei (figs. 151, $A, d, B, b, D, b$ and $e$, and $F, d)$ or double indentations (figs. 136, 137, and 151, C.e), and sometimes the indentation cuts the nucleus into two equal or uncqual parts (figs. 138, 151, $B, e$ and $F . b$ ). This varial)ility must be kept in mind when a differential comnt is being made so that some monocytes will not he omitted from the count becanse they have atypical muclei.

Nuclear structure.-Nuclear structure is a pattem that is often viewed impressionistically without giving deliberate attention to the parts. When the pattern is carefully surlied, it breaks down into a complex of interrelated details such as size, shape, and distribution of chromatin chmps. the character of the reticulum and its relation to the basichromatin and the tinctorial reactions of the uncleoplasm. When viewed superficially the monocyte unclens gives the impression that it has a delicate lacelike reticular pattern of chromatin and a transparency that is not generally observed in the lymphocyte moleus.

Upon close examination, it may be observed that the clumps of chromatin at the interstices of the network are often small, as in figme 127. Sometimes they may be relatively large and dense, as in figure 125. which has a highly colored nucleoplasm and thus would not give a transparent effect. In lymphocytes a reticular appearance was often found associated with larger nuclei. Whether the more open reticulum and smaller chromatin clumps commonly found in monocytes represent a characteristic difference between the two cell types, or are nothing mole than a reflection of the larger nuclear size, is undetermined. Nuclear paltern carries relatively little weight in the separation of the two cell types, chiefly hecause a definite type of chromatin organization cannot be considered specific for each of these cells. Yet any survey involving hundreds of nonocytes and lymphocytes will clearly reveal that each type has its own general pattern. It will also reveal that monocyte nuclei fall into two groups-those with a delicate open reticulum and those with coarse blocks. The same differences may be found in the im. mature stages (figs. 139-144).

Cell division.- The indentation of the mucleus -o common in monocytes is often carried further. leading to various degrees of constriction that may approach the center from two sides (figs. 136-138) or cut the muclens from one sicte only (fig. $151, B, e)$. This may lead to complete division of the nuclens into two parts. When they are equal in size, they suggest cell division lyy amitosis; but the ocenrence of nnequal nuclei (fig. 151, F, b) raises the question of whether this iype of nuclear duplication has any more relationship to amitosis than has the lobulation of the granulocyte nucleus. No actual pulling apart of the eystosome to form two cell bodies has ever been observed. Constriction of the nuclens is much more frequently found in monocytes than in lymphocytes. and this is a useful molphologic feature that aids in separating these two leukocytes.

Conclusions derived from use of table 3.-Frequent mention has been made of the fact that one cannot decide whether a particular cell is a monocyte or a lymphocyte without considering numerous characteristics, which must be balanced against one another. A few cells, questionable ones as well as those that are obviousty of one type or the other, have been presented in tabular form in table 5 to show how the various characteristics given in table 3 have been applied. Table 5 should make clear why some questionable cells have heen classed as monocytes instead of lymphocytes and vice versa and it brings ont that oftentimes a cell will show a characteristic that is just as frequently found in monocytes as in lym. phocytes, and there may be a "+ " in both rows of the table.

\section{Developmental stages foumd in circulating blood (figs. 139-144)}

Lymphocytogenesis and monocytogenesis are vague and controversial subjects, chiefly because 
Table 5.-Classification of individual cells into lymphocytes and monocytes ${ }^{2}$

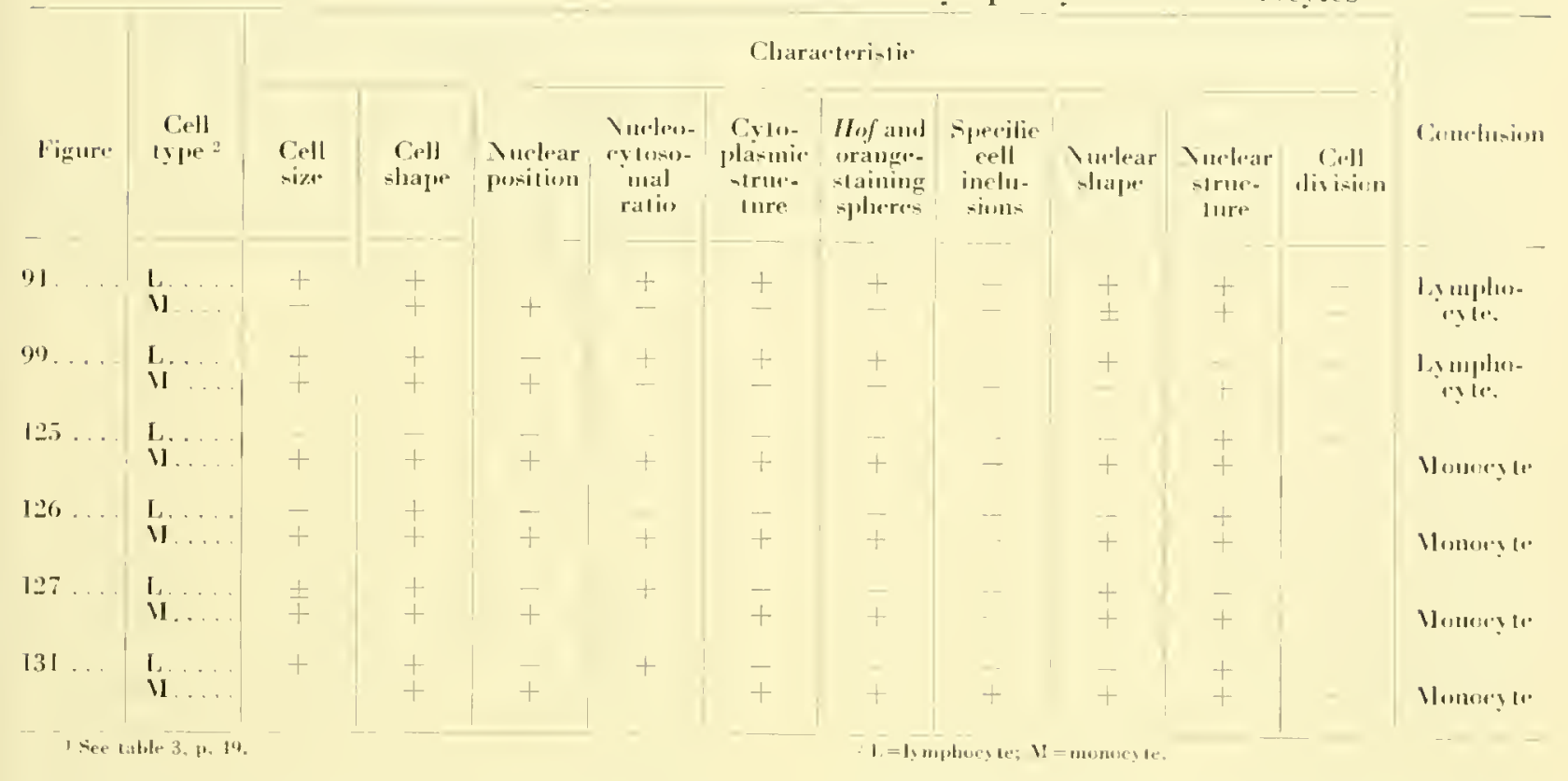

the cells lack a sufficient number of cell features by which differentiation can be followed. In contrast, erythrocytes have hemoglobin: gramulocytes and thrombocytes their varions types of specifie granules. All these aids are lacking in lymphocytes and monocyles. One must resort to less reliable criteria such as lobulations, nu(lear structure, and cytoplasmic texture and color. Three cells in the process of monocytogenesis have been shown in the spleen of a chitk 35 days of age (fig. 331. 16-19). The immature cells have lobulated eytosomes with a uniform basophilic granulation and nuclei with small clumps of chromatin, which are generally uniformly scattered. The immature monocytes of figures 139-144, foumd in the circulating hood, have two types of muclei-those with a fine reticulum in which the chromatin stains a pale purple color, and those in which the nuclens iakes an overall magenta color, including the nucleoplasm. None of the cells in the first row (figs. 139-142) came from the hirds that gave figures 1 13-145; therefore, the difference in coloration may be due either to technic or to the bird, and we should probalsly guard against overemphasizing this difference.

Two early immature cells have been drawn (figs. 139 and 140) hut these are seen very rarely in circulating blood; they may be foumd in blood dyscrasias. The fine, highly dispersed pattern of unclear chromatin and the few remaining mito- chondrial spaces in the cytosome all indicate immaturity, and lobulation when combined with the nuclear patterm. points to the same thing. Young primary erythroblasts in the eirenlating blood of the 48-hour chick emloryo are another example of cells showing lolulations as an indication of their immaturity. The azurophilic granules in the cytosome of fignre 140 aid in identifying it as a monocyte, and the lobulation and nuclear pat. tern identify it as a young cell. A few of these granules take a magenta stain like the nucleus and the specifie gramules of lymphocyles; a pair of them, along the lower edge of the nucleus, actually appear to be contuected with the nuclear membrane by delicate strands. If it could be established that magenta bodies actually arise as extruded nuclear substance, it would go far toward establishing that the usual type of azuro. philic material of the monocyte, and the magenta bodies found in a few monocytes and in many abnormal and reactive lymphorytes, are not the same.

The amoeboid cell (fig. 143) is also a young monocyte but it shows more extensive vacuolization of the cytoplasm than figures 139 and 140 . In some cells. lileds project that appear to be piuching off. Later immature monocrtes are illustrated in figures 14l, 142, and 144. Some blebs are still present, the nucleus may be roumd or nearly so, and a clear Hof has appeared. 
Abnormal monocytes (figs. 115-147)

The two cells shown in figures 145 and 146 are classed as abnormal because they are undergoing early autolysis. In the former there are only early manifestations of cell breakdown, the vacuolization in the region of the Hof has become amorphous, and the remainder of the cylosome has an atypical tinge of color. The concentration of basophilic bodics at the cell margin is probably not indicative of abnormality.

A somewhat later stage in antolysis is shown in figure 146, in which the cytoplasm has taken on an overall reddish color and there is a decreased color difference between nucleus and cytosome. Otherwise the structural breakdown has not been extensive. There is no indication whether the nucleus will go in the direction of lysis or of chromatin clumping.

Abnormality has been expressed in still an. other way (frg. 147). The orange spheres of the IIof increased in size whereas ordinarily they are relatively uniform. The increase might be due either to an abnormal growth of a sphere or to the coalescence of adjoining spheres accompanied by changes in the reticulum. Aside from this one point there is very little indication that the cell is abnormal.

\section{Techuic artifacts (figs. 148, 149)}

Only one type of technic artifact has bcen found thus far in monocytes-a squashing of the cell when the smear is made. A squashed monocyle is rarely identified with certainty. In fig. ure 148 the large size and the indented uncleus aided in the exclusion of other cells. The monocytes, for some reason, were the only cells in the slide from which figure 149 was taken that showed fragility. This slide gave an excellent series of stages from a slightly squashed monocyte to the extreme condition shown in figure 149. When it reaches the last condition there is nothing by which the squashed cell may be identified as a monocyte. Its size so far exceeds the size of the normal monocyte nucleus that it has very little meaning. The significance of the configuration of such cells has been discussed in mammalian literature, where they are called basket cells and disintegrating cells when they have the appcarance shown in figure 149. Osgood and Ash- worth (1937) in speaking of them say (p. 20), "These cells are probably not artifacts made in smearing but remnants of dead cells."

Kracke and Garver (1937) mention (p. 84) that in mammalian literature smudged cells have been divided into two types: "It has been stated that smudge forms are degenerating lymphocytes and that hasket cells ... are degenerating granulocytes. . . . Nevertheless, it seems more probable that the smudge cell is an early stage and the basket cell a late stage of the same process.

"Crushing and rupturing of monocytes, neutrophils, eosinophils and basophils . . . occur in improperly made smears, especially when too much pressure is applied to the drop of blood. These cellular remnants are found in various ab. normal states where there is excessive destruction of lenkocytes. In these cases their occurrence is probably the result of toxic agents or of an increased fragility of the cellular elements." This point of view is in agreement with our opinion that the actual production of smudged cells comes at the time the smear is made and that it is not a record of in vivo degeneration of leukocytes. The basis for this opinion is the conspicuous difference between smears made from the same bird at the same time and also the fact that large numbers of smudged cells often occur at thimned-out portions of the smear where presumably the pressure is greater. This point of view is not in conflict with the idea that there are differences in cell fragility and that increased fragility may accompany diseased conditions.

Osgood and Ashworth (1937) say (p. 20) that, "One should not, however, make the error of omitting to include the disintegrated cells in the differential count as a large number of disintegrated cells is strongly suggestive of a diagmosis of leukemia and failure to include them may give an erroneous impression of the true incilence of other cell types."

We have not found at this Laboratory that the presence of smudged cells aids in the diagnosis of the avian leukosis complex, but it is agreed that smudged cells can influence the differential count. A good example is the slide from which figure 149 was made. Snudged monocyte nuclei similar to the one illustrated were found in abundance; yet intact monocytes were scarce and were actually fewer than the smudged nuclei. Should they be counted? It has been our experience 
with avian blood that it is impractical. In mammalian blood only the leukocytes have nuclei, and so any smudged nucleus must at least be a leukacyte. But in avian blood where the erythrocytes and thrombocytes are nucleated also, the possibility of error in identification of a smudged nucleus becomes so great that any possible value of its addition to a count is nullified by the increased source of error; and if some cannot be properly classified, those that can be identified, such as the three granulocytes, should not be included either. On the other hand, if in a particular bird the smudging affects only one of the types of white cells. some account must be taken of the fact, or the differential values will be biased.

\section{Granular Leukocytes}

There are three granular leukocytes in birds as in mammals - heterophils, eosinophils, and basophils. Eosinophils and basophils received their names because the cells contain granules that have an affinity for eosin and for basic dyes. The term "heterophil," which was suggested by Kyes (1929), applies to the third granulocyte cell type, in which the specific inclusions of homologous cells among the various classes of vertebrates show great diversity in reaction to stains. The heterophil of birds and reptiles is the equivalent of the neutrophil in man. The term "neutrophil" is based on the staining reactions; the term "heterophil" is not.

Ryerson (1943), from his comparative studies, suggests that the morphology of heterophils and eosinophils has been influenced by two lines of evolution through the vertebrate classes (p. 44), " . . one line contains the selachians, reptiles, and birds; the other contains the cyclostomes, teleosts, amphibians, and mammals."

\section{HETEROPHILS}

\section{Normal mature heterophils (figs. 154- 167)}

Heterophils as nsually seen in the circulating blood show a low variability in size. Some indication of range may be obtained by comparing the varions drawings and, particularly, the graph (fig. 197). Kennedy and Climenko (1928) gave a range of 4.2 to $9.0 \mu$ with an average of $6.35 \mu$, which is nearly $2.3 \mu$ less than the average of $8.7 \mu$ from these data. Under stimulation such as replacement after irradiation, a shower of smaller cells may be liberated. Perhaps this reflects a factor of cytoplasmic growth, independent of seeming maturity that is indicated by nuclear lobulation, in that smears made from bone marrow show many more small heterophils than are found in circulating blood, and yet these cells show multilobed muclei and in this respect are considered to be mature. This fluctuation in size of heterophils, and also of eosinophils, is a factor that may account for differences in size reported by different investigators for these cells. If one emphasized the size of heterophils as some have emphasized the size of lymphocytes, it might be that cell size would prove to be a criterion as useful as number of nuclear lobes in indicating the condition of health of the bird.

From thcse figures of heterophils it can be seen that the dominant shape is a circle, which is surprising in view of the fact that in life heterophils are actively amoeboid.

In a strict sense practically none of the heterophils from circulating blood should be regarded as representing their true structure and appearance. Nearly all these cells reveal an artifact involving the nuclens, and many reveal a second artifact that involves the rods. The artifact in the nucleus is so constant with Wright's stain that it is of considerable value in identifying the cell type, but the one in the rods is an ever-present cause of confusion between heterophils and eosinophils.

The rods, which are the specifie inclusions for heterophils, have typically the appearance shown in figures 154 and 155 . They are long fusiform bodies, they are pointed at each end, and they take the eosin stain brilliantly. Both Dantschakoff (1909a and b and 1916b) and Hamre 
(personal communication) have ofserved that in some cells the rods are grouped in a fanlike eluster. This arrangement has never been observed in malue cells in any of our smears: inslead the rods are always seattered like a pile of short straws with pointed ends. Ryerson (1943), in his study of heterophils in turtles. shows a radial arrangement of the rods in the myelocytes but not in the mature cells. There may be con. siderable variability among cells in the length of these rods. Some are long and narrow (fig. 154) and olhers short and relatively broad (fig. 2, 1). In some cases these differences can be characteristic of a speeies (figs. 400, 401, 403, and 406.)

In many heterophits some rods may conlain central granules. Hamre is of the opinion that each rod contains a central gramule that is revealed when Wright-Giemsa is used (p. 230).
The research necessary to prove or disprove the poin has never been undertaken but the results oblained with Wright's stain gave no indicalion that every rod has a eentral granule and the same opinion is supported by evidenee from a sludy of developmenal slages in bone marrow and spleen stained wilh May-Grünwald Giemsa. Even in squashed cells where the individual rods are thrown apart from each olher, eentral granules may be absent in one case (fig. 175) and present in anolher (fig. 176). Additional evidence on this point contes from the fact that in cells where the rods have disappeared there may remain numerous central granules (fig. 161) or they maly be alssent (fig. 165).

Sometimes insead of a granule there may be a vacuole or at least a nonstaining clear space in the cenler of each rod (figs. 166 and 167). In the second figure most of the rod substance has

Figures 154-176.-Heterophils from eireulating blood-mature, immature, and smudged cells. Some evidence of teehnic artifaet is apparent in practieally all normal mature heterophils. (The terms "contral bodies" and "central granules" as applied to heterophils are svnonymous.) $2,470 \times$.

Figcres 154-167: Normal mature heterophils selected to show variabitity in structure and size of cells and in staining defects.

154 Well-preserved rods, without central granules. Nuclear lobes are poorly stained.

I55 Rods with a few central bodies. Tariable staining of the nuclear lobes.

156 Approximately one central granule per rod. Nuclear lobes are fully stained.

157 Partial dissolution of rods; eentral bodies are large and do not disappear. Variable staining of the nuclear lobes.

158 Nearly complete dissolution of rods; the rod substance gives to the eytoplasm an overall pink color with Wright's stain. Central bodies are small.

159 Nearly eomplete dissolntion of rods, which gives an intense eolor to the entire eytosome. The outer portions of the nuclear lobes are well stained; inner parts are poorly stained.

I60 Small heteroplil showing only eentral bodies of varying size.

161 Heterophil with only central bodies visible. The large central bodies of this and the preceding cells cause these cells to resemble the cosinophils, but they ean be separated by the difference in color of the eytoplasmie ground substance. Compare with figures 177-180.

162 Completely dissolved rods with onfy relatively few small central bodies. Nuclear lobes are weakly stained.

Ifi3 Central bodies few, with a range in size varying from small to large.

Ift Ileterophil with but few central bodies and no rods.

165 Heterophil without rods or central bodies.

166 Heterophil in which the eentral bodies appear as vacuoles within the rods.

167 Heterophil in which the rods have contracted around the vacuolar-type central bodies.

FIGUREs 16S-173: Developmental stages of heterophils found in circulating blood.

I68 Hetcrophil granuloblast. No nucleolus visible. Found on same slide with heterophil myelocytes, figures $169-172$.

169 IIeterophil pronyelocyte. Nucleus in lower twothirds of eell appears to merge with the eytosome. Magenta granules and rings identify this as a heterophil.

I70 Heterophil promyelocyte. Approximately the same stage of development as preceding cell, but smaller.

I7I Ifetcrophil promyelocyte.

I72 IIeterophil promyelocyte. Greater vacuolization of cytoplasm than in preceding cells. Nucleus is not yet clearly separated from cytosome.

173 IIeterophil mesomyelocyte. Early stage in the differentiation of the specific heterophil rods.

FigURES 174-176: Technic artifacts.

174 Mature heterophil. M. G. G.; the central bodies were retained as they are following Wright's stain but the rod substance was almost completely dissolved. Nueleus poorly stained.

175 smudged heterophil with two nuelear lobes. Rods retained their form.

176 smudged heterophil with rods dissolved. The large spheres are the central gramules and the small ones are serum granules 


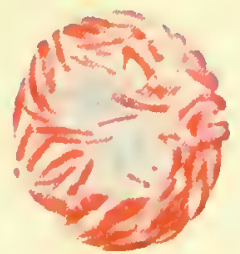

154

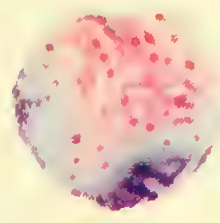

159

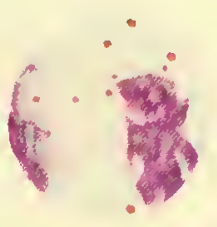

164

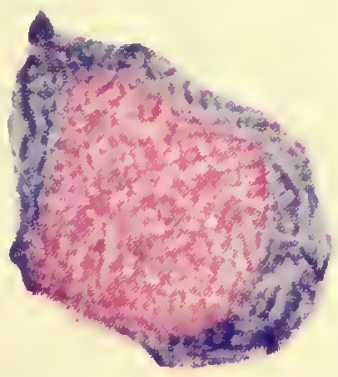

168

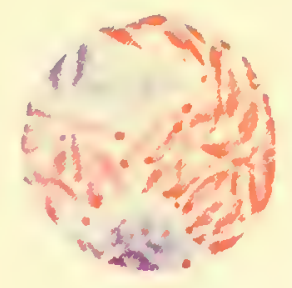

15.5

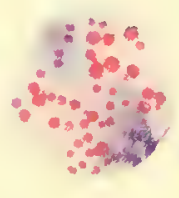

160

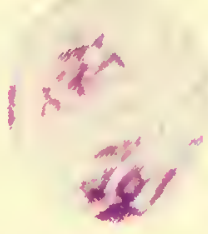

16.5

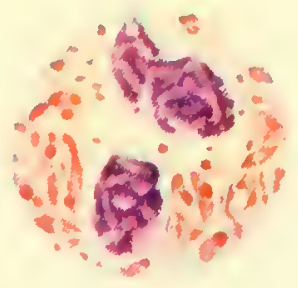

156

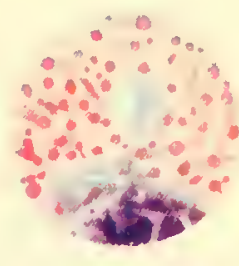

157

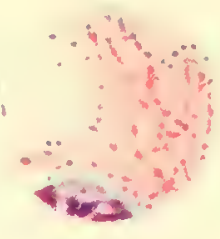

158

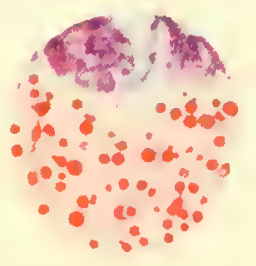

161

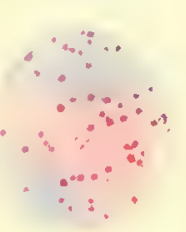

162

163

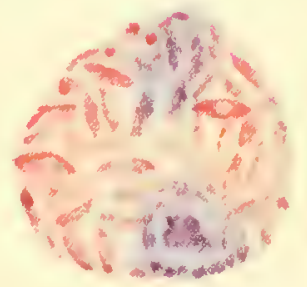

166

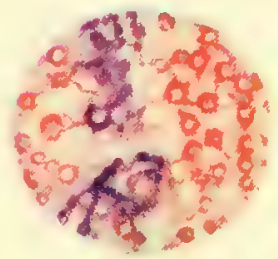

167

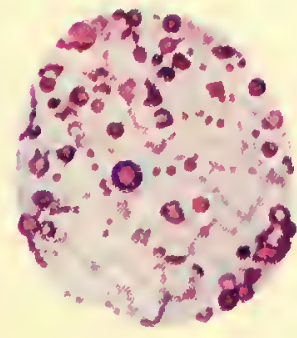

169

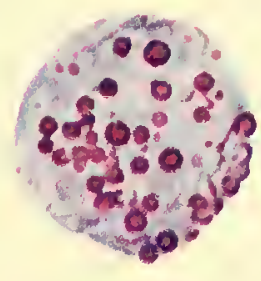

170
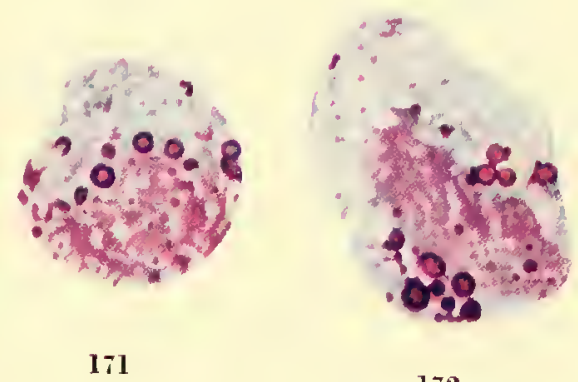

172

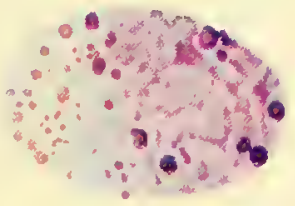

173
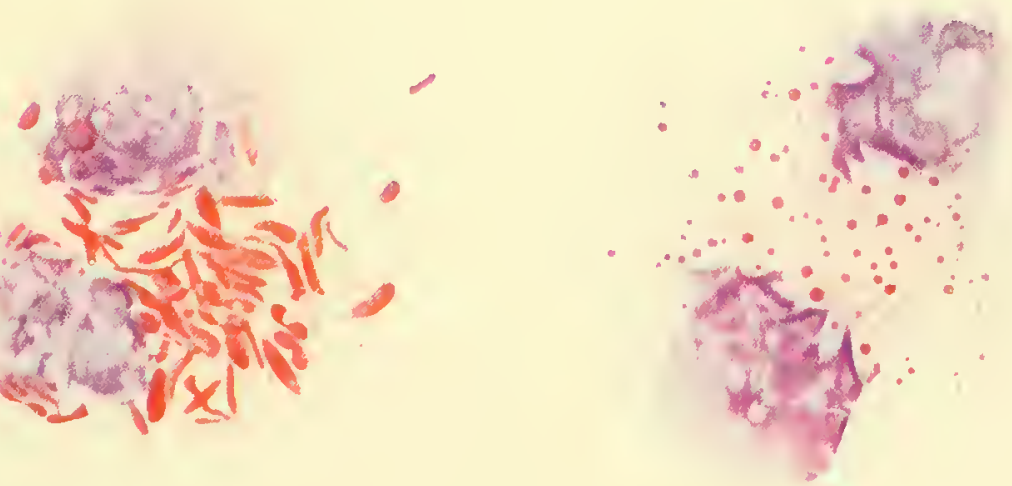

174 
Figures 177-187. - Eosinophils from circulating blood-mature, immature, and smudged cells. $2,470 \times$.

Figures 177-183: Normal mature eosinophils that show size range.

Figures 177-180: Typical eosinophils. The light bluestaining cytoplasmie background is an identifying characteristic of these cells; so is the full staining of the nuelcus.

177 The eosinophilic granules can be composed of 4 smaller granules in a square.

178 The eosinophilic granules can appear as scattered small granules on a reticulum.

179 The cosinophilic granules can have a size range of large to small and be interminglerl.

180 The eosinoplilic granules can appear as large splueres with a clear space in the center, with little or no indication that they are made up of 4 smaller granules.

Figures 181-183: Small normal mature cosinophils, not so common as the larger size.

181 Eosinophilic granules, closely aggregated. Cell might be confused with a heterophil.
182 Eosinophilic granules, small and closely aggregated.

183 Small eosinophil with a high nucleocytoplasmic ratio.

Frgunes 181-186: Developmental stoges of eosinophils found in circulating blood.

184 Eosinophilic mesomyelocyte. Strong basophilic cytoplasm with specific granules in early stages of development.

185 Eosinophilic metamyelocyte. Later stage of development than the preceding cell.

186 Late cosinophilic metamyelocyte, almost fully differentiated.

FIGURE 187: Technic artifact.

187 Smudged eosinophil. The grouping of small granules to form large granules duplicates what was observed in the intact cell, figure 177 . 


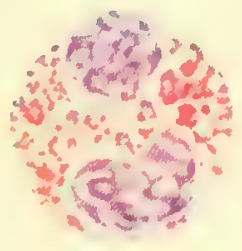

178

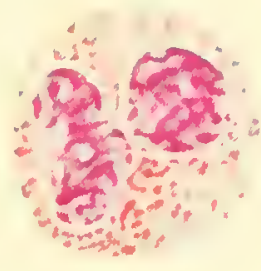

178

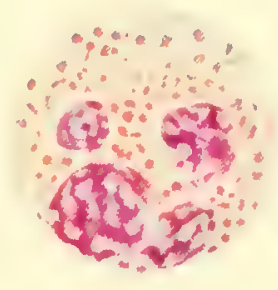

179

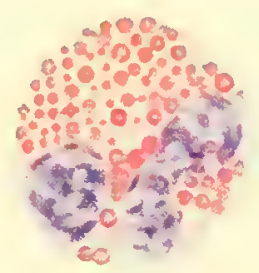

180

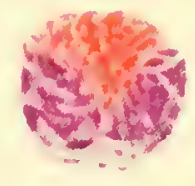

181

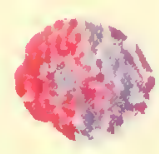

182

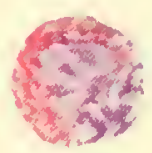

183

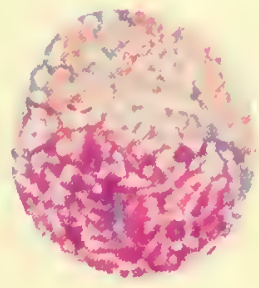

181

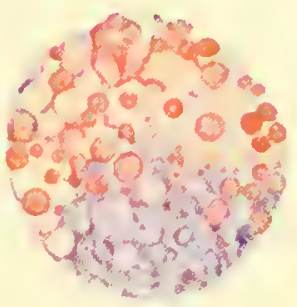

185

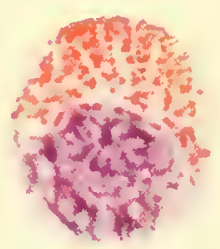

186

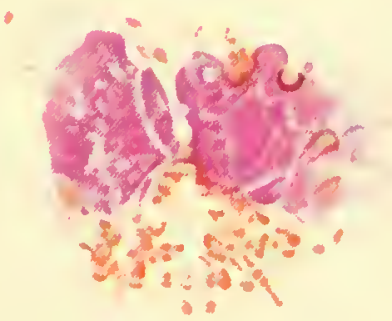

187 
Figures 188-196.--Basophils from cireulating blood-mature, immature, and smurlged cells. $2,470 \times$.

Figures 188-192: Normal mature basophils, all of which show slight to extensive artifacts due to the water used with H'right's staining technic.

188 Basophil having an appearance approaching that following methyl aleohol fixation, figure 390 .

189 Basophil showing early artifact of coalescence and dispersion of granules.

190 Basophil showing moderate artifact of coalescence of granules above the nueleus and discharge from the eell surface.

191 Basophil showing extensive artifact. Complete loss of eytoplasmic granules exeept for two pairs on the cell margin and those above the nuelens that conlesced when the cell dried.

192 Basophil showing extensive artifaet. Magenta masses above the nuelens represent basophilie granules of the eytosome, not basochromatin of the nucleus.

193 Basophil promyelocyte.

Fugures 194-196: Technic arlifacts, smudged cells.

194 Slightly smudged basophil.

195 Moderately smudged basophil.

196 Extensively smudged basophil. 


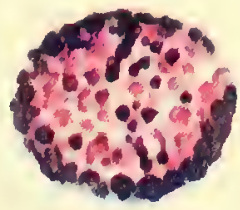

188

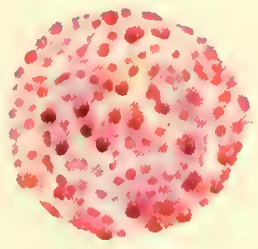

189

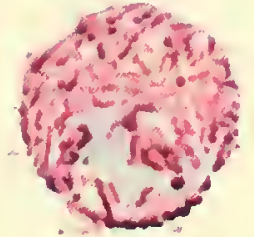

190

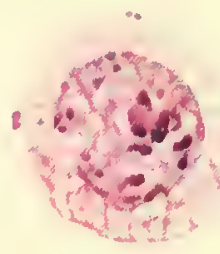

191

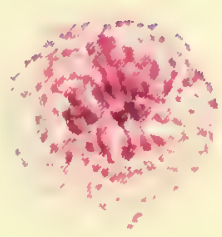

192
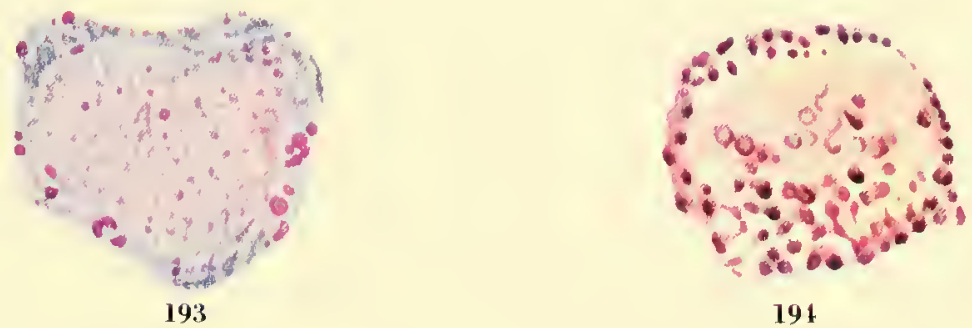

191

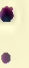

$\checkmark$

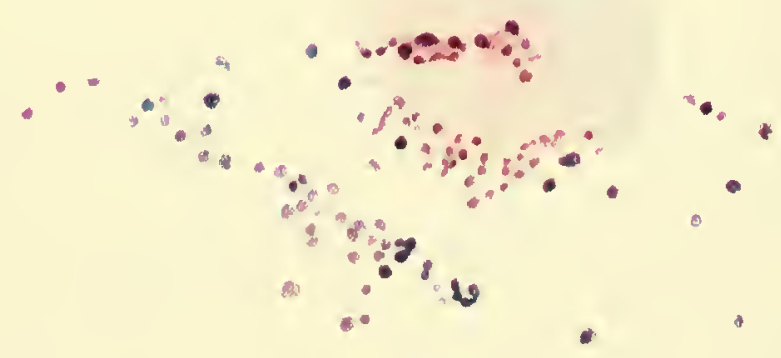

$8=$

195
196 


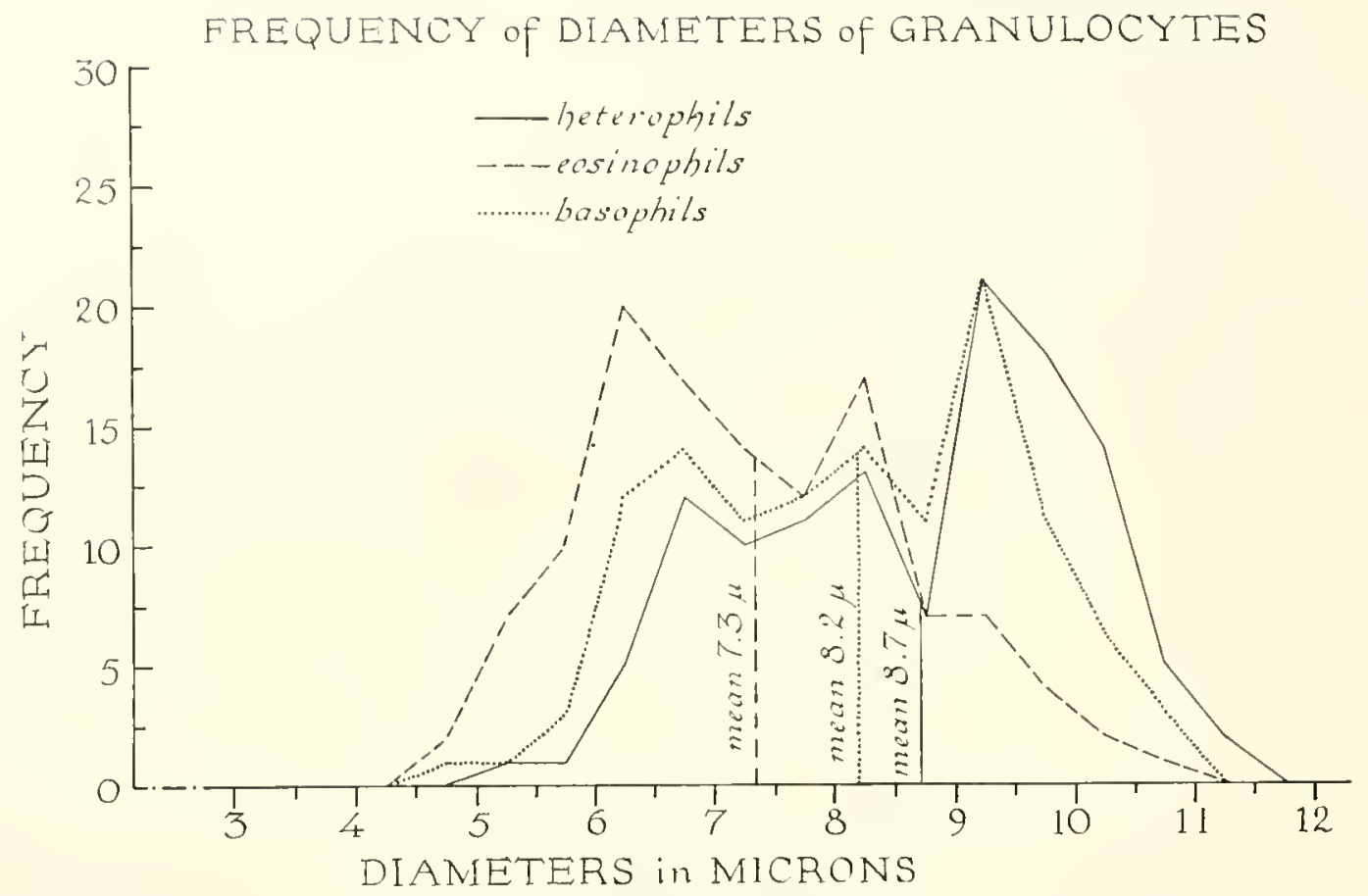

Figure 197.-Frequency distribution curves for cell diameter of heterophils, eosinophils, and basophils.

Figures 198-223.-Effect of Petrunkevitch No. 2 fixation and M. G. G. stain. Granulocytes arranged to give a series of nuclear lobes for Arneth counts. 2,470X.

198 Erythrocyte nucleus with this technic almost a solid dark blue.

199 Small lymphocyte with cytoplasmic blebs and pachychromatic type nucleus.

200 Average lymphocyte with leptochromatic type 111. cleus. Perinuclear space in this and the precerling cell.

201 Monocyte. This technic shows the stainability of the substance filling the vacuoles of the IIof.

202 Thrombocyte. The specific granule of the thrombocyte lies within a vacuole.

203 Heteroplit, 3 nuclear lobes. This technic dissolved out completely all rods and granules, leaving only a cytoplasnic framework.

201 Heterophil, 1 nuclear lobe.

205 Heterophil, 1 nuclear lobe.

206 IIeterophil, 2 nuclear lobes.

207 Ifeterophil, 2 nuclear lobes.
208 IJeterophil, 3 nuclear lobes.

209 Icterophil, 3 nuclear lobes.

210 IIeterophil, 4 nuclear lobes.

211 Heterophil, + nuclear lobes.

212 Heterophil, 4 nuclear lobes.

213 Ileterophil, 5 nuclear lobes.

214 Heterophil, 5 nuclear lobes.

215 Eosinophil, 2 nuclear lobes. Specific granules are not destroyed by this technic in the chicken.

216 Eosinophil, 1 nuclear lobe.

217 Eosinophil, 3 nuclear lobes.

218 Eosinophil, 3 nuclear lobes.

219 Eosinophil, 3 nuclear lobes.

220 Eosinophil, 1 nuclear lobes.

221 Basophil, 1 nuclear lobe. preserved.

222 Basophil, 1 nuclear lobe.

223 I3asophil, 2 nuclear lobes. 


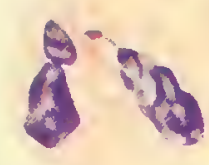

203

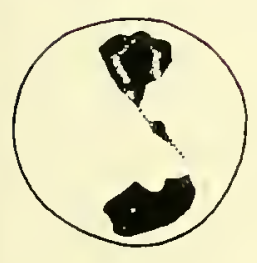

207

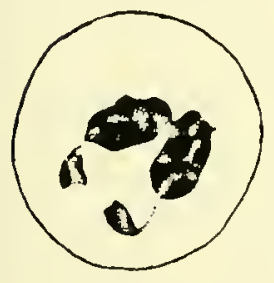

211

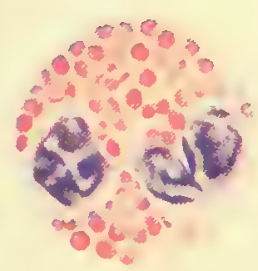

215

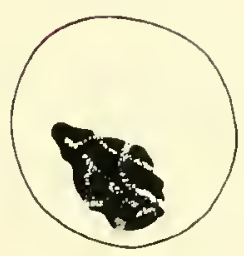

201

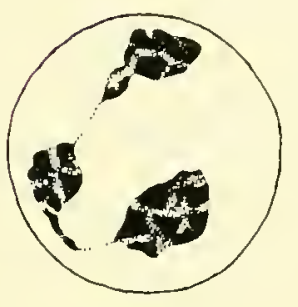

208

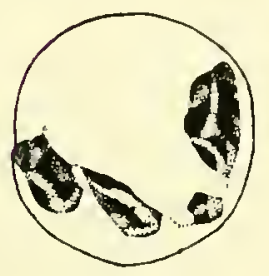

212

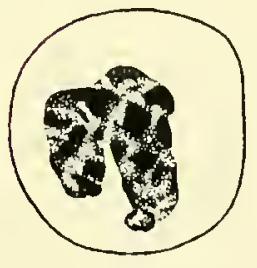

216

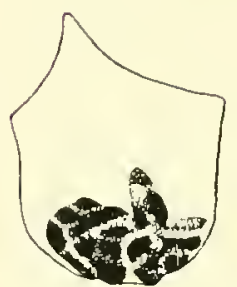

20.5

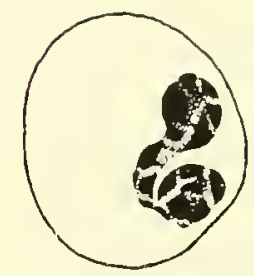

206

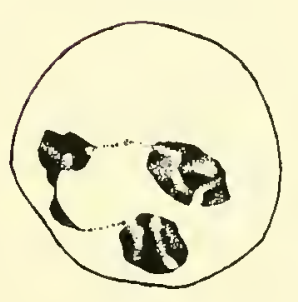

209

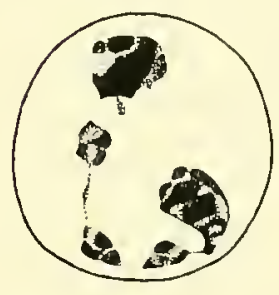

213

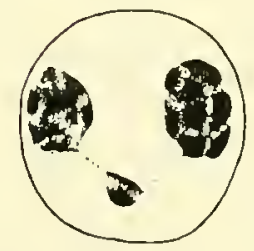

217
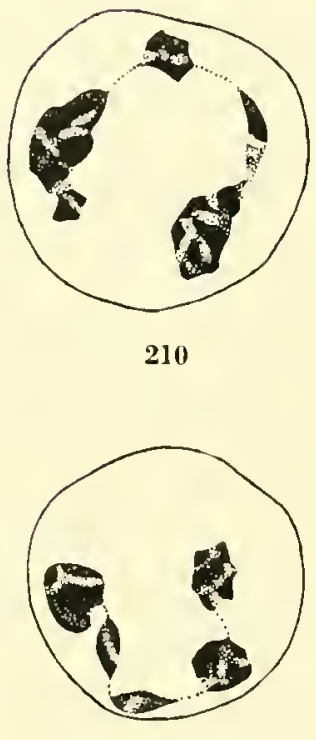

214
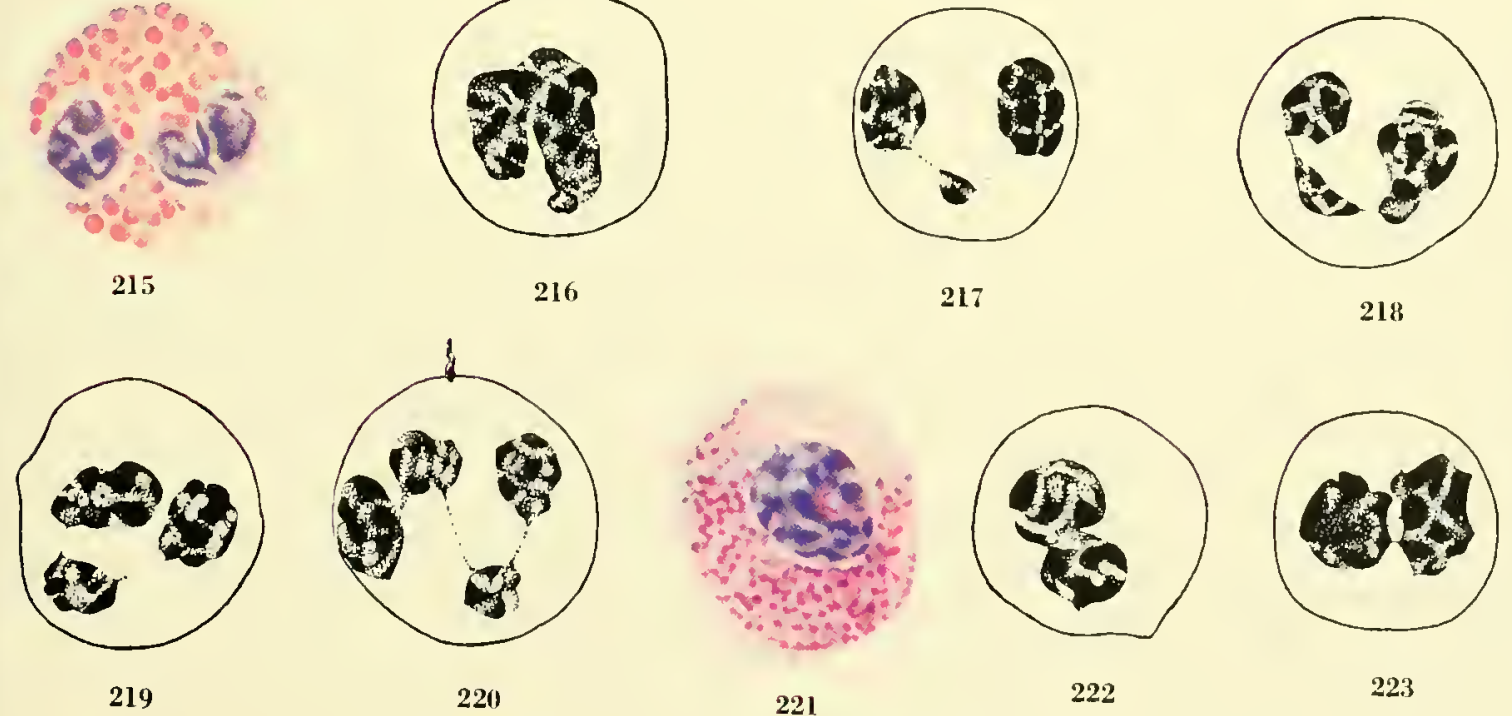

222

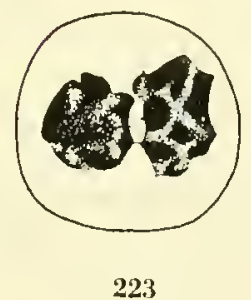



disappeared, leaving vacnoles with a narrow rim of stainable material. The significance of different types of rods, some with granules, some with vacuoles, and some with neither, is not known. Are they nothing more than differences between individuals or are they handles that can lie used to gain an insight into the bird's condi. tion of health and disease?

Information is needed also on the chemical nature of the rods and their gramules. Whatever may he the significance of the gramules, they are part of the apparently normal development and may be found in heterophil myelocytes. Weid. enreich (1911) according to Lundquist and Hedlung (1925) conclurled that the uncolored spots within the rods are merely optical phenomena. Lundguist and Hedlung fomd central granules in vital preparations lut not in stained smears and agreed with Weidenreich that the central granules are not definite organelles. Burckhardt (1912) expressed essentially the same point of view: "... In ter Mitte der Spindel wird oft ein ungefälbter Punkt sichtbar, der je nach der Stellung der Mikrometerschraube bald anflilitzt, hald Schwarz erscheint. Ueler die Zusammensetzung dieses Punktes wurde schon mehrfach diskutiert, mir scheint er am einfachsten als Lichtbrechurgsphänomen zu erklären."

Anyone sundying avian blood soon recognizes the fact that the rods show varying degrees of dissolution. Figures 154-165 show a progressive series from clearly defmed and well-developed rods to no trace of rods. but the story does not read in quite this sequence. The granules are more resistant to the processes of dissolution ihan are the rods. If the rods without granules disappear from figure 1.51 there is left a cell like that shown in figure 165 , lut if a rell like that shown in figure 15.5 loses its rods there remains a cell like figure 164. Figme 156 would result in something like figme 163 , and figme 157 would result in something like figmre $16 \mathrm{I}$. In each case of the loss of rod substance, the eell has come to look more like an eosinophil: in some instances the resemblance is quite rose (fig. 161). However, there is no implication in what

\footnotetext{
${ }^{B}$ Translation: In the middle of the spindle there can often be seen an unstained rot. and after the adjustment of the micrometric screw this often shows up as light, sometimes as dark. There has heen much discussion already over the com. position of this dot: it suems to me simplest to explain it as a phenomenon of light difTraction.
}

has been said that heterophils become eosinophils. This similarity of appearance under some courlitions is probably the basis for more confusion in making accurate differential counts than any other single factor.

How are such heterophils and eosinophils to he distinguished? This will be discussed more fully after the eosinophils have been deseribed, but the most important fact is that the rods as they break down or go into solntion give the cytoplasm an orange or pinkish color such as is readily seen in figures 158-162. The background color of the true eosinophil is practically always light l,he. That difference, combined with the fact that in most cases some part of the heterophil nuclens is pale and poorly stained, makes it relatively simple to distinguish the two granulocyles. This characteristic difference in background color was olserved in the helerophils and eosinophils of reptiles by Ryerson (1943).

Nuclear staining is extremely variable. as may be seen in the series of figures 2. 1 and 154-167. Sometimes the staining is vigorous as in figure $2, l$, where the nuclear lobes are clearly defined. In other examples the nuclei vary in their receplivity to stain from those moderately well stained as in figures 156 and 167 to those in which there is no trace of chromatin pattern or a distinct muclear houndary. In the same cell (figs. 157 and 158 ) one lolse of the molens may he stained and the more central ones may not he stained. Often there will be a difference in staining of the same lolve, ihe more central portion being faint and the part adjacent to the cell wall fainly dark. Fail. mre of the nueleus to stain is not a mark of degencration as indirated hy Emmel (1936) but merely means that Wright's stain failed to penetrate the cell and color the nucleus properly.

The momality of the heterophil nucless wan he quite easily and convincingly demonstrated if. after the smear is matle on the slide, the bloot is allowed to acquire a dull sheen and is then dipped immediately into Petrunkevitch No. 2 (see .h. 7). If slained with May-Grïnwald Giemsa the mucleus appears as shown in figure 203. The treatment destroys the rods or distorts them so that they run rogether as a network but reveals the muclear structure in all its detail. In none of these slides was there any indication of nuclear degeneration. It is olsvions that an Arneth index could not be obtained from a dry fixed Wright's or a May-Grümwald Giemsa 
stained slide. Two slides are necessary for bird's blood-one processed to show the struc. ture of the cytosome and its inclusions, and the other to show the nucleus. This may be the reason why so few counts thus far have been published for birds on the number of lobes in heterophils.

Avian blood has not as yet received the same critical study as human and mammalian bloods nor have avian diseases been approached with the idea of closely conelating the physiology of the diseased condition with the hematologic response, although from the reviews given by 01 . son (1937 and 1952) it is indicated that many workers have made important contributions to blood diseases of birds.

Differential counts serve a useful purpose but actually hold only a small place in the total of blood reactions. The Arneth or Cook-Ponder counts can contribute additional information. Figures 203-214 show the range of variation in number of nuclear lobes in heterophils. It is obrious that a single nucleus will be separated into two lobes by a gradual process. Thus all stages will be foumd, and it becomes necessary to decide arbitrarily when one nuclear mass has been suffieienty separated from another to be called a second lohe. Figures 204 and 205 would each be considered to have a single nucleus. In mammalian work cells of this type are often called jureniles, nonsegmenters, and hand cells.

There may be some question as to the proper designation for figure 206 but sinee there is a deep constriction. rather than a broad band, it has been called two-lobed. In chicken blood, a small particle of nuclear material nay lue retained more frequently along the length of the desmos as the lobes pull apart than in mammal. ian blood. An example of this is seen in figure 207: it meets the requirements of a distinct lobe in that it is separated from adjacent lobes by a complete constriction hut, to be arbitrary. and to give some meaning to the Arneth connt, it seems inadvisable to count these small nuclear masses as lobes. On this basis the figure referred to has 2 instead of 3 lobes. Three lobes are shown in figure 203.

Three lobes are shown in figure 208, and if the small spatulate portion still attached to the upper lobe were completely separated by a constriction, it would be counted as a fourth lohe.
The spatulate portion is somewhat larger than the small mass discussed for figure 207.

Fonr lobes would he counted in figures 210212. The fouth lobe in figure 210 is the long narrow structure that is separated from the lower lobe by a complete constriction: no connecting thread has yet been formed. The constriction near the tip of the left lobe is not sufficient to warrant counting this body as 2 lohes. Figures 211 and 212 have 4 lobes each, and figures 213 and 214 have 5 each. Sometimes the lobes lreak apart and no trace of a connecting line between is visible (fig. 2]3, upper lohe).

Judgment in commting lohes of eosinophils and of basophils is hased on the same eriteria aheady described for heterophils. The eosinophil, figure 216, is counted as one lobe. In this particular cell, there actually may be two lobes, one overlying the other, but it is less confusing and probably sufficiently accurate to include this in the single-]obe class. Figure 215 is an example of a nucleus helonging to class II. Figures 217219 are examples of nuelei belonging to class III. In fignre 217. the middle lobe, although small, is sufficiently large and definite to be counted as one lobe. Figure 220 is an example of a mucleus belonging to class IV. No examples of class V were found among the eosinophils.

Basophils usually have hut a single muclear lobe (figs. 221 and 222). Rarely the nucleus may be divided into two lobes (fig. 223).

The Armeth index gives a useful statistic that measures the rate at which old cells are being replaced. There are 5 classes. Class I includes all cells in which the nucleus is composed of one lobe. The remaining classes-II, III, IV, and $\mathrm{V}$-inchude cells that have the corresponding number of nuclear lobes; class $V$ includes, also, those of over 5 lobes. Cells with more than 5 lobes are rare; none were found in a sample of 1,500 cells counted. The results of one Arneth count on 1,500 heterophils, 142 eosinophils, and 295 basophils are given in tahle 6 . Arneth used nuclear lobe counts on eosinophils and basophils but they have never been found as useful as the counts made on the heterophils. In the literatmre it is stated that heterophils have more lobes than eosinophils. This observation is supported Jo the data in tahle 6 where the index for the former is 2.44 and for the latter 1.97. However, the presence of more lobes is definitely not a characteristic by which the two cell types can 
be separated. It should be noted that the largest class for both of these cell types is II. In some eounts on a Canada goose the index for the eosinophils was considerably greater than for the heterophils (table 24).

Since but few had previously used nuclear lobe indiees of this sort on lirds, it was considered desirable to make a sample count to determine the index variability and to find any possible suggestion of a relationship to livability or to infection with the agent of lymphomatosis (table 7 ). Of the 13 eases that showed values above the mean of 2.44 (a shift to the right) there were 2, or 15 percent, that were grossly diagnosed as lymphomatosis and 12 of 17 cases, or 70 percent, witls index value below the mean (a shift to the left) were diagnosed as lymphomatosis. A correlation was run between age at death and index value. It resulted in an $r$ value of +0.423 , significant between the 2- and 1-percent level. One test made on another group of birds did not give the same results. Obriously this type of test should be repeated and carried out on a much larger scale.

\section{Table 6.-Arnell counts on granulocetes of clickens}

\begin{tabular}{|c|c|c|c|c|c|c|}
\hline \multirow{2}{*}{ Cells } & \multicolumn{5}{|c|}{ Clan (nuclear lolies) } & \multirow{2}{*}{ Index } \\
\hline & 1 & 11 & 111 & 11 & 1 & \\
\hline & $\begin{array}{l}\text { lipr- } \\
\text { rent }\end{array}$ & $\begin{array}{l}\text { Per- } \\
\text { erme }\end{array}$ & $\begin{array}{l}\text { l'er- } \\
\text { cent }\end{array}$ & $\begin{array}{l}\text { l'er- } \\
\text { crnt }\end{array}$ & $\begin{array}{l}\text { ler- } \\
\text { cent }\end{array}$ & \\
\hline Il'lerophils & 8.7 & 15.9 & 38.8 & 6.0 & 0.7 & 2.11 \\
\hline Eosinepoluils. & 17.5 & 69.8 & 11.2 & 1.5 & () & $1.9 \%$ \\
\hline Basopphils... & 99.0 & 1.0 & 0 & 0 & 0 & 1.01 \\
\hline
\end{tabular}

In an Arneth count, the elasses are arranged so that the first lies to the left and the fifth to the right, and thus, in relation to the average or index value, the yonngest cells are to the left and the oldest to the right. The shifting of the index either to the right or to the left has significance in the evaluation of the extent of morbidity of the individual.

Arneth subdivided each class several times, which added cytologie criteria to the classification based on lohe number. Schilling (1929)

Table 7.-The heierophil Arneth index

[Cunnt taken for earli bird at 70) 1ays of age.] Irnell
index

Bird No. $\begin{gathered}\text { Age } \\ \text { at } \\ \text { death }\end{gathered}$

\begin{tabular}{|c|c|c|}
\hline & {$[2.96$,} & 160133 \\
\hline & 2. 82 & $1112 \mathrm{~J} 5$ \\
\hline & 2.80 & $6 C 3$ \\
\hline & 2.71 & 205 l: 5 \\
\hline$\equiv$ & 2. 70 & 1111111 \\
\hline$=$ & 2. 70 & 5103 \\
\hline$\Xi$ & $\left\{\begin{array}{l}30 \\
60\end{array}\right.$ & $\begin{array}{ll}100+2 \\
-7\end{array}$ \\
\hline$\Xi$ & 2.60 & $216,0=2$ \\
\hline & 2.58 & 69 1'3 \\
\hline & 2.56 & $205 \mathrm{I} 1$ \\
\hline & 2. 52 & $205 \mathrm{E} 5$ \\
\hline & 2. 52 & I1 J 2 \\
\hline Arg. & 2. 41 & \\
\hline & $(2.10$ & $201 \mathrm{k} 3$ \\
\hline & 2. 33 & 216122 \\
\hline & 2. 36 & $6.5 \mathrm{~L}, 3$ \\
\hline & 2.36 & $75[3$ \\
\hline & 2.31 & 205 C 5 \\
\hline & 2.31 & $1102 \times 1$ \\
\hline & $\begin{array}{l}2.32 \\
0.32\end{array}$ & 3013 \\
\hline & $\Rightarrow$ & (n) \\
\hline & 30 & -178 \\
\hline $\overrightarrow{\boldsymbol{r}_{i}}$ & 2.28 & 203163 \\
\hline & 2.26 & $72 \mathbf{E} 4$ \\
\hline & 2.261 & 7513 \\
\hline & 2. 26 & $30+$ F 3 \\
\hline & 2.21 & 20113 \\
\hline & $\because .12$ & I. \\
\hline & & \\
\hline
\end{tabular}

lavs

\begin{tabular}{|c|c|}
\hline 315 & Termination. negative \\
\hline 6.52 & Termination, begative \\
\hline 511 & Lnuletrerminerl \\
\hline 6.58 & [ndelermined (in good llesh) \\
\hline & Termination, wyative \\
\hline & [Tuletermined \\
\hline 15 & Termination, negative \\
\hline & $\mathrm{LO}$ \\
\hline & l'rolapaed ulerus \\
\hline & $\begin{array}{l}\text { LX. l, and muscular } \\
\text { atrophy }\end{array}$ \\
\hline & ['ndetermines] \\
\hline & Emaeiation, delı̣ulration \\
\hline & Emaciation, dehyetration \\
\hline & $\begin{array}{l}\text { Aremumlation of ascoitic fluid } \\
\text { (110 ece), enlarged horart }\end{array}$ \\
\hline 93 & L.) \\
\hline 86 & L.) \\
\hline 26 & lilond poisming \\
\hline & I. \\
\hline & $1+1$ \\
\hline & LO, prolapseal uterus \\
\hline 65 & $\mathrm{~L} \backslash, \mathrm{L}(1)$ \\
\hline & Terminationl, negalive \\
\hline ] & Emaciatin, dehỵlration \\
\hline & Lnaciation and delyydration \\
\hline & L.) \\
\hline & $1.1 . \mathrm{L} \mathrm{T}^{\top}$ \\
\hline & 1.1 \\
\hline & 1, I. \\
\hline & LV, cannibalism \\
\hline
\end{tabular}

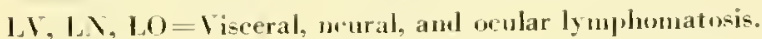

criticized the basic principles of an Arneth comnt and index as follows (p. 148):

"White Arnetlis theory takes info aceount only a jurenile shift to the left. we distinguish two elasses, (a) regenerative shift, (b) degenerative slift."

Nany others have prepared systems of classifying heterophils and other granulocytes. Their contributions have been reviewed by Richter (1938) and by Sugiyama (1938). The latter author has presented a table of nuelear types for representative fish. amphibia, reptiles, birds. and mammals. For the heterophits of the domestic fow , he gave class I. 12.0 percent: class II, 62.0 percent : class III, 22.5 pereent : cliss IV, 2.3 percent. These values caleulate to an index of 2.17.

Examination of table 7 raises the question of whether the mean value of 2.44 is a normal one for birds. When the smears were taken at 70 days of age, all the chickens were seemingly nor- 
nal; yet the averagc index for the 4 that went to the temination date and were found grossly negative was 2.65. Perhaps this is a more nearly normal index than the lower value. A group of chickens known to be free from the agent of lymphonratosis and other diseases is needed in order to arrive at a set of normal standard hlood values. The question also arises, Are the birds that are destined to develop grossly visible tumors infected and fighting against the disease during the several hundred days before neoplasia appears?

Before leaving the subject of the normal heterophil, the fact should be mentioned that the French veterinarian, Lesbouyries, (1941) described a sixth type of white blood cell in chickens. He listed a neutrophil in addition to a heterophil. In his descriptions they are not synonymous. His sixth cell is the type shown in figure 165 and it does resemble superficially a mammalian neutrophil. Our own studies have slown it to be a heterophil from which the rods (without granules) luave dissolved, and there is no justification for giving it a different name and creating a separate class for it. Breusch (1928) listed 4 types of gramulocytes-eosinophilic leukocytes, amphophilic or pseudoeosinophilic leukocytes, basophilic leukocytes, and neutrophilic lenkocytesbut described only the first 3 , and includes only these 3 in his tables of differential counts. The application of terminology whereby heterophils and eosinophils are correctly identified has not been a simple matter. Magath and Higgins (1934) have listed the various synonyms that have been used from 1880 to 1931. Even separation of these cells on the basis of those with eosinophilic rods and those with eosinophilic granules leads to difficulty in identifying these 2 cell types in ducks (sec p. 207). Loewentlual (1930) also found what he called neutrophiloid cells. which in lis opinion were derived from rods by a process of dedifferentiation: he sug. gested that in the course of evolution it was this type of cell that produced the mammalian neutrophil.

\section{Developmental stages found in circulating blood (figs. 168-173)}

Immature cells of the heterophil series are rare in normal blood, but probably not more so than are the inmature stages of red cells when the difference in relative numbers is taken into ac- count. If the heterophil count is recovering after destructive irradiation, the immature heterophils may be quite numerous.

A gramuloblast found in the circulating blood is shown in figure 168 . There may be some question of whether it is destined to be a heterophil or a basophil, but the large size of the cell, the rim of basophilic eytoplasm broken by many mitochondrial spaces, and the miform reticular pattern of the nucleus, all identify it as a blast cell. When compared with the gramulohlasts of figures $330, l$ and 2,366 , and 367 , little doubt remains as to its identification as a gramuloblast.

The metagranuloblast stage of development has not been seen as yet in the circulating blood, but is found in bone marrow (figs. 368 and 369 ).

Four examples of pronyelocytes (figs. 169 172 ) have been illustrated. The nuclear boundary in the earlier phase of development (figs. 169 and 170) is even less distinct than in the bone marrow, and the number and density of magenta rings and granules are greater. Figures 171 and 172 are not good examples of late promyelocytes, becanse the contents of the vacuoles did not take the stain. It is assumed that the same stage, had it been taken from the bone marow. would have looked like figures 370-372.

These immature heterophils in circulating blood have a different appearance from those in bone marrow. Perhaps this is due to the fact that different stains were used in the two situa. tions, or it may be due to the effects of these environments on the penetrability or selectivity of the stains. Whatever the cause, the difference in appearance should be kept in mind and not be allowed to hamper identification.

A typical nesomyelocyte (fig. 173) has less than half of the defmitive gramules. Many of the precursor orange spheres have attained a dense coloration but none of them have elongated as in figure 373. Two sizes of granules are present. and there is a possibility that the small ones become the central bodies for the rods that devclop out of the large ones. The carryover of magenta rings and gramules from the early to the late stages sometimes occurs as it has in fignre 173. The whole process of myelopoiesis will not he discussed at this time since a rather critical and detailed comparison, which is presented later, is necessary in order to relate what is found in birds to the named stages given for mammals. See also the discussion by Lucas (1959). 


\section{Abnormal heterophils}

The only cell defect recognized thus far is the fractured nuclei such as shown in figure 3,1 . In this case, 2 of the 3 lobes showed a nonstaining band. It is apparent that the same type of nuclear chromophobia occurring in the erythrocytes. lymphocytes, and other cells can also occur in heterophils. The possibility that these fracture lines and empty nuclei represent pathologic conditions. rather than technic defects, has been discussed (pp. 32 and 65).

Undoubtedly other abnormal heterophils exist in birds as they do in manmals hut up to this time sufficient knowledge of the normal by which identification of the abnormal can be made is lacking. Toxic gramules in human neutrophils are considered abnormal and play an important role in prognosis. Osgood and Ashworth (1937) note three points of difference from normal cells-color of cytoplasm, presence of vacuoles. and coarse granulation. Osgood goes on to say (p. 51), "The author predicted death of more than 100 consecutive patients from a three or four plus change in two of these factors. Ninety percent of these died within a week after the prediction was made. These patients died of a wide variety of conditions. including malignant tumors and leukemias as well as infections." In view of its vahe in human hematology, it would seem desirable to further study avian blood in search of this mammalian counterpart. Thus far, however, nothing has heen observed that could be identified in avian blood as toxic granules. Perhaps this is because most of these studies have been on hirds that showed no obvious disease.

\section{Technic artifacts (fig. 174)}

The effect of water on the rods was emphasized lyy soaking the slide for 20 minutes after methyl alcohol fixation and hefore staining in MayGrünwald Giemsa. The result of sucli treatment is shown in figure 174. All trace of rods has disappeared; instead there is a cytoplasmic network with a granule in the center of each space. The technic used in figures 154-165 was Wright's stain but it was applied by the bulk methor ( $p$. 229 ) instead of to individual slides on a rack. Since the bulk method requires somewhat longer staining and slower drying, it involves longer ex. posure to aqueous solutions. Hence one finds in this serics of slides more examples in which rods have disappeared than one nsually finds in normal hirds by using the staining rack technic. No technical method has yet been found that will hold the rods well enough to insure confidence that the appearance of the heterophil is really due to the bird and not to technic. Such a method is urgently needed. Even the Petrunkevitch fixed smears show dissolution of the rods (fig. 203) and in this case neither rods nor granules were visille. Petrunkevitch No. 2 (p. 230) is an alcoholic solution with copper, ether, and other substances, and it would not be expected to act like an aqueous fixative. Bradley (1937), quoted on p. 88 , olserved that adequate fixation would not hold the rods if followed by aqueous stains.

In view of the high lability of the rods, it seems appropriate to raise the question, How faitl. fully has the heterophil rod heen preserved in tissne section? If rods disappear but granules remain. a heterophil can look like an eosinophil. Thus, the descriptions of tissue infiltration or of myelopoiesis as worked out on tissue sections may be open to question until it has heen demonstrated that the technics used do not destroy the rods. Dantschakoff (1909a and b) in her study on the bone marrow of birds follows the processes of myelopoiesis through the stages showing rods, and her beautiful colored plates show them well preserved. Our sections of hematopoietic embryo tissues failed to show these rods.

Nuch that is seen in the dried smear from circulating blood may be artifact; yet the opinion is maintained that bind differences are in part responsible for some of the deviations from the typical. Althongh all slides are handled alike in bulk staining, some birds show rods and in others hardly a rod can be found. It would go far toward solving some of these problems if fresh blood preparations were carefully studied under the phase microscope. The variability due to technic and that due to bird differences could be separated. Additional evidence that rods of heterophils can come to look like gramules of true eosinophils in vivo is indicated in the examination of smears from blood spots of eggs. Here every heterophil simulated an eosinophil (Lucas, 1946). Natt and Herrick (1954) have reaffirmed what others liave demonstrated, that loss of rod substance leaves a central granule 
that gives to the heterophil an appearance similar to that of the eosinophil.

The literature on the sulject of heterophils and eosinophils reflects some of our present un. certainties. The observation that aqueons solution canses a legradation of rods is not new. Bizzozero and Torre (1881) stated that if one treats a blood preparation with water the white corpuscles in question swell; the same thing hap. pens to the rods themselves. which become pale and at last disappear. They also found that upon treatment with dilute citric acid the motoplasm of the white corpuncles hecomes swollen and pale. The rods first draw together so that there is formed a shining heap that hides the nuclens. This heap very suddenly hecomes pale and finally disappears. Although Bizzozero and Torre recognized only four kinds of white blood cells. they did include the true gramular eosinophil as distinct from the rod eosinophil. Denys (1887) writing on the bone marrow of pigeons is less defunite about the number of types of white blood cells, does not distinguish hetween the two eosinophils, and says it seems probable that most. if not all. of those seen as dots are simply rods viewed from the axis.

Lundquist and Hedlung (1925) have presented a review of the subject and mention those who believe the eosinophils in birds represent two distinct types and those who consider that there are only four hinds of leukocytes in hirds. They quote S. Henschen. who concludes that there are two distinct lypes but who also mentions that post mortem processes can cause the rods to go over into granules. Lundquist and Hedlung's own investigations led them to the unique opinion that the granular eosinophil cell represents the tue condition and that the rods are artifacts, produced at the time the smears are made. They point out that the inclusions have the form of gramules after methyl alcohol fixation and of rods after formalin or trichloracetic. In order to follow the transformation from gramules to rods they diluted the blood in a white cell pipette with 0.9-percent sodium chloride solution. which was considered to be isotonic with chicken blood. The diluent was allowed to act for 2 minutes before the blood mixture was put into a counting chamber, then an eosinophil was olserved in order to note the form of gramulation present. After this, a solution of higher or lower concen. tration was added to the side canal of the count- ing chamber and the changes in the cells were followed. Usually filter paper was touched to the fluid layer on the opposite side in order to hasten the exchange. When the preparation was diluted with water they found large, clear cells with large, clear, scarcely visible round granula. tions: when it was diluted with 0.7 -percent $\mathrm{NaCl}$ solution. all the granulations were round and were larger than in the previous solution. Preparations treated with 0.9-percent $\mathrm{NaCl}$ produced mostly round granulations in the cells, but in a few cells these bodies took the rod form. At 1's-percent $\mathrm{NaCl}$ concentration, the cells contained rod-form granulations, and now and then spherical granules. They summarize by saying that in water the cells and granules swell and become faint, but in 1.5-percent salt solution the cells shrink and the round granulations are transformed into the rod form. If not carried too far these are reversible reactions, and thus the rod eosinophil is an artifact brought about by osmotic conditions.

The chief reason why the interesting conclnsions of Lundquist and Hedlung have relatively little value is that their study of cellular change was made at the relatively low magnification required in using a comting chamber, and, although they mention these changes in the same cell, it would seem rather difficult to keep a particular cell in the field during a rapid exchange of fluids.

Brarlley (1937) examined the hlood of numerous birds and made observations similar to our own. He reports (p. 995) that, "When the color of the rod bodies has been partially removed, . . demonstration is made of darker or lighter parts, giving the impression of deeply stained granules along the paler length of the body." In regard to technic he says (p. 997), "Arian (fowl) blood is luest stained by a method which applies the eosin or related acid stain in alcoholic solution and when the use of water or saliue solution forms no part of the process until after the alcoholic stain has acted.

"Adequate fixation before treating with water or watery stain is no preventive for the destructive action of the latter on the rods. Water applied in moderation after staining is not detrimental to the result, and when left in contact with the stained preparation for a longer time is the means of showing up details of structure of the rod bodies not otherwise appreciated." 
Interpretation of the loss of rods is sometimes influenced by the type of problem involved. Hewitt (1940) attributes this loss to degeneration or phagocytosis due to the malarial parasite. Difficulty in the identification of eosinophils and heterophils is not limited to the older literature; for example, Diesem (1956) found it difficult to separate these two cell types, and combined them in his cell counts.

The most recent opinion on the subject of rod degradation has been expressed hy Dr. Hamre (personal communication). The opinion is that the rods themselves remain unchanged when acted upon by varions stains and aqueons solutions but that the capacity of the rod sulstances to absorly the stain does change, and that if $\mathrm{W}$ right-Giemsa is used as he has modified it (the technic he recommends is given on p. 230) rods will always stain and each rod will contain a central granule.

One additional cellular defect remains to be described-squashed cells. Squashed or smudged lieterophils are probalily the easiest cells to recognize becanse the specific cellular inclusions are preserved. Squashing takes place at the time the smear is made; yet the same variability is to be found in the rods broken out of the cell as was found in the intact cell (figs. 175 and 176). Figure 175 shows rods without central granules and figure 176 shows central granules with dissolved and almost completely faded rods. These were taken from different hirds but both smears were made the same day. The birds were exactly the same age and the slides were stained together. Both cells show many fine magenta-colored granules. partly among the broken fragments of the cell but mostly smrounding the cell. These small, darkly stained bodies are serum granules. Something is liberated from the broken cell that acts as a mordant on the serum granules and causes those in the immediate vicinity to take the stain. As may he seen from figure 176 their color and size differ from even the smallest of the central granules of the rods. The central granules show a variability in size among themselves similar to that found in the intact cell.

\section{EOSINOPHILS}

The fact that both heterophils and eosinophils stain with eosin has led to the use of numerons terms for designating these two cell types, such as "rot eosinophils." "granular eosinophils," "pseudoeosinophils." and "true eosinophils." Some have reversed the last two terms so that "true cosinophil" applies to the heterophils. For this reason, the use of "true" and "pseudo" can lead to confusion. The terms "rod" and "granular" are not good either because rous often change to spheres. Therefore, the terms "heter. ophil" and "eosinophil" have been chosen. These have the added advantage that the cells are each designated by one word instead of two. The eosinophil of birds is homologous with the cell receiving the same name in other classes of vertebrates.

\section{Normal matme cosinophils (figs. 177- 183)}

The eosinophil shows a rather wide range in size: some are large. like figures 177-180. and some small, like figures 181-183. Usually they are about the size shown in figure 177. The range for size (fig. 197) is shown by a frequency distribution curve in which there is a minimum of a little over $4 \mu$ to slightly over $11 \mu$. The average size of $7.3 \mu$ is approximately 1 micron less than for beterophils or basophils, and prob. ably was brought about by the occurrence of small eosmophils in circulating blood: whereas, cells of the size shown in figmes 181-183 are rare for heterophils or hasophils. The cell is nearly round as may be seen from the figures.

The cytoplasm stains a pale, clear blue color, which, of course, shows best when the granules are not crowded together. The granules are often crowded and there is not much cytoplasm to be seen: yet the background blue color is one of the lest means of separating the two types of eosin-staining cells when the rods of heterophils have been degraded to granules. The bluestaining gromd snbstance is readily apparent among the granules of large eosinophils, but the blne color is often obscured in small cells. Small cells, such as those shown in figures 181-183, are relatively rare. Their identification is aided by the strong affmity of the nucleus for stain.

There is some variation in the structures of the gramules. Often they appear as homogeneous bodies, but sometimes when they are larger and 
not so crowded. the structure of each granule is revealed. It is made up of 3 or 4 smaller loodies held together in a ring. This is shown especially well in figure 177. The small granules that make up the ring give it an angular contour and in the center is a clear spare. Sometimes one may have an impression of a clear space in the center of the sphere (fig. 180) and yet the individual particles that go to make up the ring cannot he separated.

A knowledge of the detailed structure of the eosinophil granule (or ring) in the chicken is necessary for the identification of the eosinophil in various species of wild birds, especially the ducks. The space may he responsible for the general report that the cosinophil gramules are refractile. In formalin-fixed cells that are stained with phloxine and floated on a slide, as they are in the counting chanher when $\mathbb{W}$ iseman's method has been used in preparing the material, they can readily be distinguished from heterophils by their strong refractility. Had these differences been olserved by Lundquist and Hedlung (1925) they probably would not have concluded that these two eosin-staining cells belong to the same 1уре.

Usually, gramules are uniformly stained but it is fainly common, especially in medimm to large cells, to find that some of the gramles stain faintly, as shown in figures 178 and 179 . Quite often in association with this variation there are differences in concentration of grannles in dif. ferent parts of the cell, as shown in the two examples. It may be that these deficiencies represent immaturily of the cell; yet the fact that there are four muclear lobes is evidence that the cell in figure 179 is not an immature cell: perhaps the eytoplasm continued to increase in volume after the process of gramule formation had ceased. Further discussion of the prolilem of variation in the size and arrangement of eosinophil gramules appears later (ch. 6 and fig. 411).

One characteristic of the grammles in the eosinoplits that aids in separating them from heterophils containing granules is the imperviousness to aqueous solutions: the gramules of the eosinophil are never affected in the chicken and the same difference is shown following Petrunkevitch No. 2 fixation (compare figs. 203 and 215 ).

The nucleus always stains well in the eosinophil. Except for the masking of lolses by the granules. it would he possible to comt the nuclei quite accurately. No rell with more than 4 nuclear lobes has been illustrated, and the data for eosinophils in table 6. lased on 142 cells counted, also indicate that an eosinophil with 5 or more lobes would be rare in the chicken. The Armeth index for eosinophils, 1.97, is lower than for heterophils.

To point up the differences between these two cell types for purposes of identification, tal)le 8 was prepared.

\section{Table 8.-Characteristics of heterophits and eosinophils}

\begin{tabular}{|c|c|}
\hline Characteristic & Hoterophil \\
\hline Cell size. . . . . . . . . . & $\begin{array}{l}I^{\top} \text { sually a relatively small range of variation in } \\
\text { rirenlating bloml lut a large range of variation } \\
\text { in the bone narrow. }\end{array}$ \\
\hline Cyruplasm ........ & 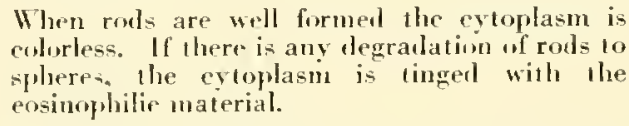 \\
\hline Specifie granules. . . . . & 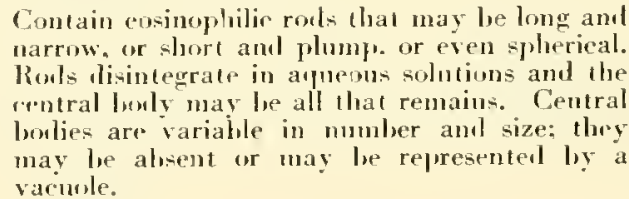 \\
\hline
\end{tabular}

Vinvelear lobesc

Vurlear staining.
The average Innelh index is 2.41 or higher for rhichens.

Wriglut's stain usually fails 10 stain the nucless completely or well.

\section{Eosinophil}

Wide range in size but usually not in the same slicle.

The rytuplasm maintains a pale blue barkground color for the red-staining granules. Only rarely is there an exception to this.

Contain eosinophilir borlies that are nniform in size in the samu cell and usually miformly distributed. Eusinophilic bulies may be liomoaneous spheres or ringa. often with 4 granules in the ring, or scattered separate small granules. Resistant to arufous solntions. In some species the rings may be flattrued and elongated to give the superficial appearance of a rod.

The average Irneth imdex is slightly less than 2.00). Cells with class $I$ nuclei are rare in chickens, if they wist at all.

Wriglats stain shows a strong affinity for the mupleus and brings out the details of Chromatin pation. 


\section{Developmentul stages found in circulating blool (figs. 181-186)}

The low percentage of eosinophils in the differential comt makes it difficult to find developmental stages of eosinophils in the cirenlating blood of normal birds. The youngest olserved thus far is shown in figure 184-a mesomyelocyte in which there are fewer than half the mmmber of granules fouml in the mature stage. The cytoplasm is still strongly basophilic. The range in coloration of the specific gramules is not so great as has heen olsserved in these cells in the bone marrow (fig. 379). The large size of the granules in the metanyelocyte (fig. 185) stands in contrast to the groups of small granules in figure 186. These gramles in figure 185 give the cell an appearance similar to that of the mesomyelocyte stage of the heterophil (fig. 374) and it is possible that this cell has loeen misplaced, especially since small granules are mixed with the large ones. Difference in granule size is a characteristic found in heterophil, lut not in eosinophil. myelocytes. There is no question about the identity of the cell in figure 186; the strongly stained nucleus and the small uniform granulations establish it as an eosinophil.

\section{Abnormal cells}

No cells belonging to this classification have been seen.

\section{Technic artifucts (fig. 187)}

This is an example of a smudged eosinophil. The characteristic of a strong affnity for stain hy the nucleus of the eosinophil, in contrast to the tendency toward defective staining in the heterophil, is still retained in the squashed cells. The scattered contents of the broken cell (fig. 187) demonstrate again that the large eosinophil granule is composed of smaller granular units.

\section{BASOPHILS}

Specific granules for these cells have an affinity for basic dyes and show metachromasia. In chickens this cell is more abmudant than the eosimophil, averaging about 2 percent in a differential count. There is no confusion in terminology for this cell and basophils are homologous through various classes of vertebrates. The only confusion comes in the theoretical relationship between the lJlood hasophil and the tissue mast cell.

Aqueous solutions have a severe detrimental effect here, as they have on heterophils; therefore, all basophils in a dried smear show technic artifacts in varying degrees. This same reaction exists in mammalian cells and has been discussed lyy Michels (1938). Because of this fact, alnormal cells have not been identified.

\section{Normal mature busophils (figs. 188-192)}

Basophils are only slightly smaller than heterophils, as shown in the graph (fig. 197). This slight difference would not be apparent visually. The impression has been gained during the routine examination of many slides that when the technic defects are minimal the cell is relatively small; whereas. when there has been extensive washing out of granules the cell seems larger. Not only is the size of the cell less but even the granules are smaller when they are well preserved. See, for example, figures 389 and 390 , which show hasophils from bone marrow; the cells were fixed in methyl alcohol and stained with thionin in alcohol. Basophils are round, as are the other two granulocyte types, and they are not severely deformed when other cells press against them. Sometimes the cell membrane hecomes irregular in contour owing to the extrusion of particles ( fig. 190).

The cytoplasm of basophils is colorless. Usually it is masked by the granules but when they are washed out there is very little residual color (figs. 191 and 192). More convincing, perhaps, are the small breaks seen between the granules when they have not been severely disturbed (figs. 188 and 189). In the Petrunkevitch No. 2 fixed smear there is a basophilic tinge to the cytoplasm (fig. 221). The spaces between the granules seem larger than normal because the granules are either shrunken or partially dissolved.

The granules in the dried smear are basoplitic and metachromatic; that is, they have an affinity 
for hasic dyes and the resulting color produced in the stained object is different from the color of the dye in solution. Even with a gromp of slides that receive the same treatment, there is considerable variability between hirds in the resistance of the gramules to water. This may in part reflect differences in age of the cells lut it has not been proved that the granules developing in basophil myelocytes are more resistant to water than they are in older cells.

The nucleus of basophits is usually masked by granules, hut occasionally it may be visible as a structureless, pale blue staining body lying in the center of the cell. The penetration of Wright's stain. foumd to be poor in the heterophil nucleus is practically nil in basophils. Sometimes it appears as if chromatin clumps of the muclens were being stained (figs. 190, 191, and 192), but this is due to the basophilic bodies of the cytoplasm that are trapped above or below the nucleus when the cells are flattened in drying. For some reason the messing of the nuclear membrane against the cell membrane protects the gramules to some exient from the action of water. Failure of the nuclens to stain is not evidence of degeneration-when fixed with Petrunkevitch No. 2 , they stain as strongly as any normal nucleus (fig. 221).

Variations in shape of nuclei and number of lobes are seen in figmes 222 and 223. Usually the nucleus is centrally placed and has a round shape. Constricted nuclei may he seen, but only rarely. A nucleus in the condition shown in figure 222 is counted as one lobe: only when the isthmus between is reduced to one or more delirate strands is the miclens regarded as bilobed (fig. 223). A trilobed mucleus has never been observed in a basophil, and from the Arneth rounts on these cells (table 6), the bilobed condition occurs only abont once in one hundred cells.

After one has seen a representative collection of hasophils, this cell type Jecomes the most easily recognized leukocyte of the blood. Yet errors have been made in the literature; Emmel ( 936 ) labeled as "nommal premyelocyte" (his fig. 6E) a cell that is a typical basophil of circulating blood, as nearly as can be determined from his lolack-and-white drawing. This would belp to explain why he found only two basophils in differential counts made on 50 chickens. In normal chickens tested at this Laboratory, these cells run about 2 percent of the differential count, and in pheasants it may be 10 percent (table 20).

\section{Derelopmental stages foumd in circulating blood (fig. 193)}

This is the only immatme hasophil that has been seen in the circulating lolood. It closely resembles in rellular and nuclear detail the heterophil gramuloblast (fig. 168): but resemb) ance is lacking in one respect-the cytoplasm contains numerous magenta gramules. These bodies are equivalent to the granules and rings found in heterophils at this same stage of derelopment. and often the wo cells are hard to separate. Usually the magenta rings of the heterophil are larger than those of the basophil, and in the latter there is less vacuolization of the rytoplasm and the nucleus tends to remain in the center of the cell more frequently than in the heterophil. These points are made evident by a comparison of immature gramulocytes from bone marrow shown in figures $370-372$. 382, and 383. The magenta body in the basophil promyelocyte is not the definitive basophilic granule and is not affected by aqueous solutions.

\section{Techuic arlifacts (figs. 191-196)}

Since aqueous staining methods dissolve the basophilic gramules, every cell illustrated as typical of the normal is, in reality, an example of a technic artifact, and the same can be said for the failure of the mucleus to take the stain. In ardition to these artifacts, squashed cells may be found. Figmes 194-196 show three degrecs of severity. In figure 194 the cell is only slightly squashed: the gramules are separated and they are larger than normal. and the mucleus of the cell shows ear. y autolysis. In figure 195 the cell membrane wall is definitely broken and some of the gramles are scattered. In this particular cell there is considerable variation in the way the gramules take the stain. This, however, may have existed in the cell before it was broken. The granules from the cell shown in figure 196 have been willely scattered and for some reason retain a strong affinity for stain. Obviously, all the factors responsible for dissolution of gramules are not yet fully known. The clefts in the autolysing mucleus are probably the spaces between the blocks of chromatin. 


\section{Hemokonia and Serum Gramules}

Hemokonia, or blood dust (the English equivalent), refers to the cell fragments, debris, and minute horlies floating in the serum. Most of these lie near the limits of microseopic visibility When rell fragments are large they are called plastids, but when small they are called hemokonia.

Little has been written about cell debris. Downey does not have "hemokonia," "hlood dust," or "serum granules" in the index of his 4-volume work on hematology. This is true for some of the atlases on blood. Kracke and Garver (1937) give one paragraph on the subject in which they say (p. 107), "These particles do not stain and their nature is unknown. 'They appear similar in size to the granules in the cytoplasm of gramular leukocytes. This has led to the supposition that they are extruded gramules but no conclusive proof has been given for this identity."

In avian blood occasional small fragments from broken cells may be found. These are chielly heterophil rods or myelocyle rings and granules. Their presence is due to the breaking of cells that oceurs when a smear is made. They appear in practically any smear of bone narrow; and recognizable rods from granulocytes, especially heterophils, can be found here and there over most slides. Since granulocytes are so much more abundant in bone marrow than in circulating blood, it is not surprising that debris of this sort is also more abundant.

What should be included minder the term "hemokonia" has never been well defined; thus it is not possible to decide whether sermm grannles should be included under the term. For the present they are considered to be different from hemokonia. They are found in great abundance in the blood of hirds. Usually they do not take the stain but when they do, they produce a stippled mask over the cells (figs. 72 and
322). Even when they do not stain, they can he seen by reducing the diaphragm of the nijeroscope to increase the apparent refractility. In embryo smears and in lone-marrow and thymus smears of the embryo, they are especially abundant (figs. 329 and 332 ). The typical appearance is shown in figure 322. Among the serum granules of this field are fragments of broken cells also. Most low-power drawings from hematopoietic organs of hoth adults and embryos have heen made withont including the serum granules. Cell identifications cannot be made accurately where the gramules lie on top of the cells in large numbers. As may be seen in figure 322 , the serum itself may take up the stain as well as the gramules in it.

Two other granules should be mentioned-(1) definite yolk gramules fomm when blood is taken from the early embryo at 48 to 72 hours, and (2) chylomicrons. which Gage and Fish (1924) describe. Yolk gramules are larger than serum granules and sometimes a whole yolk sphere is seen. Yolk is not present in adult cirenlating blood.

Whether chylomicrons are present in birds has never been determined. As the term was first used it referred to the submicroscopic spheres found in lacteal drainage from the small intestine of nummals. It las a broader meaning than this and in general refers to lipid splueres found in blood, chyle, or lymph. Dark field is required to see them. It would be interesting and useful to detemine whether chylomicrons of mammals and serum gramules of birds are the same thing. There is considerahle difference in size, the serum gramule being larger.

The sermms of pigeons and chickens are said to contain a lipochrome pigment (Hallihmrton, 1886) that gives to them a color identical with that found in fat cells of these birls.

\section{ADDENDUM}

The irregularity in the shape of erythrocyte nuclei is described in the early part of chapter 2 and is illustrated in figure 29. The cause is not known, but Bessis (1956, fig. 195) photographed similar irregularly shaped nuclei in chickens after treatment with folic acid antagonists. 


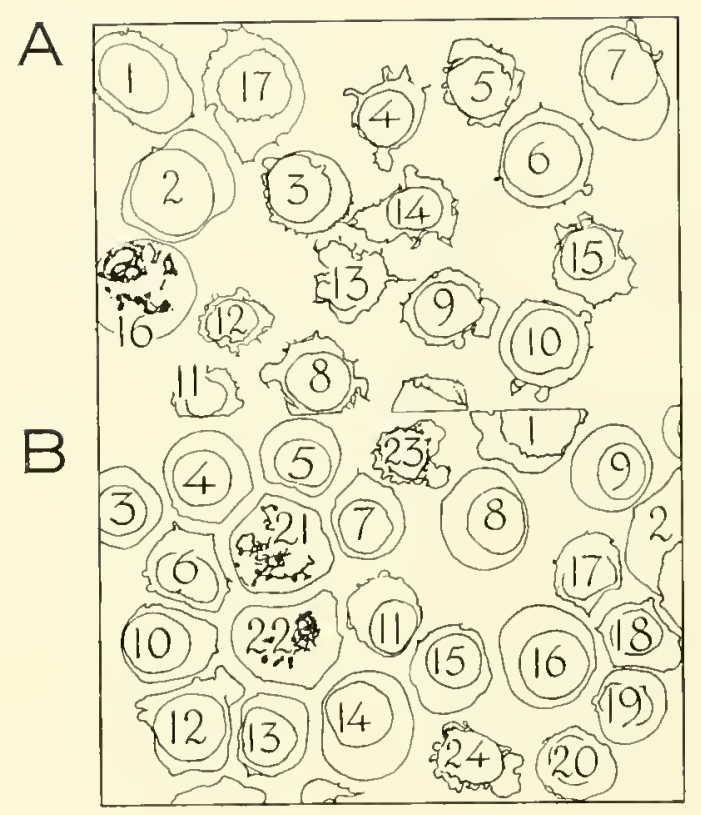

Figure 224.-Blood from dorsal aorta of early chick embryo. 1,370X.

slides of embryo blood stained with May-Grinwald Giemsa.

A Incubation age, 1 day 22 hours.

1-10 Typical early primary ery throblasts with lobulated basophilic eytosome and 1 or 2 nucleoli.

11-15 Small shrunken primary erythroblasts. Frayed and shrunken appearance of sume cells probably due to delay in drying the cells; especially true of 11 and 12 .

16 Primary erythroblast in mitotic division.

17 Slightly smudgel erythroblast.
13 Incubation age, 1 day 23 hours.

1- 2 Large primary erythroblasts, similar to the stage shum in A or younger.

3-20 Late primary erythroblasts of varions sizes from large ( 14 and 16) to small (IS and 19).

2I-22 large primary erythroblasts in mitotic division.

23-24 Small cells with lobulated cytusomes. Probably early embryonic thrombucytes. 


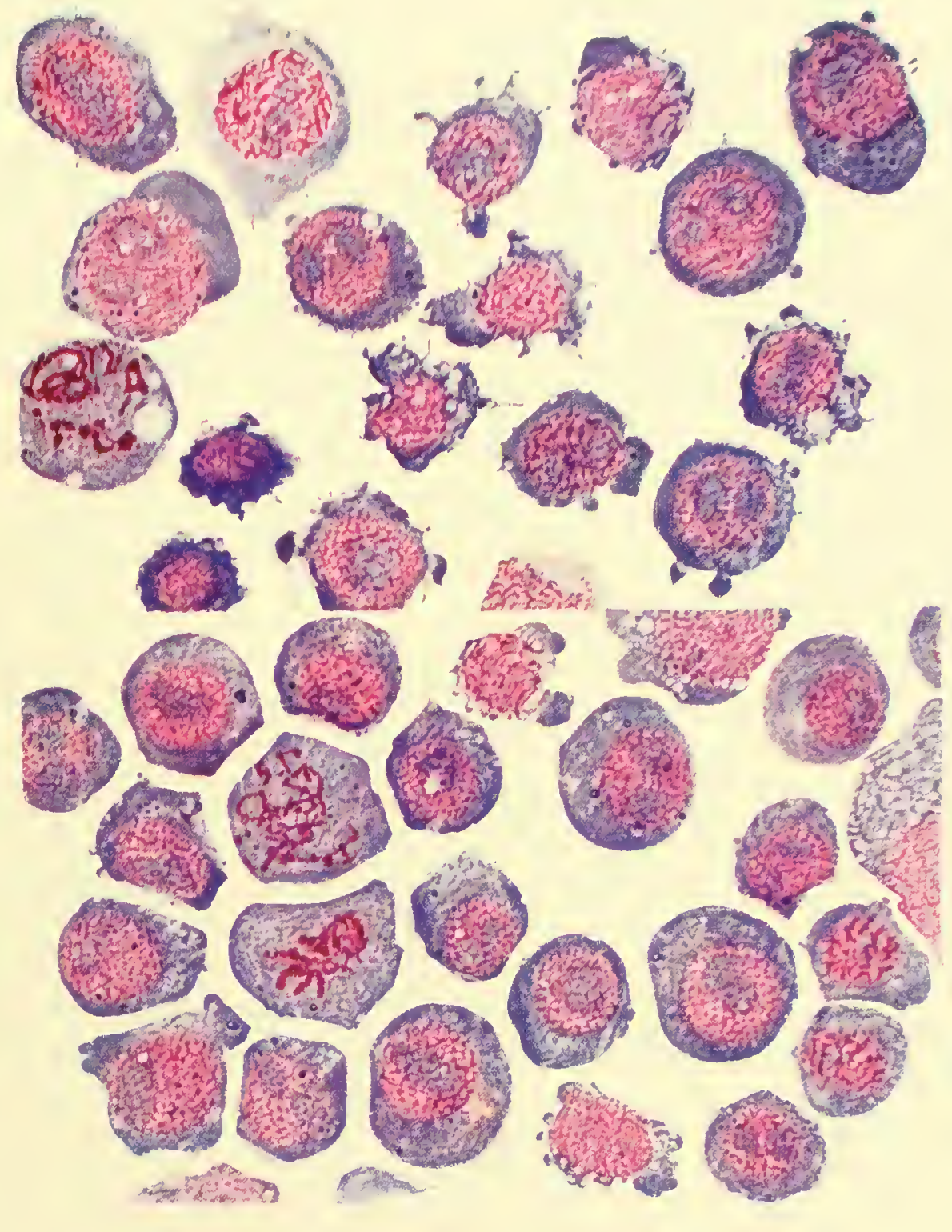




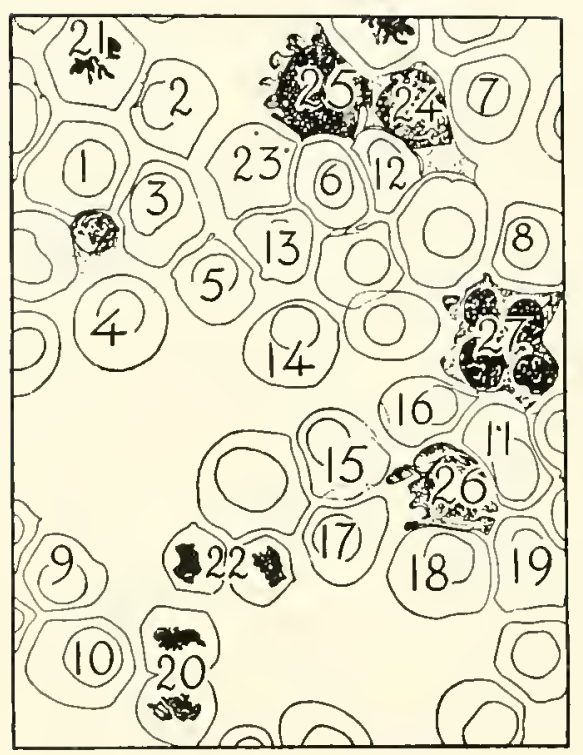

Figure 225.-Blood from dorsal aorta of early chick embryo. Incubation age, 2 days 17 hours. $1,370 \times$.

1-11 Early polychromatic primary erythrocytes.

12-19 Mid-polychromatic primary erythrocytes.

20 Mitotic telephase of early polychromatic primary erythrocyte.

21 Mitotic metaphase of early or mid-polychromatic primary erythrocyte.

22 Mitotic tclephase of early or mid-polychromatic primary erythrocyte.
23 A mid-polychromatic primary erythroplastid.

24 Large embryonic thrombocyte.

25 Embryonic thromboblast.

26 Medium embryonic thrombocyte.

27 A group of 4 small embryonic thrombocytes clumped together but fixed before disintegration set in. 


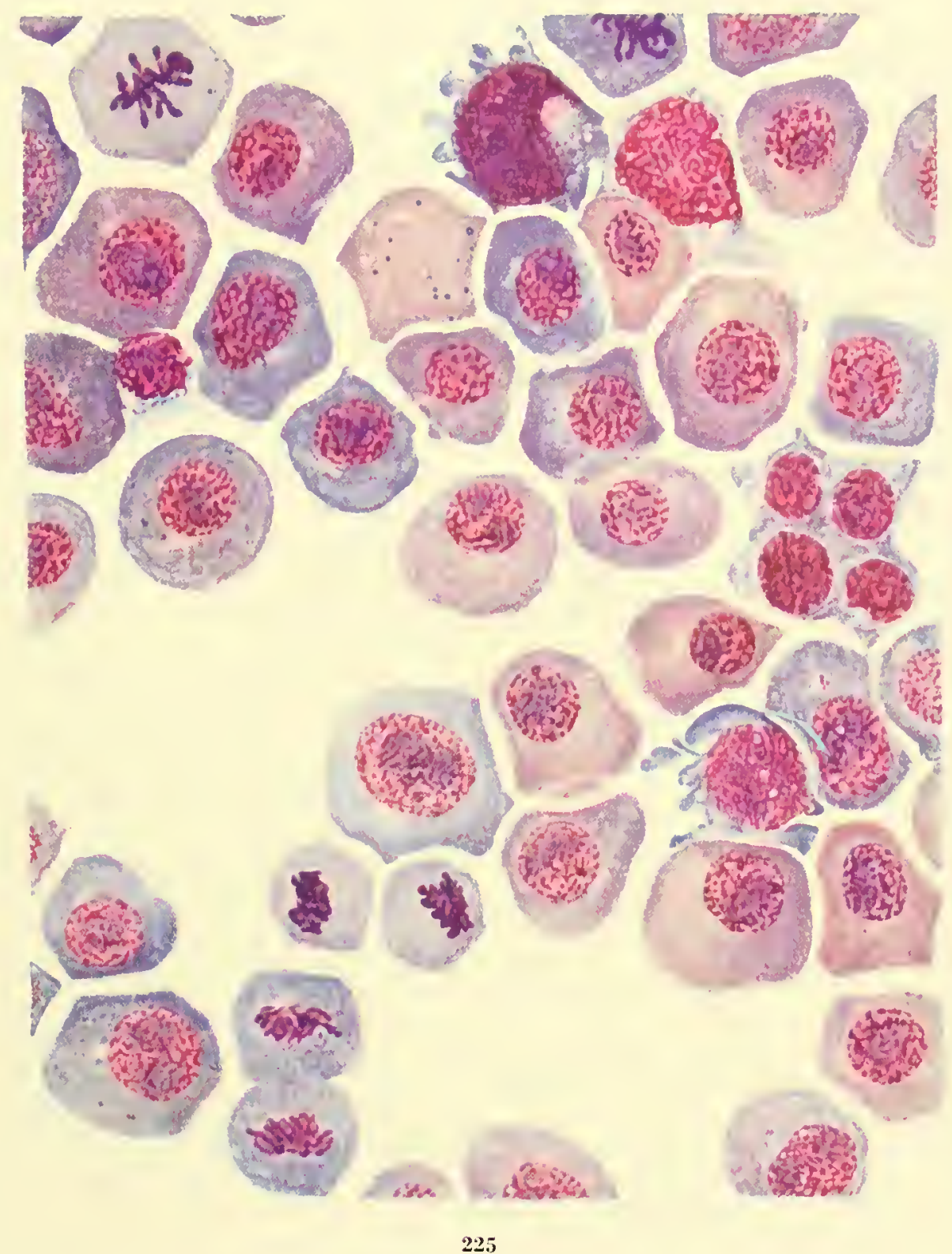




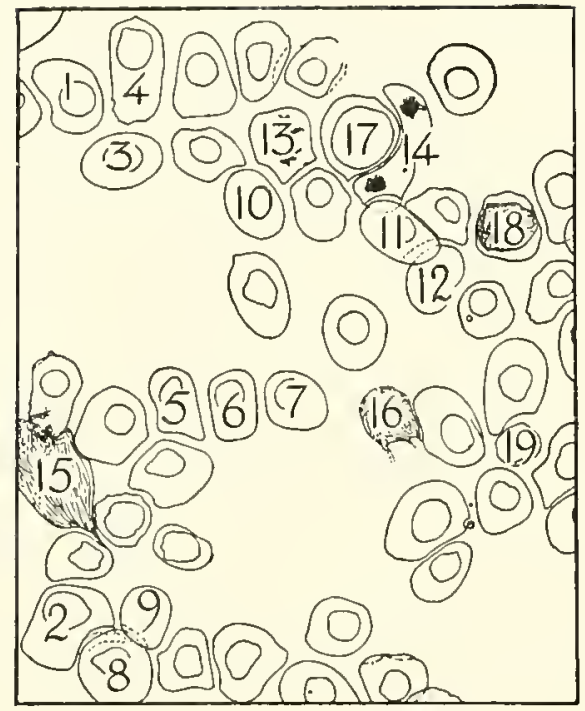

Figure 226.-Blood from heart of chick embryo. Incubation age, 4 days 12 hours. 1,370X.

1-2 Mid-polychromatic primary erythrocytes.

3-9 Late polychromatic primary erythrocytes.

10-12 Late polychromatic erythrocytes showing early stages of eytosomal fracturing, an artifact.

13 Late polychromatic primary erythrocyte near the metaphase stage.
14 Late polychromatic primary erythrocyte in the late telephase stage.

15-16 Smudged primary erythrocytes.

17 An erythroblast of later embryonic generation, or an embryonic thromboblast.

18 A medium embryonic thrombocyte.

19 A small embryonic thrombocyte. 


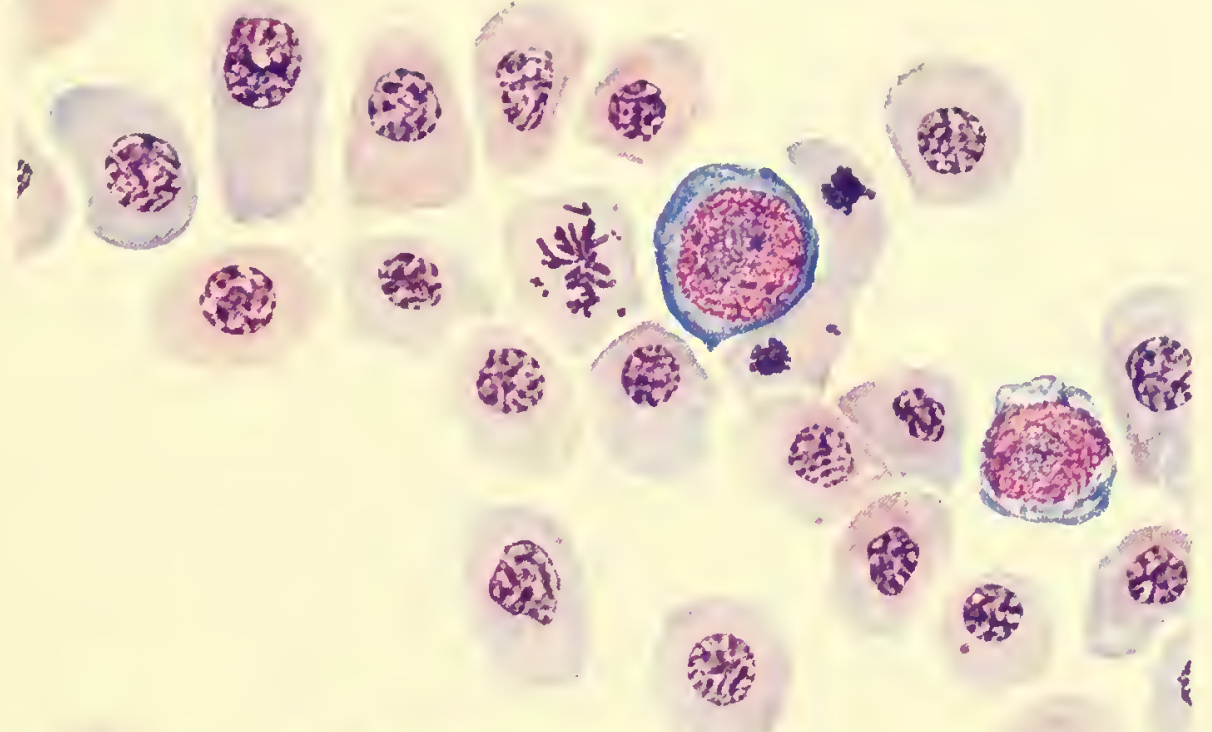

4

as

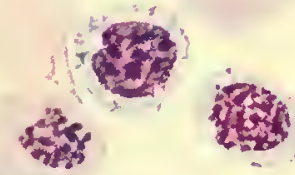

19.

(4)

3.

政

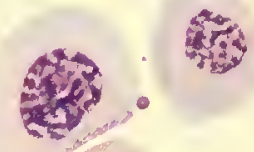

样

3

(69.

226 


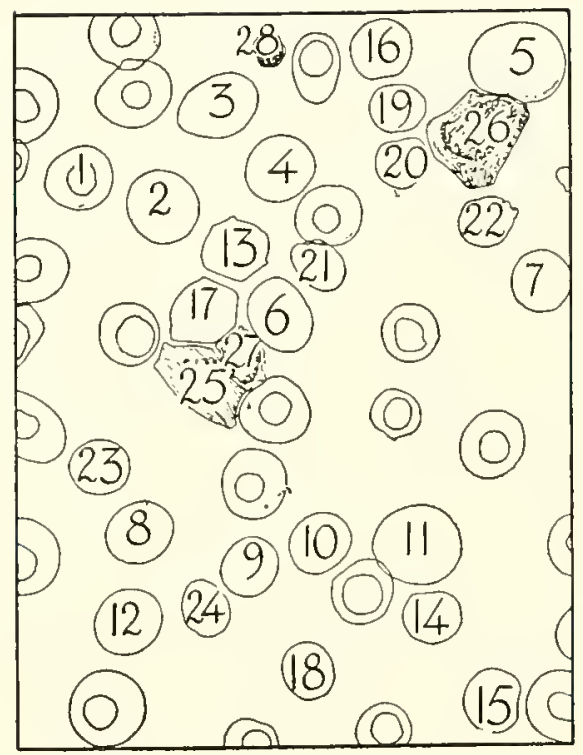

Figure 227.-Blood from heart of chick embryo. Incubation age, 5 days 21 hours. 1,370 $\times$.

1-12 Mature primary erythrocytes ranging in size from large (5) to small (9 and 10).

13-15 Nid-polychromatic ery throcytes of later embryonic red-cell generations.

16-18 Late polyehromatic erythrocytes of later embryonic red-cell generations. Cell $\mathbf{1 7}$ is at the transition between mid- and late polychromatic stages.
19-24 Late polychromatic erythrocytes in which the artifacts of cytosomal fracturing are present.

25 Early polychromatic erythrocyte in mitosis, probably an early anaphase.

26 Erythroblast of later embryonic cell generations.

27 Medium embryonic thrombocyte.

28 Small embryonic thrombocyte. 


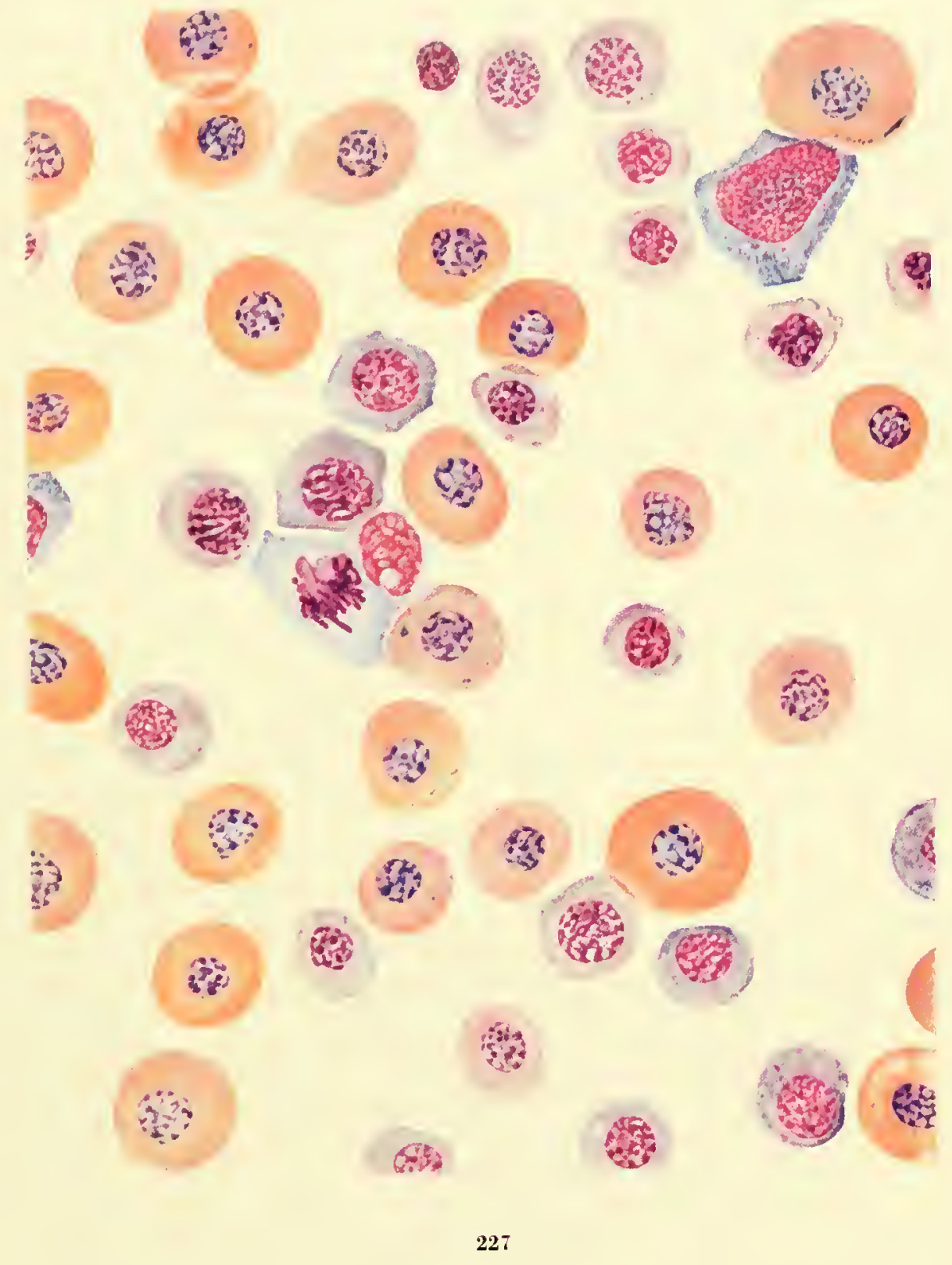




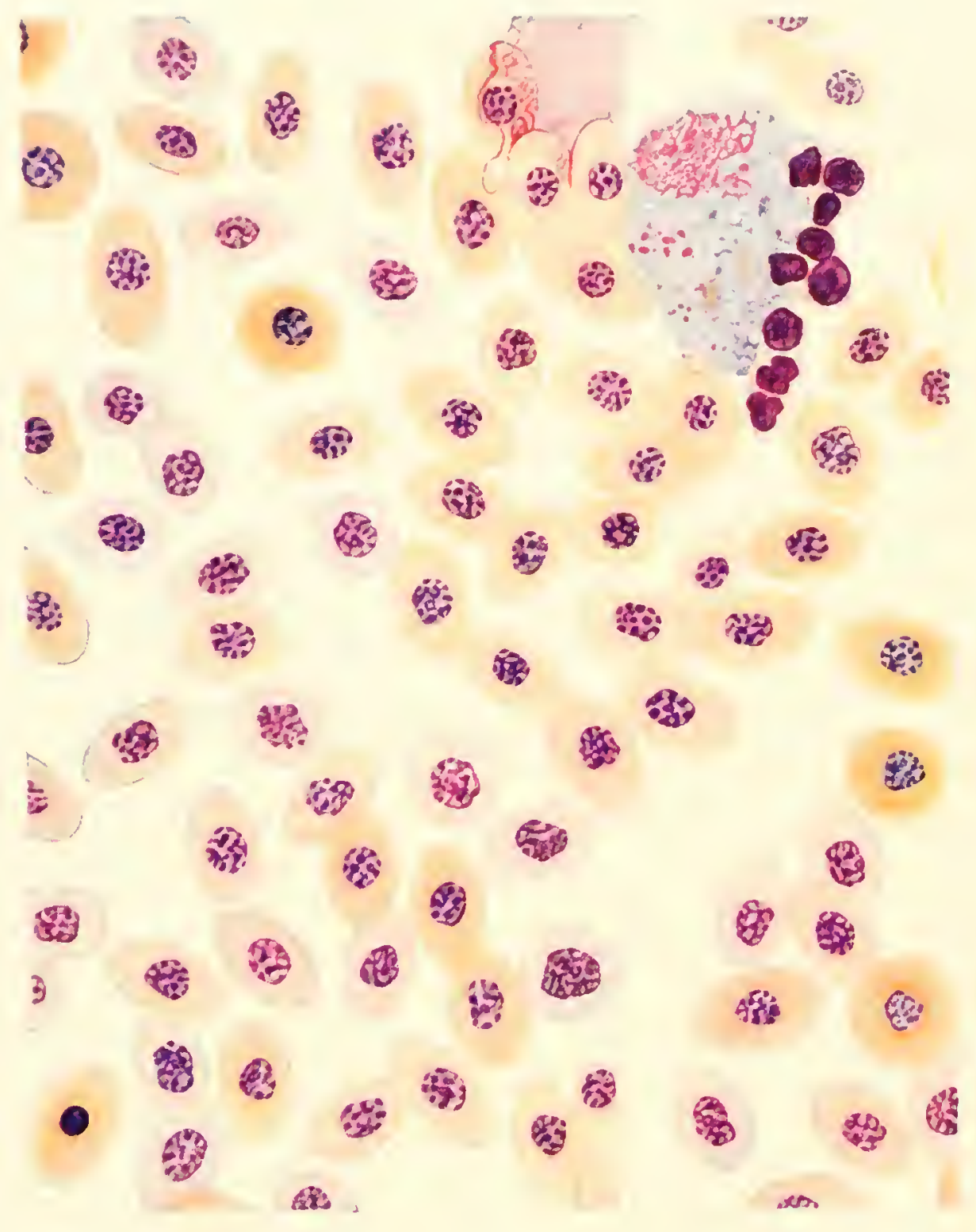




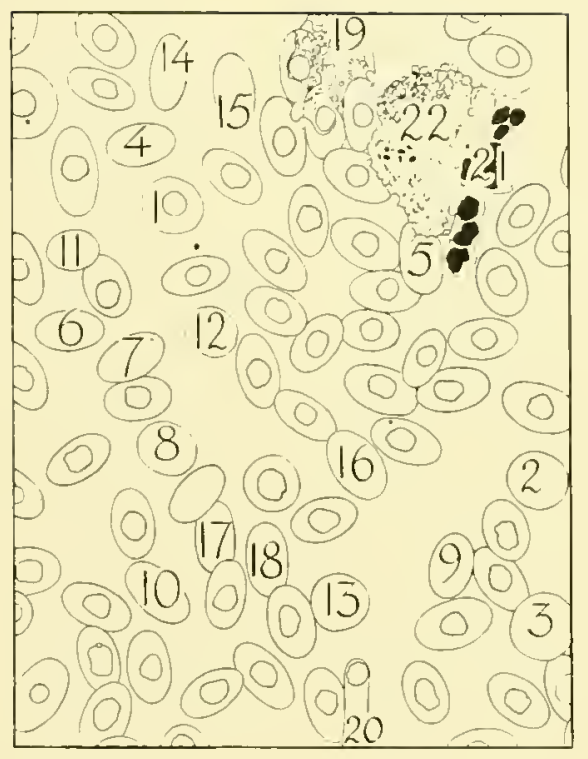

Figure 22S.-Blood from heart of chick embryo. Incubation age, 9 days 15 hours. 1,370X.

1-3 Mlature primary erythrocytes.

4, 6-10 Late polychromatic erythrocytes from later embryonic red-cell generations.

11-13 Late polychromatic erythrocytes in which the artifacts of eytosomal fracturing are present.

5, 1t-18 Mature erythrocytes from later embryonic red-cell generations.
19, 20 Smudged erythrocytes.

21 Small embryonic thrombocytes that have clumped, accompanied by degeneration as shown by loss of cytoplasm and by pyknosis of the nucleus.

2.2 Embryonic macrophage. 


\section{Circulating Blood of the Embryo}

\section{ERYTHROCYTE CHANGES DURING INCUBATION}

Early in the process of blood development, mesenchyme transforms into angioblasts or into primitive erythroblasts. The red blood cellsin the first generation, at least--develop from the walls and within the lumen of the newty formed vessels (Sabin, 1920). This process of development is well under way before the first circulatory arc through the embryo has been completed. As soon as afferent and efferent channels have been joined, the heart pumps through them the cells that previously had accumulated in the yolk sac. This event begius at 33 to 36 hours and is well established by 48 hours incubation, which is the age when the first smears were made in this study. Before this, the development of hemoglobin has caused the blood to take on a red color. In the primary generation of red cells, the hemoghobin is acquired much more rapidly than in the later generations, with the result that, although the cell has a red color as seen with the unaided eye, the stained cytoplasm retains a strong affinity for basophilic dyes. It is this fact that leads to misunderstanding in cell terminology and to error in identification of the stage of development. As successive generations appear this source of error becomes less and less.

Dantschakoff's (1907 and 1908a and b) ob. servations of the early transformation of mesenchyme into blood islands and thence into intra. vascular and extravascular blood elements were based on celloidin-sectioned material. The statements agree closely with those of Sabin (1920) hut the names and interpretations are different. Both authors agree that blood cells can be produced from the endothelium of the blood islands of yolk sac and the dorsal aorta of the early embryo.

Dautschakoff (1907) summarized her basic hematologic theory as follows (p. 166):

"Auf Grund des Erorterten komen wir also eine vollstandige Arralogie zwischen der ersten
Blutbildung ausserhalb und imerhalb des embryonalen Korpers annehem. Die ersten Blutzellen treten hier wie dort zuerst als Lymphozy. ten kleinerer und grosserer Form auf,-diese mussen also als die Stammzellen aller Blutelemente betrachtet werden und erzeugen durch Proliferation und Differenzierung in verschiedenen Richungen die mamnigfaltigen Formen der roten und weissen Blutkorperchen, die wir im erwachsenen Organismus finden." "

Murray (1932) analyzed the observations of Sabin and of Dantschakoff by studying early blood formation in tissue culture. He used parts of the primitive streak of the chick embryo before the head fold developed. From these undifferentiated cells, he obtained cultures that went through all the early stages of blood island formation, with angioblasts enclosed within an endothelial boundary. These earty stages agreed very closely with the olsservations made by Sabin on the living chick. Murray observed in tissue culture all the steps in primary erythrocyte differentiation up to cells that had an oval shape and contained hemoghobin, even up to a fully mature cell. This entire process took place in his cultures within 24 hours.

It has been pointed out by Dantschakoff (1908b and 1909b) that whereas Maximow (1909) fonnd but two generation types in the development of red blood cells in mammalsprimary and definitive--she found that in chickens there was a succession of generations by which the transition from the primary to the definitive type was accomplished. Each generation of cells attained maturity within its life span.

The primary generation of red blood cells in the chick embryo is so conspicuously different

\footnotetext{
${ }^{1}$ Translation: On the basis of the discussion we can assume a complete analogy between the first blood formation outside and inside the embryonal body. The first blood celts in both nlaces first appear as imphocytes of large or smalt size,these must be considered the parent cells of all the blood elements, and through proliferation and differentiation in different directions they make the numerous forms of red and white blood corpuscles such as we find in the mature organism.
} 
from all subsequent generations that the oceurrence of slight differences in these later generations is often overlooked. The existence of a succession of generations brings our terminology into question. In both birds and mammals the term "primary" for the first generation of red cells is satisfactory, but in the chick the cells that follow cannot be called definitive generations since actually it is not until near the end of the embryonic life that the definitive type of red blood cells appears. Probably the term "enbryo erythrocytes" or "embryonic erythrocytes" would more aceurately designate these cells in the chick. In the embryonic span there are numerous generations beginning with the primary, so that first, second, third (and so on) generations could be designated. Actually, the term "generations" in reference to red blood cells is somewhat misleading since the cells are being produced continuously and not periodically. The term is applied in the same sense as it is used for human populations in that one speaks of different generations: whereas, in fact, there is a complete and unbroken frequency distribution in age from youngest to oldest. Even the mitotic periodicity known to exist in adult hirds and mammals is not present in the embryo.

Evidence for the existence of successive generations of red cells following the primary generation is based almost entirely on the appearance of the mature cell, the shade and hue of the cytoplasm, the shape of the nucleus and cell, the nucleocytoplasmic ratio, and the tendency of the nuclens to become dense and pyknotic. Realization that there are successive generations is one thing, but saying that a particular cell belongs to a particular generation-such as the third or fifth-is another. It has not heen possible to say this. Moreover, it has not been possible to say for sure how many generations there are during embryonic life. We know that there are more than 2 , and the total is probably about 4 .

Embryonic erythroeyte generations can be fol. lowed quite well in Amblystoma. Cameron (1941) demonstrated that cells of the first generation contained 128 yolk plates and each sueceeding generation held half the number contained in the parent cell from which it arose by division. After eight generations the yolk plates were reduced to one per cell and then the plates degenerated. At the time of hatehing, definitive erythrocytes appeared that lacked yolk plates.
The early generations of embryonic erythrocytes retained round forms, whereas later generations took on elliptical forms. Yolk plates are absent from avian embryonic erythrocytes but the possibility exists that the pattern of reproduction in amphibians may be carried over to some extent in birds.

Figure 232 was prepared so as to show the succession of forms. For the sake of simplicity, the embryonic erythrocytes have been divided into only two groups - the primary generation and sueceeding generations. Under the age baseline the hours given are 3 less than the actual duration of the egg in the incubator. This period of time was estimated to be required for the egg to become warm and for developmental processes to get under way. All embryonic ages given in captions or text are estimated on this basis. Incubation age is given either in hours or in days and hours. Table 9 has been included because it is useful in converting from one kind of time scale to the other.

Dawson (1936a) made a similar statistical and eytological study on the shift of erythroeyte stages during embryonic development. His table 1 should be compared with our figure 232 , and his photographs of smears from embryos that ranged between the age of 4 days of incuba. tion and hatching age should be compared with figures 226-230, which cover essentially the same range. Under each group of erythrocytes, whether primary or later generations. there are five subdivisions-erythroblasts; early, mid-, and late polychromatic erythrocytes; and mature erythrocytes. The data included in the differential counts included all these stages but the only stages seleeted for illustration in figure 232 were those that during embryonic life became dominant cells. Each curve was plotted as a hand-drawn average from a large number of differential counts made from closely spaced ages. Sometimes, among the differential counts for a particular cell type at a particular age, the range of variability would run almost 100 percent, but in other cases all the values would he close'y clustered.

The first samples of blood were taken from the dorsal aorta of 46- and 47-hour embryos. The technic employed for obtaining intraembryonic blood at this early age is given in chapter 7 . Low-power drawings from such embryos are shown in figure 224, $A$ and $B$. Although these 


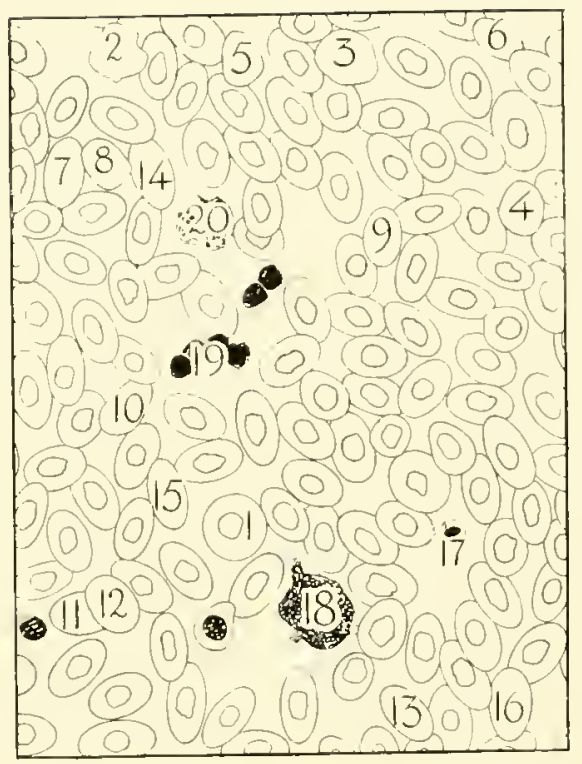

Figure 229.-Blood from heart of chick embryo. Incubation age, 13 days 16 hours. 1,370.

1 Mature primary erythrocyte.

2-4 Mid-polychromatic erythrocytes, all of which show artifacts of cytosonal fracturing.

5-13 Late polychromatic erythroeytes; some show artifacts of eytosomal fracturing. Two cells, 7 and 13 , are nearly mature.

14-16 Mature erythrocytes.

\section{Microcyte.}

18 Erythroblast or thromboblast.

19 Small embryonic thrombocytes that have clumped and disintegrated the eytoplasm.

20 Basophil mesomyelocyte. The presence of any granulocyte in the circulating blood of the embryo is rare. 
3

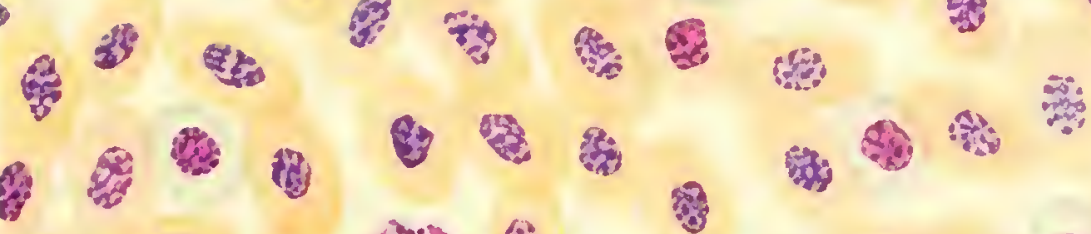

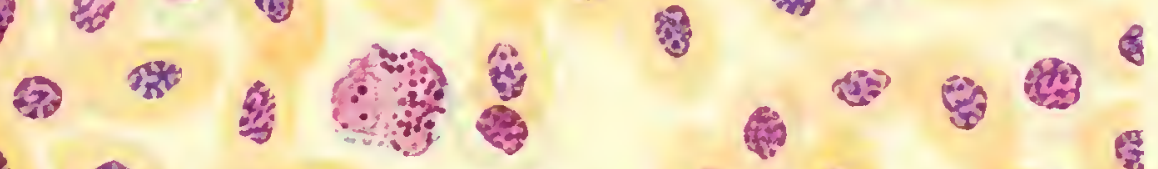
-

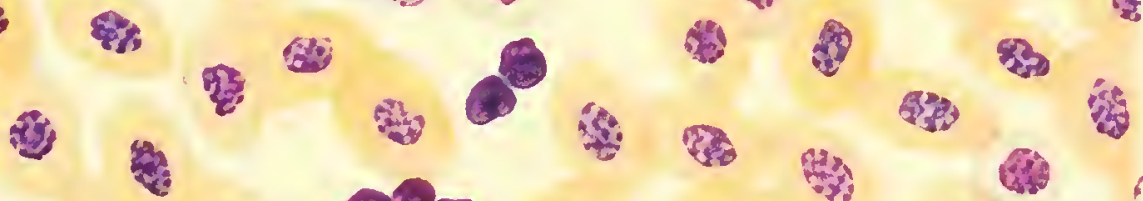

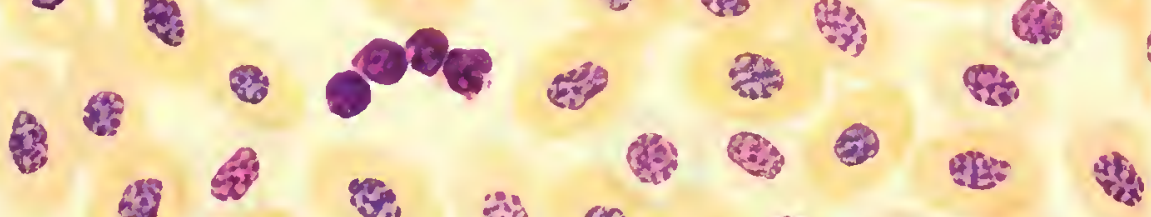

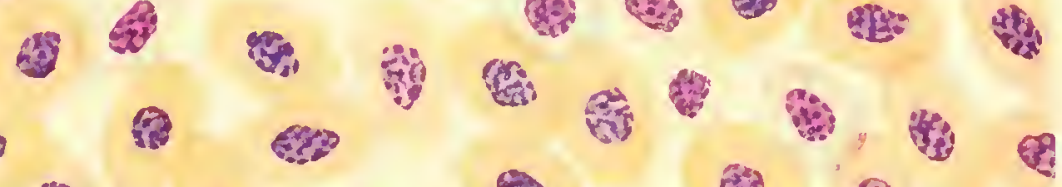
6 管

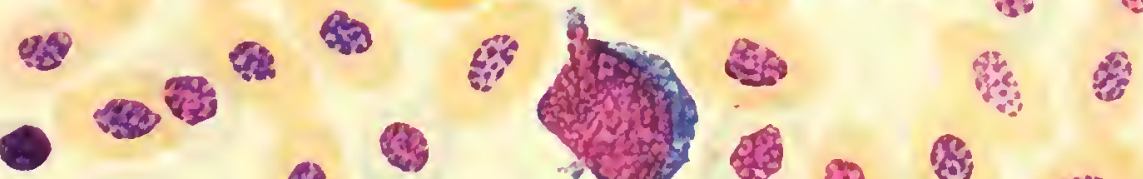
- 5 (1)

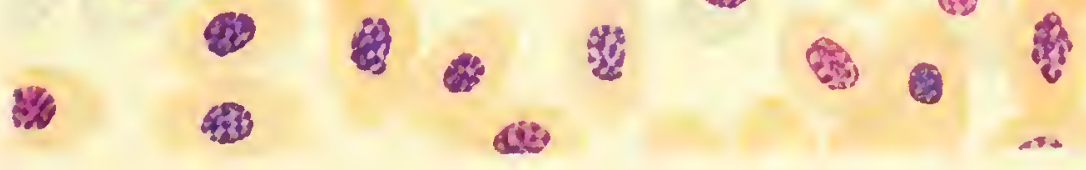




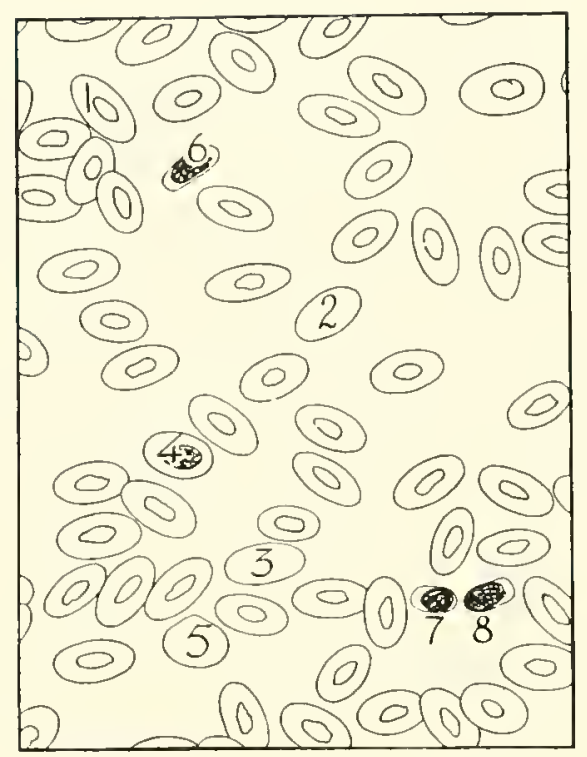

Frgure 230.-Cireulating blood taken from basilic (cubital) vein of the chick about 4 hours after hatching. $1,370 \times$.

1-3 Mature erythrocytes.

6-8 Mature thrombocytes of varying size and shape.

4, 5 Late polychromatic erythrocytes. 


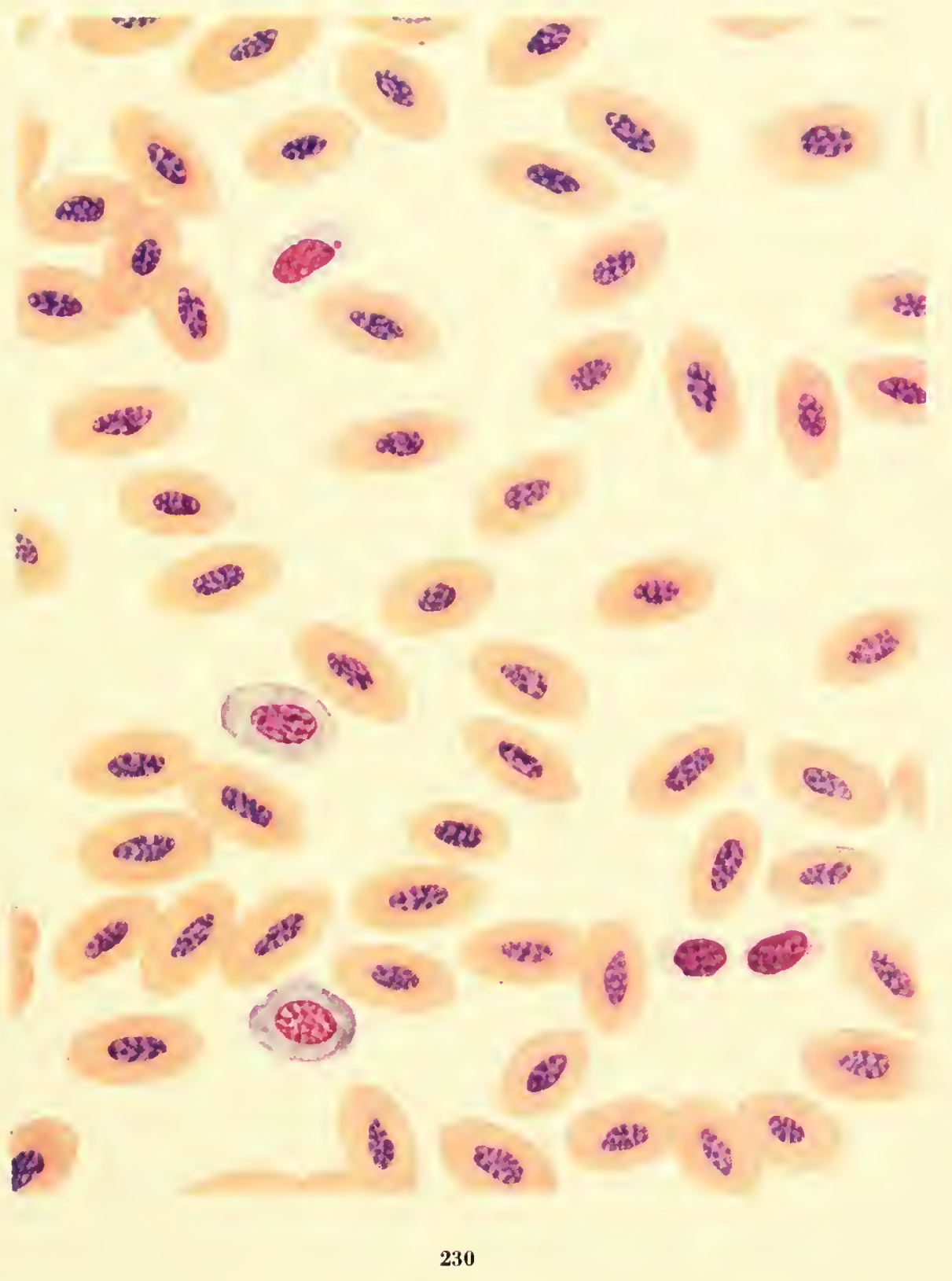




\section{1.}

6 的

4.

愛

\section{政}

(3)

8

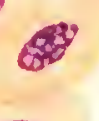

(1)

(4)

20

6ii 궁

解

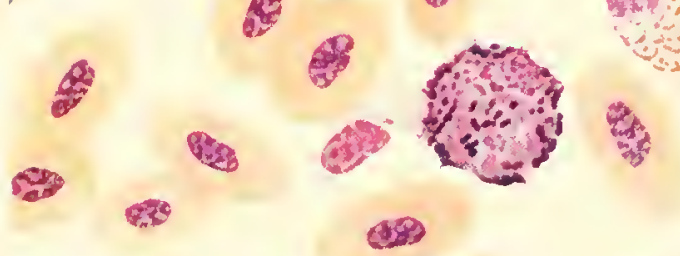

罗

종

5

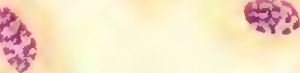

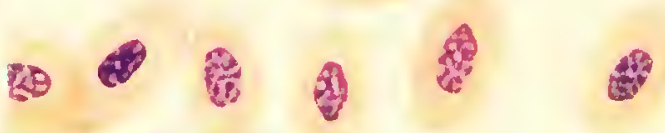

12

(동

(2)

20

S

2.

3

要

慈

1.

(2)

(6)

6

ब㞔

-

2

a 


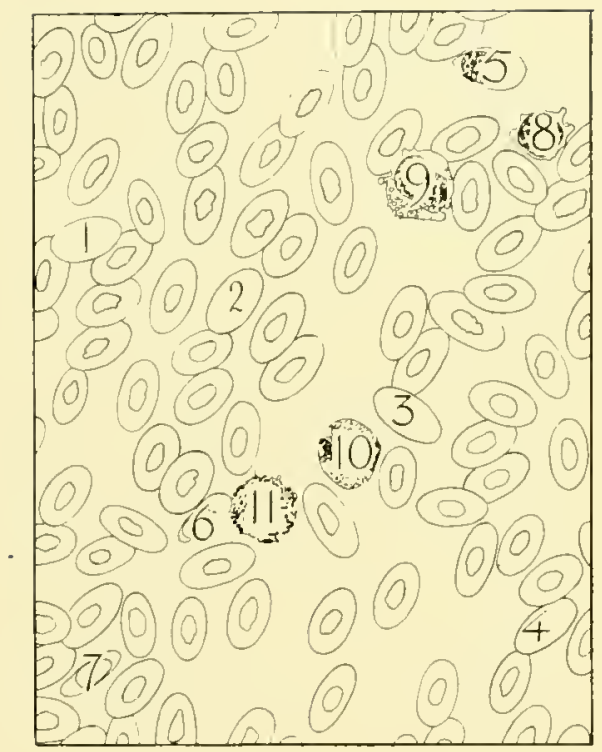

Figure 231.-Blood from basilic (cubital) vein of a 7 -day-old chick. $1,370 \times$.

A region was selecter for drawing that had more than the average number of lenkocytes for this number of erythrocytes.

1-t Mature erythrocytes.

5. Slightly immature thrombocyte.
6, 7 Mature thrombocyte.

8 Mature lymphocyte.

9 Mature monocyte.

10 Nature heterophil.

11 Mature basoplil. 
Table 9.-Time table-chick incubation

\begin{tabular}{|c|c|c|c|c|c|}
\hline Total hours & Days & Hour: & Total homrs & Days & llours \\
\hline 6. & 0 & 6 & 258. & 10 & 18 \\
\hline 12. & 1) & 12 & 261 & II & 0 \\
\hline 18. & 0 & 18 & 270. & 11 & 6 \\
\hline $24 \ldots \ldots$ & 1 & 0 & 276. & II & 12 \\
\hline $30 \ldots \ldots$ & l & 6 & 282. & 11 & 18 \\
\hline $36 .$. & 1 & 12 & $288 \ldots$ & 12 & 0 \\
\hline $42 \ldots$ & l & 18 & $291 \ldots$ & 12 & 6 \\
\hline $18 \ldots \ldots$ & 2 & 0 & $300 \ldots \ldots$ & 12 & 12 \\
\hline $51 \ldots \ldots$ & 2 & 6 & $306 \ldots \ldots$ & 12 & 18 \\
\hline $60 \ldots$ & 2 & 12 & $312 \ldots \ldots$ & 13 & 0 \\
\hline $66 .$. & 2 & 18 & $318 \ldots \ldots$ & 13 & 6 \\
\hline $72 \ldots$ & 3 & 0 & $324 \ldots \ldots$ & 13 & 12 \\
\hline $78 \ldots \ldots$ & 3 & 6 & $330 \ldots \ldots$ & 13 & 18 \\
\hline $84 \ldots$ & 3 & 12 & $336 \ldots \ldots$ & 14 & 0 \\
\hline $90 \ldots$ & 3 & 18 & $312 \ldots \ldots$ & 11 & 6 \\
\hline $96 \ldots$ & 1. & 0 & $318 \ldots$ & 11. & 12 \\
\hline 102. & 1 & 6 & $351 \ldots \ldots \ldots$ & 11 & 18 \\
\hline $108 \ldots \ldots \ldots$ & 1 & 12 & $360 \ldots \ldots$ & 15 & 0 \\
\hline $111 \ldots \ldots$ & I & 18 & $366 \ldots \ldots$ & 15 & 6 \\
\hline $120 \ldots$ & 5 & 0 & $372 \ldots \ldots$ & 15 & 12 \\
\hline 126. & 5 & 6 & $378 \ldots \ldots \ldots$ & 15 & 18 \\
\hline $132 \ldots \ldots$ & 5 & 12 & $381 \ldots \ldots$ & 16 & 0 \\
\hline $138 \ldots \ldots$ & 5 & 18 & $390 \ldots \ldots$ & 16 & 6 \\
\hline 144.. & 6 & 0 & $396 \ldots \ldots$ & 16 & 12 \\
\hline $150 \ldots$ & 6 & 6 & $402 \ldots$ & 16 & 18 \\
\hline $156 \ldots$. & 6 & 12 & $408, \ldots \ldots$ & 17 & 0 \\
\hline $162 \ldots$ & 6 & 18 & $411 \ldots \ldots$ & 17 & 6 \\
\hline 168. & 7 & 0 & 420. & 17 & 12 \\
\hline 174. & 7 & 6 & $126 \ldots$ & 17 & 18 \\
\hline 180. & 7 & 12 & $432 \ldots$ & 18 & 0 \\
\hline $186 \ldots$ & 7 & 18 & $138 \ldots$ & 18 & 6 \\
\hline 192. & 8 & 0 & $\$ 11 \ldots$. & 18 & 12 \\
\hline $198 \ldots$ & 8 & 6 & $450 \ldots$ & 18 & 18 \\
\hline $201 \ldots$ & 8 & 12 & $456 \ldots$ & 14) & 0 \\
\hline $210 \ldots$ & 8 & 18 & 462. & 19 & 6 \\
\hline $216 \ldots$ & 9 & 0 & 468. & 19 & 12 \\
\hline 222. & 9 & 6 & $474 \ldots$ & 19 & 18 \\
\hline 228. & 9 & 12 & $480 \ldots$ & 20 & 0 \\
\hline $234 \ldots$ & 9) & 13 & $486 \ldots$ & 20) & 6 \\
\hline 210. & 10 & 0 & $492 \ldots$ & 20 & 12 \\
\hline 216. & 10 & 6 & $498 \ldots$ & 20 & 13 \\
\hline 252. & 10 & 12 & $504 \ldots$ & 21 & (1) \\
\hline
\end{tabular}

cells are known to carry hemoglol,in, they fill the requirements of an erythroblast in that they have a strongly basophilic cytoplasm and contain nucleoli. At this age practically all cells show an almost identical stage of development, and yet there is a wide range of size as a result of cell division.

A digression for discussion of the implications of these facts may be desirable. Sabin (1920) has shown that the first erythoblasts appeared even before 24 hours of incubation. She also indicated that new erythroblasts contimuously de. veloped from their stem colls and that while this was taking place there was a rapid multiplication of cells that had already hegun differentiation. This information might lead to the conjecture that, at a later time, when these cells were thrown into the circulation, there would be a wide range of developmental stages present. Instead, one actually finds a remarkable degree of uniformity in the level of differentiation. Therefore, it is suggested that antecedent to the completion of the embryonic and yolk sac circulatory ares the ery. throblasts lie dormant within the vitelline channels and that cytoplasmic and nuclear differentiation is inhibited, although mitosis continues at a rapid rate. Only one phase of differentiation is taking place - that in which the synthesis of hemoglobin is involved-but the nuclear and cytoplasmic changes that ordinarily accompany this process are lacking in these cells. Once circulation is established and the cells begin to move with the flowing blood that has now created a new environment, differentiation proceeds, and about a day and a half later (at 65 to 69 houl's, fig. 225) the erythroblasts are transformed into the early, mid-, and late polychromatic erythrocytes of the primary generation. At 48 hours practically all the cells are erythroblasts, but at 65 hours only a few erythroblasts are present, and after that they disappear from the circulating blood. From this time on there is an everincreasing tendency for immature stages of erythrocyte development to be retained at the loci of their origin.

Apparently blood cells in themselves are not fully erpuipped to bring about their complete differentiation but something is added while they are being circulated that enhances differentiation. Moreover, as development of the embryo proceeds it is no longer necessary for the immature cells to enter the circulation in order to receive the chemical stimulus that is to be found there. It is no longer necessary because the circulating blood is brought into intimate contact with the areas where the cells are being produced and thus more and more of the immature stages are almost completely differentiated before being released into the circulation. (See Gordon, 1959.)

It is obvious that the suggestions made need the support of additional evidence obtained from experimentation. The effort required to sort ont the fartors involved in stimulating differen. tiation would be justified since it is apparent that the same problems of differentiation that have heen solved by the embryo are unsolved in cases of lenkemia. The cells seen in lenkemia of birds and mammals often closely resemble those of fignre 224 and may have the large size and con- 
spicuous nucleoli of figure 251. It is generally believed that some change has taken place in the cell metabolism that prevents the normal process of differentiation. The great mass of data on the cytology and propagation of leukemic and other neoplastic cells amply substantiates the idea that an intracellular change can and does occur; but this does not exclude the presence in the plasma of a "differentiating" factor, and the sequence of events observed in embryonic blood before and after circulation is established suggests that such a factor does exist. Whether such a factor is sufficiently potent to force the differentiation of a leukemic cell to the point where it performs the equivalent function of the normal cell is, of course, unknown.

Dantschakoff (1909a) made an interesting observation on erythropoiesis. The phenomenon she saw is undoubtedly an expression of the difference between intravascular and extravascular environment. In the early chick embryo, primary erythroblasts are being rapidly prodnced both inside and outside the vessels of the vitelline membrane and of the embryo. In both environments, differentiation to the extent of taking up hemoglobin is started but only inside the ves- sels does the process go to completion. The cells of the primary erythrocyte series in the mesenchyme tissue outside the vessels are destroyed, either by disintegration or by phagocytosis.

Let 11 return to a description of the changing picture of the circulating blood. The rapid shift between 48 and 65 hours has already been indicated. The mid-polychromatic primary erythrocytes are present at a higher percentage level at 65 hours than are the early polychromatic erythrocytes and, with variations, remain high after the latter have declined to a low level. The maximum reached in the differential counts was 71 percent at 93 hours. There is an irregular decline in mid-polychromatic primary erythrocytes at 97 to 120 hours, and there is a tapering off at 120 to 142 hours. Late primary polychromatic erythrocytes are present only in small numbers at 65 honirs, and the number increases gradually until it reaches a peak at about 120 hours (fig. 226). Beyond that age there is a rather rapid dininution in number for this stage of development and by 160 hours (fig. 227) all have disappeared. It is not until after 100 hours that the primary generation of erythrocytes

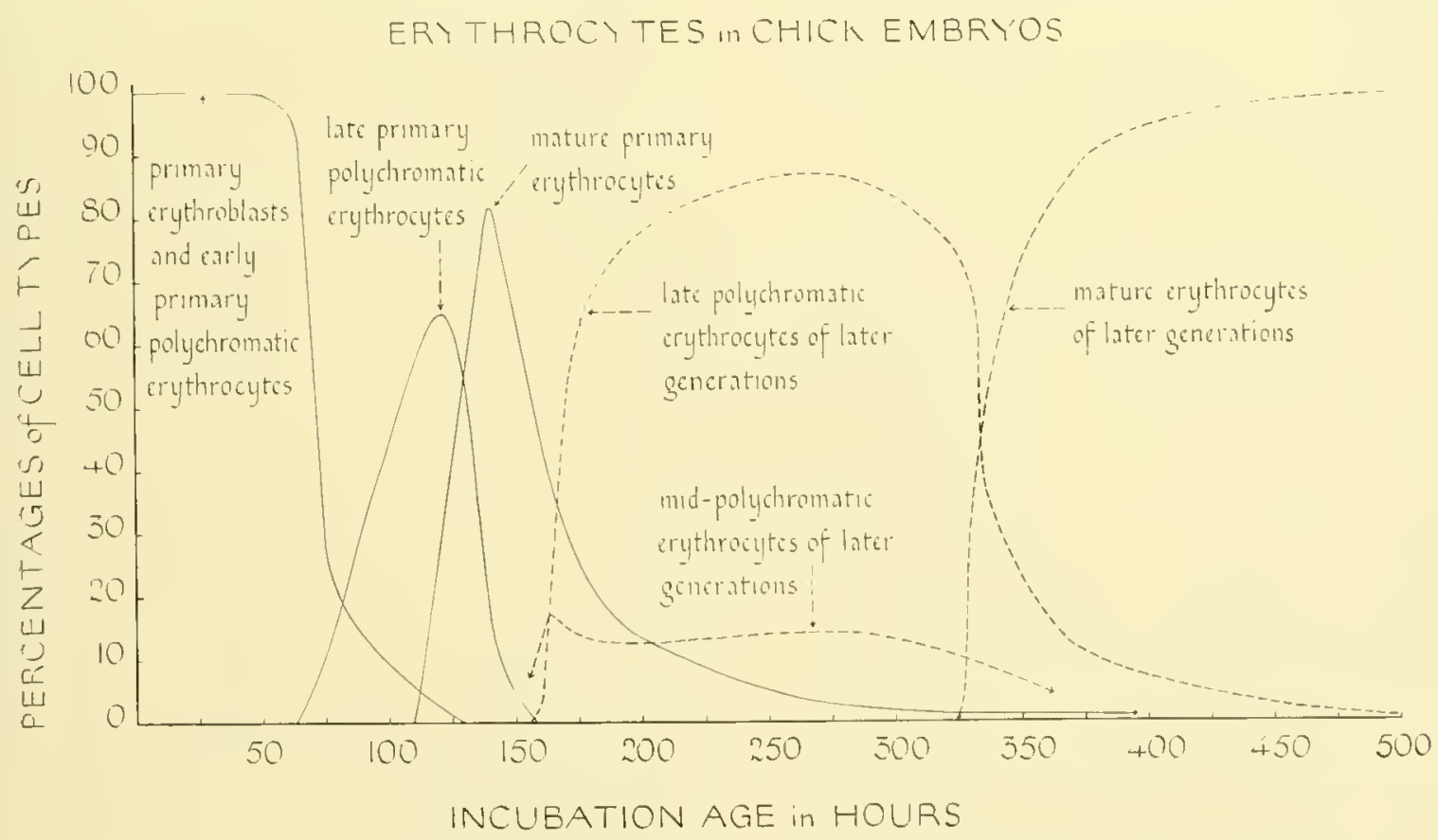

Figulie 232.-Curres showing the percentage rise and fall of three stages of maturity in the primaly and hater cmbryo erythrocytes. Solid lineprimary erythroeyte. Dotter line-combined later generations of embryo erythrocytes. 
reaches maturity; then they differentiate rapidly to become dominant cells at 140 to 142 hours; from that time on these cells may be found in the circulating blood in considerable numbers up to 16 days of inculation. Occasionally they have been seen after hatching.

The tabulation shom in figure 232 gives us some information ahout the processes of intravascular differentiation, but the picture of decline is always masked by the rise of the next higher stage of development. Undoubtedly much of the apparent decline in mature primary erythro. cytes is dne to the increase in the proportion of sulseyuent generations since the data for these curves have been collected as percentage values. A study is defmitely needed in which the absolute number of each cell type is obtained, as Kindred (1940) has done with the rat. Then the true picture of the rise and decline of cell types can be visualized: in addition. rate of differentiation and the true life span of the cells during embryonic life will be known.

Following the primary generation there is a succession of generations-secondary, tertiary, and others. Since it is practically impossible to separate them except in the fully differentiated cell, and then only in a general way, all genera. tions after the first have been grouped together. Graphically this produces long Jow curves instead of a succession of sharp peatis.

Erythroblasts with nucleoli and hasophilic cytoplasm are picked up occasionally at between 141 and 214 hours (fig. 227). They may be scen even later but would not constitute a significant percentage in a differential connt. Early polychromatic erythrocytes are never alumdant; between 160 and 243 hours they vary from 0 to 11 percent, and occasionally cells may be found up thongh the second week of emliryonic life. Most of the cells of these two slages are retained at the site of origin in the yolk sac. Differentiation processes within the circulating blood are limited largely to development from the mid. polychromatic erythrocyte on to the mature form.

The percentage of mid-polychromatic erythrocytes of the later generations never reaches a ligh level-38 percent at 160 hours is the maximum in our data. The talular data from which the graphs of figure 232 were constructed suggested that there was a sharp rise in percentage level at about 160 hours, followed by a sharp decline that does not continue downward hecanse the later embryo generations of mid-polychromatic erythrocytes continne to be present at a low but fairly constant level until about 285 hours of incubation and then drop off gradually.

The frequency distribution curve for the late polychromatic erythrocytes of later embryo generations does not show a sharp peak. Late poly. chromatic erythrocytes are present in the blood at a high level throughout the period from 212 to 312 hours, after which they decline rapidly at first but later continue to be present at a lower percentage level. The course for these cells trails out up to the time of hatching. They are still present in variable numbers after hatching and practically any slide, even from older birds, will always show a few.

Mature late embryo erythrocytes do not appear until after 210 hours. Later they rise rapidly and from about 375 hours until hatching maintain a high level in the blood. On about the 16 h day of incubation, they constitute about 90 percent of the cells present. On the day liefore hatching close to 100 percent of the erythrocytes present belong to this stage of development and this, of course, is the condition that continues after hatching (fig. 230).

No one, to our knowledge. has as yet attempted to prepare a table of hematologic values for the chick embryo at various ages. The data presented by Flemister and Cumningham (1940) are at least a hegimning. They found that in the allantoic circulation at 8 days incubation there were $1,210,000$ erythrocytes $/ \mathrm{mm}^{3}$, and at 10 days, 1,880,000. The hemogloluin at 8 days was 9.3 grams $/ 100 \mathrm{cc}$. and at 10 days, it was 14.7 . Their percentage valnes for the types of leukocyles listed are such as to indicate that they did not identify the nonhemoglobin containing cells the same way we have in this study.

Data for each day of the last week of inculation were given by Roberts, Severens and Card (1939). They presented erythrocyte, total white cell, heterophil, and lymphocyte comnts for two lines of chicks. Up to the time of hatching, 75 to 96 percent of the white cells were heterophils. The total white cell counts were generally helow 10,000 per rubic millimeter from the 15 th throngh the 19 th day of incubation. On the 20th day the count reached ahout $11.000 \mathrm{and}$ on the 21 st day alout 16,000 cells. It has been our impression that heterophils were not such a constant comstituent of embryo l, lood. and that 
lymphocytes appeared only sporadically in the circulating blood. even uj through hatching.

It is apparent that additional studies on the number of cellular elements in the rirculating blood of the embryo are needed to give us a more firmly established baseline.

\section{DESCRIPTION OF THE CELLS}

A great deal can loe learned concerning bloodcell hineage and morphogenesis from a study of the circulating hlood in embryos at various ages. When this is supplemented by studies on hematopoietic tissues, spleen, bone marrow, and thymus, a failly complete picture can be olstained of the interrelationship of cells. Without this background the various circulating hlood and hematopoictic tissues of the adult fall into nmmerous unrelated series of cells.

\section{Primary erythrocytes}

Satisfactory preparation of the primary erythrocytes at 2 days incubation requires careful attention to terhnic. Most of the early smears gave shrunken cells that carried numerous protoplasmic proceses around their periphery. They looked like cells A. 11-15, of figure 224 but unost of them were worse. Any contamination of the pipette with saline userl to float the embryo or with allumen or yolk would produce this effect, and if there was any detay in getting the cells on the slide. spreading them out into a thin layer, and drying them, they would be greatly distorted.

At all early incubation stages. satisfactory preparation was found to dejend greatly on speed in making the smears. With a few refmements in technic, blood could be taken from the dorsal aorta of the embryo as soon as circulation hegins, or it could be taken from vitelline ves. sels without contaminating it with other fluids.

A considerable difference in degree of differentiation exists between $A$ and $B$ of figure 224; yet there is only 1 hour of difference in incubation age. It is suspected that the develojment of the embryo represented by $A$ was retarked. Practically all the cells at this age, according to the terminology of Doan, Cuminglam, and Sabin
(1925), are megaloblasts and are destined to produce erythrocytes.

The structure of the early primary erythroblast is shown in cells $1-10$ of figure $224 \mathrm{~A}$. Probally the least differentiated cell is 2. whirh has a cytoplasm of uniform texture quite different from that of the other cells. This cell was added to the drawing from another part of the same slide, as were also 5, $11-14$, and 77 . Consideration of the significance of ilis cell is helped by looking ahead to figure 225. Within less than 24 hours of additional ineubation these will have differentialed in the blood into two distinct cell lines-the dominant primary erythrocytes and the embryo thrombocytes. The latter are said to come from the same precursor cells as the ervthrocyles. Therefore, it is quite possible that these are early embryonie thrombohlasts. Harl Ralph's benzidine technic been applied (p. 231). the point in question could have been settled easily; with this technic the cytoplasm of primary erythrocyte cells gives a positive yellow color when hemoghobin is present. while the cytoplasm of the thrombocytes is negative. The appearance of the cell differs also from that of the early primary erythohlast shown in figure 233. The latler has a cytosome filled with mitochondrial spaces ${ }^{2}$ surroumderl by granular cytoplasm that has a type of texture charactristic of primary erythroblasts. The primary erythroblasts in which this texture is foumd include those undergoing mitos is (fig. 224. A 16. B 21. and 22.

In the cytosome of the primary erythroblast are three types of spherical bodies. One of these is probahly an artifact. It appears in the cells of figure $224 A$ as clear spherical spares. The spaces may be small as in 2 and 5 or large as in 15 and 16 . Although they appear to lie within the nucleus this is an artifact. A vacmole or other

\footnotetext{
"Takagi (1931) showed that rod and filamentous nitochondria are present in the blood cell of the yolk sac of the early embryo. but he was not coneerned with the sperific problem of the identity of mitochondria with cytoplasmic spars. fones (1947), who was interented in the structure of primitive erythrohlask, concluded that (p. 317):

-Light areas in basophilic cytoplasm previously described as hyaloplasin or paraplasm represent, for the most part, the negative images of unilerlying mitorhontria."

${ }^{3}$ Takagi (1932) studied the distribution of chondrinsomes in diviling blowel cellh. He need the yolk sar of chick embryos and made his observations on material sectioned in paraffin At the mitapliase the chondriosomes were grouped around the poles of the diviling cell: none were located either in or on the spindle. During anaphase and telophase, they moved towart the region of the constricting cell walls.
} 
body that has considerable rigidity will push up through the substance of the nucleus when the cell is flattened, even though it is formed in the cytosome. With the nuclear substance displaced, the vacuole appears to be within the nucleus. An additional hasis for suggesting that these granules are artifacts is the fact that they tend to ocem most abundantly in cells that are most distorted $(A, 13,15$, and $B .23)$.

The second type of racuole is a highly refractory one. In the drawings each such vacuole is indicated by a blue ring (figs. 224 and 225). The number within a cell varies widely from none to as many as are seen in figure 225,23 , but three seems to be an average number. Only a few are present in the cells of figure $224 \mathcal{A}$, and by 69 hours incubation (fig. 225) they have practically disappeared; but these vacnoles are typical for the cells of figure $224 B$. The nature of the sul). stance they contain, their function, and their specificity are unknown. Microchemical studies, or the tracing of their conrse of appearance and disappearance with the phase microscope in living cells, might he revealing.

The third type of vacuole is small and round, is not refractile, bas a tinge of color, and tends to form clusters. At the stage represented by figure $224 . A$ they are best shown in cell 1 . hut in $B$ numerous cells show these bodies $(4,5,8$, and 12-14). When they first appear, they are seattered hut as they increase in nnmber they form a group of spheres. By 6.5 hours inculation the individual bodies of these chusters have coalesced and are responsible for the light area in the cytoplasm adjacent to the nucleus. Dantschakoff (1908b and 1909a) observed in her sectioned material the prescnce of an orange-stained area beside the muclens of the early erythrocyte found in the yolk sac. Similar orange-staining spheres were illustrated and described by Maximow (1909) in his study of early formation of blood cells in the mammalian embryo. The whole. process of differentiation of primary erythroblasts from mesenchyme has been described by Murray (1932). He used tissue culture preparations of the primitive streak of the chick embryo. It was observed that the immature primitive erythrocytes were rather small cells with psendopodia and with nuclei which contained one or two mucleoli. The cytoplasm was strongly basophilic and contained one or more eosinophilic masses adjacent to the nu- cleus. From such cells as these arose the later stages in the differcntiation process. The orange-stained area may well have consisted of vacuoles of this type. If additional study should prove that the vacuoles seen heside the nucleus both in sectioned material and in dried smears are the same, this would offer an excellent cell organelle that could be used as a common basis for identifying the same cell under two different technics. Dantschakoff (1908h) observed that the light-staining spheres contained centrosomes.

None of the three types of vacuoles or spheres observed in the cytosome of the primary generation of erythroblasts werc observed in the cytosome of later generations. This difference between the first and subsequent generations is in agreement with observations by Dantschakoff (1908b) on sectioned material.

Since none of these types of spheres have been observed in later generations of erythroblasts in smears, it might be possible to establish whether later generations are similar to the cells (megaloblasts) ${ }^{4}$ of the primary generation and to the megaloblasts of anemia-a question that has been ably discussed by Jones (1943). This author has pointed ont that there are differences in nuclear cytology anong primary and normal defunitive megaloblasts and megaloblasts of anemia.

Studies by the smear method show that such differences certainly do exist in the primary and normal definitive erythroblasts of the chicken. As an example of this difference, the muclens of the primary erythroblast generally contains two nucleoli. No other blood cell included in this study has been observed to have this number of nucleoli. The chromatin reticular pattern is somewhat coarser in primary erythroblasts than in the cells of a corresponding degree of differentiation in later embryonic generations. The nucleoli seem to be more prominent in the first generation than in later ones but this is probably due entirely to physical causes associated with the coarseness of the screen which permits a better view of the interior of the nucleus than can be obtained when looking through the fine screen that is characteristic of later generations of erythroblasts.

Differences in size among primary erythroblasts have not been specifically mentioned thus far. The differences may be seen by glancing

"Erythroblasts" and "megaloblasts" are used as synonymous terms. 
at figures 224, 233, and 234, which were selected to show range in size and in nucleocytoplasmic ratio. Mitotic figures are alundant at this age, as shown by cell 16 in figure $224 A$ and cells 21 and 22 of $B$. For persons seeking a large tough cell suitable for the study of the avian chromosomes, the writers know of no better material, although they have not examined the neurol, last that has been used so frequently. In smears fixed in Petrunkevitch No. 2 and stained with May-Grünwald Giemsa it has been possible to count about 60 chromosomes and it is likely that some of the problems in this field could be solved with technics selected specifically for cytogenetic studies.

There is perhaps one word of caution to he given. Cytologic evidence indicates that the prime function of this generation of erythrocytes is to form hemoglolin. This is accomplished independently of the differentiation stages that usually accompany this process. As a result, mitosis is often abnormal, and frequently chromosomes lag behind in the anaphase stage. The abnormalities observed at mitosis in the primary generation of erythrocytes are similar to those reported on mitosis in neoplastic cells. Almormally large size often occurs in neoplastic cells and an occasional giant cell may he found among primary erythroblasts (fig. 251). ${ }^{5}$ Such mitotic abnormalities and giant cells probably mean little or nothing toward the production of later blood neoplasias in the bird but since some em. bryonic cells have certain points in common with neoplastic cells, the possibility always exists that a residual, dormant cell of this type, if not destroyed. could later be stimulated to reproduce itself. Most primary erythroeytes degenerate along conventional lines, as seen in figures 249 , 250,252 , and 253.

Hemoglobin development proceeds very rapidly and by 65 hours inculation (fig. 225) has reached the early and mid-polychromatic stages. This terminology is based on the tinctorial quality of the cytosome and not on nuclear or cytoplasmic differentiation. On the lrasis of criteria

\footnotetext{
${ }^{5}$ Dawson (1933a) observed that giant atypical erythrocyles were produced in Necturus in the regeneration process that followed a destruction of normal erythrocytes by lead poisoning. The occurrence of gigantism in mammalian erythropoiesis has been reviewed by Berman (1947). It may express itself as a largc uninucleated cell, as shown here for the chicken, or as a giant multinucleated cell. The latter may undergo multipolar nitoses and Berman is of the opinion that some of these may return to normal, uninuclear celle.
}

usually applied to the human species, these cells would still be called erythroblasts, since the term "polychromatic" is applied to cells after the normoblast stage has passed, but for the bird, the usage followed here seems to give maximum uniformity of nomenclature for comparative purposes with other species having nucleated red cells. These terms-early, mid., and late-refer to the blue, gray, and orange phases of color. As previously indicated, the blue represents a predominant strona of luasophilic material. The gray stage appears gray because there is a mixture of two opposite colors-blue and orange - and as more of the original basophilic stroma is lost, there is no longer a balance and the orange color predominates. In later generations of cells this transition is a period of cytosomal weakness, and artifacts readily appear in polychromatic erythrocytes. In the first generation, however, the transition is so rapid that the cytosome does not develop a weakened condition; hence artifacts are not commonly seen (fig. 225). Artifacts appear in some cells after they have reached the late polychromatic stage (fig. 226). Erythrocytes at 65 hours inculation hare taken on spherical shapes but they may be pressed into angular shapes when the smear is made, and there may be overlapping of cells that produces clear bands and crescents in the cytosome ( $f_{\text {ig. }}$ 225, 15 with 17).

The eytosome is closely packed with mitochondrial spaces that have undergone a cliange from the rods of the carlier stage to innmmerable small gramules that give to the cytosome a texturial quality, and would be inaccurate if a homogeneous wash of color were applied to the drawings of these cells.

A peculiarity of these cells is the presence of a seemingly ectoplasmic mantle around the periphery of some cells (figs. 225. 4. and 235). the significance of which is monkown. Illustrations of immature human red cells from various sonrces have not shown anything similar to it. This leads one to suspect that it may possihly be an artifact associated with the large size of the avian cell. A tendency toward the same type of reaction is shown in some of the cells of frgure 226 but this reaction does not reappear in any of the later generations, nor do smaller cells of the same age (fig. 236) show the marginal rim.

At this age (about 65 hours) the mucleoli. usually two in number, are even more distinct than 
in the cells shown in the preceding plate. The greater distinctness is due to the contraction of the chromatin network into larger but more widely spaced clumps. Mitotic figures are still abundant. and in cells 20 and 22 of figme 225 it is evident that division reduces the size of the cell to half of the original volume. Undoubt. edly cell growth ocenrs during the interkinetic period hut average size decreases as the rells get older (compare figs. 225 and 227).

A statistival study on the percentage of mitosis present in the early embryo has been prepared by Dawson (1936a), who says (p. 262). "In the blood stream there is little restriction of mitotic capacity in the differentiating primitive line until the mature stage is reached."

Two types of cells are distinetly visible at 6.5 lours. One is the primary erythrocyte line, and the other is the embryo thrombocyte line. The cytology of the latter will be discussed after the description of the red cell has been completed. After 4 days incubation little cliange is visille in the primary erythrocyte except additional hemoglobin accumnlation. a greater range in size, and a sharper distinction hetween red-cell and thromhocyte lines. The elaracteristic intensity of cylosomal hue is shown in figures 238-240 and ranges from early to late polychromatic. A comparison of fignres 238 and 239 brings ont an interesling point-the latter is a small cell with a small, densely stained muclens and indications of eytoplasmic differentiation, yet the hemoglobin content is low in comparison with that of figure 238, which is not so well differentiated cytologically.

The primary erythroblasts at 65 to 93 hours of inculation shown in figures 235, 236, and 238 may reveal a faint tinge of eosin coloration but in some preparations made at this age the cytoplasm may take a completely basophilic coloration. The henzidine test $(\mathrm{p} .231)$ reveals that, nevertheless, hemoglohin is present (fig. 237). Thus this test demonstrates that basophilic coloration of the cytoplasm does not prechute the existence of hemogholin and it is for this reason that the stage of erythrocyte development called basophil erythroblast has been omitted from the series of erythrocyte stages presented in table 2 .

Hemoglobin is present in erythroblasts of embryos incubated 48 hours, although the cytoplasm is fully basophilic. No benzidine tests were made at this age, but the blood flowing through the vessels of the embryo and area vasculosa is clearly red.

Additional hours of development prodnce defmite changes, which are seen in fignre 226 and in figures 241 and 242. where the cytoplasm has lost nearly all of its mitochondrial spaces and the periunclear, vacuolar space characteristic of earlier stages, is nearly gone. Most of the cells

Fugres 233-243. - Stages in the differentiation of primary erythoeytes selected to show variations in size and structure. $2,470 \times$.

Firunes 233, 234: Primary crythroblast from dorsal aorta of an rmbryo incubated 1 day 22 hours. Same slible as figure 221 .

233 Early primary "rythroblast. Large nucleohs fills upper half of nucleus.

234 Prinary reythroblast. Lobulations are few and smalt.

Figures 235-237: Primary erythrocytes from embryo incubated 2 days $1 \%$ hours.

235 Jate primary trythroblast. Same slide as figure 225. Rounded cytusome. The effects of an ectoplasmic mantl. is characteristic of cells of this size and degres of differentiation.

236 Small early polychromatic erythrocyte. From same slide is preceding figure.

237 Late primary erythohlast. Ralph's benzidine methorl and M. G. G. P'resenee of hemoglobin in eytosone indicated hy yellow color. Cell equivalent to figure 235 - taken from same rmbryo.
Figted 23s, 239: Cells from an cmbryo incubated $s$ days 21 hours.

238 Mict-polychromatic primary erythrocyte, Still shows a refractite granule and mitochondrial spaces characteristic of crythroblasts.

239 Early polychromatic primary erythrocytu. Less hemoglobin than preceding cell hut further differentiation.

210 Late polychromatic primary erythrocyte in mitcsis. Polar view of what is apparenty metaplase. Embryo incubated 1 days.

Figtress 241, 242: Late polychromatic primary crythrocytes from an cmbryo incubated 5 days 3 hours.

211 Average size.

242 sinall size.

213 Late polychromatic primary erythrocyte. Larger than average, almost a mature cell. From same slide as figure 227 

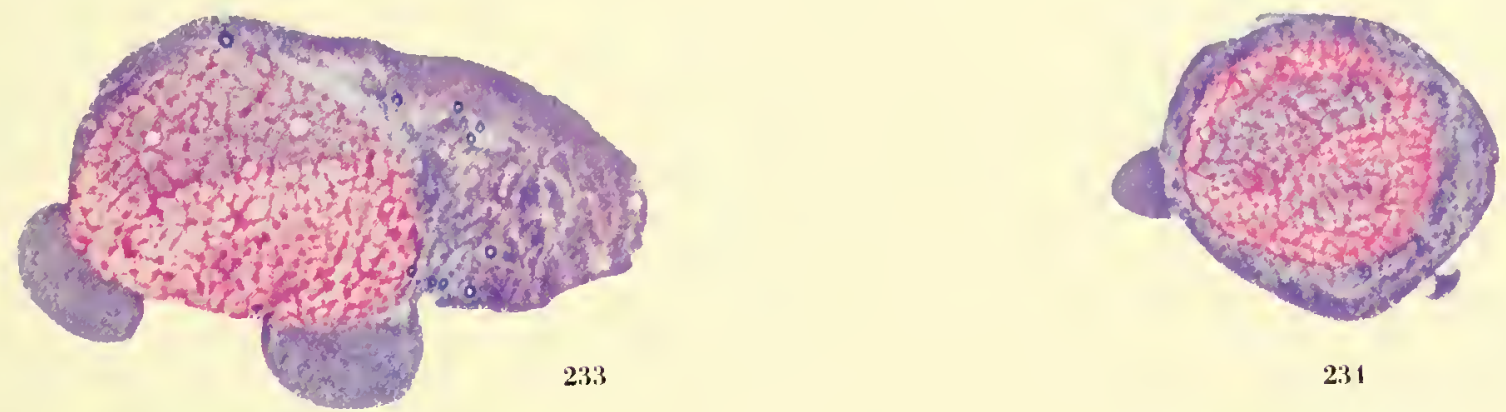

231

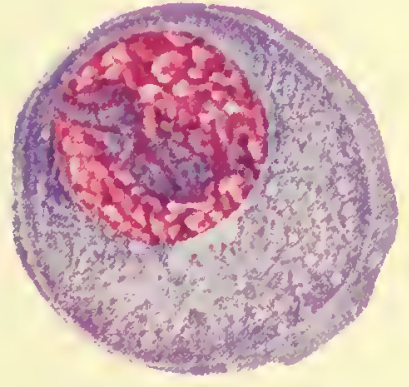

235

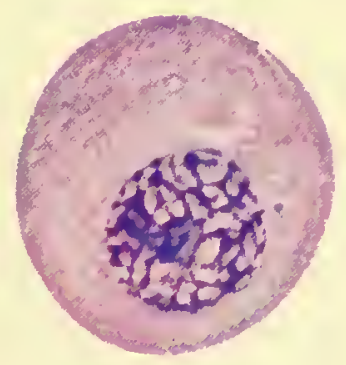

238

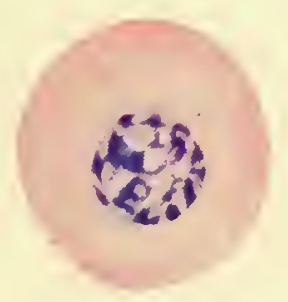

241

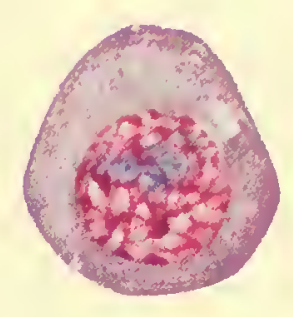

236

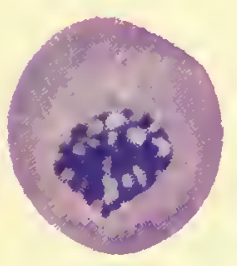

239

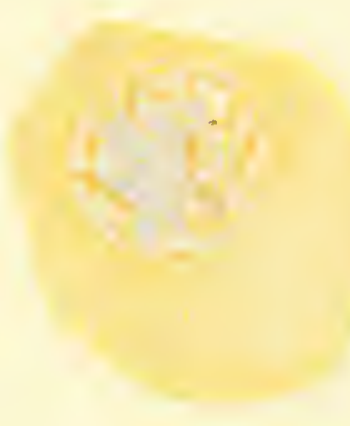

237
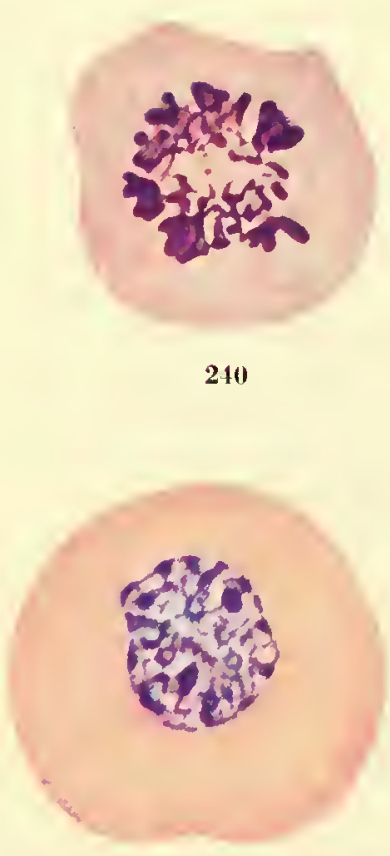

243 


\section{Figures 244-253.-Primary erythrocytes-mature and abnormal. 2,470.}

FirUREs 24t-248: Mature primary erythrocyles.

24t, 245 Same slide. Embryo incubated fi days 22 hours. The second cell has taken on a shightly oval shape.

246 A rare example of constricted eytosome as well as nucleus, characteristic of amitosis. Embryo incubated 9 days 14 hours.

247 The primary erythroeytes are distinguished from later generations of $\mathrm{re}^{2} \mathrm{l}$ cells by the more intense coloration of the ertoplasm. Enbryo incubated 8 days 21 hours.

248 A primary erythrocyte in which an oval shape las developed. Embryo ineubated 11 days 1 hotr.

Figures 249-253: Abnormal primary erythrocytes.

249 A primary erythroplastid with a body of chromatin material still remaining. Embryo in- cubated 13 days 15 hours. Nany examples of degenerating primary erythrocytes are found in olcler embryos.

250 Poor stainability of the nucleus is characteristic of aging primary erythrocytes. Embryo incubated 15 days 23 hours.

251 A giant late polychromatic erythrocyte-very rare. Nuclear ehromatin less dense than normal, thereby revealing elearly the nucleolus. Found in same slide from which figure 240 was taken.

252 Karyorrhexis of nucleus in a primary erythroblast or an early polychromatic erythrocyte, observed rather regularly at young ages. Embryo incubated 2 days 18 hours.

253 Polynuelear primary erythrocyte. Cell shows evidence of aging and decadence. Embryo incubated 9 days 14 hours. 


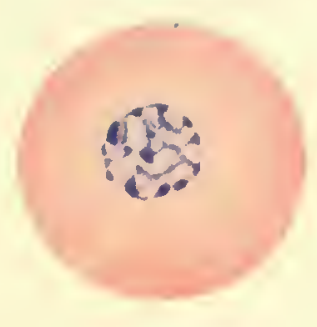

211

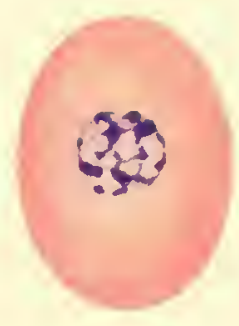

21.5

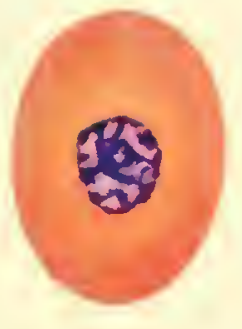

248
219
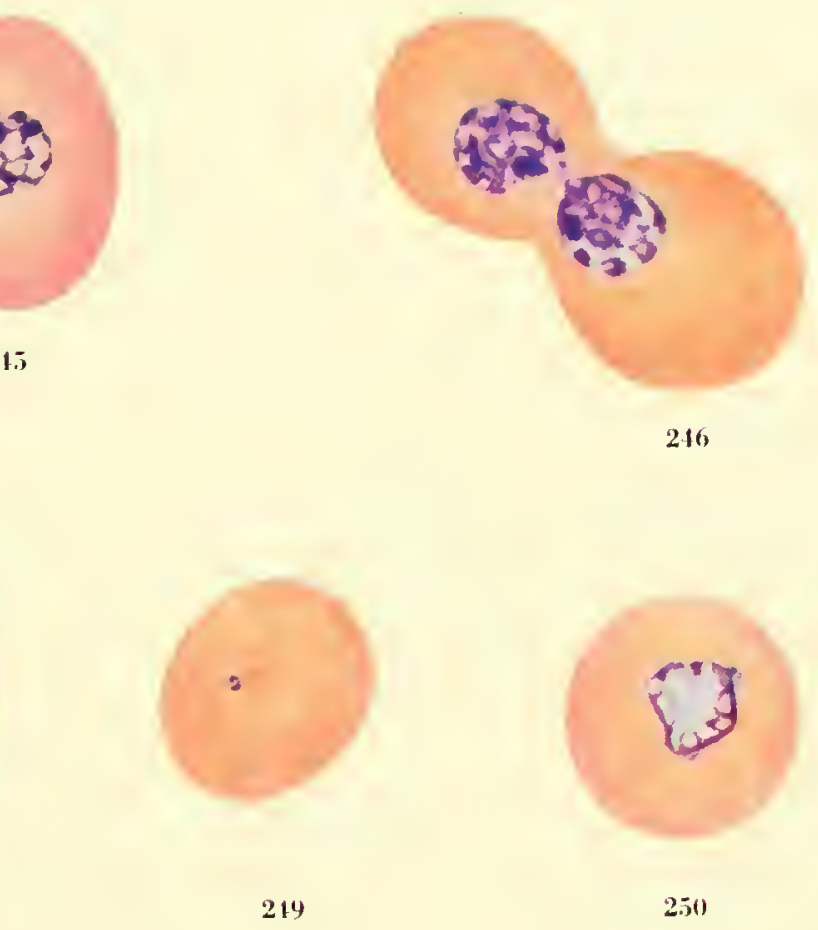

246

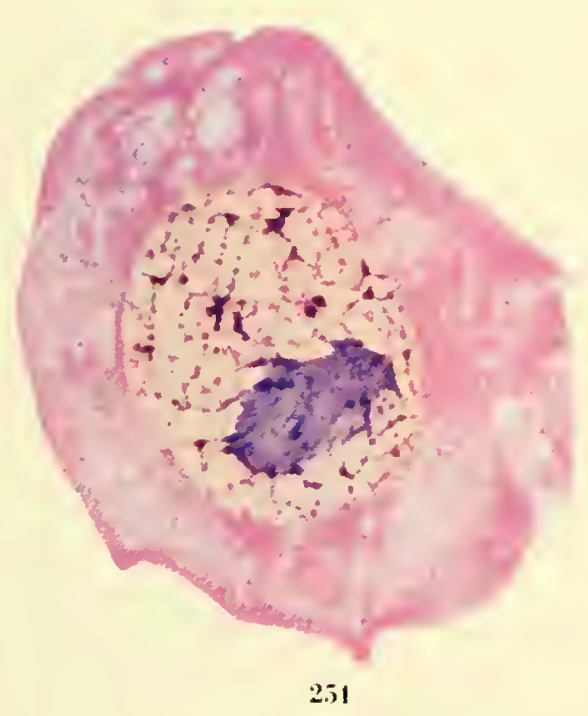

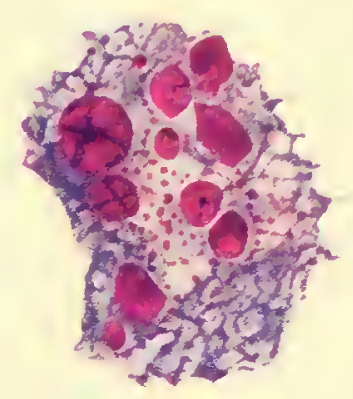

252

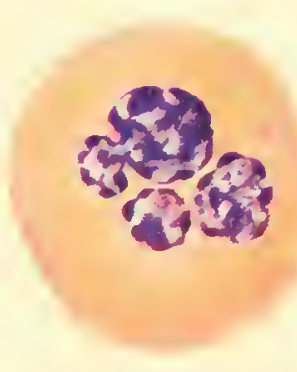

253 
Fraules 254-264.- Developmental stages of embryo erythrocytes following the primary generation, often called sccondary or definitive erythrocytes. $2,470 \times$.

Figires 254-256: Erythroblasts. All from the same slide. Embryo incubated 5 days 21 hours.

$25+$ Early erythroblast.

255 Erythroblast.

256 Late erythroblast.

FIGIRES 257, 258: Late erythroblasts or early polychromatic erythrocytes in mitotie division. Embryos incubated 9 days 18 hours.

257 Late analphase.

258 Late telephase.

F1GUREs 259-261: Erythroblasts showing various degrees of failure of nuelear staining. Ill from the same stide. Embryn incubated 5 ays 3 hours.

259 The nuckeus has an empty appearance owing to its incomplete staining.
260 Slight staining toward the right of the nucleus.

261 Overall staining of the meleus but not sufficiently intense to be fully useful for cell identification.

Ficitres 262-264: Early polychromatic frythrocytes. Same slide as figures $959-261$.

262 The cytoplasm resembles that of the late erythroblast but the eondensation of nuclear ehromatin is characteristic of the early polychromatic erythrocyte.

263 A more differentiated cell than figure 262 .

264 A more differentiated cell than figure 263. 


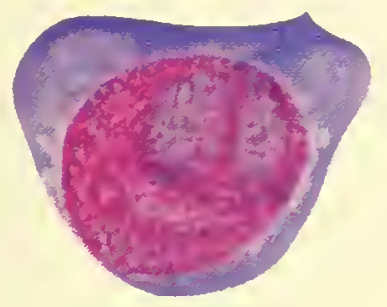

251

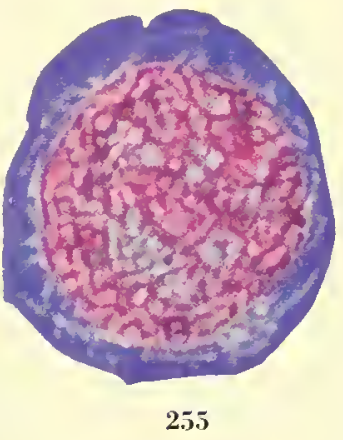

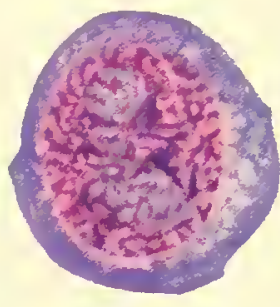

256

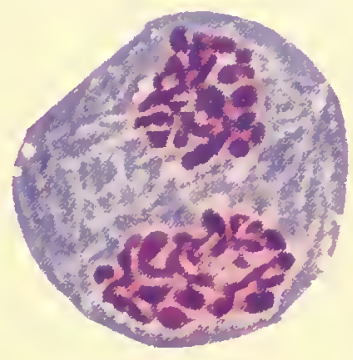

257

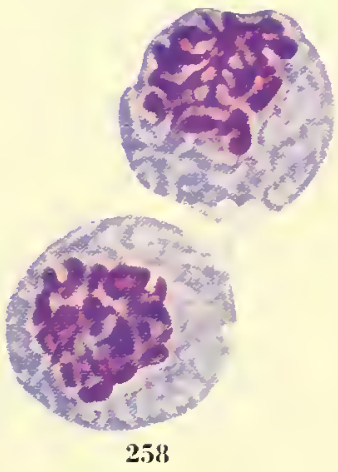

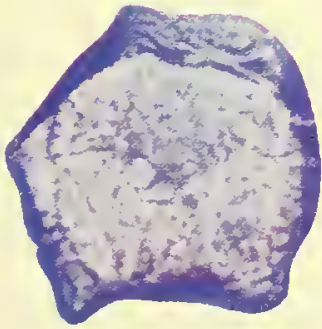

259
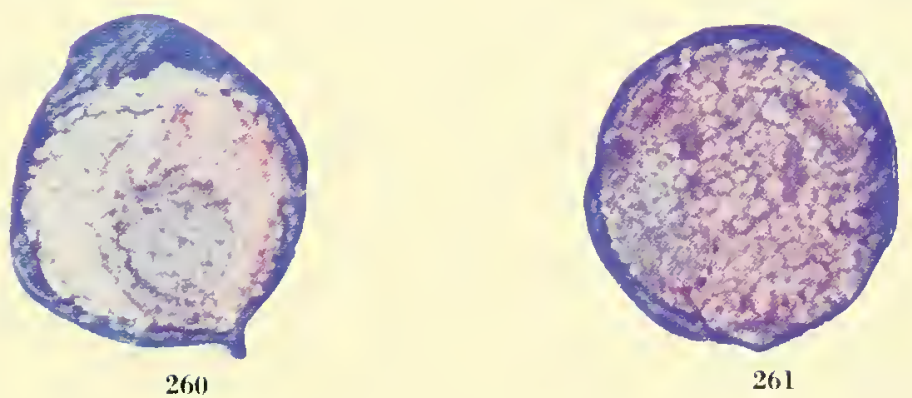

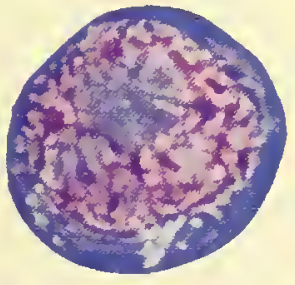

262
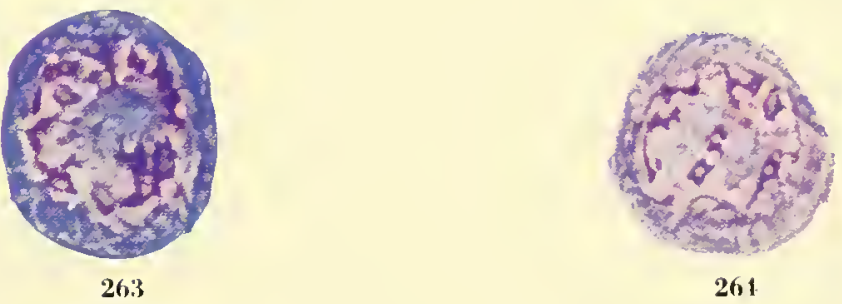
Figures 265-275.-Late developmental stages of embryo erythrocytes; also three cells that show technic artifacts. $2,470 \times$.

265 Early polychromatic erythrocyte, typical of this stage as scen in the late embryo. and after hatching. Embryo incubated 5 days 22 hours.

266 Mid-polychromatic erythrocyte. Cytoplasm fractured. Embryo incubated 6 days 22 hours.

Figures 267, 268: Late polychromatic erythrocytes. Same slide as figure 266.

267 Nearly round cell.

268 Slightly ovoid cell.

Figures 209-272: Mature embryo erythrocytes.

269 Mature erythrocyte. Embryo incubated 8 days 21 hours.

270 Mature erythrocyte. The large cell size, the condensed nucleus, the small nuclear size relative to the cytosome, and the color of the cytoplasm, all suggest that this cell may belong to the primary erythrocyte series. Embryo incubated 11 days 1 hour.

271 Mature erythrocyte typical of the older embryo. Embryo incubated 13 days 5 hours.

272 Mature erythrocyte identical with the red cell after hatching. Embryo incubated 16 days.

Figures 273-275: Cells showing the defect of cytoplasmic fracturing. This generally occurs in the polychromatic stages.

273 Mid-polychromatic erythrocyte. Embryo incubated 5 days 18 hours.

274 Late polychromatic erythrocyte. Disturbed stroma but no instained spaces. Same slide as preceding figure.

275 Late polychromatic erythrocyte. Partial margination of the hemoglobin-bearing stroma. Embryo incubated 6 days 22 hours. 


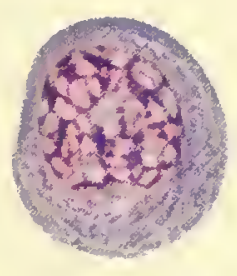

26.5

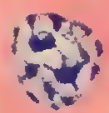

269

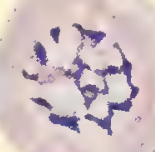

266

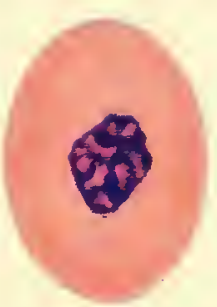

270

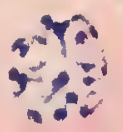

267

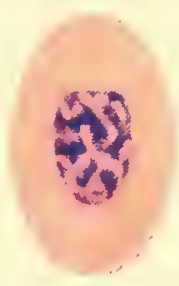

271

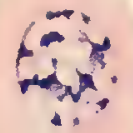

268

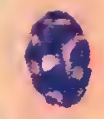

272

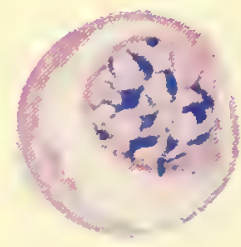

275 

have reached the late polychromatic stage but a few show the color typical of the mid-stage (fig. 226, 1 and 2). A different type of cytosome rarefaction appears at this age - the fracture breaks (cells 10 to 12 and others) that in the primary erythrocytes are not as severe as in later generations. Some cells, 3, for example, show change toward the oval form; the final nucleocytoplasmic ratio is not yet established but the nucleus has undergone considerable contraction, and the chromatin now forms coarse blocks. The muclcoli have practically disappeared but mitotic figures are still large and conspicuous. The capalility of a cell for mitosis is considered by Osgood and Ashworth (1937) to have considerable value for the proper placement of a cell in its developmental series.

Maturity of primary erythroblasts is attained during the fifth day of incubation and reaches the peak percentage loy ahout the sixth day (fig. 232). Dantschakoff (1908h) states that primitive erythroblasts attain their complete maturity on the fifth day. Figure 227 shows a typical low-power field in which there is a mixture of mature firstgeneration red cells and early stages of succeeding generations.

The primary erythorytes still show a wide range in size (fig. 227, 5 and 9) although they are now all equally mature. Such variation. were it to occur after hatching, would indicate a pathological condition and would probably be classed as anisocytosis. Among these mature cells there are shades of color difference. Althongh all have a deep orange hase color, some of them (cell 5 and the one just below 12) have some gray mixed with them. The cytosome has lost the coarse textural quality of the eryth. rocytes at earlier embryonic ages (figs. 235. 236. 238, and 239) and taken on a miform, finely gramular quality (fig. 243). This cytoplasmic textmre, characteristic of a cell that is mature or nearly mature, may be observed at 5 days of incubation (figs. 241 and 242).

Since the study of reticnlocytes in the blood of the hatched chick came rather late in the program of work, there was no opportmity to rexamine the primary erythrocytes to determine whether they passed through a reticulocyte stage; but Dawson (1936a) showed a series of figmes of primary erythroblasts and erythrocytes stained with brilliant cresyl blue, and these closely resemble what we have pictured for the reticulocytes in the definitive cells after hatching.

The particles near the margin of cell 5 of figure 227 are merely foreign bodies that have fallen on the surface. The nucleus now holds a central position in the cell. There is considerable variation in the ratio of mucleus to cytoplasm and in some of the cells-for example, 2 and 11 of figure 227-the mucleus is smaller relative to the size of the cell than in the definitive erythrocytes. This is a characteristic of the mature primary red cell (figs. 244 and 245). In general the cells and their nuclei are still round, only a few showing a slight elongation.

Chomatin of the nucleus is not so intensely stained in the primary erythrocytes as in the later gencrations of red cells in the same blood. This type of faint coloration of the nueleus is found as a general characteristic of the primary cells (figs. 244 and 250); where extreme, it has heen classified as indicative of deterioration and degeneration, but as seen in figure 227, it hardly seems likely that this is the case at this age. Later generations of erythocytes first appeared at about 120 hours ( 5 days) and it is hardly to be expected that the primary generation would be disappearing 21 hours later at a time when the succeding generations of erythrocytes are just making their appearance. It is true that definite examples of degeneration can he seen at all ages, such as karyorrhexis (fig. 252) and erythroplastid production (fig. 249) in early generations of erythrocyles, and multiple nuclei (fig. 253) in later generations.

Figure 228 shows that new generations have been poured out into the hlood and that they have become the dominant cells; only a few mature primary erythrocytes remain- 6 to 17 percent of the total number of cells. The mucleus and cytoplasm have the same appearance that they had earlier. It is a question whether these cells ever become oval in large numbers. Cells typical of this age are shown in figures 247 and 248; the latter is slightly ovoid. Degenera. tion appears in erythroplastid formation, as weak affinity of chromatin for stain, and as pyknotic nuclei (lower left-hand cell of fig. 228). Mature primary erythrocytes become increasingly scarce as the embryo grows older: one is shown in figure 229 (ccll 1) from an embryo 13 days 16 hours old. They may be scen the first day after hatch- 
ing but not from every chick. None are shown in figure 230.

Figure 246 was included because amitosis is said to occur in human. amphibian, and hird blood cells after reproduction by mitosis has enderl. Constricted cells, cells with indented muclei. and cells with two nuclei can often be found. but according to E. B. Wilson (1925) (quotation on p. 31 ), amitosis iuvolves constriction of both eytoplasm and nuclens. Of the lundreds of slides examined, this is the only cell which entirely fulfilled the criteria of amitosis and. when a cell having this appearance occurs so rarely. adhitional evidence is needed before we can consider that amitosis is a normal means of increasing cell number.

\section{Later embrymic erythrocyte gemerations}

The term "later" embryonic erythroyte genera. tions" is used in the legend luecause it fully dif. ferentiates between the cells to which it refers and the cells of the primary generation: but it is a cumbersome term, and in this scetion the cells with be referred to simply as erythrocytes.

Cells that produce the later generations of em. bryonic erythocytes undergo a spurt of multiplivation within the lumina of the venous reticulum. According to Dantschakoff (1908b), this occurs on the fourth day of incubation, and the venous reticulum appears at the time the yolk sac membranes grow into the yolk sulsstance.

Cells of this series appear first alyout the fifth dar, as observed by Fennel (1947) and by others who have followed the changing blood picture in the enbryo. Dawson (1936a) repots that stem cells of this series appear on the fourth day. It bas heen our olservation that up to 96 hours incubation the only cells present are the primary erythocytes and the embryonic thrombocytes, and that the blast cells seen on the fourth day helong to the latter series. These puickly differentiate into thrombocytes, and the blast cells seen on the fiftl and sixth days are the precursors of the later erythrocytes. Cytologieally there is no real difference between the thrombohlasts of 4. days and the erythroblasts of 6 days (compare figs. 255 and 280). At 4 days incubation the structural series leads to the thrombocytes, but at 5 days and later it leads to the erythrocytes. Further lesting might show that the same stem cell serves both lines. A common intravascular origin has been suggested for these cell lines. (See Sugiyama, 1926. for review of the literature.) The cells shown in figure 226, 17 and in figure 227,26 camot be classified with certainty; either cell may belong to either of the lines mentioned. Blast cells of both lines contain mucleoli. The blast rells of the two lines can be separated fairly accurately later-during incubation and. in the adult, when bone marrow produces these cells.

The erythroblast has a more alunulant, more lightly stained eytoplasm than the thromboblast, in which the eytoplasm is a darkly slained rim around the nucleus. In the erytholnlast the chromatin pattern is reticulate. whereas in the thrombocyte it is more particulate and punctate.

Anvthing subsequent to the blast stage is easy to illentify: for example, in figure 227 , cells 13-15 are mid-polychromatic erythrocytes and cells $16-18$ are late polychromatic erythrocytes. Many of the latter type (cells 19-24) reveal cylosomal artifacts. Early polychromatic eryth. rocytes are scarce; one is shown in mitosis (cell 25) and even this approaches the color of the mid-erythrocyte. Differentiation proceeds slowly and even by the ninth day there are only relatively few mature cells: at least there are only a few that give a good vigorous color. Most of them are late polychromatic erythocytes. By the 13 th day mature cells are considerably more ahundant, lunt at hatching or within the first 24 hours after hatching, the dominant cell is the ma. ture erythrocyte, with a few scattered immature cells (fig. 230).

The steps involved in the differentiation proc. css of the erythrocyte line as well as some typical artifacts of the mid. and late polychomatic erylhrocytes are sluown in figures 254-275. The least differentiated cell olscrved is illustrated in figure 2.54. It has a slight amoehoid shape and a smooth-lextured cytoplasm, which has a few small spaces. The muclens is a reticulum with fne meshes, and individual chromatin granules are indistinct. A nucleolus is very faintly visible at the upper side of the nucleus.

A type of blast cell much more commonly found is that shown in figure 255, which is round. The cytoplasm with its mitochondrial spaces is a narrow, strongly basophilic rim around the nucleus. The latter is a coarse reticuhum, still without sharp distinction between chromatin and 
linin network. Another cell taken from the same slide (fig. 256) is smaller but is essentially at the same stage of development as the larger cell except for a slightly more eondensed pattern of nuclear chromatin.

Mitosis continues. The cells in figures 257 and 258 were found in the circulating blood of wo embryos, both incubated for 9 days 18 hours. The clumps of basophilic cytoplasm are $u n$ iformly distributed. In the process of division the cell loses all its identifying marks and it can only be suggested that these two cclls are either late erythroblasts or early polychromatic erythrocytes.

The next three cells ilhustrated (figs. 259-261) probably should be inchuded with examples of artifacts. They are presented with the idea of showing how blast cells appear when they are improperly stained. The cytoplasm in each cell slained well and showed the mitochondrial spaces but, becanse the nucleus was colored only faintly, the boundary between uncleus and cytosome was not definite and the vaenoles of mucleoplasm and cytoplasm merged. It is interesting to note again that when the surface reticulum is lightly colored the internal structures become visible; thus the existence of a mucleolus is revealed in figures 259 and 260 , but in 261, where the reticulum takes the stain more energetically, the nucleolus is only vagucly indicated as lying to the left sicle of the nucleus.

The failure of the stain to penetrate the mucleus in figures 259-261 is limited to the large blast cells. In more differentiated cells such as figures 262-264, taken from the same slide, the surface chromatin of the nuclens is intensely colored. The difference is not due to cell size since the larger and snaller are equally flattened; it seems more reasonable to suppose that there is a difference in the pliysical character of the nuclear membrane.

The eytoplasm in figures 262 and 263 slows the same intense, dark blue that is shown in the blast-cell stage; it is still a narrow rim extending only slightly beyond the nucleus, and mitochondrial spaces are still present. The nucleus re. tains a nucleolus that is conspicnous even in figure 264; yet differentiation has occured, as clearly evidenced by the clumping of the chromatin pattern and the taking up of hemoglobin. This sequence of differentiation is reminiscent of the precocious development occurring in the first generation of erythrocytes, where chromatin chmping and hemoglolin acquisition developed alread of cellular differentiation.

In the generation succeding the primary one, the precocious development of these two factors does not get as far ahead of general eellular differentiation as bcfore and, with each sncceeding generation. there is a gradual approach to the condition found in the adult bone marrow, where cellular differentiation and liemoglobin accummlation keep pace with each other. Thus, all three cells within this gromp have been designated as early polychromatic erythrocytes, and in figure 264 the tinctorial quality of the cytosome clearly indicates that hemoglobin is present. Figure 265 has heen included under the same category. In this case, however, all the features that are used to measure cytologic differentiation have shifted to indirate a more differentiated cell: the nucleus has becone slightly eccentric, the eytosomal rim around the mucleus is greater in proportion to nuclear size than in the preceding cells. the mitochondrial spaces have become small and the chromatin clumps have grown in size and density and in their closeness to each other.

The mid-polychromatic erythrocytes present no difficulty in identification and several examples are pointed out in figure 227, cells $13-15$. Figure 266 is a cell at this stage, drawn at a higher magnification. There is, of eourse, a range of color in the cytoplasm of rarious cells at this stage as there is for the one before and the one following, and so some mid-polychromatic erythrocytes may appear gray and others nearly blue.

The next stage of derelopment is the late polychromatic erythrocyte (figs. 267-269). The cytoplasm is more homogeneous than it was in the previous stage, and at the begimning of this phase it still contains considerable hasophilic material. Many of the cells in figure 228 are at this stage of development. As hemoglobin accummlates, the cell elongates and the ratio of cytosome to nucleus increases. The nucleus also becomes slightly clongated and the chromatin pattern takes on the characteristics of the leptochromatic type of muclens found in mature cells.

The mature embryo erythrocyte often continues its hemoglolin synthesis until it reaches a linctorial level equal to that of the primary generation of erytluocytes (figs. 269 and 271). 
This makes it quite difficult to identify with cerlainty a cell of the type shown in figure 270 , where the cyloplasm is slightly grayish, and the mucleus is shrunken and has started toward de. generation. These are all features characteristic of the primary erythrocyte.

By the end of the second week of inculiation and from then on until hatching, the mature erythrocytes are indistinguishable from defini. tive cells (figs. 228, 229, 271, and 272). The three cells slowing artifacts (figs. 273-275) have already been mentioned and they illustrate the defects in greater detail than do the low power drawings (figs. 227-229). Only the cytosone is affected, never the nucleus. In the cytoplasm any odd eflect may he produced.

\section{Embryo thrombocytes}

The thombocytes of the embryo appear as a definite cell line soon after the primary erythroblasts are well established and are clearly present by 68 hours inculation (fig. 225), but whether they are present at 48 homrs also (fig. 224 ) is still moletermined. The cells of 224 $A, 2$ and $224 B, I$ and 2 may be primary thromboblasts. When seen in its entirety, cell $224 \mathrm{~B}$, 2 resembled in some respects a yolk sac macro. phage such as shown in figure 308 . The erythrocytes contain hemoglolin and the thrombocyles do not; so if the two cell types are mingled they could be sorted rather readily by Ratph's benzidine method.

There is a peculiar behavior of the primary prythrocyles at the 48-hom age that may have a bearing on the problem. If the primary eryth. rocytes taken up into the cannula are not discharged immediately onto the slide and there spread so that they dry quickly, they will chump and drgenerate, as the thrombocytes will at an older age. Many cells will elump together and their appearance when partly degenerated is similar to figure 224 A. 11 and 12 . If erythrocytes and thrombocytes come from the same primordial cell, perhaps erythrocytes for a short period of early embryonic life assume a function peculiar to thrombocytes.

Sugiyama (1926) conchuded that thombocytes of the early chick emlryo first arose liy a transformation of megaloblasts into thrombo1) lasts. The transition involved loss of hemo- globin and reduction in cell size. Our studies have not supported the idea that the thromboeyte series arises from hemoglobin-bearing cells, althongh it is recognized that a close parallelism in development exists between erythrocytes and thromlsocytes. Six other theories on the origin of thrombocytes have been reviewed by Sugiyama. Some have called these small elumped cells of the embryo "lymphocytes," and Sugi. yama (1926) presents convincing evidence that this is an error. Typical lymphocytes in his preparations did not appear in the circulating blood of the embryo until 17 days" ineubation. Our olservations agree with his and further show that lymphoeytes, even in the late embryo, are inconstant, and that they do not become a constant, ealculalile component of the blood until after hatching.

It is obvious from the papers of Dantschakoff (1908h) and Sngiyama (1926) that both allthors were studying the same cell, the embryonic thrombocyte. Dantschakoff claimed that primordial cells (large lymphocytes) of the early emlnyo. produced microblasts and then mieroeytes (dwarf lymphocytes). She suggested that the dwarf lymphocytes might he related to the spindle cells (thrombocytes) and that the dwarf lymphocytes were different from the small lymphocytes that appeared rather late in emhronic life. According to Dantschakoff (1916a) the latter appeared between the fifteenth and seventeenth day of incubation.

By 65 lours of ineubation, the thromboyte line is easily distinguishalle from the erylurocyte line: the cells of the former tend to clump readily but the latter no longer exhilsit this property, and since the erythrocyte line is a group of cells fairly well synchronized in development, a structural series does not logically lead back to the blast cell such as shown in figure 22.5. 25: yet a complete gradation of cells does lead from this to the small embryonic thromborytes (fig. 225, 27). which supports the conclusion that the hlast cell shown in figure 225 belongs to the thrombocyte series. The same is true of the cell shown in figure 276 from the same slide. Cell 25 in figure 225 appears to he discharging eytoplasmic blehs: whereas, in figure 276 only large protrusions are present. Both show cytoplasmie spaces lon probal,ly the feature that most strongly suggests their thrombocytic affinity is the punctate character of the nuclear chromatin. This 
cytologic detail of the immature thrombocyte nuclens was not observed by Sugiyama (1926). probably because Wright's stain was used.

Beyond the blast stage, thrombocytes can be identified easily; thus even in one field ( fig. 225) two older stages are visible. Cells 24 and 26 are probably at about the same level of differentiation, and cells of this size do not tent to clump together as readily as do the smaller cells (27). In the clumping process, cytoplasmic l, lels are thrown off. A duplicate slide. made from the same embryo thit was used for figure 225. was stained with Ralph's modification of the benzidime test. Two cells (figs. 277 and 278 ) demonstrate that hemoglohin is absent from the throm. bocyte even at an early stage of differentiation. Figure 277 is probably equivalent to cell $26 \mathrm{in}$ figure 225: figure 278 is smaller and the nucleus is not visible. Dividing thrombocytes are somelimes found. Unlike the erythrocytes which maintain a compact cytoplasm, the thrombocytes even during mitosis (fig. 279) can les stimulated to give off protoplasmic fragments.

Spreading and drying the cells is not always rapid enough to prevent degencration of the thromborytes. Many of the cells illustrated in figures 276-295 are not typical of what one so often fincls on the slide, since the ones selected were those least degencrated. A degenerated thrombocyte looks like a lymphocyte. Not every slide marle from a series of embryos is equally productive of early stages. but the embryo that contributed fignres 280 and 286 had an almulance of them.

A typical thrombolnast at 4 days of inculuation is shown in figure 280. Il has a narrow tim of cytoplasm that stains an intense dark lolue or deep violet. Within are large mitochondrial spaces. The reticulum at the surface of the nucleus in figure 280 appears more clearly defined than that in the nucleus of the amoeboid thromboblast in figure 276. Associated with this more open network is a vague suggestion of a nucleolus.

Failure of the nuclear surface to stain is a common feature of yomng cells with large nuclei. and three degrees of incomplete staining are shown in figures 281-283. These duplicate the reaction that ocemred in young erythrocytes (figs. $259-261$ ) in that the nucleolus is more readily visible than in the well-stained cell. In these turee examples, deficiency in unclear affuities does not influence the quality of cytoplasmic staining: full differentiation of alundant mitochondrial spaces is attained, especially in figures 283 and 284.

Shifting of the nueleus to an eccentric position may occur in thrombolilasts (figs. 283-285) but, as in the erythrocytes, the mueleus tends to remain in the renter of the cell, as in figures 280 and 286. and in the fonr small thrombocytes in figure 225, i.e. 27. By 4 days of incubation a wide range in stages of development has appeared: the celts form a series of decreasing size and jucreas. ing cytoplasmic differentiation ( figs. 286-292); yet the impression is gained that this differentiation process does not exactly parallel that which takes place at older embryonic ages and after hatching. Like the prinary generation of erythrolulasts, this primary generation of thrombocytes seldom produces an oval cell. Later. however, cells of this shape can be found frequently if the preparation is made quickly enough. A few cells will oval shape have heen seen at 4 days ( fig. 287) and again once or twice at 5 days, but these cases are too rare to be called typical. Sugiyama (1926) pictured a thrombocyte of oval shape, taken from an embryo inculiated only 2 days. We have never seen a thrombocyte having this shape in an embyo this young.

The first step in the differentiation process following the blast stage is the loss of staining af. funity by the cytoplasm (figs. 286 and 288) and the next is extensive vacuolization (figs. 290 and 291). In figure 290 a single magenta gramule appears to be present outside the melear margin, and in figure 291 such bodies are numerous. They are not the specific granules of the definitive thrombocyte but resemble exinded chromatin particles more than anything else. The delicate, fine pink granules that are characteristic of defintive thrombocytes never appear in the first generation of thrombocytes: the two hodies shown in figure 293 from an embryo inculuated 5 days 21 hours are about the size of definitive gramules but belong to the chromidial type.

Thrombohlasis soon disappear from the circulating blood of the embryo, aftes which only large. medium, and small embryo thrombocyles are seen. By the ninth day the occurrence of specific granules is fairly common. The granules may appear as early as the eighth day (fig. 294) but many of the cells still do not show them until later in development. They are present in those cells selected for illustration chiefly be- 
cause such cells were chosen in order to make more convincing the evillence that these are thrombocytes and not lymphocytes. Lymphoevtes, monocytes, and gramulocytes are not norsually present in circulating blood of the embryo, although cells helonging to these types may be seen occasionally, and they will be considered more fully when the cells fouml within the hematopoietic organs are described.

lt has been indicated already that mature stages from later generations of thrombocytes, like later generations of erythrocytes, approach a higher level of terminal diffcrentiation than did earlier generations and thus during the second week of embryonic development, all cylologic features that eharacterize the definitive cell can he seen lout not exactly as they will appear in the circulating blood of the adult bird. Specific granules of the type shown in figure 296 are atypical in that they are larger than normal and in that each lics within a vacuole. This vacuolar effect may possibly be duc to technic since it is found also in mature thrombocytes from the circulating blood of the adult fowl, when the blood smear has leen fixed in Petrunkevitch No. 2 and stained with May-Grïnwald Giemsa (fig. 202). The general appearance of the cell (fig. 296), the lightly stained vacuolated cyioplasm. the condensation of the nucleus, and the acidophilic affinity of the cell nuargin, all establish this particular cell as an embryo thrombocyte. Typically the specific granules are distributed among the strands of the cytoplasmic reticulum (figs. 297-299, 302, 303, and 305).

The last-mentioned point, the affunity of the cell perimeter for eosin, is especially significant. This reaction by the cell margin is often seen in embryo thromboeytes of this age. The same reattion oecurs in thrombocytes of adult birds (fig. 85), lut after hatching, the disintegration process is less frequently stopped at the exact moment when this initial stage in cytoplasmic breakdown would be revealed.

Other examples of crumpling and acidophilic staining of the eell margin, an initial reaction in the disintegration process, are shown in fignres 297 to 299. There is merely a single indentation of the cell wall in the first two of these figures, but in the third the entire margin is scalloped. There is a question of whether the shift from a basophilic to an acidophilic affunty (1) was a result of cell disintegration, (2) preceded it, or (3) was under the control of a different set of factors with little or no causal relationship to cellular breakdown. For the present, only examples can be mentioned, and these do not always support the same hypothesis. Figures 302 and 303 show a defmite acidophilic margin and slight diffusion of the reaction into cell protoplasm; yet there is no indication of cell rupture. On the other hand, figure 306 shows cytoplasmic disintegration well started. yet hasophilic affinities have been retained, and figure 295 shows both rupture and acidophilic staining. These examples come from different sliules. The cytoplasm of thrombocytes under the best conditions stains so delicately that only with optimum illumination corrcctly aligned can these differences in color and structure be detected.

The cell represented by figure 302 was selected to show that an intact, almost definitive. thrombocyte can lie found as early as 9 days 15 hours. This cell was not seen until after a number of slides had becn made. This degree of differentiation is not typieal for this age. Usually small thrombocytes of mid-embryonic life look like figures 300,301 , and 306 , or those of figures 228 and 229. Cells (figs. 300 and 306) were selected for drawing in which specific granules were still visible; when these granules are not visible. disintegrating thrombocytes so elosely resemble small lymphocytes that have discharged part of their cytosome, that the identification might be questioned. Some rounded cells (fig. 304) in which specific gramules are absent lut in which disintegration has not begun can definitely be identified by the lightly stained vacuolated cytosome. If the lechnic methols could be improved, probably most of the embryo thrombocytes after 10 days of inculation would look like figure 302 .

When a coll reaches a stage of degeneration such as shown in figure 301 and a specific granule is not visible, one can only guess at its identity; if it is part of a cluster (fig. 229, 19) it is probal,ly a thrombocyte. but if it is an isolated cell, it may be a lymphocyte. Generally, however, the nucleus of even the small lymphocytc is larger than that of the thrombocyte.

Even at the cnd of the second wcek of inculyation, thromborytes in general have not taken on the definitive form and many, even with specific granules, still have an appearance of immaturity (fig. 305). This may be true until nearly hatch. 
ing time (fig. 307), lut by the 21 st day (fig. 230 , cells 7 and 8 ) cells having this appearance can be considered to be truly definitive and mature.

\section{Cells occasionally found in circulatiug blood of the embyro}

Granulocytes may be found in the circulating blood during the last week of embryonic life and occasionally during the second week. Their occurrence. however, is sporadic, and in many smears none were present; yet a study of hematopoietic organs during this same period-and even of organs like the pancreas, which is not a hematopoietic organ in adult life - shows that tremendous numbers of granulocytes are being produced, but apparently they are being held in storage and normally are not liberated until after hatching, so that the typical blood smear even for a few hours after hatching shows only erythrocytes and thrombocytes (fig. 230 ).

When granulocytes do appeal in the circulating blood of the embryo, this question comes to mind: Is it rough handling. or is it infection of the egg, that caused these granulocytes to appear in some embryos and not in others? When the egg is opened, the embryo with its membranes is slid into a bowl of warm saline and then is lifted to a filter paper in a flat Petri dish. Here the amnion is opened, and often in the moving process the other membranes are ruptured or torm away. If the ventral body wall has closed over, the tissnes in this region are lail apart in order to expose the heart and then the cammula is inserted. No matter how dexterously these steps are execuled, there is still enough roughness to dislodge some granulocytes from embryonic depots.

On the other hand, approximately 8 percent of hens" eggs have been found to carry a bacterial contaminant after all precautions have been taken to prevent entrance of organisms from ontside the shell. From indirect evidence viruses also can be transmitted from the hen to the egg (Cottral, 1950 and 1952). Probably our best evidence comes from work done at this Laboratory-evidence that lymplomatosis, a virus dis. ease. is transmitted through the egg (Cottral, Burmester, and Waters, 1954, and Bumester, Gentry. and Waters, 1955). If some eggs carry bacterial or virus infections, and if phagocytic cells are allearly on hand, it seems entircly pos. sil)le that the chick could be stimulaterl to give a defensive response just as well before hatching as after hatching.

Chick embryos have been inoculated with so many different viruses and bacteria that it is probably safe to say that growth or serial passage of every well-known disease has been attempted on this medium. In nearly every case, the embryo was used mercly as a test tube because a better, synthetic one has not yet been devised. Embryos have been used as a culture medimm without much regard for possible contamination of the egg. The studies of embryo reactions are often based on grossly visihle lesions, which do not tell the full story. Studies of egg-borne diseases must be carried hack to the cells of the embryo. These cells must be searched for inconspicuous deviations from the normal, some of which may represent defense reactions to pathogens. The meaning of the presence or absence of heterophils in the circulating hlood is a case in point: there is certainly no a priori reason why the chick embryo could not he studied in health and in disease just as scientifically as the adult fowl. Zuckerman (1946) has provided us with an example of hlood response to infection in the embryo. Introduction of Plasmodium gallinaceum stimulated the heterophils to become almost as mmerous as thrombocytes. In the differential connt on one embryo, there were 44.5 percent thrombocyies: 19.0 percent mature heterophils, and 24.0 percent heterophil myelocytes, a total of 43.0 percent. In addition there were 1.0 percent macrophages, 8.0 percent monocytes, and 3.5 percent lymphocytes.

Roberts, Severens, and Card (1939) found the white cells of the embryo composed of neutro. phils and lymphocytes. During the last week of hatching there was a fairly constant number of each of these cell types. Their values were averages and the variability among individual birds was not indicated. No mention was marle of the thrombocytes, which in the embryo often look like lympocytes. Whether some, or all, of the white cell types are constant components of embryo circulating blool can be decided definitely only by additional investigations.

The macrophage is another cell sporadically found in smears of blood taken from the cmloryo heart. The large cell shown in figure 308 came from blood drawn from the dorsal aorta and differs in appearance from all the other cells 
shown in figures 309-318. The nuclens is in. mense and has a uniformly delicate granulation. The eytosone carries clear vacuoles ranging from small to very large. There is much to suggest that this rell is a yolk sac or endodermal macrophage. How so large a cell can flow through capillary channels is not understood. Cells of similar size but of different structure were found in blood taken from the heart, but as already mentioned these were present in only a few embryos and absent from most of them. and were fouml most commonly at about 10 days of incubation. This age (10 days) agrees with the span from 7 to 12 days of incubation when Sugiyama (1926) found macrophages in the embryo blood.

The cell shown in figure 310 is defuitely a macrophage although the cylosome contains but a few inclusions, which are represented by several magenta granules and numerous vacuoles. 'The nucleus was pressed down on some of the vacuoles when the cell dried; these vacuoles made the nucleus appear to be vacuolated also, lout actually it was not. An earlier less differentiated stage is represented ly the three cells clumped together in figme 309 . The nurlear structure is identical with that shown in figure 310 , but differentiation of the cytoplasm loward the phagocytic condition of the macrophage has not progressed as far as in the latter cell. The ruclear strurture of both of these cells is similar to that observed in macrophages seen so abundantly in blood spots (Lucas. 1946). In blood spots they appeared to be derived from fibroblask and the same type of cell with long mi- polar or bipolar processes was found also in the embryo (figs. 314-316). Whether these precursor cells are reticular cells or fibroblasts needs to he determined, hut at least it can he stated that in the embryo and in blood spots of eggs the precursor cell is not a lymphocyte. In the circulating blood of the aduh, lymphoeytes differentiate into a reactive type cell, and it has been suggested that this may lue leading toward a matrophage, hut never has a series of stages heen olserved spanning the gap from the reactive lymplocyle to the type of macrophage shown in figures 310, 3]3, or 318.

In the same slides that contained the cells of figure 309 were numerous protoplasmic spheres (fig. $31 \mathrm{~L} A$ to $D)$. Although differing in size they all stained in the same way and resembled closely in sricture the cytoplasm seen in figure 309. These cytoplasmic spheres were vacuolated like the cytoplasm of macrophages and probably were pinched off from cells of this type-al least no other cell visible in the blood at this lime seemed large enough to have produced them. The cytoplasm of the macrophages has a structure identical with that found in the pinched-off fragments.

Later in the study, cells grouped in a mass were discovered (fig. 312). In nuclear and cytoplasmic structure they were jdentical with the small group of three discovered earlier (fig. 309). Many large macrophages had been observed up to this time but the bulkiness of this group precluded the assumption that it conlel get through the smaller circulatory channels. It is entirely

\section{Figulies 276-287.-Ferty developmental stages of the embryo thrombocytes. $2,470 \times$.}

276 Early thromboblast, lobulated stage. Embryo incubatid 2 days 17 hours.

278 Eithur a late thromboblast or a large rarly thrombocyta. Duplicate slide from samo embryo as precerling figure. Treated with kalph's benzidine and stained with M. G. G. No trace of hesueglobin in cytosome.

278 Medium embryo thrombocyte. Samo slide as pre(reding figure.

279 Thrombublast in the thenhase of mitotic division. Embryo inembated 2 days 18 homrs.

Figrtess 280-286: Drawn from the same slide. Embryo incubated \& days.

230 Large embryonic thromboblast.
F1GrREs 2S1-2S3: Embryo thromboblasts showing incomplete staining of the nucleus.

281 This type of empty mucleus often seren in blast cells following Wright's stain, less often with M. G. G.

282 A partial staining of the nuclens.

283 Nuelear content well stajned but muclear boundary not well delimated.

284 Enbryo thromboblast that shows the punctate character of the chromatin granules.

285 Large embryo thrombocyte. Cytoplasm still shows the structure of the thromboblast. Nucleolus present.

286 Large imbryo thrombocyts. Rarely fixed in this romind form.

287 Large embryo thrombocyte that shows precocions develupment to the oval form. Same age as preceding one. 


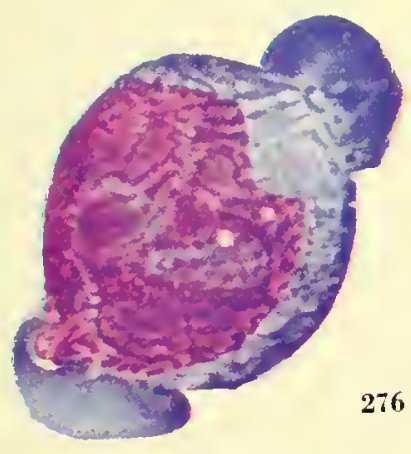

276

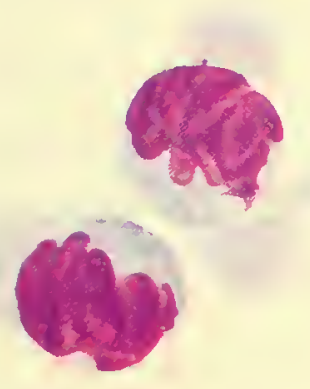

$2 \div 9$

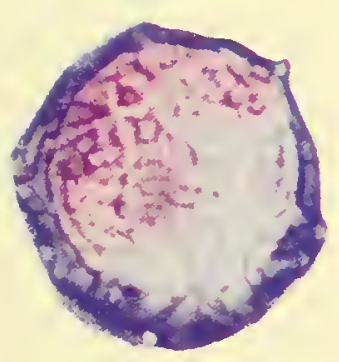

282

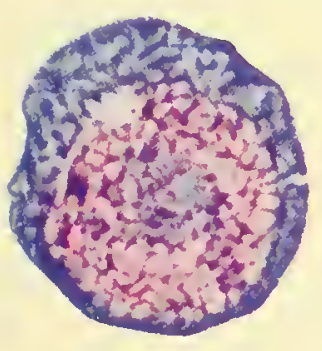

285

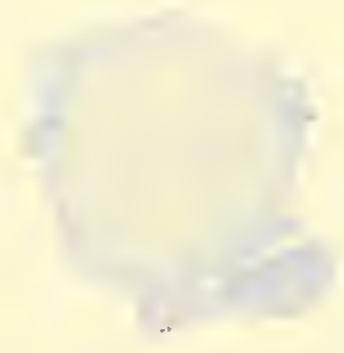

277
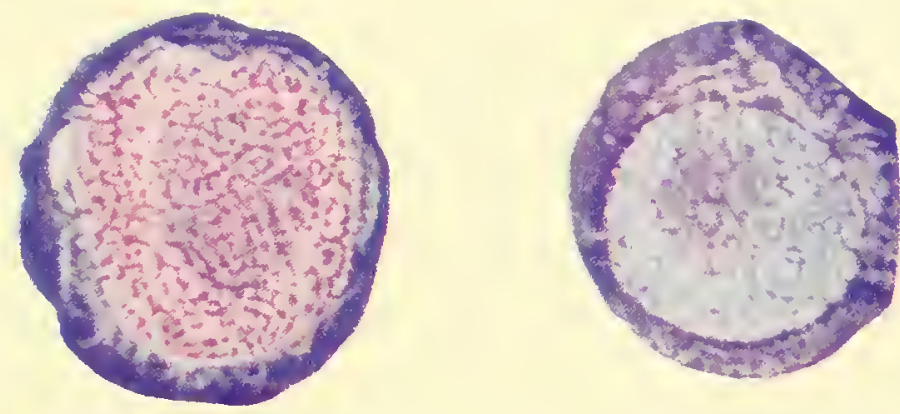

280

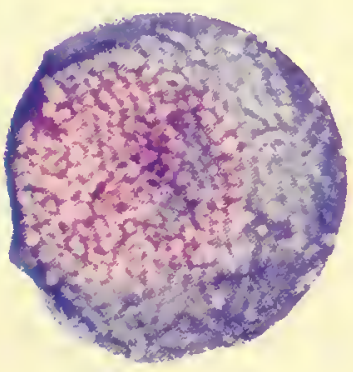

283

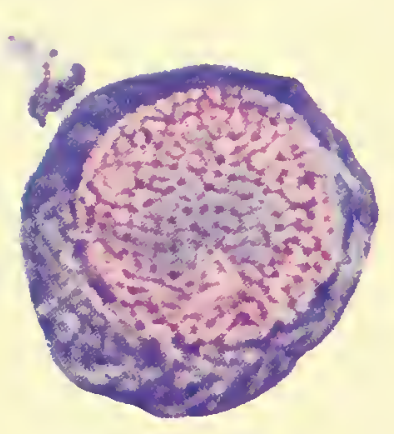

284

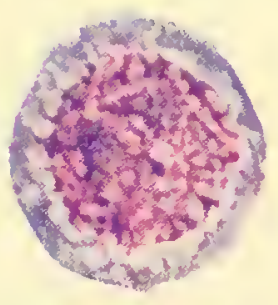

286

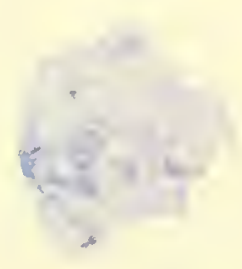

278
281

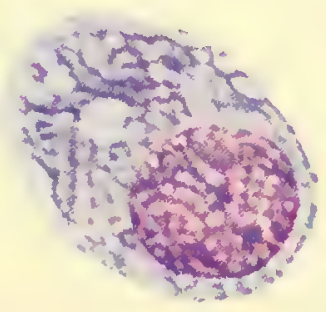

287 
Figures 288-307.-Late developmental stages of the embryo thrombocyte. $2,470 \times$.

Figures 288-291: Lorge functional embryo thrombocytes. Draun from same slide as figures $280-286$.

288 Large embryo thrombocyte showing blebs of early disintegration.

289 Large embryo thrombocyte showing partial loss of basophilic eytoplasm.

290 Vacuolization of eytoplasm with loss of staining affinity. A stage in the differentiation process.

291 Discharge of elromatin gramules into the eytoplasm. Found only in well-preserved early embryo material.

Figures 292-295: Medium and small embryo thrombocytes.

292 Medium embryo thromboyte. Vacuolization and some discharge of nuelear chromatin.

293 Medium embryo thromboyte. Several chromatin bodies in cytoplasm. Pink color due to early disintegration of the eell. Embryo incubated 5 days 21 hours.

291 Small enbryo thrombocyte. Same type shown in figure 229, 19. Embryo incubated 7 days 23 hours.

295 Medium embryo thrombocyte. Cytosome partly disintegrated. Embryo incubated 8 days 21 hours.

Figures 296-303: Stages in development and breakdown of late embryo thrombocytes. Embryo incubated 9 doys 15 hours.

296 Medium embryo thrombocyte. Slight autolysis at the cell margin. Cytosome contains more than the usual number of specific granules.
297 Nedium embryo thrombocyte. Acidophilia and folding of cell margin are first steps in cell disintegration. Three specific gramules present.

298 Medium embryo thrombocyte. Isess differentiated than preceding cell. One specifie granule.

299 Mediun embryo thrombocyte. Folding of cell margin well started. Two specific granules.

300 Small embryo thrombocyte. Much of the eytoplasm lost. One specific granule.

30 S Small embryo thromboeyte. Much of the eytoplasm lost. No specific granule visible.

302 Mature embryo thrombocyte. A specific grauule at each pole.

303 A binuclear mature embryo thrombocyte. Numerous specific granules.

Figures 304-307: Dcvelopmental stages of thrombocyte gencrations coming late in embryonic life.

304 Medium embryo thrombocyte. Early stage of development. No specifie granules. Embryo incubated 13 days 15 hours.

305 Medium enbryo thrombocyte. Later stage in differentiation than preceding cell. Same slide as figure 304 .

306 Small embryo thrombocyte. Nucleus and cytoplasm undergoing degeneration. One specific granule.

307 Definitive thrombocyte, nearly mature. One speeific granule. Embryo incubated 17 days 14 hours. 


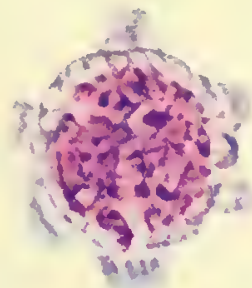

288

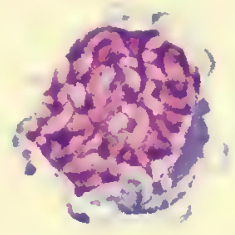

289

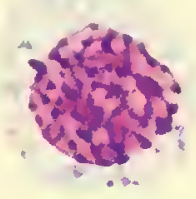

290

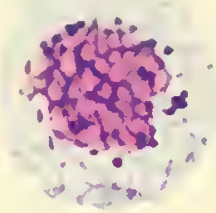

291

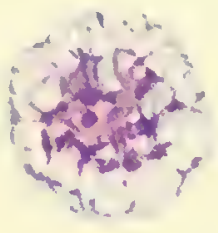

292

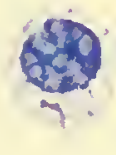

291

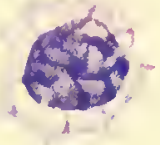

295

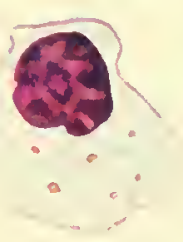

296

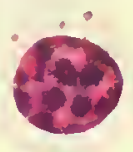

297

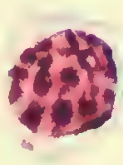

300

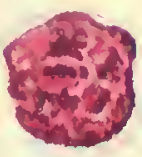

301

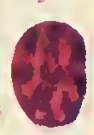

302

298

299

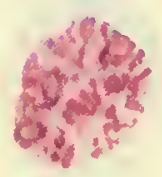

301

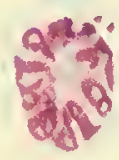

305

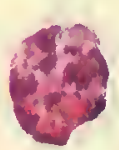

306

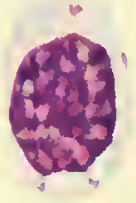

307

303 

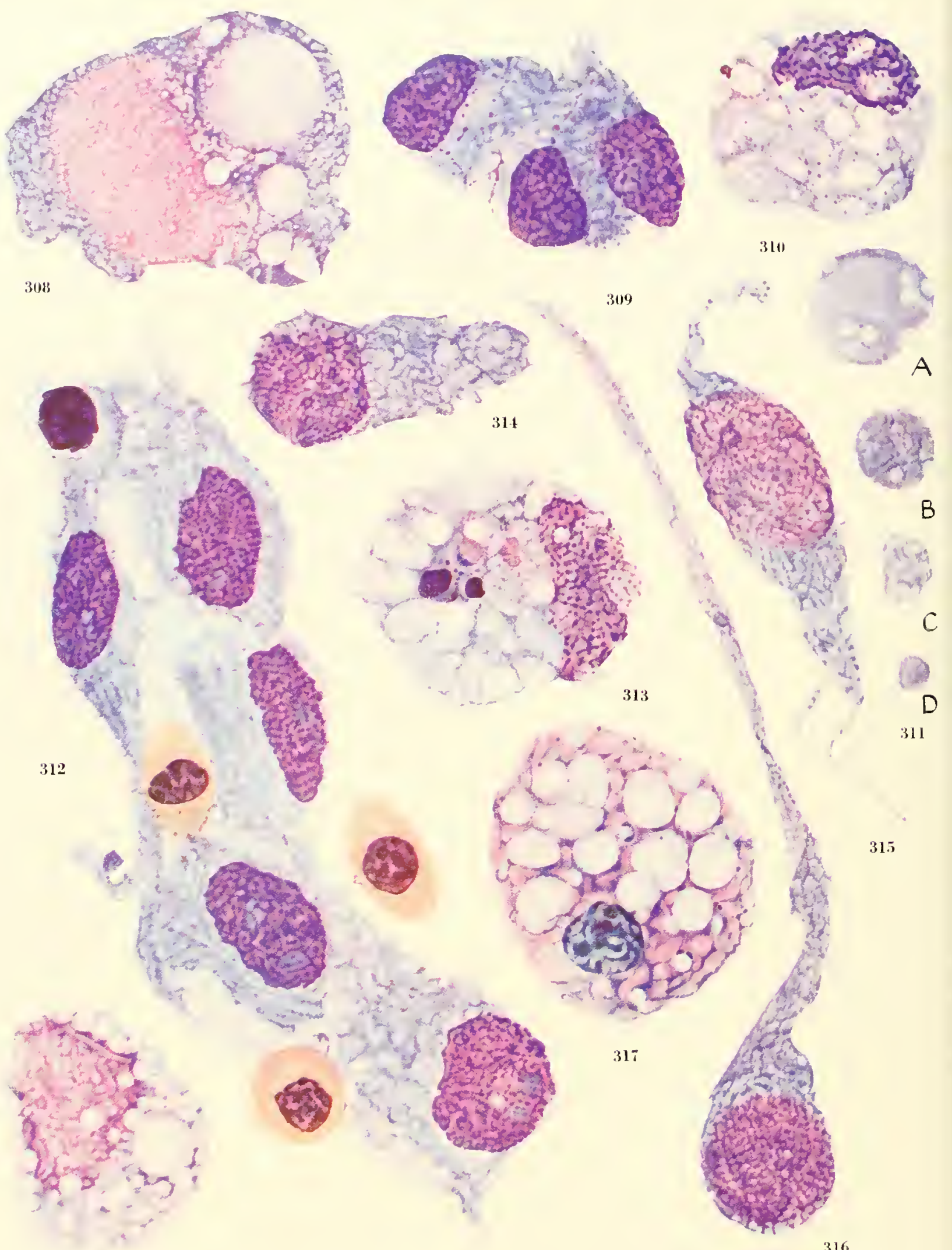
possible that an embryo carying a pathogenic organism could produce masses of reactive cells that, after leaving their point of origin, become thrombi of the circulating channels, but a simpler explanation seems more reasonable at present. When the glass cammula penetrated the ventricle, it was quite likely, if the tip were dull or jagged, that some heart tissue, particularly the lining cells, would be separated from the wall and would then be sucked up with the blood. Hearts from embryos of the same age-10 days of inculsation-were used in a test of this hypothesis. They were removed from the lody and opened, and the blood was washed out. A slide was pressed against the endothelial surface and from it came the type of cells shown in figures 314-3] 6 . Figure 316 was the longest cell obtained by this method. Most of the cells were of the size and shape shown in figure 314 and some were like 315. There is a measure of similarity of nuclear and cytoplasmic pattern between these cells and those of figures 309 and 312, but there is still room for doubt that they are all of the same type.

The endothelial cells of the liver and spleen are phagocytie in pigeons (Kyes, 1915). The cells are capable of ingesting erythrocytes under normal conditions and after the contained erythrocyte has been digested, the hemophage reverts to a flattened endothelial cell. Kyes' olservations are mentioned here hecause it may help toward an understanding of the oceurrence of macrophages within the heart of the emlnyo chick.

It was noted, in the study of blood spors, that macrophages underwent degeneration and only some of the cells retained the punctate paitem of chromatin of the type seen in figmres 309. 310 , 312 , and 313. Ofien when karyolysis of the nucleus occurred, the underlying nucleolus was brought into view. There is a suggestion that nucleoli are present in figure 312 . Nucleoli were conspicuous in some slides of chick embryos that were sent to this Laboratory for cell identification; the embryos had been inoculated with a pathogen from man and the circulating blood showed a series of transitional stages from the reticular cell to the reactive cell.

Some studies have been made on the defense. reaction mechanism in birds lut perhaps the greatest need at present is to identify by the smear method the cells that, in the celloidin sectioned material, are called resting amoel jojd and wandering cells. As the problem now stands, a sudy of the actual number of different lypes of macrophages is confused by differences in technics that make even identical cells look different.

It has been claimed by Dantschakoff (1931) that the endodermal wandering cell was actually the primordial germ cell caught in its migra. tion from the extraembryonic splanchnopleure to the gonadal ridge. Dr. Robert E. Smolker of

Figures 308-318. - Reticular or phagocytic cells found in blood and vascular organs of the embryo.

$$
2,470 \times \text {. }
$$

308 Early embryo materophage, yolk sac type. Blood from dorsal aorta. Embryo incubated 1 day 22 hours.

309 Embryo macrophage, beginning differentiation from its stem cell. Circulating blood taken from the heart. Embryo incubated 9 days 16 hours.

Figures 310-313: Wature embryo macrophages and cell fragments. Blood taken from the heart. Embryo incubated 9 days 16 hours.

310 Mature enbryo macrophage. Only a fen granular inclusions.

311 Cytoplasmic spheres ranging in size from large to small, A to D. Believed to be pinched-off pieces of macrophage ertosome.

312 A group of macrophage stem cells, essentially mesenchyme. Probably pushed into the cardiac blood strean by the entrance of the cannula. Two nucleoli in each nucleus. Three embryo erythrocytes shown in the field.

313 Mature embryo macrophage containing acidophilic and basophilic inclusions. Vacuolization typical of functional macrophages.

Figures 314-316: Cclls from a touch preparation of inner surface of embryo heart. They resemble, but may not be ideritical with, those of figures 309 and 312. Embryo incubated 9 rays 22 hours.

314 A nearly rounded cell.

315 Cell with bipolar processes.

316 Cell with a long unipolar proeess.

317 Postmortem degeneration of a maerophage, embryo (21st day of incubation) killed and held in the cold 2 hours. Embryo still had a large external yolk sac. Cell from spleen impression smear.

3 Is Macrophage from blood of basilic (cubital) vein. Chick just hatched. 
the Department of Natural Science, Michigan State University, has demonstrated (personal communication) sections of early embryos that clearly revealed the primordial germ cells. Even in sections they were considerably larger than any of the blood cells seen in the embryo, including the primary generation of erythrocytes. Very probably we have never seen primordial germ cells in our smears.

A final bit of data is the macrophage shown in figure 318 . It was not obtained by cardiac puncmue hut in a drop of blood from the hasilic vein of a chick hatched only a few hours before the sample was taken. In some ways the high degree of vacuolization and the rather delicate muclear pattern resemble the yolk macrophage of a 2 -dayold embryo more than they do the macrophages of a 10-day-old eminyo.

An impression smear from the spleen of a late embryo that, after killing, was left at room temperature for about 2 hours produced still another type of phagocytic cell (fig. 317). The strong acidophilic reaction of the eytoplasm is characteristic of post mortem degeneration and this type of vacuole formation can be seen in tissue-culture rells when the culture is held under unfavoral,le conditions. The muclear structure is entirely different from that found in the 10-day-old embryo; in fact, the entire cell is morphologically different from any macropliage described thus far.

\section{ADDENDUM}

Throughout this hook and in a recent publication (Lncas. 1959), it has heen repeatedly mentioned that in smears or touch preparations the nuclei of erythroblasts and thromboblasts nsually reveal their nucleoli, whereas the nuclei of gramuloblasts and lymphoblasts rarely do. During the period following the completion of the mannscript, an effort has been directed (1) toward the identification of the tissue components in different hematopoietic organs from which the various blood cell lines take their origin and (2) toward the identification of equivalent cells in sectioned material with the named stages of de. velopment fonth in touch preparations.

From onl studies thus far it appears that the presence or absence of a mucleolus is a variable that is dependent more upon the size of the cell and its level of metabolic activity than upon its leing a fixed morphologic structure. We are not including here the pseudo-nucleoli that are chromocenters in some animal cells. From sec- tions showing stages in development of the granulocyte series the nurleolus appears first in the metagramuloblast, reaches its maximum size in the promyelocyte and then disappears during the subsequent stages. The areas on the right of the muclei in figmes 382 and 383 that stain a faint bluish color are probably nucleoli of the basophil promyelocytes.

Ackernan and Knonff (1959) picture the lymphoblast in the bursa of Fabricius with a mucleolus. Our own studies indicate that this is probably true also in the thymus, but it is still mnertain that this is the case in spleen and bone marrow.

Regardless of how miversally a nucleolus may prove to be present, based on sections of avian tissues, the usefulness of its variable visibility as a tool in the study of smear preparations is not nullified; by this tool. erythroblasts and thromboblasts can be distinguished from granuloblasts and lymphoblasts. 


\section{Blood Cells From Hematopoietic Organs of the Embryo}

There is gencral agreement that during the life of the chicken, erythrocytes have an intravascular origin and myelocytes an extravascular origin. From the present study, and the work of others, it appears proloalole that the broader generalization can be made that viahle erythrocytes and thrombocyles have an intravascular origin and all leukocytes have an extravascular origin. Basically, this agrees with Dantschakoff's (1908a and 1909a) concept, except that she calls a prim. itive blood cell a lymphocytc; whereas, in this study a lymphocyle is considered to be the mature stage of a distinct lenkocyte line and not a stem cell or primitive blood cell.

The erythrocytes and the thrombocytes are the only two cell types normally present in the circulating lolood of the chick embryo. All others that devclop within hematopoietic organs are held there until after hatching. Granulocytes appear in great abundance in bone marrow, spleen, kidney, pancreas, and sometimes in the liver and other parenchymal organs. According to Dantschakoff (1908a and b) and Danschakoff (1916h and c), gramulocytes also develop in the yolk sac and in the thymus, and Nonidez (1920) found developmental stages in the ovary after hatching. The bird in its hematology is reminiscent of some of its reptilian and amphibian ancestry where blood-cell development is willely scattered over the hody (Dawson, 1932). Danschakoff (1916c) observed that in emlryo chicks there was a similar wide potency of the mesenchyme to form l)lood cells. She found that during normal development this potency was restricted to certain tissues but if transplants of picces of adult organs were made on the allantois of the early embryo, the mesenchyme cells among the striated muscle fibers, and among the cells of liver, kidney, and ovary, and in the walls of major vessels, took on hematopoietic functions. Often the circulating blood simulated that of lenkemia.
Were we to judge from information on manmals, we might expect the liver to be an active cmbryonic hematopoictic organ; but in the chicken it remains practically free of developing blood cells (Bizzozero, 1889, and Dantschakoff, 1908a and b). The difference between birds and mammals may be due to the existence of a large yolk sac in birds and a reduction to a rudimentary condition in mammals. Dantschakoff observed that the liver of the normal chick embryo was not a hematopoietic organ, but according to Haff (1914) it does have such a function for both erythocytes and gramulocytes. The endothelial cells of the liver sinusoids proved to be the point of origin by way of a "large lymphocyte" for the different cell types. Wislocki (1943) observed that in a species of monkey that had adapted the placenta to the function of a hematopoietic organ, the liver had heen relieved of this function and showed no blood-cell development. The pancieas of the chick at 19 days of incubation is packed with heterophils. Whether this organ serves as a hematopoictic center or as a storage depot for the grammlocytes produced ly spleen and bone marrow has not been determined. It was noted by Mrs. Effie M. Denington, a member of the staff of this Lab. oratory who made thesc observations, that, among different embryos, there is wide variability in the number of heterophils present.

\section{EHBIRYO BONE MARROW}

Certain differences between bone-marrow formation in bircls and in mammals has been pointed out by Hamilton (1952), who says (p. 508):

"There is never any independent epiphysial center of ossification in long bones of birds, as there is in mammals. The ends of the bones remain cartilaginous for awhile and provide for 


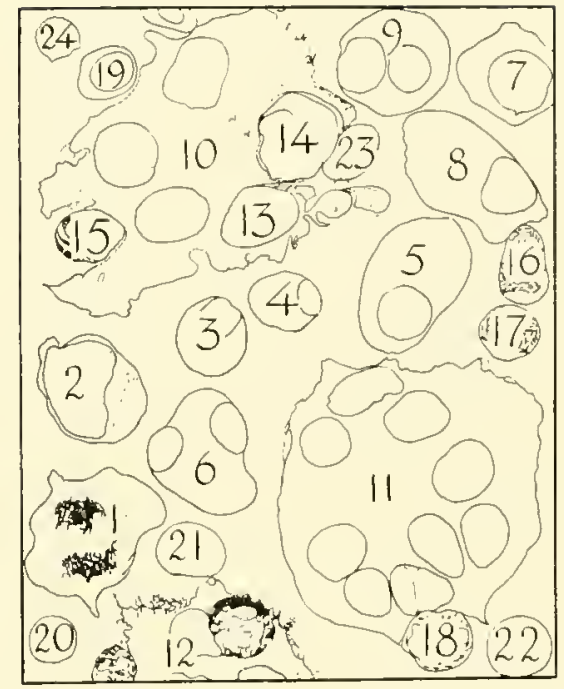

Figure 319.- Embryo bone marrow. Composite from two slides. Embryos incubated 11 days 21 hours.

$$
1,370 \times \text {. }
$$

1 Primordial osteogenic cell in mitosis, late anaphase.

2 This cell resembles a metagranuloblast except for the Ifof. Contains a few small magenta bodies.

3, 4 Simall mature osteoblasts.

5 Large young osteoblast.

6 Two small young osteoblasts dumped closely together.

7 Early mononuclear osteoclast.

8 Large monomuclear onteoclast.

9 Binuclear osteoelast.

10 Mutinuclear osteuclast indented by three cells of the granulocyte series.

11 Iultinuclear usteoclast.
12 Part of a multinuclear osteoclast showing a magenta sphere near the upper edge.

13 Cranuloblast indenting an usteoclast.

14 Heterophil promyelocyte.

15 Heterophil metanyelocyte.

16-19 Mature granulucytes. Some show degradation of the rods.

19 Early nolychromatic embryo erythroeste.

20 Late nolychromatic embryo erythroeste.

21,22 Mature enbryo erythocyte of the primary erythrocyte type.

23 Mature embryo ersthrocyte of the later generations type.

24 A pinched-oll protoplasmie mass. 


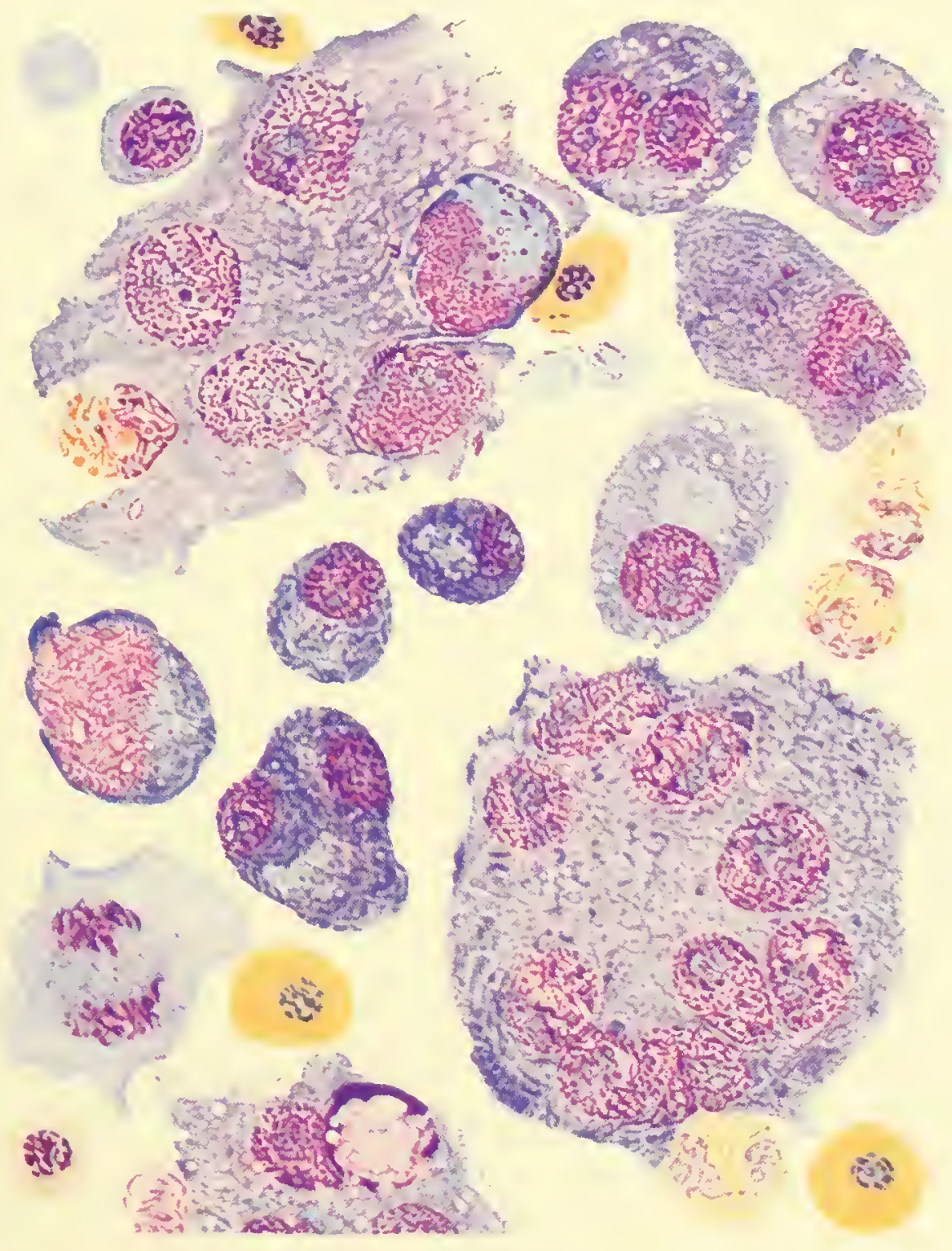




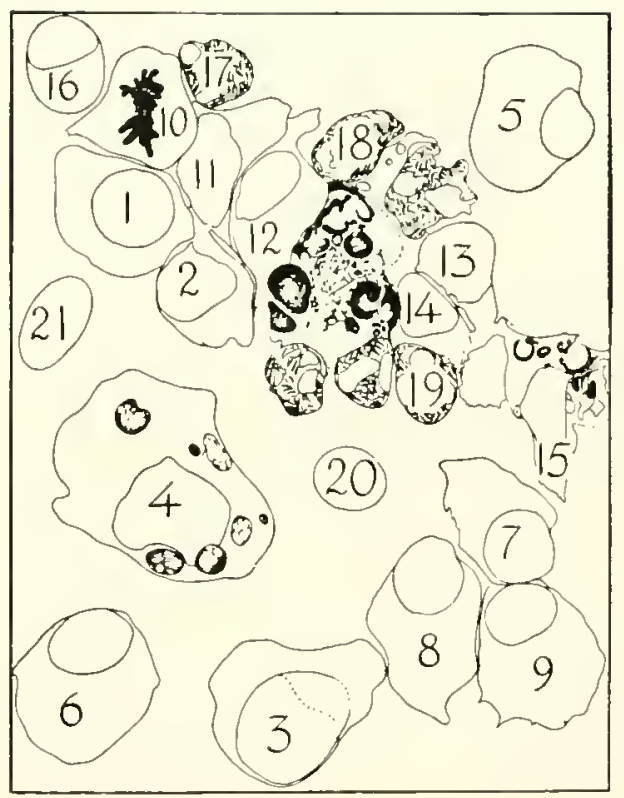

Figume 320.-Embryo bone marrow. Composite made from 3 places on the same slide--the long cluster of cells from 1 area, 6 cells from a nearby area, and 3 from another area. Embryo ineubated 12 days. Nearly the same age as embryo used for preceding plate, yet definitely more advanced in development. $1,370 \times$.

1-3 Primordial osteogenic cells. Cell 2 is more differentiated than 1 and 3.

4 Primordial osteogenic cell with 2 magenta granules and 5 magenta spheres.

5-9 Large young osteollasts.

10 A primordial osteogenic cell or granuloblast in mitosis, early anaphase.

11, 12 Netagranuloblasts. The identification could have been made more certain had they been fixed in their spherical shape.
13, 14 Probably belong to the granulocyte series.

15 A cell with magenta spheres in the cytosome.

I6 Heterophil mesomyelocyte.

17-19 All these cells are mature heterophil granulocytes.

20 Late polychromatic erythrocyte with fractured eytosome, a technic artifact.

21 Mature embryo erythrocyte of a later generation. 


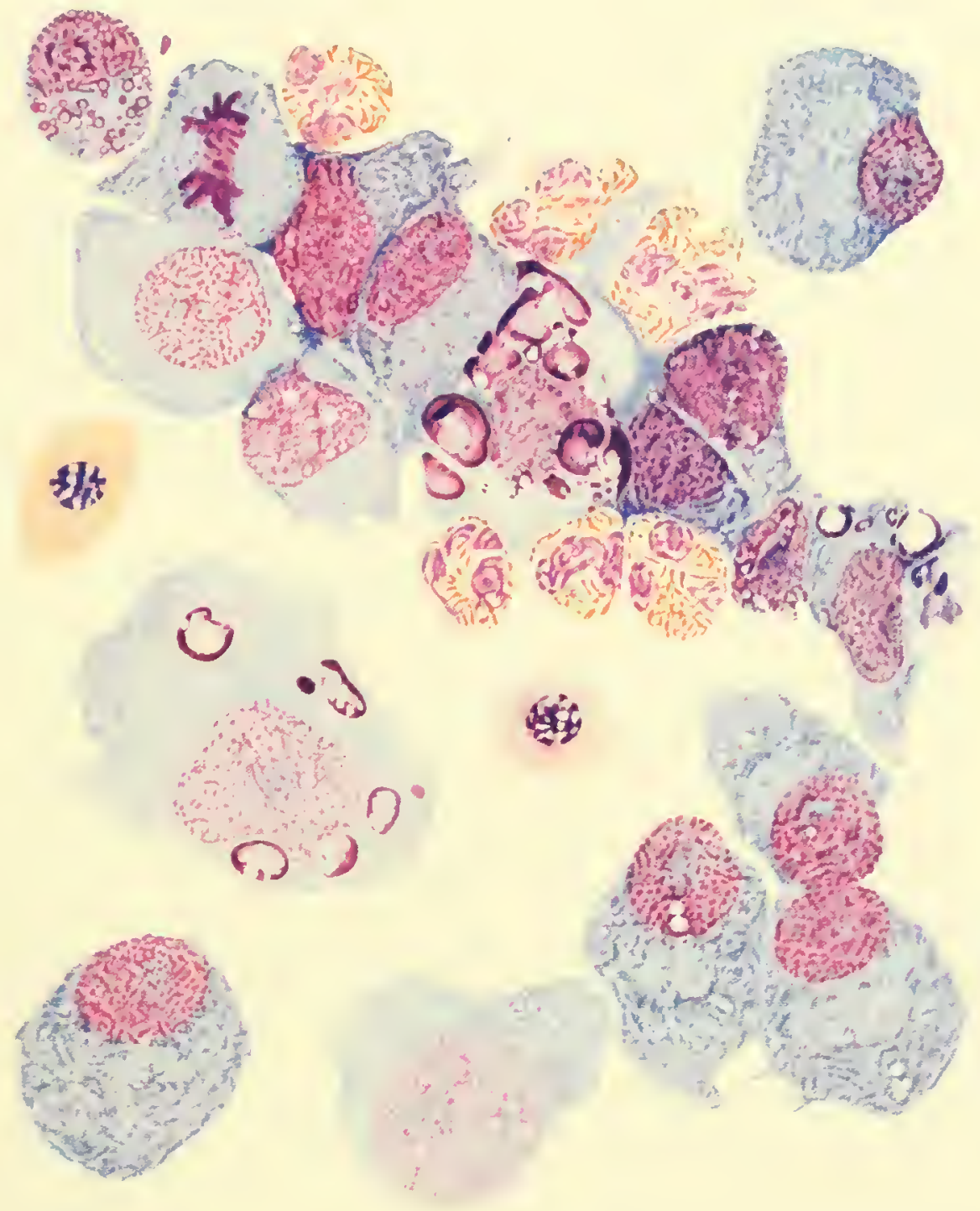




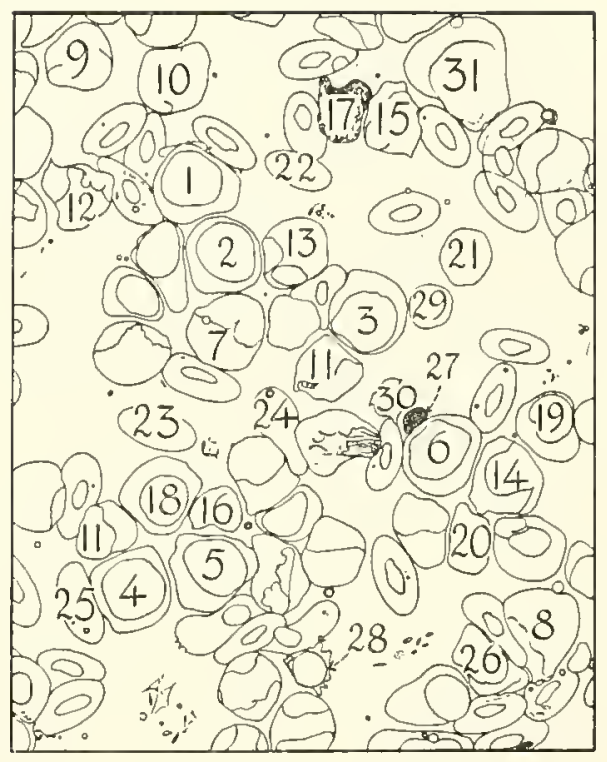

Figure 321.-Embryo bone marrow. Embryo incubated 20 days. 1,370 .

1-6 Granuloblasts, all at about the same stage of development.

7,8 Heterophil mesomyelocytes.

9-11 Heterophil granulocytes with one nuclear lobe.

12-14 Mature heterophil granulocytes with more than one lobe.

15, 16 Eosinophil granulocytes with one nuclear lobe.

17 Mature or nearly mature basophil granulocyte.

18-20 Early polychromatic erythrocytes.

21 Mid-polychromatic erythrocyte.
22, 23 Mature definitive erythrocytes.

24, 25 Erythrocytes showing magenta rings and a rod of heterophils that fell on top of the red cell when the smear was made.

26 Thromboblast.

27 Degenerated thrombocyte.

28 Lymphocyte.

29 Naked nucleus.

30 Snudged rucleus.

31 Partially smudged primordial osteogenic cell. 


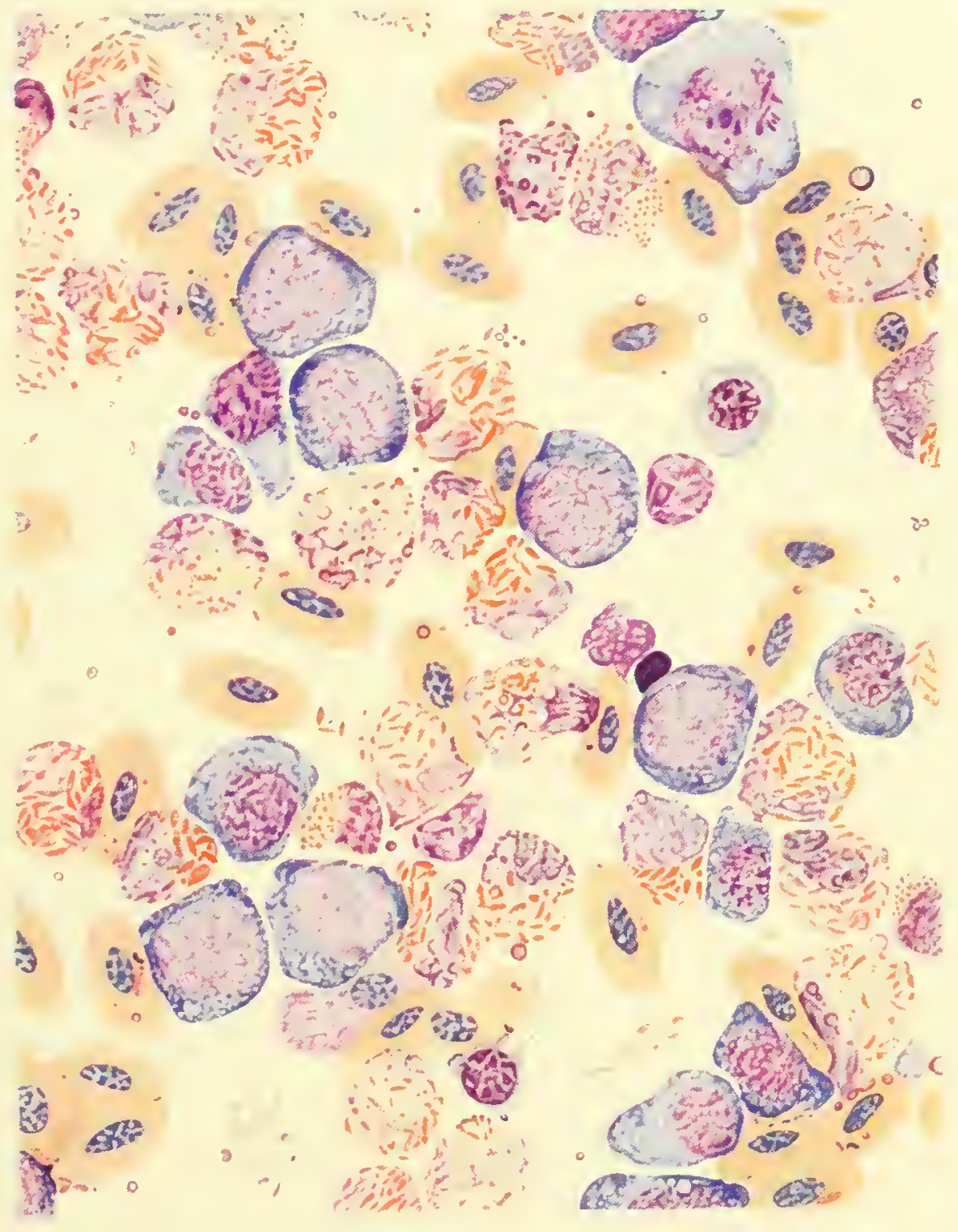


Figures 322-328.--Embryo bone-marrow cells and serum. 2,470 $\times$.

322 Stained serum fuid and granules that almost always cover the cells in embryo bone-marrow smears. Embryo incubated 19 days 18 hours. Figures 319 , 320 , and 321 drawn with these granules and stained serum omitted.

323 A large young osteoblast, not as typical as those shown in figure 320 . Embryo incubated 14 days 11 hours.

324 Primordial osteogenic cell. Some vacuoles with magenta crescents. Embryo incubated 11 days 21 hours.

325 Slightly smudged primordial osteogenic cell. Same slide as in preceding figure.
Figures 326, 327: Mononuclear osteoclasts. Same slide as in figure 324 .

326 Faint acidophilic material filling the cytoplasmic spaces on the upper left side of the nucleus is characteristic of osteoclasts from adult bone marrow. Compare with figure 398.

327 Two magenta spheres at the tip of the cell.

328 Mononuclear osteoclast with numerous magenta spheres. At the left are acidophilic bodies characteristic of the osteoclast. Embry o incubated 16 days 19 hours. 


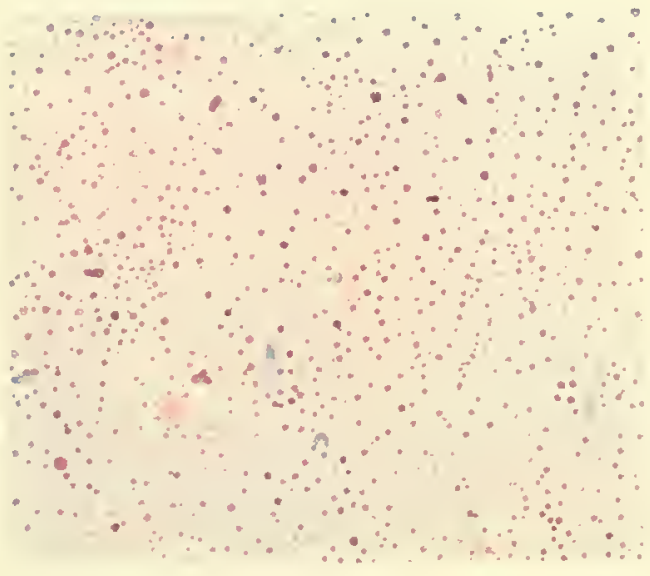

322

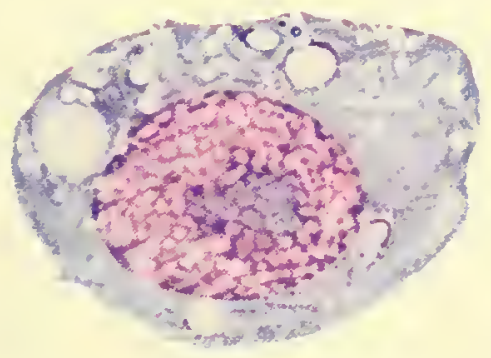

324

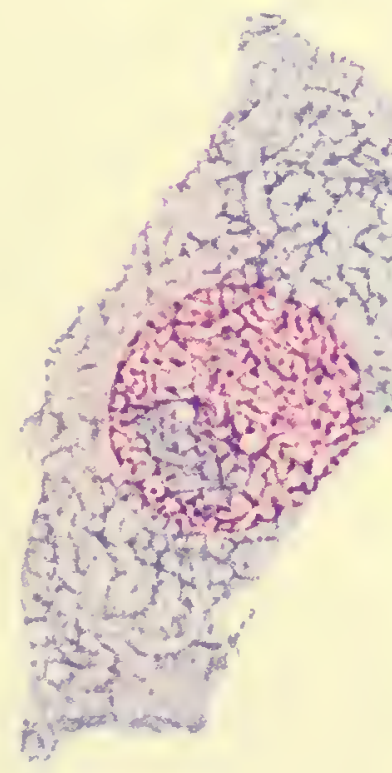

326

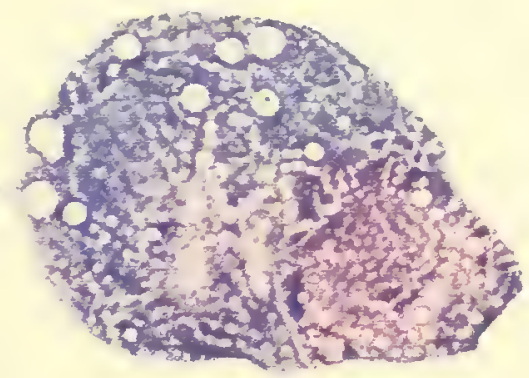

323

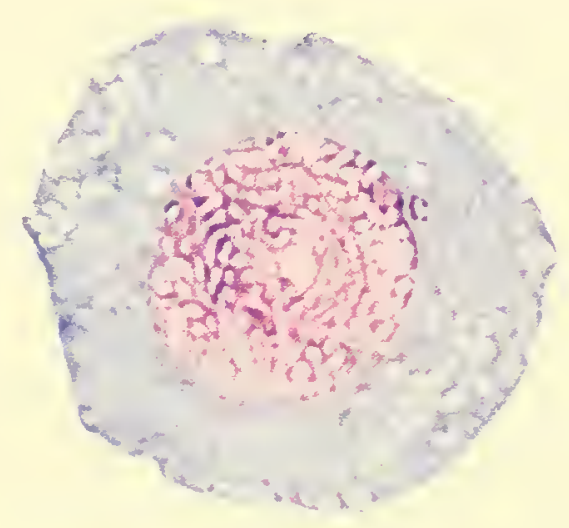

325

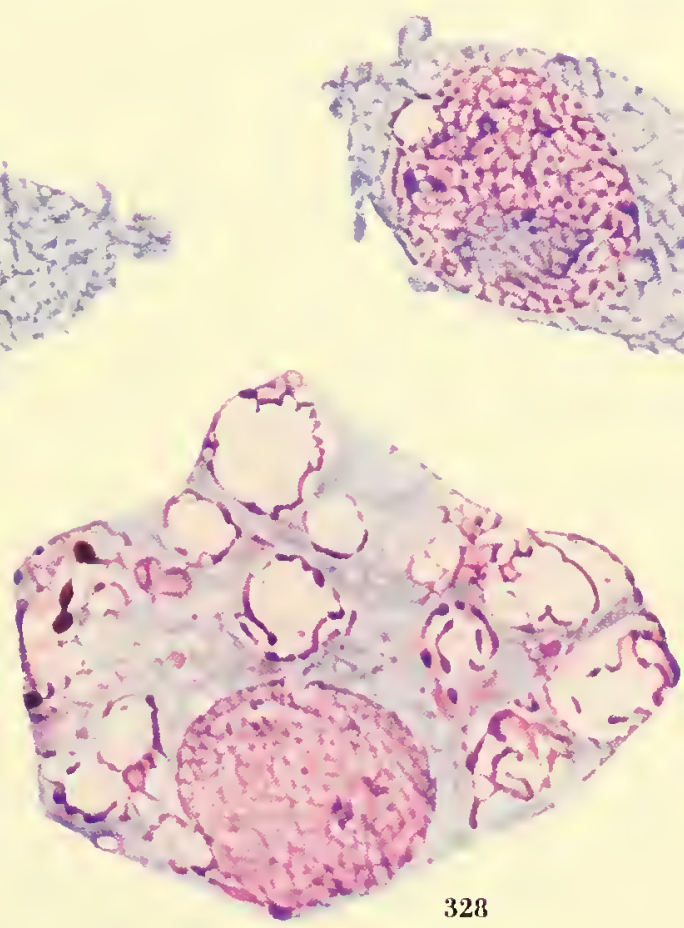



growth in length, but they are eventually ossified and united with the shaft as the marrow cavity of the latter extends out into them.

". . The marrow cavity is enlarged by the chondrolytic action of all the vascular elements, but chiefly by the walls of the budding blood ves. sels. As the chondrocytes are liberated from their enclosing matrix, they rapidly degenerate and are apparently not converted into marrow cells as previously believed; the cells of the marrow are presumably brought in from the mesenchyme and periosteum by the intrusive blood vessels.

"In birds, calcification does not precede absorption of the cartilage, as it does in mammals, until the greater part of the marrow cavity is formed. The cones of cartilage, referred to above, that are continuous with the articular cartilages, are absorbed about ten days after hatching."

The histologic details of cartilage and bone formation in the appendages of the embryo chick have been described by Dantschakoff (1909b). The marrow cavity appears in the humerus, tibia and femur on the eighth to ninth day of incubation. She finds that the initial perforation into the region of the marrow cavity comes from the action of osteoclasts breaking through the thin wall of newly formed bone. The opening permits the entrance of surrounding mesenchyme cells.

She divides marrow cavity production into two phases (p. 876) :

"In der Fntwicklung des Knochenmarks bei den Vögehn gibt es eine gewisse, ziemlich lange, von 9, bis 12. Tage dauende Periode, während welcher seine Struktur und seine Differenzierungsprozesse sich so sehr von dem endgül. tigen Zustand am Ende des fetalen Lebens interscheiden, dass es wohl berechtigt ist, wenn ich diese Periode von den ibrigen tremne, und das Mark während derselben als primitives Knochenmark bezeichne. Das hauptsachlichste Unterscheidungsmerkmal dieser Periode ist das vollständige Fehlen einer Blutbildung in den Gefässen, diese letzteren dienen zu dieser Zeit bloss zur Ernährung des Gewebes nnd enthalten zirkulierendes Blut, welches aus mehr oder weniger reifen Elementen besteht. . . ."1

The description of these first vessels is as follows (p. 877):

"Die Blutgefässe haben im primären Knochen- mark eine sehr charakteristische Lage. In der Mitte, parallel der Längsachse der Markhöhle, verläuft eine Arterie, die sich in den änssersten Teilen der Höhle stark erweitert und dann in zwei noch breitere dünnwandige Venen übergeht. Ein Unterschied im Inhalt der beiden Gefässe existiert vorläufig nicht. Die Kapillaren sind spärlich." 2

The histogenesis of bone has been a secondary consideration in this study, but osteoblasts and osteoclasts were encountered during the search for early stages of blood-cell development.

When the femur of a chicken, incubated about 12 days, is split open so that a plug of marrow projects beyond the spicules of bone and this is tonched to a slide, cells of the types shown in figures 319 and 320 are found. The embryo that produced the cells shown in figure 319 was a few hours younger than the embryo that produced figure 320 . In all bone-marrow smears made at this age an abundance of serum granules as in figure 322 , is always present. Numerous smears were made to get one sufficiently clear for detailed study. For this reason, the low-power drawings in figures 319 and 320 are composites. Serum grannles were present in the fields from which these two plates were made but were omitted in the drawing.

The least differentiated cell in bone-marrow smears from embryos of 11 to 12 days of incubation is the type shown in cell 1 of figure 319. Figure 320 shows three additional cells belong. ing to this category. Cells $I$ and 3 of figure 320 are typical of the early osteogenic cell and cell 2 is somewhat more differentiated. The lightly stained cytoplasm is the most characteristic fcature, along with a pattern of scattered, basichromatin granules that are delicately stained.

\footnotetext{
${ }^{1}$ Translation: In the development of the bone marrow in birds there is a certain rather long period, lasting from the 9 th to the 12 th day, during which its structure and its process of differentiation are so distinct from the final circumstances at the end of the fetal life that there is good reason for me to separate this period from the rest, and to designate the marrow during this time as primitive bone marrow. The most important mark of distinction of this period is the complete lack of a hematopoietic process in the vessels; at this time these serve only to nourish the tissue and conlain circulating blood, which consists of more or less malure elements. . . .

"Translation: The blood vessels have a very characteristic location in the primary bone marrow. In the middle, parallel to the longitudinal axis of the marrow cavity, there runs an artery that widens greatly in the outermost portion of the hol. low and then merges into two still wider thin-walled veins. At the time there is not any distinction in the contents of the two vessels. The capillaries are scanty.
} 
The nucleolus is visible in 2 of the 3 cells shown in figure 320. Since primordial osteogenic cells are relatively rare, it has not been possible to study them in as wide a variety of circumstances as would be desirable. At one time it was thought that they stained lightly because they were partially squashed, and the nuclear staining in figure 325 and in cell 31 of figure 321 may be evidence for this: but the idea has been given up because, if squashed, the chromatin should show some liquefaction. It is agreed that they are probably delicate and easily broken, but they have been seen intact in sufficient numbers to warrant the belief that they make up a distinct cell type.

Cell 2 of figure 319 shows cytoplasmic differentiation leading toward the osteoblast or the gramulocyte. Had a nucleolus been visible, the possibility of development toward the granulocyte would have been excluded. Cell 2 of figure 320 shows differentiation toward the osteoclast. It is believed that both osteoblasts and osteoclasts of these cell lines arise from a com. mon sten cell, called the primordial osteogenic cell, which, as shown in these figures, is a large cell witl abundant pale-staining cytoplasm and a definite nucleolus. At the same time osteo. genic activity is taking place, myelocytes also are making their first appearance. This cell lias many features in common with the primordial osteogenic cell. The nuclear stricture of ccll 2 of figure 319 resembles that of a myelocyte, but the strong mitochondrial spaces, the intense blue staining, and especially the clear area beside the nucleus indicate that it is an early osteoblast. The magenta granules are not so large as they typically are for myelocytes and there may be some question of whether they are on or in the cell; if they were in it, the fact would add weight to the idea that this was a metagranuloblast or an early promyelocyte. In figure 320 somewhat similar cells ( 11 and 12 ) have been identified as metagranuloblasts and probably cells 13 and 14 are the same.

Dantschakoff (1908b) states that the hone marrow begins its blood-forming function on the 14th day of incubation.

Large young osteoblasts (cell 5 of fig. 319 and cells 5-9 of fig. 320) sliow their inmaturity by their large size, lightly stained cytoplasm, open reticulate chromatin pattern, and clearly risible nucleoli. Vacuoles are present in the cytosome and some of these are pushed up into the nuclear substance but they are not so abun. dant as in the osteoclasts.

Small mature osteoblasts (cells 3, 4, and 6 of fig. 319) are more differentiated than their precursors, the large young osteoblasts. The cytoplasm stains more intensely than any other cell of the marrow. Mitochondrial spaces are not so distinct as they were previously and the clear area adjacent to the nucleus is often masked. The nucleus retains the eccentric position it previously had but now it is smaller, and the chromatin pattern is condensed. which causes it to stain more intensely. All these features are shown in the high-power drawing of a cell from an embryo incubated 14 days 11 hours (fig. 323). Osteoblasts may clump as in cell 6 of figure 319 but this apparently binucleated condition does not make this an osteoclast like cell 9.

These small cells are called mature because they are morphologically identical with cells observed adjacent to bone in sections. They have a darkly stained cytoplasm and a distinct paranuclear area. The texts on general histology call these blast cells, but, functionally, they are mature. $^{3}$ They form a row along the bone spicule and produce a bone matrix. Eventually they will be surrounded by this matrix and will rest within a lacuna; they will then be called osteocytes.

Cells 7 and 8 of figure 319 are mononuclear osteoclasts. The appearance of the cytoplasm of one of these cells is quite different from the cytoplasm of the other; cell 8 has many orangecolored granules to the left of the nucleus and no vacuoles; cell 7 has only a few orange-colored bodies but has many vacuoles. The binucleate cell, 9, also has numerous vacuoles but no orange

\footnotetext{
${ }^{3}$ This Atlas may not be a suitable work in which to propose changing the name of the functional bone-producing cell from osteoblast to something more appropriate, but it does seem somewhat confusing to retain the suffix "blast" through all the developmental stages of this cell. It is recornized that "large young osteoblast" is not an adequate substitute lerm for the immature stage. Any attempt to standardize hema. tologic nomenclature should include all the connective-tissue derivatives, the phagocytic cells. and the cells of the circulating blood and their developmental stages, and this must come from the united efforts of many scientists. The same confusion exists in assigning terms to the developmental stages of the osteoclast. They could be called osteoclastblasts and osteoclastcytes, but these terms are awkward. For the present the stages are separated on the basis of the number of nuclei, on the assumption that the number is a fair measure of the stage of differentiation.
} 
bodies; the multinucleate cell, 10 , has both; cell 11. which is similar to 10 , has neither. The cell in figure 326 is shown under high magnification to reveal the orange bodies in greater detail. These characters are present in some cells, and are absent from others. This is true not only in the embryo but also in the adult bone marrow (figs. 398 and 399). Regardless of these variations the bone marrow of the bird contains but a single type of giant cell, the osteoclast, whereas in mammalian bone marrow there are two typesthe one just mentioned and the megakaryocyte, which produces platelets. Nucleoli found in the binucleate and mononucleate stages of development are still retained in the nuclei of the fully differentiated osteoclasts of bone marrow from adult birds.

A conspicuons nucleolus, characteristic of the osteoclast, may be found also in tissue culture of this cell (Hancox, 1946). This author expressed the opinion that the multinucleated condition of this type of giant cell arose by a fusion of cells, rather than by multiple division of a nucleus within a single cell.

The cytoplasm of some multinucleate osteoclasts contains magenta-colored bodies. Some of these bodies have irregular shapes; some, like the example in cell 4, of figure 320 , are spherical; and some - see those between cells 12 and 14 of figure 320 -are masses of stainable substance without definite form.

A series of mononuclear osteoclasts have been drawn under high power in order to give a closer view of this substance. Figure 326 is a young osteoclast showing the characteristic vacuolization of the cytoplasm, but without magentacolored strands. In figure 324 a slight amount of this material exists in the form of curved bars concentric to the vacuole walls. Two spheres are shown in the lower tip of figure 327; the magenta bodies contained within them are not as definitely an integral part of the cell as are the curved bars in figure 324. A rather extreme condition is shown in figure 328 , where many vacuoles contain many, twisted threads of this substance, but more important is the fact that at the left side of the cell this substance appears to be undergoing a transition to the typical orange masses characteristic of osteoclasts generally.

The magenta sulstance seemed to have a predilection for osteoclasts even in the early stages (cell 15, fig. 320). This was not always the case, however, and other cell types might show vacuoles with colored strands of this type. These magenta masses did not appear in sectioned material, which suggested that they are artifacts but did not prove it.

Sometimes magenta masses occur in the serum outside the osteoclasts. Since they appear to merge with the serum, it is possible that serum condensations on the cells at the time the slide is made could account for all these irregular magenta-stained bodies but certainly this is not a convincing conclusion at present.

Another possibility considered was that this substance represented a dissolved cartilaginous matrix taken up by the osteoclasts, or that cells containing this substance represented hypertrophied and degenerating cartilage cells liberated into the expanding marrow cavity. Cartilage at the end of the femur was pressed hard against the slide in making the smears but no cells were found with a morphology that would support the idea that nugenta-colored masses and strands arose from cartilage cells. In fact no evidence was obtained by the smear method that cartilage cells were liberated into the marrow cavity after the cartilage was dissolved. By the section method, Dantschakoff (1909b) observed that viable cartilage cells survived after the lacunae broke down. She stated (p. 874):

"Die Knorpelzellen, die dabei aus ihren Kapseln befreit werden, bieten besonders bei dem ersten Auftreten der Markhöhle keinerlei Anzeichen von Degeneration. Sie bleiben als runde helle Zellen zwischen den Elementen des von aussen eindringenden Mesenchymgewebes liegen. Einige von ihnen, die dem Rande der Höhle unmittelbar anliegen, zeigen sogar im Gegenteil mitotische Teilungsfiguren. . . ." 4

Conceming their later history, she says ( $p$. $882)$ :

“. . . Die aus den Kapseln befreiten Knorpelzellen vermischen sich in der engsten Weise mit den Elementen des in dasselhe Gebiet eindringenden jungen Mesenchyms. Bei ihrer allmählichen Entfermung von der Knorpelgrenze scheinen sie sich zu strecken und Ausläufer zu bilden.

\footnotetext{
${ }^{4}$ Translation: The cartilage cells which thus become free of their capsule do not give any sign of degeneration especially at the first emergence of the marrow cavity. They persist as round clear cells among the etements of the mesenchyme tissue that is penetrating from the outside. On the contrary, some of them, lying right against the edge of the hollow, exhibit mitolic division forms.
} 
̈̈hnliche Bilder lassen mich annehmen, dass die sich befreienden Knorpelzellen an der Ausbildung des Knochemmarkstromas aktiv teihnehmen können. Wit Sicherheit kann nan błoss ihre unmittelbare Teilnahme an der Bhutbildung verneinen. Es ist aber sehr schwer, etwas bestimmtes über ihr weiteres Schicksal auszusagen, weil sie ja wenigstens zum Teil, wie gesagt, allmählich alle histologischen Merkmale der umbebenden Mesenchymzcllen annehmen und infol. gedessen nicht mehr erkannt werden kömmen."

Gramulocyles in all stages of development from granuloblast to mature heterophil are found in figures 319 and 320 . The developmental stages will not be described here since they are to be discussed fully under adult bone marrow, but one characteristic noted at this time is the tendency of heterophils, whether they be immature or mature, to clump with other cells. Three heterophils lie within marginal depressions of the osteoclast. cell 10 of figure 319 , and in figure 320 cells of various types, including heterophils, have clumped together. Developmental stages of erythrocytes do not clump. Femnel (1947) reports (p.237) that "Giant . . . cells frequently give rise to one or more granulocytes by the production of cellular blebs. Such blehs ultimately pulled away from the surface and hecame free. Giant cells under other conditions fragnented to form thrombocytelike cells." The cellular details shown in his drawings of this process taken from vital-stained preparations are not sufficient to permit determination of whether his giant cell was an osteoclast, a macrophage, or a clump of cells. Nothing has been observed in this study to indicate that any type of giant cell ever produces thrombocytes or granulocytes.

The manow, during embryonic life, is involved primarily in the production of granulocytes and erythrocytes, and although probahly more erythrocytes than granulocytes are actually produced, it appears to be the other way around

\footnotetext{
- Translation: The cartilage cells released from the capsule mingle in the most intimate way with the elements of the young mesenchyme that are penetrating into the same terri. tory. As they gradually get farther from the cartilaginous boundary they seem to siretch out and to form outrunners. Similar pictures lead me to assume that the cartilage cells that are freeing themselves can take an active part in the formation of the bone marrow stroma. One can with surety only deny their direct participation in hematopoiesis. But it is very hard to state anything certain about their future destiny. since, as has been said, they gradually take on, at least to some extent, all the histological earmarks of the surrounding mesenchyme cells, and hence cannot be recognized any longer.
}

because the erythrocytes are discharged into the circulating blood and the granulocytes are held in depots until after hatching. A study of the whole matter of relative production rates in various hematopoietic organs should be carried out. It should include a study of the yolk sac. Hematopoiesis in the yolk sac has been omitted from this study for two reasons-first, it does not lend itself to the smear method and, second, it has been covered by the extensive writings of Dantschakoff (1908b) on sectioned material and of Sabin (1920) on living preparations. The importance of using the smear method for a study of erythropoiesis and granulopoiesis in the case of the pigeon has heen emphasized by McDonald (1939), who says (p. 293), “. . . The chief advantage of the imprint method is that it brings out the finer structural features, especially those of the nucleus, which are so important in critical studies of immature cells. . . ."

Gramuloblasts are much more abundant in the bone marrow before hatching (cells 1-6, fig. 321 ) than aftcr. Six of them are shown in one field and they occur in the spleen at this age (frg. $330)$ in the same high concentration as in bone marrow. Actually cells 2 and 4 are the least differentiated; the nucleus lies in the center of the cell and the rim of cytoplasm is narrow and staina intensely bine. The remaining cells show defi. nite changes leading toward the metagranuloblast-the muclei have a shightly eccentric position, some of them show points of chromatin condensation, and the cytoplasm is partially broken up by mitochondrial rods. At the metagranuloblast stage, which is not represented on this plate, the cytosome shows vacuoles and inchusions by which a reasonably accurate guess can be made as to the type of granulocyte the cell will be when it is mature. This is not the case in the blast forms shown in cells $I$ to 6 .

Cell 7 of figure 321 is classified as a lieterophil mesomyelocyte but actually it has barely passed the promyelocyte stage. The magenta lings, the indefinite boundary of the mucleus, and the paleorange precursor bodies are all present in cell 7 , but in addition there are a few darkly stained orange bodies. When they have elongated, the orange bodies will be the defmitive rods. Their presence is the basis for calling the cell a mesonyelocyte. Cell 8 is also a mesomyelocyte but it is somewhat older than cell 7. All the characteristics of the promyelocyte are still present but 
more of the definitive bodies are visible. Some of the bodies appear in the round form and some in the rod form. The total number is less than half of the number found in the mature heterophil. A metamyelocyte is shown in the heterophil above cell 28 of figure 321 . This cell does not yet have a full complenrent of rods but the nucleus has condensed until its boundary is distinct.

Other cells (9-1l) are mature, or nearly so, but since they contain but a single nuclear lobe they would be classed as juveniles or as band cells in mammalian blood terminology. Mature heterophils are abundant throughout the smear and some of those having more than one lobe are designated by the numbers $12-14$.

Eosinophils also are held in depots until after hatching. Two cells each with a single nuclear lobe are indicated by numbers 15 and 16 (fig. 321 ) and, in the same field, part of one other cell is shown at the border. With the exception of cell 15 , all these cells are of the small type that, in the bone marrow, is considered to be the source of the small eosinophils sometimes found in the circulating blood (figs. 181-183).

The basophil (fig. 321, 17) is an adult cell in which the distortion due to action of water on the gramules is as great as in the circulating blood, and the poor stainability of the nucleus is as evident here in the bone marrow of the embryo as it was found to be in the circulating blood of the adult (fig. 190).

In this field of bone marrow, no erythroblasts are present but there are three early polychro. matic erythrocytes (fig. 321, 18-20). These examples show considerable range in size, yet all are ahready older than erythroblasts. Cell 21 is a good example of a mid-polychromatic erythrocyte. There are no late polychromatic erythrocytes in this field, and the remaining erythrocytes are mature. It is assumed, not that these mature erythrocytes represent cells held in storage, ready to be discharged later, but that they came into the bone marrow by way of nutrient vessels from outside.

Cell 26 (fig. 321) has been identified as a thromboblast. It has the characteristics of the early stage of this cell line in its densely stained nucleus and cytoplasm. Had the cell not been pressed out of shape during the making of the smear, its identification would have been more certain, but it does not have the characteristics typical of the erythrocyte or the gramulocyte line. Previously it was stated that the erythrocytes and the thrombocytes of an early embryo were difficult to separate; but with increasing age of the embryo, separation becomes easier, and in the adult marrow there was relatively little confusion.

Naked nuclei and smudged cells (fig. 321, 29 and 30 ) need no additional explanation, and the primordial osteogenic cell (31) has already been discussed. The most important cell remaining for consideration is 28 , which has been called a lymphocyte. It appears to be a small cell undergoing bleb formation. The nucleus is too large for the definitive thrombocyte; moreover, if it were a thrombocyte the structure of the nucleus would not have been so clear cut and definite at this stage of cytoplasmic disintegra. tion.

\section{EMBRYO SPLEEN}

The spleen is an organ that develops quite early in embryonic life; according to Hamilton (1952), it appears on the last half of the fourth day. Efforts to procure satisfactory impression smears before the beginning of the eighth day were unsuccessful because the cells were so fragile that all broke, and the naked nuclei were covered by a layer of blue-stained tissue fluid. The smears resembled that portion of figure 329 where there are naked and ruptured nuclei and strands of dissolved chromatin; therefore no intact, recognizable cells could be seen. By the eightl day some cells remained unbroken in carefully made smears. Why cells should be delicate in early embryonic life and much tougher at older ages is not known; cytologically they appear identical at both ages, and the size does not change much with age. All the serum gramules and disturbing elements in the smear were included when the drawing (fig. 329) from the spleen of the 8-day-old embryo was prepared.

Danschakoff (1916a) reviewed the early development of the avian spleen and reaffirmed her observations on the function of lymphocytes as the progenitors of other cell types. Antibodies against adult spleen tissue were produced by transplanting pieces of the spleen to the allantois of the embryo. 
A review of the differences in the histology of the avian and mammalian spleens has been given by Lucas et al. (1954).

Whereas the embryo bone marrow produced both granulocytes and erythrocytes in about equal numbers, in the embryo spleen it is the granulocyte that is the dominant cell. After hatching, the spleen becomes predominately a lymphocytogenic and monocytogenic organ. The shift in the cell picture is shown graphically by a com. parison of figure 329 ( 8 days of incubation), figure 330 (121\% days of incubation), and figure 331. (35 days after hatching). In the first of this series of three plates are two typical metagranuloblasts (cells 1 and 2 ) and in the same field are mmmerous others (cells 3-6) that are covered too heavily with stained serum to show the details of their structures.

The next stage in development of the granulocyte is the promyelocyte, in which vacuoles and magenta granules and rings are present in the cytoplasm adjacent to an eccentric nucleus. Mlost of these characteristics are to be found in cell 7, and lightly stained orange spheres are present also. This cell has been classified as a promyelocyte. Had some of the spheres taken on the dense coloration that occurs antecedent to the transformation into definitive rods, the cell would have heen classed as a mesomyelocyte.

Cell 8 clearly fulfills the characteristic of the mesomyelocyte. This particular cell has no definitive rods but now there are present numerous darkly stained orange spheres that represent the precursor substance. In this cell the mucleus has become smaller and the chromatin more condensed. Other developmental stages are not shown in the field: cell 9 and the cell below 8 have already differentiated into the manre form.

Cell 11 of figure 329 is an erythroblast; the chromatin pattem of the nucleus and the faint nucleolus are the features which most readily identify it. The umnumbered hlast cell at the bottom of the plate is probably of the same type but the details of its structure are masked in part by the serum. There are at least five small embryo thrombocytes in the field; two of them are indicated at 12. One cell (10), in the prophase of mitosis, camnot be identified because the cytoplasmic structure is not sufficiently distinctive and the nuclear pattern has been lost in the process of cell division.
The interval between 193 and 299 hours of incubation has wrought developmental changes that advance the architecture of the spleen to a level that will be maintained up through the hatching process. Since a low-power drawing had been made of the bone marrow both at 12 days and at 20 days of incubation, it was originally planned that a low power drawing of the spleen would also be made at these ages, but a study of spleen impression smears made after 12 days of incubation showed that no significant changes had taken place ix cell types; thereforc a drawing at 20 days of incubation has been omitted. The spleen at 8 days of incubation is at about the same level of development as bone marrow 4 days later, as far as the general appearance of the cells in the smears is concemed.

When the spleen has reached its 12-day level of development, blast forms of gramulocytes become relatively rare. Only two examples (cells $I$ and 2) are shown in figure 330. One is shown only in part, lout the narrow, dense blue-stained ring of cytoplasm in cell 2 is typical of the structure of such cells in the hatched chick. Most of the cells of this line in figure 330 have reached the metagramuloblast and promyelocyte stages of development. However, figure 330 cannot be taken as representing an exact replica of what every slide examined at 299 hours of incubation will show because among smears from a dozen embryos there will be definite shifts in the dominant cell type of a particular series. This might be accomnted for on the basis of slight differences in developmental rates that always exist among embryos or on the basis of cycles in cell production. The latter would agree with the suggestions given in the literature for blood-cell development in the yolk sac and bone marrow.

Cells 3-6 (fig. 330) are identified as metagramuloblasts of the heterophil line but they are not so clearly typical of this stage as is the eosinophil metagranuloblast (cell 11). A question might be raised regarding cells $3-6$, in which the nuclear stucture, instead of retaining the delicate, lightly stained pattern of the granuloblast, shows an increased density of staining and clumping of chromatin, which is characteristic of the early erythrocyte line; had nucleoli been visible in these cells as in cell 12 , these 4 cells would have been called erythroblasts. One expects to find in the inetagramuloblast stage an eccentric, faintly stained nucleus that has an indefinite 
boundary between it and the adjacent highly vacuolated cytosome.

Cells 7 to 10 show the precursor spheres from which develop the densely stained orange bodies. In cell 7 they are harely visible as light orange bodies from the vacuoles produced in the metagranuloblast slage. In cell 9 the spheres are slightly more intensely colored. In cells 8 and 10 a few orange spheres are alnost as darkly stained as in the mesomyelocyte stage, but in none of the four cells $(7-10)$ have the orange spheres taken on the deep eosin coloration that precedes the elongation of a sphere into a definite rod. Description would probably be facilitated if uames were given to the lightly and the darkly stained orange splieres; when a thorough cytological and cytochemical study of rod production has heen made, logical names will suggest themselves.

Cell 12 of figure 330 is an erythroblast and is clearly identified by its typical structure as helonging to the blast stage of development. Sucli cells are relatively rare at this age. Numerous early polychromatic erythrocytes are present. Cells 13 and 14 are examples: so is the cell located between 3 and 4 . Cells 15 to 17 are examples of mid-polychromatic erythrocytes, and cells 18 to 21 of late polychromatic erythrocytes. There are cells in the field other than those designated by number: they also belong to these various groups. Mitosis, at least in the embryo, can take place in late polychromatic erythrocytes (cells 23-27) and, of course, at earlier stages of development also (cell 22). It would he interesting to follow the plasmosome nucleolus during mitosis and note how it is reconstituted during the interkinetic period, but the technics used here are not suitable for such a study.

Thrombocytes are less common in smears from hematopoietic organs than from circulating blood and it may he that this is due to the delay in opening the embryo and dissecting out the organ before the smear is made. It is quite possible that in fixed and sectioned material some thrombocytes undergo degeneration and become cells that resemble small lymphocytes or naked nuclei. A reinvestigation of thrombocyte development from stained sections might help to clarify the stages in thrombocyte differentiation. Cell 29 (fig. 330) is a thrombocyte of medium size and looks somewhat like figure 289 , except that the chromatin is less clumped. Typical small thrombocytes are shown in the cells mumbered 30 in figure 330.

Smudged cells are present in every smear and usually are more numerous than the one example shown in figure 330,31 .

\section{BLOOD CHANGES AT HATCHING}

During the 24 hours after the latching of the chicks dramatic alterations occur in the circulating blood, spleen, and bone marrow. The most complete change appears in the spleen, where a gencral outpouring of heterophils is followed by a massive development of lymphocytes and monocytes. Within several days following hatching the bone marrow becomes an organ that produces, predominately, erythrocytes, thrombocytes, and granulocytes. No extensive series of illustrations covering these events has been prepared, chicfly because in any period of rapid transition what may be seen at one moment in one chick may be entirely different in anotlıer.

Notes were taken on smears from a group of chicks ranging from a few hours to several days after hatching. The actual protocol taken at the time probably tells the story as well as a more studied rewrite of the same thing. We recommend a similar study to anyone who has atrained some proficiency in cell identification and is grasping for a feeling of the dynamics of development and balance as it occurs hidden from our usual vision.

Throughout this transition period there was considerable variability between birds and it would be necessary to use a larger number of chicks at each age to determine the exact typical sequence of events. At each period usually four chicks wore used.

\section{TO 3 HOURS POSTHATCHING}

Circulating blood.--Only in an occasional chick was the number of white blood cells anywhere near a norunal ratio; in most cases, the number was definitely below normal. This was especially true in regard to the lymphocytes, monocytes, and basophils. The predominant cell in the early chick blood, just after hatching, is the lueterophil. The other cells come into the picture at a later age. Even the heterophil, immediately after hatching. may be absent from the blood (fig. 230). Immature stages of erythrocytes are usually present. 


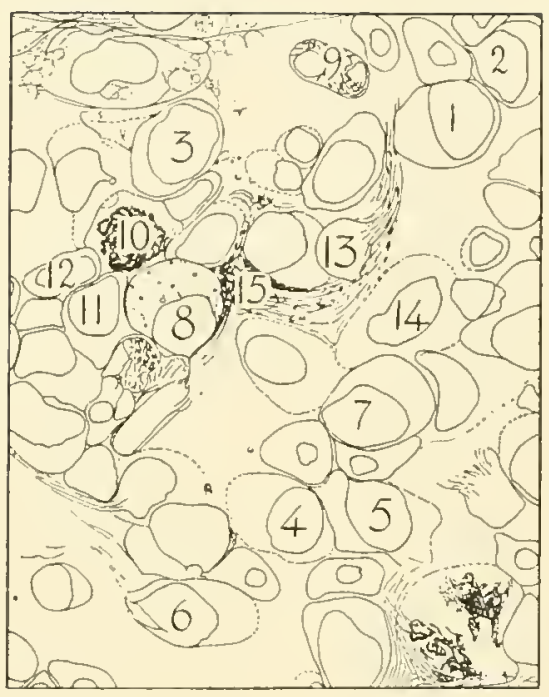

Figure 329.--Embryo spleen. Embryo incubated 8 days 1 hour. At this age it is difficult to obtain a goor smear because of the great fragility of the cells and the masking by the stained sermm fluid and granules. $1,370 \times$.

1,2 Metagranuloblasts.

3-6 Metagranuloblasts in which the cytoplasm is masked by the overlying stained serum.

7 A heterophil promyelocyte.

8 Heterophil mesomyelocyte with many eosinophilic spheres, some light and some dark.

9 Mature heterophil.
10 Immature cell in mitosis, prophase.

11 Embryonic erythroblast.

12 Embryonic thrombocytes.

13, 14 Broken cells with liberated naked nuclei.

15 Strands of chromatin from the nuclei of cells broken when the slide was made. 


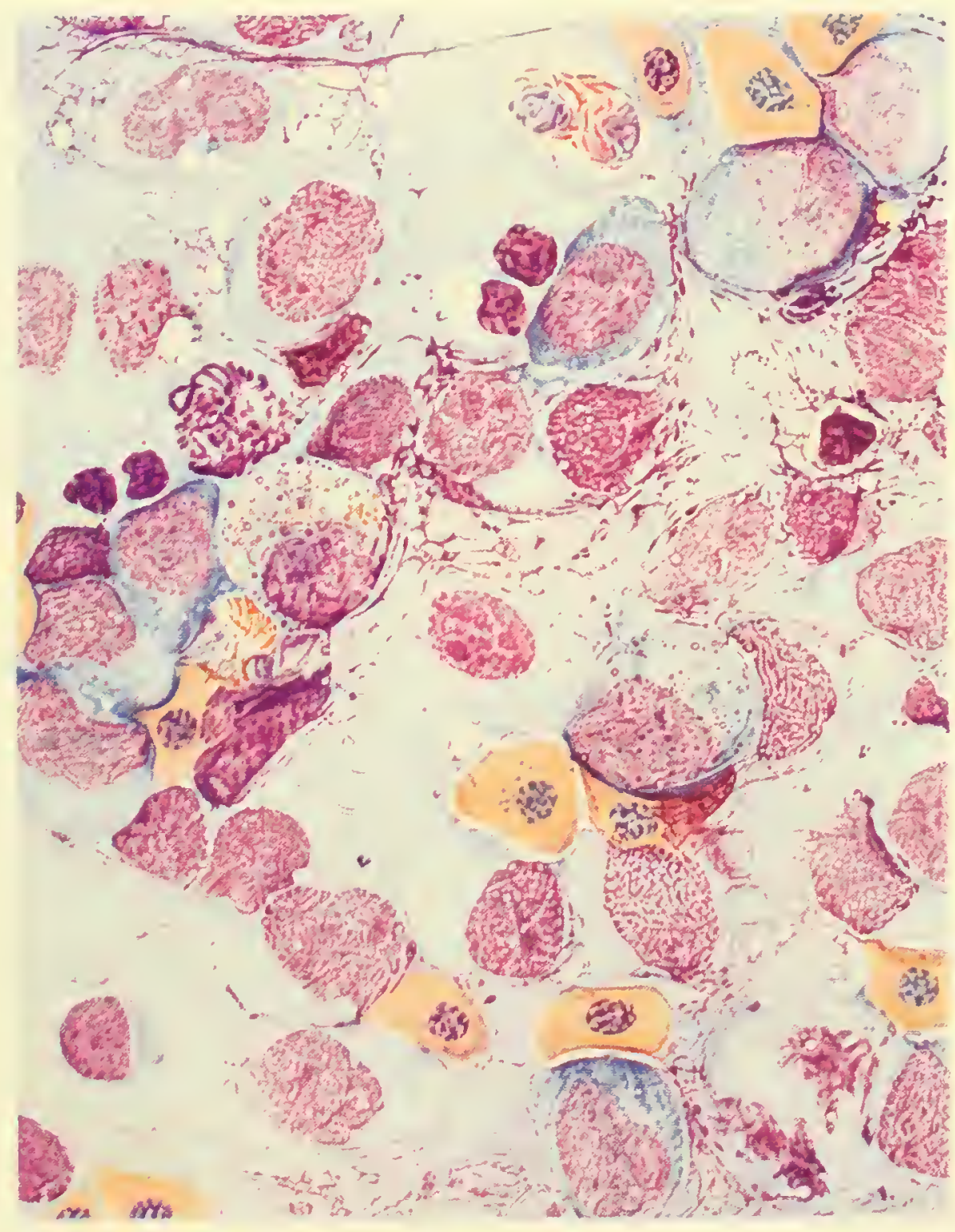




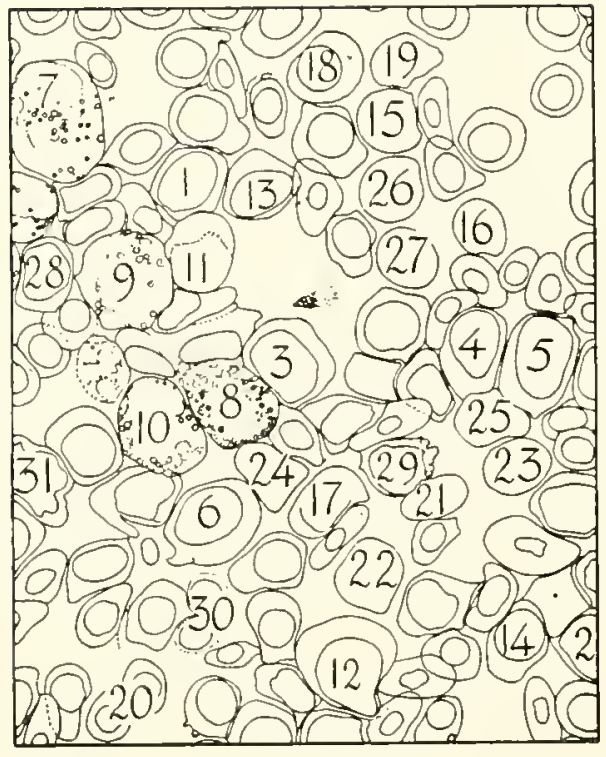

Figure 330.-Embryo spleen. Embryo incubated 12 days 11 hours. 1,370X

1, 2 Granuloblasts.

3-6 Metagranuloblasts.

7-10 Ileterophil promyelocytes.

11 Eosinophil metagranuloblast.

12 Erythroblast.

13, 14 Early polychromatic erythrocytes.

15-17 Mid-polychromatic erythrocytes.

18-21 Late polychromatic erythrocytes.

22 Mid-polychromatic erytlirocyte in mitosis, probably early anaphase.
Figures 23-27: Late polychromatic erythrocytes in mitosis.

23 Early prophase.

24 Tate prophase, nuclear membrane broken down.

25,26 Late prophase, uncoiling of spireme thread.

27 Jate anaphase.

28 Late embryo thromboblast or early embryo thrombocyte.

29 Medium embryo thrombocyte.

30 Small embryo thrombocytes.

31 Snudged cell. 


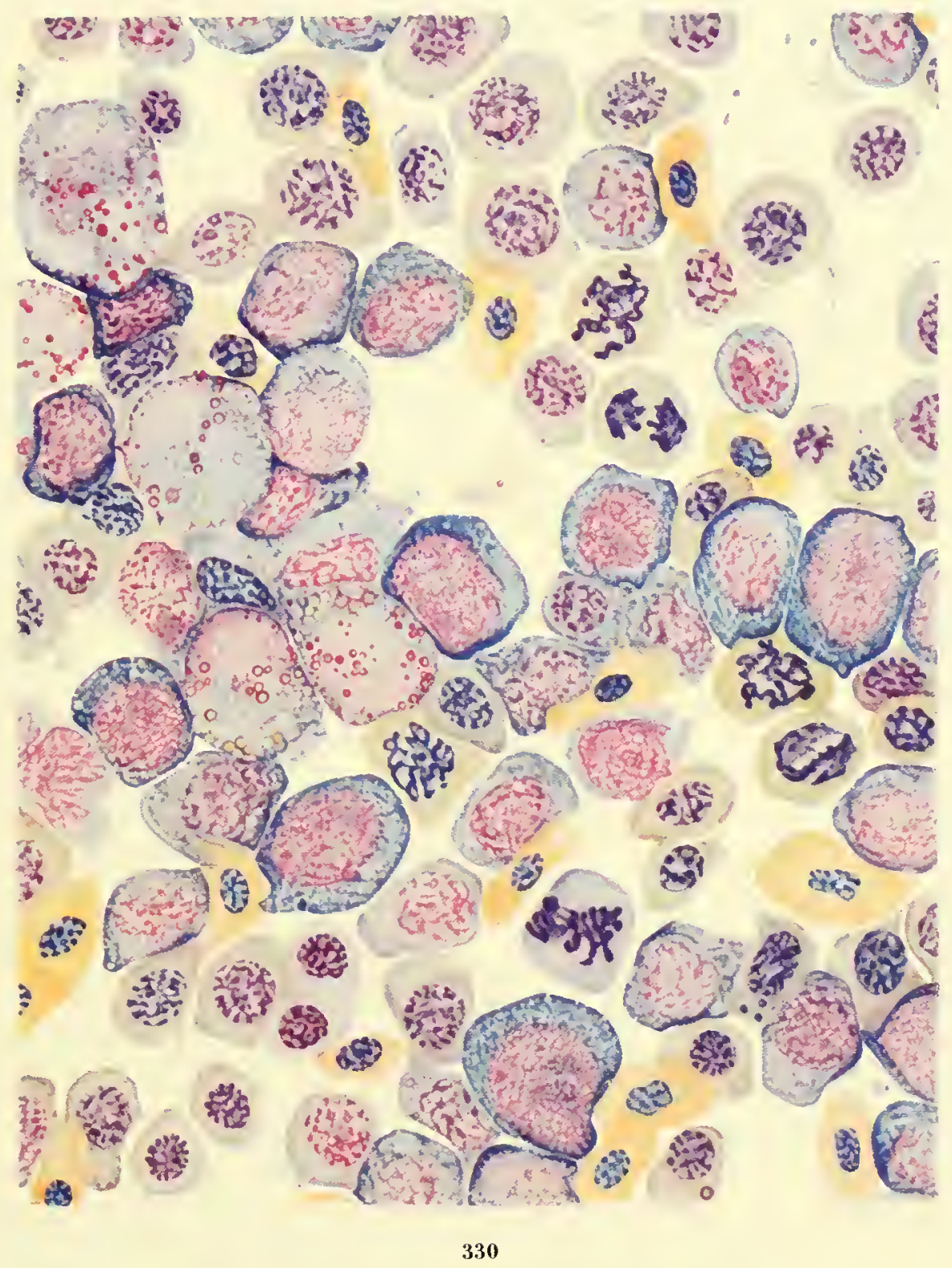




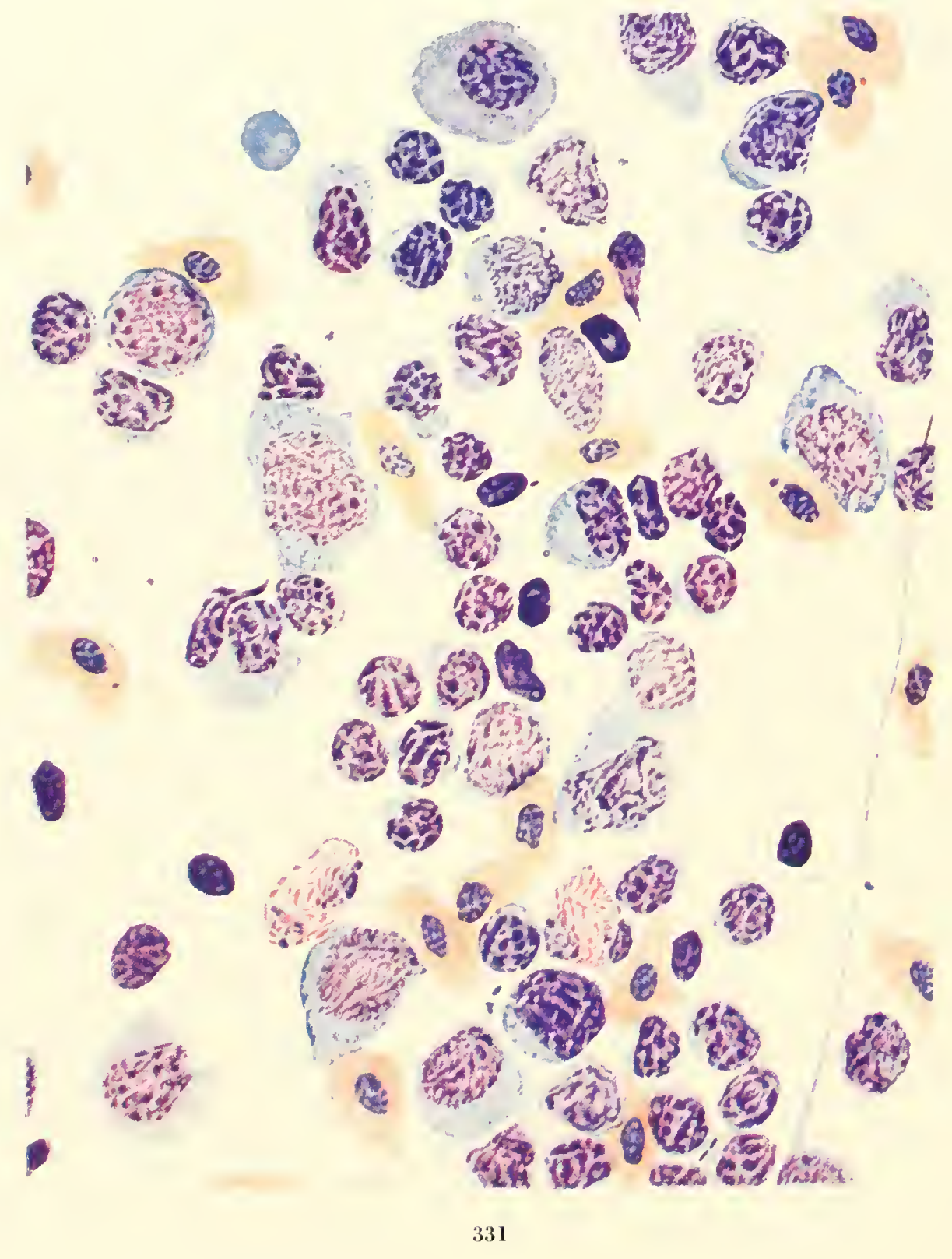




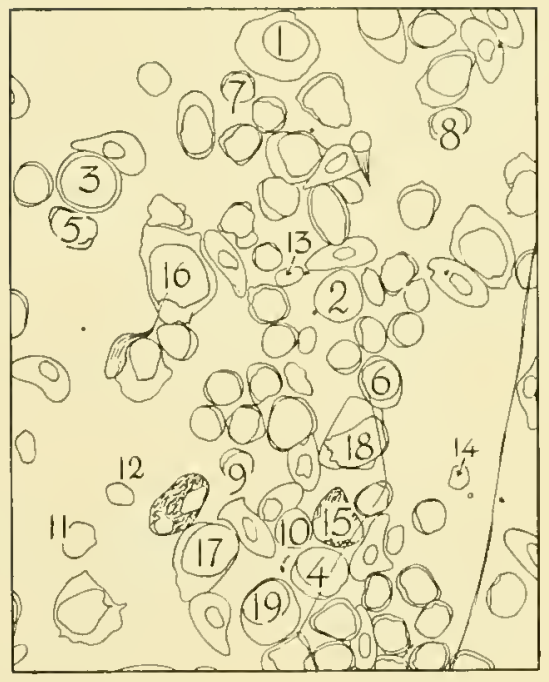

Figure 331.- Spleen of chick 35 days after hatching. $1,370 \times$.

1 Early immature plasmacyte.

2 Late immature plasmacyte.

3 Inmature Iymphocyte.

4-6 Mature Iymphocytes, medium size.

7-10 Mature lymphocytes, small size.

11 Naked lymphocyte nucleus.
12-14 Naked thrombocyte nuclei.

15 Mature heterophil.

16 Possibly a monoblast or early immature monoeyte

17, 18 Early immature monocytes.

19 Late immature monocyte. 
Spleen.-Apparently at the time of hatching, and very rapidly thereafter, the spleen discharges its heterophils; thus, in this period of 1 to 3 hours, one can find a spleen filled with numerous mature heterophils; in other cases, at the same age, there will be very few heterophils, and in their place will be early cosinophil metagranuloblasts, and even the early lymphoid series is making its appearance. At this period of transition it is quite common to see numerous macrophages in the spleen. At this age and even up to 24 hours of age there are many opportunities to study the development of the eosinophil and the lymphocyte.

Bone marrow.- Of the 4 chicks used at this age, 2 showed numerous late heterophils, and 2 did not. There appears to be a transitional change in the bone marrow. It prolubly begins somewhat earlier than 1 to 3 hours after hatching, because the bone marrow is already taking over the hematopoietic function in regard to gramulocytes that the spleen is giving up. In addition, in the bone marrow one finds numerous examples of the red cells from early to late stages of development. Mononucleated osteoclasts were ahways present in these early stages, and were particularly numerous in one case where very few heterophils were present in the bone marrow. Osteoblasts also were visible, but in those smears where heterophils are numerons, osteoblasts are relatively rare. The third cell. nlar element coming up at this time is the thrombocvte series. Just as early erythroblasts may be found. so also may early thromboblasts be identified. These are relatively large cells and have a characteristic punctate, strongly granular nucleus that stains more intensely than the erythroblasts. Nost of these cells, however, contain a well-developed nucleolus. This structure aids in the identification of the cell, but in the thromboblast it is often masked and covered over by strongly stained chromatin spheres. The thrombocyte as it gets older has, typically, a very dark blue cytoplasm and frayed edges. In these early bone marrow smears the transitional stages down to the small thrombocyte can be followed. The fully formed thrombocyte. however, does not have the form present in the circulating blood because of degeneration of the cytoplasm that takes place during fixation. Cells of the thrombocyte series are never numerous in the bone marrow but some are always present.

\section{TO 12 IOURS POSTHATCHING}

Circulating blood.--At this stage there may be some holdover of what was found at 1 to 3 hours, because the dominant type of cell among the white blood cells is the heterophil. Sometimes the white blood cells are few in relation to the red cells and sometimes they are at about the normal ratio. At this age the number of heterophils is generally out of proportion to the other white blood cells and the lymphocytes and monocytes are definitely fewer than they will be later. It is characteristic of the circulating blood of the recently hatched chick that the red blood cells show a wide range of immature stages of development, but predominantly the stages most commonly seen begin at about the midpolychromatic erythrocytt and continue on to maturity (fig. 230). One gathers the impression by comparing the development of red blood cells as seen in the bone marrow with that seen in the circulating blood that there is a tendency for the bone marrow to throw out the cells at about the mid-polychromatic erythrocyte stage or a little earlier. Later stages are present in the bone marrow but cells of older ages do not dominate the picture.

Spleen.-In the 4 chicks used at this age $(8$ to 12 hours) there was a wide range in the number of heterophils but in general they had almost completely disappeared and in their place were numerous eosinophils in about the mid-stage of development. Nany macrophages were present and there was an increase in number of small lymphocytes. In another chick at this same age there was a moderate number of mature heterophils with developing eosinophils and developing basophils; in the third chick there were numerous early heterophils, practically no eosinophils, and some early basophils; and in the fourth there was a mixture of mid-heterophils and early eosinophils. In spite of this variability, there still exists an extensive discharge of the heterophils into the circulating blood. This is followed by a wave of development of eosinophils and perhaps in some cases an additional group of heterophils and basophils. At this time, also, there is some indication that the lymphocytes are taking the dominant place that they will hold later in the spleen.

Bone marrow.-In the bone marrow of all these chicks ( 8 to 12 hours) there were a great many mature heterophils. This seems to be characteristic of the bone marrow at this stage and later. Almost equally conspicuous are the developing red blood cells and the scattered thrombocytes. Some small thrombocytes are present also, and one can find the developmental stages in the production of granulocytes, but these are mingled with the adult stages and are not so conspicuous as they are in the spleen.

\section{HOURS POSTHATCHING}

Circulating blood.-At 24 hours the white blood cells in the circulating blood are predominantly heterophils. Other cell types are present, of course, but they have not reached their usual ratio and, in many cases, lymphocytes or monocytes, or both, may be lacking or at least be so scarce that a great deal of searching is required to find them. At this stage there are abundant examples of late-developing red cells.

Spleen.-Only in 1 of the 4 chicks at this age was there even a moderate number of mature heterophils in this organ. At this stage the lymphocyte development is coming into view. This is an excellent stage at which to study lymphopoiesis: some of the cells can be traced back to lymphoblasts and to the reticular cells from which they appear to have come. Among these early lymphoid cells are some eosinophil myelo- 
cytes, usually quite early in their development. Numerous macrophages are still present.

Bone marrow.-At this stage in the bone marrow there is a variation from a very high percentage of mature heterophils to relatively few, and red blood cells are dominant. These two are always present simultaneously but the ratio varies at this age.

\section{DAY 18 HOURS POSTHATCHING}

Circulating blood.-At this age there is still a dominance of leterophils and a general absence of the agranulocytes in the circulating blood.

Spleen.-At this period the dominant picture is lymphoid with a variable number of heterophils, both early and late stages. Early stages of eosinophil development are present also.

Bone marrow.-In one of the specimens there were still a few primordial osteogenic cells but otherwise there was a fairly constant picture of mature granulocytes and red-cell developmental stages.

\section{DAYS 18 HOURS POSTHATCHING}

Circlating blood.-In one chick there was a normal blood picture and in the other there was still a predominance of granulocytes and a lag in lymphocyte development.

Bone marrow. - In both cases the bone marrow contained a great many fully developed heterophils as well as developmental stages of red cells.

\section{DAYS 18 HOURS AND 6 DAYS POSTHATCIING}

Circulating blood.-The chick at 5 days 18 hours showed an abnormal number of monocytes; lymphocytes were relatively few; the lieterophils were not predominant; and there were some basophils. The 4 slides taken at 6 days show a fairly normal picture and a fairly normal proportion of the different types of white cells.

Spleen.- - In every case the dominant picture is lymphocytogenesis with only a few granulocytes developing. In some slides, stages in lymphocytogenesis are well slown.

Bone marrow.-All the bone-marrow slides show about the same cell types as do those for the preceding age. This is a good age for study of developmental stages along the various lines. In one slide a thromhoblast was clearly seen.

\section{DAYS POSTHATCHING}

Circulating blood.-In most of these smears there was the usual ratio of white cells to red cells and the different types of white cells were present in their usual proportions. In one chick there was a monocytosis and many cells were smudged. This seems to be the stage at which monocytes make their appearance; some of these monocytes show the typical reticular appearance of the cytoplasm.

Spleen.-Occasionally there are some late heterophils in the spieen but it is now predominantly a lymph. oid picture.

The circulating blood, 7 days posthatching, is illustrated in figure 231. The structural char. acter of a lymphocyte, a monocyte, a heterophil, and a basophil, as well as of some thrombocytes and erythrocytes at this age, is shown. This proportion of leukocytes to erythrocytes is greater in the field selected for illustration than is usually found.

The spleen after its reorganization produces blood smears of the type seen in figure 331 , which was from a chick 35 days posthatching.

The statement has been made several times that granulocytes held in hematopoietic organs of the embryo are discharged into the circulation soon after hatching. A contrary point of view has been given by Nonidez (1920) from his study on eosin-staining cells in the gonads of bantams. They were abundant in the embryo and began to disappear after hatching but he concluded that the cells did not pass into the blood stream, but underwent disintegration and were taken up by special cell elements and endothelial lining cells of blood vessels. In the protocol numerous macrophages were noted in the spleen at $I$ to 3 hours, 8 hours, and 24 hours after hatching (which agrees with the observations made by Nonidez on the tissues of the gonads), and 1 phagocytic cell was pictured in figure 317 . From the data thus far accunulated it would appear that both gonad and spleen tissues are acting similarly, but additional study is needed to determine whether the granulocytes of the embryo organs after hatching are the defnitive cells of the circulating blood or whether all the masses of embryo cells are destroyed and only those developed in the bone marrow after hatching reach the circulating blood. Danschakoff (1916a) observed in sectioned material what has been reported here that, after hatching, earlier leukopoietic functions are reduced and the spleen becomes chiefly a lymphocyte-producing and an erythrocyte-destroying organ.

Plasna cells are rare in the normal chicken 
but may be seen in spleen and bone marrow occasionally. According to T. Makinodan (personal communication), plasma cells are abundant in the spleen under experimental conditions. These cells are only rarely observed in our stock of untreated adult chickens. The pure light-blue color of the cytoplasm and the few mitochondrial spaces of the early immature plasmocyte separate it from other cells. Other identifying features are the clear area adjacent to the mucleus and the presence of vacuoles of uniform, small size in the cytoplasm. An early immature plasmocyte with one vacuole is shown in cell 1 of fig. ure 331. Early in the differentiation process, the nuclens shows a contraction of chromatin into large, dense clumps and the cell shows an amount of cytoplasm relative to muclear size that exceeds the proportion found in other cells, especially at the corresponding stage of differentiation. Other cells at the same stage of development would show a reticulum of chromatin in the mucleus.

From this carly stage to the late immature plasmocyte there is a diminution in size of both nucleus and cytosome (cell 2). Usually the IIof is definite but often the dense bhe of the cytosome masks it. A plasmocyte at this stage resembles a mature osteoblast and it has been suggested that they may have a common cell of origin. Plasmocytes and osteoblasts look so much alike that they could be confused readily in the bone marrow, but in the spleen it is assumed that osteoblasts are not present. In the bone marrow it is the clear blue color of the plasmocyte that aids in distinguishing it from the osteoblast, which takes a violet hue. The observations on the cytology of plasma cells, made by Dantschakoff (1909b) from sectioned material, agrees closely with the description given here, based on impres. sion smears. From sections of bone marrow, she observed that plasma cells are always located inside vessels and that they became especially numerous when the bird suffered from general. ized exhaustion. Irradiation by $X$-rays caused the formation of plasma cells in the thymus (Danschakoff, 1916h).

Lymphocytes are the dominant cells of the spleen beginning with the second day posthatching. Mjassojedoff (1926) found the spleen of the adult fowl to be predominately a lymphocyteproducing organ. This is true to a greater de- gree in hirds than in mammals. At 35 days of age (fig. 331) developmental stages can be scen in abundance. Previous to this study of the spleen, the thymus had been examined by the smear method and drawings had been made of the changes in cell morphology from lymphoblast to small, mature lymphocyte (figs. 334338). These cells will be described in more detail when the plates illustrating the thymus are described, but several lymphocytes in figure 331 are worthy of mention here.

Cell 3 is an immature lymphocyte; the narrow rim of cytoplasm in a cell of this size with this peculiar nuclear pattern (partly reticular and partly clumped) is typical for the young lymphocyte. Somewhat similar examples of this were found in the circulating blood (figs. 96-98) and under these conditions they were called mature lymphocytes of medium size, but as found in the young spleen they are called immature lymphocytes. This certainly appears to be an inconsis. tency in cell identification but it is more a reflection of the fact that in spite of a great deal having been written about the lymphocyte, we actually know less concerning its developmental stages than we do of any other leukocyte. Perliaps this is in part due to the fact that those who have written most about the lymphocyte have regarded all sizes from the largest to the smallest, including all stages of cytoplasmic and nuclear differentiation, as insignificant in comparison with the fact that the cell is totipotent in its capacity to produce other cells, and that every lymphocyte is a hemocytoblast, or common stem cell, to all other cells.

In the circulating blood of one chicken the lymphocytes may be small and in another they may he predominantly of medium size. The grapli (fig. 152), based on numerous slides, shows a typical distribution curve for size. More on the size of lymphocytes will be given in chapter 6. Careful statistical studies on the relation of size to the health of the individual are needed. From studies on the thymus at least three stages of development can be recognized-lymphoblast, immature, and mature. This represents fewer subdivisions than for any other cell type. It is suggested that lymphocytes of the type shown in fignres 96-98 are immature and to regard them as such makes the developmental series consistent, but we do not yet have experimental data for the circulating blood that enable 
us to say that, when a differential count is made, the lymphocytes of medium size with reticular nuclei should he classed as immature and only small lymphocytes with dense chromatin should be called mature.

The medium-sized lymphocytes of figure 331 (cells 4-6 as examples) show a degree of chromatin clumping intermediate between the immature lymphocyte (cell 3) and the small lymphocyte (cells $7-10$ ) but the character of the cytoplasm does not change significantly from one stage to the other as seen in the spleen; how ever, in the lymphocytes of the thymus some differences in cytoplasmic structure did occur.

It is generally agreed in mammalian hematology that monocytes arise in the same organs where lymphocytes have their origin, and this appears to be true in birds also, but in avian species there are no lymph nodes, which are the organs chiefly responsible for lymphocytes and monocytes in mammals. The spleen of birds after hatching is a lymphogenic organ and it is not surprising that developmental stages of monocytes should also be present in this organ. In the protocol above, developmental stages of the monocytes were mentioned as occurring in the circulating blood of the young chick. Jordan's (1938) statement (p. 731) concerning the development of blood cells in the lung fish (Protopterus ethiopicus) is interesting: "While monocytes are probably formed in the general circulation, they may also arise in the spleen." The idea of the maturation of monocytes in the circulating blood was expressed also by Dawson (1933a). His studies of hematopoiesis were based on the amphibian, Necturus. In this species, some monocytes arose in the spleen but most of them differentiated in the lymphogranulopoietic aggregations scattered through the tissues.

A superficial examination of the cells in fignre 331 might lead to the suggestion that large cells of the type shown at 16 are metagranuloblasts, but a closer examination shows that this is a different cell. The nucleus is a typical monocyte nucleus even at this early stage and there is no tendency toward vacuolization of the cytoplasm as in metagranuloblasts. In the early immature monocyte (cells 17-18) there is some further condensation of the nucleus to a condition seen in many monocytes but no bodies characteristic of granulocytes appear in the cytoplasm. The late immature stage (cell 19) is readily recognizable as a monocyte and cells like this are commonly seen in the circulating blood. The Hof, azurophilic staining of the cytoplasm, and nuclear indentation have not yet appeared.

The implication was given under the discussion of thrombocytes in bone marrow that it was difficult to see how such labile cells as throm. bocytes could retain their normal morphology during the procedure leading up to the fixation of tissue. Impression smears fix the cells more quickly than the average fixative, which penetrates a block of tissue relatively slowly (Under. hill, 1932, and Medawar, 1941); yet even in the smear practically every thrombocyte appears as a naked nucleus (12-14 are cxamples). Even 11, which has been labeled as a naked lymphocyte nucleus because of its larger size, may actually be the nucleus of an immature thrombacyte.

A few mature heterophils may be seen in spleen smears at this age but whether they represent cells brought in by way of the splenic arteries or are cells that developed in this locus during embryonic life, and have not yet been discharged into the circulation, camnot be determined.

\section{LYMPHOCYTOGENESIS IN THE THYMUS}

Cells of the thymus have been called thymocytes but they are identical with lymphocytes, and the latter term has been used here. Wiseman (1931b and 1932) differentiated 5 stages in the cytomorphosis of lymphocytes: lymphoblast, young cell, mature cell, old cell, and degenerate cell. The classification presented for the lymphocyte series in table 2 (p. 10) includes the first 3 of these 5 stages.

Many smears were made before a satisfactory one was obtained; most of them failed to show as many intact cells as have been illustrated in figure $332 A$, which came from an embryo incubated 9 days 4 hours. The fragility of the cells continued well past the age of figure $332 \mathrm{~B}$ (11 days 10 hours); yet in the older ages large lymphoblasts were relatively rare.

The high-power drawings (figs. 334-338) were made after searching the slide to find suitable stages in an embryo that had been incubated 14 days 11 hours. At the earlier ages, because 
there was so much distortion of the cells and because the serum precipitate was so dense, it was difficult to distinguish between mesenchymal cells and young lymphocytes. In $332 A$ no attempt has been made to place a label of lymphocyte on any of the cells, although some of them appear to be undergoing a transition from primordial (mesenchyme) tissue to lymphoblass.

Cell 1, which is fairly well preserved, shows a faint nucleolus in the lower part of the mucleus, and other cells in the same field show nucleoli vaguely. It is this type of cell in the older chicken that would be called the reticular cell. Somewhere in the transition to the lymphoblast the mucleolus is lost, or at least it becomes hidden beneath the delicate reticular pattern of the chromatin at the surface of the nucleus. In figure 334 this is true even when the chromatin is lightly stained. As stated hefore, whether a nucleohs is actually present must be determined from sections but, if present, it definitely disappears before the stage of the small lymphocyte has been reached. This has been confirmed in sections by Dantschakoff (1908b and 1909a).

In Sundberg's study of lymphocytogenesis (1947) in man and other mammals, observations were made that were almost identical to those reported here for birds. She found that a reticular cell was the precursor for the lymphocyte line. The nucleus of the reticular cell showed a mucleolus, whereas this organelle if present in the lymphoblast was not visible. The reticular cell described by Sundberg closely resembles in appearance the primordial osteogenic cell of the embryo chick bone marrow (fig. 320 , cells 1-4).

Broken nuclei produce long strands of stained basichromatin across the slide and sometimes it looks as if a particular strand could be traced back to the granule in the muclens out of which it had formed a streamer (fig. $332 \mathrm{~A}, 8$ ). Some cells (like the two to the right of cell $l$ ) stain intensely and the chromatin is clumped, but the cells are crowded and thus fail to show clearly the type to which they belong. They resemble in a general way the amoeboid wandering cell described by Dantschakoff.

Cells from an embryo that has been incubated 11 days (fig. $332 \mathrm{~B}$ ) were somewhat better preserved in smears than were cells taken from embryos of younger ages; hence the cells that are going to produce granulocytes can be identi- fied. The thymus has a lesser gramulopoietic function than the spleen. Cell 11 has many structural characters of the promyelocyte but the magenta masses are not the sharply defined rings and granules usually found, which might be due to the unfavorable environment in which it was fixed. Cell 12 is definitely atypical. Some might identify it as a macrophage, and cell 11 as its early stage. It also is reminiscent of the peculiar defect noted in bone marrow where large spheres and masses of magenta material were deposited in the cytosome of primordial osteogenic cells (figs. 320 and 328). Cell 12 may well be a naked nucleus surromnded by cytoplasmic residue and serum artifacts.

Cell 1 in figure $332 B$ closely simulates the primordial cells of $332 \mathrm{~A}$ but, also, it is identical in appearance with the type of cell called the lymphoblast (fig. 334). The lymphoblast decreases in size during differentiation and, although the chromatin is not clumped, it does become coarser (cells 2 and 3 ) and forms what is called an early phase of the immature lymphocyte; soon the forming of blocklike chmps of chromatin begins, usually at one side of the mucleus, which indicates that the differentiation process has reached the late phase of the immature stage (cells 4 and 5 ). Cell 5 in the circulating blood would probably be called a mature lymphocyte of medimm size. Small mature Jymphocytes are present at this age but uone are shown in the field that has been illustrated.

The thymus at this age is not a suitable source of material for making smears and evidence for this is shown by the distortion exhibited by dividing cells 6 and 7 ; these may be compared with dividing cells in the spleen at $12 \frac{1}{2}$ days, where the mitotic figures are well preserved.

The cells shown in figures 334-338 represent a developmental series taken from the thymus when the embryo had been incubated 14 days 11 hours. Search was made for well-preserved cells. All cells as large as figure 334 had nuclei that took the stain poorly. This poor reaction has happened before with May-Grünwald Giemsa but usually there were similar cells on the same slide or equivalent slides that showed the nuclear surface well stained. With Wright's stain, cells this large and immature rarely show the nucleus properly stained.

By the methods used here a nucleolus is not visible at any stage of lymphocytogenesis al- 
though, as pointed out earlier, it is present in the primordial embryonic cell from which the lymphoblast is derived. Even if it can be demonstrated by sections that a mucleolus is present, this would not invalidate the usefulness of the smear method as a means of differentiating between the early stages of various cell lines, and for practical purposes it can be stated that, in smears, crythroblasts and thromboblasts have nucleoli and that lymphoblasts and granuloblasts do not. (For discussion of monoblasts, see Lucas, 1959.)

The cells in figures 335 and 336 are still sufficiently large to be designated as immature lymphocytes, and the immature cell (fig. 122) found in circulating blood closely resembles figure 336. Other cells somewhat more advanced in development in which the clromatin shows early stages of clumping have already been discussed in connection with figures 331 and 332 , and the medium and small mature lymphocytes (figs. 337 and 338) will be mentioned again in connection with figure 333.

The general appearance of a smear from the thymus 35 days after hatching is practically indistinguishable from a smear of the spleen at the same age. The medium to small lymphocyte is the dominant cell of both organs, but the developmental stages of the monocytes have not been identified in the thymus. Cell 3 (fig. 333) is a rather small lymphoblast similar to figure 335 ; cells that are not much smaller reached a stage of nuclear clumping equal to the immature lymphocyte (cells 4 and 5 and the cell below 17). There are many medium and small mature lymphocytes, some of which are indicated by cells 6-12. In these the chromatin is clumped into heavily stained blocks. As mentioned earlier, at low magnification there are no visible significant changes in cytoplasmic structure during the differentiation of the lymplocyte, but under high magnification (figs. 334-338) mitochoudrial spaces may be seen in some of the young cells. The spaces disappear as the cell grows older.

The framework of the thymus is composed of reticular cells and their fibers. These cells are often called epithelial or epithelioid cells. In section they are readily recognized by the acidophilic cytoplasm, which is large compared with the small nucleus. Cells in section show very little structural detail in the cytosome but in smears considerable structure is visible, the most conspicuous being the mitochondrial spaces. A well-defined plasmosome nucleolus lies near the center of the nucleus in cell $I$ of figure 333 . The color taken by the cytoplasm is similar to that of the plasmacyte of the spleen (fig. 331). Cell 2 is a slightly crushed reticular cell.

Not as many reticular cells are found in smears as might be expected from the large number seen in sections because in making them the loose cells in the meshes of the reticulum are given up more readily than the framework itself. The reticular cells seen here are very similar to the primordial osteogenic cells of the embryo bone nuarrow, and if the cells of figure $332 \mathrm{~A}$ could be laid out, separate from each other, it is probable that both the reticular cells and the primordial osteogenic cells would have an appearance quite sinilar to the mesenchyme of the embryo. The reticular tissue of the adult organism is said to be wore like the embryonic mesenchyme especially in potentiality for producing other cell types than any other comnective-tissue cell of the body.

Dancliakoff (1916h) in her study of thymus development in the chick embryo concluded that the cells of the thymus cortex are derived from small lymphocytes that originally came from mesenchyme cells. The small lymphocytes are said to produce fibroblasts, macrophages, plasma cells, and myelocytes.

Granulocytes are common in the thymus, and in sectioned material the heterophils often lie in a mass of reticular cells and debris that form a Hassall's corpuscle. Other cells found in the avian thymus but not in the mammalian gland are the isolated striated nuscle cells. The eosinstaining affinities of these cells cause them to stand out conspicuously from the blue nuclei of the lymphocytes (Wassjutotschkin, 1913 and 1914). It was expected that these cells would be seen in smears but none were found.

\section{FEATHER SHEATH CELL}

This is not a blood cell and is not directly related to one. It is a contaminant that was found on many slides made from late embryos. Before its significance was known, it caused a great deal of confusion and concern. It was called an x-cell when discovered, and that name 


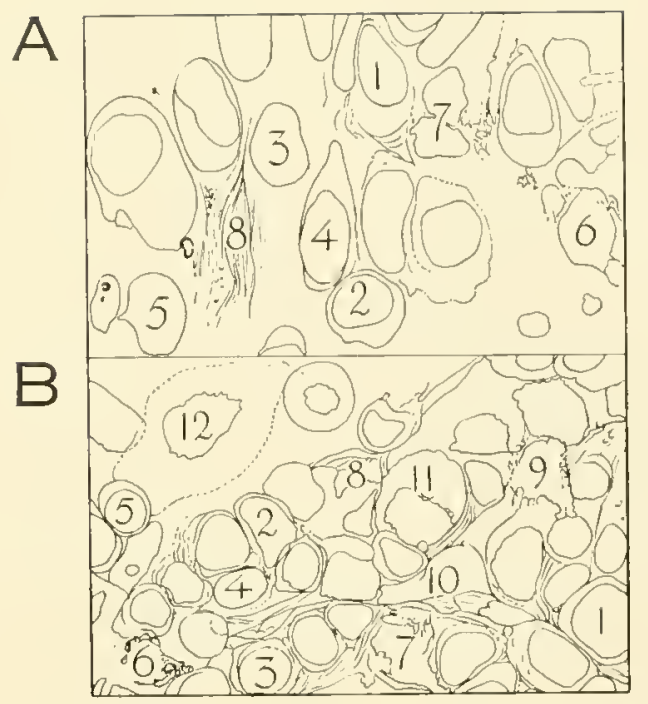

Figure 332.-Embryo thymus.

A Embryo incubated 9 days 4 hours. Mesenchymal cells of the embryo thymus early in its development. $1,370 \times$.

1 Primordial cell with a nucleolus.

2 A rounded primordial cell.

3,4 Cells in which the eytoplasm is merged with the stained serum.

5 Naked nucleus.

6 Broken, naked nucleus.

7 Shrunken, broken cells.

8 Strands of basichromatin from broken nuelei.
B Embryo incubated 11 days 10 hours. $1,370 \times$.

1 Lymplioblast.

2,3 Early immature lymphoeytes.

4, 5 Late immature lymplocytes.

6, 7 Mitosis, prophase. Cells probably are developing lympliocytes.

8-10 Sinudged, naked nuclei.

11, 12: Identification uncertain; either macrophages or heterophil promyelocytes.

11 Closely resembles a promyelocyte.

12 A highly atypical cell. It contains magenta spheres like the primordial osteogenic cell. 


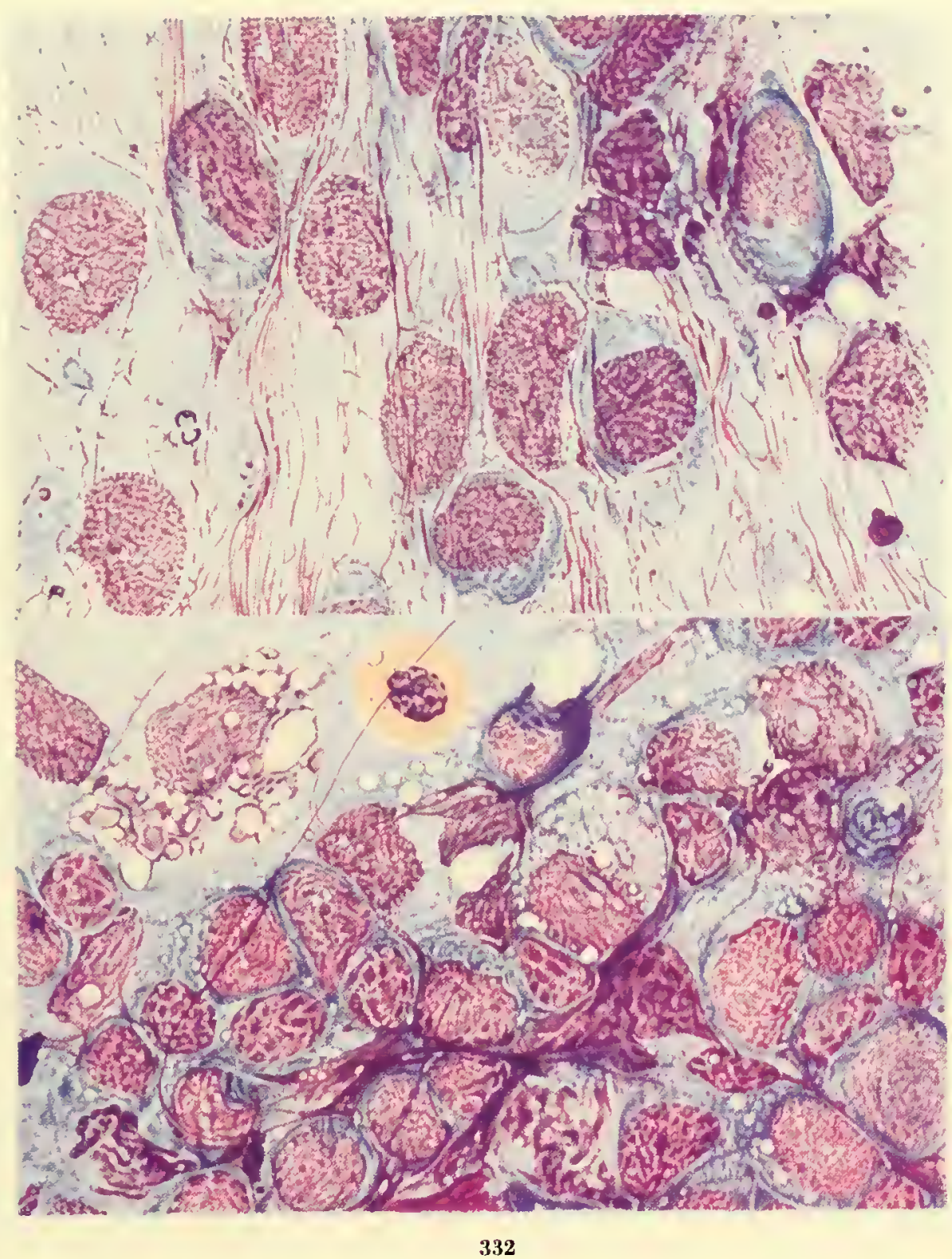




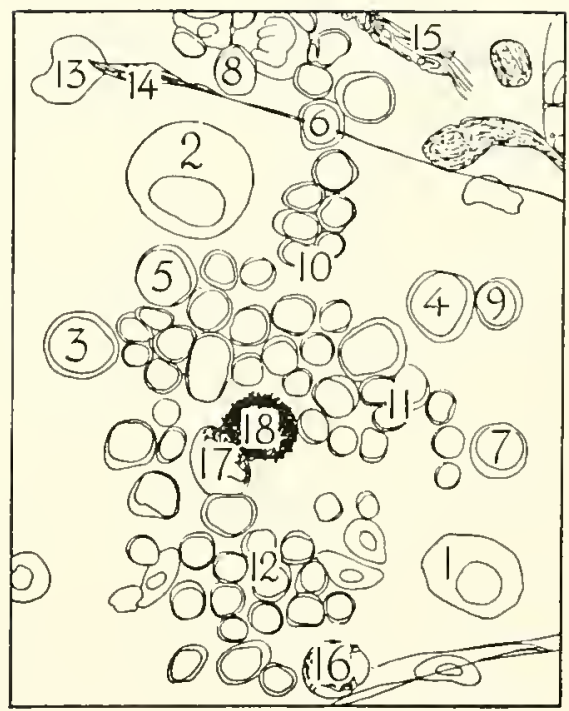

Figure 333.-Thymus. Chick, 35 days after hatching. Composite drawing from 4 places on same slide. $1,370 \times$.

1 Rounded thymus reticular cell. A primordial cell.

2 Slightly squashed reticular cell.

3 Lymphoblast.

4 Immature lymphocyte at transition to mature lymphocyte.

5 Immature lymphocyte, slightly more differentiated than 4 .
6-9 Medium mature lymphocytes.

10-12 Small mature lymphocytes.

13-15 Smudged nuclei.

16 Mature heterophil.

17 Smudged heterophil.

is Mature basophil. 


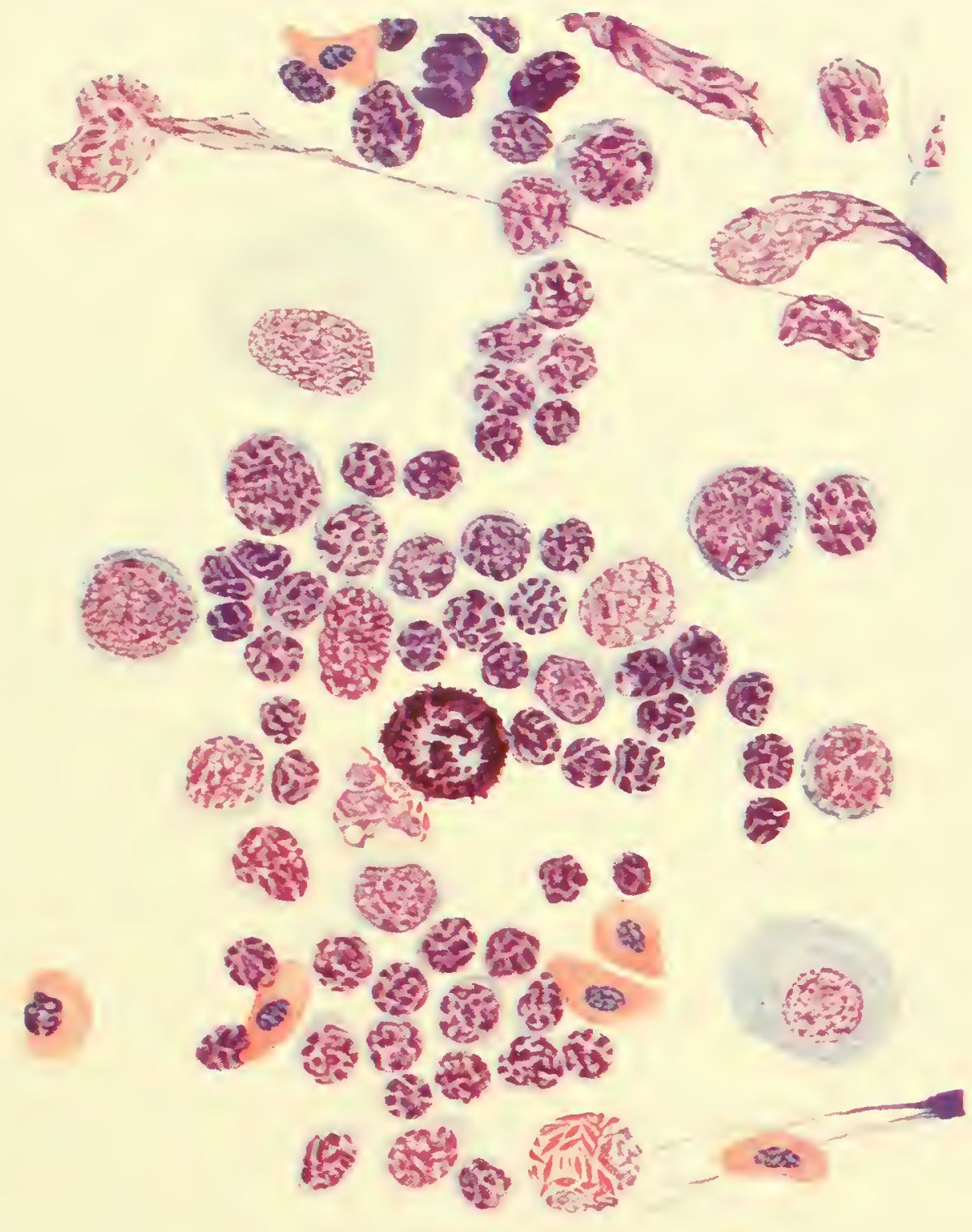


Figures 334-338. - Stages in the development of lymphocytes in the thymus. All figures from the same slide. Embryo incubated 14 days 11 hours. 2,470×.

334 Large lymphoblast. Nueleus incompletely stained. 337 Mature lymphocyte of medium size.

335 Iymphoblast at transition to immature lymphocyte. 338 Mature lymphocyte of small size.

336 Immature lymphocyte. 


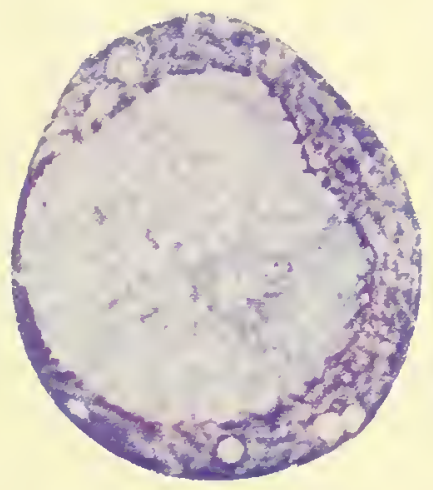

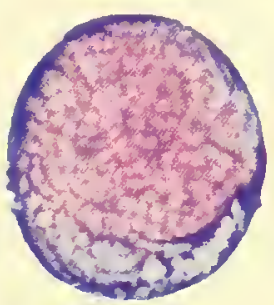

335

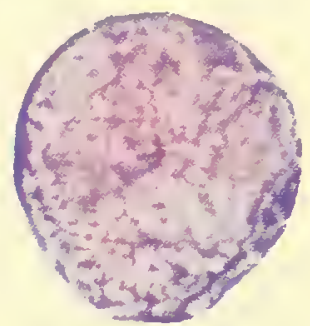

336

334

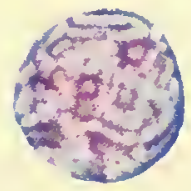

337

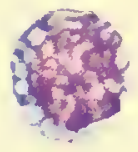

338 
Figures 339-342.-Squamous epithelial sheath cells covering down feathers. These cells separate readily and as a contaminant frequently fall on impression smears made from embryonic and young chick organs. $2,470 \times$.

339 A relatively small cornified down-sheath cell found in bone-marrow smear. Oval area of dead nucleus slightly to the left of center. No keratin granules. Chick just hatched.

340 An elongated down-sheath cell found in bone-marrow smear. Dead nucleus in the center. Numerous keratin bodies formed in the cytoplasm. Chick just hatched.
341 A large and slightly smudged down-sheath cell found in a spleen smear. Coalescence of keratin bodies. No nucleus visible. Orange body with a dense nucleus is a broken erythrocyte on the surface of the sheath cell. Embryo incubated 20 days 4 hours.

342 A final stage in the keratinization of a down-sheath cell found in bone-marrow smear. Remains of the dead nucleus visible in the center. Embryo incubated 19 days 19 hours. 

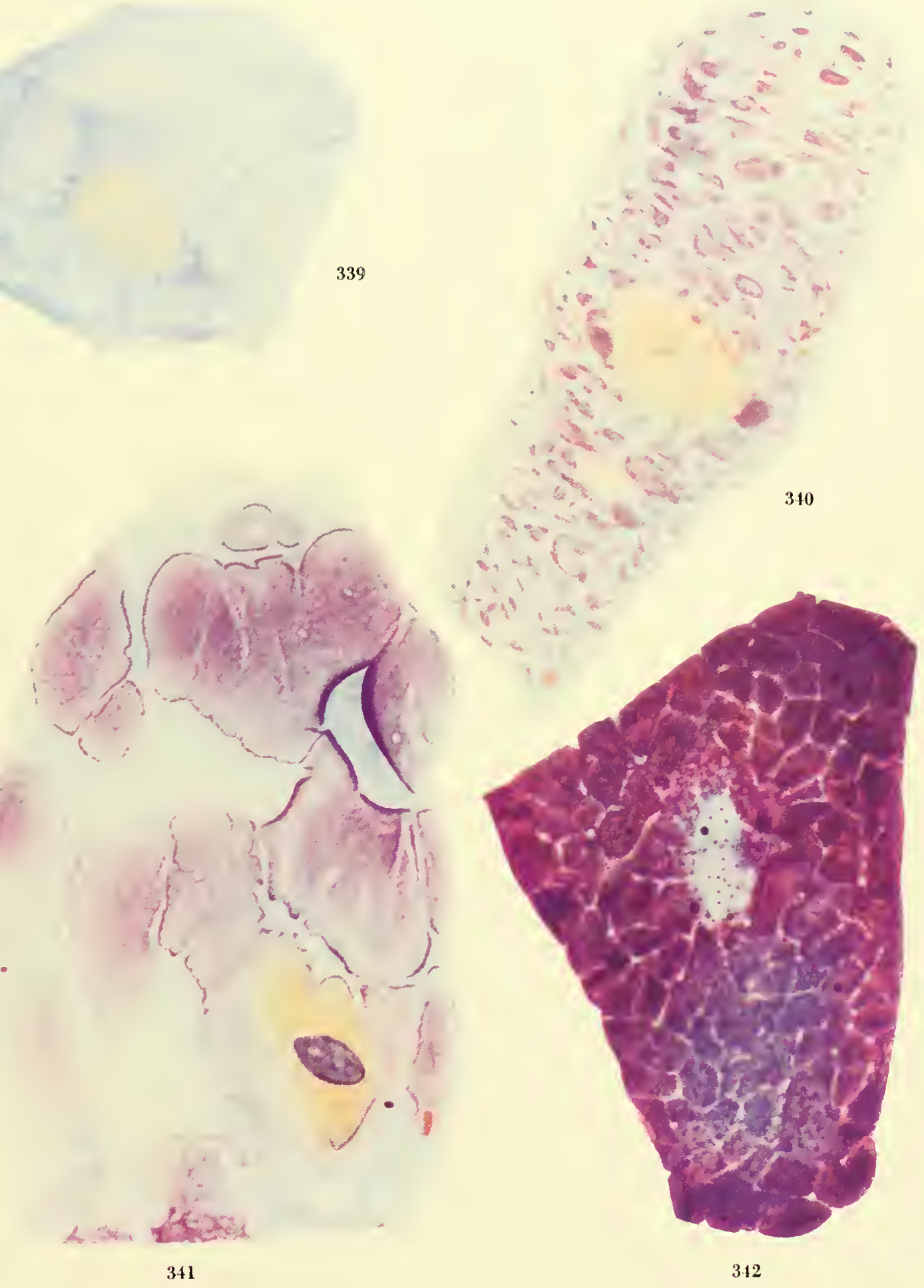


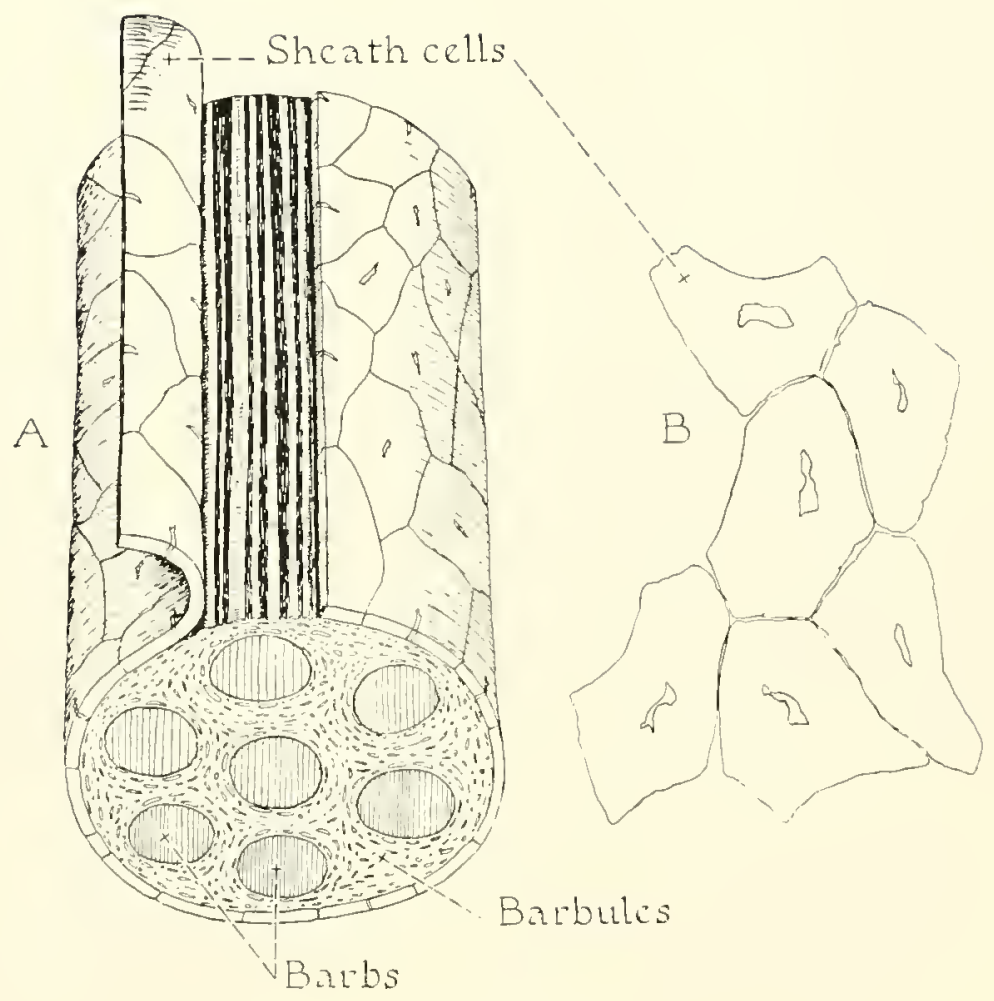

FIGURE 343.

A Part of an emerged down feather in which is diagramed the down-sheath cells that enclose the barbs and barbules of the down feather.

B The sheath forms a simple squamous layer of keratinized dead cells. 
indicated the state of knowledge alout this ceil for a considerable length of time.

Cells like figure 312 were most commonly seen. They occurred in mos hone-mannow smears and later in some spleen smears. Since all the cells in figures 339-342 were drawn at the magnification used for other high-power drawings, it is apparent that they were many times larger than erythrocytes. When cells like figure 340 were found, a protozoan parasite was suspected, lout none were known that closely approached this morphology and retained a large central mocleus. As different tissues were used for smears, the mose widely did these cells seem to be distributed. Finally, after they had been seen in smears from commective tissue of the groin region and from air sacs as well as from bone marrow, thymus, spleen, and lumsa, it hecame evident that this was a contaminant.

A seareh for the source led to an examination of the surface of the late embryo and of the young ehick, the scalps of the people who were making the slides, and the towels nsed to wipe the hands and instruments.

The x-cells were oltained only from the surface of the chick. If a slide was covered with albumen and the down was lorushed with a pencil while the newly hatched chick was held several inches above the stide, many cells of the type shown in figures 339-342 were seen. It was then but a short step to locate the sheath of cells that encloses the emerging down. When they were seen in sheets, as in $343 \mathrm{~B}$, it was evident whence they had come. The remarkalle thing about them was their ability to separate them. selves so easily and completely from other cells of the same epithelium that nearly always they were found as isolated cells. Although their source was now known, there was still the question of how they came to be a contaminant on impression smears, since the down of many embryos was wet and it was milikely that the cells could be spread by air. The crevices of the mouse-tooth forceps used to pull the tissues apart carried these cells. Although the forceps were not tonched to the slide when the smear was made, they must have been the chief sonrce becanse, subsequent to this period of investigation, no down-sheath cells appeared in smears if the teeth of the forceps were carefully cleamed after each step in the dissection process.
After it had been learned that these cells were specifically ansociated with the down of the young chick or the late embyo and that they were readily separated and disieminated. it was decided to conduct an experiment with two of the men who take off the rhick hateh each week. This Laboratory maintains a quarantine, and a man coming onto the premises changes his lothes, washes his hands, and puls on loots and coveralls fumished by the Laboratory. When men enter the incubator rooms, a second change of clothing is made. After the two men had taken off the hateh they went through the quarantine in reverse, so that they entered the Laboratory in their street clothing. Previously 6 albuminized slides had been prepared. Now each man was asked to bonsh his hair about 6 inehes from 3 of the slides.

All 3 slides of 1 gromp showed sheath cells when stained, and $]$ of the other 3 slides showerl them. Therefore, any truly effective fuarantine should eliminate the possible transfer of these cells from one group of chicks to another, or else it should be shown that these desquamated cells cannot serve as carriers of pathogenic organisms.

The cells selected for illnstration are intended to show three steps in the process of keratinization (figs. 339, 340, and 342) and one atypical cell (fig. 341). In figure 339 a muclear ghost is indicated by its slight orange color and oval shape. In this cell the cytosome is uniformly vacuolated and the ground substance takes a light-blue stain. Often the thin edges of these cells are folded and in this case there are 2 folds, 1 above and I helow the level of the muclens.

Usually the cells have greater length than width. The nucleus is orientated with its long axis transversely placed across the midlle of the cell (fig. 340). It, of course, is dead and no chromatin particles are visible, only a faint orange coloration withont stmcture. Keratin particles develop in the cytosome from many separate centers. Some grow larger and flow together with adjoining masses. The typical appearance of the last stage when no more heratinized material can be packed into the cell is shown in figure 342 . The nuelear ghost is visible in the center of the cell. The cytosome is divided into multisided angular compartments with a small residne of blue-staining cytoplasm between them to mark their boundaries. The intense 
affinity of the keratin for the stain makes cells at this stage of development appear nearly black nuder low nagnification.

The cell shown in figure 341 is atypical in that the keratin has flowed together into large. irregular masses. The nucleus does not show and the orange body with its blue nncleus is an ery. throcyte on the surface of the cell. The general appearance of the down-sheath cell is suggestive of a partially squashed cell but there is little evidence beyond its atypical appearance to indieate that this was the case.

The barbs and barlmles of the chick down are held by a thin layer of these epidermal cells (fig. 313 A). Upon drying, the slieath breaks readily, allowing these structures to spread and assume the fluffy appearance characteristic of down. 


\section{Blood Cells From Bone Marrow of the Hatched Chicken}

Bone marrow of the adult chicken differs in its general appearance from the bone marrow of the embryo or the recently hatched ehick lyy its abundance of mature erythocyles. Blast and developmental stages are present but are not so numerous as in the younger ages. These shifts in the incidence of different cell types with age will be described more fully when table 10 is discussed.

Jordan (1936 and 1937) has described the bone marrow of several species of ljirds. In the marrow of all young binds he found lymphoid nodules. These he regarded as centers of hematopoietic activity, especially of erythocytes. He also olscrved small vessels plugged with lymphocytes. Jordan and Robeson (1942) observed after splenectomy in pigeons that the lymphoid foci and plugged vessels in the hone marrow were inereased. Their interpretalions need to he reviewed rather critically in the light of olservations made since then that lymphoid foci are abnormal in entocrine glands (Payne and Breneman, 1952), in ressels of nerves and among nerve fibers (Oakberg, 1950), and in the pancreas (Lnras, 1949; Lucas and Oakherg, 1950: Lueas, Craig and Oakberg, 1919; Juncas and Breitmayer, 1919: Jucas, 1950 and 1951; Oakherg. 1949 and 195l) and in the livel (Dening. ton and Lucas, 1960; Lucas et al., 1954). The spleen like the bone marrow is a hematopoictic organ, and in addition to the white pulp. contains lymploid foci. Statistically, these are related to the infection by the agent of avian lymphomatosis (Lucas et al.. 1954). Before similar lymphoid foci and phugged ressels in the bone marrow can he accepted as normal for lirds, it should be demonstrated that these are not equivalent to the abnormal lymphoid foci and plugged vessels found in other organs of the liody.

A study by Erdmann (1917) of chicken hone marrow in tissue culture failed to produce a variety of differentiated cell types from the small lymphoeyte. Cultures in a plasma medium showed, first, a degeneration of mature and late polychromatic erythroeytes and some maturation of granulocytes, hut this was followed by degeneration. There was no evidence of cell division in myelocytes or in microlymphocytes. Hetheringlon and Pierce (1931) gave a confirmatory olservation when they noted that in explants of the buffy coat of chicken lilond, all of the lymphocytes degenerated after 48 homs.

Mention has been made of practically all the developmental stages that are to be found in the hone marrow of the hatched chicken but a special effort has been made to bring them all together in a series of drawings under high magnification (figs. 345-399) in order that studies of hont marrow in the chicken can be made as useful for diagnosis and for following the conrse of diseases as hone marrow studies have been in human medicine.

\section{ERYTHROCYTES AND THROMBOCVTES}

The erylluroblast shown hy cell $l$ of figure 344 is almost an early polyehromatic erythroeyte. Younger blast cells may be seen in figmres $345-$ 317. The last of the three elosely duplicates cell $I$ of figure 344 . Cell 2 is an early polychromatic erythrocyte but shows slightly less condensation of chromatin than either of the cells represented by figures 347 and 348 . In the lowpower field (fig. 344) there are no good examples of mid-polychromatic erythrocytes, although cell 4 has not passed far beyond this stage. Beside the two cells at 3 , there are several additional late polychromatic erythrocytes in the field. Cell 5 is one of these in division. which again demon- 


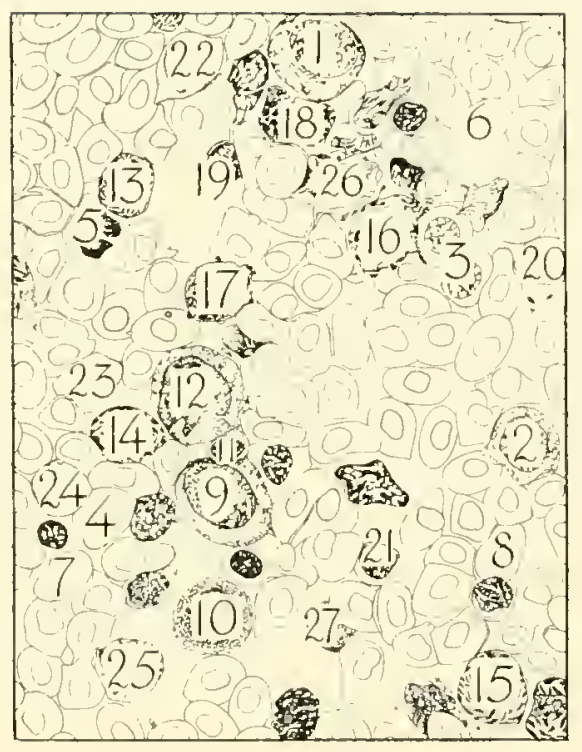

Figure 344.- Bone marrow from a whicken, 145 days old. 1,370

I Late erythroblast.

2 Early polychromatic erythrocyte.

3,4 Late polychromatic erythrocytes.

5 Dividing late polychromatic erythrocyte.

6-8 Mature erythrocrtes.

9 Thromboblast.

10 Farly immature thrombocyte. Typical cell at this stage for adult bone marrow. Aclded to the drawing from another bone-marrow smear.
11 Disintegrating mature thrombocyte.

12 Metagranuloblast.

13-15 Mature heterophils.

16 Basophil mesomyelocyte.

17 Mature or nearly mature basophil.

is 21 Lymphoeytes, medium and small.

22-25 Cells slightly smudged.

26, 27 smudged naked nuclei. 


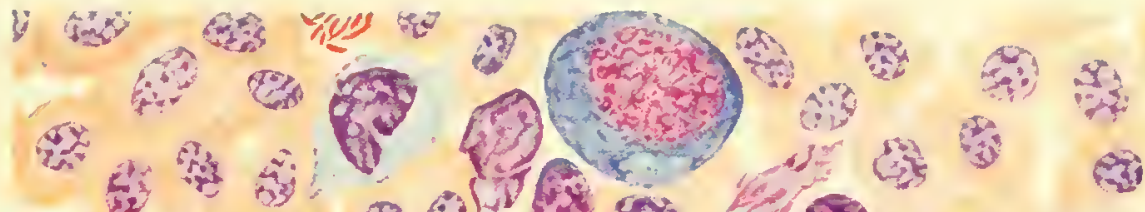
की

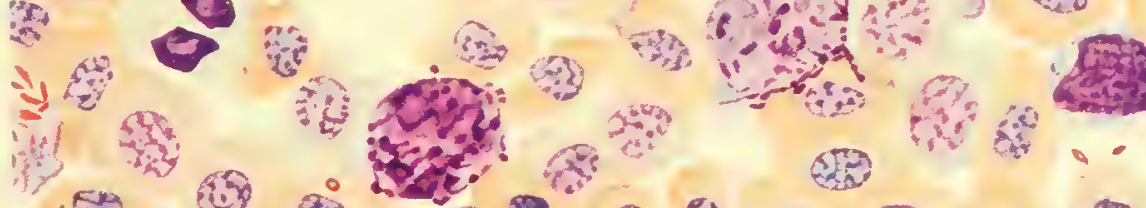
(2)

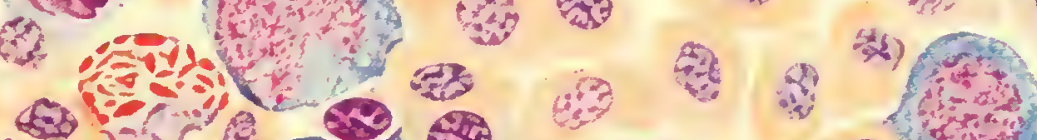

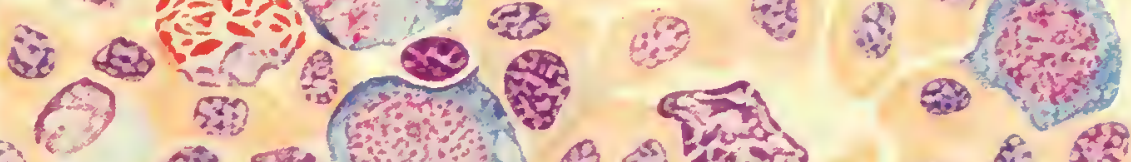

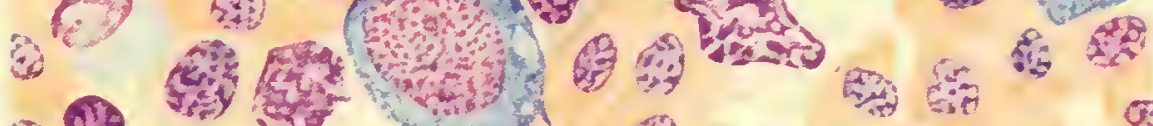

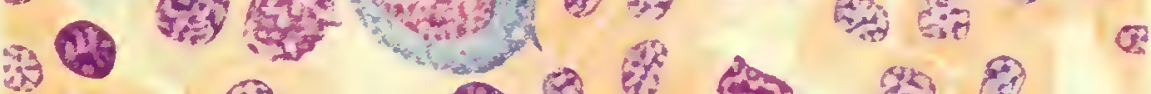

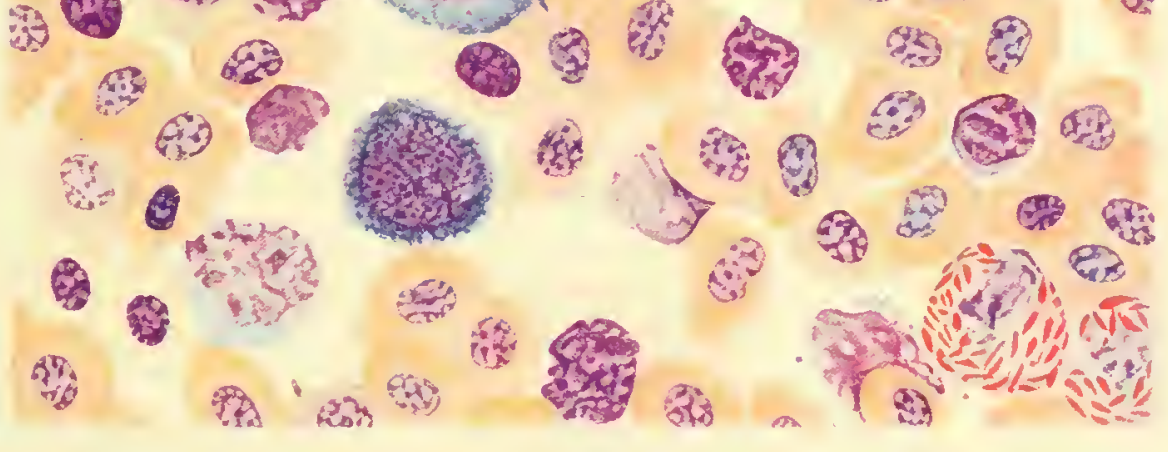


Figures 345-356-Cells of the erythrocyte series found in the bone marrow of adult or nearly adult chickens. $2,470 \times$

345 Large early erythroblast. A cell this large and immature is relatively rare in adult bone marrow. Nucleolus occupics the right third of the nucleus.

346 Erythroblast.

347 Late erythroblast. This cell and the preceding one are typical of the erythrocyte stem cells in bone marrow.

348-349 Early polychromatic erythrocytes. Both show faint indications of their nucleoli at the lower left of each nucleus.
350, 351 Mid-polychromatic erythrocytes.

352-354 Late polychromatic erythrocytes. Each cell in the series is slightly more differentiated than the preceding one.

355 Cell with full complement of hemoglobin as judged by the color and a fully differentiated nucleus but with a round shape.

356 Normal mature erythrocyte. 


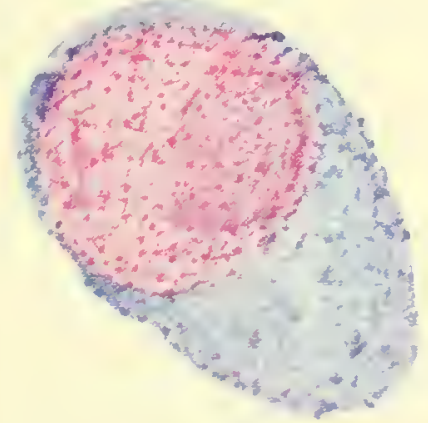

345

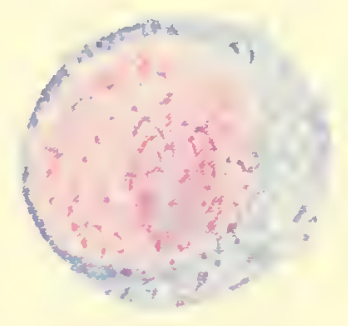

346

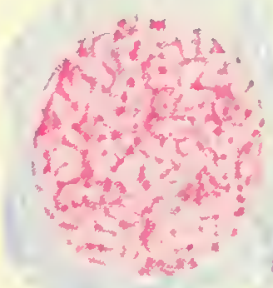

317

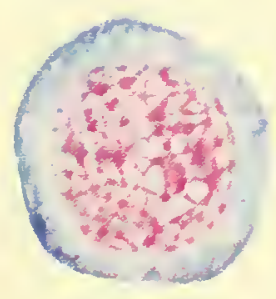

318

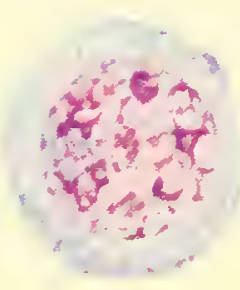

349

350
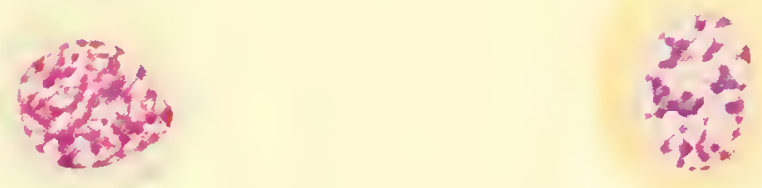

352

3.3

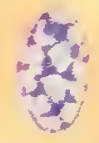

356 
Figures 357-365.-Cells of the thromboeyte series found in bone marrow. Figures 357,363 , 364, and 365 from the adult bird and 358-362 from 6-day-old chick. 2,470X.

357, 358 Thromboblasts. A nucleolus is present in each but is faint beeause masked by chromatin granules, which are dense.

359-362 Early immature thromboeytes. The lighter peripheral cytosomal margin as in figure 362 is characteristic of thromboeytes at this age but may represent an early disintegration reaction.

363 Mid-inmature thrombocyte.

$36+$ Late immature thrombocyte.

365 Mature thrombocyte. 


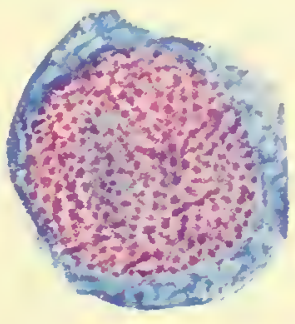

357

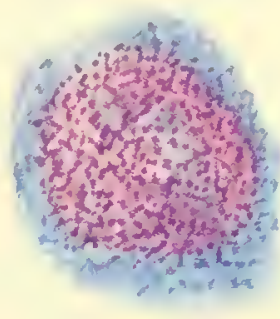

358

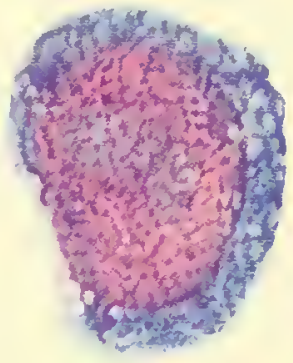

359

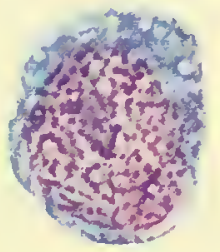

360

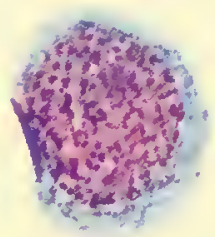

361

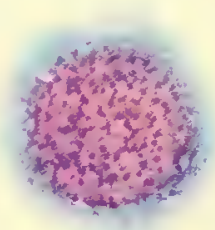

362
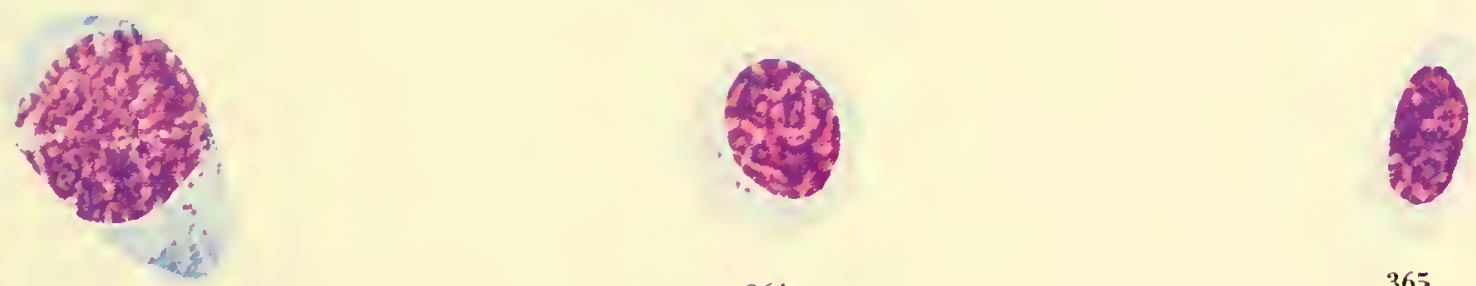

364

365

363 
Figures 366-377.-Cells of the heterophil granulocyte series found in bone marrow of adult chicken, except figure 376, which was from a day-old chick. 2,470×.

366 Large early granuloblast. This size is found but rarely.

367 Typieal early granuloblast. It is not possible in the granuloblast stage to determine which type of granuloeyte will be produced from it.

368,369 Heterophil metagranuloblasts.

370-372 Heterophil promyelocytes. Magenta rings are present and also cytosomal vacuoles eontaining rod precursor spheres.
373,374 Heterophil mesomyelocytes. The beginning rods are indicated by the darkly stained bodies eoming from the precursor spheres.

375 Heterophil metamyelocyte. More than half of the full complement of rods have appeared.

376 Heterophil metamyeloeyte in mitotic division. Early telephase.

377 Mature heteropliil. 


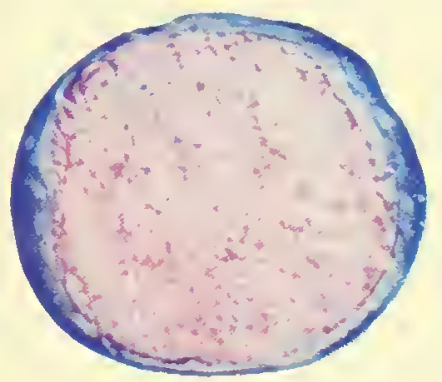

366

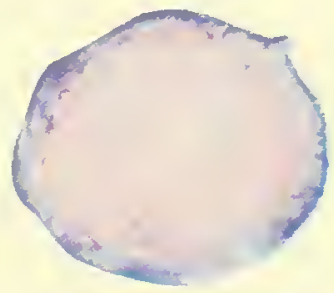

367

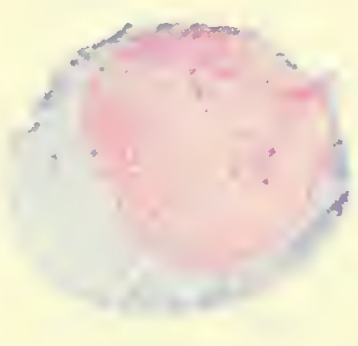

368

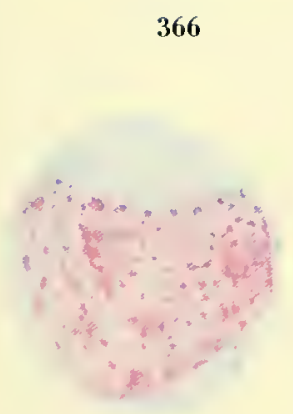

369

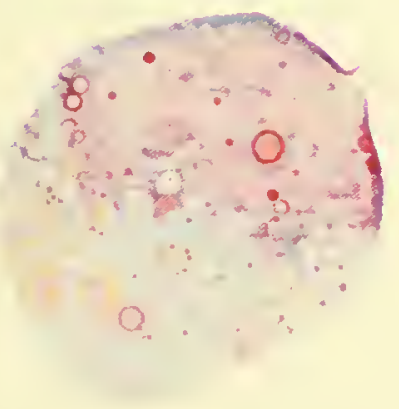

372

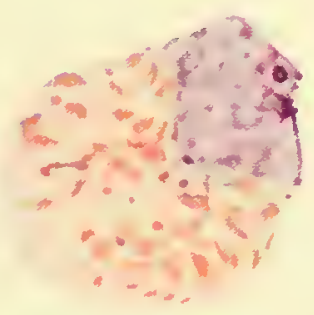

375

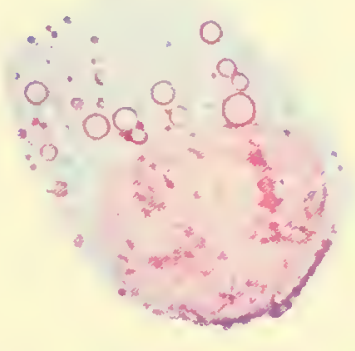

370

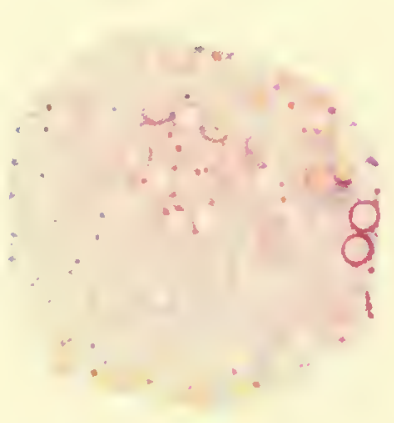

371

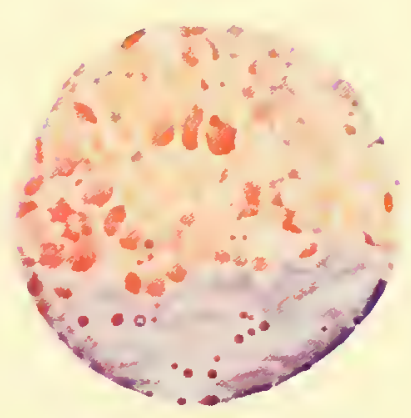

373

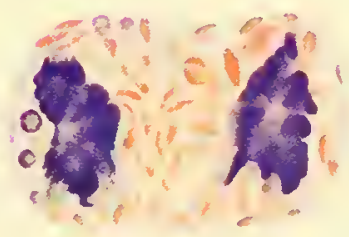

376

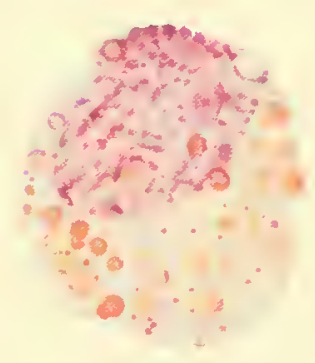

374

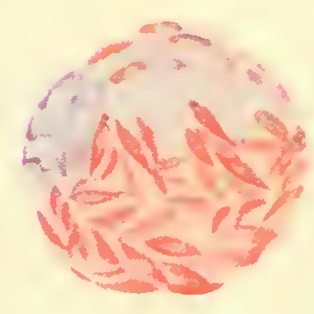

377 


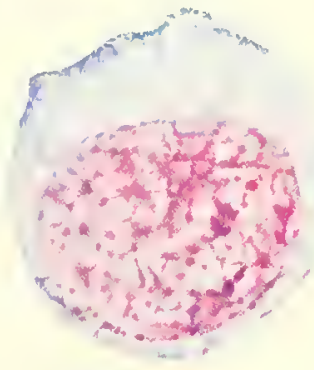

378

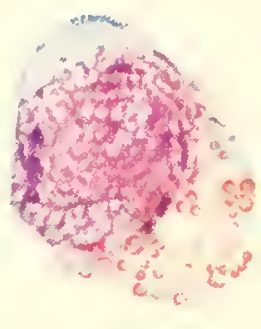

379

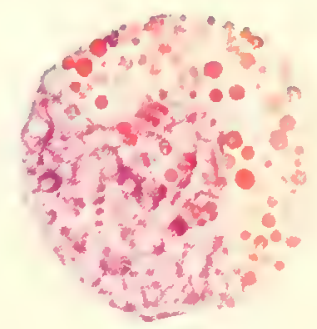

380

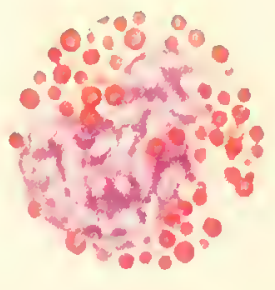

381

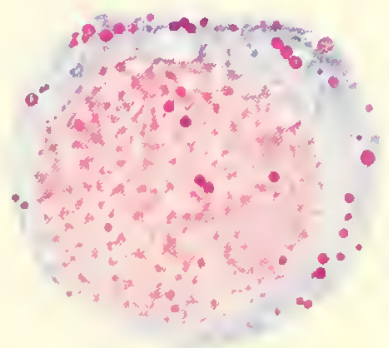

382

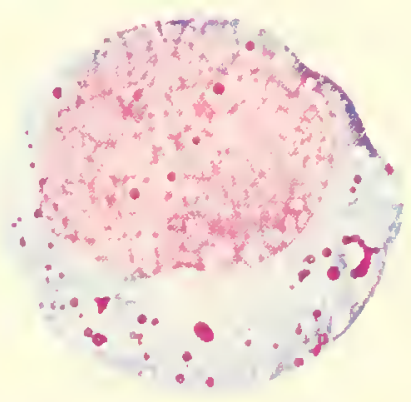

383

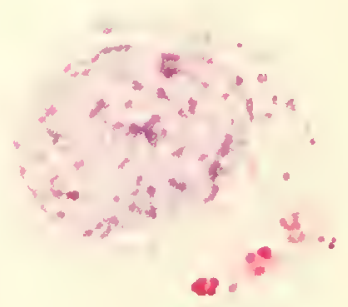

381

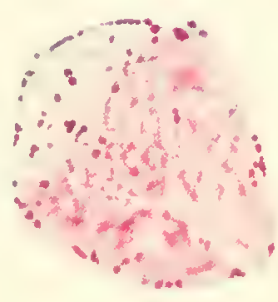

385

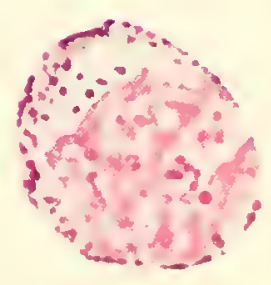

386

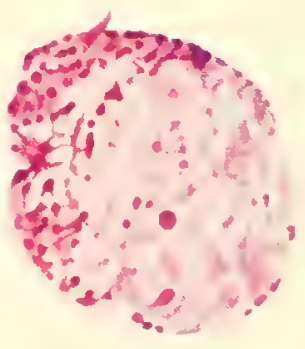

387

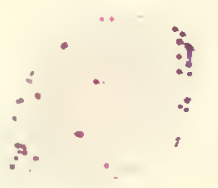

388

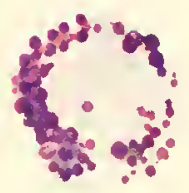

389

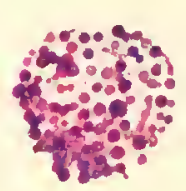

390 
strates that mitosis can occur in birds relatively late in the differentiation process, and in the erythrocyte derelopment of the human being this would be equivalent to alout the nomolnlast slage.

All of the field of figure 314 was drawn as it appeared under the microscope except for one cell ( 10 ) and that was added from another slide. Cells 9 and 10 form two stages in the thrombocyte series. The former is the blast stage and is relatively rare lun is recognizable ly its punctate pattern of nuclear chromatin. Cell 10 is the most commonly seen early thrombocyte and was added to the drawing so that its size and coloration could be compared with those of young erythrocyles and myelocytes in the same field. Its rim of dark-violet cytoplasm with a tendency to stain more lightly at the periphery is a characteristic of the early thrombocyte (fig. 362), at least as seen in bone marrow.

Mature thrombocytes that have not disintegrated are rarely seen in smears from bone marrow for reasons already discussed. One ruplured thombocyte (cell 11) ean lie identified by the remnant of acidophilic cytoplasm that is still attached to it. A close sudy of the several naked nuclei in the fictd reveals that some could have come from thrombocytes hut some undoubtedly came from broken erythrocytes.

When mumcrous fields of hone marrow are examined it is not hatd lo find all stages in granulocytic development in the embryo, but the hone marrow of the adult. untike that of the embrvo, selulom shows more than 1 or 2 early stages in a single field. Ouly 2 stages of development of the heterophil series are shown in figure 344-the metagranuloblast (cell 12) and mature cells $(13-1.5)$. A badly distorled basophil (cell 16) has heen labeled as a meso- myelocyte because it appeared to have less than half the normal number of basophilic gramules, but in view of the disintegrating effect of aqueous solutions it may be older. Cell 17 is either a mature or nearly mature hasophil.

In all bone-marrow smear's there are smudged cells. some that are slightly crushed (cells 22 25 of fig. 314) and others (cells 26 and 27) that are destroved beyond recognition.

Lymphocytes (cells $18-21$ ) show a range from mediun to small but they are all mature and in this particular field there is no evidence that the hone marrow is a lymphocytogenic organ. A better measure of this function comes from a sudy of table 10. These mature lymphocytes shown in figure 344 could have come into the bone marrow l,y way of the circulating blood, as most of the mature erythrocytes presumably did.

In figures 345-390 and 39l-397 an attempt has heen made to show each cell line as completely as possible. Obriously, many cells are similar to those pictured in the circulating blood and in other hematopoietic organs, but even considering all the rells pictured, relatively few examples are shown of each cell type, and no matter how extensive the illustrations may loe they cannot sulstitute for the actual examination of slides where, in a short time, far more cells than those represented in this volume can he seen.

Three erythroblasts from bone marrow. differing considerably in appearance, have heen illustrated (figs. 345-317). Two show nucleoli and one does not; one has a narow hand of cytoplasm and two have extensive cyloplasm. The type represented by figure 345 is rate. Most of the erythroblasts seen in adult hone manow look like figure 346 or 347 . The latter with its

Figures 378-390.-Cells of the eosinophil and hasophil granulocyte series from lone marrow of adult chicken, exrept figure 379, which was fiom a day-old chick. $2,470 \times$.

378 Eosinophil metagramuloblast.

379 Eosinophil mesomyelocyte.

380 An eosinophil mesomyelocyte more differentiated than the preceding cell.

38t A late eosinophil metamyelocyte.

382,383 Basophil promyeloeytes. Figure 383 is slightly more differentiated than figure 382 .

Figures 384-386: Basophil mesomyelocytes.

381 Early phase of the mesomyelocyte.
385 Mesonyelocyte with a moderate number of basophilic gramules.

$3 S 6$ Late phase of the nesomyelocyte.

$3 s 7$ Basophil metanyelocyte.

Figures 3S5-390: Basoptial gramulocytes from bone marrow fixed in methyl alcohal and stained in thionin.

$3 s s$ Mesomyelocyte.

389 Metamyelocyte.

390 Mature basophil. 
denser ehromatin pattern is somewhat more differentiated than the cell in fignre 346 .

Erythoblasts have leen seen in the circulating blood of the adult (figs. 9 and 121), in the circulating hlood of the early embryo (figs. 224 and 233-235), in the later embiyo (figs. 251256). and in embryo spleen (figs. 329 and 330 ). To all of these Sabin (1920) applied the term "megalolılast," but it has been claimed that the stem cells of all erythroeytes at all ages are not alike and also that those of normal hloou are not identical with those of anemia (Jones, 1943). Anemias have not been studied in the chicken lut from the other olservations it is evident that all erythroblasts do not look alike cytologically. The differences are due in part to the fact that the erythroblast is not a static cell covering one point of time in development, lut is a cell that during the differentiation process can often be divided into early and late phases, both of which are capable of mitosis and the production of progeny.

Another factor that modifies the cytology of the erythroblast is the degree of urgeney for hemoglohin. In the first generation of erythrocytes it is evident that a high rate of hemoglobin acquisition has been given priority over cylologic differentiation. With each generation of erythroblasts there is a gradual change to the definitive condition where the raking on of hemoglobin hecomes an integral part of cell differentiation.

As this study shows, the erythrohlasts under these various conditions have a different appearance cytologically. Thus the names primary erythoblast, embryo erythroblast, and definitive erythroblast have heen nsed. It is conceivalle that nnder the stress of a severe drain on the erythrocytes in the adult these cells might be pushed lack to the same demand for new hemoglohin that occurred in the first embryonic generation. Under these circumstances it might be expected that they would look alike, but under nommal conditions the definitive erythrohlast of the bone marrow does not look like the primary erythroblast, and thus there is less confusion if specific terms are used whenever possible.

Beyond the erythol, last there are three polyclromatic stages that cover the period of differentiation from a cell with a small amonnt of hemoglobin up to one with its full capacity. These three stages are, of course. arbitrary ones, and in selling them mp an effort has been made to divide the range into equal parts. In spite of full awareness that there were three stages in this range, and after considerable deliberation hat been given to the eriteria of color and cellular morphology, there were times when immature erythrocytes on a particular slide were not naned as they shonld have heen. It was felt that the difficulty might we due to a tendency, inherent in human nature, to divide any continuous variability into smaller mits. If such a tendency were to influence an investigator when he liad a slide under examination, and if the slide did not have the full range of polychromatic eryhlinocytes in the fields examined, the investigator might he impelled to divide what range there was into three parts. Repeated surrender to this tendency-one slide to the next. or one day to the next-might result in inconsistent determinations. After the drawings for the Atlas were completed and arranged, a uniform scheme was set up and with the ithstrations in hand there has been no recent diffinlty in calling cells of the same type by the same name.

Early polychromatic stages of the bone marrow are represented by figures 348 and 349 , and hoth show shadows of nucleoli against the lower muclear margins. The furst of these two cells is not far removed from the blast stage and the second has a eytoplasmic coloration approaching the mid-polychromatic erythroeyte. In these cells mitochondrial spaces are still visible; yet in some examples of early polychromatic eryth. rocytes the textural quality of the cytosome nina he as uniformly homogeneous as in later stages of derelopment.

Mid-polychromatic erythrocytes are represented lyy two drawings (figs. 350 and 351 ); the one in the first drawing is the younger. In these particular examples, the nuclens is still large relative to the size of the cell. In some mid-polychromatic erythorytes the nuclei may show greater chromatin condensation than in figures 350 and 351. They may be more like the one shown in figure 352. This figure shows a cell lying at the borderline between the mid-and late stages of erythrocyte development. The cell has been placed in the late stage group because the bisophilic substance has almost disappeared and the acidophilic materials in the stroma are begin. ning to dominate. The cell represented by figure 353 is clearly more differentiated than the preceding one and not as far along in its develop. 
ment as the cell in figure 35t. Accompanying the increase in hemoglobin is a shight elongation of the cell and an increased nuclear condensation. The tawny color, so often observed in late polychromatic erylhrocytes just before maturity, may he due to the diffusion of basophilic granular material associated with the reticulocyte stage of development.

Differentiated cells with a full complement of hemoghohin and a small nucleus with a condensed chromatin pattern of the mature cell, yet will a round, rather than an oval shape, may be found in the bone marrow of the adult chicken (fig. 355). When such cells were olserved in the embryo, they were interpreted as representing an atypical condition associated perhaps with forced development, and probably the same can be said for such cells when they appear at older ages. A mature, normal, typical erythrocyte is illustrated ly fignre 356 and is identical with those seen in circulating blood, even to the tone of cytoplasmic color, in spite of the fact that the cells in the loone marrow were stained with May-Grinwald Giemsa and those of circulating blood with Wright"s.

Thrombol, hasts were not recognized in the bone marrow until after the developing stages had been worked out in the circulating blood of the entryo. One reason was that they resembled the erythoblasts. In fact, one cell in this series (fig. 357) was originally placed among the erythroblasts, but its punctate nuclear structure soon indicated that it was in the wrong series. Two stem cells of the adult bone marrow, the granuloblast and the thromboblast, have narrow cytoplasmic rims of cytoplasm around their nuclei. The cytosones take an intense violet color, but these two cell types are readily distinguishable by their difference in muclear structure.

The erythrocyte was divided into five levels of development and the same number of sulydivisions has been proposed for the thrombocyte, but for the thrombocyte series these are based on struchural and size changes without the assistance of significant tinctorial changes as in the erythrocytes; thus it has been somewhat diffrcult to estalylish terminal criteria for each stage of development of the thrombocyte. The thromboblasts are large cells (figs. 357 and 358) with a densely stained cytosome that has numerous vacuolar and mitochondrial spaces.

The appearance of definitive thrombolshasts of the bone marrow is not much different from that of the embryo thromboblast (figs. 280-284). In both, the nucleolus may or may not be visible, depending upon the extent to which the plasmosome is masked by the overlying chromatin. The frayed appearance of the peripheral margin of the cytoplasm seen in figure 362 may also occur in the blast stage.

The term "early immature thrombocyte" is a rather awkward one; perhaps other investigators, after they have reexamined the problem, will think of a shorter name. In the early immature thrombocyte, there is some clumping of the muclear chromatin and often the structure of the nuclens will appear similar to that of the par. tially autolysed cell where the chromatin chmmps have vagne indefinite boundaries like those shown in figure 363 . Figures 358 to 362 were made from cells of the bone marrow of the 6-day. old chick rather than from the adult because there were a large number of earty stages available for observation. This made it possible to arrange them in their proper developmental sequence.

The mid-immature thrombocy te lias already acquired the characteristies that definitely identify it as a thrombocyte-namely, the shift in nuclear staining from violet to purple, the appearance of defmitive gramules (fig. 363) and the elongation of shape as in the immature enloryo thrombocyte. The cell at this stage of development has a deep basophilic cytosome, which, during differentiation to the late immature stage. fades to a lighly stained cytoplasmic framework (fig. 364). The cell has not yet assumed its mature oval shape. The nucleus is still larger than in the mature stage; it is still round, rather than oval. Cells of this type are often fonnd in the circulating blood, as shown in outline (fig. $88 i$ ). Late immature and mature thrombocytes may he found in bone marrow but they are not common; usually they have undergone at least partial disintegration. The cell shown in figure 365 is identical in appearance with that in figure 73 - a thrombocyte from cirenlating blood.

\section{GRANULOCY'TES}

The classification of gramnlocyte stages of development has been outlined in table 2, which gives 6 steps for the heterophil, 5 for the eosino- 
phil, and 5 for the basophil. Each of the 3 granulocytes reveals the characteristics of each of the 6 steps in development: lout in the eosinophils and basophils, 2 of the stages have been telescoped and the name elosen for the combination is the last one in the series.'

The granuloblast is identified hy its large uucleus surromded by a narrow rim of cytoplasm densely stained. Relatively few cytoplasmic spaces are in the cytoplasm (figs. 366 and 367). and these lie adjacent to the nucleus.

The intencely colored narrow rim of violetstained cytoplasm. combined with the delieately stained muclear reticulum and lack of visible nucleohs, makes the granulolilast readily recognizable even under lelatively low magnifiration. Figure 366 is the largest gramuloblast observed, and figure 367 represents the size usually seen. These cells resemble very closely the lynphoblast, but are different from the thromboblast and the erythroblast.

The scheme presented in table 2 has lieen written under the assumption that the granuloblast has equal potentialities to produce a heterophil, eosinophil, or basophil. Early in this study it was thought that the stem cell for each type of granuloeyte had a different appearance, but it has since been decided that these were either meta. gramuloblasts or promyelocyte stages. Hamre

\footnotetext{
${ }^{1} \mathrm{Six}$ subdivisions of the granufocyte series are mggrsted in the First Report of the Committee for Clarification of the Nomenclaturp of Cells and Diseases of the Blood and BloodForming Oroans (19.181. and Dr. L. WT. Diggs states I personal communication), "... it is my opinion that trminologies nsed in human hematology and widely acceyted and under stwod. should be used for lower animals when applicatife." This is a commendable point of view: unfortunately it has been necessary to denart in some cases from the terminology proposed by the Committee because the definitions associated with rertain terms $11=0$ d in stulies on blood of mammals to not adequatefy cover the ofiservations made on hirds. As pointed out by Jones (1919), zoologists, embryologists, and physiologists all have a take in these problems.

"Mlyelo" is an inappropriate term for immature stages of granuloryte devefopment becanse it means "marrow" and in the hirds granufocytes develop in many organs other than the lone marrow. "To have substituted the term "granulocyte" for "myelocyte" would have been acceptable as far as the dr. velommental stages are concerned but would have conflicted with the term almost miversally accepted for the aclult celt. It cepms confusing to use the term "myeloblant" for the earliust stage and "progranuloryte" for the nrit stage and then follow with two myelocvte stages. Therefore, for this study on avian hematology these terns have been changed to "wranuhblast" I an old term) and "metagranulobłas." respertively: these are foltowed by the pro- meso-, and meta- stages of the myelonyte. and these are followed by the mature cell. The pretix "meno" was userl so that eart of thes" nhases of dewtoment could lic identidiert without confusion. and so that the term "myefocyte" without any prefix could be used as a general term signifying the full range of devefopment from the metagranubblast up on the matur rell. Metagranubulast is a new term.
}

has prepared a colored plate showing granulopoiesis; it was based on the use of a different stain but in the serfuence of stages (Hanre. 1952) there was nearly complete similarity with the data given here. The privilege of examining lis data hefore publication has been helpful in this complex prohlem. He did not set apart as a separate stage what has leen given here as the netagranuloblast.

The metagranuloblast is derived from the granulollast liy a great expansion in the eytoplasm at one side of the nucleus, and by an increase in the varuolization of this portion of the eytosome. Often the remainder of the cytosome is unchanged from the condition characteristic of the gramuloblast - that is, it stains an intense violet color. This was the case in figure 368 but not in 369. At this stage the muclens may remain round (fig. 368) or it may be partially collapsed (fig. 369). The reticular patten of the nucleus may be just as finely patterned and delicately stained as in the granuloblast stage, or it may show clumping. The nucleus collapses or hecomes irregular in shape more readily in the helerophil metagranuloblast than in either the eosinophil metagranulohlast or the basophil promyelocyte. Also, the chromatin condensation is greater in the last two cells. The metagranuloblast stage of the heterophil and of the cosinophil can be readily separated. The difference is apparent when a comparison is made between figure 368 and 378. In the heterophil. the boundaries of the vacuoles are rather indefinite and they appear oftentimes as spaces in a reticulum. but in the eosinophil they are round areas with cleancut loundaries. This difference was the ehief factor in ealling cell 11 of fignre 330 an eosinophit metagramuloblast rather than a heterophil of the same stage.

One group of hematologists (Anonymous, 1949) gives only the term "myelocyte" to cover the entire span of specific gramule production. In avian blood for the heterophil at least, there is a definite stage of development hetween the metagranulololas and the sage where specific granules fust appear. Microscopically, it is one of the most conspicnous of the entire progression and it would be awkwand not to have a name for it. Its two oustanding thararteristies are the prescnee of (1) eytoplasmir rings and gramules hat take the same intense magenta stain as the 
nucleus and (2) light-staining orange spheres (figs. $370-372$ ). In figure 370 only vacuoles are present in the cylosome but in figure 371 some vacuoles are filled with lightly stained orange spheres, and in figure 372 one or two of these spheres have taken on the dark-orange color that places them at the transition where the specific bodies make their appearance. Because the stages antecedent to specific granule production can be followed so readily in birds, it seems that use of avian blood would be advantageous in further study of the early stages of granulopoiesis. The magenta rings and the granules vary in number; in some cells there are but few and in others they are abundant. The nature of the stainal)le material inside the magneta ring is not known.

The small gramules are of two types; one takes a magenta stain and the other, a deep orange. If figures 370 and 372 are compared, it will be noled that in the latter the magenta-stained granules are scattered around the orange-stained spheres and not in them; but in figure 371 many of the orange gramules lie in the exact center of each sphere and others do not. These orange granules are abundant in figure 374 . The question has come to mind repeatedly, Are the orange granules identical with the central bodies of the mature heterophil granulocyte? It might seem that this should be easy to determine by following the development of the rods to see where the gramules go, but the presence or absence of a central body in the rods is not constant, as was seen in figures 154-165, and not a single rod in figures 373-377 shows a central hody inside it. In figme 372 the small gramules lie at the periphery of the orange spheres.

It was the opinion of Dantschakoff (1908h) that there was metachromasia of the specific granules of heterophils during the early stages of differentiation. This reaction would agree with the ohservations reported in the paragraph above, to the extent that the first granules to appear are of two types, magenta-staining and pale orangestaining. The magenta rings appear to be a different organelle than the magenta granules and were not observed by Dantschakoff in her sectioned material. In a study by Lucas and Denington (1956, umpublished data) magenta rings wele observed in sectioned material.

The nucleus of the promyelocyte may be distinct but often it appears as in figures 371 and
372, where nuclear boundaries are vague, and at this stage they appear the same as they do in the embryo spleen.

Several steps are involved in the production of a rod. First a vacuole is formed, it is occupied by a light-orange sphere, which progresses to a darkly stained orange sphere, and this in turn becomes a rod. The development of a sphere and its transformation into a rod mark the beginning of the mesomyelocyte stage (figs. 373 and 374).

The mesomyelocyte stage has a nucleus that may be large and indefinite (fig. 373) or small with definite chromatin clumps (frg. 374). Also, some magenta rings and granmles may persist (fig. 373). The process of rod differentiation is more advanced in figure 373 than in 374 ; in the latter it is not much farther than the "darkorange sphere" stage. When the rods form

\footnotetext{
${ }^{2}$ One clinical hematologist, after seeing colored reproductions of these avian myelocytes, said:

"The myelocytic series may be drawn exactly as they appeared, but if that is true, they appear to be inadequately stained. If we had a human bone marrow or blood snear that had nuclei which were as pale and the structures as ill defined as painted, we would say that the stain was unsatisfactory, would not attempt a differential or diagnosis and would ask for better stained preparations or a restain of the same preparation. A combination of Giemsa as a counterstain for the Tright's or a change of the buffer water or a longer staining
} tine might give better results."

Various technics, including Wright-Giemsa, have been tried, and although differences in the appearance of the cells may occur-with the same or different technics-the general picture of heterophil granulopoiesis as shown here is representative for the normal chicken. Nothing has heen seen that supports the idea that avian myelocytes look the way they do in impression smears because inappropriate technics were chosen or because appropriate technics were faultily applied. It is suggested that the promyelocytes often appear the way they do because the cell undergoes extensive hypertrophy, both of the nucleus and cytosome, as one of the first steps in heterophil myelopoiesis and hecause the firm vacuoles and the lightorange bodies give a honeycomb appearance to the nucleus and cytosome by puncturing these structures at the time the cell is flattenerl in the process of making the smear (fig. 371 ).

A little later in development, nuclear detail becomes visible again (fig. 371). In the interim the nucleus has not changed its apnearance to any great extent (compare figs. 369 and 374 ). Therefore, not much has been lost by using a technic (May. Grünwald Gipmsa) that does not reveal all the detail of the nucleus at the promyelocyte stage. On the credit side, this stain reveals the subtleties of changing form and color in the rod precursors, which seems important when studying granulocyte development. When Petrunkevitch's No. 2 was used on spleen myelocytes, followed by May-Grünwald Giensa, the border of the nucleus could be traced readily, and the nucleus appeared as a large body containing a delicate granulation, but the cytoplasmic inclusions suffered severely by this technic.

The author of the paragraph quoted is not mentioned here by name for the reason that it is not intended to make this volume a springhoard for a controversy. He is respected as an outstanding clinical hematologist of human blood and he may be expressing an opinion that would be shared by all hematologists of mammalian blood who look at these illustrations. A common ground of understanding is, of course, neces. sary for any discussion and this can be reached more quickly when it is recognized that many details of luman and avian blood are not the same. 
they produce bodies of irregular shape-some pointed, some rounded, and some multiangular.

After the cell has developed abont half of its normal complement of rods, it is called a metamyelocyte up to the stage where, at matmrity, it has the full number of rods. This is a purely arbitrary division and armittedly not exact, but it would be still more difficnlt in avian blood to follow the eriterion "Bean or kidney shaped nuclens" (Anonynons, 1949) becanse, with approaching maturity, the typical artifact of the heterophil mincleus becomes apparent; therefore, in figme 377 it would be impossible to say whether this cell had an indented or bean-shaped melens but it is quite evident that it has abont as many rods as the cell will hold.

Figures 375 and 376 are examples of metamyelocytes. In both there are one or two magenta rings still carried over to this late stage; usually, of conrse, they have disappeared by this tine. From fignre 376 it is obvious that mitosis does not stop at the granuloblast stage or even when the specific grammles first appear.

Developmental stages of eosinophils are as scarce in the bone marrow as are the mature forms in the circulating blood. The finding of developmental stages went slowly but eventually after enongh cells had been studied certain definite features were established that lielped to separate them from heterophils. The qualities of cytoplasm and nucleus that make the eosinophil metagranuloblast distinguishable from the heterophil of the same age have already been discussed in part. The nucleus of the eosinophil thronghout its developmental stages generally is more intensely stained than that of the heterophil. Usually the vacuoles are clear-almost refractile-but as shown in figure 378 a few faintly stained bodies are visible. These differentiate directly into the specific granules, and the mesomyelocyte (fig. 379) shows a full scale of tinctorial range from the faintest to the darkest. It is this direct transition from seeming vacuole to defmitive gramules that eliminated the promyelocyte stage. There appears to be nothing equivalent to the magenta rings.

In the heterophil the developmental steps of the precursor spheres were moderately well syuchonized in their formation; whereas. in the eosinophil, development of the spheres begins at different times, so that all stages are present at any one time. Even in the older age (fig. 380) the full range-vacuole to faint sphere to dark sphere-is clearly shown and the framework cytoplasm has the same pale-blue color that it has in the adult cell.

In the legend for figure 380 this cell is called a mesomyelocyte, and this stage, as defined here, is one that has less than half of its granules. At first glance this cell appears to have half of its granules. or more. But this cell and the heterophil are dealt with in the same way-only those grannles are counted that have arrived at matnrity and have their full tinctorial density. On that basis the cell definitely has less than half of its granules.

Had the late metamyelocyte (fig. 381) been found in the circulating blood it would probably have been counted as a mature cell_-similar cells from circulating blood. shown in figures $177-$ 180, have been so named. The difference is that the cylosome of the cell in figure 381 was not fully packed with granules. When the eosinophil of the circulating blood was discussed. it was pointed ont that the specific granule for this cell varied from a large homogeneous body to a group of four small bodies in a cluster. At no time have the small bodies been found in the developing stages of eosinophils in embryo spleen or adult bone marrow. This variation is an im. portant one, and will be discussed again when the blood of ducks is described, but its significance in the cytomorphosis of the cell is still mnknown.

Studies of basophil and eosinophil differentiation are handicapped by the fact that so small a proportion of cells belong to these groups. As with the eosinophil it has been assumed that the gramuloblast stage of the basophil has the same appearance as described for the heterophil. When cells like those in figmres 366 and 367 are found, there are no identifying eytologic landmarks to indicate the direction in which they will develop. It was not difficult to locate cells that resemble those in figures 384-386, but cells like figures 382 and 383 were classed at first as heterophils because they showed magenta bodies. Further study proved, however, that they were not quite identical with those in the heterophils. In the cells under study the magenta bodies were predominantly granules ranging from small to large; the large ring cliaracteristic of the heterophils was ahsent or relatively rare. There were 
a few small rings as is shown in figure 382 , but these are not like the large thin-walled rings shown in figures $370-372$. It was chiefly because of these characteristics that the decision was made to place a cell found in the circulating blood (fig. 193) among the basophils and not among the heterophils.

The question arises. At what stage of derelopment are the cells that are represented by figures 382 and 383? It is best that the magenta bodies be ignored for the time being and that attention be given to the nucleus and cytoplasn. The cytoplasm of cell 382, slightly liypertrophied at one side of the nucleus, is vacuolated and is beginning to lose the strong basophilia of the granuloblast. If it did not have the magenta granules it would he classed as an early metagranuloblast, and figure 383 would be classed as a slightly more differentiated cell at the same stagc, but the presence of the magenta bodics has been given as characteristic of the promyelocyte. It is as if two steps in development liad been compressed into one; thereforc it is identified by reference to its most conspicuous feature and is called a promyclocyte-this is simpler than contriving a new name to cover the two phases of development.

This immediately raises the question, Are these magenta bodics the specific granules characteristic of basophils? If they are, these cells should be called mesomyelocytes. At present the opinion is held that these are not mature specific granules and it is suggested that the definitive basophilic granules of the more mature cell derelop out of the faintly stained substance of the vacuoles. Thus, when the granules first appear, they are the pale-magenta bodies shown in figure 384 and from this pale staining condition, by a progressive transformation, they produce the dark-magenta bodies shown in figure 384 and more ahundantly in the three succeeding figures. The nucleus of the basophil promyelocyte does not lose its sharp boundary or the details of its internal structure. This is becanse the cytoplasmic vacuolization in the basopliil is not so vigorous as in the heterophil.

On the right side of the mucleus of figure 382 is a bluish shadow that looks very much as if a nucleolus were present below the surface. This may be the case but in the granuloblast nucleus it is not typical. (Sec addendum, p. 140.)

Figures 384-386 are all mesomyelocytes, yet each of the cells in the series is older than the one preceding. Cell 384 represents the first step in the production of fully differentiated basophil granules, and cells 385 and 386 show an increasing number. By this method of fixation and staining they appear to lie on a reticulum, but in cells 388-390, which are fixed in methyl alcohol and stained with thionin, no network joining the granules is visible. It is probable that the network is an artifact and the idea of differentiation of granules from vacuolar substance was stated only as an opinion becausc it is ohvious that in the bone marrow, as well as in the circulating blood, aqueous solutions tend to dissolve and distort the basophil granules. The mucleus also seems to be adversely affected by the technic treatment (figs. 385-387). Figure 387 is a late metamyelocyte.

There is need for additional search for a technic that will preserve the basophil granules and still reveal the detailed structure of the cell. Methyl alcohol and thionin preserve the gramules, but nucleus and cytoplasm stain alike and have such a delicate blue color that no structural details are visible; so when it is stated in the legend that figure 388 is a mesomyelocyte, figurc 389 a metamyelocyte, and figure 390 a mature basophil granulocyte, this is based only on the number of granules present.

\section{PLASMA CELLS}

Plasma cells may be found in spleen and bone narrow but are not common in normal healthy chickens. A few examples from bone marow have been secn and are presented here, and some that were ohserved in the spleen are illustrated in fignre 331 , but in no case has a cell been found that could qualify structurally as a plasmablast. The possibility that such a cell might be the primordial osteogenic cell in bone marrow or the reticular cell in the spleen is a reasonable assumption since the early immature plasmacyte (fig. 331, 1) resembles these primordial cells. Mjassojedoff (1926) found numerous plasma cells in the loose comnective tissue of adult chickens. He considcred this abundance to represent a point of differen.e from mammals where they are said to be scarce.

Figure 391 represents the earliest stage that lias bcen found. The cytoplasm form a much 
larger area around the nucleus than is characteristic of blast cells but is considerably less than found in the mature plasmacyte, and this particular cell has been called an early immature plasmacyte. The cytosome shows a mixture of mitochondrial spaces and the spherical vacuoles that are typical for the plasmacyte, both immature and mature. The bluish color taken by the cytoplasm has little or no red in it; thus it has an azme quality usually not found in other cell lines. The nncleus, even at this stage of immaturity, stains intensely; the chromatin is miformly distributed hut is composed of blocks larger than commonly found at this early stage of differentiation. This was true also of the immature plasmacyte pictured in the spleen (cell 1 , fig. 331) .

The next four cells (frgs. 392-395) are classed as late immature plasmacytes. They are almost as large as the early immature plasmacyte but proportional size of the nucleus has decreased. The sequence in this progressive change is indicated by the arrangement of figures. The most differentiated cell of the group is figure 395 , in which a small nucleus lies at one side of a large cell having a strongly basophilic cytoplasm. During this process the chromatin aggregates into large clumps, hut the clumps do not fill the entire nucleus. In figure 393 the cytosome is filled with small vacuoles; in the others there is a range in size from small to large.

The mature plasmacyte (figs. 396 and 397) is smaller than the immature stages. The nuclens still holds an eccentric position in the cell. The Hof, which was present in some of the immature cells, usually persists. Thus, the Hof is present in figure 396 and absent from 397. Vacuoles characteristic of plasmacytes are still present in the cytosome. A drawing was made of a cell identified as a mature plasma cell in the circulat. ing blood, but since the cell occurred only once among many slides exanined, the drawing has been omitted. It did not have a vacuolated cytoplasm, and this raised some doubt that it was a plasmacyte.

\section{OSTEOCLASTS}

Osteoclasts can be found in most bone marrow smears. They are readily recognized by their large size (figs. 398-399). Cells of this size are multinucleated, as shown in figure 399. Search was made for a mononucleated osteoclast and it was thought that such a condition had been found in figure 398 , but beneath the pink-stained material in the center of the cells were faint traces of other nuclei. Small mononucleated cells like those found in the bone marrow of the embryo (figs. 319, 326, and 327) probalbly exist in adult bone marrow, also, but were not scen.

The cytoplasm of osteoclasts in smears seems to merge into the surrounding serum and only rarely can one identify with any accuracy the exact boundary all the way around the cell; often it appear's as shown at the left end of figure 399. The cytoplasm forms a network and in it are vacuoles of various sizes and granules of varions sorts; most of the latter-for example, the rods and magenta rings from heterophils-fell on the surface of the cell when the smear was made. Sectioned material usually gives an indication that the osteoclast has polarity-one end pressed against the spicule of bone and the other free in the marrow cavity. The appearance of the cell in figure 399 would suggest that the left side of the cell has been adjacent to the bone and the basophilic right end toward the cavity.

\section{DIFFERENTIAL COUNTS ON BONE MARROW}

Differential counts have been made on the cells of bone marrow in the chicken at 3 ages before and at 4 ages after hatching. One hundred cells were counted from each of five chicks at each age. The average was based on 500 cells. This number is small for bone-marrow studies but, even in this preliminary smrvey, certain ratios and trends are indicated. Late polychromatic and mature erythrocytes are abundant at all the ages covered in table 10 , but it is questionable whether the fluctuations in the two cell types have significance; for example, where there were 16.8 and 29.2 percent at 285 hours, 49.6 and 18.4 percent at 347 lours, and 6.0 and 29.4 percent at $48 \mathrm{l}$ hours. Stages younger than the late polychromatic erythrocyte are always scarce.

Thrombocytes are present at all ages and are distributed fairly miformly among the various slages of development except for the thrombo- 
blast. None of these were found at any of the ages examined, and the same was true for tymphoblasts, monoblasts, and immature and mature plasma cells.

Immature and mature lymphocytes were found at 285 honrs, and appeared at all ages after hatching. No monocytes were found in this survey until after hatching.

The heterophil is the dominant granulocyte and is present at all ages and the incidence of granuloblasts just before hatching ( 481 hours) is higher than after hatching. The data in table 10 indicate that this is true also of the other immature and mature stages of the heterophil. The same tendencies are indicated in the eosinophits, where they were found most abundantly at 347 and 481 hours incubation age; after hatching they remained at a fairly low level. Perhaps the same tendency is indicated also in the basophils but the number of cells counted was too small to definitely establish a picture of a prehatching rise.

Anong miscellaneous cells, some primary erythrocytes were observed at 285 hours and none after that. This cell is one that is known to arise in the yolk sac; therefore it was probaluly brought into the bone marrow through the embryonic circulation.

Osteogenic activity was indicated at 285 hours but none later except perhaps immediately after hatching, and the fact that the elongated reticular cells were found only at these same two ages is probably due to more than chance. Two macrophages were included in the counts at 285 hours and again at 8 days after hatching, but it would be expected that this cell might be seen at any age. Mitosis for all types of cells was 1 percent or less. The number of squashed cells fluctuated irregularly. Cells that could not be identified were most abundant at 285 hours. Following that there was a downward gradient until the percentage reached a level of 0.2 at 4 days 18 hours, and a level of 0.4 at 8 and at 175 days.

In respect to cell counts the data presented here differ greatly from those presented by Burmester, Severens, and Roherts (1941). They found large numbers of lymphocytes, whereas we found only a few. The data by Forkner (1929) for the adult chicken show some differences from that given in table 10. Our data show a higher heterophil than eosimophil count, whereas Forkner's values have the reverse order. He did not inchude thrombocytes in his tabulation. His lymphocyte count was considerably higher than ours.

Marvin (1954) calculated the total number of bone marrow cells in both femurs and both tibia in a strain of young White Carneau pigeons. His mean normal value on 4 pigeons was $10^{8} \times 32 \pm 5$ cells for the total marrow of these four leg bones. 
Cell type

Erviturngle series:

Erythroblast. .

Early polychromatic erylh. roigte

Mid-polvelormatie eryihro-

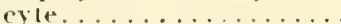

Late polymiromatic eryhim.

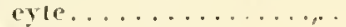

Mature erythyreyte.

Thrombucyce series:

Thromlublulast.

Early immanre throuloerte...............

Mid-immature thromborste Late immature thromloneyte

Nlature thrombocyte.....

Lymphoy to series:

lymphinblast. . . . . . . .

limmature lympheyle.....

Mature lymplueydr.

Nomoryte serits:

Monmilast.

Farly immature monocste.

Late immalure monocyle.

Malure monoryte.

Iletronhlul series:

Granuloblast.

Metagranuloblast........

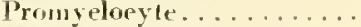

Mesn- and metanyeloryce

Mature heterophil.

Eusinophil siries:

Metagranulololast.

Mesomyeloryte.

Vetamvelocyte.

llature eosinophil.

liasopliil suries:

I'romyelocer

Meso-and melanveloeyto

Maturr losopjobil..

Miscrilaneulls cells:

Primary aryllirocyles.

Primoritial osteogenic cells

Osteordasts

Osiculidasts.

Plammacyte series...........

Elongated reticular cells.... I

$M$ acropluagrs.............

Cells in mitusis. . . . . . . . . .

Squashed cells......... 12 liefore hatching

\begin{tabular}{|c|c|c|c|c|c|c|c|c|c|c|c|c|c|c|c|c|c|}
\hline \multicolumn{6}{|c|}{285 hours of incubation } & \multicolumn{6}{|c|}{317 hours of ineubation } & \multicolumn{6}{|c|}{481 hours of ineulation } \\
\hline \multicolumn{5}{|c|}{ Bird } & \multirow{2}{*}{$\begin{array}{l}\text { Aver- } \\
\text { age }\end{array}$} & \multicolumn{5}{|c|}{ Bird } & \multirow{2}{*}{$\begin{array}{l}\text { Aver- } \\
\text { age }\end{array}$} & \multicolumn{5}{|c|}{ Bird } & \multirow{2}{*}{$\begin{array}{l}\text { Aver- } \\
\text { age }\end{array}$} \\
\hline 1 & 2 & 3 & 4 & 5 & & 1 & 2 & 3 & + & 5 & & 1 & 2 & 3 & 4 & 5 & \\
\hline l'ct. & Pet. & l'ct. & l'ct. & l'ct. & I'ct. & Pet. & l'ct. & Pct. & Pet. & l'ct. & I'ct. & P'ct. & Pet. & I'rt. & l'ct. & Pet. & Prt. \\
\hline ] & 1 & & & & 0.4 & 1 & 3 & 1 & & 2 & 1.4 & & 6 & 1 & 6 & 1 & 2.8 \\
\hline & 1 & & & & 0.2 & 1 & 2 & 2 & I & 1 & 1. 1 & 3 & 7 & 3 & 4 & 2 & 3.8 \\
\hline 1 & 3 & 2 & & 1 & 1. 4 & 5 & 8 & 5 & 6 & 2 & 5.2 & 3 & 9 & 1 & 9 & 1 & 5.2 \\
\hline 29 & 1 & 13 & 22 & 19 & 16.8 & 41 & 56 & 55 & 50 & 16 & 19.6 & 5 & 18 & 2 & 4 & 1 & 6.0 \\
\hline 27 & 2 & 51 & 12 & 21 & 39.2 & 10 & 18 & 15 & 24. & 25 & 18.4 & 17 & 15 & 38 & 30 & 47 & 29.4 \\
\hline
\end{tabular}

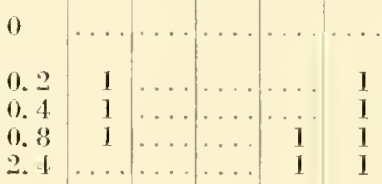

0
0.4
0.1
0.6
0.4

0

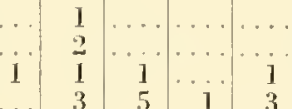

2. 4

3

0

1. 6

2.6

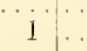

0.4 .

$\frac{2}{2}$

3

i

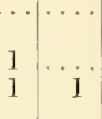

0. 2

1. 1

0. 6

0.4

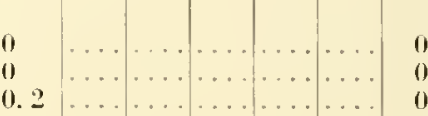

0. 2

0

0

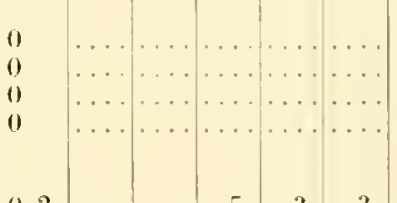

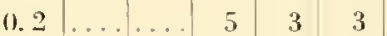

$\begin{array}{llllll}11.2 & 3 & 2 & 2 & 3 & 6 \\ 0.1 & 9 & 4 & 8 & 8 & 7\end{array}$

0.4

8.1

i
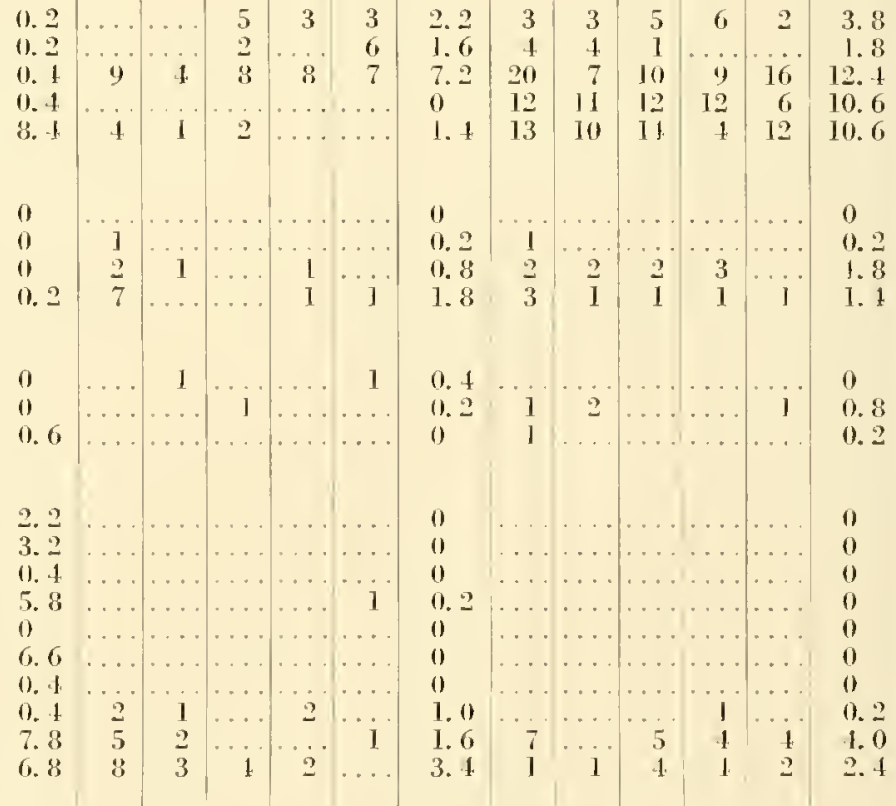


\begin{tabular}{|c|c|c|c|c|c|c|c|c|c|c|c|c|c|c|c|c|c|c|c|c|c|c|c|}
\hline \multicolumn{5}{|c|}{ Bird } & \multirow{2}{*}{$\begin{array}{l}\text { Iver- } \\
\text { age }\end{array}$} & \multicolumn{5}{|c|}{ liird } & \multirow{2}{*}{$\begin{array}{l}\text { Aver- } \\
\text { age }\end{array}$} & \multicolumn{5}{|c|}{ Birl } & \multirow{2}{*}{$\begin{array}{c}\text { Aver- } \\
\text { age }\end{array}$} & \multicolumn{5}{|c|}{ Bird } & \multirow{2}{*}{$\begin{array}{c}\text { Aver- } \\
\text { age }\end{array}$} \\
\hline 1 & 2 & 3 & 4 & 5 & & 1 & 2 & 3 & 1 & 5 & & 1 & 2 & 3 & 4 & 5 & & 1 & 2 & 3 & 4 & 5 & \\
\hline
\end{tabular}

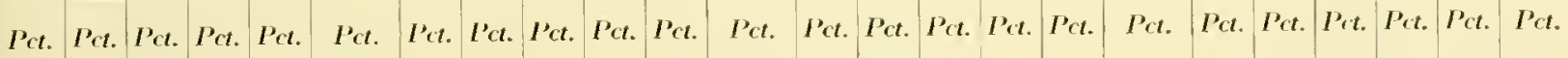

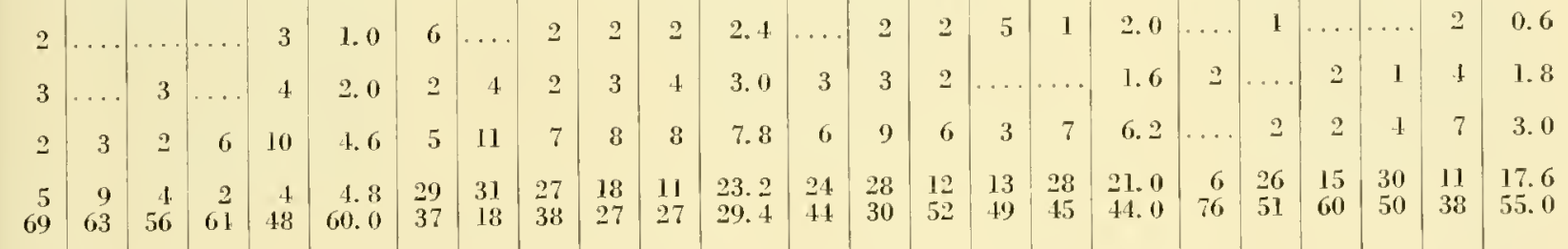

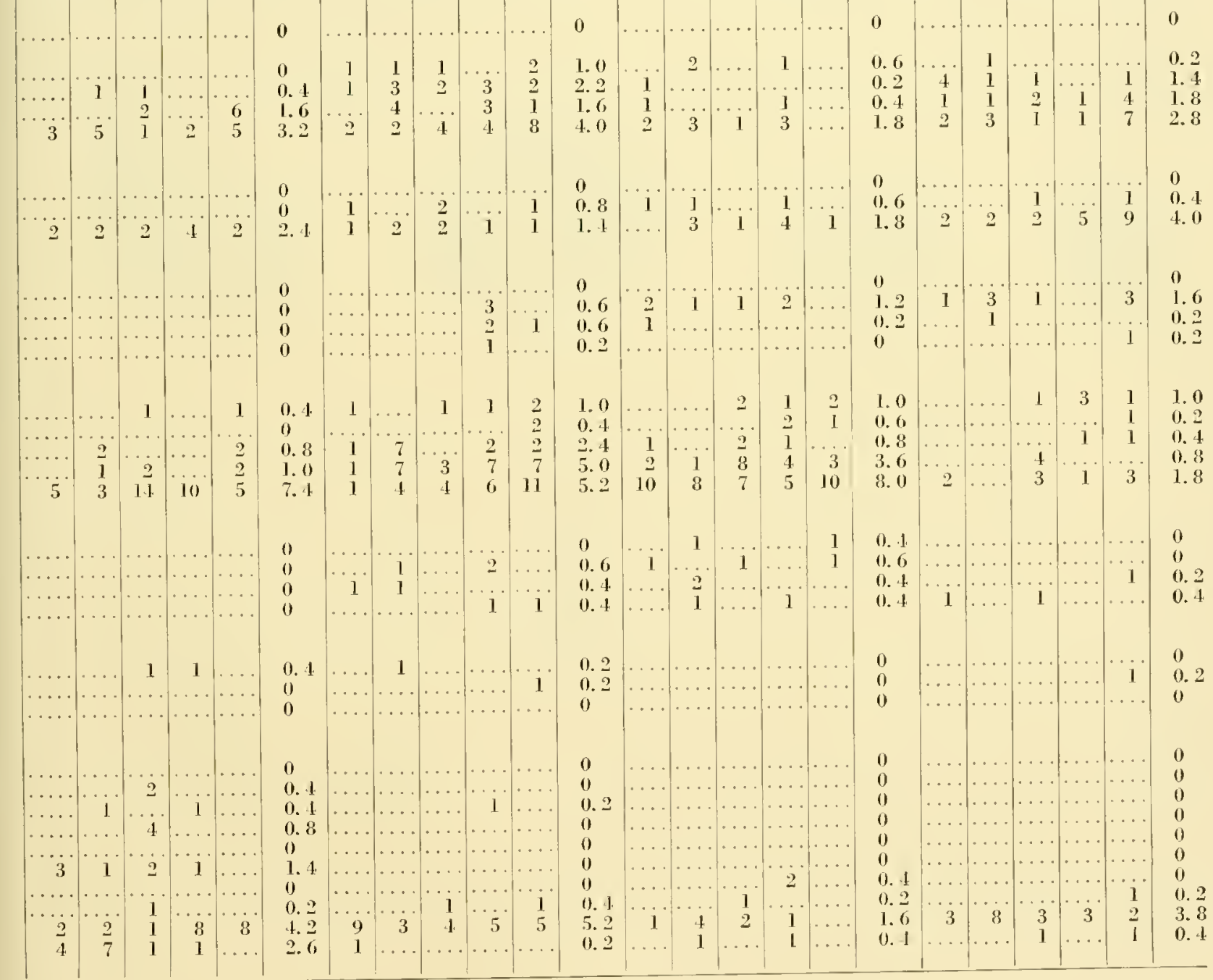




\section{Blood Cells of Other Avian Species}

\section{DESCIRIPTION OF CEILS}

Although this study has been concerned primarily wilh the blood of the chicken, the authors have not been unmindful of the requirement, implicit in the title of this volume, that attention be given to the hlood of other species of birds.

Specimens have been collected from other domestic birds and from wild birds. But cells from such speeimens are illustrated and described only if they differ appreciably from cells found in chicken blood. There seemed to be no reason why a cell from another species should be illustrated and described if its counterpart in chicken blood conld be readily located in the Atlas.

Tahle 11 lists the birds from which speeimens were taken. The study included the circulating blood of all these species and the bone marrow of many of them.

After the blood cells of the chicken, with all their variations, have been thoroughly studied, no difficulty should be experienced in identifying the various blood-cell types in other birds, because the same cell type is closely similar in ap. pearance in most avian species. The only possible points of confusion have been illustrated in figures 400-410, and are to be found in the

Table II.-Birds, other than the chicken, from which blood-cell specimens were taken

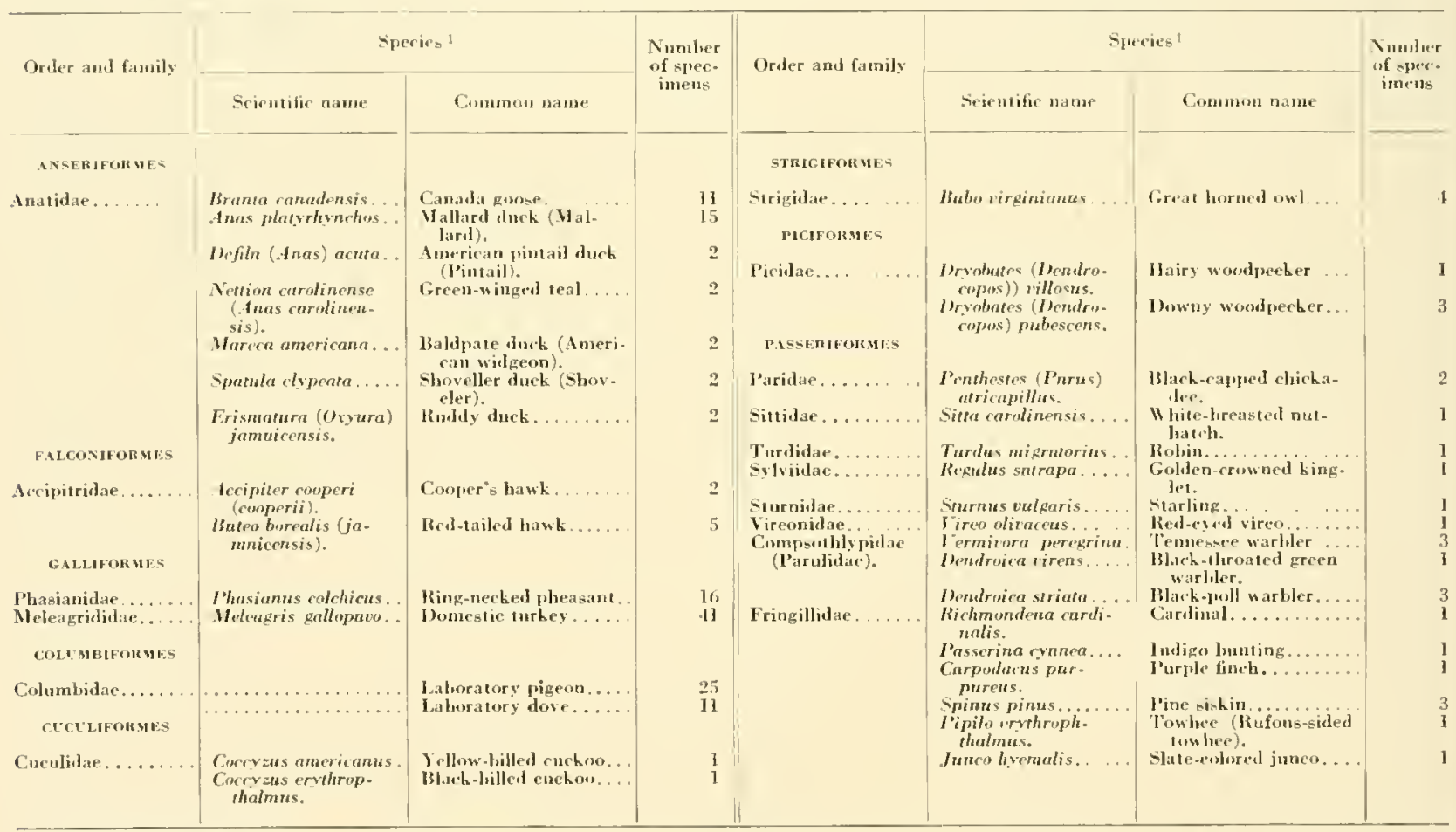

1 Names in parentheets are from the fifth edition (1957) of "Check-List of North American Birds," hy a committee of the American Ornitbologists" Unim; others are from the fourth edition (193i). 


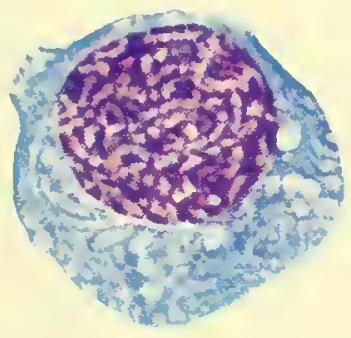

391

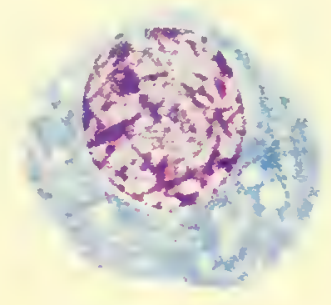

392

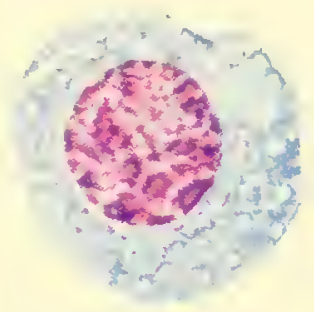

393

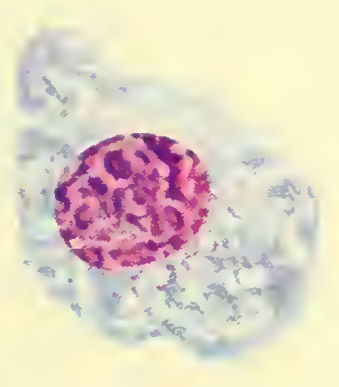

391

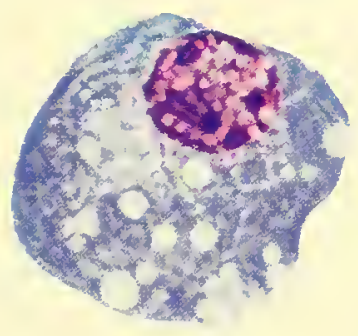

395

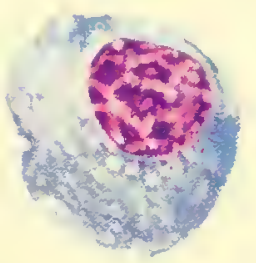

396

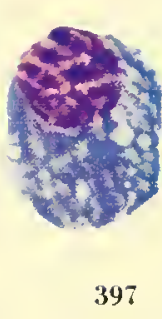

397

Flaures 391-397.-Cells of the plasmacyte series found in bone marrow of adult chickens. 2,470X

391 Early immature plasmacyte.

392-395 Late immature plasmacytes.

396, 397 Mature plasmacytes. 
Figures 398, 399.-Osteoclasts from the bone marrow of adult chickens. $2,470 \times$.

398 Osteoclast that appears to have but one nucleus, but others were present at lower focal levels. Acidophilic material in the central portion characteristic of osteoclasts.

399 Multinucleated osteoclast. Boundary of cell of ten diffieult to determine. 


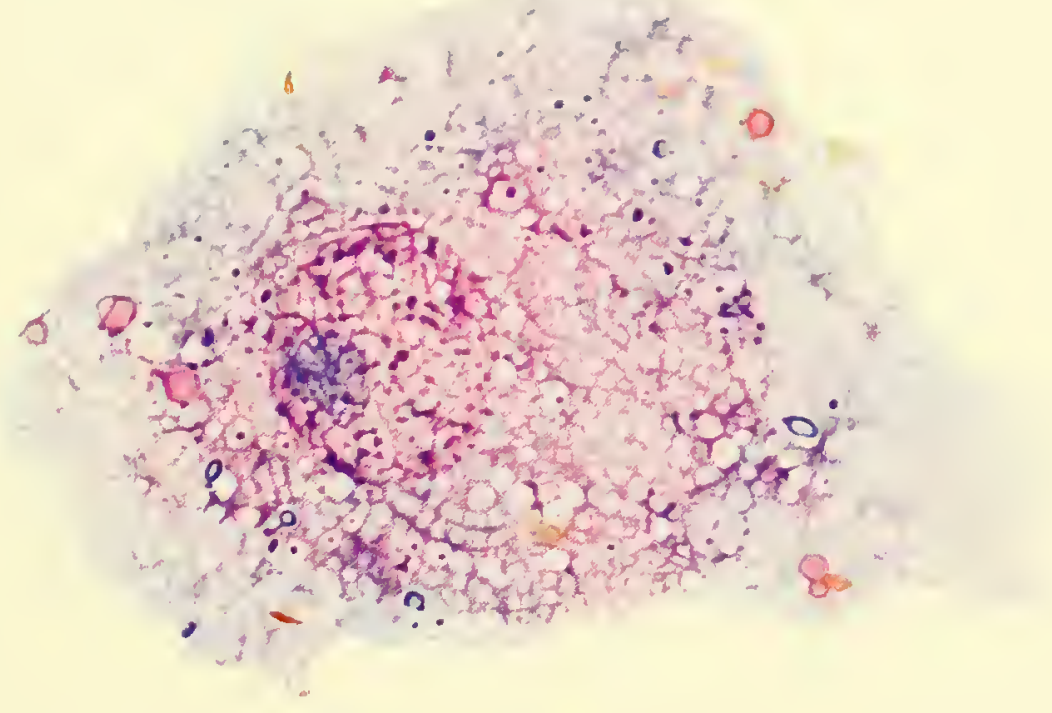

398

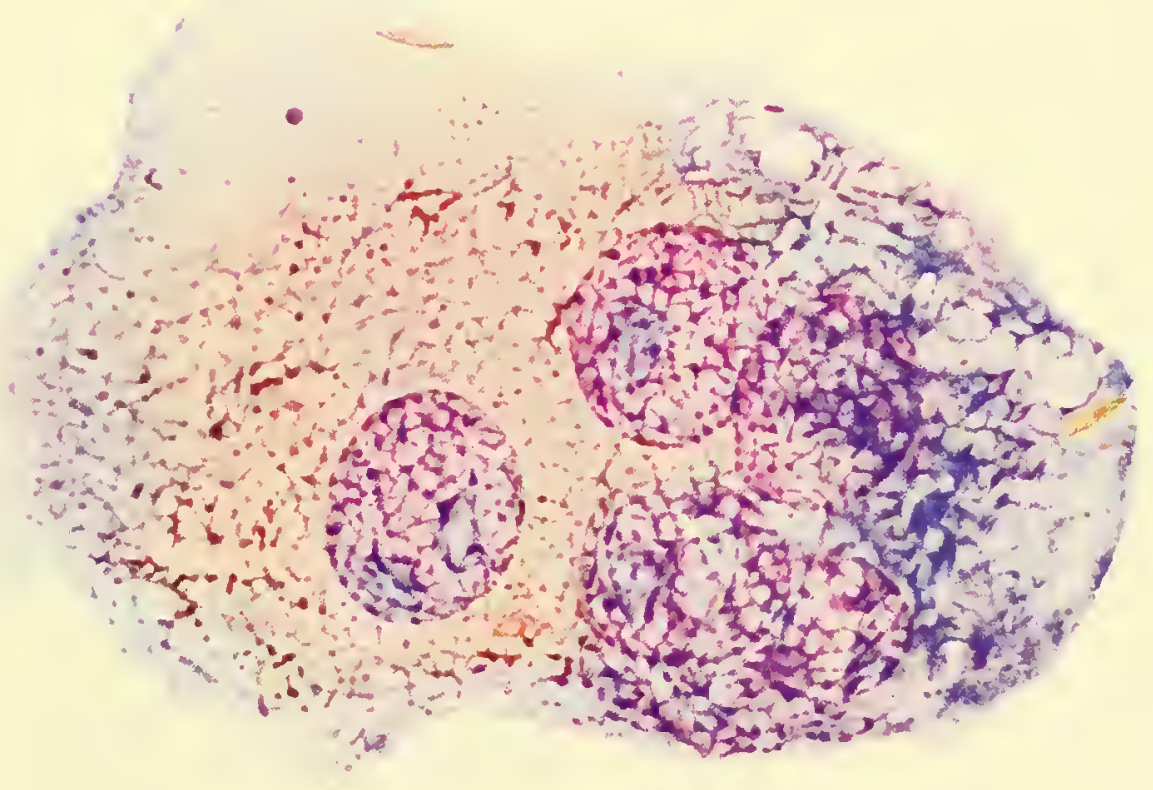




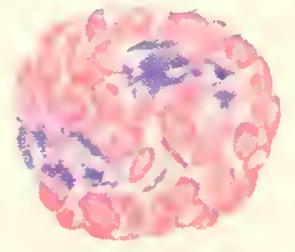

400

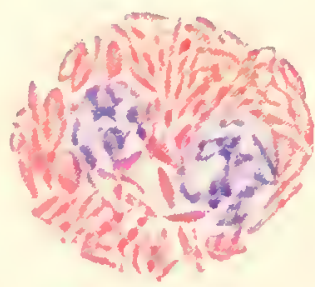

401

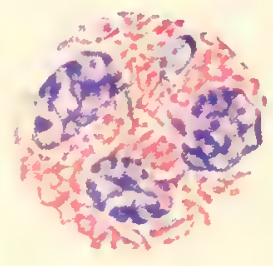

402

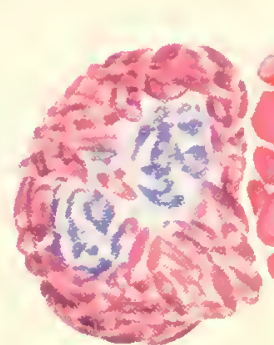

403

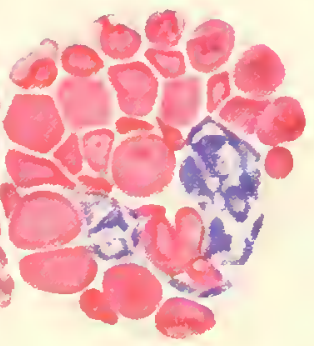

101

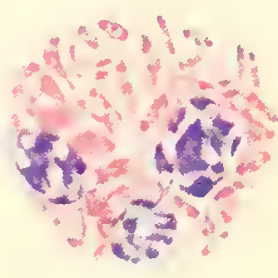

405

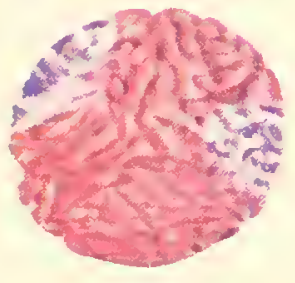

106

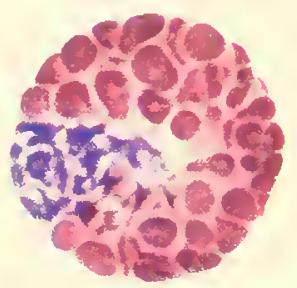

407

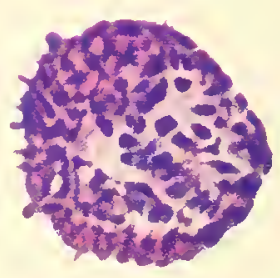

408

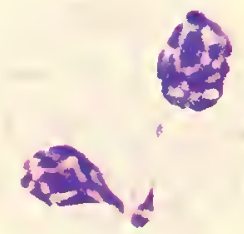

409

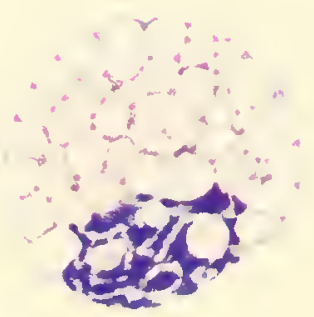

410 
heterophils and eosinophils of ducks and turkeys. Cullen (1903) noted that in guinea hens and in kingfishers the percentage of heterophils was lower than for eosinophils, a relationship that was the reverse of that found for other species of birds, therefore, close attention was given to these cells in the blood of wild birds and it was readily apparent that the confusion arose from the fact that heterophils and eosinophils are bighly variable in their appearance; some heterophils resemble eosinophils and some eosinophits resemble heterophils. Confusion has been created by the fact that in some species - the duck, for example - the eosinophils are often rare, and it may be that, in making differential connts, certain variants of the heterophils were classified as eosinophils and the remainder as heterophits.

Figure 400 is a heterophil from a mallard duck taken in Dlichigan and figure 401 is from an individual of the same species taken in Utah. It should not be assumed that the cytologic differences are due to geographic habitat; this much variation can be found in a group of slides from a species within a particular locality. One of these cells (fig. 400) has broad, short, rounded rods that look mnch like large eosinophil spheres (compare with fig. 404). The rods of figure 400 are not uniformly stained. The deusity of staining is greater toward the edge of the rod than toward the center. The clear area of the center is not sharply defined like the vacuole in the center of the rod in chicken blood (fig. 166).

The rods in another specimen of mallard duck were small, narrow, and tapering with pointed ends (fig. 40l). It is this shape that is characteristic of heterophil rods in most birds. In the specimen from which the heterophil (fig. 401) was taken, the cosinophils, of which figure 402 is an example, looks somewhat like heterophils. This similiarity in appearance is a possible cause of confusion.

The two types of specific inclusions are not actually alike when examined under high magnification. The specific eosinophilic granules are composed of very small bodies that appear to lie on a network. If the granules merge with the network, because they are small or because there is no color difference between the two, the network may then simnlate a mass of poorly preserved rods in a heterophil.

Wright's stain, when applied to chicken blood, often incompletely colors the chromatin of the heterophil nucleus. Heterophils of many other species show the same artifact. The difference in staining affmity between the nuclei of heterophils and eosinophils has been utilized to aid in distinguishing the two cell types, and a search for this difference is always made at the beginning of a study on blood from a species not previously examined.

Incomplete nuclear staining of heterophils is shown in figures 400,401, and 403, and complete nnclear staining of eosinophils in figures 402 , 405 , and 407.

When a specimen is found where the heterophil nucleus stains as well as the eosinophil nucleus, considerable study may be required before the two cell types can be distinguished readily. Hewitt (1942) faced the same problem in the selection of proper terms for heterophils and eosinophils. Eosinophils with round granules occurred only in bone marrow. Therefore, without attempting to solve the homologies of heterophils and eosinophils in ducks with those

Figures 400-410.-Granulocytes from ducks and turkeys. 2,470X.

FIGUREs 400, 401: Heterophits from adult male mallard ducks. Wright's stain.

400 From Lowell, Mich.

401 From Utah.

402 Eosinophil from same slide as preceding one.

FiguREs 403, 404: Two granulocytes adjacent to each other. From a bald pate drake. Wright's stain.

403 Heterophil.

404 Eosinophil.

405 Eosinophil. Ruddy duck. Juvenile male. MayGrünwald Giemsa.
Figures 406-40s: Granulocytes from the turkey. Wright's stain.

406 Heterophil.

407 Eosinophil from same slide as preceding one.

tos Basophil.

Figures 409, 410: Turkey granulacytes from a smear fixed in Petrunkevitch No. 2 and stained with May-Grünuald Giemsa. Same bird as the one from which figures 406 and 407 were taken.

409 Heterophil.

410 Eosinophil. 
cells in other birds, he grouped all cells in which the specific grauules stained with eosin into two types of heterophils: heterophils witl ellipsoidal rods and heterophils with bacillary rods.

When the eriteria set up in table 8 (p. 90) are applied, as far as they may be applicab]e, to Hewitt's colored figures of these two cell types, the cells with the ellipsoidal rods beeome heterophils and those with bacillary rods beeome eosinophils. The close agreement between the differential counts on ducks that he nsed and the counts on the common mallard (p. 216) offer further confirmatory evidence that his heterophils with bacillary rods are eosinophils in spite of the fact that they superficially resemble the heterophils of other species of birds.

The percentage values for leukocytes obtained by Magath and Higgins (1934) for adult tame mallard. Anas platyrhynchos L., differ somewhat from those given in table 18. Like Hewitt, he found that polymorphommclears with granules were more abundant than those with rods, namely, 24.3 and 2.1 percent, respectively.

Figures 400-402 are from the mallard, figures 403 and 404 from the baldpate duck, and figure 405 from the ruddy duck. The three were selected because they again illustrate the wide variation in the appearance of the eosinophil. Figures 403 and 404 are cells that were adjacent on the same slide. The rods of the heterophil are cigar shaped with a vacuole in the center of each rod. The spheres of the eosinophil are very large and most of them are homogeneous, but in a few there are small granules on a reticulum; the granules are arranged in a square.

The type of eosinophil in figure 405 is a source of confusion. It appears but little different from the heterophil in figure 401 . The specific bodies of the eosinophil are present in the form of short rods with granules. Sometimes these gramles are located at the end and sometimes in the middle of each body. The eosinophil of the turkey (fig. 407) stains almost the same color as the heterophil rods of the baldpate duck. A clear, lightstaining space is present in the center of some of the spheres.

Perhaps all these variations can be resolved into some definite overall plan. Although much sturly still remains, there seems to be some evidence that the specific gramule of the eosinophil has two morphologic forms with transitional stages between, not only in the same speeies but also in the same individual. In the chicken there were snall, fine granules on a reticulum (fig. 179) and larger spheres, nearly homogeneons in struclure (fig. 180). The condition in figure 402 is equivalent to that in figure 179 . The important fact to note is that, at least in chickens, the large type eosinophilic body is actually composed of four small granules arranged in a square (fig. 180). Therefore, it is particularly significant that in the sphere loeated at about 1 o'clock on figure 404 there should be 4 small, distinet gramules in the form of a square with homogeneous material around them. In figure 405 they have taken another form, and here the unit granules have moved apart in pairs so that a rod is produced.

These variations and their possible relationships are presented in figure 411, in which the progression is from the homogeneous sphere, stage $A$, to the development of an enclosed tetrad of grammles, $B$, which in ducks may pull apart by pairs to form psendorod structures, $B^{\prime}$ and $B^{\prime \prime}$. The homogeneous sphere, $A$, may develop into a square of four granules surrounded by much matrix, $B$, or only a little, $C$. Step $D$ has never been observed but its existence, as a transitional configuration between the seattered tetrads of $C$ and the reticulum with granules at the interstices of $E$, is assumed. Any such scheme of progression should agree with the development of the cell through myelogenic stages, maturity, and aging. During myelopoiesis, the only expression of the specific eosinophilic granule in the chicken is in the form of homogeneous spheres (figs. 379381). The same was true in a case of eosinophil myelogenous leukemia. Of the immature stages that were drawn from circulating hlood (figs. 184 and 186), the first had homogeneous spheres and the second a tetrad type of arrangement of small granules. Since the second is a more differentiated cell than the first, it might have been concluded that the spheres were changed into granules, but when figure 186, a young cell with granules, is compared with figure 180 , a mature cell with three nuclear lobes, it could be concluded equally well that the proeess of change was going in the opposite direction.

Well exeeuted color drawings of the blood from an African vulume have been presented by Neave (1906). He ilhstrates three morphologic types of eosinophilic polymorphs, but does not attempt to name them. 


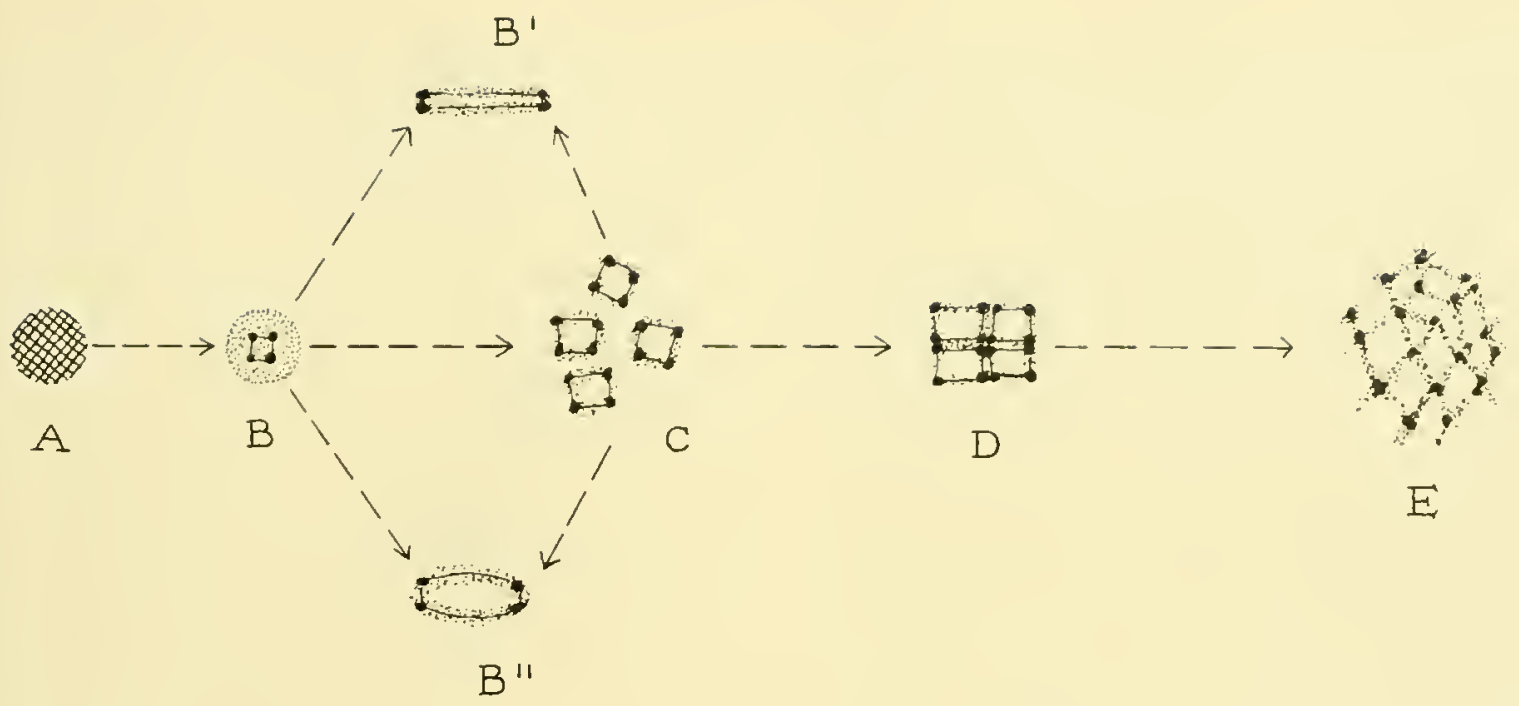

FIgUra 411. - A diagram in which relationships have been suggested for the different types of eosinophil granules that have been observed.

A A large homogeneous sphere seen during myelopoiesis.

B A combination of sphere and small granules arranged in a square (for example, see fig. 404).

C The type of granule often seen in the eosinophil of the chicken-four small granules in a square, jouned by lines (figs. 177,178 ). The presence of a matrix around them is questionable.

Figures 406-410 illustratc the granulocytes found in turkeys. The rods in the heterophil (fig. 406) can be identified readily for what they are, but if they are much thimmer than shown in this cell, they take on the effect of a reticuluman effect that may cause them to resemble the fune-gramule type of eosinophil. Actually, there was no confusion in the identification of heterophils and eosinophils on the slide from which figures 406 and 407 were taken because the eosinophil (407) was so strikingly different from the heterophil in both color and structure. This again emphasizes the fact that among various species the tinctorial qualities of cells of the same type are not always alike; for example, the rods of the heterophil (fig. 403) are colored about the same hue as are the granules of the eosinophil (fig. 407) and neither of these are greatly different from the dark-magenta bodies of the basophil (fig. 408).

Duplicate smears were made of blood taken from some of the species listed in table 11 . One was fixed dry and the other in Petrunkevitch No. 2 and stained with May-Grünwald Giemsa. By
$B^{\prime}$ and $B^{\prime \prime}$ From the type of granule in either B or C elongation of the square into either a rod or oval shap, ean be produced (fig. 405). The rod and oval forne can be confused easily with the rods of heterophils bus have no relationship.

D A transition stage leading to $\mathrm{E}$, a reticulum carrying small granules at the interstices (fig. 402).

the latter method the nuclear lobes were clearly shown and were used for Arneth counts. In the chicken heterophil (fig. 203) the rods were completely dissolved and only the protoplasmic network remained. The same picture has been seen in the turkey (fig. 409). This technic, however, produced different effects on the eosinophils of these two species. In the chicken (fig. 215) the eosinophil gramules are well preserved, but in the turkey (fig. 410) they are completely dissolved, with the result that heterophils and eosinophils appear quite similar in this species; a close examination of the two cell types in turkeys does reveal a difference. The protoplasmic framework around the eosinophil granules is sharp and definite and the size of the spaces is equivalent to the area of the large granules that fill them (fig. 407). The spaces within the heterophil vary in size and are irregular in shape, and the protoplasmic network is not sharply defined. Once these differences are recognized there should be no difficulty in the separation of heterophils and eosinophils when making Arneth counts in the turkey. 
When smears were taken from pheasants, it was noted that the blood had a surprisingly high viscosity. When the drop collected on the pusher slide had been touched to the smear slide, it did not spread easily to the opposite comers, as does the blood of chickens and geese. Only after considerable moving around of the pusher slide did the drop spread laterally to form a uniform column of substance. This property of the pheasant blood made it difficult to obtain a thin, uniform smear.

The erythrocytes of the species of ducks, cuckoos and the liawk mentioned in table 1] were larger than those of the chicken; the erythrocytes of all the other species had approximately the same size as those of the chicken. These statements are based on visual comparisons and not on measurements. Wintrobe (1933) has given the length and width of erythrocytes for the chicken, guinea, goose, and pigeon. A further discussion of the size of erythrocytes in the chicken will be given when table 12 is considered.

Immature stages of development and erythroplastids of all sizes were found in many of the species of wild birds; they were especially numerous in some of the slides from ducks and from the indigo bunting. In mature cells, the nucleus was slender and rodlike with dense chromatin clumps like figure 5 . In slides from some specimens of mallard ducks the nuclei were so contracted and slender that the dense chromatin chumps bulged outward, giving it a mulberry appearance. Scarcely any spaces could be seen between the clumps.

Smears from ducks and pigeons showed erythrocytes that were distributed in pairs and in a crossed position. With each erythrocyte in a pair crossing the other at 90 degrees, and with the centers coinciding, a pinwheel effect was produced. This peculiarity has never been observed in chicken blood.

The thrombocytes in the shoveller duck, turkey, pheasant, pigeon, dove, owl, black-capped chickadee, cuckoo, and white-breasted nuthatch were larger than those in the chicken. Except for these differences in size, the thrombocytes in all the species listed in table 11 were similar to those of the chicken. The specific granules of the turkey thrombocyte were usually in vacuoles.

There is always a possibility that thrombocytes will be confused with lymphocytes. Confusion is especially likely to occur in the case of the pigeon. In this species the cytoplasm of thrombocytes takes a more intense coloration than it does in most avian species, and the cells are nearly round. Moreover, the thrombocytes of pigeons appear to disintegrate less readily when the smear is made than they do in most species; thus the form of the cell is retained. This, of conrse, aids in holding the specific granule of the thrombocyte intact so that identification can be made easily when neither lym phocytes nor thrombocytes have disintegrated. If the cytosome of these two cell types has been lost they can still be separated by the fact that the nucleus of the lymphocyte is larger than that of the thrombocyte.

Lymphocytes in all species of wild and domestic birds examined appeared the same as in chickens. Magenta bodies or reactive lymphocytes, or both, were found in nine species, including a species of duck.

Monocytes in other species are the same as found in the chicken. Those of the great horned owl were large with round nuclei and large, dense chromatin clumps.

Heterophils were variable within an individual or a species, as they were in chickens. Differences in the shape of the rods in ducks have already been mentioned; in turkeys the rods dissolve readily as they do in chicken cells; in the owl the rods were of the "typical" type, pointed at both ends. In other species of birds, as well as in the chicken, central bodies exist inside the rods, but their occurrence is not constant.

The eosinophils for some ducks have been pictured. Figure 402 represents the granular type, figure 404 the large sphere type, and figure 405 the rod type; in figure 411 these have been diagramed as $E, B$, and $B^{\prime}$, respectively. In the pintail duck the specific bodies are spheres and vary in size from medium to large; in the greenwinged teal, rods and granules are mixed; and in the shoveller duck small granules are clumped to form rods. The Canada goose and the owl have small gramles, and the plueasant and the dove have large ones. In many of the passerines they are like those in the chicken but in the redeyed vireo and purple finch they have fine granules and in the robin the bodies are almost refractile.

Basophils in other avian species appear as they do in the chicken except that the cells of the turkey are larger and those of the owl are smaller. The mucleus of the pigeon basophil is often ec- 
centrically placed so that the granules lie at one side of the cell. This cell in the mallard duck is extremely susceptible to aqueons stains; even Wright's stain dissolves most of the granules and when this happens so that the cell contains only a few granules, the nucleus hecomes more intensely stained and the cell closely resembles a lymphocyte with magenta bodies. Often it is only the pinkish ground color of the basophil cytoplasm and the blue of the lymphocyte that distinguishes one cell from the other. Both MayGrünwald Giemsa and MacNeil's tetrachrome stains dissolve the cytosome and its granules to such an extent that basophils could not be found in smears following these stains.

\section{SIZE OF CELLS}

Graphs in chapter 2 (figs. 89, 152, 153, and 197) give the average sizes of thrombocytes, lymphocytes, monocytes, and the three granulocytes. With the possible exception of the curves for the granulocytes, they are umimodal. Actually the data for these graphs represented a composite from four sources:

Stock from the U. S. Regional Poultry Research Laboratory:

Single Comb White Leghorns. line 6-relatively resistant to lymphomatosis.

Single Comb White Leghorns, line 15-relatively susceptible to lymphomatosis.

Stock from a commercial breeder:

New Hampshires.

Columbian Plymouth Rocks.

Slides were taken from individuals of each group and the various cell types were measured.

The most challenging data came from differences in size of erythrocytes. The length and width of the cytosomes and nuclei of 25 cells from each bird were measured. The ranges and the averages are given in table 12 . The average length of the erythrocyte for our stock was $10.6 \mu$, and the width was about $6.6 \mu$; the nucleus was $4.1 \times 3.0 \mu$. There was little difference between lines 6 and 15. Both breeds of chickens procured from commercial sources had erythrocytes that averaged about $1.6 \mu$ longer and the nuclei were about $1.0 \mu$ longer, but the widths of each were the same as for the smaller cells from our birds. Even among the individuals of a group there may be considerable difference in a particu- lar set of measurements; for example, the erythrocyte nucleus of the first Columbian Plymouth Rock was 18 percent longer than that of the second one. These data raise again the questions, What is the form of a typical erythrocyte? Are the rounded cells with oval leptochromatic nuclei less mature than the longer cells with rodlike pachychromatic nuclei?

Keller (1933) studied cell and nuclear size in dwarf and normal breeds of chickens. In embryos, during the incubation period of 4 to 8 days, there was no significant difference in lengths of erythrocytes. At hatching, the average dimensions of length and width for the dwarf breed was $8.05 \times 3.88 \mu$ and for the breed of normal size, $7.51 \times 3.77 \mu$. In the grown birds, the dwarf showed 7.84 $\times 4.19 \mu$ and the chicken of normal size, $8.19 \times 4.50 \mu$. It was concluded that the size of the breed had no influence on the size of the erythrocytes. It should be noted that the average values given in her work are in every case less than the minimum of the range given in table 12.

Kitaeva (1939) also studied the size of erythrocytes from three European breeds of chickens-Langshans, Brown Leghorns, and Benthams. The differences were slight. Averages computed from his data on all adult birds were, length $11.0 \mu$ and width $6.6 \mu$. These values fall within the ranges given in table 12 .

An extensive study of cell size in relation to body weight was made by Melnner (1938) on 11 breeds of chickens. He used epithelial cells, striated muscle cells, and erythrocytes. The bird weights varied from 335 to 2900 grams. The area of the erythrocytes varied from 62.3 to $77.2 \mathrm{sq} . \mu$ and. in spite of considerable variability, he obtained a correlation of $-0.54 \pm 0.08$ between body weight and erythocyte area. He studied size of erythrocytes in the White Leghorn from 1 day of age to 54 months of age. When dividing the series into those younger than 9 months and those older than 9 months, he obtained an average erythrocyte area of $70.0 \mathrm{sq} . \mu$ for the former and $66.5 \mathrm{sq} . \mu$ for the latter.

Kalabukhov and Rodionov (1934), who were interested in the problem of changes in the blood with age, gave the following figures, based on the sparrows Passer montanus L. and P. domesticus L., which have altricial young: age 1-5 days, hemoglohin 4.0 percent, number of erythocytes 


\begin{tabular}{|c|c|c|c|c|c|c|c|c|c|c|}
\hline \multirow{3}{*}{ Breed } & \multirow{3}{*}{ Source ${ }^{1}$} & \multirow{3}{*}{ Bird ${ }^{2}$} & \multicolumn{4}{|c|}{ Cytosene } & \multicolumn{4}{|c|}{ Truelems } \\
\hline & & & \multicolumn{2}{|c|}{ Lenguth } & \multicolumn{2}{|c|}{ Width } & \multicolumn{2}{|c|}{ Length } & \multicolumn{2}{|c|}{ Width } \\
\hline & & & ${ }_{\mu}$ liange & $\begin{array}{l}\text { Aver- } \\
\text { age } \mu\end{array}$ & $\underset{\mu}{\text { Range }}$ & $\begin{array}{l}\text { Iver- } \\
\text { age } \mu\end{array}$ & $\underset{\mu}{\text { Range }}$ & $\begin{array}{l}\text { Iver- } \\
\text { age } \mu\end{array}$ & $\underset{\mu}{\text { Range }}$ & $\begin{array}{l}\text { Aver- } \\
\text { age } \mu\end{array}$ \\
\hline $\begin{array}{l}\text { Single Comb II hite Lrig- } \\
\text { liorns. } \\
\text { Iverage for grmul. . . }\end{array}$ & RPL $6 \ldots$ & $\begin{array}{l}1 \\
2 \\
3\end{array}$ & $\begin{array}{r}9.6-11.8 \\
10.0-11.6 \\
9.7-11.8\end{array}$ & $\begin{array}{l}10.8 \\
10.8 \\
10.7 \\
10.8\end{array}$ & $\begin{array}{l}6.2-3.0 \\
5.9-7.7 \\
6.0-7.7\end{array}$ & $\begin{array}{l}7.0 \\
6.6 \\
6.6 \\
6.7\end{array}$ & $\begin{array}{l}3.1-1.9 \\
3.6-4.6 \\
3.1-4.6\end{array}$ & $\begin{array}{l}\text { 4. } 3 \\
\text { 1. } 1 \\
\text { 4. } 1 \\
\text { 4. } 2\end{array}$ & $\begin{array}{l}2.7-1.1 \\
2.7-3.5 \\
3.0-3.5\end{array}$ & $\begin{array}{l}\text { 3. } 1 \\
\text { 3. } 1 \\
\text { 3. } \\
\text { 3. } 1\end{array}$ \\
\hline $\begin{array}{l}\text { Single Comb White Leg- } \\
\text { horns. } \\
\text { Average for gronj. . . }\end{array}$ & RPL $15 \ldots$ & $\begin{array}{l}1 \\
2 \\
3\end{array}$ & $\begin{array}{l}9.2-11 . \mathrm{J} \\
9.4-11.6 \\
9.3-11.6\end{array}$ & $\begin{array}{l}10.6 \\
10.3 \\
10.4 \\
10.4\end{array}$ & $\begin{array}{l}6.2-7.2 \\
6.0-7.4 \\
6.0-7.5\end{array}$ & $\begin{array}{l}6.7 \\
6.5 \\
6.7 \\
6.6\end{array}$ & $\begin{array}{l}3.0-5.2 \\
3.5-1.8 \\
3.6-5.3\end{array}$ & $\begin{array}{l}3 . \overrightarrow{8} \\
4.1 \\
4.3 \\
4.1\end{array}$ & $\begin{array}{l}1.8-3.6 \\
2.8-3.1 \\
2.6-3.7\end{array}$ & $\begin{array}{l}3.1 \\
3.0 \\
3.1 \\
3.0\end{array}$ \\
\hline New 11 ampshires...... & Commercial & $\begin{array}{l}1 \\
2 \\
3\end{array}$ & $\begin{array}{l}10.9-14.0 \\
10.6-13.1 \\
10.9-13.2\end{array}$ & $\begin{array}{l}12.4 \\
12.1 \\
12.0 \\
12.2\end{array}$ & $\begin{array}{l}6.0-7.5 \\
6.2-8.2 \\
4.6-7.2\end{array}$ & $\begin{array}{l}0.0 \\
6.8 \\
7.2 \\
6.5 \\
6.8\end{array}$ & $\begin{array}{l}\text { 1. } 1-5.7 \\
\text { 1. } 6-6.3 \\
\text { 3. } 0-6.0\end{array}$ & $\begin{array}{l}4.1 \\
4.9 \\
5.1 \\
5.3\end{array}$ & $\begin{array}{l}3.0-3.7 \\
2.7-1.1 \\
2.8-3.5\end{array}$ & $\begin{array}{l}3.0 \\
3.4 \\
3.3 \\
3.2 \\
3.3\end{array}$ \\
\hline $\begin{array}{l}\text { Columbian l'lymoulh } \\
\text { liorks. } \\
\text { Average for group. . . }\end{array}$ & Commercial & $\begin{array}{l}i \\
2 \\
3\end{array}$ & $\begin{array}{l}11.0-13.4 \\
11.2-12.9 \\
10.9-14.2 \\
\ldots \ldots \ldots\end{array}$ & $\begin{array}{l}12.1 \\
12.0 \\
12.6 \\
12.3\end{array}$ & $\begin{array}{l}5.0-7.7 \\
6.0-7.6 \\
6.0-8.3 \\
\ldots \ldots \ldots\end{array}$ & $\begin{array}{l}6.8 \\
6.9 \\
7.0 \\
6.9\end{array}$ & $\begin{array}{l}4.9-7.0 \\
4.4-6.0 \\
4.7-7.3 \\
\ldots \ldots .\end{array}$ & $\begin{array}{l}3.1 \\
5.9 \\
5.0 \\
5.5 \\
5.5\end{array}$ & $\begin{array}{l}2.0-3.7 \\
2.5-3.6 \\
2.8-1.4 \\
\ldots \ldots\end{array}$ & $\begin{array}{l}3.3 \\
2.8 \\
3.3 \\
3.3 \\
3.1\end{array}$ \\
\hline
\end{tabular}

RI'L= stoek from the U. S. Regional l'oultry Researeh Laboratory.

2 Neasurements hased on 25 cells per lird.

1,028.000; age 10-15 days, hemoglobin 6.8 percent, number of erythrocytes $1,645,000$, area of an erythrocyte $74.5 \mu^{2}$; age 1620 days, hemoglobin 7.7 percent, number of erythrocytes, $2,177,000$ area of an erythrocyle $72.7 \mu^{2}$ : and age 2]-30 days, hemoglobin 11.4 percent, number of erythrocytes $2,425,000$, and area of an erythrocyte $55.8 \mu^{2}$. Essentially similar changes in increase of bemoglobin and cell number, and decrease in cell size with age, occurred in the gull, Larus ridibundus L., which have praecocial young.

Bartsch et al. (1937) gave average length and widtl of erytbrocytes and length and width of their nuclei for 50 species of birds from eastern North America. They say (p. 516):

"The largest cell was found in the Osprey, which yielded the length 16.5 microns, while the smallest length was observed in the Carolina Chickadee, which gave a length of 6.0 microns. The greatest diameter of the cell was found in the Osprey and the Red-lreaded Woodpecker, both of which gave a reading of 10.0 microns, while the Eastern Tree Sparrow yielded the least diameter, namely 4.0 microns.

"In the measurements of the nucleus the largest diameter fell to the Red-headed Woodpecker; which yielded 7.87 microns, while the shortest lengtb of the nucleus fell to the White-breasted
Nuthatch and the Yellow-throated Warbler, both registering 3.10 microns. The greatest diameter of the micleus fell to the White-breasted Nuthatch and the Eastem Hermit Thrush, both of which yielded 1.10 microns."

These authors listed five earlier papers, not quoted here, in which erythrocyte size had been determined in wild birds.

Table 13 gives measurements of length and width of thrombocytes for the same four groups of chickens. Nuclear measurements were not taken. The cells in the New Hampshire and in the Columbian Plymonth Rock were about 1 micron longer than in the Laboratory stock of Single Comb White Leghorns, and the width was greater also.

The irregular shapes of the lymphocytes and monocytes make it impossible to take simple length and width measurements. This irregularity of form is shown in figures 150 and 151 . On page 65 it was explained that the areas were determined by tracing the outlines of cells and nuclei with a camera lucida and then using a planimeter. The diameters given in table 14 are calculated values derived from the areas. The areas of lymphocyles for the three groups. RPL 6, RPL 15, and the Columbian Plymouth Rocks, were close - 54.7, 52.6, and $54.2 \mu^{2}$, respectively. But the average area for the three New Hamp- 


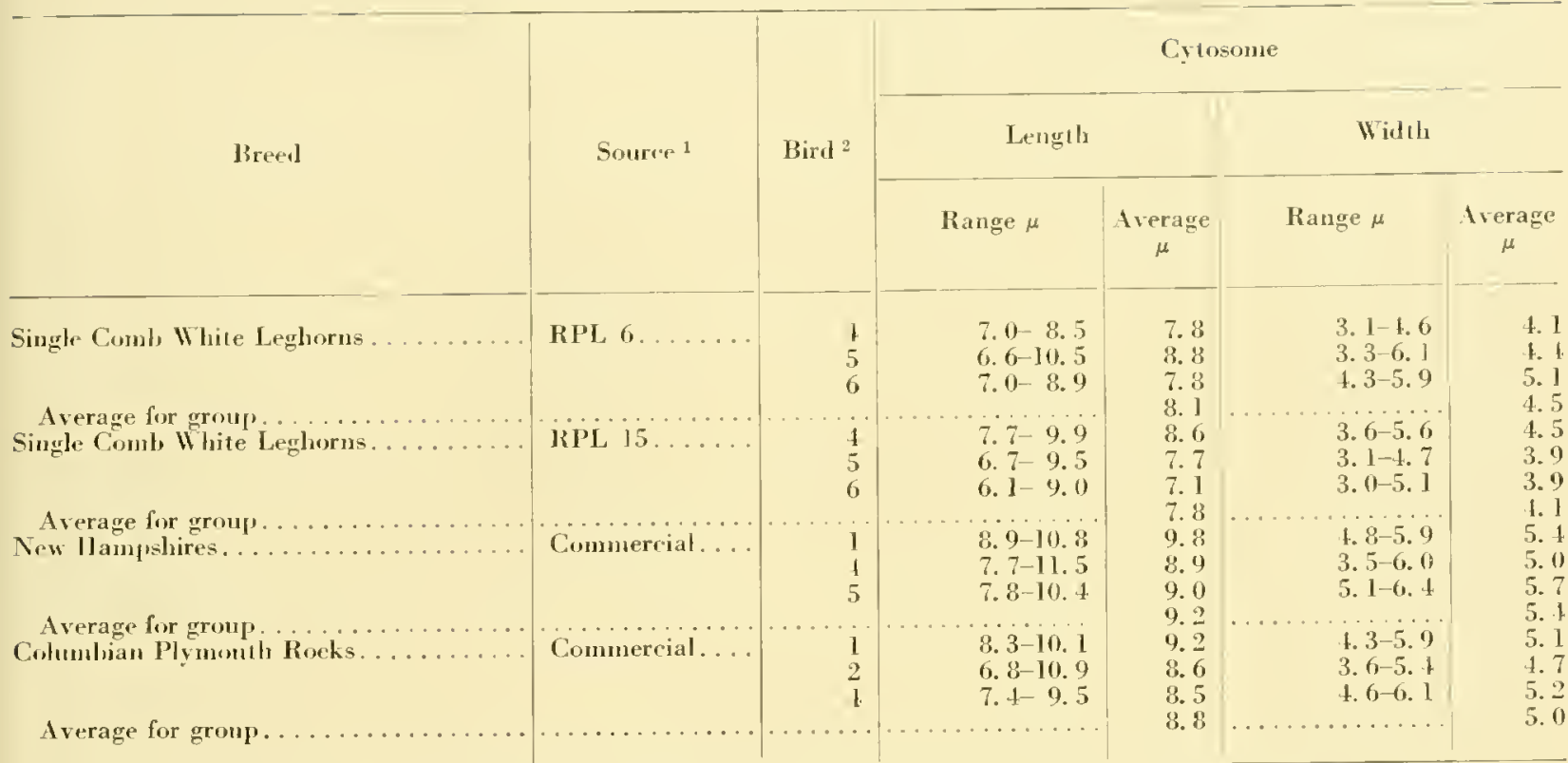

${ }^{1}$ RPL $=$ stock from the U. S. Regional Poultry Research Laboratory. ${ }^{2}$ Measurements l,ased on 10 cells fer bird.

Table 14.-Area and diameter of lymphocytes

\begin{tabular}{|c|c|c|c|c|c|c|c|c|c|c|}
\hline \multirow{3}{*}{ Breed } & \multirow{3}{*}{ Source ${ }^{1}$} & \multirow{3}{*}{ Bird 2} & \multicolumn{4}{|c|}{ Cytosome } & \multicolumn{4}{|c|}{ Vuckens } \\
\hline & & & \multicolumn{2}{|c|}{ Area $\mu^{2}$} & \multicolumn{2}{|c|}{ Diameter $\mu$} & \multicolumn{2}{|c|}{ Area $\mu^{2}$} & \multicolumn{2}{|c|}{ Diameter $\mu$} \\
\hline & & & Range & $\begin{array}{l}\text { Aver- } \\
\text { age }\end{array}$ & Range & $\begin{array}{c}\text { Aver- } \\
\text { age }\end{array}$ & Range & $\begin{array}{l}\text { Aver- } \\
\text { age }\end{array}$ & Range & $\begin{array}{l}\text { Iver- } \\
\text { age }\end{array}$ \\
\hline $\begin{array}{l}\text { Single Cumb White Leg- } \\
\text { borns. } \\
\text { Average for gronp.... }\end{array}$ & RH'L $6 \ldots$ & $\begin{array}{l}1 \\
2 \\
3\end{array}$ & $\begin{array}{l}20.5-102.7 \\
38.5-105.3 \\
25.7-118.1 \\
\ldots \ldots\end{array}$ & $\begin{array}{l}49.7 \\
61.7 \\
53.2 \\
54.7\end{array}$ & $\begin{array}{l}5.1-11.1 \\
7.0-11.6 \\
5.7-12.3\end{array}$ & $\begin{array}{l}7.8 \\
8.7 \\
7.9 \\
8.1\end{array}$ & $\begin{array}{l}12.8-57.8 \\
23.1-88.6 \\
20.5-60.3 \\
\ldots \ldots \ldots .\end{array}$ & $\begin{array}{l}34.5 \\
12.1 \\
35.0 \\
37.2\end{array}$ & $\begin{array}{l}4.0-8.6 \\
5.1-10.6 \\
5.1-8.8\end{array}$ & $\begin{array}{l}6.5 \\
7.3 \\
6.6 \\
6.8\end{array}$ \\
\hline $\begin{array}{l}\text { Single Comb White Leg- } \\
\text { horns. } \\
\text { Arrrage for group..... }\end{array}$ & Rl'L $15 \ldots$ & $\begin{array}{l}1 \\
2 \\
3\end{array}$ & $\begin{array}{l}38.5-106.6 \\
30.8-118.1 \\
25.7-100.1\end{array}$ & $\begin{array}{l}65.5 \\
48.7 \\
43.5 \\
52.6\end{array}$ & $\begin{array}{l}7.0-11.6 \\
6.3-12.3 \\
5.7-11.3\end{array}$ & $\begin{array}{l}9.1 \\
7.7 \\
7.3 \\
8.0\end{array}$ & $\begin{array}{l}28.2-61.6 \\
25.7-69.3 \\
23.1-59.1\end{array}$ & $\begin{array}{l}10.9 \\
35.1 \\
35.8 \\
37.3\end{array}$ & $\begin{array}{l}6.0-8.9 \\
5.7-9.4 \\
5.4-3.7\end{array}$ & $\begin{array}{l}\text { 7. } 2 \\
6.6 \\
6.7 \\
6.8\end{array}$ \\
\hline New llampshires... & Commercial. & $\begin{array}{l}1 \\
2 \\
3\end{array}$ & $\begin{array}{l}25.7-79.6 \\
15.4-53.9 \\
12.8-61.2\end{array}$ & $\begin{array}{l}39.4 \\
37.1 \\
30.4 \\
35.6\end{array}$ & $\begin{array}{l}5.7-10.1 \\
4.1-8.3 \\
1.0-9.0 \\
\ldots\end{array}$ & $\begin{array}{l}7.0 \\
6.8 \\
6.1 \\
6.6\end{array}$ & $\begin{array}{l}18.0-43.7 \\
12.8-38.5 \\
10.3-41.1\end{array}$ & $\begin{array}{l}29.0 \\
27.4 \\
22.1 \\
26.2\end{array}$ & $\begin{array}{l}1.8-7.4 \\
1.0-7.0 \\
3.6-7.2 \\
\ldots\end{array}$ & $\begin{array}{l}6.11 \\
5.8 \\
5.2 \\
5.7\end{array}$ \\
\hline $\begin{array}{l}\text { Columbian Plymouth } \\
\text { Rocks. } \\
\text { Arerage for group..... }\end{array}$ & Commercial. & $\begin{array}{l}1 \\
2 \\
3\end{array}$ & $\begin{array}{l}20.5-92.4 \\
25.7-92.4 \\
28.2-110.4 \\
\ldots \ldots \ldots \ldots\end{array}$ & $\begin{array}{l}42.8 \\
50.7 \\
69.1 \\
5 \% .2\end{array}$ & $\begin{array}{r}5.1-10.8 \\
5.7-10.8 \\
6.0-11.8 \\
\ldots \ldots\end{array}$ & $\begin{array}{l}7.3 \\
7.9 \\
9.2 \\
8.1\end{array}$ & $\begin{array}{l}15.4-48.8 \\
20.5-16.2 \\
20.5-53.9 \\
\cdots\end{array}$ & $\begin{array}{l}28.8 \\
32.8 \\
39.1 \\
33.6\end{array}$ & $\begin{array}{r}4.4-7.9 \\
5.1-7.7 \\
5.1-8.3 \\
\ldots \ldots \ldots\end{array}$ & $\begin{array}{l}6.0 \\
6.4 \\
7.0 \\
6.5\end{array}$ \\
\hline
\end{tabular}


shires was definitely smaller-35.6 $\mu^{2}$. The same difference in size for this breed is reflected, as wonld be expected, in the nuclear area and in the diameters of the cells and nuclei. If the lymphocytes and their nuclei when flattened had been circular and the nuclens had been in the center, the cytoplasm would have formed a rim around it hardly more than a half micron in width.

The striking difference in size and nucleocell ratios of lymphocytes and of monocytes is well brought ont by comparing the data of table 14 with those of table 15. The monocyte area for both lines of Laboratory stock was large, and for both the commercial lines it was small. In other words, in 3 of the 4 groups lymphocyle and monocyte areas appeared to be positively correlated, but in the Columbian Plymouth Rocks the association was negative. The area of the monocyte unclens is approximately half the area of the total cell or, comparing nucleus with cytosome, the ratio is approximately $1: 1.1 \mathrm{in}$ contrast to the lymphocyte, where the ratio is approximately $1: 0.5$.

Heterophils show a greater variability among birds within a group than among groups (table 16) and from this there is probably relatively little significance to the difference in size from $7.9 \mu$ diameter for RPL line 6 birds and $9.9 \mu$ for the
New Hampshires. The data for the eosinophils emphasize a point that was brought out when the eosinophil of circulating blood was discussedso often an individual chicken showed almost exchusively a large or a small type of cell. This is evident in table 16, where maximum size was $6.0 \mu$ for bird 6 of RPl, line 15 , but the minimum for bird 4 was greater- $6.4 \mu$. Almost the same situation existed in birds 4 and 6 of RPL line 6 , and in 1 and 4 of the Columbian Plymouth Rock.

The average for the basophil dianeler of $7.8 \mu$ for Lahoratory birds is less than 8.1 and $9.1 \mu$ for chickens from commercial sources, but the samples are probably too small to have much significance in view of ranges in diameter as great as 4.9 to $10.9 \mu$ within a hird and rather wide variability in the averages among groups of birds.

\section{CELL COUN'TS, HEMOGLOBIN LEVELS, AND HEMA'TOCIRTS}

An important function of an atlas on blood is to aid in cell identification so that accurate differential counts can be made. A review of earlier cell counts in some cases, as well as tabulation of new data of their own has been given by

Table 15.-Area and diameter of monocytes

\begin{tabular}{|c|c|c|c|c|c|c|c|c|c|c|}
\hline \multirow{3}{*}{ Breed } & \multirow{3}{*}{ Sonree ${ }^{1}$} & \multirow{3}{*}{ Bird $^{2}$} & \multicolumn{4}{|c|}{ Cylosone } & \multicolumn{4}{|c|}{ Nucleus } \\
\hline & & & \multicolumn{2}{|l|}{ Area $\mu^{2}$} & \multicolumn{2}{|c|}{ Diameter $\mu$} & \multicolumn{2}{|c|}{ Area $\mu^{2}$} & \multicolumn{2}{|c|}{ Diameter $\mu$} \\
\hline & & & Range & $\begin{array}{l}\text { Aver- } \\
\text { age }\end{array}$ & Range & $\begin{array}{c}\text { Aver } \\
\text { age }\end{array}$ & Kange & $\begin{array}{c}\text { Aver } \\
\text { age }\end{array}$ & Range & $\begin{array}{l}\text { Aver. } \\
\text { age }\end{array}$ \\
\hline $\begin{array}{l}\text { Single Comb While Leg- } \\
\text { Ihorns. } \\
\text { Average for group. . . } \\
\text { Single Cumb White Leg- } \\
\text { liorns. } \\
\text { Average for gromp.... } \\
\text { New } 11 \text { annshires...... }\end{array}$ & RPL $6 \ldots$. & 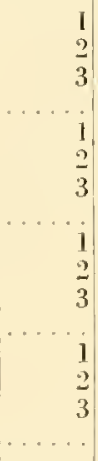 & $\begin{array}{r}107.9-151.5 \\
102.7-151.5 \\
97.6-116.1 \\
\ldots 1.7-116.4 \\
105.3-226.0 \\
87.3-138.7 \\
\ldots 6.8-179.8 \\
77.0-169.5 \\
53.1-136.1 \\
\ldots 1.6-148.9 \\
61.6-133.5 \\
51.4-139 \\
71.9-113.8 \\
\ldots \ldots \ldots\end{array}$ & $\begin{array}{r}129.0 \\
125.4 \\
124.2 \\
126.2 \\
120.7 \\
151.9 \\
113.2 \\
128.6 \\
100.3 \\
107.7 \\
101.1 \\
103.0 \\
93.4 \\
95.7 \\
111.7 \\
101.3\end{array}$ & $\begin{array}{l}\text { 11. } 7-15.9 \\
11.4-15.9 \\
11.1-13.6 \\
10.1-13.6 \\
11.6-17.0 \\
10.5-13.3 \\
\ldots .2-15.1 \\
9.9-11.7 \\
8.7-13.2 \\
\ldots \ldots 9-13.8 \\
8.9 \\
8.1-13.0 \\
9.6-13.5 \\
\ldots \ldots\end{array}$ & $\begin{array}{l}12.9 \\
12.7 \\
12.5 \\
12.7 \\
12.1 \\
13.9 \\
12.0 \\
12.8 \\
11.2 \\
11.6 \\
11.3 \\
11.4 \\
10.8 \\
11.0 \\
12.0 \\
11.3\end{array}$ & $\begin{array}{l}16.2-66.8 \\
13.7-64.2 \\
43.7-66.8 \\
\ldots 3.7-61.2 \\
16.2-84.7 \\
48.8-71.9 \\
38.5-97.6 \\
41.1-79.6 \\
36.0-66.8 \\
36.0-69.4 \\
23.1-61.2 \\
38.5-69.3 \\
\ldots \ldots\end{array}$ & $\begin{array}{l}57.9 \\
51.2 \\
56.7 \\
56.3 \\
51.3 \\
67.4 \\
57.0 \\
59.6 \\
50.5 \\
51.8 \\
51.4 \\
51.2 \\
49.2 \\
47.1 \\
52.9 \\
19.8\end{array}$ & $\begin{array}{r}7.7-9.2 \\
7.1-9.0 \\
7.4-9.2 \\
\ldots \ldots i-9.0 \\
7.7-10.4 \\
7.9-9.6 \\
\ldots . .11 .1 \\
7.0-11 \\
7.2-10.1 \\
6.8-9.2 \\
\ldots .3-9.1 \\
6.8-9.9 \\
5.4-9.0 \\
7.0-9.4 \\
\ldots \ldots\end{array}$ & $\begin{array}{l}8.6 \\
8.3 \\
8.5 \\
8.5 \\
8.3 \\
9.2 \\
8.5 \\
8.7 \\
8.0 \\
8.1 \\
8.0 \\
8.0 \\
7.9 \\
7.7 \\
8.2 \\
7.9\end{array}$ \\
\hline
\end{tabular}

${ }^{1}$ RIL $=$ stock from the U. S. Regional Poultry Research Laboratory.

2 Measurements based on 25 cells per hiril. 
Table 16.-Diameler of granulocytes

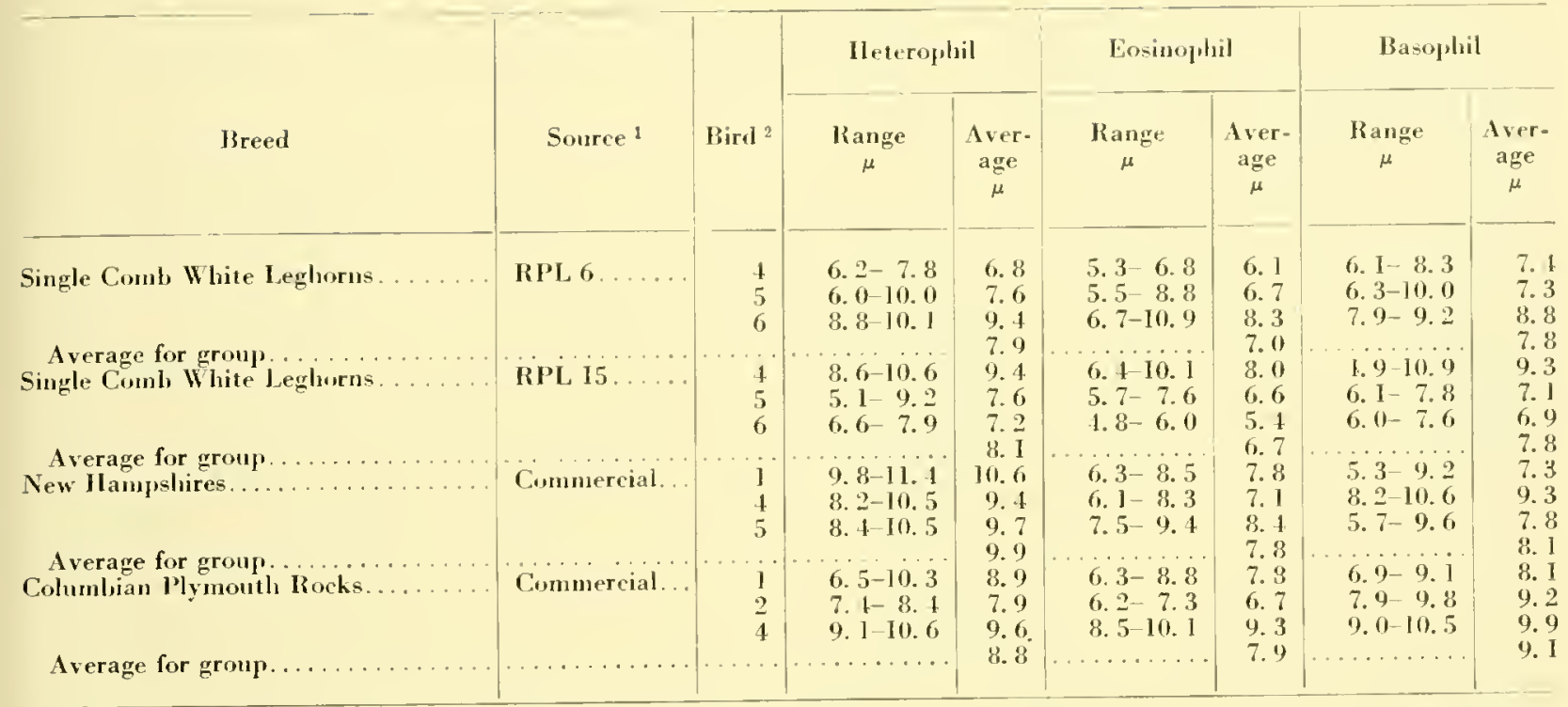

1 RPL= stock from the U. S. Regional Poultry Research Laboratory.

2 Measurements based on 10 cells per bird.

Burnett (1908), Goodall (1909), Burckhardt (1912), Forkner (1929), Hayden (1929), Blakemore (1934), Cook and Dearstyne (1934), Magath and Higgins (1934), Biely and Palmer (1935), Kelly and Dearstyne (1935), Palmer and Biely (1935a and b), Cook (1937), Olson (1937), Twisselmann (1939), Blount (1939a), Hamre and McHenry (1942b), and Rhian, Wilson, and Moxon (1944). Twisselman clearly demonstrated that there has not always been agreement in regard to cell identification or cell terminology. Breusch (1928) mentions the high variability of cell counts for chickens and considers it to be normal. Palmer and Biely (1935a), in an exhaustive study, concluded that "... the erythrocyte and lencocyte counts of a bird fluctuate around a certain level characteristic of the individual." Similar observations were made on cattle by Ferguson, Irwin and Beach (1945). Excellent reviews on variabil. ity in blood counts have been given by Garrey and Bryan (1935) and by Sturgis and Bethell (1943). Although these reviews deal primarily with a discussion of cell counts of blood samples taken from mammals, the problems and principles involved are equally applicable to the avian species.

Diesem (1956) and Lucas and Deninglon (unpublished data) have sought to establish the 95-percent fiducial interval for the normal blood values of chickens. The latter authors also noted that the variability of blood-cell counts in birds was no greater than that reported in mammals.

A superficial comparison of talles 18, 19, 20, and 21 (for ducks, geese, pheasants, and pigeons) with table 17 (for chickens) might give the impression that the first four species were highly variable in comparison with the last. However, this is not the case, and individual records for chickens are just alsout as variable as for wild birds. The values in table 17, which seem relatively uniform, are based on large groups of chickens-33 to more than 100 in each group. The data from the Laboratory stock were part of a project carried out under a grant from the United States Atomic Energy Commission. Two inbred lines were used, 6 and 15. and data from the two lines have been combined in table 17. Line 6 was developed toward resistance to avain lymphomatosis and line $15 \mathrm{lo}-$ ward susceptibility to this pathologic condition (Waters, 1945). There was a statistically significant difference between the means for each line on a most every type of blood determination; thus the values for erythrocyte count, hemoglobin, hematocrit, and buffy coat were higher for line 6 than for line 15. The only values not significantly different were the eosinophil averages.

In view of the high varialjility in counts on individual birds, two qucstions are raised: 


\begin{tabular}{|c|c|c|c|c|c|c|c|c|c|c|c|c|}
\hline \multirow{3}{*}{ Blood component } & \multicolumn{8}{|c|}{ RPL ${ }^{1}$ stock Single Comb White Leghorns } & \multicolumn{4}{|c|}{ Farm stock } \\
\hline & \multicolumn{6}{|c|}{ Fcmale } & \multirow{2}{*}{\multicolumn{2}{|c|}{ Male arlult }} & \multirow{2}{*}{\multicolumn{2}{|c|}{$\begin{array}{l}\text { Single Comb } \\
\text { White Lrg- } \\
\text { horns female } \\
\text { adult }\end{array}$}} & \multirow{2}{*}{\multicolumn{2}{|c|}{$\begin{array}{c}\text { Rhorle Island } \\
\text { Reds female } \\
\text { adult }\end{array}$}} \\
\hline & \multicolumn{2}{|c|}{6 weeks } & \multicolumn{2}{|c|}{12 wecks } & \multicolumn{2}{|c|}{ Adult } & & & & & & \\
\hline \multirow[t]{2}{*}{ 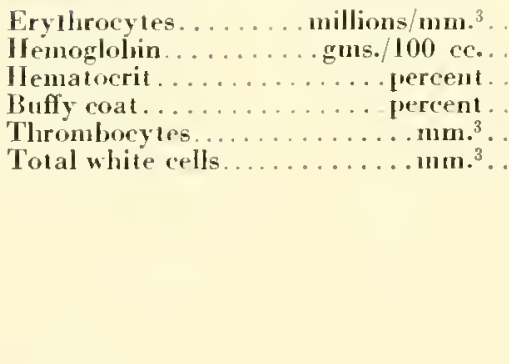 } & \multicolumn{2}{|c|}{$\begin{array}{r}3.02 \\
10.10 \\
30.90 \\
1.00 \\
30.457 \\
28,612\end{array}$} & \multicolumn{2}{|c|}{$\begin{array}{r}3.02 \\
9.80 \\
30.40 \\
1.00 \\
26.254 \\
31,256\end{array}$} & \multicolumn{2}{|c|}{$\begin{array}{r}3.00 \\
9.70 \\
30.80 \\
1.00 \\
30.856 \\
29,397\end{array}$} & \multicolumn{2}{|c|}{$\begin{array}{r}3.78 \\
13.50 \\
40.00 \\
27.58 \\
16.615\end{array}$} & \multicolumn{2}{|c|}{$\begin{array}{r}2.96 \\
10.70 \\
31.90 \\
37.211 \\
28.863\end{array}$} & \multicolumn{2}{|c|}{$\begin{array}{r}2.88 \\
11.00 \\
30.80 \\
60,311 \\
35,787\end{array}$} \\
\hline & $\begin{array}{l}\text { Vum- } \\
\text { ber } \\
\text { per } \\
\text { rat. num. }\end{array}$ & $\begin{array}{l}\text { I'er- } \\
\text { cent }\end{array}$ & $\begin{array}{c}\text { Num- } \\
\text { ber } \\
\text { per } \\
\text { cu. mu. }\end{array}$ & $\begin{array}{l}\text { Per- } \\
\text { cent }\end{array}$ & $\begin{array}{l}\text { Vum- } \\
\text { ber } \\
\text { per } \\
\text { cu. num. }\end{array}$ & $\begin{array}{l}\text { l'er- } \\
\text { cont }\end{array}$ & $\begin{array}{c}\text { Vurn- } \\
\text { ber } \\
\text { per } \\
\text { cu. mm. }\end{array}$ & $\begin{array}{l}\text { I'er- } \\
\text { cent }\end{array}$ & $\begin{array}{c}\text { Num- } \\
\text { ber } \\
\text { per } \\
\text { cu. mm. }\end{array}$ & $\begin{array}{l}\text { Per- } \\
\text { cent }\end{array}$ & $\begin{array}{l}\text { Vum- } \\
\text { ber } \\
\text { per } \\
\text { cu. } \mathrm{mm} \text {. }\end{array}$ & $\begin{array}{l}\text { Per- } \\
\text { cent }\end{array}$ \\
\hline 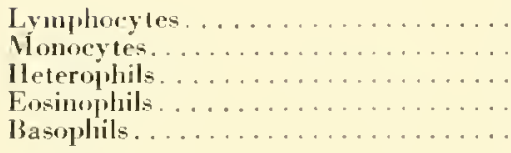 & $\begin{array}{r}23,328 \\
1,286 \\
2,898 \\
438 \\
662\end{array}$ & $\begin{array}{r}31.5 \\
4.5 \\
10.1 \\
1.5 \\
2.3\end{array}$ & $\begin{array}{r}24.310 \\
1.512 \\
3,654 \\
1.210 \\
510\end{array}$ & $\begin{array}{r}77.8 \\
1.9 \\
11.7 \\
3.9 \\
1.7\end{array}$ & $\begin{array}{r}22.371 \\
1,663 \\
3,917 \\
728 \\
718\end{array}$ & $\begin{array}{r}76.1 \\
5.7 \\
13.3 \\
2.5 \\
2.4\end{array}$ & $\begin{array}{r}10.626 \\
1.065 \\
4.288 \\
241 \\
395\end{array}$ & $\begin{array}{r}61.0 \\
6.4 \\
25.8 \\
1.4 \\
2.4\end{array}$ & $\begin{array}{r}20,701 \\
326 \\
6,831 \\
110 \\
592\end{array}$ & $\begin{array}{r}71.7 \\
1.1 \\
23.7 \\
1.4 \\
2.1\end{array}$ & $\begin{array}{r}20,791 \\
880 \\
12,551 \\
410 \\
1,121\end{array}$ & $\begin{array}{r}58.1 \\
2.5 \\
35.1 \\
1.2 \\
3.1\end{array}$ \\
\hline
\end{tabular}

${ }^{1}$ RPL $=$ stuch from the U. S. Regional Poultry Research Laboratory.

1. How much value is there in blood determinations based on a single bird?

2. How many hirds must be included in one population to give mean values that are significantly different?

At present the opinion is held that some types of blood values, for a single bind, offer rela. tively little information about the health of that particular bird. This is particularly true for total white cell and differential counts.

\section{Table 18.-Blood values for common mallard} duck (adult males)

[Differential counts in percent]

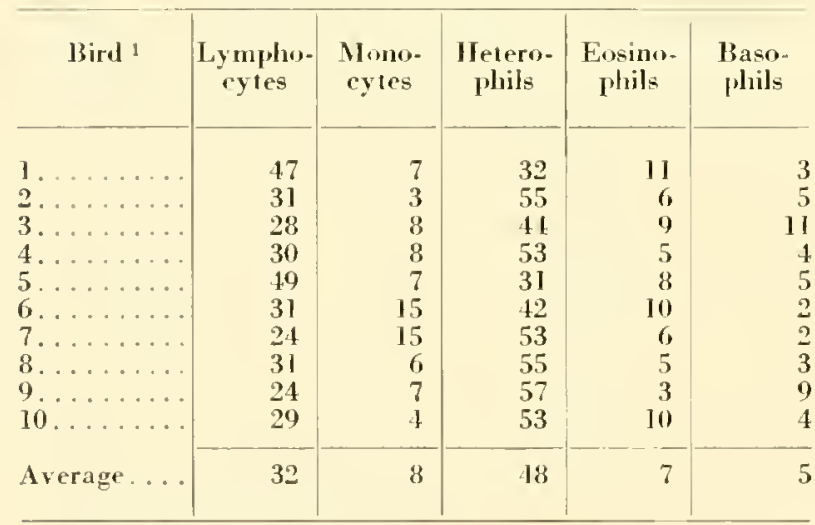

1100 cells counted from each hird.
This is evident not only in chickens but also in other species of birds. Cook and Dearstyne (1934) arrived at an estimate of the importance of the value given by a single count by grouping all comnts into classes in a frequency distribution table. This method is more informative than either an average or a range.

Some types of blood data on chickens gave a narrow range in values for the normal population. Under such conditions, a wide departure

\section{Table 19.-Blood values for Canada goose (adult males)}

[Differential counts in percent]

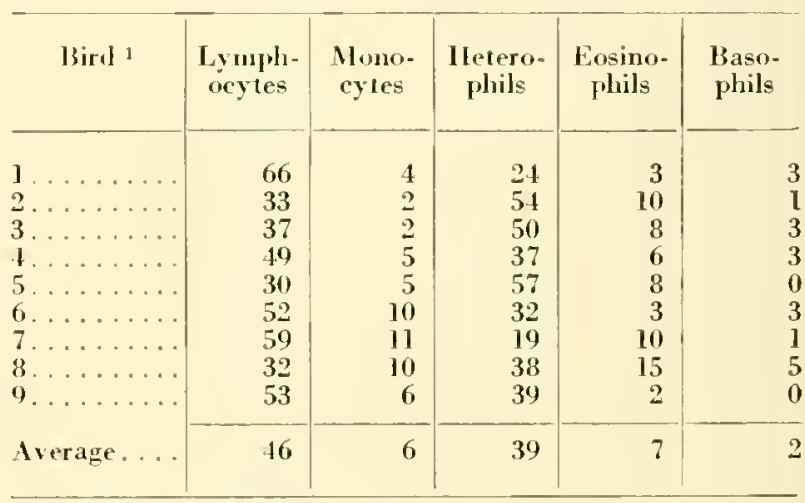

1100 cells comned from each bird. 
from the average, even by a single bird, may indicate ill health. A shift of probably as little as a half million erythrocytes per cubsc millimeter could be significant. Likewise, hemoglobin values show a relatively narrow range of variability, and a difference of as little as 1 gram per $100 \mathrm{cc}$. might be viewed with suspicion. Hematocrit values do not as a rule vary more than about 5 percent either way. The average hematocrit values in table 17 are only 1 to 2 percent higher than those given by Hamre and McHenry (1942a) except for the males. Buffy coats were read in the Van Allen hematocrit tubes with a low-magnification hand lens and as long as there was no hemolysis the normal values usually did not vary more than \pm 0.2 percent.

On the other hand, thrombocytes, total white cells, and individual cell types often varied from half to twice the average, and thus individual readings do not mean much. This was found to be the case whether the comparison was among different individuals or among repeated bleedings from the same bird. Palmer and Biely (1935a) studied the variability of cell counts in great statistical detail and conchuded that when careful attention has been given to technics the fluctuations in normal erythrocytes can be reduced to 15 percent. In their data, the coefficient of variability was generally quite low.

This hrings us to the second question. An an-

\section{Table 20.-Blood values for ring-necked pheasant (arlult males)}

[Differential counts in perceul]

\begin{tabular}{|c|c|c|c|c|c|}
\hline Bird 1 & $\begin{array}{c}\text { Lympho- } \\
\text { cytes }\end{array}$ & $\begin{array}{l}\text { Mono. } \\
\text { rytes }\end{array}$ & $\begin{array}{c}\text { 1letero- } \\
\text { phils }\end{array}$ & $\begin{array}{l}\text { Eosino. } \\
\text { phils }\end{array}$ & $\begin{array}{l}\text { Baso- } \\
\text { phils }\end{array}$ \\
\hline $1 \ldots \ldots \ldots$ & 28 & 11 & 42 & 11 & 19 \\
\hline $2 \ldots \ldots \ldots \ldots$ & 19 & 6 & 10 & 0 & 5 \\
\hline $3 \ldots \ldots \ldots$ & 43 & 5 & 41 & 0 & 11 \\
\hline $4 \ldots \ldots \ldots$ & 17 & 8 & 60 & 0 & 15 \\
\hline $5 \ldots \ldots \ldots$ & 43 & 8 & 31 & 1 & 14 \\
\hline $6 \ldots \ldots \ldots$ & 63 & 3 & 23 & 2 & 9 \\
\hline $7 \ldots \ldots$ & 39 & 2 & 65 & 0 & 4 \\
\hline $8 \ldots \ldots \ldots$ & 24 & 23 & 47 & 0 & 6 \\
\hline $9 \ldots \ldots$ & 29 & 7 & 53 & 0 & 11 \\
\hline $10 \ldots \ldots \ldots$ & 20 & 18 & 52 & 3 & 7 \\
\hline $11 \ldots \ldots \ldots$ & 44 & 9 & 38 & 2 & 7 \\
\hline $12 \ldots \ldots \ldots$ & 42 & 3 & 41 & 1 & 13 \\
\hline $13 \ldots \ldots$ & 26 & 4 & 65 & 2 & 3 \\
\hline $14 \ldots \ldots \ldots$ & 10 & 5 & 75 & 4 & 6 \\
\hline $15 \ldots \ldots \ldots$ & 41 & 6 & 39 & 0 & 14 \\
\hline Average.... & 34 & 8 & 48 & 1 & 10 \\
\hline
\end{tabular}

1100 cells counted from each bird. swer based on some figure derived from a statistical analysis takes into account the variability within and between groups and thus could be different, depending on the scope of the population under study. In the Atomic Energy studies on two inbred lines of Single Comb, White Leghorn chickens, birds 6 weeks and 12 weeks of age in groups of 151025 birds were used, but in laying hens the numbers were reduced for various reasons to 7 to 12 birds in a group. Working with these data led to the conclusion that 10 was the minimum desirable number in an experimental group and that 15 was preferable.

This is only a rough estimate derived from studies by Lucas and Denington on whole body X-ray irradiation. In this same study they found (umpublished data) that if the coefficient of variability for the 95-percent fiducial interval were to be held to some fixed value, for example, \pm 10 percent of the group mean, then the following number of lirds wonld be needed for a study on each of the components of the blood:

Blood component:

Number of chickens in a group

Red blood cells $/ \mathrm{mm}^{3}{ }^{3}$

Hemoglobin, gms./100 ml._______ 12

Hemalocril in percent_._._._._._. 8

Buffy coal in percent_._._. 33

Thrombocytes $/ \mathrm{mm}^{3}{ }^{3}$ -

White blood cells $/ \mathrm{mmm}^{3}{ }^{3}$

Lymphocytes/mm, ${ }^{3}$ _._._._._._. 130

Monocytes/nm. ${ }^{3}$-______________ 352

Heterophils $/ \mathrm{mm}^{3}{ }^{3} \ldots$

Eosinophils/mm. ${ }^{3}-\ldots$

Basophils/mm. ${ }^{3}-\ldots \ldots$

Table 21.-Blood values for laboratory pigeon [1)ifferential cunts in percent]

\begin{tabular}{|c|c|c|c|c|c|}
\hline Jird 1 & $\begin{array}{c}\text { Lympho- } \\
\text { cytes }\end{array}$ & $\begin{array}{l}\text { Mono. } \\
\text { cyles }\end{array}$ & $\begin{array}{l}\text { lletero- } \\
\text { phils }\end{array}$ & $\begin{array}{l}\text { Fosino- } \\
\text { phils }\end{array}$ & $\begin{array}{l}\text { Baso. } \\
\text { phils }\end{array}$ \\
\hline $1 \ldots \ldots$ & 19 & 11 & 61 & 4 & 5 \\
\hline $2 \ldots \ldots \ldots$ & 28 & 1 & 61 & 0 & 4 \\
\hline $3 \ldots \ldots$ & 14 & 25 & 60 & () & 1 \\
\hline $4 \ldots \ldots$ & 32 & 8 & 58 & 0 & 2 \\
\hline $5 \ldots \ldots \ldots$ & 1.4 & 23 & 59 & 0 & 1 \\
\hline $6 \ldots \ldots$ & 42 & 11 & 42 & 0 & 2 \\
\hline $7 \ldots \ldots$ & 50 & 11 & 37 & 1 & 1 \\
\hline $8 \ldots \ldots$ & 8 & 20 & 66 & 1 & 5 \\
\hline $9 \ldots \ldots$ & 51 & 14 & 29 & 0 & 6 \\
\hline $10 \ldots \ldots$ & 16 & 19 & 32 & 0 & 3 \\
\hline $11 \ldots \ldots$ & 49 & 12 & 31 & 0 & 5 \\
\hline Average.... & 32 & 15 & 19 & 0.5 & 3 \\
\hline
\end{tabular}

1100 cells counted from tach bird. 
These calculations were based on normal adult female Single Comb White Leghorn chickens. It is evident, therefore, that the desirable number of birds to be used in an experimental group is determined by the blood component that is of particular concern to the problem at hand. Fewer birds would be needed in each group if red-cell counts were of chief concern than if eosinophils were to be followed critically. The high variability for some of the blood components makes it necessary for practical reasons to accept high coefficients of variability in order that the number of birds involved in each experimental group can be small enough to make the experiment practical.

Another problem studied by Lucas and Denington (unpublished data) has been the number of cells that should be tabulated from a slide when making a differential count. The accuracy increases by the square root of the multiples of 100 cells counted. In other words, 400 cells give vahues that are twice as accurate as when 100 cells are counted, and 900 cells give values three times as accurate as when 100 cells are counted.

The question arises, When is the point of diminishing returns in accuracy reached for the time spent in making the counts? In the studies made by Lucas and Denington, it was found that 100 cells were sufficient for lymphocytes and heterophils; but for monocytes, eosinophils, and hasophils, 292 cells were needed to give the maximum accuracy for the time spent in making the counts. In making the counts, 300 cells were used. Lucas and Denington found also that the number of birds used in an experiment can be reduced if the number of cells counted per bird is increased. The gain comes chiefly in those blood components having high variabilityespecially so when the variability within birds is as great as the variability between birds.

In the same experiment there were males from the same source and they were killed at about 550 days of age. Thirty-three individuals went into the averages presented in table 17. Labora. tory males showed higher values than Laboratory females for number of erythrocytes, grams of hemoglobin, and volume of packed cells (hematocrit percentage). The total white-cell count was lower for males than for females. The sexes did not differ widely in the percentage values for monocytes, eosinophils, and basophils. Fe. male chickens showed a higher percentage value for lymphocytes than did male chickens. The reverse was true for heterophils.

A higher erythrocyte number for adult males than for adult females agrees with the work of Juhn and Domm (1930). Before maturity there was no difference between the sexes. The average values given for males of $3,600,000$ and for females of 2,700,000 given by Taber et al. (1943) agree fairly well with those given in table 17. The averages computed from Kitaeva's data (1939) for adult birds were 3.40 million eryth. rocytes per mm. ${ }^{3}$ for males and 2.92 million per mm. ${ }^{3}$ for females. Domm and Taber (1946) obtained an average erythrocyte count for males of 3,250,000 and for females of 2,610,000. They songht to determine if a diurnal rhythm for erythrocytes in the circulating blood existed in chickens, comparable to that which had been found in some mammals. They took their samples at noon, 6 p. m., midnight, and 6 a.m. They found a definite tendency in males to give highest values at midnight and lowest at moon. The same tendencies were evident in females also, but the difference in averages at these two times of the day was not as great in females as in males. Domm and Taber found a seasonal variation in erythrocyte counts; the lowest counts came at the period of highest reproductive activity and the highest counts at the time of lowest activity. See also Domm, et al. (1943).

Kakara and Kawasima (1939) found that birds sitting on eggs had a lower red-cell count, lower thrombocyte count, and lower total white cells than did laying hens.

Chickens moved to a high altitude, 6,000 feet, showed a slight increase in hemoglobin and erythrocyte count, according to Vezzani (1939).

An extensive study of erythrocyte numbers for many species of birds was made by Nice et al. (1935). Counts on wild birds ranged from $3,930,000$ (tufted titmouse) to $7,645,000$ (junco). The median count was 5,230,000. All of the counts are higher than the arerage for chickens. In the bobwhite, a gallinaceous bird, the average was $3,532,000$. Erythrocyte counts and hemoglobin determinations on pigeons and on doves by Riddle and Braucher (1934) gave higher values for males than for females. They observed seasonal differences also, with the high. est values occurring in the autumn and lowest values in the summer. 
Venzlaff (1911) made erythrocyte counts from 45 species of birds. In collecting his material he attempted to obtain a reasonably uniform representation of most of the families of hirdsfrom the Struthioniformes to the Passeriformes. Body weight and size of the erythrocyles were given, also, but the interrelationship of these variables is still open to question.

Percentage values are often misleading - the real differences between sexes are seen more clearly in the data giving the number of cells per cubic millimeter (table 17). The Rhode Island Reds had a high thrombocyte count, and a slightly elevated total white-cell count in comparison with the others. The monocytes of both farm stocks were low both in absolute and in percentage values. This may be the reason why some investigators group monocytes with lymphocytes in their differential counts. Heterophils were even more variable than lymphocytes, ranging from 10 percent to 25 percent, and on the basis of absolute numbers per cubic millimeter, the differences are even greater-2,900 to 12,600 -over a fourfold difference. The range in average number for the lymphocyte groups was slightly over twofold.

The low heterophil count for our birds may be due to the fact that these chickens are held indoors throughout their lives and are relatively free from parasites and conmon poultry infections except lymphomatosis. The count was the highest for Rhode Island Reds, yet in all groups of chickens it was definitely less than in wild birds (tables 18, 19, 20, and 21). In fact there are several points of difference between the percentage values of leukocyte types in chickens and wild birds, the most striking being the low value for lymphocytes, the high value for heterophils, and a consistently high level for monocytes. Eosinophils in the Canada goose and the mallard duck ran 7 percent and in pigeon and pheasant the averages were low. Basophils ranged from 2 to 10 percent. Any comparison of these tables with the data on the chicken indicates that absolute values have greater usefulness than percentage values, and any extensive studies on comparative avian hematology should include data on the actual number of cells per cubic millimeter.

The values on counts made by Wickware (1947) should be compared with those given in table 17 for the leukocyte types. About the only generalization that can be made is that these data further emphasize that there is high variability among different groups of chickens.

Cell counts on pigeons, more extensive than given here (table 21), were made by DeEds (1927). He found a very high variability for the counts of each cell type; for example, small lymphocytes varied from 5 to 53 percent, large lymphocytes from 9 to 67 percent, heterophils from 0 to 25 percent and the remaining cell types showed a similar variability. Thrombocytes varied from 8,000 to 89,000 per $\mathrm{mm}^{3}$

Less variability was experienced in a later study on pigeon blood cells by Schoger (1939). In his data, lymphocytes varied from 40.5 to 62.0 percent, monocytes from 4.0 to 6.5 percent, heterophils from 29.0 to 48.5 percent, eosinophils from 2 to 4 percent, and basophils from 0.5 to 2.0 percent. He used 16 mature, healthy birds. The variability in his data was less than shown in table 21. Red cell counts, hemoghobin, and differential counts for leukocytes were made by Gauger et al. (1940) on normal pigeons and on pigeons infected with paratyphoid. Their counts on both normal and infected birds were also highly variable. They concluded that, due to this variability, chronic carriers of this pathogen could not be distinguished from noninfected pigeons by bloodcell counts.

The values given by Hewitt (1942) of differential comts on laboratory ducks (breed not given) agree closely with our averages in table 18, based on common mallards. Hewitt's averages were: Lymphocytes, 40.4 percent; monocytes, 5.3 percent; heterophils, 44.4 percent; eosinophils, 7.1 percent; and basophils, 2.4 percent. Normal differential blood counts for turkeys, as given by Johnson and Lange (1939), are: Lymphocytes, 50.6 percent ; monocytes, 1.9 percent; heterophils, 43.4 percent; eosinophils, 0.9 percent; and basophils, 3.2 percent. McGuire and Cavett (1952) gave the counts for normal values of turkey blood in cells per mm. as follows: Total leukocytes, 38,700; lymphocytes, 17,200; monocytes, 1,900; heterophils, 16,600; eosinophils, 40; and basophils, 1,700. These data give essentially the same percentage values as obtained by Johnson and Lange. A review of earlier literature on blood values for ducks is given by Magath and Higgins (1934). They also determined for other anseriform spe. 
cies, the size of erythrocytes and the number per cubic millimeter.

Perhaps some of the variability in heterophil count on pigeons experienced by different in. vestigators was due to diumal rhythm, the existence of which was worked ont by Shaw (1933). He found that heterophil counts on the average were 76 percent higher in the afternoon than in the morning. The afternoon rise for 7 birds was: 1, no change; 2 , rise of 106 percent; 3 , rise of 38 percent; 4, rise of 55 percent; 5 , rise of 143 percent; 6, rise of 54 percent; and 7, rise of 138 percent.

\section{ARNETH COUNTS}

Arneth counts were given for a group of chickens discussed in chapter 2, page 85; and in

Table 22.-Domestic Iurkey (While Holland) : Arnelh counts on helerophils

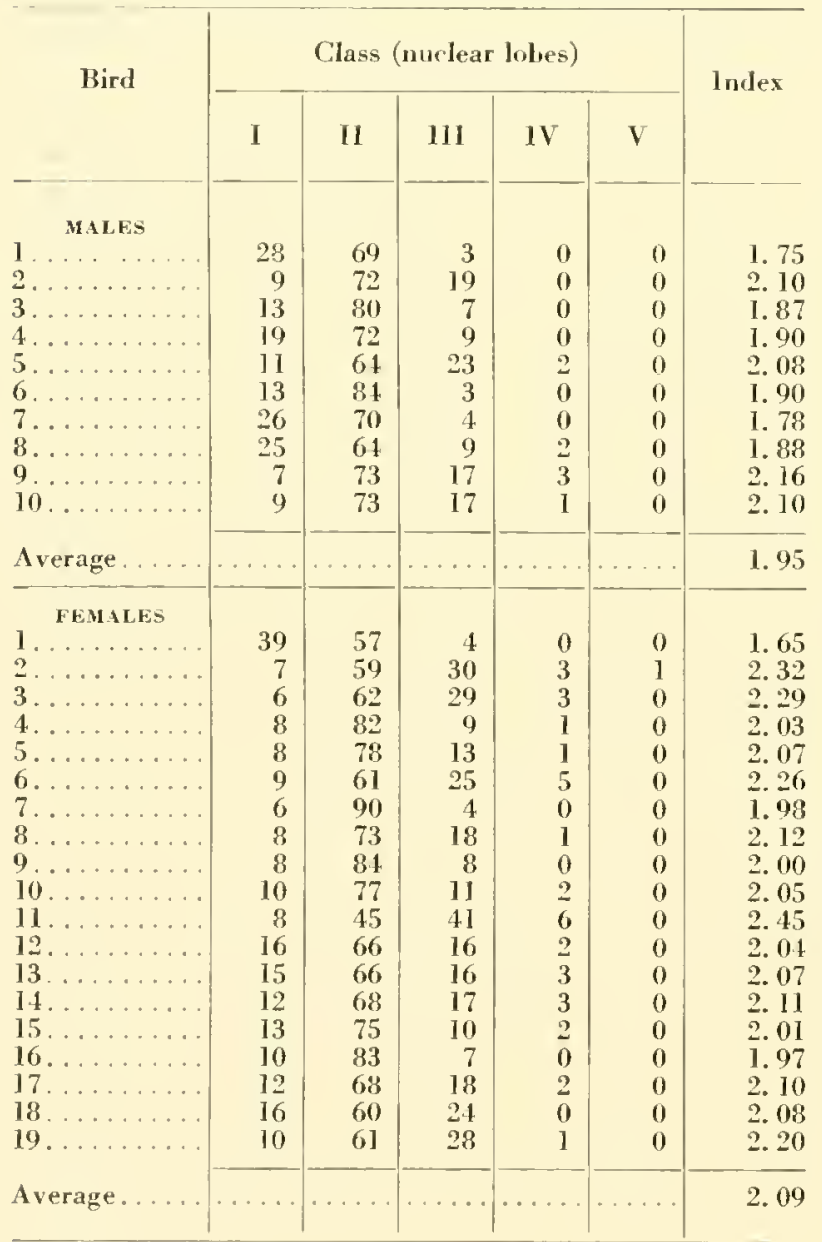

heterophils and eosinophils no more than 5 lobes were found. Likewise, no more than 5 were found for turkeys (table 22), pheasants (table 23 ) and geese (table 24). The index values for male turkeys ranged from 1.75 to 2.16 , with an average of 1.95; for females, it was from 1.65 to 2.45 , with an average of 2.09. For pheasants it was from 1.84 to 2.58 , with an average of 2.27 . Only two slides were obtained from the geese; they read 2.06 and 2.38. Counts were not made on eosinophils for any species except the Canada goose - after considerable searching 16 cells were found on each slide. The indices were 3.75 and 4.25 ; thus there is a preponderance of cells with 3,4 , and 5 lobes-a situation that thus far has not been observed either in eosinophils or in heterophils for this or any other species studied.

Sugiyama (1938) gave Arneth counts for 8 species of birds. His data for the domestic

\section{Table 23.-Ring-necked pheasanl (adult males ): Ameil counis on heferophils}

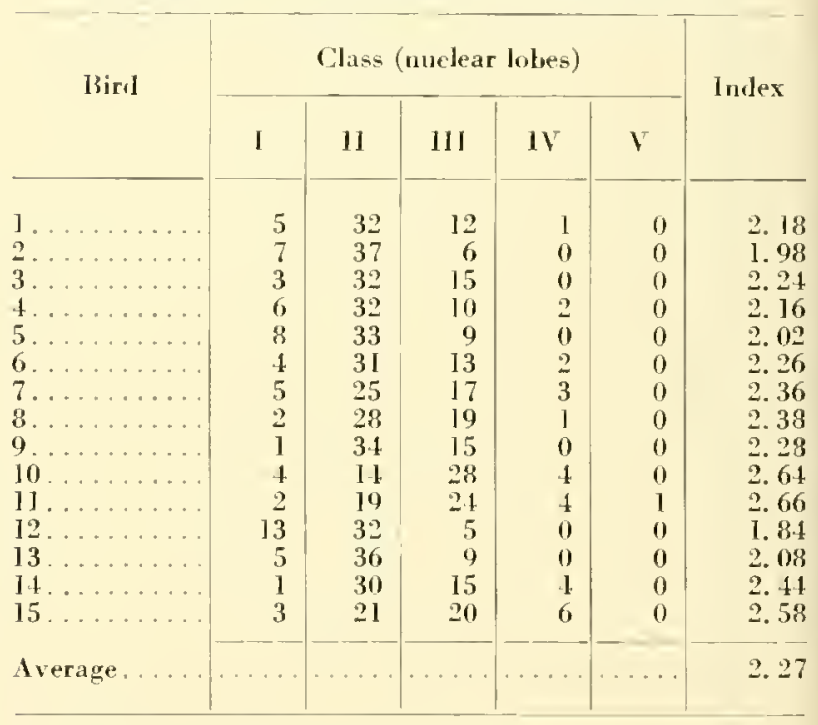

Table 24.-Canada goose (adult males) : Arneth connts on cosinophils and heterophils

\begin{tabular}{|c|c|c|c|c|c|c|}
\hline \multirow{2}{*}{ Cells } & \multicolumn{5}{|c|}{ Class (nuclear lobes) } & \multirow{2}{*}{ Index } \\
\hline & 1 & 11 & III & 15 & $V$ & \\
\hline \multirow[t]{2}{*}{ lleterophils. } & 1 & 30 & 18 & 1 & 0 & 2. 38 \\
\hline & 3 & 41 & 6 & 0 & 0 & $\begin{array}{l}2.06 \\
2.22\end{array}$ \\
\hline \multirow{2}{*}{$\begin{array}{l}\text { Average } \\
\text { Eosinophils. }\end{array}$} & 0 & 1 & 1 & 7 & 7 & 4.25 \\
\hline & 0 & 2 & 4 & 6 & 4 & $\begin{array}{l}3.75 \\
\text { 4. } 00\end{array}$ \\
\hline
\end{tabular}


chicken have already been reported (p. 85). The values for the remaining 7 are given herc, since many libraries do not have the journal. The classes are indicated by Roman numerals, followed by a figure that is the percentage having this number of nuclear lobes. At the end of the series, the mean or index is given by an italicized number:

Cockatoo: I, 36.0; II, 60.0 ; III, $4.0 ; 1.68$

Quail: I, 27.0; II, 59.0; III, 13.5; IV, 0.5; 1.88

Sparrow: I, 26.0; II. 60.0 ; III, 12.5; IV, $1.5 ; 1.90$

Swallow: I, 12.5; II, $65.5 ;$ III, $22.0 ; 2.10$

Pigeon: I, 20.5; II, 63.0; III, 15.5; IV, 1.0; 1.97

Owl: I, $20.0 ;$ II, 48.0 ; III, $29.0 ;$ IV, $3.0 ; 2.15$

Bunting: I, 14.0; II, 57.0; III, 23.0; IV, $6.0 ; 2.21$

Perhaps the first investigator to compile Arneth counts on birds was Shaw (1933) in his study on pigeons. He took blood samples from April through September. The index varied from 1.76 to 2.11 but there was no seasonal trend. The average index for the 6 -month period was 1.95, which is almost the same as Sugiyama found in the pigeons he studied. However, the breakdown into classes was somewhat different. Shaw found: Class I, 33 percent; II, 42 percent; III, 23 percent; and IV, 2 percent. Shaw also studied an owl, and the percentages in the various classes were as follows: I, 34; II, 48; III, 18; $\mathrm{IV}, 0$. The index was 1.84 . This was somewhat lower than found in the owl studied by Sugiyama.

Shaw compared the Arneth counts of the bone marrow with the connts of the blood of pigeons. The averages based on three specimens were as follows:

Blood: I, 36, II, 41; III, 22; IV, 1; 1.87

Bone marrow: I, 75; II, 30; III, 5; IV, 0 ; 1.30

It seems odd that during the twenty years, and more, since the publications of Sugiyama and of Shaw on Arneth counts for normal birds, this technic, so common in the mammalian field, has not been applied to the study of blood diseases in birds. 


\section{Technics for Avian Blood}

Lack of satisfactory technics is one of the rea. sons why studies of avian blood have not heen carried forward as energetically and successfully as have studies of mammalian blood. Students of avian hematology have found that they frequently get unsatisfactory results when they attempt to apply technics that are known to be suitable for studying the blood of mammalian species.

Over a period of years this Laboratory has modified a number of commonly used technics to suit the needs of avian hematology.

\section{THE MICROSCOPE AND LIGHT}

Perhaps the greatest deterrents to accurate and critical study are (1) lack of a good microscope, (2) lack of a good light source, and (3) deficiencies in setting up and using microscope and hight.

Here is what one often finds in a laboratory: The "good" microscope is tucked away in a box. When a special occasion arises, it is brought forth and placed on a table close to a 75- or 100 . watt bulb or a lamp with a frosted glass in front. Then the condenser is dropped below the level of the stage until the amount of light is right, or the diaphragm is closed so that the object shows up well.

For a quick look with low magnification, such procedure may be satisfactory, but efforts are often made to do critical studies under an oil immersion lens with this type of set-up. The efforts are disappointing hecause the microscope is prevented from giving top-quality performance.

Many good books have been written on the use of the microscope. Nevertheless it is not uncommon to see research workers, technicians, veterinarians, and physicians using the instrument as if there were no directions. Correct use is emphasized here not only hecause the authors hope that their comments may he helpful to other workers, but also because it is desired to assure the reader that the structures depicted in the il. lustrations have actually heen seen in specimens. The reader who fails to locate, in specimens of his own, the small structural and tinctorial differences depicted here should not conclude that they do not exist; he should consider the possibility that he is not working under optimum conditions.

The information that follows was obtained from the late Dr. Max Poser of the home office of Bausch \& Lomb Optical Co. and from Mr. H. L. Shippy of the Detroit office of that company. Similar information has been presented by Dr. Oscar. WT. Pichards in Color and Illumination, published by the Spencer Lens Co. Two other useful reference items by Dr. Richards will be found in Literature Cited (Richards, 1938 and 1949). Another reference (Spitta, 1920) has provided particularly helpful explanations of the differences between achromatic and apochromatic lenses, and of why Huyghenian eyepieces should be used with the former and compensating oculars with the latter.

An ideal light source is a small, brilliant point of light that is passed through a lens designed to produce parallel or nearly parallel rays. All the drawings in this Atlas were made with a tungsten arc light.

The lamp shonld be placed about 2 feet in front of the microscope and the image of the light source brought to a focus on a white card placed in front of the microscope mirror. Adjustments in focus can he made by moving the lamp condenser in and out. Just in front of the condenser lens of the lamp is a leaf diaphragm, which should be wide open at this stage of setting up the lamp and microscope. The next step is to place a clear bhe daylight filter in one of the three slots in front of the lamp diaphragm. The slots are constructed to hold 2 " $\times 2$ " filters. One may purchase a good lamp capable of giving critical or Köhler illumination, ${ }^{1}$ then nullify its value by placing a ground glass in the path of the light.

\footnotetext{
${ }^{1}$ The essential differences between critical and Kölıter il. lumination are given hy Richards (1954) in a booklel accompanying each research microscope when purchased. This booklet also contains a helpful bibliography.
} 
In order to do critical microscopic work, one should have a box of neutral intensity filters, graded $0.3,0.6,0.9$, and 1.2 . These numbers represent the logarithms of the opacity; each filter has double the opacity of the one preceding it. By placing filters, one can reduce the light until there is no danger of eye injury. Place a pre. pared slide on the stage of the microscope. Adjust the flat mirror so that, when the low-power objective focuses on the specimen, the light falls directly in the center of the microscope field. To ascertain that it is centered, close the lamp diaphragm as far as it will go and then elevate the microscope condenser until the opening of the lamp diaphragm appears as a sharp ring. With the flat glass mirror usually present on research microscopes, there will he three circles instead of one. Critical work can be carried out with the glass mirror but for these studies on avian blood, this mirror was replaced with a flat. front-surfaced mirror, which eliminated all images except one.

After manipulating the mirror to bring the light to the center of the field-or to what appears to be the center-and after focusing the condenser to the level of the specimen, check to see that the circle of light really is in the center of the field. This is the time to ask the question, Is the condenser perfectly in line with the optical axis of the objective, tube, and eyepiece? To find the answer, proceed as follows:

Open the diaphragm on the lamp as far as it will go, then close the microscope diaphragmall the way. Lift out the eyepiece and look through the tube. There will be a circle of light that does not fill the front lens of the objective. Is this circle of light in the center? It is difficult to tell, hecause moving the head makes the light appear to move. Freedom from the uncertainty can be gained by using a pinhole eyepiece, which has a small hole in the exact center (but no lens). With this in place the position of the circle of light can be determined easily and accurately. If it is not in the center there are two or three screws with which adjustment can be made. The screws are on most microscopes. They are not on some of the less expensive student instruments.

If an adjustment is necessary to bring the image of light to the center of the front lens, make it, then return the regular eyepiece to the tube. Now open the microscope diaphragm and close the lamp diaphragm. Is the image still in the center of the field. If it is not, readjust the mirror, look through the open tube of the microscope, and check again with the pinhole eyepiece.

When. finally, the condenser seems to be in perfect alignment, it can be checked by moving the tube up and down. The circle of light will enlarge above and below the focal point. If these two light cones remain on the same axis within the tube the task has been completed. But if the light beam shifts to one side of the tube axis as the tube is moved up and down, the adjustment procedure should be repeated. Books hy Belling (1930) and by Beck (1938) should be consulted for further refinements on testing the alignment of the condenser.

After the tests on alignment have been completed, put in the eyepiece and open the lamp diaphragm all the way. It probably has ahready been noted that the field of light from the lamp illuminates only a small circle in the center of the low-power field and that the marginal half or two-thirds of the field is dark. The tendency of many is to drop the condenser until the field is fully lighted. Doing this is unobjectionable if you wish only to examine large masses in the slide, lut it is objectionable if you are interested in details. The correct procedure for filling the low-power field with light will be given after adjustments relating to the use of the oil immersion lens have been described.

Starting with the microscope condenser elevated so that the edge of the lamp diaphragm is in sharp focus and wide open, shift to the olyjective of next highest magnification and note whether the field of light is still in the center. Do the same for the other objectives. If all the lenses do not show the circle of light in the center of the field, at least one is not par centered. This adjustment should be made at the factory or with the help of a competent representative of the company. If most of the microscope work can be done with only one lens, all adjustments can be made to fit the particular leus. (Most of the work reported in this Atlas was done with the oil immersion lens.) All the lenses screwed into one nosepiece should he par focal: as each is moved into position, only a slight movement of the fine-adjustment screcn should be necessary to bring it into focus. Shifting lenses in this way is recommended for the "dry" lenses but certainly it cannot he recommended as standard procedure for the oil immersion lenses. How to bring the 
ail immersion lens into focus is described in most of the instruction booklets provided by manufacturers of microscopes.

After the oil immersion lens has been focused on the cells or tissues on the slide, the lamp dia. phragm is again closed and the mirror adjusted slightly so that the circle of light is centered in the fiekd. Then the lamp diaphragm is opened slowly until its margin barely passes out of the microscope field. If one goes much further a flare is produced across the objects on the slides, which is disturbing.

Next the eyepiece lens is removed and the microscope condenser diaphragm is opened slowly: this action enlarges the circle of light seen throngh the back lens of the objective. The movement should be stopped as soon as a point is reached where further opening of the diaphragm no longer enlarges the circle. An unlighted rim remains on the margin of the back surface of the lens. This is due to the fact that air sepa. rates the top of the condenser from the bottom of the slide, setting a theoretical limit of a numerical aperture (N.A.) of 1.0 for the entire lens system. If oil is placed on the condenser and the condenser is again brought to a focus at the level of the objects on the slide, it will he found, after the microscope diaphragm has been opened still further, that the lrack lens of the oljective is fully illuminated. This will occur if the numerical aperture of the condenser is as high as, or higher than, the mumerical aperture of the oil immersion objective. If less-for example, an N. A. 1.25 condenser and an N. A. $1.3 \mathrm{ob}$ jective-there will still remain a narrow dark ring.

Oil on the condenser and on the bottom of the slide often makes a mess if the slide is moved aromnd much. The use of oil between condenser and slide is necessary if a single cell or part of a cell is to be photographed or if ohjects within the cell are much less than a micron in diameter. The procedure outlined gives maximum resolv. ing power. The resolving power can be estimated by means of a monogram (Richards, 1938). The objects usually studied in blood cells are large enough to preclude the need for oil between the condenser and slide.

It has been said that use of an air-space instead of oil gave a theoretical limit of N. A. 1.0 but Spitta (1920) suggests that in actual practice it is an average of the theoretical himit of 1.0 and the N. A. of the objective; thus for an N. A. 1.3 the effective N. A. would be 1.15.

In selecting the most desirable filter, each worker should consider the sensitivity of his eyes to light; he should try a number of filters and se. lect the one that enahles him to study cellular details without suffering eye fatigue.

Do not close the microscope diaphragn or drop the condenser out of focus to reduce the intensity of hight. Closing the diaphragm reduces the effective N. A. and hence the resolving power, but it increases the apparent refractivity of cells and their parts. Sometimes individuals mistake this effect for what is described as "seeing the objects hetter:" A worker must have considerable experience in the correct use of the microscope hefore he realizes that he can see more with the condenser focused and the diaphragm open. If preparations of unstained cells, either living or dead, are to be studied satisfactorily, the dia. phragm must be closed nearly all the way. The cells are distinguished by differences in refractibility, and closing the diaphragm emphasizes these differences.

On page 223 it was said that the problem of filling the field at low magnification with a lamp giving collimated light would be discussed later. The procedure for the high dry $(4 \mathrm{~mm}$. focal length objective) lenses is the same as for the oil immersion lenses. In general, there are lenses manufactured at three numerical apertures0.66. 0.85, and 0.95. Each has its advantages and disadvantages; only the N. A. 0.66 has suf. ficient working distance to be used with the usual thick cover glass of the blood-counting chamber.

When the 8 or $16 \mathrm{~mm}$. oljectives are used the light does not fill the field. If the work is not critical, a quick examination of a section is suffi. cient to see whether it is flat and whether the stain and counterstains are lua lanced. For connting objects in the sections, a frosted blue light bulb in a gooseneck lamp (or sinilar adjustable lamp) brought close to the flat mirror of the microscope is adequate. If the lamp is close enough it will fill the freld with light. When the condenser is focused, an image of the light bulb appears in the field. To avoid the printing, take the light from the side of the bulb rather than from the end. The mirror should not be moved when the frosted bulb is lrought into position. If movement is limited to the lamp bulb 
the light from the microscope lamp behind it is still in alignment when the luull is taken away.

If critical studies are to be made under low magnification, or if photomierographs are to he taken, an ordinary light bulb is not adequate, and one returns to the are or ribhon filament lamp or other light source which will provide critical or Köhler ilhumination. The upper and lower lenses of condensers on most research microscopes can he separated-usually by sliding or screwing them apart. The upper element is laid aside and the lower element is moved up or down until the light source itself or the edge of the diaphragm in front of it is sharply in focus at the level of the objects on the slide. After the condenser has been lowered as far as possible (up to the point just short of tonching the edge of the mirror) it may still be necessary to elevate the slide above the level of the stage by as much as 1.5 cms., in order to bring the image of the light source or its diaphragm into focus. With another make, the condenser is moved down close to the mirror but the slide does not have to be elevated above the stage in order to bring the light to a focus on the slide.

Technicians accurately identified cell types and their developmental stages when microscopes provided with N. A. 1.3 apochronratic objectives and N. A. 1.4 condensers were furnished and when the light sources were carefully aligned with the microscope.

The illustrations shown in this Atlas were used during the training of the technicians.

\section{PROCURING BLOOD}

\section{Preparation of cammulas for taking blood from early embryos}

The problem of drawing out glass tuling to a small diameter seemed on the face of it to be a rather simple one, but it was soon discovered that a broken, jagged tip would not smoothly enter the dorsal aorta of embryos, 2 to 3 days old, or the tip of the heart of older embryos. The task called for a delicate, almost microscopic tip with a smooth-beveled point like that of a hypodermic needle.

Pyrex tubing, $2 \mathrm{~mm}$. inside diameter and $4.5 \mathrm{~mm}$. outside diameter, was used. An area in the center was heated with an oxygen-gas flame. The ends were pulled apart quickly in order to give a rapid taper and to keep the walls thin. As the tuljing was pulled, a $60^{\prime}$ angle was made between the thin center portion and the unheated ends. After a dozen or so of these had been made, the thin portion was hroken off sev. eral centimeters from the point where the taper legegan.

The next step was the preparation of a microburner. Any burner will to if the flame can be reduced to a height of ahout $2 \mathrm{~mm}$. A glass sleeve, tapered to a small opening, was placed over the metal tube of a microbumer, and this gave a small flame. Even though the flame was small, it was approached eautionsly. While the thin part of the tuhe was heating a slight tension was exerted so that as soon as the thin glass had softened it conld be pulled quickly to a thin, short tip. If pulled too quickly the tip was long and thin and not stiff enough to push through the tissues of the emlryo and, if one hesitated too long, the walls thickened and the bore became excessively small. The hest tips were selected from those made and the delicate. thin tuljing was broken off about a half centimeter from the portion of intermediate thickness.

The next step was to grind the end to a bevel tip. The method followed was not the bestthere was a certain amount of breakage-but after studying the principles set forth one can add refinements that will make the process easier. A small highspeed motor that carried a threejawed chuck over the end of the shaft was used. It was mounted vertically in a bracket and two rheostats were hooked in series to the current line. One rheostat of the correct type wonld be sufficient if it could be regulated delicately enough; the only requirement is that the motor tum at a slow, constant speed. The speed was not measured but it was estimated to be 1 to 4 revolutions per second. Into the chuck was inserted a small spindle that carried near the end a flat emery disk ahout an inch in diameter. When the enery disk was in place and rotating slowly, a flat dish of water was lifted up beneath it so that the disk turned jus below the surface of the water. With the set-up described, the increased friction often stopped the motor: probably a worm-gear reducing unit would have given greater power and a nearer constant speed.

The fine glass tip of the cammula was lightly touched to the flat surface of the moving emery 
wheel. The first trial demonstrated that the particles of emery and glass would completely plug the small bore of the glass tip. A thin-walled flexible rubler tubing was attached to the large end of the tip. An effort was made to dislodge the particles by blowing through the tubing during the grinding process. But blowing by mouth did not keep the lore free. It was found neces. sary to make a commection to an air or oxygen pressure tank in order to keep a flow of air or oxygen that wonld prevent the entrance of particles into the glass tip. The progress of grinding was checked under the microscope and was considered finished when there was a beveled. smooth, sharp tip.

When the grinding was finished the tubes were cleaned with alcohol and ether, and dried with air.

\section{Method for taking blood from the dorsal aorta of the 18. to 72-hour embryo}

Eggs that are presumed to be fertile are taken from the cool room where they have been held at a temperature of about 55 degrees since they were laid. They are placed in the incubator with a record of the hour and date. In these studies the age has been taken as 3 hours less than the total time held in the incubator. When the embryo has reached 48 hours, incubation age (51 hours actual time in the incubator), it is removed, opened carefully, and slid into a bowl of warm saline or Ringer's solution. Sugiyama (1926) followed Sabin's suggestion and increased the salt content of Locke-Lewis solution to 1.04-percent $\mathrm{NaCl}$ for an embryo on the second day of incubation, to 1.0-percent for an embyro on the third day of incubation, and to 0.9-percent for an embryo on the fourth rlay of incubation and older. These improvements in technic are useful if the embryos are to be held for study over a period of time. Where the whole procedure can be completed within a few minutes, the use of 0.85-percent or 0.90-percent solution of sodium chloride alone produces no ill effects.

Prior to opening the embryo, rings from filter paper were cut. These had an outside diameter slightly larger than the margin of the area vascu. losa, and the inner diameter was slightly less than this margin. The saline was removed from the bowl until the emliryo lay above the level of the surrounding fluid. The vitelline membrane

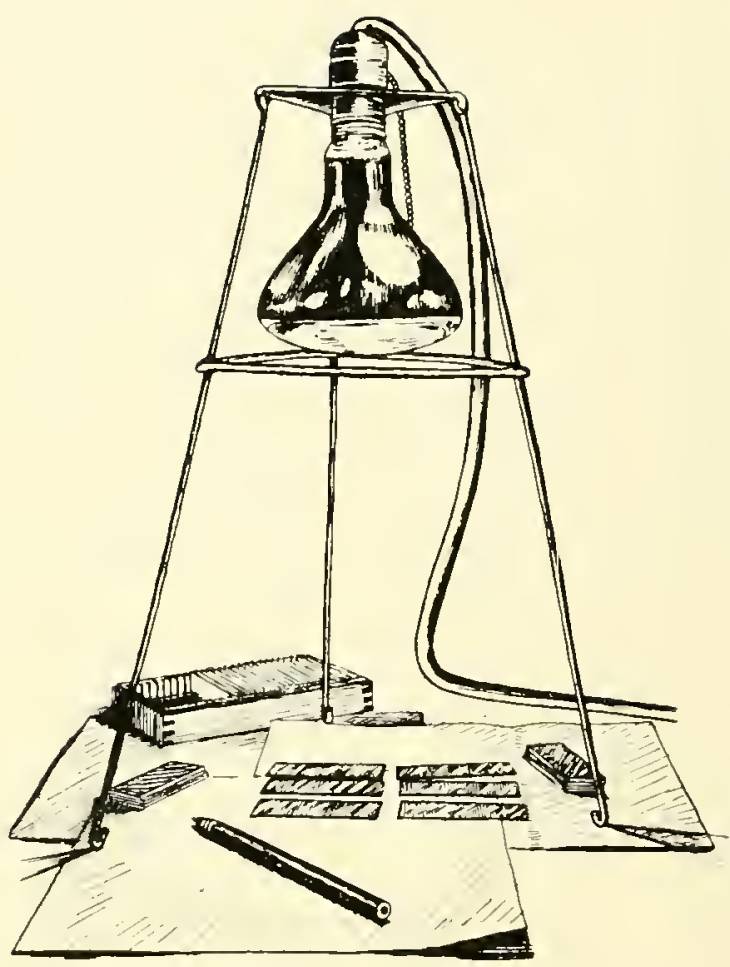

Figure 412.-A tripod to hold an infrared lamp, used to warm slides and to drive off moisture before the smear is made and to dry the blood after it is spread.

was lifted off and the filter ring was placed over the embryo, which usually adhered readily to the surface. With fine curved scissors and forceps the embryo was cut free from the yolk sac, washed in saline, and lifted to a Syracuse watch glass. It was then placed under a low-power dissecting microscope.

In the meantime clean microscope slides were drying and warming under the infrared lamp (fig. 412). The slides should feel warm, not hot, to the back of the hand or the cheek. A flexible, thin rubber tuling of the type used for taking blood in erythrocyte counts was attached to the glass cammula, and under the low power of the dissecting microscope the cannula was guided into the dorsal aorta. The heart must be beating and the blood flowing in order to obtain a satisfactory preparation. A slight positive pressure is set up with air from the mouth as the tip approaches the moist surface of the embryo. If this is not done capillary attraction tends to draw saline and embryonic fluids into the tube and these fluids quickly distort the embryo blend cells. 
The blood was drawn quickly by suction and then immediately expelled from the tube onto the warmed glass slide. As the blood leaves the cannula the tip is moved back and forth so as to distribute the cells and prevent them from piling up in heaps. If there is any delay in entering the aorta, in taking the blood, in making the preparation, or in drying it, the cells will be distorted. This is especially likely to happen if contaminating fluids have entered the camnula ahead of the cells or along with them. Efforts to prevent distortion of cells by other means were made. Heparin and silicone coatings over the inside of the cannulas were tried. Neither method gave improvement over careful, rapid use of a clean, dry tube. Essentially the same procedure was used for embryos a day older. The filter-paper rings used to hold the embryo were slightly larger than those for 48-hour embryos.

\section{Method of taking blood from the heart of embryos of 96 homes and older}

The same type of cannula was used as described previously except that it had a slightly larger bore. A camnula with a still larger bore was used when embryo age increased. A different technic was used to procure blood from the second week of incubation to hatching.

After 5 to 6 days of incubation the procedure of moving the tip of the camnula back and forth across the slide, as the blood was being expelled, was discontinued and a new procedure was leegun-a drop of llood was placed on the end of the smear slide and distributed with a pusher slide. In still older embryos, the tip of the heart was cut open and the drop collected directly onto the end of a pusher slide, but in doing this there must be freedom from fluids around the heart, and the heart should he elevated above the surounding tissue. At about mid-embryonic age of incubation this drop of blood will often be carried across from one end of the slide to the other and will leave only a few scattered cells over the surface of the slide. The ways in which the physical properties of the blood at this age differ from those that obtain just before hatching and after hatching is not known, but obvionsly the blood has a poor affinity for glass. Schechtman (1952) showed that the surface tension was less in the embryo than in the chick after hatching, and this may be one of the factors that influence the spread of the blood over the glass slide. The difficulty usually can be circumvented by placing the pusher slide at a low angle, by barely touching it against the smear slide, and by giving it one quick movement to the opposite end.

\section{The infraced lamp and its use in drying and rarming slides}

A tripod carrying an infrared bull, vertically suspended (fig. 412) has been used for many vears in this Laboratory in making l, lood smears. The legs and lraces were made from $1 / \mathrm{s}$-inch wires welded together. On top was a flat niangle of sheet metal with a hole large enough to receive a light socket. An infrared bulb was placed in the socket. Clean paper toweling or cloth was spread on a table beneath the bulb, and on this the slides were stacked. Usually the slides were stacked around the margin of the circle of light and then about a dozen were spread under the light.

The heat from the lamp drives the moisture from the slides, and when the smear is made the film of cells dries quickly. It was necessary to have the warmed slides close to the point where they were heing used; otherwise, the slide cooled before the film was spread. The pusher slides should not be heated. If the slide is too hot, artifacts will appear. They will he similar to those that appear in erythocytes (see chapter 2). After the smear is made the slides may he returned to the lamp for complete drying of the cells or they may be put directly into a box. In either case, they are gently heated again just bcfore staming in order to drive off any moisture that may have accmulated when the slides were cooled.

\section{Method for collecting and carrying blood samples}

Denington and Lucas (1955) have described a box in which 15 muits can lue carried conveniently and safely (fig. 413). The tray holding the red-cell pipettes is removable. Upon returning to the laboratory, the worker can separate the tray from the rest of the equipment and place 


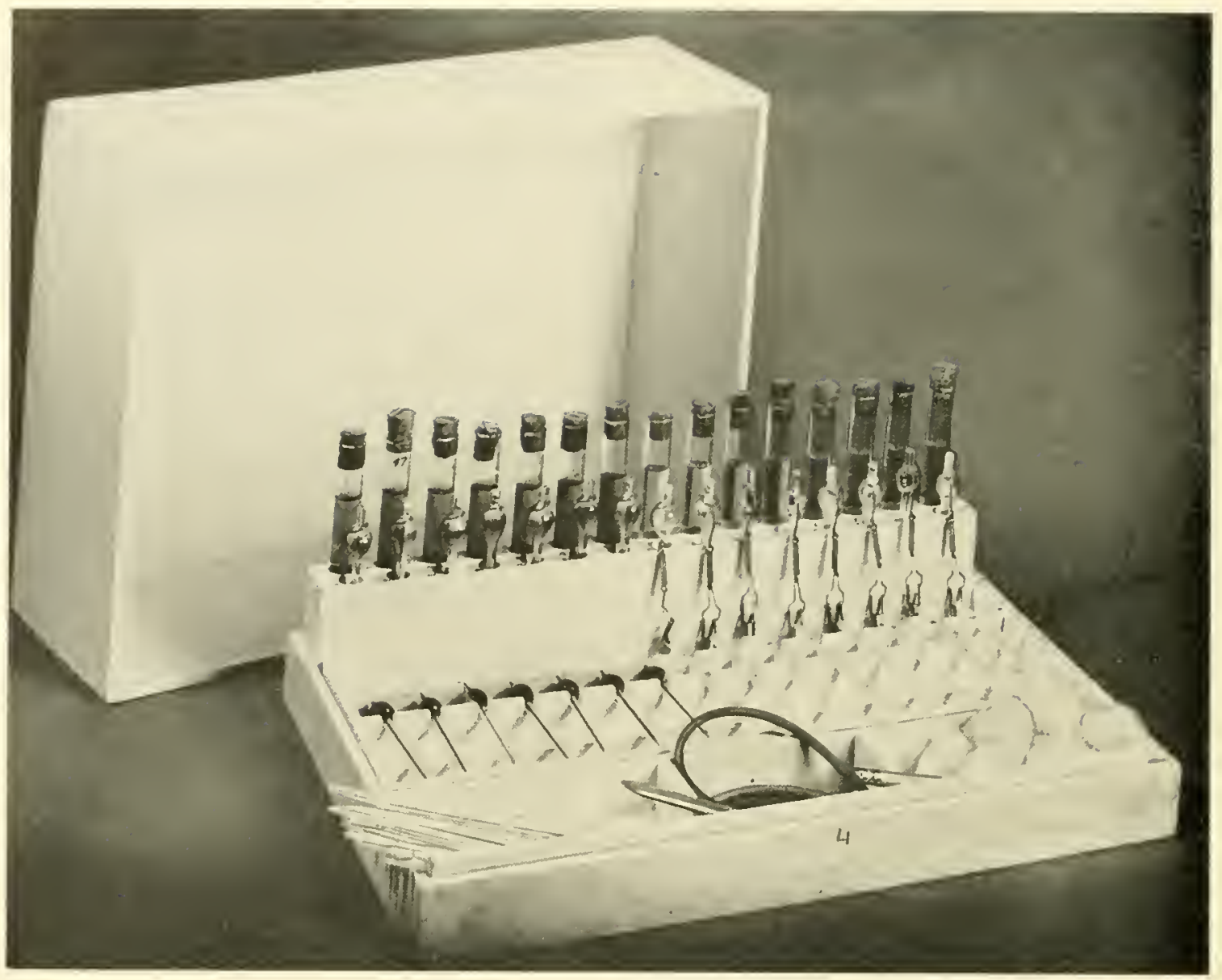

Figure 413.-A box and cover suitable for carrying 15 tuhes for the lemoglobin test, the same number of Van dllen hematorit tubes, and red-cell pipettes. The tray holding the last of these can be lifted out and stored in the refrigerator until they are ready for counting. Front compartments carry hemoglobin pipettes, knife, cotton bats, and rubber tubes for drawing up blood and fluids.

it in the refrigerator. where it remains until other procedures involving the hemoglobin and the VanAllen hematocrit tulies have been completed. The box witl clean slicles and the infrared lamp are separate items; they are not inchuded in the box used for collecting blood samples.

\section{STAINING}

\section{Selection, proparation, and use of Wright's stain}

Solutions containing dried Wright's powder have been made at the Laboratory and used; commercially prepared solutions have also been used. The difficulty in finding a $W_{\text {right }}$ 's stain suitable for avian blood has been discussed by
Denington and Lucas (1955). When dried powder was used, 3.3 grams were added to a 500 -ce. bottle of pure metlyyl alcohol, freshly opened. This quantity of stain is approximately double the quantity used in making Wright's stain for human-l)lood studies. The stain is ripened for several months either at room temperature or in the incubator at 38 to 40 degrees centigrade.

A great many samples of dye, both from powders made up into solution at the Laboratory and from bottles of the dye that had been put into solution ly a supply house. were tested. Some gave too red a color to the cytosomes of erythrocytes and gave pale. incompletely stained muclei, and others stained the molei very intensely but gave a pale bluish color to the cytosomes of erythocytes. The color balance of other cell 
types was also effected. It was sometimes possible to take a solution that produced too much red and too little blue coloration of the cells and follow this with a stain that was equally out of balance in the opposite direction and so procure a reasonably satisfactory slide. Much the same result could be obtained by using a mixture of the two solutions.

Wright's stain was obtained from various commercial sources. One product was found that, as a single staining solution, gave satisfactory results. Anyone seeking a Wright's stain for use on avian blood should test out samples from different sources in the hope that one of them will be properly balanced. Buffers of various sorts were tried with samples of Wright's stain. These manipulations still gave results that were too red or too blue.

The slides are spread on a staining rack over a sink or tray and flooded with stock Wright's stain. Use enongh stain. If the stain is dry 5 minutes after it is applied, too little was used. Usually after this interval of time the surface of the solution has a metallic sheen and an equal quantity of distilled water is added. The slides are allowed to stand for another 5 minutes. There is wide variation in the periods of time that can be allowed for the concentrated stain, and the water that follows it, to stand on the slide. Different standing periods should be tried before concluding that the stain is msatisfactory. The following are some of the periods that have been used in this study for the first and second solutions: 5 minutes and 2.5 minutes, 5 minutes and 5 minutes, and up to 9 minutes and 9 minutes. It was found that as the stock solution of stain aged, longer periods were necessary.

After the staining time has been completed, the slides are drained and blotted. Before the coverglass is put on, they are again warmed under the infrarcd lamp and the coverglass is heated over an alcohol lamp.

Many investigators do not cover blood smears but it has been a procedme followed in these studies on blood, and it has seemed that doing so makes the colors slightly more brilliant and the small details a little sharper.

\section{Bulk staining with Wright's stain}

When many slides are to lue done at one time, the job is usually speeded up by using bulk stain- ing methods. Stainless steel racks that hold 25 to 100 slides are used, and 2 stainless steel trays with covers, or glass dishes with covers, are arranged conveniently. Wright's stain is poured into one tray or dish and distilled water into the other. The slides are left in the stain 5 to 15 minutes and then dipped slowly 2 or 3 times in the water. The rack is shaken to remove the excess water and then placed on a towel in a warm place (such as on a radiator or in an incubator) to diy. Small drops of water that adhere to the surface of the smear and afterward dry slowly often produce faded round spots. These spots usually do not interfere with the study of the smcar.

The bulk staining method causes greater damage to watcr-soluble components of cells than does the rack method. Damage is less if the second solution is stain and water, equal parts.

\section{May-Grïmald Giemsa}

Although May-Grünwald Giensa (M. G. G.) is a more vigorous stain than Wright's, the coloration that it gives to the cytosome and nucleus is much like that given by Wright's. Wright's stain is preferred for circulating blood of the hatched chicken. The azurophilic substances in the monocyte are differentiated better with it than with M. G. G., and the heterophil rods are preserved better. But if the blood is leukemic or for some other reason contains ummerous immature cells, use M. G. G. or (if two slides are available) both stains. Because M. G. G. stains intensely, it is recommended for all impression smears from hematopoietic organs, both adult and embryonic, as well as for the circulating blood of the embryo. Both May-Grünwald and Giemsa were purchased as prepared solutions and have been entirely satisfactory. The following procedure was used:

1. Dry slides under the infrared lamp and place on a staining rack.

2. Cover with May-Grünwald solution, 5 minutes.

3. Dilute with equal quantity of distifled water and mix 1-2 minutes.

4. Pour off and without rinsing add diluted Giemsa, ${ }^{2}$ 15-20 ininutes.

5. Methyl alcohol. 1-3 dips.

6. Blot immediately.

7. Put on coverglass.

${ }^{2}$ Add 40 drops of stock Giemsa solution to $40 \mathrm{cc}$. of distilled waler. If the color is weak, 80 drops to 40 cc. may be used. 


\section{Wright-Giemsa}

The technic for Wright-Giemsa was suggested to us by Dr. C. J. Hamre of the University of North Dakota, who has found this stain satisfactory for the study of myelopoiesis in birds. It is a valuable method and for any critical study on myelopoiesis should be used in addition to May-Grünwald Giemsa.

1. Clean slides in concentrated $\mathrm{HNO}_{3}, 3$ hours.

2. Wash slides in rumning tap water, in distilled water, and in 95-percent alcohol.

3. Nake smear of blood and dry in air.

4. Use Wright's stain on rack, 4 minutes. (Proper length of time is determined by appearance of metallic sheen.)

5. Adld distilled water, \&5 minutes.

6. Wash in stream of running water and without drying add Giemsa, ${ }^{3} 15-20$ minutes.

7. Wash in running distilled water. If precipitate is present run Wright's stain over the slide.

8. Wash off with rumning water.

9. Stand slides on edge-do not blot.

\section{Petrunlievitch No. 2 and N. G. G.}

Petrunkevitch No. 2 is primarily a tissue fixative. It penetrates rapidly and since it is made up in alcohol it does not require washing. The original formula as given by Petrunkevitch (1933) has been modified slightly to adapt it for use with avian tissues.

80-percent alcohol

Nitric acid

Cupric nitrate

Paranitrophenol

Mix and filter

Ether

3 liters

$90 \mathrm{cc}$.

$60 \mathrm{gms}$.

150 gms.

$150 \mathrm{cc}$.

Combine the chemicals in the order given. Store in a cold place and in a well-sealed bottle.

In handling the paranitrophenol, do not inhale the dust and do not allow it to remain on the wet skin. Wear rubber gloves when weighing out the material and when handling the prepared fixative; this precaution is especially pertinent if there is danger that the prepared fixative may be splashed on the skin.

The paranitrophenol should be chemically pure. Before using it, note whether there is an indication of deterioration-brownish discolora. tion of the clumps of powder.

Petrunkevitch No. 2 fixative was used here

\footnotetext{
${ }^{3}$ Use 15 drops of Giemar stock to $10 \mathrm{ce}$, of distilled water.
}

chiefly to show nuclear structure of heterophils for making Arneth counts. After the blood was spread, it was held for a second or two until a dull effect, which comes with the drying of the slide, began to replace the high gloss of the wet surface. At that instant the slide is put quickly into a Coplin jar of fixative. Since the fixative contains ether, it is better to use a Coplin jar with a screw top. Fix, 1 to 24 hours. Wash in several changes of 80-percent alcohol and run up to absolute methyl alcohol. Staining with MayCrünwald Giemsa is done in a Coplin jar rather than on a rack and the staining times for one or both dyes should be increased, sometimes as much as 50 to 100 percent over that given under the technic for staining the usual dry smear with M. G. G. On one set of slides. May-Grünwald was applied for 10 minutes and Giemsa (80 drops in 40 cc. of distilled water) for 20 minutes. When used this way on blood from the early embryo, sharply defined chromosomes are obtained in mitotically dividing cells.

\section{Methyl alcohol and thionin}

The chief use in this study for the combination of methyl alcohol fixative and thionin stain has been to hold the granules of basophils in their normal size and relationships within the cell. This requires that the film of blood or impression smear be fixed luefore it dries.

1. Fixation in absolute methyl alcohol, 5 minutes.

2. Stain in thionin, ${ }^{ \pm} 24-48$ hours.

3. Differentiate in 95-percent alcohol.

4. Clear in 100-percent alcohol. xylene. and mount with cover glass.

\section{Reticulocyte stain}

One-percent brilliant cresyl blue was made up in 25 cc. of 0.85 -percent salt solution or in avian Ringer's solution- $\mathrm{NaCl}, 8.5$ gms., KCl, 0.42 gms., CaCl., 0.25 gms.; and water; 1,000 cc. The solution should be kept cold and should be filtered before using. Various methods were tried, including (1) mixing a drop of blood and a drop of stain on the slide for periods varying from 1 to 5 minutes and (2) drying a film of dye made with 0.3-percent solution of dye in 95-percent alcohol and making the blood smear over this. In the second method, the films of blood dried

\footnotetext{
Thionin. calurated solution in 50-percent alcohol.
} 
quickly and thus the dye on the slide was in solution for an insufficient period of time to give adequate staining. For avian blood the first method worked best, but more brilliant staining was accomplished when the mixture was held for at least 2 minutes before the smear was made. The same reticle used for making thrombocyte counts can be used for making reticulocyte counts.

Graam (1934) used a method that is essentially the same as given in the preceding paragraph, but added 0.3 percent sodinm citrate. Six drops of this solution were mixed with about two drops of fresh pigeon blood. The cells were allowed to stain for 10 to 30 minutes before a drop of the mixture was removed and spread across a slide to dry. This long staining time may have been the basis for the statement (p. 202). "Practically every red cell of the pigeon's blood contained some 'basophilic' substance in the protoplasm." She goes on to say, "The younger cells contain the most of this socalled 'basophilic' substance. One must learn to be consistent and he must arbitrarily decide which of these cells to call reticulocytes. I arbitrarily called those cells reticulocytes which had a completc chain of basophilic substance around the nucleus."

Peabody and Neale (1933) used Löffler's methylene blue in 0.85 percent solution of sodium chloride. Air-dried smears were immersed in this stain for about 3 mimutes, washed briefly in water and again air-dried. This stain was useful for temporary mounts but the preparations faded after a few hours.

The basic method for staining reticulocytes from which slight variations in procedure have arisen, was given by Osgood and Wilhelm (1931). They used, for mammalian blood, equal parts of venous blood that had been mixed with $2 \mathrm{mg}$. potassium oxalate per cc. and 1 percent brilliant cresyl blue in 0.85 percent $\mathrm{NaCl}$. These substances were mixed in a test tube and after one minute a drop was removed and a smear made. This is the techuic used by Magath and Higgins (1934) to stain the reticulocytes of mallard ducks.

\section{Ralph's modification of the benzidine tech- nic for hemoglobiu in cells}

The method given by Ralph (1941) is applicable to air-dried blood smears. The slide is flooded with 1-percent solution of benzidine in absolute methyl alcohol and allowed to stand 1 minute. The solution is poured off the slide and, without washing, it is replaced with a 25percent solution of superoxol in 70-percent ethyl alcohol, which is allowed to stand $1 \frac{1 / 2}{2}$ minutes. This is poured off and the slide rinsed for 15 seconds in distilled water, after which it is dried by blotting and covered. Cells and other structures containing, henoglobin stain dark or light brown. The dried slide should be counterstained with Wright's in order to reveal the cells and parts of cells that do not contain hemoglobin. In this study it was found that fine. needlc-slraped crystals were sometimes deposited on the slide but usually these did not interferc with study of the cells.

\section{MISCELLANEOUS TECHNICS}

\section{Method for hemoglobin determination}

This subject has been discussed by Denington and Lucas (1955) and only a summarization is presented here.

Fill a test tube with 10 cc. of 0.4 -percent solution of concentrated anmonium hydroxide in distilled water. Take up a 0.02-cc. sample of blood with a hemoglobin pipette; immediately discharge it into the ammonia solution; after rinsing the pipette several times in the solution, seal the test tube with a cork that has been washed, dried, and infiltrated with paraffin. Invert the tube 2 or 3 times; after an hour add 0.36 cc. of concentrated $\mathrm{HCl}$ to the tube and invert the tube 1 or 2 more times. This amount of $\mathrm{HCl}$, namely, $11 \%$ times as much as previonsly recommended, prevents formation of cloudiness in the tube; the precipitate that does form, aggregates into large masses, which usually fall to the bottom of the tube or float on top. Hemoglobin is not bound to this precipitatc. The density of color is determined colorimetrically at a wavelength of $410 \mathrm{~m} \mu$. These values are compared with those on a standard curve previously prepared; the curve is based on a series of 16 dilutions of hemin. Standard curves were made both from dried commercial hemin and from fowl hemin prepared according to the method given by Elvehjem (1931); the results were the same. When the transmission value, transposed into grams of hemin per cc. of 
blood, is multiplied by a factor of 2.3736 , the product is the number of grams of hemoglobin per $100 \mathrm{cc}$ of bloor. The derivation of the constant is given by Bankowski (1942).

\section{Method for hematocrit determination}

Van Allen hematocrit tubes were found suitable for embryos, small chicks, and the adult fowl. They are simple to use, give accurate results, and are easy to clean. From a small puncture about one drop of blood was drawn into the tulve. The column of blood should be stopped exactly at the 100-percent mark; then the open tip of the tube should be quickly immersed in the diluent1.6-percent solntion of sorlium oxalate in distilled water-which is sucked into the tube until the bull, is half full. Then the springclip cap is placed over the open end; fluid is not allowed to fall out of the open end as this is done. The springchip cap must be firmly and carefully seated.

The tubes are placed in the lirass shields of the centrifuge and the shields are filled to near the top with water and are balanced by the amount of water ardled. They are spun at $2000 \mathrm{r}$. p. m. for 20 minutes. The radius to the middle of the shield was $7 \frac{1}{2}$ inches. The level of packed cells and the thickness of the buffy layer were read with a hand lens.

After they are used, the tubes must be carefully cleaned and dried. The use of acid was avoided because, if not thoroughly washed out of the tube, it will hemolyse the red cells the next time the tube is used.

It must be remembered that the buffy coat is composed of both leukocytes and thrombocytes, and the latter constitute half or more than half of the buffy coat.

\section{Method for making thrombocyte comuts}

Althongh an indirect method was used to determine the number of thrombocytes per cubic millimeter, it seemed reasonably accurate. At the time blood was taken for use in erythrocyte counts, a dried smear was made. After the counts had been recorded, the stained slide was examined with an ocular reticle that had been scribed with two concentric squares. The inner square had one-twentieth the area enclosed by the larger square. The latter was of such size that it would fit within the opening made by the diaphragm ring of the eyepiece.

The thrombocytes in the large square and the erythrocyles in the small square are counted. Cells that touch two of the sides are counted; those that are crossed by the lines on opposite sides are not counted. If the small square is exactly one-twentieth of the large square, a tabulation of 250 erythrocytes in that square is the equivalent of 5,000 erythrocytes in the large square. The figures now collected are substituted in the following formula:

$$
\text { Throm./mm。 }{ }^{3}=\frac{\text { Throm. counted } \times \mathrm{ery}_{\circ} / \mathrm{mm}_{.}{ }^{3}}{5,000}
$$

The values for erythrocytes per cubic millimeter were determined from the counts made with the hemocytometer.

If the inner square is not exactly one-twentieth of the area of the larger one, differences can be compensated for ly varying the counts of erythrocytes above and below 250 by an amount needed to give the equivalent of 5,000 in the large square.

\section{Methods for white-cell counts}

The relative merits of three methods - direct, semi-indirect, and indirect-were discussed by Denington and Lucas (1955) but no conclusion as to which is the best was given. Many anthors have suggested technics that fall into these three categories. The indirect method is the simplest-after a total erythrocyte count has been made, the number of white cells relative to the number of erythrocytes is counted on the stained slide and from that ratio, the number of white cells per cubic millimeter can be estimated. The same reticle and procedure that were described for thrombocytes can be used.

The Wiseman (1931a) method is classed as a semi-indirect method. It is based on the prin. ciple that the total number of white cells in a cubic millimeter can be calculated if (1) the eosin-staining cells are counted directly in the counting chamber of a hemocytometer and (2) these values are used in conjunction with the percentage of eosin-staining cells tabulated in differential counts obtained from a stained slidc.

Wiseman based his method on the affinity of phloxine for cells he called eosinophils, lut both 
heterophils and eosinophils take this dye; therefore, the extrapolation to give a total cell comt from a differential count must include both cell types. If this is kept in mind, accurate results can be obtained with the $\mathrm{W}$ iseman table. For convenience, the table was increased to half units so that the calculations could be made on the basis of the average of cells counted in both chambers of the hemocytometer.

The following formula, which calls for less than half as much pliloxine as recommended by Wiseman, was used:

Phloxine $20 \mathrm{mgm}$.

Formalin $5 \mathrm{cc}$.

Ringer's solution $95 \mathrm{cc}$.

To each $100 \mathrm{cc}$. of dye was added $0.5 \mathrm{cc}$. of $0.1 \mathrm{~N} \mathrm{HCl}$, which gave a $\mathrm{pH}$ of 5.7 to the solution. The dilution in the red-cell pipette was 1 to 200. The pipette was held in the refrigerator 1 to 3 hours and then placed on a slow-moving Bryan-Garrey (1935) rotating cylinder, which does not damage the cells. The fluid in the tip of the pipette was drawn off onto a piece of gauze before the chambers of the hemocytometer were filled. Heterophils and eosinophils in all squares of both chambers were counted and divided by 2 . If onc chamber gave results considerably different from the other in the number of eosin-stained cells present, a new preparation was made. The volume of fluid under all the squares of one side of the counting chamber is 0.9 cubic millimeters. Therefore, if only one eosin-stained cell were seen, this would represent-

$$
\frac{1 \times 200}{0.9} \text { (ditulion factor) }
$$

or 222.2 cells (hetcrophils and eosinophils) per culic millimeter of blood. If in the differential count these two granulocytes were the only cells present, the lenkocytes would also total 222.2 ; but if these two types represented 50 percent of the leukocytes present, the white cells would total Iwice as much-444.4 cells. If the eosin-stained cells represented I percent, the total cell count would be $22,222.2$ cells. It is possible to prepare a table by which the total number of white cells per cubic millimeter can be determined, or the table given by Wiseman can be used for this purpose. The number of eosin-stained cells counted in one side of the chamber multiplied by the factor in the table for the percentage of com- bined heterophils and eosinophils found in the differential comt gives the total number of white cells per cubic millimeter.

When the total number of heterophils and eosinophils counted in the chamber is high and the percentage level in the differential count is also high, the Wiseman method has reliable accuracy; but when both these varial,les are low, the probability of error is increased proportionately.

The Rees-Ecker method probably is the best of the direct methods for estimating total white-cell counts. It is an adaptation of a method designed for counting platelet number in human blood (Wintrobe, 1952) and has been used by students in the Poultry Department at Cornell University. (Ram, 1949; Goodwin, 1950; and Machado, 1951). The method was first used for making cell counts on avian blood l,y DeEds (1927) who based his technic on the publication of Rees and Ecker (1923). The only difference between this method and the one given here, luased on Wintrobe's procedure, is in the amount of brilliant cresyl blne. Rees and Ecker (1923) used only 0.1 grams of the dye instead of 0.5 grams. The diluent is composed of:

Sodium citrate

Neutral formalin

Brilliant cresyl hlue

3.8 gns.

Distilled water

$0.2 \mathrm{cc}$.

0.5 gins.

Keep in a glass-stoppered bottle in the refrigerator and filter before using. If formic acid is produced from the breakdown of formaldehyde, erythrocytes will be hemolysed and the solution should be discarded.

Blood is drawn to the 0.05-cc. mark on the pipette and the diluent added to bring the fluids up to the mark above the bulb. The tube is shaken in the Bryan-Garrey pipette rotor to give an even distriluntion of cells; then a suitable quantity of the mixtme is placed on each side of the counting chamber.

Coates (1929) adapted a different direct method, using brilliant cresyl blue, for the counting of chicken leukocytes. He used two solutions: Brilliant cresyl blue in water, and potassium cyanide in water. We have not testerl the Coates method.

One of the chief difficulties in using some of the direct methors for avian blood was the confusion that came in separating thrombocytes and lymphocytes. The brilliant cresyl blue stains 
the specific granules of the thrombocytes. If the top lens of the microscope condenser is removed and the light bronght to a focus at the level of the cells in the chamber-with the diaphragm partially closed, if preferred-there is no difficulty in separating thrombocytes from each of the leukocytes. It is recommended. however, that differential counts not be attempted in the counting chamber: It is better to make them on the shide, where each cel] can be checked for its identity under the oil immersion lens. Both with the Wiseman and the Rees-Ecker method, erythrocytes can be counted in the same preparation or, if some drying has occurred, the counting chamber can be cleaned and refilled. Erythrocytes in millions per cubic millimeter are estimated in the same way as for human blood. The correct procedure for counting erythrocytes is given in numerous books on tech. nic of hematology for the human. 


\section{Literature Cited}

Anonymous. 1949. Recommended terms and definitions for cells of the leukocytic, erythrocytic and thrombocytic series. Jour. Amer. Ned. Assoc. 139: 175-176.

Batfour, A. 1911. Fallacies and puzzles in blood examination. 4th Rpt. Wellcome Trop. Res. Labs. Khartoum. Vol. A : 109-125.

Bankowski, R. A. 1942. Studies of the hemoglobin content of chicken blood and evaluation of methods for its determination. Amer. Jour. Vet. Res. 3: 373-381.

Bartscil, P. W. Ball, W. H., Rosenzweig, W., and Salmian, S. 1937. Size of red blood corpuseles and their nuclei in fifty North American birds. Auk $54: 516-519$.

Beck, C. 1938. The Microscope. Theory and Practice. $264 \mathrm{pp}$. R. and J. Beck, Ltd. London.

Belling, J. 1930. The Use of the Microscope. 315 pp. McGraw-Hill Book Co., Inc. New York.

Berman, L. 1947. The clinical significance of cellular gigantism in human erythropoiesis. Jour. Lab. and Clin. Med. 32: 793-806.

Biely. J.. and PAlmer. E. 1. 1935. Studies of tutal erythrocyte and leucocyte counts of fowls. III. Variation in number of blood cells in normal fowl. Canad. Jour. Res.; Sci. 13, Sec. D.: 61-71.

Bizzozero, G. 1889. Neue Untersuchungen über den Bau des Knockenmark bei den Vögeln. Arch. f. mikr. Anat. 35: 424-469.

and Torre. A. A. 1881. Teher die Entstehung und Entwicklung der rothen Blutkörperchen. I. Ueber Entstehung und Entwicklung der rothen Blutkörperchen bei Vögeln. Noleschotts' I'ntersuch. z. Naturlehre d. Menschen u. d. Thiere 12: 626-652.

Blackfan, K. D., Dianond, L. K., and Leister, C. M. 1944. Atlas of the Blood in Children. $320 \mathrm{pP}$. The Commonwealth Fund. New York.

BLAKEMORE, F. 1934. The leucocytes of fowl blood with special reference to fowl paralysis. Vet. Rec. 14: 417-422.

BLoom, W. 1938. Lymphocytes and monocytes. Theories of hematopoiesis. In Downey's Handlook of Hematology. 374-435. P. B. Hoeber, Inc. New York.

Blount, W. P. 1939a. The blood picture at birth in the chick. Vet. Jour. 95: 193-195. 1939b. Thrombocyte formation in the do. mestic hen. Vet. Jour. 95: 195-198.

Bradley, B. 1937. Observations on the comparative anatomy of blood. Merl. Jour. Austral. 24:992999.

Breusch. E. 1928. Beiträge zur Blutmorphologie des Huhnes. Zeit. f. Infektionshr., par. Kranklı. u. Hyg. d. Haustiere. 33: 219-237.

Bryax, W. R., and Garrey, W. E. 1935. A mechanical device that produces uniform dispersion of blood cells in the diluting pipette. Jour. Amer. Med. As. soc. 103: 1,059-1,060.

Burckhardt, J. L. 1912. Ueber das Blutbild bei Hühnertuberkulose und dessen Beziehungen zur sogenannten Hühnerleukämie nebst Bemerkungen über das normale Hühnerblut. Zeit. f. Immunitäts. forsch. u. exp. Therapie. 14:514 604 .

Burmester, B. R., Gentry, R. F., and Waters, N. F. 1955. The presence of the virus of visceral lymphomatosis in embryonated eggs of nomal appearing hens. Poultry Sci. 34: 609-617.

- Severens, J. M. and Roberts, E. 1941. Blood cells in the bone marrow of the chick before and after hatching. Poultry Sci. 20: 391-394.

Burnett, S. H. 1908. The Clinical Pathology of the Blood of Domesticated Animals. 158 pp. Taylor and Carpenter. Ithaca, N. Y.

Caneron, J. A. 1941. Primitive blood-cell generations in Amblystoma. Jour. Morph. 68: 23I-239.

Cilaripper, H. A., and Dawson, A. B. 1928. Direct division of erythrocytes and the occurrence of eryth. roplastids in the circulating blood of Necturus. Anat. Rec. 39: 301-307.

Contes, 1. 1929. A method of counting white cells in the blood of fowl. Rept. Ontario Vet. Col. 1928; 63. (Quoted from Biol. Abst. 1931. 5:15346.)

Committe for Clarification of the Nomenclature of Cells and Diseases of tile Blood and Blood. Forming Organs. 1948. First report. Am. Jour. Clin. Med. 18: 443-450.

Cook, F. W.. and Dearstyne, R. S. 1934. Hematology of the fowl. A. Studies on normal avian blood. B. Studies on the hematology of avian typhoid. N. C. Agr. Expt. Sta. Tech. Bul. 44, 46 pp.

Соok, S. F. 1937. A study of the blood picture of poultry and its diagnostic significance. Poultry Sci. 16: $291-296$. 
Cottral, G. E. 1950. Avian lymphomatosis, another egg-borne disease. Proc, 53d Ann. Meet. U. S. Livest. Sanit. Assoc. 1949. 183-192.

1952. Endogenous viruses in the egg. In The chick embryo in biological research. Ann. N. X. Acad. of Sci. 55: 221-234.

-, Burmester, B. R., and Waters, N. F. 1954. Egg transmission of avian lymphomatosis. Poultry Sci. 33: 1.174-1.184.

Cullen, E. K. 1903. A morphological study of the blood of certain fishes and birds with special reference to the leucocytes of birds. (Including a note on the occurrence of filariae in the blood of two birds and two porcupines.) Bul. Johns Hopkins Hosp. 14: $352-356$.

DanschakofF, V. 1916a. Equivalence of different lematopoietic anlages. $1 \mathrm{Br}$ method of stimulation of their stem cells.) I. Spleen. Amer. Jour. Anat. $20: 255-327$.

1916l. The differentiation of cells as a criterion for cell identification, considered in relation to the small cortical cells of the thymus. Jour. Expt. Med. 24: 87-105.

1916c. Myeloid metaplasia of the embryonic mesenchyme in relation to cell potentialities and differential factors. Camegie Inst. of Wash. Pub. No. 271. Contrib. to Embryol. 9: 1-32.

DaxtschakofF, W. 1907. Über das erste Auftreteu der Blutelemente in Hühnerembryo. Fol. Haem. 4: Supp. 2: 159-166.

1908a. Leber die Blutbildung in Dottersack des Hühnchens. Verhandl. Anat. Ges. Ber. 22: 72-81.

1908b. Untersuchungen über die Entwickelung des Blutes und Bindegewebes bei den Vögeln. I. Die Entstehung der Blutzellen beim Hühnerem. bryo und der Dottersack als blutbildendes Organ. Anat. Hefte. 37: 471-589.

1909a. Lntersuchmoen über die Funwickelung von Blut und Bindegewele bei Vögeln. Das lockere Bindegewebe des Hühnchens im fetalen Leben. Arch. f. mikr. Anat. 73: 117-181.

1909b. Über die Entwickelung des Knock. enmarks bei den Vögeln und über dessen Veranderungen bei Blutentziehungen und Ernährungstorung. en. Arch. f. mikr. Anat. 7.1: 855-926.

1931. Keimzelle und Gunade. Die endodermale Wanderzelle als Stammzelle in der Keimhahn. Zeitschr. f. Wissenschaftliclıe. Biol. Abt. B. Zeitscl. f. Zellforsch. u. mikros. Anat. 14: 376-384.

Dawson, A. B. 1931. The occurrence of atypical vacuolated erythrocytes in the circulating blood of Necturus. Anat. Rec. 50: 23-31.

\section{Hemopojetic loci in Neclurus maculo.}

sus. Anat. Rec. 52:367-379. 1933a. An experimental study of hemopoiesis in Necturus: effects of lead poisoning on normal and splenectomized animals. Jour. Morph. 55: 349385.

1933b. The leucocytic reaction in Necturus maculosus to intravascular injections of colloidal carbon. with special reference to the behavior of the basophils and thrombocytes. Anat. Rec. 57 (Supp.): $351-359$.

1936a. Some olservations on the primitive and definitive erythrocytes of the developing chick. Ztschr. f. Zellforsch. 11. mikros. Anat. 21: 256-268.

1936b. Prolonged observations on splenectomized Necturus maculosus following intravascular injection of India ink. Arch. d'Anat. Micro. 32: 235-247.

DeEns, F. 1927. Normal blood counts in pigeons. Jour, Lab, and Clin. Med. 12: 437-438.

Denington, E. M., and Lucis, A. MI. 1955. Blood technics for chickens. Poultry Sci, 34:360-368.

Denys, J. 1887. La structure de la moelle des os et la genese du sang chez les oiseaux. La Cellule 4: $199-210$

Diesem. C. D. 1956. A study of arian blood cells. Thesis: Ohio State Univ. 197 pp.

Dosx. C. A. 1932. Current views on the origin and maturation of the cells of the llood. Jour. Lab. and Clin. Med. 17: 887-898.

Cunvingham. R. S.. and Sabix, F. R. 1925. Experimental studies on the origin and maturation of avian and mammalian red blood-cells. Carnegie Inst. Wash. Pub. No. 361. Contrib. Embryol. 16 : $163-226$.

Domm, L. V.. and TABER, E. 19.46. Endocrine factors controlling erythrocyte concentration in the blood of the domestic fowl. Phrsiol. Zool. 19:258-281.

TABer, E., and Davis, D. E. 1943. Comparison of erythrocyte numbers in normal and hormonetreated Brown Leghorn fowl. Proc. Soc. Expt. Biol. and Ned. 52: 19-50.

Dorst, S. E., and Milus, C. A. 1923. Comparative studies on blood clotting in mammals, birds, and rep. tiles. Amer. Jour. Physiol. 64: 160-166.

DoWrey, H., and McKinlay, C. A. 1923. Acute lymphadenosis compared with acute lymphatic leukemia. Part 1. Clinical study. Arch. Int. Med. $32: 82-112$.

Elvehjem. C. A. 1931. The preparation of standard acid hematin solutions from hemin. Jour. Biol. Chem. 93: 203-210.

Enmel, II. IT. 1936. The etiology of fowl paralysis, leukemia and allied conditions in animals. VII. Hemocrtoblastosis in chickens as induced by Sal. 
monella aertryclie. VIJl. Hemocytoblastosis in naturally occurring cases of fowl paralysis and lymphomatosis, as well as in other birds from the same flocks. Fla. Agr. Expt. Sta. Bul. 306, 42 pp.

Erduaxs, R. 1917. Cytological observations on the behavior of chicken bone marrow in plasma medium. Amer. Jour. Anat. 22: 73-I 25.

FexielL, R. A. 1947. The relation between age, number. and types of cells in the peripheral circulation of chicken embryos under normal and experimental conditions. Jour. Agr. Res. 74: 217-239.

Ferguson, L. C., lrwin. M. R., and Beach. B. A. 1945. On variations in the blood cells of healthy cattle. Jour. Infect. Dis. 76: 24-30.

Flemister, L. J.. and Cunvinghan, B. 1940. The effects of increased atmospheric pressure on the allantoic vascular bed and the blood picture of the developing chick. Growth. 4:63-71.

Foot, N. C. 1913. The growth of chicken bone marrow in vitro and its bearing on hematogenesis in adult life. Jour. Expt. Ned. 17: 43-60.

Forkner. C. E. 1929. Blood and bone matrow cells of the domestic fowl. Jour. Expt. Mled. 50: 121-142.

Frank. J. A.. and Dolgherty. T. F. 1953. Cytoplasmic budding of human lymphocytes produced by cortisone and hydrocortisone in in vitro prepa. rations. Proc. Soc. Expt. Biol. and Med. 82: 17-19.

Furtil, J., Seibold, H. R.. and Ratinboxe. R. R. 1933. Experimental studies on lymphomatosis of mice. Anser. Jour. Cancer. 19: 521-604.

GAge, S. H., and Fish, P. A. 1924. Fat digestion, absorption. and assimulation as determined in man and animals by the dark-field microscope, and as a fat soluble dye. Amer. Jour. Anat. 34: 1-77.

Garrey, W. E., and Bryan, W. R. 1935. Variations in white blood cell counts. Physiol. Rev. 15: 597638.

Gauger. H. C.. Greaves. R. E.. and Cook. F. W. 1940. Paratyphoid of pigeons. I. Serological, bacteriological. and hematological studies of spontancously infected birds. N. C. Agr. Expt. Sta. Tech. Bur. 62. $71 \mathrm{pp}$.

Goodsll. A. 1909. The numbers. proportions and characters of the red and white blood corpuscles in certain animals. Jour. Patlı. and Bact. 14: 195-199.

Goovwn, K. 1950. A genetic and physiological study of a sex-linked lethal in the fowl. Thesis. Grad. School, Cornell Univ.

Gornox, L. 1926. Untersuchungen üher die Spindelzellen in Blute von Tieren mit kernhaltigen roten Blutzellen, ihre eigentliche Gestalt. Abstammung und funktionelle Bedeutung. Virehow's Areh. path. Anat. u. Physiol. 262: 19-38.
Graal, D. G. 1931. The effect of lowered temperature on reticulocyte formation in the pigeon. Proc. lnd. Acad. Sci. 43: 201-204.

1935. The length of the reticulocyte cycle in pigeons. Proc. Ind. Acad. Sci. 44:224-227.

Gray, J. E., Syoeyenbos, G. H., and Reynolds, I. M. 1954. The hemorrhagic syndrome of chickens. Jour. Amer. Vet. Mled. Assoc. 125: 141-151.

HAFF, R. 1914. Bindegewebs- und Blutbildungsprozesse in der embryonalen Leber des Huhns. Arch. f. mikr. Anat. 84:32I-350.

Halliburtox, W. D. 1886. Note on the colouring matter of the serum of certain birds. Jour. Physiol. 7: 324-326.

Hamilton, H. L. 1952. Lillie's Development of the Chick. Ed. 3, 624 pp. Henry Holt and Company. New York.

Hamre, C. J. 1952. Origin and differentiation of heterophil, eosinophil and basophil leucocytes of chickens. Anat. Rec. 112:339-340.

and McHesry, J. T. 1942a. Metluods of obtaining blood of fowl for complete blood examination. Poultry Sci. 31: 30-34.

- and McHenry, J. T. 1942b. Blood values of hens fed a yeast-fermented mash supplemented adequate diet. Poultry Sci. 31:333-339.

Haxcox, N. M. 1946. On the occurrence in vitro of cells resembling osteoclasts. Jour. Physiol. 105: 66-71.

Harne, O. G., Lutz, J. F., Zimmerman. G. I., and Davis, C. L. 1945. The life duration of the red blood cell of the Macacus rhesus monkey. Jour. Lab. and Clin. Med. 30: 247-258.

Hartmann, E. 1925. Beiträge zur Thrombozytengenese bei niederen Vertebraten, sowie zur Frage ihrer Stellung zum Mlegakaryozyten der Säuger. Fol. Haem. 32: 1-14.

Hayde., C. E. 1929. Blood physiology of chickens. Rept. N. Y. State Vet. Col. at Cornell Univ. (19271928). Legislative Doc. (1929) No. 18: 213-220.

Hetuerington, D. C., and Pierce, E. J. 1931. The transformation of monocytes into macrophages and epithelioid cells in tissue cultures of buffy coat (demonstrated by trypan blue). Arch. expt. Zellforsch. 12: $1-10$.

Hevesy. G., and Ottesen, J. 1945. Life-cycle of the red corpuscles of the hen. Nature. 156: 534. London.

Hewitt, R. 1940. Bird Malaria. 228 pp. The Johns Hopkins Press. Baltimore.

1942. Studies on the host-parasite relationships of untreated infections with Plasmodium lophurae in ducks. Amer. Jour. Hyg. 36: 6-42. 
IsAacs, R. 1925. The refractive granule red blood corpuscle. Its behavior and significance. Anat. Rec. 29: 299-3ł3.

1928. Alterations of tissue cells in the blood stream. Science. 68: 547-548.

Johnson, E. P.. and Conner, B. V. 1933. Blood studies of fowls with various forms of lymphomalosis (fowl paralysis). Jour. Amer. Vet. Mled. Assoc. 83 : $325-343$.

and LANGe. C. J. 1939. Blood alterations in typhlohepatitis of turkeys with notes on the disease. Jour. Parasitol. 25: 157-167.

JoNes, O. P. 1943. Morphologic. physiologic, chemical and biologic distinction of megaloblasts. Arch. Path. 35: 752-775.

1947. Mitochondria and their relation to the so-called hyaloplasm. Jour. Lab. and Clin. Med. 32: $700-719$.

1948. Nuclear structure versus nuclear pat. tern. Blood. 3: 967-986.

4: $777-779$.

Jordax. H. E. 1936. The relation of lymphoid tissue to the process of blood production in avian bone marrow. Amer. Jour. Anat. 59: 249-297.

1937. The relation of lymphoid nodules to blond production in the bone marrow of the turkey. Anat. Rec. 68: 253-259.

1938. Comparative hematology. In Dow. ney's Handbook of Hematology. 703-862. Paul B. Hoeber. Inc. New York.

and Robesor, J. M. 1942. The production of lymphoid nodules in the bone marrow of the do. mestic pigeon, following splenectomy. Amer. Jour. Anat. 71: 181-205.

Junx. M... and Domm, L. V. 1930. The relation of gonadal condition to erythrocyte number in fowls. Amer. Jour. Physiol. 94: 656-661.

KAKARA, K.. and KaWASIMA, M. 1939. Hematological changes in the setting hen. Seventh World's Poultry Cong. and Expo. Proc. pp. 115-116.

Kalabeкhov. N.. and Ronlonov, V. 1934. Changes in the blood of animals according to age. 1. Changes in the blood of rodents (Mus musculus L. and Citel. lus pygmaeus Pall.) and birds (Passer montanus L. and Larus ridibundus L.) during the growth period. Fol. Haem. 52: 145-158.

Kasarinoff. D. 1910. Experimentelle Blutuntersuchungen bei Vögeln. Fol. Haem. 10:391-413.

Keller, C. 1933. Vergleichende Zellen- und Kermmessungen bei grossen und kleinen Hühnerrassen zur Prüfung der genetisch begingten Wuchsunter- schiede Zugleich ein Beitrag zur Frage des rhythmis. schen Wachstums der Kerne. Zeitschr. Wiss. Biol. Abt. B. Zeitschr. Zellforsch. u. mikrosk. Anat. 19: $510-536$.

Kelly, J. W., and Dearstyne, R. S. 1935. Hematology of the fowl. A. Studies on normal chick and normal adult blood. B. Studies on the hematology of chicks suffering from pullorum infection and on adult carriers of pullorum disease. N. C. Agr. Expt. Sta. Tech. Bul. No. 50, 69 pp.

Kennedy, IT. P.. and Cumenko. D. R. 1928. Studies on the blood of birds. I. The corpuscles of the pigeon. Quart. Jour. Expt. Physiol. 19: 43-49.

Kindered, J. E. 1940. A quantitative study of the hemopoietic organs of young albino rats. Amer. Jour. Anat. 67: 99-149.

Kirschraum, A.. and Downey, H. 1937. A com. parison of some of the methods used in study of hemopoietic tissues. Anat. Rec. 68: 227-235.

Kitaeva, O. N. 1939. Breed determined differences in blood indices of fowls. Comp. Rend. (Doklady) de l" Académie Sc. U. R. S. S. 25: 304-307.

Knisely, 11. H., Block. E. H., Eliot, T. S., and Warver, L. 19.17. Sludged blood. Science 106: $4.31-1.10$.

Knowles, R., Actox, H. W.. and Das Gupta. B. M. 1929. Puzzles and fallacies in the examination of stained films in the tropics. Indian Med. Res. Mlem. No. 13, 1-35.

Kracie, R. R., and GARver, H. E. 1937. Diseases of the Blood and Atlas of Hematology. 532 pp. J. B. Lippincott Co. Philadelphia.

Kyes, P. 1915. The physiological destruction of erythrocytes in birds. Internat. Monatschr. f. Anat. u. Physiol. 31: 543-551.

1929. Normal leucncyte content of bird's blood. Anat. Rec. 43: 197-198.

Lesbouyries, G. 1941. La Pathologie des Oiseanx. $868 \mathrm{pp}$. Vigot frères. Paris.

Loewenthal, N. 1930. Nourelles obserrations sur les globules blancs du sang chez les animanx vertébrés. Arch. d'anat. d'hist. et d'embry. 11:215-332.

Lucas, A. 11. 1940. The cytology of fox encephalitis and the effects of centrifugation upon the intranuclear inclusions. Amer. Jour. Path. 16:739-760.

1946. Hematology of blood spots in eggs of White Leghom chickens. Amer. Jour. Anat. 79: $431-472$.

19.19. Lrmphoid tissue and its relation to so-called normal lymphoid foci and to lymphomatosis. 1. Qualitative study of lymphoid areas in the pancreas of chickens. Am. J. Path. 25:11971213. 
1950. Lymphoid tissue and its relation to so-called normal lymphoid foci and to lympliomatosis. V. A study of lymphoid areas in the pancreas of pheasants and wild Mallard ducks. Poultry Sci. 29: 450-461.

1951. Lymphoid tissue and its relation to so-called normal lymphoid foci and to lymphomatosis. VI. A study of lymphoid areas in the pancreas of doves and pigeons. Poultry Sci. 30: 116124.

and Breithayer, J. B. 1949. Lymphoid tissue and its relation to so-called normal lymphoid foci and to lymphomatosis. III. Qualitative and quantitative comparison of lymphoid areas in the pancreas of the White Pekin duck with those in chickens. Poultry Sci. 28: 436-445.

L, CRAIG, C. C.. and OAKBERG, L. F. 1949 lymphoid foci and to lymphomatosis. IV. Simplification of methods for quantitative analyses and its application to the turkey. Growth 13:339-357.

and Deningtox. E. M. 1956. Morphology of the chicken liver. Poultry Sci. 35: 793-806.

, Denington, E. M., Cottral, G. E., and Burmester, B. R. 1954. Production of so-called normal lymphoid foci following inoculation with lym. phoid tumor filtrate. 1. Pancreas. 2. Liver and spleen. Poultry Sci. 33: 562-584.

and Herriann. W. W. 1935. Effect of centrifugation on herpetic intranuclear inclusions with a note on cytoplasmic inclusions of unknown origin in the rabbit cornea. Amer. Jour. Path. 11 : 969-975.

and OAsBerg, E. F. 1950. Lymphoid tissue and its relation to so-called normal lymphoid foci and to lymphomatosis. Il. Quantitative analysis of lymphoid areas in the pancreas of laboratory and farm chickens. Amer. J. Path. 26: 75-111.

and Riser, W. H. 1945. Intranuclear inclusions in panleukopenia of cats. Amer. Jour. Path. $21: 435-465$.

Lundquist, C. W., and Heduung, B. $1925 . \quad$ Über die verschiedenen Granulaformen der sog. pseudoeosinophilen Leukozyten im Hühnerblut. Fol. Haem. 31 : 253-264.

MCDonald, J. G. 1939. Avian bone marrow with particular reference to red cell development. Amer. Jour. Anat. 65: 291-307.

McGuire, W. C.. and Cavett, J. W. 1952. His. tomonas in turkeys. Poultry Sci. 31:610-617.

Machado. A. V. 1951. The effect of infectious bronchitis and Newcastle disease on the blood cells of chickens. Thesis. Grad. School, Cornell Univ.

Magatir, T. B., and Higgras, G. M. 1934. The blood of the normal duck. Fol. Hacm. 51:230-241.
Mainland, D., Coady, B. K., and Joseph, S. 1935. Lymphocyte sizes in human blood films. Fol. Haem. $53: 407-425$.

Marvin, H. N. 1954. Phenylhydrazine-induced changes in metabolism of pigeon blood and bone marrow. Amer. Jour. Physiol. 179: 338-342.

Maxisow, A. 1909. Untersuchungen ülser Blut und Bindegewebe. I. Die frühesten Entwicklungsstadien der Blut- und Bindegewebeszellen heim Saügetierembyro, bis zum Anfang der Bluthildung in der Leber. Arch. f. mikr. Anat. 73: 444-561.

and Bloom, W. 1931. A Textbook of Histology. 833 pp. W. B. Saunders Co. Phila. delphia.

MEDAWAR, P. B. 1941. The rate of penetration of fixatives. Jour. Roy. Micr. Soc. London. Ser. 3, $61: 46-57$.

MehneR, A. 1938. Beziehungen zwischen Zel]grösse und Körpergrösse. Zeit. Züchtung. Reihe B. Tierzüchtung und Züchtungsbiologie. 40: 1-48.

Michels. N. A. 1938. The mast cells. In Downey's Handbook of Hematology. 235-372. Paul B. Hoeher. Inc. New York.

MuassojedofF, S. W. 1926. Die Zellformen des Bindesgewebes und des Blutes und die Blutbildung beim erwachsenen Huhn. Fol. Haem. 32: 263-296.

Murray, P. D. F. 1932. The development in vitro of the blood of the early chick embryo. Proc. Roy. Soc. London. Ser. B, 111: 497-521.

NAtt, M. P., and Herrick, C. A. 1954. Variation in the shape of the rodlike granule of the chicken heterophil leucocyte and its possible significance. Poultry Sci. 33: 828-830.

NeAvE, S. 1906. Report of travelling pathologist and naturalist. 2nd Rpt. Wellcome Res. Labs. Khartoum. 183-204.

Nesterow, W. 1935. Das Schicksal von Hühnererythrozyten im Fremden Organismus. Zeitschr. f. Wissenschaftliche Biol. Abt. B. Zeitschr. f. Zellforsch. u. mikrosk. Anat. 22: 263-274.

Nice, L. B., Nice, M. M., and Kraft, R. M. 1935. Erythrocytes and hemoglobin in the blood of some American birds. The Wilson Bul. 47: 120-124.

Nittis, S. 1930. A surface structure (?) in normal nucleated erythrocytes. Anat. Rec. 46: 365-376.

Novidez, J. F. 1920. Studies on the gonads of the fowl. I. Hematopoietic processes in the gonads of embryos and mature birds. Amer. Jour. Anat. 28: 81-115.

OAKBerg, E. F. 1949. Effect of age, sex and individual variability on lymphoid tissue of the pancreas in White Leghorn chickens. Poultry Sci. 28: 675-685. 
1950. Distribution and amount of lymphoid tissue in some of the splanchnic nerves of chickens in relation to age, sex and individual constitution. Poultry Sci. 29: 420-436.

1951. Influence of genetic constitution on growth of lymphoid tissue in liver and pancreas of White Leghorn clickens, and correlation of lymphoid tissues with weights of some visceral and endocrine organs. Growth 15: 79-100.

OLson, C. 1937. Variations in the cells and hemo. globin content in the blood of the normal domestic chicken. Comell Vet. 27: 235-263.

1952. Avian hematology. In Biester and Schwarte's Diseases of Poultry. pp. 71-91. Iowa State Col. Press. Ames, Iowa.

Orten, J. M. 1934. The properties and significance of the reticulocyte. Yale Jour. Biol. and Med. 6: 519-539.

and Surtit, A. H. 1934. The proportions of reticulocytes in the blood of albino rats. Amer. Jour. Physiol. 108: 66-73.

OsGood, E. E. 1935. Fenestration of nuclei of lymphocytes. Proc. Soc. Expt. Biol. and Mled. 33: 218-219.

1938. The histogenesis, classification and identification of the cells of the blood and marrow based on cultures and hematologic studies of human marrow and blood. Amer. Jour. Clin. Path. 8: $59-74$.

and Ashworth, C. M. 1937. Atlas of Hema. tology. 255 pp. J. W. Stacey, Inc. San Fran. cisco.

BAKER, R. L., and WilHelM, M. M. 1934. Reticulocyte counts in healthy children. Amer. Jour. Clin. Path. 4: 292-296.

and Wilheli, M. M. 1931. Reticulocytes. Proc. Soc. Expt. Biol. and Med. 29: 53-54.

Palier. E. I.. and Biely, J. 1935a. Studies of total erythrocyte and leucocyte counts of fowls. I. Repeated erythrocyte and leucocyte counts. Fol. Haem. 53: 143-154.

and Biely, J. 1935b. Studies of total erythrocyte and leucocyte counts of fowls. IV. Erythrocyte and leucocyte counts of birds raised in confinement. Canad. Jour. Res. 13: Sec. D: 85-88.

Payne, F., and Breneman, W. R. 1952. Lymphoid areas in endocrine glands of fowl. Poultry Sci. 31: 155-165.

Peabody, W. A., and Neale, R. C. 1933. The pigeon as a hematopoietic test animal. Jour. Amer. Pharm. Assoc. 22: 1231-1237.

Petrunievitch, A. 1933. New fixing fluids for general purposes. Science 77: 117-118.
Price-Jones, C. 1910. The development of red blood cells in the chick. Jour. Path. \& Bact. 14: 218-223.

RalpH, P. H. 1941. The histochemical demonstration of hemoglobin in blood cells and tissue smears. Stain Tech. 16: 105-107.

Ram, T. 1949. The relation of body temperature, blood cells and genetic resistance to Salmonella pullorum in fowls. Thesis. Grad. School, Cornell Univ.

Rees, M., and Ecker, E. E. 1923. An improved method for counting blood platelets. Jour. Amer. Med. Assoc. 80: 621-622.

Rhiax, M., Wilsox, W. O., and Moxox, A. I. 1944. Composition of blood of normal turkeys. Poultry Sci. 23: 224-229.

Ricinards, O. W. 1938. A monogram for the resolv. ing power of microscope objectivcs. Trans. Amer. Micr. Soc. 57: 316-318.

1949. The history of the microscope. Trans. Amer. Micr. Soc. 68: 55-57, 206-207, 275-276.

1954. The Effective Use and Proper Care of the Microscope. Amer. Optical Co. $63 \mathrm{pp}$. Spencer Lens Co., Buffalo.

Richardson, A. P. 1937. Comparative effects of Congo red and liver extract on reticulocytes in pigeons. Proc. Soc. Expt. Biol. and Med. 37: 397400.

Richter, M. N. 1938. Leucocytosis. In Downey's Handbook of Hematology. 2846-2886. Paul B. Hoeber, Inc. New York.

Riddle, O., and Braucher, P. F. 1934. Hemoglobin and erythrocyte differences according to sex and season in doves and pigeons. Aner. Jour. Physiol. 108: 554-566.

Roberts, E., Severexs. J. Ml.. and Card, L. E. 1939. Nature of the hereditary factors for resistance and susceptibility to pullorum disease in the domestic fow. Seventh World's Poultry Cong. 1939: 52-54.

Robertson, E. I., Fiala, G. F., Scott, M. L., Norris, L. C. and Heuser, G. F. 1947. Response of chicks to pteroylglutamic acid. Proc. Soc. Expt. Biol. and Med. 64: 441-443.

Ryerson, D. L. 1943. Separation of the two acido. philic granulocytes of turtle blood, with suggested phylogenetic relationships. Anat. Rec. 85: 25-49.

SABIN, F. R. 1920. Studies on the origin of bloodvessels and of red blood-corpuscles as seen in the living blastoderm of clicks during the second day of incubation. Carnegie Inst. of Wash. Pub. No. 272. Contrib. to Embryol. 9: 213-262.

Schechtman, A. M. 1952. Physical and clemical changes in the circulating blood. In The chick embryo in hiological research. Ann. T. Y. Acad. of Sci. 55: 85-98. 
Schilling, V. 1929. The Blood Picture and Its Clinical Significance. Translated and edited by P. B. H. Gradwold. 408 pp. C. V. Mosby Co. St. Louis.

SCHOGER, A. 1939. Beitrag zum Blutbild der Laboratoriumstiere unter besonderer Berïcksichtigung des Bluttplättchenbildes. Das Blutbild der Taube. Pflüger's Arch. ges. Physiol. 242: 494-503.

Scurwarz, E. 1946. Cellular gigantism and pluripolar mitosis in human hematopoiesis. Amer. Jour. Anat. 79: 75-115.

Seyfarth, C. 1927. Experimentelle und klinische Untersuchungen über die vitalfärbbaren Erythrozy. ten. Fol. Haem. 34: 7-38.

Shattuck, G. E. 1928. Hemolysis of chicken blood. Jour. Gen. Physiol. 12: 17-28.

Shaw, A. F. B. 1933. The leucocytes of the pigeon with special reference to a diurnal rhythm. Jour. Path. and Bact. 37: 411-430.

Shrpey, P. G. 1916. The development of erythrocytes from hemoglobin-free cells and the differen. tiation of heart muscle fibers in tissue cultivated in plasma. Anat. Rec. 10: 347-353.

Speinel, C. C. 1932. Studies of living nerves. I. The movements of individual sheath cells and nerve sprouts correlated with the process of myelin-sheath formation in amphibian larvae. Jour. Expt. Zool. 61: 279-331.

Spitta, E. J. 1920. Microscopy. Ed. 3, 534 pp. John Murray. London.

Sturgis, C. C., and Bethell, F. H. 1943. Quantitative variation in normal leukocytes. Physiol. Rev. 23: 279-303.

Sugryama, S. 1926. Origin of thrombocytes and of different types of blood-cells as seen in the living chick blastoderm. Carnegie Inst. of Wash. Pub. No. 363. Contrib. to Enbryol. 18: 123-147.

1938. The nuclear shift of leucocytes and its clinical significance. Trans. Soc. Path. Jap. 28: 649-672.

Sundberg. R. D. 194. Lymphocytogenesis in human lymph nodes. Jour. Lab. and Clin. Med. 32: $777-792$.

Taber. E.. Davis, D. E., and Domi, L. V. 1943. Effects of sex hormones on the erythrocyte number in the blood of the domestic fowl. Amer. Jour. Physiol. 138: 479-487.

TAKaGl, S. 1931. Studien über die Differenzierung der Blutzellen, Beobachtet aus dem Standpunkt der Chondriosomenforschung. Hämatopoese im Dottersack des Hühnerembryos. Annot. Zool. Jap. 13: $105-115$.

1932. Über das Verhalten der Chondriosomen bei der mitotischen Zellteilung der jüngeren Blutzellen. Annot. Zool. Jap. 13: 355-359.
Tate, P., and Vincent, M. 1932. The occurrence of peculiar bodies in blood cells of animals after treatment with some chemical compounds. Parasitology 24: 284-288.

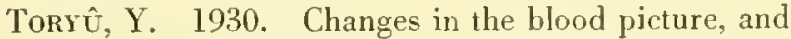
in the oxygen capacity of the blood haemoglobin of the carrier-pigeon following splenectomy. Sci. Rpt. Tohoku Imp. Univ. 4th Ser. Biol. 5: 391-402.

1931. Haemopoiesis in the liver and bone marrow of the carrier pigeon after splenectomy (Japanese with the English summary.) Ni Zyu. Gak. Ztschr. 10: 381-390. 1933. Abs. Jap. Jour. Zool. 4: (39).

Twisselmanx, N. M. 1939. A study of the cell content of the blood of normal chickens, with special reference to comparative differential leucocyte counts made with supravital and Wright's staining technics. Poultry Sci. 18: 151-159.

UNderinLl, B. M. L. 1932. The rate of penetration of fixatives. Jour. Roy. Micr. Soc. London. Ser. $3,52: 113-120$.

VenzlafF, W. 1911. Über Genesis und Morphologie der roten Blütkörperchen der Vögel. Arch. f. mikr. Anat. Abt. I. 77:377-432.

VezzAvi, V. 1939. Influence of a sojourn in the mountains on the blood composition, body development, and egg production of White Leghorn pullets. Proc. World's Poultry Cong. and Expo. 7: 117-119.

Wassjutotscinkiv. A. 1913. Untersuchungen über die Histogenese der Thymus. I. Über den Ursprung des mvoiden Elemente der Thymus des Hiihnerembryos. Anat. Anz. 43:349-366.

1914. Untersuchungen über die Histogenese der Thymus. 1I. Ưher den myoiden Elemente der Thymus in zusammenhange mit degeneratinen Veränderungen der Muskelfaser. Anat. Anz. 46:57 600 .

WATERs, N. F. 1945. Breeding for resistance and susceptibility to avian lymphomatusis. Poultry Sci. 24: 259-269.

Weloenteich. F. 1911. Die Leukozyten und verwandie Zellformen. Wiesboden. (Quoted from Lundquist and Hedlung.)

Weiss. L. P.. and FawcetT. D. W. 1953. Cylochemical observations on chicken monocytes. macropliages and giant cells in tissue culture. Jour. Histochem. and Cytochem. 1:47-65.

Wickifare, A. B. 1947. The differential blood picture in chickens before and after administration of embryonated eggs of Heterakis gallinae with notes on pathogenicity. Canad. Jour. Comp. Med. 11: 78-83.

WILls, L. 1932. Spontaneous flucluations in the reticulocyte count in pigeon's blood. Brit. Jour. Expt. Path. 13: 172-175. 
Wulsov, E. B. 1925. The Cell in Development and Heredity. 1232 pp. The Macmillan Co. New York.

Wintrobe, M. M. 1933. Variations in the size and hemoglobin content of erythrocytes in the blood of various vertebrates. Fol. Haem. 51:32-49.

1952. Clinical Hematology. Ed. 3, 1,048 pp. Lea and Febiger. Philadelphia.

WiRTh, D. 1950. Grundlagen einer Klinischen Hamatologie der Haustiere. 375 pp. Urban and Schwarzenherg. Vienna.

Wiselian, B. K. 193la. An improved method for obtaining white cell counts in avian blood. Proc. Soc. Expt. Biol. and Med. 28 : 1,030-1,033.

1931b. Criteria of the age of lymphocytes in the peripheral blood. Jour. Expt. Med. 54:271294.
1932. The identity of the lymphocyte. Fol. Haem. 46: 346-358.

Wislocki, G. B. 1943. Hemopoiesis in the chorionic villi of Platyrrhine monkeys. Anat. Rec. 85: 349363.

Wright, G. P. 1930a. Factors influencing the respiration of erythrocytes. I. Primitive avian erythrocytes. Jour. Gen. Physiol. 14: 179-199.

- 1930b. Factors influencing the respiration of erythrocytes. Il. Mammalian reticulocytes. Jour. Gen. Physiol. 14: 201-213.

and Vay Alstyne. I. 1931. The development of primitive avian red corpuscles on incubation in vitro. Fol. Haem. 46:26-36.

Zuckeriax. A. 1946. Infections with Plasmodium gallinareum in chick embryos induced by exoerythrocytic and hood stages. J. Infect. Dis. 79: 1-11.

\section{ADDENDUM}

Ackerman, G. A., and Knouff, R. A. 1959. Lym. phocytopoiesis in the bursa of Fabricius. Amer. Jour. Anat. 104: 163-177.

Bessis, M. 1956. Cytology of the Blood and BloodForming Organs. 629 pp. Grume and Stratton. New York.

Biggs, P. MI. 1957. The association of lymphoid tissue with the lymph ressels in the domestic chicken (Gallus domesticus). Acta Anat. 29: 36-47.

Bigland. C. H.. and Triantaphyllopollos, D. C. 1960. A re-evaluation of the clotting time of chicken bloorl. Nature 186: 644.

Clebani, J. B.. and Johrson, T. H. 1911. Relative dimensions of the red blood cells of vertebrates, especially of birds. Emu 11: 188-197.

Cook, F. W. 1959. Staining fixed preparations of chicken blood cells with combination May-Creenwald- Wright-Phloxine B stain. Arian Dis. 3: 272290.

Crass, G., and Rignon, R. H. 1954. Histologic study of the bone marrow in normal White Pekin ducks. A.M.A. Arch. Path. 58: 159-167.

Deningtov, E. M.. and Lucas. A. M. 1960. Influence of heat treatment on the number of ectopic lymphoid foci in chickens. Amer. Jour. Vet. Res. 21: 734739.

Diesem. C. D., Bletner, J. K., and Venzke, W. G. 1957. The effect of estradiolcyclopent ylproprionate (ECP) on the blood cells of chickens. Arian Dis. $2: 63-75$.

, Venzke, W. G., and Moore. E. N. 1958. The hemograms of healthy chickens. Amer. Jour. Tet. Res. 19: 719-724.
Fredrickson. T. N., Cinute, H. L., and O'Meara. D. C. 1957. Preliminary investigations on the hematology of broiler flocks. Avian Dis. 1: 67-74.

Gormox, A. S. 1959. Hemopoietine. Physiol. Rev. 39: $1-40$.

Kanesada, A. 1956. Lymphoid tissues occurring in the liver and bone marrow of reptiles and birds. Arch. Hist. Jap. 10: 471-481. (Jap. with Eng. summary and legends.)

1956. Postnatal development of lymphoid tissnes in the liver and bone marrow in 1 thite Leghorn chickens. Arch. Hist. Jap. 10: 525-530. (Jap. with Eng. summary and legends.)

Licas, A. M. 1959. A discussion of synonymy in avian and mammalian hematological nomenclature. Amer. Jour. Vet. Res. 20: 887-897.

and DeNington. E. M. 1957. Effect of total body x-ray irradiation on the blood of female Single Comb White Leghorn chickens. Ponlt. Sci. 36: 1290-1310.

and Dexingtox. E. M. 1958. The statistical reliability of differential counts of chicken blood. Poult. Sci. 37: 544-549.

MenWAY, II.. and Kare, M. R. 1959. Blood and plasma volume. hematocrit, blood specific gravity and sermm protein electrophoresis of the chicken. Poult. Sci. 38: 624-631.

Oнno, S., and Kinosita, R. 1956. Three-dimensional ohservations on the intranuclear structure. Exp. Cell Res. 10: 569-574. 


\section{Acknowledgments}

This study of avian hematology was initiated in 1944 and has received help and encouragement from many sources. We want to express our deepest appreciation in particular to the institutions and persons listed below for the contributions indicated:

Live birds: Dr. Donald W. Douglass, Dr. Lawrence Fay, Mr. Herbert J. Miller, Mr. Roy Hunt, and Mr. Martin Pollok, all in the Michigan Department of Conservation; Dr. M. R. Irwin, Department of Genetics, University of Wisconsin, Madison, Wis.; Dr. Charles C. Sheppard, Poultry Department, Michigan State University, East Lansing, Mich.; and Mr. A. G. Lohman, Manager Hamilton Farm Bureau Cooperative, Inc., Hamilton, Mich.

Slides: Dr. John W. Gowen and Miss Janice Stadler, Department of Genetics, Iowa State College, Ames, Iowa; Dr. Wade M. Smith, Jr., and Miss Enid B. Allbaugh, Hy-Line Poultry Farms, Des Moines, Iowa; Dr. E. N. Moore, Poultry Science Department, Ohio Agricultural Experiment Station, Wooster, Ohio; and Dr. George W. Sciple, Bear River Research Station, Brigham City, Utah.

The library work was greatly facilitated by the many courtesies extended by the staff of the Medical Library, University of Michigan, Am Arbor, Mich.

The authors appreciate the help given to the project by all members of this Laboratory. Those most directly concerned were: Mr. Berley Winton, Director; Mrs. Hazel W. Garrison, secretary; Mr. Seymour Albert; Mrs. M. Gay Flokstra, Mrs. Isabelle M. Letts, Mrs. Georgiann S. McClure, Mrs. Ellen Reibeling, and Mrs. Carolyn Tull, technicians; Mrs. Anne C. Garrison, translator; and Mrs. Coletta S. Waggoner, librarian.

To Swift \& Co., Chicago, 1ll., we want to express our sincere appreciation for its generous financial support of this research through grants to Michigan State University. Dr. O. A. Newton, who represented the Company, fully appreciated the significance of the research and consistently encouraged its execution.

We also desire to express to Michigan State University our thanks for administering the research grants made by Swift \& Co. 



\section{Index}

Abnormal cell(s), 15

eosinophil, 91

erythrocyte, 30-33, 34, 41

primary, 120

heterophil, 87

lymphocyte, 5 I, 56, 6 I

monocyte, 60,72

separation from artifact(s), 16, 33

thrombocyte, 45-46

See also Cell

Accipiter cooperi. See Hawk, Cooper's

Accipitriidae, 202

Achromatic. See Nucleus, chromophobic

Aged cell(s)

erythrocyle, 23

nucleus, $11,30,32$

primary, 120

lymphocyte, 167

thrombocyte, 15

Albumen, effect on primary erythroblast, 115

Allantois, spleen implants. 155

Amblystoma. See Amphibian

Amitosis

definition, 31

erythrocyte, 23-2t, 26, 31

primary, 120,128

monocyte, 70

Amphibian

Amblystoma, embryonic erythrocyte, 105

Batluachoceps attenuatus, thrombocyte, 45

erythrocyte

amitosis, 23-24

reticulocyte, 28

Necturus

erythrocyte, 31,40

macrophage, 68

monocyte, 68

thrombocyte, 45

Anas platyrlirnchos. See Duck, mallard

Anatidae, 202

Anemia, megaloblast of, 192

Angioblasts, 104

Anisocytes, 34

Anisocytosis, 26, 31, 127

Anonymous (1919), 8, 191, 196

Anseriformes, 202

Antibodies, against spleen, 155

Arneth count (s) , 220-221, 230

bunting, 221

chicken, 84

classes, 81

cockatoo, 221

goose, 85,220

nuclear lobe (s)

basophils, 80, 85
Arnetl count (s) - Continued

uuclear lobe(s) - continued

criteria of, 84

eosinophils, 80, 85

heterophils, $80,81,85$

owl, 221

pheasant. 220

pigeon, 221

bone marrow, 221

quail, 221

sparrow, 221

swallow, 221

turkey, 220

Arneth index

lunting. 221

chicken

basophil, 85

eosinophil, 85, 90

heterophil, 83, 84, 85, 90, 220

mortality correlated with, 85

shift, 85

cockatoo, 221

goose, 220

owl, 221

pheasant, 220

pigeon, 221

bone marrow, 221

effect of season, 221

quail, 221

sparrow, 221

swallow, 221

turkey, 220

effect of sex, 220

Artifact (s)

basophil, 92

eosinophil, 76, 91

erythrocyte, 33-34, 36, 39-11

embryo, 98, 100, 115. 117, 121, 129

heat, 36,40

heterophil, 73, 74, 87-89

magenta bodies, 40

mechanical, 36

monocyte, $60,72-73$

nucleus

clear area, 17

extrusion, 31,36

polychromatic

late, 11,33

mid-, 11

pressure, 34

separation from abnormal cells, 16, 33

technic, 33-34, 36, 39-41, 46-47, 72-73, 87-89,

91, 92

vacuolization, 36,40

See also Smudged (squashed) cell (s) 
Ascheim (Dantschakotf, 1908h), 26

Atomic Energy Commission, project, 215

Atypical cell (s)

category of, 16

erythrocyte(s), 31

See also Cell

Avian leukosis complex

lymphocytes, 51, 61

smudged cells, 72

Avian species, blood cells of, 202-221

Azurophilic granule

lymphocyte, 54,56

monocyte, $19,58,69,71$

immature, 60

early, 12

late, 12

mature, 12

relation to magenta granule, 51,71

See also Magenta granule

Balfour (1911), 41

Bankowski (1942), 232

Bartsch et al. (1937), 212

Basichromatin

dissolved in nucleoplasm, 34

outside cell, 34, 168

Basket cell. relation to smudged cell, 72

Basophil (s)

artifact(s), 78.91.92

smudged, 78, 92

circulating blood. 78, 91-92

developmental stages in, 92

count (s)

Arneth, 80, 85

chicken. 216

duck, mallard. 216

goose, Canada, 216

pheasant, ring-necked, 217

pigeon, 217

sex, 216.218

turkey, 220

granule(s) . 78, 91-92

dissolution of, $78,91,155$

in duck. 211

magenta, 13, 78, 92. 197

metachromasia, 91

granuloblast, 10, 13

in spleen. 164

mature, 10. 13, 78, 91-92, 111, 146, 165, 172, 182,

191, 200

mesomyelocyte, 10, 13. 106, 182, 191. 197, 200

metagranuloblast, 10, 13, 197

metamyelocyte. 10, 13, 191, 197.200

nucleus

Arneth count. 84

Arneth index, 85

eccentric, pigeon, 210

failure to stain, $91-92$

promyelocyte. $10,13,92,200$

nucleolus, 197

separation from heterophil promyelocyte, 92
Basophil(s) - Continued

series, 10,13

in bone marrow, 196-197, 200

size, 214

frequency curve, 80

in owl, 210

in turkey, 210

range, 80

technic

aqueous solutions, 91, 155

methyl alcohol and thionin, 191

Petrunkevitch No. 2 and M. G. G., 80

Bathrachoceps attenuatus. See Amphibian

Bausch and Lomb Optical Co.

Poser, Max, 222

Shippy, H. L., 222

Beck (1938), 223

Belling (1930), 223

Benzidine test, Ralph's, 115, 118, 130, 131, 134 technic, 23 1

Berman (1947), 117

Biely and Pahner (1935), 215

$\operatorname{Bird}(\mathrm{s})$. See under scientific or common name

Bizzozero (1889), 141

and Torre (1881), 27, 88

Blackfan, Diamond, and Leister (1944), HI, 64.

Blakemore (1934), 215

Blast cell(s), 9, 11, 24, 50, 56, 66. 128, 129

See also specific cells

Blood

cell

count (s), 211-220

accuracy, 218

Arneth, 80, 84, 85, 220-221

bone marrow, 198, 199, 200

chicken. 216

diurnal effect, 220

effect of altitude, 218

embryo, 113-114

pheasant, 215, 217

pigeon, 217, 219

sex values, $216,218,2\} 9$

value of a single count, 216-217

variahility, $215,217,218$

wild birds. 218

distortion, effect of deluy, 227

from bone marrow, hatched chicken, 181-201

from hematopoietic organs, embryo, 14.1-180

from other avian species, 202-221

See also Cytoplasm and cytosome; Differences;

changes at hatching

bone marrow, 161, 165

circulating blood, 157, 164, 165

spleen, 161, 165 
Blood-Continued

circulating

diflerentiation factor for erythrollasts. 112, 113

emliryo. 10 t-140

cells normally-

alssent, 132

present, 133, 141

cells occasionally present, 133, 139-140

defense reaction in, 133

dorsal aorta. 91. 96, 226-227

heart, $98,100,103,106,139,227$

hatched chicken, 17-93, 111, 157, 164, 165

low leukocyle level, 157, 161.

ratio of hetcrophils to nongranular lenkocytes,

clotting, compared with mammal, 46

164,165

from cubital vein, 18, 108, 111, 139

serum

compared with mammal, 41

granules, stained, 41, 93

smear, gross appearance, 4,15

spot

heterophil. rod to granule, 87

macropliage, 64, 139

from fibroblast, 134

surface tension, 227

teclmic

avian, 222-234

cannula, 139, 225-226, 227

procuring, 225-228

samples, carrying lox, 227-228

smear

cockroaches and flies

damage from, 34

protection against, 39

contaminant. 41. 169.176, 179

cover glass on slide, 229

distribution of cells, 15

embryo. 226-227

infrared lamp, 226, 227, 229

number of slides needed, 84, 217

relative value, $1-3,154$

values. See Buffy coat; Hematocrit; Hemoglobin;

etc.

$\operatorname{ressel}(\mathrm{s})$

erythroblasts

inside, 104. 112, 113

outside, 113

of bone marrow, 151

plugged

effect of splenectomy, 29, 181

in bone marrow, 181

viscosity, 210

See also specific cells

Bloom (1938), 47

Blount (1939a). 215

(1939b), 4l, 42

Bobwhite, erythrocyte count. 218

Bone

epiphyseal center, lacking in hirds 141

vessels of marrow, 151
Bone marrow, 157, 161, 165, 181-201

basophil. 182

series, 191

cavity

l,lood

beginning formation, 152

vessels, 151

cartilage cells in, 153

cells from mesenchyme, 151

development pliases, 151

enlargement, 151

count

Arnetl, 221

differential, 198-199, 200

embryo, 141, 112, 144, 146, 148, 151-155

eosinophil. 146

series, 191

erythroblast, 182

erythocyte, 142, 144, 146, 164

discharge at mid-polychromatic stage, 164

series, 184

granuloblast, 146

granulucyte, 141, 193-197

heterophil, 142, 144, 146, 164, 165, 182

small size. 73

series, 138

lymphocyte, 182

lymphoid nodule, 181

osteoblast, 142.141, 148, 151, 152, 164, 200

osteoclast, 13, 151, 152, 153, 198, 200, 204

mononuclear, 13, 142, $148,153,164$

multinuclear, 13, 142, 198

series, 13

plasma cell, 166, 197-198, 203

primordial osteogenic cell, 142, 144, 146, 148, 151,

serum, stain in, 41,148

thromboblasts, 146, 164, 182, 193

thrombocyte, 146, 191, 193

series, 164, 182, 186

Bradley (1937), 11, 12, 87, 88

Branta canadensis. See Goosc, Canada

Br'cusch (1928), 23. 86, 215

Brilliant cresyl-blue. See Stain and staining

Bryan and Garrey (1935), 233

Bubo virginianus. See $\mathrm{Owl}$ great horned

Buffy coat

cell types in, 232

line difference, 215

scx, 216

significant variability, 217

Bunting

Ameth count, 221

indigo (Passerina cyanea), 202

crythrocyte. 210

Burckliardt (1912), 28, 83, 215

Burmester, Gentry, and Waters (1955). 133

-Severens, and Roberts (1941), 199

Burnett (1908), 215

Buteo borealis. See Hawk, red-tailed 
Cabot's ring. See Erythrocyte

Camera lucida, 14, 212

Cameron (1941), 105

Canary, 33

Cannula. glass, $225-226$

effect of entrance into heart, 139

grinding tip, 225

plugging, prevention of, 226

Cardinal (Richmondena cardinalis), 202

Carpodacus purpureus. See Finch, purple

Cartilage. 151

cell ( $\mathrm{s}$ )

liluerated into marrow. 153, 154

produce stroma, 154

matrix in osteoclast, 153

mitosis. 153

smear, 153

Cell(s)

border

colored

azurophilic bodies in monocyte, 69

thrombocyte, 11, 42, 132, 136

poorly defined, multinuclear osteoclast, 13, 198 ,

broken, erythrocyte, 33,34

204

characteristic(s)

basophil. 13

eosinophil, 12-13, 90

erythrocyte, 11, 27, 48

heterophit. 12.90

lymphocyte, 12, 19, 71

monocyte. 12. 49, 71

multiple, 48, 65

osteogenic cells, 13

plasmocyte, 13

thrombocyte, 11

counts. See Blood. cell

degeneration

thrombocyte, $46.182,186,191.210$

embryo, 103, 106, 131, 132, 136

development, synchronism of parts, 25

division

erythroblast primary. 94

erythrocjte, 26, 31, 118

primary polychromatic, 96,98

heterophil. 188, 196

lymphocyte, 49, 53

monocyte. 49,70

primary osteogenic cell, 142

thrombocyte, embryo, 131

distortion, erythrocyte, $31,33,34$

endothelial, 139

epithelial, 211

epithelioid, 169

fragments, 93. 134, 139, 142, 198

See also Erythroplastid

giant, 17, 41, 117, 120, 154

See also Osteoclast

identification

interference from stained granules. 93, 148, 158 ,

168

value of size, $1 . t$
Cell (s)-Continued

life span

erythrocyte, 32

embryonic, 114

thrombocyte, 45

permeability, weakened by disease, 7

polarity, osteoclast, 198

primordial, in embryo thymus, 170,172

ruptured by pressure, 34,72

shape

amochoid (pseudopodia), erythrocyte, embryonic,

elongated

bipolar, 139

erythrocyte, 31

fibroblast, 131 .

mononuclear osteoclast, 13

reticular cell, 131

unipolar, 139

erythrocyte, 211, 212

poor criterion of age, 26

relation to size of bird, 211

subsidiary criterion of maturation, 27

lynphocyte, 49, 50-51, 62

monocyte, 63

immature, 71

oval

erythrocyte

mature, 11,17 change to round, 26

primary, 120

thrombocyte, 12

embryo, 131, 131

primordial osteogenic, 13

round

basophil, 91

erythrocyte. 23

produced by lysins, 26

granuloblast, 12

heterophil, 73

lymphoblast, 12

See also specific cells

thromboblast, 11, 131

size, $211-214$

basophil, $80,21+t$

effect of fixation, 14, 91

eosinophil, 80, 89, 214

erythrolılast, primary, 116

erythrocyte, 212

primary, 118,127

heterophil, $73,80,214$

impression of, 14,66

lymphocyte, 49, 50, 62, 66, 67, 212, 213, 214

possible significance of, $66-67$

monocyte, 49, 63, 66, 212, 214

possible relation to age, $73,118,211$

thrombocyte, 41, 42, 44. 213

variable

anisocyte, 26, 34, 127

plasmocyte. 14

visual (mental) impression of, 14, 66 
Cell $=1$ - Contirucal

squashed. See Smudged (squashed) cell

striated muscle, 169, 211

type

eategories, 15

totiputent. 9, 166

unidentified in bone marrow, 199, 200

See also Abnomal cell; Aged cell; Bluod, cell: Bone marrow; Development of cells; Differences; specific cells

Charipper and Dawson (1928), 23, 24, 31

Chickadee

black-capped (Penthestes atricapillus), 202

thrombocyte size, 210

Carolina, erythrocyte size, 212

Chicken

breed

Ancona, 62, 63

Benthain, 211

Langshan, 211

Leghorn, Brown, 211

Leghorn, White, Single Cumb, 17, 18, 20, 32, 62,

$63.211 .212,213,214,216$

New Hampshire, 62, 63, 211, 21 2, 213, 214, 215

Plymouth lioek

Barred, 62, 63

Columbian. 211, 212. 213, 214, 215

Rhode Island Red, 62, 63, 216

source

farm stock, 216

Hamilton Farm Bureau, 62, 63

Hy-line Poultry Farms, 62, 63

lowa State College, Geneties Department, 62, 63

Laboratory, 218

No. 2, 17, 32, 39, 40

Regional Poultry Researelı, 17, 216

line $6,211,212,213,215$

line $15,211,212,213,215$

Chondrocyte(s). See Cartilage

Chromatin

elumped, 4

eosinophil

mature, 13

metamyelocyte, 13

erythrocyte

mature, $17,30,210$

polychromatic, 11, 25, 26

primary greater than definitive, 116, 129

heterophil, 12

metagranuloblast, 154, 194.

lymphoeyte

immature, 12

mature, $12,49,53,5 \mathrm{l}, 169$

monocyte, $12,49,70$

plasmocyte

immature, 166, 198

mature, 11 .

thrombocyte

embryo. 11

immature. 11. 45

malure, 12
Chromatin-Continued

dissolved-

by secretions of coekroaehes and flies, 34

into nucleoplasm, 30

extruded from nucleus, 3 t.

granular

osteublast, 13

osteoclast. 13

primordial osteogenic cell, 13

net work (reticulum)

coarse

erythroblast. $11,116,118,128$

basophil metamyelocyte, 13

fine

erythrocyte embryo, 128

granuloblast, 12, 19!

Iymphoblast, 12

lymphocyte, 53

metagranulohlast, 12, 194

monocyte

early immature, 12

mature, 12

punctate

macrophage, 139

multinuclear osteoelast, 13

thromboblast, 11, 128, 130, 131, 161, 191

staining, primary greater than definitive, 127

strands of, $34,158,168,170$

See also Chromosome, avian; Nucleus

Chromopholic. See Nucleus

Chromosome, avian

lag in anaphase, 117

material for study, 117

Petrunkeviteh No. 2, 230

poor in air-dried smear, 53

Chylomicrons, relation to serum granules, 93

Coates (1929). $23: 3$

method, 233

Coccyzus-

americanus. See Cuckoo, yellow-billed

erythropthalmus. See Cuckoo, black-billed

Cockatou, Arnetl count, 221

Cockroach. See Blood, technic, smear

Columbidae, 202

Columliformes, 202

Committee for Clarification of Nomenclature, ete.

Compsothlypidae. 202

$(1948), 194$

Cook (1937), 215 and Dearstyne (1934), 215, 216

Cook-Ponder counts, 84

See also Arneth count

Cottral (1950, 1952). 133

_Burmester and Waters (1954) . 133

Cuckoo

hlack-billed (Coccyzus erythropthalmus), 202

erythrocyte, 210

thromboeyte size, 210

yellow-billed (Coccyzus americanus), 202

Cneulidae, 202 
Cuculiformes. 202

Cullen (1903), 67, 207

Cytoplasm and cytosome

border

acidophilic, pink

monocyte. 69

thrombocyte, $11,42,69$

embryo, 132. 136

crumpled. thrombocyte. emhryo, 11. 132. 136

poorly defined, multimuclear osteoclast, 13, 198

centrosome sphere, 116

clear =pace around nucleus

erythrocyte. 1?

lymphocyte. 80

at side of nucleus

Jympliverte, 52

osteoblast

imnature. 13

mature. 13,152

plasmocyte

immature, 14

mature. 14,166

primary erythroblast, contains centrosone. 116

color after staining

acidophilic, orange, pink

erytlirocyte

mature. 17

polychromatic, late, 25

heterophil. 74,83

spheres. primary erythrolilast. 116

See also Eosinopliil: Heterophil

basophilic. clear. light hlue

eosinophil, mature, 89

monocyte, early immature, 12

plasnocyte, immature. 13. 198

thrombocyte. immature. 11

basophilic. dark. intense blue

granubliast, 12

lymphoblast, 12

osteob]ast, mature. 13

plasmocyte. 198

thromboblast. enbryo, 131

colorless. basophil, 91

gray

erythrocyte

mid-polychromatic, 25. 26

primary, 127

range. 26

mixture of blue and orange. 25

polycliromasia

erythrocyte. 26

monocyte, 58

transition

erythrocyte. 33

thrombocyte, 132

division. See Amitosis: Cell. division

inclusions. 6

macrophage. 139

result of flattening. 6
Cytoplasm and cylosome-Contimued

sliape

bleb formation

lymphocyte. 50-51,51

monocyte, 67

jroduces granulocytes and thrombocytes. 154

thrombocyte, embryo, 130, 131

crescent around nucleus, metagranuloblast

eosinophil, 12

heterop]iil. 12

narruw rin around nucleus. 9

granuloblast. 12, 193, 194

lymphoblast. 12

lymphocyte, immature. 166

thromboblast. embryo, 131, 193

spherical bodies in-

erytlirocyte. 33

primary, 115

stigmata, erythrocyte, 33

structure

ectoplasmic mantle, 117

fractured-

erythrocyte, $11,33,31,36$

primary, 127

glass head, monocyte, 65,68

granules

basophil, 91-92

eosinophi], 90, 208, 209, 210

gramulated and basophilic

Jimphocyte. 51,52

inonocrte, ]ate immature. 12

hraline. 50.51.52,67-68

rarefied area, spindle erythrocytes. 31

reticular, monocyte, 12,68

texture

fine granular, erythrocyte, primary, 127

miform. ervthrocyte. mature, 11

See also Vacuole in cytoplasm and cytosome toxic granules. 87

See also Artifact: Mitochondria: Tacuole in cyto.

Cytosome. Sre Cytoplasm and cytosome plasm and cytosome

Dafila acuta. See Duck. pintail. American

Danschak off (1916a), 130, 155, 165

- (1916h), 73. 141. 166. 169

(1916c). 141

Dantschakoff (1907). 104

- (1908a), 104. 14.1

$-(1908 \mathrm{~h}), 6,8,25-26,104.116,127,128.130$,

$111,152,154,168.195$

$-(1909 \mathrm{a}), 48.73 .87,113.116,141,168$

(1909h). 73.87.151. 153.166

(1931). 139

Dawson (1931), 40

$-(1932), 141$

$-(1933 a) .68 .117 .118 .167$

$-11933 h) .45$

$-(1936 a) .29,105.118 .127 .128$

$-(1936 \mathrm{~h}) .15$

DeEds (1927). 219.233 


\section{Definition(s)}

abnormal celt, 16

artifact, 16

amphinucteolus, 14

cell types, 11-14.

sucleotus

amphinucleolus, 14

karyosome, 14

plasmosome, 14

Dendroica-

striatu. See Warl,ler, hlack-poll

virens. See Warhler, black-throated green

Denington and Lucas (1955), 227, 228, 231

Denys (1887), 88

Development of cells

characteristics, erythrocyte, 11, 25

in bone marrow, 181-201

in circulation of hatehed chicken

basophil, 92

eosinophil. 91

erythrocyte. 21-30

heterophil, 74, 86

lymphocyte, 53-54

thrombocyte, $44 \quad 15$

in embryo, 104-140

in hematopoietic organs, $141-180$

in vitro, erythrocyte. 29

Diesem (1956), 46.80), 215

Differences

abnormal cells and artifacts, 16,33

birds and mammals

hone and bone marrow formation, 141, 151

erythrocyte

generations in embryo, 104

immature in circulation, 24

nucleus, 30

physiology, 29

erythropoiesis, maturation. 30

giant cells. number of types. 153

hematopoietic reactivity, 29

intravascular and extravascular, 113, 1 .1

Iymph nodes, 167

recover'y from injury, 29

serum particles. 41

smudged cells, number, 39

spleen, histology, 156

thrombocyte, fragility, 42

thymus. striated muscle, 169

yolk sac. 141

blood rahes, sexes, 218

carly immature monocrte and metagranuloblast, 167

embryo

erythroblast and thrombohlast, 115, 120

thrombocyte. primary and late, 131, 132

ergthrocyte

mature and immature

oxygen consumption, 29

specific gravity, 29

definitive and primary, 104-105

coarseness of chromatin pattern, 116
Differences-Continued

erythrocyte-continued

lefinitive and primary continued

cytosome

fracture, 127

size range, $12 \%$

nucleoli. number. 116

nuclear staining, 12 \%

vacuoles. 116

granules, heterophil and serum, 89

hetcrophil and basophil promyelocyte, magenta

granules, 92

heterophil and cosinophil, 83, 90. 196, 207, 208, 209

lymphocyte and monocyte, 48,49

lymphocyte and thrombocyte. nucleus. 46

megalohlasts, anemia, primary and definitive. 116

spleen, before and after hatching. 156

Differential count, :3/

accuracy with number counted, 217

hasophit. 92

hone marrow, 198-199, 200

chicken. 216

duck, 216

embryo circulating blood. 133

embryonic erythrocyte, 105

goose, 216

high variability, 219

influenced by smudged nuclei, 72-73

sex, 216

Disease, 111,33

bacterial infection in egg, 133

bircls. 84

poultry, 15

See also Lymphomatosis

Distribution of structures

artifacts on slide, 33

cluring division

magenta granules in lymphocyte, 53

yolk plates in erythrocyte. 105

See also Blood, technic, smear, distribution of cells

Doan (1932), 8, 61

Cumningham, and Sahin (1925), 115

Dog. 26

Dominici stain. See Stain and staining

Domm et al. (19.13). 218

- and Taber (1946), 218

Dorsal aorta

embryo blood from, 94, 96

technic for procuring, 225-227

See also Blood, vessel

Dorst and Mlils (1923), 46

Dove

eosinophil, 210

ervihrocrte count, 218

hemoghbin, 218

Laboratory, 202

thrombocyte size. 210

Down. 179

sheath cell. 178,180

See also Feather, sheath cell

Downey, 93 and Nlckinlay (1923). 6f 
Drawing(s)

high power, 14

limitations, 191

low power, 14.15

scale of measuring. 1

Dryobates-

pubescens. See Woodpecker, downy

villosus. See Woodpecker, hairy

Duck

baldpate (Mareca americana), 202

eosinophil. 207.208

heterophil, 207.208

cell count, variability. 215

eosinophil. 207, 20: 210

erythrocyte, crossed cells, 210

heteroplit, 208

lymphocyte

magenta bodies, 210

reactive cell, 210

size, 67

green-winged teal (Nettion carolinense). 202 eosinuphil. 210

Laboratory, differential count. 219

mallard (Anas platyrhynchos) .202

basophil, 211

differential counts. 216

eosinophil, 207. 208. 219

ery throcyte, nuclens, 23

heterophil. 207.208

reticulocyte, 27

technir. 231

pintail. American (Dafila acuta), 202

eosinophil, 210

ruddy (Erismalura jumaicensis). 202 eosinophil, 207

shoveller (Spatula clypeata), 202

eosinophil, 210

thrombocvle size, 210

Ectoplasmic mantle of primary erythrolulast. 117. 118

Ehrlich (Dantschakoff, 190sb), 26

Elvehjem (19.31), 231

Embryo

allantois, 111

area opaca. 11

area pellurirla, 31

blood, 10 ]-」 10

dorsal aorta, 94, 96, 118

heart. 98. I01). 103

island, 10].

removal of, 226-227

gonadal ridge, 139

inculation age. 105. 112, 226,

primitive streak, $10 \mathrm{t}$

removal of, 226

splanchnopleure. 139

slained serum, 11

vitelline membrane. 113. 226

yolk sac, 101. 128

See also Bone marrow; Spleen; Thymus: specific

Emmel (1936), 7.83.92
Endodermal wandering cell. 1:39

Endothelium

heart, 139

phagocytic

liver, 131)

spleen, 139

tissue. 9

yolk sac, 10 I

Environment, effect on immature cells, 7. 17, 112. 113

Eosin-azure. See Stain and staining

Eosinophil, :90

Arneth count

Canada goose, 35,220

chicken, 81,85

lubes. 90

Arneth index

Canada groose, 81, 85, 220

chicken, 85,90

abnormal cell. 9]

birds, except chickens, 207, 208, 210

count is)

chicken. 216

duck, 216, 219

goose, $216,219,220$

in hemucytometer, 233

pheasant, 217

pigeon, 219

sex. 216.218

turkey, 219

cytoplasm, pale blue staining, $76,89,90$

depot, 155

develupmental stages in circulating blood, 76, 91

differences from heterophil. 90, 91, 196. 207. 208

dove, 210

effect of Petrunkevitch No. 2, 30, 90, 207

granules. 76.89

refractile, 90

relation to maturity of cell. 90

rod shape, 207,209

structure, $90.196,208.209$

types. 209

granuloliast. 10, 12

spleen, 161

emhryo, 156. 160

in bone marrow, 196

in spleen, 161, 165

leukemia. 208

mature, $10,13,76,89.90,116,158,200$

metagranuloblast, 10,12

bone marrow, 191, 196, 200

embrin, 156, 160

mesomyelucyte, 10, 13, 76, 91, 196, 200

melamyelocyte, 10, 13, 76, 91, 196, 200

promyelocyte, $10,12,200$

series. 10.12

in bone marrow, 200

size. $76.89 .90,214$

frequency curve, 80

spherical hulies, 33

smudge cell, 76.91

terminology. 89

See also Granule 
Epiphysial center, 141

Erdmanu (1917), 181

Erismatura jamaicensis. See Duck, rudly

Erythroblast(s), 10, 192

blast cells compared, 9, 192

characteristics, 11, 26, 112,192

cmbryo, 31, 114, 158

hemoglobin acquisition, 10., 112

later generations, 98, 100, 114, 128 in spleen. 156

mitosis, 122

nucleus. poorly stained, 122

thrombolblast, compared with, 128

in bone marrow, 181, 182, 184, 191. 192, 200

in circulating blood, $23,21,94$

in spleen, 157, 160

intravascular and extravascular, 113

primary

basophil. 118

cell size, difference, 116,118

changes during incubation, 1 13, 11 1, 118

chromosome, 117

disappearance from circulation, 112, 113

division. 118

mitosis, abnomal. 117

first appearance, 112 at 22 to 29 somites, 31

giant, 117

lyemoglobin

little, 26

precocious, 112,129

like thrombocyte

clumping, 130

origin, 130

smudged, 94 .

term, synonymous with megaloblast, 116

resembles large lymphocyte, 24

terminology, 192

Erythrocyte(s). 17-41, 155

abnormal, 20, 30-33, 34

aged, 29,30

artifact, $33,36,39-41$

atypical, $27,30-33,34$

bone marrow, 181, ]82, 184, 192, 193

Cabot's ring, 39,40

count (s)

birds, except chickens, 218. 219

brooding vs. laying hen, 218

chickens. 216

diurnal effect, 218

effect of -

altitude, 218

season, 218

sexes, 216,218

variability, 217

crossed cells, 210

debris on, 146

developmental stages

circulating blood, 24-30, 164, 210

tissue culture, 104, 116
Erythrocyte(s) - Continued

effect of-

antimalarial compounds, 33

fixation, 94

Petrunkevitrh No. 2, 80

splenectomy, 29

embryo, 192

artifact. $98,100,103,121,127$

bone marrow. 1.12, 144. 146

cell, description, $115-130$

changes during incubation, 113,114

developmental stages in circnlating blood, 94. 96,

$98,100,101-130$

differential count, 113, 114

division, 9 1,96

generations, 104, 114, 128-130

life span. 114

mature. 103, 113. 112, 144

polychromatic

early, 100. 124

mitosis, 128

late, 100, 103, 106, 113, 114, 124, 128, 129, 142

mili-, 100, 106. 113, 114

suleen, 157. 160

mitosis, 157

generations of, 9, 101-105, 114

giant, 17,117

hemoglobin and basophilia, 29

immature, 23

in hone marrow, 182

life span, 32

line differences, 215

mature. 10, 11, 23, 108, $111,146.182 .184$

cytopllasm texture. 11

iu bone marrow, 200

normal, 17-24, 29

typical. $17,18.20,23,211$

deviations from, 17, 18

multipolar. 17

nncleus, 20

age of. 11

aged. 23.30

donble, 23.27

size, 211.212

squashed, 18

origin, intravascular, 101, 113, 128, 141

orthochromatic, 23,26

percent rise and fall. 113

polychromatic, 24, 25, 26, 27. 192, 198

artifact, 33,144 .

basophil. synonym, 24

early, 10, 11, 23, 181, 182, 181, 192, 200

late, 10, 11, 23, 26, 108, 182, 184, 192, 200

atypical, 23

mitosis, 157, 160

mid- 10, 11.23. 26. 184, 192, 200

enters circulation, 164

mitosis. 160

primary, 115-120, 127-128

alnormal, 120

amitosis. 128 
Erythrocyte(s)-Continued

jrimary-continued

artifact, 100

cytoplasmir frartures. 127

ectoplasnic mantle. 117

nuclear vacuole, 115

smudged, 98

cytoplasm, texture, 127

development, precocious. 129

disappearance, 113.114

dominant cell, 113

generations of yolk plates in Amblystoma. 105

giant. ]20

in bone marrow, 200

mature, 100, 103, 106, 113. 111. 120, 121, 127,

mitnsis, 115

nucleus, 127

polychomatic

early, 96, 100, 113, 118

late. 98. 100. 103, 113, 118.127

mid. 96. 98.113.118, 128

terminology, 117

series. 9

size, 118,127

structure, 115-118. 127. 128

technic, damage, 115

protoplasmic process, 41, 115

ratio with thrombocyte, 42,14

method, 232

separating stages, 27

series, $9,10,11,15,184$

in bone marrow, 200

slape

distorted. 20, 115

round and mature, 184

spherical bodies, 33

stigmata, 33

size, 210.211 .212

terminology, 21, 25

types, Bizzozero and Torre, 27

typical. 17

See also Cytoplasm and cytusome: Erythroblast:

Nucleus; Reticulocyte: etc.

Erythroplastid, 20, 31, 34, 36

birds, other than chicken, 210

mid-polychromatic erythrocyte, 96

primary erythrocyte, 120, 127

survival value for cell, 3$]$

Evolution

granulocytes, 73

neutrophiloid cell from heterophil, 86

process of erythroplastid fomation, 31

Extravascular origin

all leukocytes, 141

errthrocytes. 113

thrombocytes. 42

Eyepiece. See Microscope, ocular

Falcuniformes, 202

Feather

barbs, 178,180
Feather-Continued

barbules, 178,160

diagram, 178

sheath cell, 169

carrier of pathogens. 179

contaminant

in hair, 179

on slides, 169, 179

dimn, 176

keratin, 178 granules, 176

Fennel (1947), 128. 15]

Fergusm, lrwin. and Beach (1945), 215

Finch, purple (Carpodacus purpureus) 202 eosinophil, 210

Fixation and fixatives

air-dried fixation, 2, 4, 7, 1.1, 231

effect on size of cell, 1.1.91

methyl alcohol, 14, 87, 91, 191. 197, 230

Petrunkevitch No. 2

effect on-

basophit, cytoplasm, 91

chromosome. 117

eosinophil, 90, 207, 209

heterophil, 83, 87, 195, 207, 209

thrombocyte, 132

formula. 230

nucleus. 80, 83, 90. 92. 230

perinuclear space, 17

lechnic. 230

rate of penetration, 167

wet fixation, 1. 14, 230

with May-Grünwald Giemsa, 230

Zenker formol, 1

Flemister and Cunningham (1940), 114

Fly damage to blood smear, 34

Folic acirl. effect on reticulocytes. 28

Fool (1913), 17

Forkner (1929), 17, 43, 199, 215

Frank and lougherty (1953), 5 I

Frequency distribution, thrombocyte, size, 41

Fringillidae. 202

Furth. Scibold, and Rathbone (1933), 39

Gage and Fish (1924). 93

Galliformes, 202

Garrey and Bryan (1935), 215

Gauger et al. (1940), 219

Giemsa stain. See Stain and staining

Goordall (1909), 17.215

Goodwin (1950), 233

Goose. Canala (Branta canadensis), 202 count (s)

Arneth, 220

differcntial, 216

variability. 215

easinophil, 210

erythrocyte, 210

Cordon (1926), 42

Graam (1931), 28, 231 (1935), 32 
Granular leukocyte, 73-92

in bone marrow, 193-197

See also Basophil; Eosinophil; Heterophil

Granule(s), body(ies), substance(s)

azurophilic

lymphocyte, 51

monocyte, $49,54,69$

immature, 12, 60, 71

mature, 12

basophilic

monocyte, immature, 12

osteoclast, multinuclear, 13

central granule of heterophil rod. See Heterophil

cytosome

basophil. 91

eosinophil, 89. 208, 209

in vacuole, 40

plasmocyte, mature, 14

reticulocyte. 11.27

eosinophil

on a reticulum, 76

size range, 76

See also Eosinophil, granules

eosinophilic osteoclast, 13

hemokonia. 93

keratin, 176

metachromatic, 91

nucleus. See Chromatin; Nucleus

ser1um. stained. $36,41,89,93.148,158$

soluble

basophil. 78,91, 92

mesomyelocyte. 13

heterophil after Petrunkevitch No. 2. 87

toxic granules, man. 87

See also Mlagenta granule; Specific granule; specific

Granuloblast(s), 6, 9, 10, 50, 142, 116, 196

basophil, 10, 13

bone marrow, 154, 156, 188. 194, 200

eosinophil, 10,12

granulocyte lines have common, 12, 194

heterophil, 10, 12, 71, 86, 200

mitosis, 144

nucleolus not visible. 169

nucleus, 197

number reduced, spleen, 156

resembles lymphoblast, 194

spleen, 160

Granulocyte(s), 114, 193-197

bone marrow. 92. 93. 181. 199

embryo, 142, 144, 146. 154, 156

circulating blood, 165

development. number of stages, 193-194

embryo. circulating blood, 133

mature, 142, 165

terminology, 194

thymus, 169

See also specific cells

Gramulopoiesis, 194

less in thymus than in spleen, 168

Gray, Snoeyenbos, and Reynolds (1954), 4.5
Guinea hen

eosinophil, 207

ervthrocyte. 210

heterophil, 207

Gull

cell size and age, 212

Larus vidibundus, 212

Haff (1914), 141

Hallihurton (1886), 93

Hamilton (1952), 141, 155

Hamre (1952), 191

- (personal communication), 73, 71, 89

-and McHeury (1942a), 217

-and McHenry (1942b), 215

Hancox (1916), 153

Harne, Litz, Zinmmerman, and Davis (19.15), 32

Hartman (1925), 42, 45

Hassall's corpuscle, 169

Hatching, blood changes, 157, 161-167

Hawk

Cooper's (Accipiter cooperi), 202

erythrocyte, 210

red-tailed (Buteo borealis), 202

Hayden (1929), 215

Heart

blood from, 98, 100, 103

effect of glass cannula entering, 139

smear from endothelial surface, 139

Heath-hen, erythrocyte-thrombocyte ratio, -12

Heinz (Dantschakoff, 1908b), 26

Hematocrit, 2]1.

chicken, 216

variability, 217

line difference, 215

sex, 216

compared, 218

Van Allen tube, 217

centrifugation, 232

cleaning, 232

diluent, 232

technic, 232

Hematology

approach to study of, 7-8

field of, 32

schools of. 9

Hematopoiesis

cartilage cell, 154

lymphocyte, 47

large, 18

monocyte, 47

theories

associated with terhnic, 3-1

unitarian, 9, 18

yolk sac, 154

Hematopoietic organ(s), embryo

bone marrow, 1 1]-155, 161

kichney, 141

leukocytes retained until hatching. 111

liver, rarely hematopoietic, 141

ovary, $1+1$

pancreas, 111 
llematopoietic organ (s) - Continued

placenta in monkey, 141

spleen, 1.1, 155-157. 163, 164

striated muscle fibers, between, 141

thymus, 141

walls of major vessels, 141

Hematopoietic system. labile in birds, 29

Hemin, preparation, 231

Ilemocytoblast. 166

Hemocytoblastosis, 7

Hemocytometer, counting chamber, 31, 88

Wiseman method, 232, 233

Hemoglobin

benzidine test. 115

Ralph's technic, 231

development, tissue culture, 10 l.

erythroblast, 24,26

erythrocyte stages

polychromatic, 26

poor criterion for, 25

precocious accumulation, 129

independent of-

basophilic staining, 29, 118

cell differentiation, 117

level, $21.1-220$

chicken, 216

embryo blood, 114

sexes, 216

compared, 216

sparrow, $211-212$

variability, 217

primary erythroblast

extravascular, 113

precedes cell differentiation, 112

takes on, 112

primary erytlirocyte, 117

precocious accumulation, 104

similar to, 192

reduced after splenectomy; 29

technic, 231-232

conversion factor, 232

wavelength, $23 \mathrm{l}$

thrombocyte, absent from early embryo, 131

Hemokonia

relation to serum granules, 93

what is included, 93

Hemorrhagic syndrome, 45

Heterophil(s), 73-74, 83-89

abnormal cell, 87

aderfuacy of staining, 195

artifact. $73,71,87-89$

bone marrow, 142, 141. ] 16, 15., 155, 182, 188,

clumping, 154

$191-196$

compared with eosinophil, 83, 87-88, 90, 207. 208

countis)

Arneth, 81, 85

birds, except chickens, 220-221

relation to mortality, 85

sex values. 220

bone marrow, 200

dominant cell, 199
Heterophil(s) - Continued

count (s) - continued

chicken. 216, 219

duck, 216, 219

embryo. 11 1, 133

gouse, 216

hemocytometer, 233

pheasant, 217

pigeon, 217, 219

diurnal rhythm. 220

turkey, 219

developmental stages. 7t, 86, 193-197

terminology, 194

duck, 207,208

effect of-

citric acid, 88

irradiation, 73,86

Petrunkevitch No. 2, 80, 83, 195, 209

evolution, 73

granules

difference from serum, 41.89

magenta, 86, 195

mesomyelocyte, 151

on erythrocyte, 146

granuloblast, $10,12,74,86$

immature, 74

index, Arnetl. 81, 85.90

mature, $10,12,73-74.80,83-86.111,144.146 .154$,

$155,163,172,182,188,191.200$

mesomyelocyte, $10,12,71,86,141,146,151,158$, 160, 188. 191, 195. 200

metagranuloblast, 10. 12, 188, 191, 200

metamyelocyte, $10,12,142,155,188,195,196,200$

nucleus

chromophobic band, $20,32,87$

criteria for counting lobes. 84

lack of staining, 83, 90, 195, 207

promyelocyte, 10, 12. 74, 86, 142, 154, 160, 170. 188,

ratio to eosinophils

195. 200

guinea hens, 207

kingfishers, 207

mallard ducks, 208

$\operatorname{rod}(s)$

arrangement in cell. 71

artifact, $73,87-89$

as debris

erythrocyte, 146

osteoclast, 198

central granule, body, 86, 89, 195, 210

absent, 86, 89

replaced by vacuole, 74

significance, 83

development, 195

dissolved in cytoplasm, 74, 83, 87, 88. 89, 90 significance, 83,88

duck, 207

effect of-

citric acil, 88

fixation, 88

formalin. 88

malarial parasite, 89 
Heterophil (s) - Cuntinued

$\operatorname{rod}(s)$-continued

effect of-continued

Petrunkeritch No.2. 83. 87. 209

salt solution, 88

trichloracetic acid, 89

water, \&ó

hemokonia, relation to. 93

in tissue section. 87

literature on, 88

metachromasia, I95

orange. eosinophilic spheres, $86,154,156$

shape. 73. 74, 80,208

turkey, 210

See also Eosinophil, granules

series, $10,12,188,200$

shape, 73

size, 73,90

frequency curve. 80

range, 80,214

smudged, 74.89, 172

spleen, 163, 164, 165

teminology, 86, 89

turker, 207, 209. 210

Hetherington and Pierce (193I), 18 I

Hevesy and Ottesen (1915), 32

Hewitt (1940), 28, 89

$-(19.12) .207 .219$

Hoi, 71, I42

abnormal, 60,72

ahsent from-

lymphocyte, 49

monocyte, 58

association with rosette, 69

definition, 69

orange spheres in monocyte, 12. 49, 52, 60, 69, 7I, 80

juesent in-

monocyte. $12,49.52,58,69$

plasmocyte, 166, 197-198

present sometimes in-

late immature monocyte, 12

lymphocyte, 49.7I

Homology

basophil, bird and other vetebrates, 91

erythrocyte, mature, lird and mammal, 28

11 ydrocortisone, increased Iymphocytes, 5 I

Iguana tuberculata, phagocytic thrombocyte, 45

Illumination, darkfield, 3

Immature cell (s)

appearance, different in organ of origin. $7,16.86$

circulating blood. post hatching, 23, 21

all ages, 24

compared with mature erythrocytes

oxygen consumption, 29

specific gravity, 29

eosinophil, 76, 91

heterophil, 74, 86

in mammals, suggestive of pathology, 24

normal cells, 15

wide variety, 15
Immature cell(s)-Continued

See also Embryo: Hematopoietic organ: specific

Inclusion(s)

intracytosomal

appear to be, 6

ill macrophage, 139

See also Granule; Mitochondria; Specific granule: Vacuole in cytoplasm and cytosome

intranuclear

appear to be, 6

margination, 4

vacuole, 23,195

lncubation age, 105

rise and fall of erythrocytes, 113.114

time table, 112

Infection

embryo, Plasmodium gallinaceum, effect on dif-

toxic granules, 87

ferential count, 133

Infectious mononucleosis, 64

Intravascular-

environment, 113

origin of-

erythrocyte, 104, 113.128, 141

thrombocyte, $128,14 \mathrm{I}$

In vitro, 2

differentiation of erythrocytes, 29

See also Tissue culture

In vivo, 2

test for amitosis, $3 \mathrm{I}$

Irradiation

effect on-

blood, small heterophils increased, 73

erythrocyte, 24,27

immature heterophils, 86

separating lymphocytes, and monocytes, 48

thymus, increased plasnocytes, 166

Isaacs (1925), 33

(1928), 7

Johnson and Conner (1932), 51

- and Lange (1939), 219

Jones (1943).8. 116,192

$-(1917), 115,116$

(1918), 7

1919), 194

Jordan (1936). 181

$-(1937), 131$

$-(1938) .8 .167$

-and Robeson (1912), 29, 181

Juhn and Domm (1930), 218

Junco

erythrocyte count, 218

slate-colored (Junco hyemalis) , 202

Kakara and Kawasima (1939). 218

Kalabukhov and Rodionov (1934), 2 I I

Kasarinoff (1910), 45, 47

Keller (1933), 211

Kelly and Dearstyne (1935), 215

kemnedy and Climenko (1928). 73 
Keratin

bodies in down-sheath cetls, 176, 180

process of keratinization, 179

Kindred (1910), 8, 114

Kingfisher

eosinophil, 207

heterophil, 207

Kinglet, golden-crowned (Regulus sutrapa), 202

Kirschbaum and Downey (1937), 1, 8

Kitaera (1939), 211, 218

Knisely et al. (1917), 31

Knowles et al. (1929), 41

Kracke and Garver (1937), 8. 72. 93

Kyes (1915), 139

$$
(1929) .39,73
$$

\section{Laboratory}

erythrocyte, 17, 23

quarantime, 179

smudged cells, 72

See also Chicken, source

Larus ridibundus. See Gull

Leishman's stain. See Stain and staining

Leptochromatic. See Nucleus

Lesbouyries (1941), 86

Leukemia

cell modified in, 113

in fowl

lymphocyte, large, 50

smudged nucleus, not diagnostic, 72

in mammal

lymphocyte series from lymphoblastic leukemia,

man. toxic granule, 87

mouse, smudged cell, 39

resemble immature cells, 112

simulation of, 141

See also Avian leukosis complex; Lymphomatosis

Leukocyte(s)

count (s)

chicken, 216, 219

methods for, 232-234

sex, 216, 218

varialitity, 217

granular, 10, 73-92, 193-197, 207

in buffy coat, 232

nongranular, 10, 47-73

origin, extravascular, 141

spherical bodies, 33

types in avian blood, 47, 73, 86, 88

See also specific leutocytes

Light

infrared, 226

drying slides with, 227

microscope. 222-225

tungsten arc, 222

Liver

effect of splenectomy, 2)

macrophage from, 139

Loewenthal (1930), 86
Lura= (1910). 1.30

$-(1916), 61,87,134$

(1919). 6.1. 181

(1950), 181

$-1951\} .181$

-and Breitmaser (19.19). 1:1

Craig. and Oakluerg (1919), 61, 181

- and Denington (umpublished data), 215, 218

and Denington (1956), 48, 195

-and Hermann (1935), 4

- and Oakberg (1950), 64, 181

-and Riser (1945), 4 .

et al. $(195 \mathrm{t}), 61,156,181$

Lundquist and Hedlung (1925), 83, 88, 90

Lympholifast (s), 9, 10, 12, 164

nucleolus

alsent, 169

lost. 160

thrmus, 5 $1,170,172.17+1$.

rare in older gland, 167

transition from mesenchyme, 168

Lymphocyte(s), 9, 10, 12, 18, 45, 47, 48. 50, 62, 146.

abnornal, 54, 56, 61-65

165,216

chromophobic areas, 56

hypertrophy and vacuolization. 64

magenta bodies, 54,64

age, $53-54$

area, $66,212,213,214$

ehicken

different breeds and stocks, $62,212,213$

similar to other avian species, 210

count (s)

birds. wild, 219

chicken. 216

duck, 216, 219

goose, Canada, 216

pheasant, ring-necked, 217

pigeon, 219

Laboratory, 217

sex, 216,218

turkey, 219

cytoplasm

blebs. $31.50,51.54,80.155$

antiboly formation, 50

hyaline. $50,51.54$

hypertrophy, 56

magenta bodies, 54

compared with azurophilic bodies, 54

structure, $49,52,71$

develojment, 174

to macrophage, questionable, 64, 131

to monocrte. questionable, $4 \overline{7}, 48$

See also lymphocytogencsis

developmental stages, 10

in bone marrow, 199, 200

in circulating blood, 53-54

in spleen, 165, 166

in thymus, 160. 169. 172

effect of-

fixation, 80

splenectomy: 29 
Lymphocyte(s) - Continued

immature, 10, 12. 53, 163, 166, 167, 169, 170, 172,

$174,199,200$

in blood spot, not a macrophage precursor, 131

in bone marrow, 155, 199, 200

formation due to splenectomy, 29

in spleen. $164,165,166$

in thymus, $166,168,169,172,174$

in tissue culture

degenerated. 181

no cell division, 101

no differentiation. 181

infectious mononucleosis, 64

irradiation, 48

large, $9,24,48,50,56$

range, 66

rare in differential count, $24,48,50$

magenta granules. $47,50,54$

in mitosis, 53,54

in wild birds. 210

mature, $9,10,12,111,163,167,168,172,174$,

199,200

normal, 50-53

not a hlast cell, 48

medium, 9, 10, 12, 48, 50, 163, 167, 168, 169, 172,

an immature cell, 166, 167

$174,182,191$

range, 66

mitosis, 49, 71,170

monocyte, comparison with, 47, 48, 52-53, 71, 214

nucleocytosomal ratio, $49,51-52,53,68,71,214$.

nucleus

chromophobic, $32,40,56$

mitosis, 54

naked, 163

larger than thrombocyte, 210

position in cell, 51, 71

reticular, 56

shape, $49,52,62,71$

size, $50,62,214$

frequency distribution. 66

staining poor, 168

structure, 53.71

relation to differentiation, $54,166,167$

reactive cell

cytoplasm vacuolated, 56

macrophage, no transition to, 134

wild birds, present in, 210

series, 10, 12, 161, 200

in bone marrow, 200

in thymus, 166. 174

with monocyte, 47,40

shape, $49,50-51,71$

blebs, 51, 54

lobes, 50, 51

pseudopodia. 51

size, $49,50,53,62,71$

chicken, breeds, 212, 213, 214

distribution, 66

lack of significance. $66-67$
Lymphocyte(s) - Continued

small, 9, 10, 12, 48, 50, 66, 80, 163, 167, 169. 172,

$174,182.191$

dwarf

different from small lymphocyte, 130

related to thrombocyte, 130

microlymphocyte, 181

produce other cell types, 169

stem cell, $48,104,155,166,169$

thrombocyte, separation from, 45

Lymphocytogenesis, lymphopoiesis, 166, 168

in spleen, 164, 165

in thymus, 54, 167-169

nucleolus absent, 168

reticular cell precursor. 168

Lymphoid foci. abnormal, in various organs, 181

Lympholeukocyte, same as monocyte, 47

Lymphomatosis, 86

blood picture. not an indicator of, 45

in enbryo, 133

neural, 45, 51, 85

ocular, 51. 85

relation to-

Arneth count, 85

lymphoid foci in spleen, 181

resistance, 211,215

susceptibility, 211, 215

visceral, 51, 85

See also Avian leukosis complex

l.ysin, action on erythrocyte, 26

McDonald (1939), 154

McGuire and Cavett (1952), 219

Machado (1951), 233

Macrophage

hlood spot

fibroblast, precursor for, 134

tymphocyte, not a precursor for, 134

cytoplasmic spleres, pinched off, 134 .

embryonic, 103, 139

common, 7 to 12 days' inculation. 131

in circulating hlood

magenta granules, 134

response to infection, 133

too large for capillaries, 134

vacuoles, 134

yolk sac. 130, 13I, 139

nucleus, large, 134

granulation delicate, 134

endodermal, 134, 139

endothelium, 139

hypertrophied lymphocyte, compared with, 64, 134

in bone marrow. 200

in spleen, 139, 140, 164, 165

in thymus, 170

inclusions, 139

nucleolus present, 139

post mortem effect. 139, 140

See also Phagocyte

Magath and Higgins (1934), 17, 27, 41, 67, 86, 208,

215. 219. 231 
Magenta granule, body, ring. sphere

associated with--

avian leukosis. 64

health of bird, 65

lymphocyte, $52,53,64$ pathologic significance, 64.65

chromidial type. 131

granule. different from-

azurophilic granule, 49

magenta ring, 195

in myelocyte, description of, 195

new term. 54

occasionally present in-

embryo thrombocyte, 131

heterophil mesonyelocyte, 12

monocyte, 71

present in-

hasophil promyelocyte, 13, 196-197

heterophil

mesomyelocyte, 154

promyelocyte. 12, 74. 156, 188, 194

lymphocyte

ahnormal, 49, 54

in mitosis, 53.54

wild birds. 210

mononuclear osteoclast. 118

multinuclear osteoclast, 142,153

primordial osteogenic cell, 112

relation in-

azurophilic body, 54, 71

orange spheres, 195

See also Heterophil: Lymphocyte

Magnification

high power, 4, 14

low power. 4. 1.1, 15. 17, 32

optical. 14

projected, 14

scale, 4

Mlainland et al. (1935).66

Makinodan (prersonal communication), 160

Nlammal. mammalian. man

Arneth count. 221

basket cell, 72

blood. 25.73.8.1

erythrocyte

aged cell. 30

maturation delay, 30

proloplasmic process, 41

reticulocyte, 28

giant cell, 153

leukemia cells resemble chick immature cells, 112

lymphocyte, 49

azurophilic granules. 64

stages from lymphoblastic leukemia, 53

monocyte and lymphocyte from same organ, 167

neut rophil, 86

hand and juvenile cells, 155

toxic granules, 87

)latelets. 41

serum. fewer granules than in birds, 41

smudged cells. mouse, 39

spleen, 156
Mareca umericana. See Duck, haldplate

Marrin 1 1954), 199

Nast cell. 47.91

Maturation rate, erythrocyle, 29-30

llature-

basophil, 10, 13, 78, 91, 111, 146, 155, 172, 182,

specific granule, 197

191. 200

eosinophil, 10, 13, 76, 89, 158, 200, 208

erythrocyte, $10,11,17,18,20.23 .25 .26,28,29$,

$108,111,146,182,184,198.200$

later embryonic. 103, 106, 113, 114, 124, 142, 144

primary, 100, 103, 106, 113, 120, 127, 142

heterophil, 10, 12, 18, 20, 17, 73. 74, 111, 14t, 146,

$154,155,163,164.167,172.182,188,199.200$

lymphocyte. 10, 12, 18, 48. 50, 51, 111, 163, 166.

167, 168, 172. 171. 191. 199, 200

macrophage. embryo. 139

monocyte, 10, 12.49.5\%, 72. 111. 200

osteohlast. 10. 13. 112, 152.166

Hlasmocyte, 10, 14. 198, 199. 203

thrombocyte. 10, 12, 18, 33, 42, 45. 111. 186. 191.

embryo, 136

193. 200

Naximow (1909).8. 104. 116

-and Bloom (1931), 47

May-Grïnwald Giemsa. See Stain and staining

Nedawar (1941). 167

Megakaryocyte. $41,42,153$

Megaloblast. 115, 192

produces thromboblast. 130

synonymous with-

erythroblast. 116

karyoblast, 9

Nehner (1938). 211

Mleleagrididae, 202

Veleagris galloparo. See Turkey, domestic

Mesenchyme. 104

nucleolus present. 168

tissue. 9. 153.168

Nesomyelocyte. 156

hasophil. 10, 13. 106. 182, 191, 197, 200

eosinophil, 10, 13, 76, 91. 200

combined with promyelocyte. 10, 13

heterophil, 10, 12, 74, 86, 91, 144, 116. 154. 157.

$158,160,188,200$

Netachromatic granule, 91

heterophil, 195

Metagranulolilast(s), 142, 144, 154, 156. 158.160.

182. 194, 197

hasnphil, 10. 13

combined with promvelocyte, 10,13

cytoplasm, vacuolated, 194

early inmature monocyte, different from, 167

eosinophil. 10, 12, 156, 191, 196, 200

granuloblast, changes from, 194

heterophil, 10, 12, 86, 92, 156. 191. 194. 196, 200

nucleus. eccentric, 151

Metamyelocyte, 182

basophil, 10. 13, 200

eosinophil, 10. 13, 76, 91, 160, 196. 200 
Metamyelocyte-Continued

heterophil, 10, 12, $86,112,155,188,195,200$ term, 196

Methyl alcohol. See Fixation and fixatives

Nichaelis and IVolfe (Doan, 1932).61

Michels (1938), 91

Microblasts. 130

Microburner, making cannula, 225

Nicrocyte, $3+$

dwarf lymphocyte, 130

related to thrombocyte, 130

Nicroscope

condenser, 222. 22 4,225

alignment, 223

effect of lowering, 223

separable lenses, 225

use in separating leukocytes and thrombocytes,

diaphragm, 222, 223

lamp

bulb, frosted blue, 224

diaphragm, 223. 224

filter, $222,223,224$

illumination

eritical, 222

Köhler. 222

lens, 222

light, 222-225

llare, 224

mirror, 222. 223

front surface, 223

objective, 11, 15

numerical aperture (N. A.), 224

parcenter. 223

parfucal, 223

ocular, eyepiece, 11, 15. 222

pinhole, 223

phase on heterophil. 87

use of, 222-225

Microscopy

darkfield illumination, 3

electron. 2

phase, 3

Mitochondria, mitochondrial

in mitosis, 115

in reticular cells, 169

loss in--

lymphocytogenesis, 51, 169

osteoblast. 152

primary erythrocyte development, 118

spaces

ahsent, erythrocyte

early polychromatic. $2-1$

mid-polychromatic, 11

present

embryo thromboblast, 131

erythroblast, 11, 129

erythrocyte

early polychromatic. 11, 21, 192

mid-polychromatic, 25,26

monocyle. early immature, 71

osteoclast, mononuclear, 13
Mitochondria. mitochondrial--Continued

spaces-continued

present-continued

jlasmocyte

early immature, 13, 198

late immature, 13

primary erythroblast. 115

Mitusis

primordial osteogenic cell, 13

cartilage cell, 153

embryo

erythrocyte, 129

in circulating bluod, 118,129

thrombublast, 134

thrombocyte, 131

erythroblast, 156. 192

heterophil metamyelocyte, 180

immature cell in spleen, $15:$

in bone marrow, 200

late in differentiation process, 191

lymphocyte, 53

polychromatic erythrocyte, early, 100

primary erythroblast. 91

abnormal, 117

chromosomes, 117

primary polychromatic erythrocyte

earty, 96

late. $98,157.160$

mid-, 96, 160

primordial osteogenic cell, $1+2$

reduction of yolk plates, Amblystoma, 105

technic for. 230

Mitotic periodicity, lacking in embryo, 105

Mjassnjedoff (1926), 166, 197

Monoblast, I69, 200

not seen, 12

possible monoblast, 163

Monocyte(s) . 10.47,65-73

artifacts, $60,72-73$

cell

abnormal, 60

area, 66,212

count (s)

chicken, 216

farm stock. 216, 219

duck, 216, 219

goose. Canada. 216

pheasant, ring-necked, 217

pigeon, 217,219

sex, 216,218

turkey, 219

division. 49, 70, 71

shape $49,63,67-68,71$

size, $49.63,6567,71$

chickens, different breeds, 214

frequency distribution, 67 range, 66

cytoplasm

azurophitic granules. 58, 69. 229

blebs, 67

color, 58,68

ground-glass effect, 65, 68 
Monocyte(s) - Continued

cytoplasm-continued

Hof, 49, 71, 80

definition, 69

orange spheres, $68,69,71$

vacuolar spaces, 69

hyaline mantle, $58,67-68$

specific cell inclusion, 69

struclure, 68-69, 71

derelopmental stages

in circulating blood, $60,70-72.167$

amueboid cell, 60,71

in spleen, 163, 167

fixation. Petrunkevitch No. 2, 80

immature, $70-72$

early, 10, 71, 163, 200

late. $10.71,163,200$

lymphocyte

arises in same organ, 167

compared with, 49, 65, 66-67, 70. 71. 21.1

continuous series between, $47-18$

mature. $10,111,200$

normal, $58,63,65-70$

typical, 58

metagranuloblast, different from, 167

nucleocytoplasmic ratio, $49,58,68,71,214$

nucleus

area, 66,214

lilobed, 58,70

double, 58,70

indented, 58,70

position, $19,68,71$

shape, 49, 63. 69-70.71

size, 63

frequency distribution, 67

range, 66

structure, 49.70,71

owl. 210

series. 10

continuous with lymphocyte, 47

in hone marrow, 200

smudged, squashed, $45,60,72$

Nonocy tosis. 165

Murray (1932), 104, 116

Muscle cell, striated, 211

Myeloblast(s), 9, 10, 12, 163

Myelocyte(s)

early thrombocyte. compared witl, 191

eosinophil, 91, 164

extrayascular origin, 141

heterophil, $7,83,91$

osteoblast, similar to, 152

terminology, 194, 197

tissue culture, no dirision, 181

See also Mesomyelocrte; Metamyelocyte: Promyelocyte

Natt and Herrick (1954), 87

Neave $(1906), 41,208$

Vecturus, 31, 40, 15, 68, 117, 167

Nesterow (1935), 26
Nellion carolinense. Sce Duck, green-winged teal

Neutrophil, heterophil without granules, 86

Nice et al. (1935), 218

Nittis (1930), 33

Nongranular leukocytes, $47-73$

lymphocytes. 50-65

monocytes, 65-73

theory of origin, 17

Nonidez (1920), 141, 165

Normoblast, no equivalent stage in birds, 28

Nucleocytosomal ratio

eosinophil, 76

erythroblast, primary, range, 117

lymphocyte, $49,51-52,66,68,214$

monocyte, $49,66,68,214$

Nucleolus (i)

absent or not visible

erythrocyte

definitive mid-polychromatic, 11

mature, 17

granuloblast, $6,12,74,169,194$

lymphoblast, 6, 12, 169

lymphocytogenesis, 168

monoblast, 169

thrombocyte, large embryo, 11

multiple

macrophage, 139

primary erythroblast, 9, 116, 117

plasmosome. 4, 11, 157

in reticular cell, 169

present

erythroblast, $6,11,24,56,169,184$

embryo, 128

primary, 9, 116. 118

macrophage, 139

osteoblast

immature, 13

mature, 13

osteoclast

mononuclear, 13

multinuclear, 13, 153

reticular cell, 168

thromboblast. $6,56,164,169,186$

embryo, 131

present sometimes

erythrocyte, polychromatic

early. 11. 192

late, 24

mid-, 24

thrombocyte, early immature, 11

visibility increased-

by karyolysis, 139

by weak staining of nucleus. 129

Nucleoplasm

lymphocyte, colorless, 53

monocrte, 70

tinged hy dissolved basichromatin, 34

Sce also Nucleus

Nucleus(i)

age of cell. measured hy, 23, 25, 30

artifact

basophil, 92 
Nucleus(i) - Continued

artifact-continued

heterophil, 73, 74, 195, 196

vacuoles in. 134

boundary

indistinct

embryo

erythroblast, 129

thromboblast, 134

heterophil, promyelocyte. 12, 74, 195

metagranuloblast. 156-157

indistinct sometimes, heterophil mesomyelocyte.

chromatin

extruded, 34

magenta body, possibly related to, 131

strand, 34, 158, 170

chromophobic

band

erythrocyle, $20,32,34,36$

heterophil, 20, 87

lymphocyte, 40,56

cause unknown, 32,40

reaction, 32

squashed, 40

comparison

cliromatin networks, 6

external and internal appearance. 4, 6, 7

shapes. 23

dead. 176, 179

elimination of, valuc to cell, 32

erythrocyte, typical. 17, 23

deviation from. 17, 23, 34

fixation effect, 80

basophil, 92

ghost, 179

granules of basophil mask, 7.92

inclusion, 4

vacuole, 23

karyolysis, reveals nucleolus, 139

karyorrhexis, 120, 127

leptochromatic, lightly stained, open

chromophohic. 32,34

erythrocyle, mature, 1], 17, 23, 211

monocyte, immature, 60

multiple

embryo thrombocyte, 136

erythrocyte, mature, 17, 23, 24.27

monocyte, 70

osteoclast, 142, 152, 153, 198, 204

primary erythrocyte. 127

naked. 146, 155, 158, 170

nonstaining, 7

nucleoplasm

nonstaining, 26

stained, dissolved basichromatin, 34

pachychromatic, darkly stained, dense

erythrocyte, 11, 17. 20, 23, 210, 211

aged, 11

monocyte, immature, 60

plasmocyte, late immature, 14
Nucleus(i) Continued

pachychromatic-continued

thrombocyte

embryo, 11

mature. 12

position in cell

central

basophil metamyelocyte, 13

erythrocyte, 17

granuloblast, 154

lymphocyte, 52

monocyte. mature, 68

osteoclast, mononuclear. 13

eccentric

basophil promyelocyte, 13

eosinophil metagranuloblast. 12

erythrocyle, 20

leterophil metagranulohlast. 12

lymphocyte. 52

metagranuloblast. 154, 156, 194

monocyte

inmature, 12

mature, 68

osteoblast, 152

immature. 13

plasmacyte, 14, 198

thromboblast, 131

lymphocyte and monocyte compared, 49

protrusion, erythrocyte, 17, 18, 20

pycnotic

erythrocyte, $20.23,30$

primary, 127

thrombocyte, 103

sliape

aged erythrocyte. 23

associated with chromatin clumping: erythrocyte,

bean shaped, heterophil metamyelocyte, 12

$17,23,211$

constricted

basophil. 92

eosinophil metamyelocyte, 13

erythrocyte

mature, $17,18,20$

primary, 120

monocyte, 49, 53, 70

elongated, erythrocyte, mature. 23

indented

eosinophil metamyelocyle, 13

erythrocyte

late polychromatic, 26

mature, 17, 18. 20. 23, 24

lymphocyte. 52

monocyte mature, $12,49.58,70$

lohed

Arneth counts. 80, 220-221

basophil. 13.80.92

eosinophil. 13. 80

erythrocyte, 27

heterophil, 12.74, 80

criteria for counting, 84

monocyte, 70

oval, erythrocyte. mature, 11, 17, 23

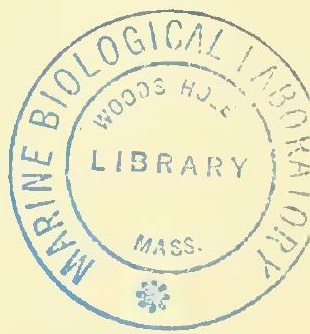


Nucleus (i) -Continued

shape-continued

round

erythrocyte, 18, 20

late polychromatic, 11

lymphocyte. 49. 52

monocyte. 49

osteoclast, multimuclear. 13

thrombocyte, mature, 12

varialility of -

eosinophil metanyelocyte, 13

erythroryte, late polychromatic, 26

lymphoryte. 62

monocyte. 63

size

ervthrocyte, 211,212

large. osteoclast. multinuclear, 13

lymphocyte, 62, 66, 213

monocyte, 63. 66, 67, 214

small

erythrocite. 18.20

plasmacyte. late immature. 14

thrombocyte, smaller than lymphocyte. 43

smudged. squashed. 18, 34, 1.16.170, 172, 182

appearance, 39-10

erythrocyte, 36,39

heterophil, 74

on adjacent cells, 39

stained poorly

erythroblast. embryo, 129

revealed nucleolus, 129

ervthrocrte

emhryo, 122

primary, 120

feather sheath cell. 179

heterophil, 74. 83, 90

lymphoblast, 168. 174

thrombocyte, embryo, 131

structure

differences among metagranuloblasts, 194

erythrocyte, embryo, 128

impression of, 70

inside and outside, 40

lymphocyte, 49, 52.70

so-called large. 56

monocyte. 49,70

See also Amitosis: Clromatin; Mitosis; Nucleocyto. somal ratio: Nucleolus; specific cells

Numerical aperture (N. A.). 224

Nuthatch, white-breasted (Sitta carolinensis). 202

erythrocyte nucleus. 212

thrombocyte size. 210

Oaklyerg (1919), 64, 181

$-(1950), 181$

(1951), 64, ]81

Objective. See Hicroscope

Ocular. See Nicroscope

Olson (1937). 34.215 (1952).64. 84

Orange stained. Ser Heterophil; Monocyte; Osteo-
Orten (1934). 28. 29

- and Smith (1934). 27

Osgood (1935), 64

$-(1938) .25$

—-and Ashworth (1937). 8.9.72.87, 127

-Baker. and Wilhelm (1934), 27

- and Wilhelm (1931), 231

Osprey, erythrocyte, 212

Osteoblast(s), 164

count, 200

development from primordial osteogenic cell. 152

immalure, 10

large young. 142. 1.14. 152

mature. 10,112

resembles plasmacrie. I60

small. 152

term. 152

variation with heterophil, 164

Osteoclast (s)

acidophilic granules in. 1.18, 152, 204.

binuclear, 142

counts. 200

development from primordial osteogenic cell. 152

giant cell, only one type in bird marrow, 153

indented ly granulocyte. 142

magenta spheres, $148,153.198$

mononnclear, $10,13,142,118,152,153,164$

multinuclear. 10. 13. 142. 153, 198. $20 \mathrm{t}$

nucleolus, 153

polarity, 198

series. 10.13

term, 152

Osteocyte(s)

series, 10.13

term, 152

Osteogenic cell. See Primordial osteogenic cell

$\mathrm{OW}$

Arneth count. 221

basophil smaller than in chirken, 210

eosinophil. granule. 210

great horned (Bubo virginianus), 202

monocyte large, 210

thrombocyte larger than in chichen. 210

Oxygen consumption, greater in immature cells than in mature, 29

Pachychromatic. See Nucleus

Palmer and Biely (1935a) , 215, 21 \%

-1 19351,1.215

Pappenheim (Dantschakoff, 1908b), 26

Paridae, 202

Passer-

domesticus. See Sparrow

montanus. See Sparrow

Passeriformes. 202

Passerina cranea. See Bunting, indigo

Passerine, cosinophil like that of chicken, 210

Pathology

air sac, white spots. 51

blood poisoning, 85 


\section{Pathology-Continued}

crop

atonicity, 51, 65

impaction, 65

dehydration, 65, 85

emaciation, 61, 65, 85

enlarged heart. ascitic fluid, 85

gasping, 51, 65

lymphomatosis

neural, paralysis. 65,85

ocular. iritis. gray eye. 51,85

visceral, 65. 35

prolapsed uterus. 51, 85

urates in kidney, 51

See also Avian lentosis complex; Lymphonatosis

Payne and Breneman (1952), 181

Peabody and Neale (1933), 27, 231

Penthestes atricapillus. See Chickadee. black-capped

Petrunkevitch (1933), 230

Petrunkevitch No. 2. See Fixation and fixatives

Phagocyte, phagocytic

embryo. response to infection, 133

endothelial cells, 139

thrombocyte. 45

See also Mlacrophage

Phasianidae. 202

Phasianus colchicus. See Pheasant. ring-nccked

Pheasant

hasophil, 92

hlood viscosity, 210

count (s)

Arneth. 220

differential, 217

eosinophil. 219

variability, 215

eosinophil. 210

ring-necked (Phasianus colchicus), 202

thrombocyle size, 210

Phenylhydrazine hydrochloride, 29

Phloxine

affuity for heterophits and eosinophils. 233

in Wiseman's method. 232. 233

Photomicrography, adjustment of contenser. 225

Picirlae. 202

Piciformes, 202

P'igeon

basophil, 210

count (s)

Arueth, 221

differential, 217, 219

paratyphoid, 219

eosinophis 219

erythrocytc, 218

in bone marrow, 199

sexes compared, 213

thrombocyte. 219

variability, 215

effect of splenectomy. 29, 181

erythrocyte. 210

crossed cells, 210

hemoglohin. sex difference. 218

hemolysis, 39
P'igenn-Continued

Laboratory, 202

macrophage from endothelium, 139

reticulocyte, $27,2:$

staining, 231

serum. lipochrome pigment, 93

thrombocyte, 42,45

confusion with lymphocyte, 210

value of smear teclunic, 154

Pipilo erythrophthalmus. See Towhee

Planimeter. 212

l'lasma. See Serum

I'lasma cellis) , 197-198

See also Plasmacyte

Plasmahlast(s). 10.13

identity, 197

Plasmacytels)

characteristics, 166

immature

early, 10, 13, 163, 197, 198, 203

late, 10.13, 163.20:3

in bone marrow, 166. 197, 200, 203

in loose comnective tissue, 197

in spleen. 166,197

mature. 10, 165. 203

resemhles osteoblast. 166

series. 10, 13. 200, 203

Plasmolium gallinaceum, increased heterophil num-

ber, 133

Platelets, 41

clumping, 15

See also Nlegakaryocyte; Thrombocyte

Poikilocytosis. 31.34

Polychromatic

color

acirlophilic and basophilic stains combined, 24 ,

terminology, 117

measure of development, 25

series, 26

See also Erythrocyte

Precipitate on slide, resembles reticulocyle granules, 28

Premyelocyte, 92

Price-Jones (1910), 33

Primary-

ervthrohlast. See Erythroblast

erythroplastid. See Erythroplastid

Primordial-

cell. See Cell

germ cell. 139

larger than blood cells, 140

Prinordial osteogenic cell(s), 9, 10, 13

count, 200

distinct cell type, 152

in mitosis. 112, 114

magenta granules, 144, 148

nucleolus, 152

produces-

osteohlast, 13. 152

osteoclast, 13, 152

plasmablast. 13, 197

resembles reticular cell. 168 
I'rimordial osteogenic cell(s) - Continued

smudged. squashed. 146, 148, 152

stem cell for-

plasmoblast, 13, 197

vacuoles. 148

Problems for study

absolute numbers of cell types in cmbryo, 114, 115

aging in erythrocites. 30

Arneth index for numal chicken. 85

cellular reactions and mortality, 65

central granules (Always present in heterophil

rorls? ) 74,93

chromophobic nucleus. 32

chromosomes of primary erythroblasts. 117

common identity of vacuoles in smears and sections in primary erythroblasts. 116 contribution of plasma to differentiation of cells, 112 ,

cytology of incipient lymphomatosis. 45

113

defense mechanism of embryo, 139

equivalent of toxic granules in avian heterophils. 87

extrusion of nuclear contents. 31

granulocytes of cmbryo (Do they hecome definitive cells?). 165

lucterophil rods (Are they faithfulty preserval in

heterophils under phase microscope, 87

tissue sections?) . 87

magenta granules, association with-

nucleus. 71

pathologic conditions in lymphocrtes, 61

microchemistry of vacuoles in prinary erythrocytes.

normal reticulocyte values, 27

116

normalcy of lenkocyles in emliryo circulation. 133

plivsiology of thrombocyte disruption, 42

plasmosome nucleolus during mitosis. 157

preservation of basophil granules, 197

production rates in hematopoietic organs, 154

reactive thrombocyte, significance, 15

relationship of azurophilic and magenta granules. 71

separation of -

alnormal cells from artifacts. 33

immature from medium lymphocytes, 166

significance of-

erythroplastid formation. 31

nuclear density in erythrocytes, 23

size of heterophil, relationship to aging, 73

terhnic to preserve thrombocytes, 132

thrombocyte degeneration unrler phase microscope.

thrombocyte development from sections. 15 -

47

Progranulocyte. 9

Promyelocyte, 9, 156. 194

atypical. 168

basophil, 10. 13. 78, 92, 197, 200

combined with metagranuloblası, 10, 13

eccentric nucleus, 156

eosinophil, combined with mesomvelocyte. 10. 12

hetcrophil, 10, 12, 74, 86, 142. 154, 15\%, 160, 188,

Protopterus ethiopicus, 167

200

Pseudoeosinophil, 47
Pycnosis, pycnotic

nucleus, 30

erythrocyte, $20,23,30$

inromliocyte, 45

vacuole formation. 30

Quail, Arueth count, 221

Quarantine. Laboratory, 179

Rabbit

erythrocytes injected into. 26

immature cells of chicken and. 29

Ralph (1941), 231

Ram (1949), 233

Rat. reticulocyte. 27

Reactive cells

lymphocyles, 56. 131

wild species, 210

thrombocytes. 38.45 .46 .47

Red blood cells. See Erythrocyte

Rees and Ecker 119231. 233

Riees-Ecker methock. 233

Regional Poultry Research Laboratory, 21 1, 212, 213,

Regulus satrapa. See Kinglet, golden-crowned

Reptile(s)

Isuana tuberculata, phagocytic thrombocyte, 45 reticulocyte, 28

turtle

arrangement of rods in heterophil. 74

box. nucleolus in immature beterophil, 6

Resting amoeboid cell, 139

- wandering cell. 139

Reticular cell(s)

acidophilic cytoplasm, 169

in bone marrow, 200

in embryo ressels, 139

in spleen. 164

in thymus, 169, 172

precursur for -

lymphocyte. 16 t. 168

macrophage, 134

plasmohlast. 13

resembles

mesenchyme. 168.169

primordial osteogenic cell, 168, 169

small nucleus. 169

Reticular tissue. 9. 169

Reticulocyter(o). 10,11,23

chicken, 28,29

color. tawny, 193

effect of

folic acid, 28

splenectomy, 29

fish. 28

frog. 28

granules. 11.23.28

all stages of erythrocyte development. 28

change with maturity, 27

percent

chicks. 28

children. 27 
Reticulocyter(s)-Continued

percent-continued

luck, mallard. 27

pigeon, 27

rat, 27

pigeon, 28

primary erythrocyte: 127

reptile. 28

respiration of, 29

separation from mature cells, 29

staining. 230-231

effect of time, 28, 231

Reticuloendothelial cells, spherical bodies, 33

Rhian. Wilson. and Moxon (1944), 215

Richards (1938).222, 224 .

$-(1919) .222$

- $(1954), 222$

Richardson (1937). 28

Richmondena cardinalis. See Cardinal

Richter (1938), 65

Riddle and Braucher (193\%). 218

Roherts. Severens, and Card (1939), 114, 133

Rohertson et al. (1947).28

Robin (Turdus migratorius), 202

eosinophil. 210

Rod(s). See Eosinophil; Heterophil

Rouleaux formation. ahsent from bird blood, 15

Ryerson (1943), 6, 73, 74, 83

Salin (1920), 101. 112, 154, 192

Salt solution

damage to -

emliryo blood cells, 226

primary ery throhlasts, 115

for chicken blood

different ages of embryo, 226

eflect on heterophil, 88

Locke-Lewis, 226

Scale magnification, 4

Schechtman (1952). 227

Schilling (1929). 85

Schoger (1939), 42. 45, 219

Schwarz (1946), 17

Separation

ahnormal and atypical cells, 16

eosinophils and heterophils. 83

lymphocytes and monocytes, 70.71

Serum, plasma

differentiating factor in, 112, 113

granules

mask underly ing cells. 41. 148. 156. 158

precipitate. 168

relation to hemokonia. 93

size relative to yolk spheres, 93

stained. 36. 89, 148, 155, 156, 158, 170

lipochrome pigment, 93

Seyfarth (1927), 28

Shattuck (1928), 26

Shaw (1933), 220, 221

Shipley (1916), 41
Similarity (ies)

hasophil and lymphocyte, 211

birds and mammals

erythrocyte protoplasmic processes, 41

specific gravity for mature and immature cells.

function of platelets and thrombocytes. 41

monocytes from lymphogenic organs, 167

chromosome lag in primary erythroblasts and neo-

eosinophil and heterophil, 83

plastic cells, 117

ery throblast and thromboblast. 128

failure of nucleus to stain, 131

primordial osteogenic cell and reticular cell, 168

smear of spleen and thymus at 35 days 169

thrombocyte, degenerated, and a lymplocyte, 131

Siskin. pine (Spinus pinus) . 202

Sitta carolinensis. See Nuthatch, white-breasted

Sittilae, 202

Slide

contaninant on. 41,179

heated, 36, 40, 41

infrared lamp, use of. 226,227

remove moisture, 227

Smear. See Blood. smear

Smolker (personal communication). 139

Smudged (squashed) cell(s), 39, 170. 132

down-sheath cell, 176, 180

erythroblast, primary, 94

erythrucyte, 36, 40, 103

primary, 98

with chromophohic bands, 40

in bene marrow, 15.5, 191, 199. 200

in spleen, 157. 160

influence on differential count, $72-73$

mature-

basophil. 7:, 92

eosinophil. 76

heterophil, 74, 89

monocyte, 72-73

Sulium cantharidate, 45

Spaces in cytoplasm. See Mitochondria: Vacuole in eytoplasm and cytosome

Sparrow

Arneth count, 221

eastern tree. erythrocyte size, 212

erythrocyte

area. 212

number, 212

hemoglobin, 21 1. 212

Passer-

domesticus. 2]1

montanus, 2l]

Spatula clypeata. See Duck, shoveller

Specific granule(s), body(ies), substance(s)

absent

eosinophil promyelocyte. 12-13

heterophil

metagranuloblast, 12

promyelocyte, 12

thrombocyte. cmbryo, 131 
Specific gramule(s) - Continued

basophil. 91-92

comparison of -

immature and reactive thromboczte. 46

Irmphocyte and monocyte. 49

discolution of

in basophil. 91-92

in heterophil, $74,87-89$

effect of fixation, $87,88,90$

basophil, :(0), 91

eosinophil. 80

Jeteromhil, 80

thromburyle, 80

metachromatic.91

present

liasophil

mature, 13

mesomyelocyte, 13

metamyelocyte. 13

eosinophil

mature. 13.89 .90

variations in form. 76

mesomyelocyte, 13,91

metamyelocyte. 13,91

heterophil

mature, $12,73,74.90$

mesomyelocyle, 12

metamyelocyte, 12

thrombocyte

Jate immalure, $11,45,46$

mature. 12

description. 42

number, 43

reactive, 38

present sometimes

azurophilic granules. monocyte. 49

magenta hodies, lymphocyte. 49

thrombocyte

medium embryo. 11

mid-inmature. 11

thrombocyte, embryo. 132

atypical. 132

staining, 234

See also Basophil: Eosinophil: Ileterophil

Specific gravity, erythrocyte, mature and immature compared, 29

Speidel (1932). 31

Spencer leens Co.. Richards, O. W., 222

Spindle cell (s)

erythrocyte, 30, 31

bipolar, 3.4

unipolar. 31 .

thrombocyte, 41. 130

Spinus pinus. See Siskin, pine

Spitta $(1920), 222,224$

Splcen. T.50. 115

basophil, 164

changes after hatching. 157. 164, 165

cmbryo. 155-157, 158. 160

eosinophil, mature, 158

erythroblast, 158.160
Spleen-Continuerl

embryo-continued

erythrocyte, polychromatic, 160

granulohlast, 160

reduced, 156

granulocyte, dominant cell. 156

heterophil

mesonyelocyle, 158. 160

promyelocyte. 160

metagranubblasts. 158.160

ruptured cells. 155. 15:, 160

serum. slained. 158

thromblulast, 160

thrombocyte. 158

time of development, 155

eosinophil, 161, 165

granulublast, 164

erythrocyte, degenerating. 30

granuloljlast. 154

heterophil. 163. 164

discharge of. 164

Jymphocyte

dominant cell. 164. 165, 166

immature. 163

mature, 163

nakerl nucleus. 163

time of appearance. 161

lymphoid fori. 18]

macrophage. 139, 140, 161

monohlast. 163

monocyte. immature, 163

plasmreyte, 166

immalure. 163

serum. stained. 41

thrombocyte. naked nucleus. 163

thymus. similar at 35 days. 169

Splenectomy

effect on hematopoietic organs. 29

pigeon, 29

Squashed cell(s). See Smudged (squashed) cell

Stain (s) and staining. 228-231

luenzidrine test. 115. 118. 130. 131. 131

technic. 231

brilliant crestl blue

eryhrocyte, stignata, 33

reficulocyte, 230-231

thrombocyte and lymphocyte separation. 233

white cell count, 233

Dominici. 26

eosin-azure. 26

Giemsa. 26

hematuxylin and azure 11 eosin, 1

janus green stain on thromburyte, 43

Leishmamn's, 33

Loeffler's melhylene blue, reticulocytes. 231

MacNeil's tetrachrome, 211

May-Crünwald Giemsa

after henzidine test. 118.134

after Petrunkeritch No. 2, 80. 83, 117. 132. 195,

20 万. 209.230

hone marrow, 193. 195 
Stain(s) and staining-Continued

May-Grünwald Giemsa-Continued

circulating blood adult. 52, 53, 54. 69. 74. 80, 83, 87, 207, 209,

embryo, 3.117.118.134.193

immatule celts. $7,14,168$

seruin, 41

technie. 229

Wright's stain, compared with, 14, 17, 11, 131,

$16 \%, 193.229$

neutral red. thrombocyte. 43, 49

penetration pour, 6, 7,92

phluxine, Wiseman's method. 232, 233

polychromatic effect. 24, 25

thionim, 91. 191. 197, 230

Wright-Giensa. 74

heterophil. stages of development, 195, 230

technic. 230

Wright's stain

after benzidine test. 231

lutk methorl, :37. 229

cireulating blood adult, 7, 14. 23, 33, 49, 52, 69. 73. 74. 78, 83 $87.90 .92 .193 .207,211$

embryo. 3. 131. 134. 168

preparation, 228

rack method, 87,229

serum. 41

variation in samples, 22:-229

See also Reticulocyte: specific cells

Starling (Sturnus vulgaris), 202

erythrocyte, nueleus, 23

Striated musete cells in thymus, 169

Strigidae, 202

Strigiformes, 202

Sturgis and Bethell (1943). 215

Sylvidac. 202

Sturnus vulgaris. See Starling

Substantia granulı-filamentosa. 28

Sugivama (1926). 31. 128. 130, 131, 131.226 (1938).85.221

Sundberg (1947). 168

Swallow. Arneth eount. 221

Sylvijdae, 202

Taber et al. (1943).218

Takagi (1931). 11.5

$-(1932) .115$

Tate and Vincent $(1932$ ). 33

Technic(s)

artifaetis). 33-34.36. 39-41. 46-17. 60, 72. 74 .

$87-89,91.92$

avian species, 16, 222-234

hlond samples, box for handling. 227-228

dorsal aorta. blood from. 226-227

erythroeyte, counting. 234

heart, blood from. 227

hematocrit, 232

hemoglobin, 231-232

infrared lamp, use of, 226, 227
Techuic(s)-Continued

smear method

drying blood slides, 226, 227

value of, 154

warning slides before using, 226,22 \%

staining, 22:-231

thrombocste eount. 232

white cell counts, 232-234.

Rees-Ecker metlıorl. 233-234

Wiseman"s method. 232-233

See also Blood: Mieroseope: Stain and staining

Terminology, 8-14

chromophobic nucleus. 32.40

eosinophil and heterophil. $\$ 6.89$

erythroblast. prinary, complieated by hemoghbin.

101

erythroeyte

hased on one ehief characteristic, 27

later embryonic generations, 105

mulychromatic. 117

primary generation, 105

gramular leukofyte. 73

gramulocyte series, 194

heterophil. 73

megralolilast. 8

myelocyte. 194

nongranular lenkucyte. 47

staudardized. 8. 194

See also specific cells

Thigmocres. 41

Thionin. See Stain and staining

Thrombohlast(s), 9. 10, 11, 146, 155

crtoplasm, basophilic. 11

einhryo. 96, 98. 106. 115, 160

chromatin, punctate, 128.134

disappearance from circulation, 131

emliryo erythroblast. eomprared with, 128

megaloliast, origin, 130

mitosis, 134

mucleus

sucleolus present, 131

staining incomplete. 131,134

primary generation. 131

series, siuctural, 130

typical. description, 131

in hone narrow. 16I, 165. 1:32, 186. 191. 193. 200

erythroblast. resembles, 193

nucleus

nucleolus present. 164

punctate chrmmatin, 164, 191. 193

Thrombrocytels). 18, 27, 38, 41-17, 108, 111, 133. 157

age groups, 15

artifact. 46

eount (s)

chicken hreeds, 2]6. 219

in lone marrow. 198. 200

in cireulating blood. 216

method. 232

ratio

blood and hematopoietic organs. 157

to erythroeyte. $42,44,232$ 
Thrombocyle (s) - Continued

count (s)-continued

sex, 216

variability, 217

degeneration, 38, 42, 16, 146, 164, 1:2, 191

orange margin, 16

effect of fixation. 80,167

embryo, 11.96, 98, 100, 103, 106, 115.128, 130-133,

binuclear, 136

150

blebs pinched "ff, 131

degeneration of. 131, 132

hlebs, 136

margin, 136

crumpled. 132, 136

stains with eosin, 132, 136

nucleus. 136

developmental stages, $11,38,134.136$

large enthryo, 11, 136

medium embryo, 11. 134. 136. 160

small embryo, 11, 136, 160

differentiation. 131

greater in later than in early embryo generations, 132

generations

later embryo, 131-132

primary, 131

hemoglolin alsent. 131

in spleen, 156

intravascular urigin, 128

large, 10,11

medium, 10, 11, 96, 98, 100, 157

mitosis, 13]

primary erythrol,lasts, appear later than, 130

-erythrocytes, common origin with, 130

series. 10,11

structural, 130

shape, oval. 134

lime of appearance. 131

small. 10, 11. 98, 100, 103, 106, 157

specific granules, 136

atypical. 132

change with later generations, 132. 136

first appearance, 131

erythrocyte, compared with, 41, 42

fragility, evolution of 42

inmature. 111. 19:.200

early, 10, 11, 182, 186, 191, 193

late, 10, 11, 186, 193

mid-, 10.11. 186, 193

in bone marrow. 161, 181, 186, $191-193,198$

in buffy coat. 232

in circulating blood. 41-47.96

life span, 45

lymplocyte, separation from, 233, 234.

mature, $10,12,38,42,108,111,186.191$

naked, 163, 191

origin

intravascular, 128, 141

lymphocyte, not from, 130

theories, 42, 130
Thrombocyte(s)-Continued

phagocytosis, 45

reactive. $38,45,46,50$

series, $10,11,200$

shape, variability, 43

size, 41-12, -14

chicken, 212, 213

wild species. compared with, 210

specifie granulels), 42, 43, 80

comparicon of immantre and reactive, 46

in racuole(s), turkey, 210

number, 12, 43

slaining of. 233-23.1

staining

janus green. 13

neutral red, 43

pigeon, 210

ty]ical, 38,42

Thromboplastid, 4.2

Thymus. 7.50, 115. 172, 174

emliryo thynus, 170

serum stained from. 4]

granulopoietic function hess than in spleen. 168

Hassall's corpuscles, 169

irradiation. plasma cells increased, 166

lymphoblast, 166. 174

lymplusyte

immature. 53. 172. 174

mature, 172. 174

lymphocytogenesis. 167-169, 174

monocite development, not abserved, 169

smear from thymus like that of spleen. 169

striated muscle cells, 160

thymocytes, 167

thinmus cortex from lymphucytes, 169

Tissue culture. 2

area opaca. 11

Iymphocyte

degencrate, 181

milosis absent, 181

monocyte. 68

osteoclasi. 153

primary erythroblast, differentiation, 116

primitive streak. 104, 116

Toryû $(1930) .29$

$(193]), 29$

Towhee (Pipilo rrythrophthalmus), 202

Trichloraretie acid. effect on heterophil rod, 88

Troje (1)antschakoff. 1908b), 26

Tufted timouse, erythrocyte count. 21:

Turdidae. 202

Turdus migratorius. See Riobin

Turkey

basophil. 210

count (s)

Arnell, 220

differential, 219

domestic (Meleagris galloparo). 202

eosinophil, 207. 209

heterophil, 207, 209 
Turkey-Continued

thrombocyte

size, 210

specific granule, 210

Twisselman (1939).215

Underbill (1932), 167

Vacuole(s) in cytoplasm and cytosome artifact, 40

basophil

metagranuloblast, 13

promyelocyte, 13

eosinophil, netagranulol,last. 12, 194

erythroblast

basophil, 24

primary, 116

erythrocyte, mature

effect of heat. 36

overlying objects, 39,40

heterophil metagranuloblast, 12, 194

pronyelocyte, 12, 74, 188

rod, 74

lymphocyte, reactive, 56

macrophage, 134, 139, 140

cytoplasmic spheres. 134

osteoblast, immature, 13, 152

osteoclast

mononuclear, 13, 152, 153

multinuclear, 13,198

plasmocyte

immature, 198

early, 13, 166

late. 14

mature, 198

primordial osteogenic cell, 13

thrombocyte

embryo, 131, 132

large, 11

medium. 11

small, 11

immature

early, 11

late, 45

mid-, 11. 44

reactive, 38,44

specific granule in, 210

Venzlaff (1911), 219

I'ermivora peregrina. See Warbler, Tennessee
Vezzani (1939), 218

Vireo, red-eyed (I'ireo olivaceus), 202 eosinophil, 210

Vireonidae, 202

Vireo olivaceus. See Vireo, red-eyed

Vulture, easinophilic polymorphs, 208

Warbler

black-poll (Dendroica striata), 202

black-throaterl green (Dendroica virens), 202

Tennessee (Vermivora peregrina), 202

yellow-throated, erythrocyte nucleus, 212

Wassjutotschkin (1913), 169

- (1914), 169

Waters (1945), 215

Weidenreich (1911), 33

Weiss and Fawcett (1953), 68

White cell (s). See Leukocyte; specific cells

Wickware (1947), 219

Wills (1932), 27

Wilson (1925), 31, 128

Wintrobe (1933), 210

$-(1952), 233$

Wirth $(1950), 29,32$

Wiseman (1931a), 232

$-(1931 \mathrm{~b}), 53,167$

$-(1932), 53,66,167$

Wiseman's method, 232-233

reliability. 233

Wislocki (1943), 141

Woodpecker downy (Dryobates pubescens), 202 laairy (Dryobates villosus), 202

red-headed, erythrocyte nucleus, 212

Wright (1930a), 29, 30

- (1930b) , 29, 30 and Vandlstyne (1931). 29

Wright's stain. See Stain and staining

X-cell, 169, 179

See ralso Feather sheath cell

Yeast cell. contaminant on slide, 41

Yolk granules. 93

_plate(s), in Amblystoma erythrocytes. 105

- sac, 104, 128, 226

macrophage, 130, 134, 139, 140

Zuckerman (1946), 133 






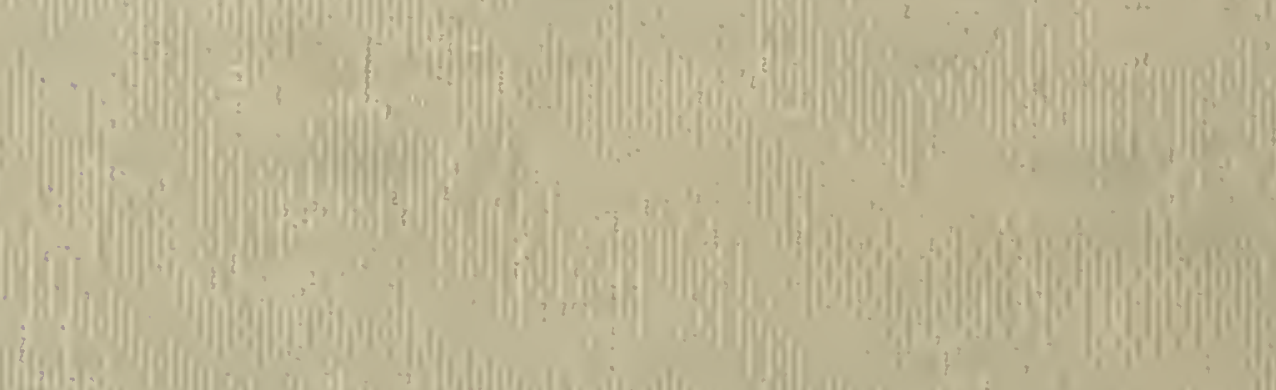

Cristion

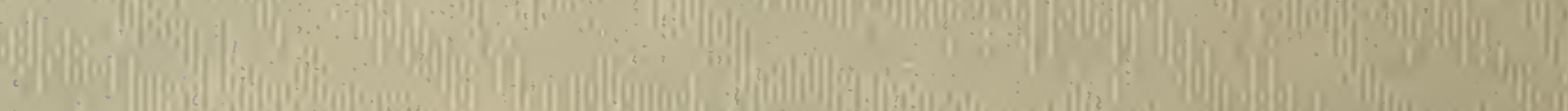

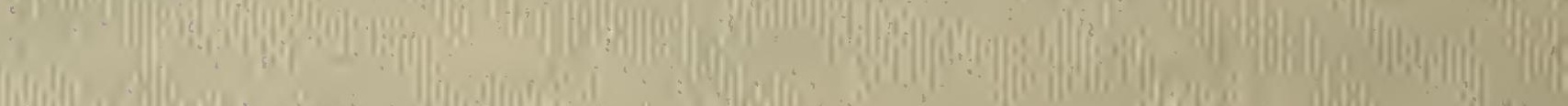
and

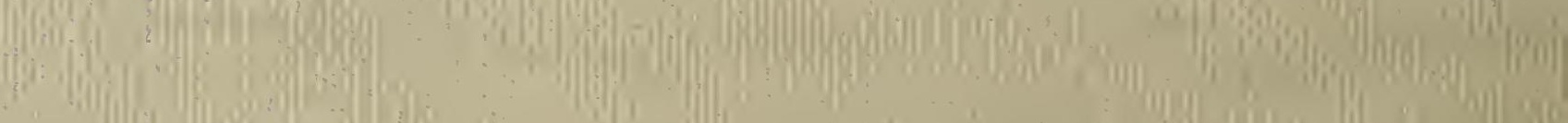
(1) and (ain

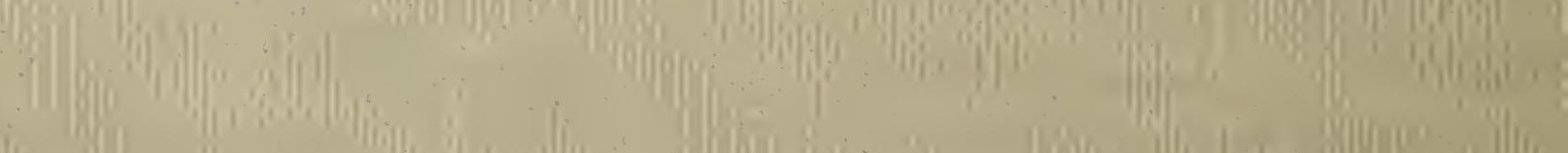

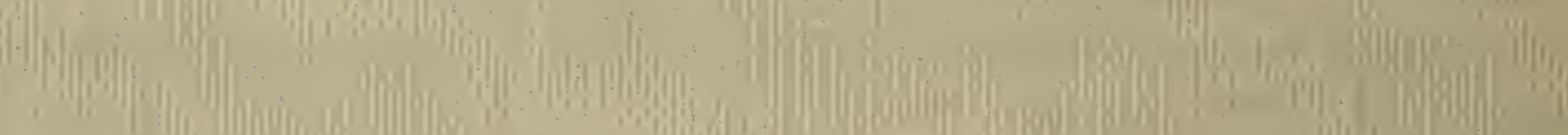

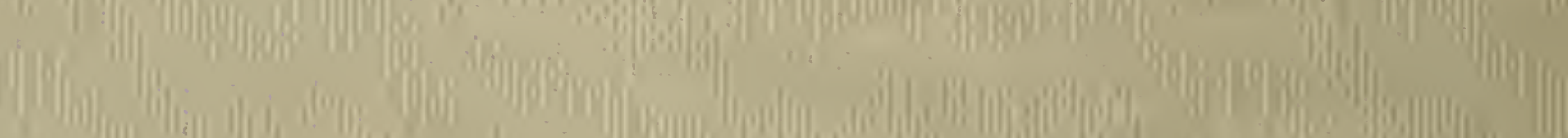

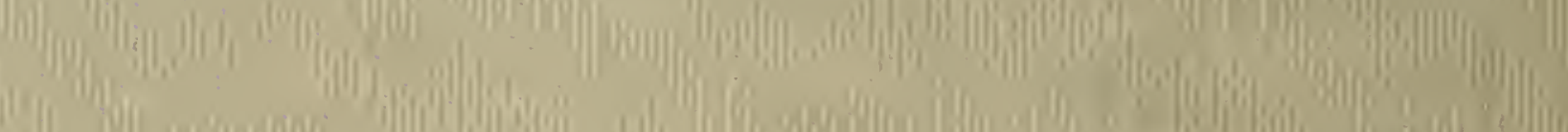
Hat

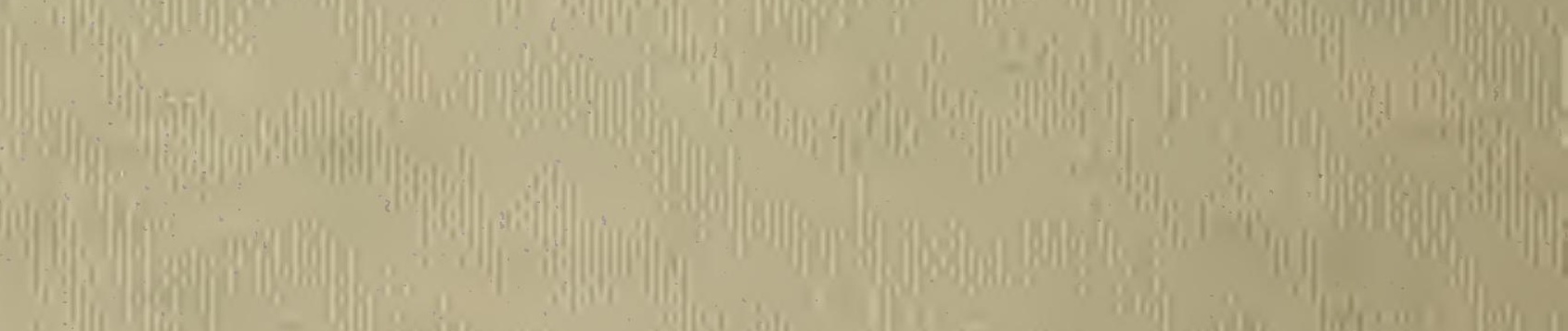

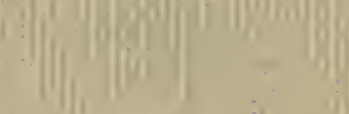

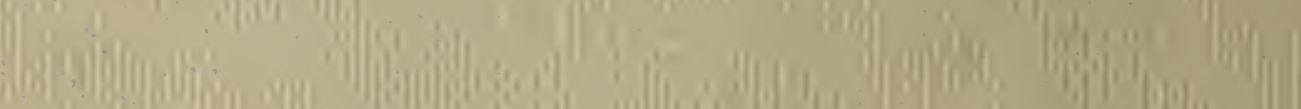
Son

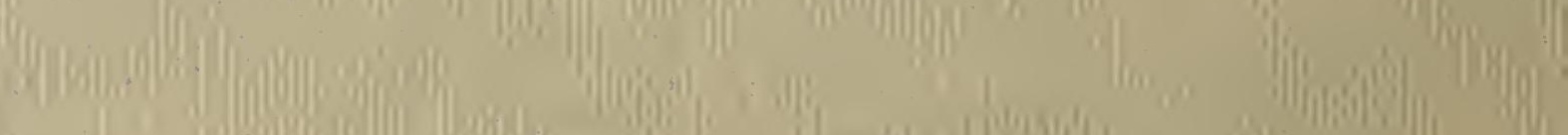
(x)

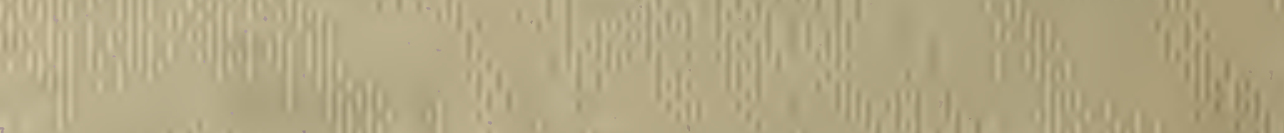
Whe

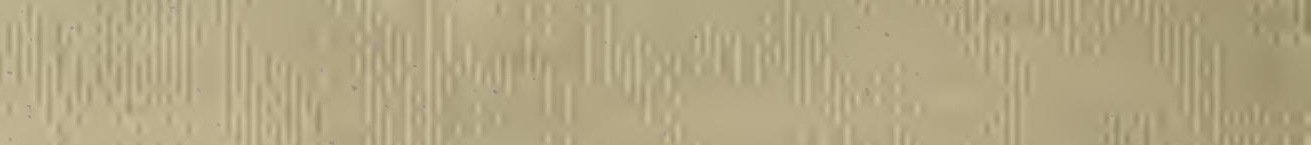

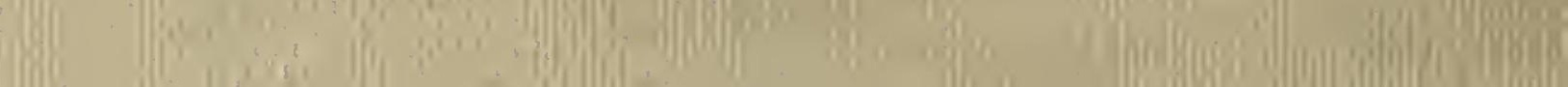

